Prepared in cooperation with the Colorado River Water Conservation District, Eagle County, Eagle River Water and Sanitation District, Upper Eagle Regional Water Authority, Colorado Department of Transportation, City of Aurora, Town of Eagle, Town of Gypsum, Town of Minturn, Town of Vail, Vail Resorts, Colorado Springs Utilities, Denver Water, and the U.S. Department of Agriculture Forest Service

\title{
Macroinvertebrate and Algal Community Sample Collection Methods and Data Collected at Selected Sites in the Eagle River Watershed, Colorado, 2000-07
}

Data Series 502 



\section{Macroinvertebrate and Algal Community Sample Collection Methods and Data Collected at Selected Sites in the Eagle River Watershed, Colorado, 2000-07}

By Robert E. Zuellig and James F. Bruce

Prepared in cooperation with the Colorado River Water Conservation District, Eagle County, Eagle River Water and Sanitation District, Upper Eagle Regional Water Authority, Colorado Department of Transportation, City of Aurora, Town of Eagle, Town of Gypsum, Town of Minturn, Town of Vail, Vail Resorts, Colorado Springs Utilities, Denver Water, and the U.S. Department of Agriculture Forest Service

Data Series 502 


\title{
U.S. Department of the Interior \\ KEN SALAZAR, Secretary \\ U.S. Geological Survey \\ Marcia K. McNutt, Director
}

\section{U.S. Geological Survey, Reston, Virginia: 2010}

\author{
For more information on the USGS — the Federal source for science about the Earth, its natural and living resources, \\ natural hazards, and the environment, visit http://www.usgs.gov or call 1-888-ASK-USGS \\ For an overview of USGS information products, including maps, imagery, and publications, \\ visit http://www.usgs.gov/pubprod \\ To order this and other USGS information products, visit http://store.usgs.gov
}

Any use of trade, product, or firm names is for descriptive purposes only and does not imply endorsement by the U.S. Government.

Although this report is in the public domain, permission must be secured from the individual copyright owners to reproduce any copyrighted materials contained within this report.

Suggested citation:

Zuellig, R.E., and Bruce, J.F., 2010, Macroinvertebrate and algal community sample collection methods and data collected at selected sites in the Eagle River watershed, Colorado, 2000-07: U.S. Geological Survey Data Series 502, 81 p. 


\section{Contents}

Introduction. .1

Sample Collection and Data Compilation Methods …............................................................

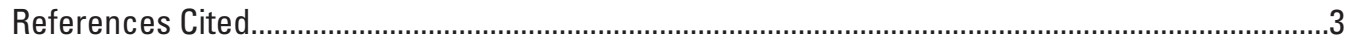

\section{Figure}

1. Map showing locations of sampling sites in the Eagle River watershed,

Colorado, 2000-07.

\section{Tables}

1. Description of sampling sites and macroinvertebrate data collected from selected sites in the Eagle River watershed, Colorado, 2000-07

2. Description of sampling sites and algal data collected from selected sites in the Eagle River watershed, Colorado, 2000-01

\section{Conversion Factors}

\begin{tabular}{|c|c|c|}
\hline Multiply & By & To obtain \\
\hline \multicolumn{3}{|c|}{ Length } \\
\hline inch (in.) & 2.54 & centimeter $(\mathrm{cm})$ \\
\hline inch (in.) & 25.4 & millimeter (mm) \\
\hline foot $(\mathrm{ft})$ & 0.3048 & meter $(\mathrm{m})$ \\
\hline mile (mi) & 1.609 & kilometer $(\mathrm{km})$ \\
\hline micrometer $(\mu \mathrm{m})$ & $1.0 \times 102$ & centimeter $(\mathrm{cm})$ \\
\hline \multicolumn{3}{|c|}{ Area } \\
\hline acre & 0.004047 & square kilometer $\left(\mathrm{km}^{2}\right)$ \\
\hline square foot $\left(\mathrm{ft}^{2}\right)$ & 929.0 & square centimeter $\left(\mathrm{cm}^{2}\right)$ \\
\hline square foot $\left(\mathrm{ft}^{2}\right)$ & 0.09290 & square meter $\left(\mathrm{m}^{2}\right)$ \\
\hline square inch $\left(\mathrm{in}^{2}\right)$ & 6.452 & square centimeter $\left(\mathrm{cm}^{2}\right)$ \\
\hline square mile $\left(\mathrm{mi}^{2}\right)$ & 259.0 & hectare (ha) \\
\hline square mile $\left(\mathrm{mi}^{2}\right)$ & 2.590 & square kilometer $\left(\mathrm{km}^{2}\right)$ \\
\hline \multicolumn{3}{|c|}{ Volume } \\
\hline barrel (bbl), (petroleum, 1 barrel=42 gal) & 0.1590 & cubic meter $\left(\mathrm{m}^{3}\right)$ \\
\hline cubic inch $\left(\right.$ in $\left.^{3}\right)$ & 16.39 & cubic centimeter $\left(\mathrm{cm}^{3}\right)$ \\
\hline cubic inch $\left(\right.$ in $\left.^{3}\right)$ & 0.01639 & liter $(\mathrm{L})$ \\
\hline cubic inch $\left(\right.$ in $\left.^{3}\right)$ & 0.001639 & milliliters $(\mathrm{mL})$ \\
\hline cubic micrometer $\left(\mu \mathrm{m}^{3}\right)$ & $1.0 \times 1012$ & cubic centimeter $\left(\mathrm{cm}^{3}\right)$ \\
\hline
\end{tabular}

Temperature in degrees Celsius $\left({ }^{\circ} \mathrm{C}\right)$ may be converted to degrees Fahrenheit $\left({ }^{\circ} \mathrm{F}\right)$ as follows:

$$
{ }^{\circ} \mathrm{F}=\left(1.8 \times^{\circ} \mathrm{C}\right)+32
$$

Temperature in degrees Fahrenheit $\left({ }^{\circ} \mathrm{F}\right)$ may be converted to degrees Celsius $\left({ }^{\circ} \mathrm{C}\right)$ as follows:

$$
{ }^{\circ} \mathrm{C}=\left({ }^{\circ} \mathrm{F}-32\right) / 1.8
$$

Vertical coordinate information is referenced to the North American Vertical Datum of 1988 (NAVD 88). Horizontal coordinate information is referenced to the North American Datum of 1983 (NAD 83). Elevation, as used in this report, refers to distance above the vertical datum.

\section{Abbreviations \\ NAWQA National Water-Quality Assessment Program \\ FS U.S. Department of Agriculture Forest Service \\ USGS U.S. Geological Survey}





\title{
Macroinvertebrate and Algal Community Sample Collection Methods and Data Collected at Selected Sites in the Eagle River Watershed, Colorado, 2000-07
}

\author{
By Robert E. Zuellig and James F. Bruce
}

\section{Introduction}

State and local agencies are concerned about the effects of increasing urban development and human population growth on water quality and the biological condition of regional streams in the Eagle River watershed (Deacon and Spahr, 1998). In response to these needs, the U.S. Geological Survey (USGS) initiated a study in cooperation with the Colorado River Water Conservation District, Eagle County, Eagle River Water and Sanitation District, Upper Eagle Regional Water Authority, Colorado Department of Transportation, City of Aurora, Town of Eagle, Town of Gypsum, Town of Minturn, Town of Vail, Vail Resorts, Colorado Springs Utilities, Denver Water, and the U.S. Department of Agriculture Forest Service (FS). As part of this study, previously collected macroinvertebrate and algal data from the Eagle River watershed were compiled. This report includes two tables: table 1, macroinvertebrate data collected by the USGS and(or) the FS from 73 sites from 2000 to 2007 (fig. 1) and table 2, algal data collected from up to 26 sites between 2000 and 2001 in the Eagle River watershed (fig. 1). Additionally, a brief description of the sample collection methods and data processing procedures are presented. The macroinvertebrate data presented herein were analyzed by Zuellig and others (2010) to assess the biological condition of selected sites in the Eagle River watershed and to evaluate whether the dominant types of land use were associated with biological condition.

\section{Sample Collection and Data Compilation Methods}

Macroinvertebrates. - The USGS collected semiquantitative macroinvertebrate samples during 2000 and 2001 following National Water-Quality Assessment (NAWQA) Program protocols described by Cuffney and others (1993). In general, five discrete collections were made from riffle habitats at each site with a slack sampler equipped with 500-micron mesh and a 2.69 square feet $\left(\mathrm{ft}^{2}\right)$ ( 0.25 square meter) sampling grid along a predefined reach (Fitzpatrick and others, 1998). The contents of the five collections were composited, and the volume was reduced in the field by elutriating and sieving (500-micron mesh-metal sieve) until the sample volume was approximately 500 milliliters (mL) (about 1 pint). All samples were preserved in the field with 10-percent buffered formalin, and stored until they could be transported to Chadwick and Associates in Littleton, Colorado, where they were processed using methods described by Klemm and others (1990). All taxa were identified to the lowest practical resolution (for example, genus or species) and enumerated. All USGS macroinvertebrate samples were collected during base-flow conditions in September 2000 and 2001. Some sites were sampled in both years (table 1). Samples collected by this method are identified as NAWQA in table 1.

The FS collected macroinvertebrate samples between 2003 and 2007 using methods described by Hawkins and others (2001). In general, eight discrete collections of macroinvertebrates were composited from four riffle locations within a stream reach using a surber sampler equipped with 500-micron mesh and a $1 \mathrm{ft}^{2}$ sampling grid. The macroinvertebrates collected from each site were composited, processed, and preserved in the field using methods similar to those used by the USGS. All FS samples were sent to Aquatics Associates, Inc., in Fort Collins, Colorado, for sample processing following protocols developed by Klemm and others (1990). Additionally, the FS sampled macroinvertebrate communities from a series of sites along the Eagle River in the upper part of the watershed (table 1, fig. 1, sites 5, 9, 11-12, 17, 22, 24). At these sites, five macroinvertebrate samples were collected from riffle habitats using a Hess sampler $\left(0.923 \mathrm{ft}^{2}\right)$ equipped with 500-micron mesh and preserved separately in the field and sent to Aquatics Associates Inc. in Ft. Collins, Colorado, for sample processing. All taxa in each sample were identified to the lowest practical resolution (for example, genus or species) and enumerated. All FS macroinvertebrate samples were collected during base-flow conditions during September (2003-07). In table 1, samples collected by the FS are identified as being collected by a surber or Hess sampler. For further information on macroinvertebrate sample collection see Zuellig and others (2010).

Macroinvertebrate Data Preparation and Comparability.Three adjustments were made to the compiled Eagle River watershed macroinvertebrate data presented in table 1. First, the taxonomic names used by the different laboratories that made macroinvertebrate identifications were harmonized. Harmonizing 


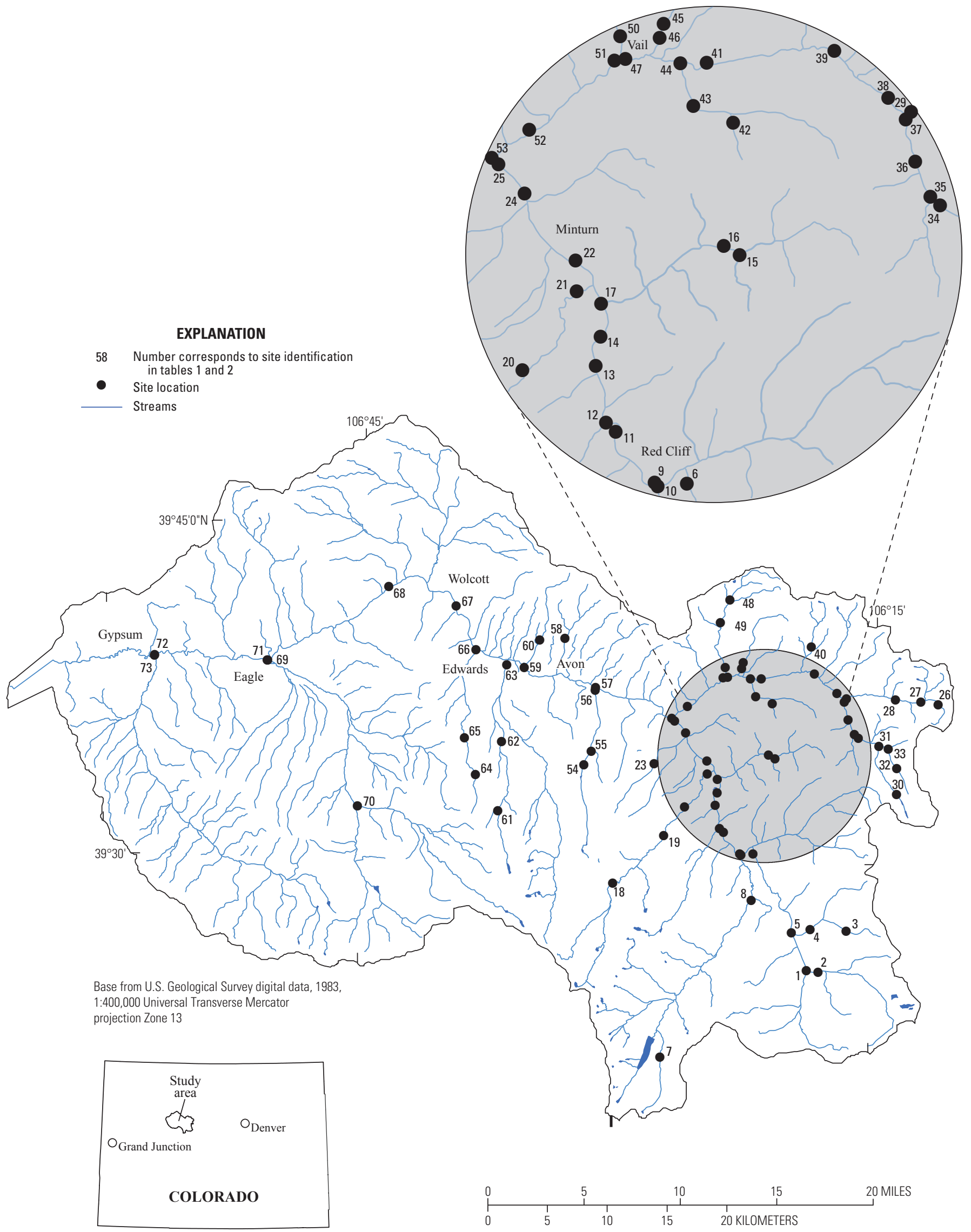

Figure 1. Locations of sampling sites in the Eagle River watershed, Colorado, 2000-07. 
the taxonomic names can make the data more comparable but often some level of resolution is lost. Second, the laboratory results were composited from the five FS Hess samples made at associated sites to better represent the composited samples required by the other two field protocols (Cuffney and others, 1993; Hawkins and others, 2001). Third, the raw data counts for each sample were standardized to 300 by randomly resampling individuals without replacement. Such adjustments to raw data counts can help alleviate the affect of varying levels of sampling effort (for example, area sampled in the field or subsample target counts) on estimates of taxa richness (Peterson and Zumberge, 2006), even when different sampling devices are used (Cao and others, 2005). These types of fixed count adjustments are necessary even if data are not compiled from different sources. For example, standardized laboratory subsampling procedures result in a wide range of individuals extracted from a sample which differentially affects taxa richness across samples (Vinson and Hawkins, 1996). For further information on macroinvertebrate data preparation, see Zuellig and others (2010).

Algae.-Quantitative epilithic algal samples were collected from submerged cobbles in different riffles associated with each USGS invertebrate sample following the top-rock scrape procedure described by Porter and others (1993). In brief, a replicate sample consisted of five discrete collections scraped from the tops of submerged cobbles in riffle habitat. The contents of the five discrete collections were composited, volume recorded, and preserved in the field with 5-percent buffered formalin to form a single replicate sample and shipped to the laboratory for processing. Additionally, the surface area scraped on each cobble was quantified by outlining the area with a wax pencil, wrapping the scraped area with aluminum foil, and digitizing the area of the foil in the laboratory. Algae were identified and enumerated from permanent slides at 1,000-X power by personnel at the Patrick Center of Environmental Research (The Academy of Natural Sciences, Philadelphia, Pennsylvania) using the methods described in Charles and others (2002). All algae samples were collected during base-flow conditions in September 2000 and 2001. Some sites were sampled in both 2000 and 2001 (table 2). Additionally, multiple replicate algal samples were collected at 6 of the 26 sites which are distinguished by a replicate number in table 2.

\section{References Cited}

Cao, Y., Hawkins, C.P., and Storey, A.W., 2005, A method for measuring the comparability of different sampling methods used in biological surveys - Implications for data integration and synthesis: Freshwater Biology, v. 50, p. 1105-1115.

Charles, D.F., Knowles, C., and Davis, R., 2002, Protocols for the analysis of algal samples collected as part of the U.S. Geological Survey National Water-Quality Assessment Program: Philadelphia, The Academy of Natural Sciences, Patrick Center for Environmental Research Report No. 02-06. (Also available at http://diatom.acnatsci.org/nawqa/.)
Cuffney, T.F., Gurtz, M.E., and Meador, M.R., 1993, Methods for collecting benthic macroinvertebrate samples as part of the National Water-Quality Assessment Program: U.S. Geological Survey Open-File Report 93-406, $40 \mathrm{p}$.

Deacon, J.R., and Spahr, N.E., 1998, Water-quality and biological community characterization at selected sites on the Eagle River, Colorado, September 1997 and February 1998: U.S. Geological Survey Water-Resources Investigations Report 98-4236, 8 p.

Fitzpatrick, F.A., Waite, I.R., D’Arconte, P.J., Meador, M.R., Maupin, M.A., and Gurtz, M.E., 1998, Revised methods for characterizing stream habitat in the National Water-Quality Assessment Program: U.S. Geological Survey WaterResource Investigations Report 98-4052, 67 p.

Hawkins, C., Ostermiller, J., Vinson, M., and Stevenson, R.J., 2001, Stream algae, macroinvertebrate, and environmental sampling associated with biological water quality assessments field protocols: Logan, Utah State University, Department of Fisheries and Wildlife, Bureau of Land Management Aquatic Monitoring Center, 23 p.

Klemm, D.J., Lewis, P.A., Fulk, F., and Lazorchak, J.M., 1990, Macroinvertebrate field and laboratory methods for evaluating the biological integrity of surface waters: Cincinnati, Ohio, U.S. Environmental Protection Agency, Environmental Monitoring and Support Laboratory, EPA-600-4-90-030.

Peterson, D.A., and Zumberge, J.R., 2006, Comparison of macroinvertebrate community structure between two riffle-based sampling protocols in Wyoming, Colorado, and Montana, 2000-2001: U.S. Geological Survey Scientific Investigations Report 2006-5117, 12 p.

Porter, S.D., Cuffney, T.F., Gurtz, M.E., and Meador, M.R., 1993, Methods for collecting algal samples as part of the National Water-Quality Assessment Program: U.S. Geological Survey Open-File Report 93-409, 39 p.

Vinson, M.R., and Hawkins, C.P., 1996, Effects of sampling area and subsampling procedure on comparisons of taxa richness among streams: Journal of the North American Benthological Society, v. 15, p. 392-399.

Zuellig, R.E., Bruce, J.F., Healy, B.D., and Williams, C.A., 2010, Macroinvertebrate-based assessment of biological condition at selected sites in the Eagle River Watershed, Colorado, 2000-2007: U.S. Geological Survey Scientific Investigations Report 2010-5148, 19 p. 

Tables 
Table 1. Description of sites and macroinvertebrate data collected from selected sites the Eagle River watershed, Colorado, 2000-2007.

[ID, identification; NAVD, North American Vertical Datum of 1988; ft, feet; mi² $^{2}$, square miles; ${ }^{\circ}$, degrees; ', minutes; ", seconds; FS, U.S. Department of Agriculture Forest Service; USGS, U.S. Geological Survey]

\begin{tabular}{|c|c|c|c|c|c|}
\hline Site ID' & Station name & Station ID ${ }^{2}$ & Latitude & Longitude & $\begin{array}{c}\text { Elevation } \\
\text { NAVD } 88 \\
\text { (ft) }\end{array}$ \\
\hline 1 & East Fork Eagle River above Colorado Trail Bridge & EFER-R1-1.06 & $39^{\circ} 25^{\prime} 11 "$ & $106^{\circ} 18^{\prime} 07^{\prime \prime}$ & 9,326 \\
\hline 4 & Resolution Creek above Pearl Creek & RESL-R1-1.680 & $39^{\circ} 27^{\prime} 06^{\prime \prime}$ & $106^{\circ} 18^{\prime} 37^{\prime \prime}$ & 9,546 \\
\hline 5 & Eagle River Below Resolution Creek & EAGL-R1-95.27 & $39^{\circ} 26 ' 57^{\prime \prime}$ & $106^{\circ} 19^{\prime} 42^{\prime \prime}$ & 9,206 \\
\hline 6 & Eagle River at Red Cliff & 09063000 & $39^{\circ} 30^{\prime} 30^{\prime \prime}$ & $106^{\circ} 21^{\prime} 58^{\prime \prime}$ & 8,654 \\
\hline 8 & Homestake Creek near Red Cliff & 09064500 & $39^{\circ} 28^{\prime} 24^{\prime \prime}$ & $106^{\circ} 22^{\prime} 02^{\prime \prime}$ & 8,783 \\
\hline 9 & Eagle River above Homestake Creek & EAGL-85.162 & $39^{\circ} 30^{\prime} 26^{\prime \prime}$ & $106^{\circ} 22^{\prime} 43^{\prime \prime}$ & 8,585 \\
\hline 10 & Eagle River below Homestake Creek near Red Cliff & 393030106224700 & $39^{\circ} 30^{\prime} 30^{\prime \prime}$ & $106^{\circ} 22^{\prime} 47^{\prime \prime}$ & 8,820 \\
\hline 10 & Eagle River below Homestake Creek near Red Cliff & 393030106224700 & $39^{\circ} 30^{\prime} 30^{\prime \prime}$ & $106^{\circ} 22^{\prime} 47^{\prime \prime}$ & 8,820 \\
\hline 11 & Eagle River upstream of Belden & EAGL-82.442 & $39^{\circ} 31^{\prime} 27^{\prime \prime}$ & $106^{\circ} 23^{\prime} 45^{\prime \prime}$ & 8,398 \\
\hline 12 & Eagle River upstream of Fall Creek & EAGL-81.615 & $39^{\circ} 31^{\prime} 37^{\prime \prime}$ & $106^{\circ} 23^{\prime} 59^{\prime \prime}$ & 8,344 \\
\hline 13 & Eagle River below Bishop Gulch & EAGL-79.449 & $39^{\circ} 32^{\prime} 41^{\prime \prime}$ & $106^{\circ} 24^{\prime} 16^{\prime \prime}$ & 8,156 \\
\hline 18 & Cross Creek near Reeds Meadow & CROS-R3-15.51 & $39^{\circ} 29^{\prime} 05^{\prime \prime}$ & $106^{\circ} 30^{\prime} 10^{\prime \prime}$ & 9,870 \\
\hline 18 & Cross Creek near Reeds Meadow & CROS-R3-15.51 & $39^{\circ} 29^{\prime} 05^{\prime \prime}$ & $106^{\circ} 30^{\prime} 10^{\prime \prime}$ & 9,870 \\
\hline 18 & Cross Creek near Reeds Meadow & CROS-R3-15.51 & $39^{\circ} 29^{\prime} 05^{\prime \prime}$ & $106^{\circ} 30^{\prime} 10^{\prime \prime}$ & 9,870 \\
\hline 19 & Cross Creek approximately 3.2 miles above wilderness boundary & CROS-R2-8.40 & $39^{\circ} 31^{\prime} 16^{\prime \prime}$ & $106^{\circ} 27^{\prime} 14^{\prime \prime}$ & 9,147 \\
\hline 20 & Cross Creek above wilderness boundary & CROSS_01R-4.9955 & $39^{\circ} 32^{\prime} 35^{\prime \prime}$ & $106^{\circ} 26^{\prime} 03^{\prime \prime}$ & 8,682 \\
\hline 21 & Cross Creek near Minturn & 09065100 & $39^{\circ} 34^{\prime} 05^{\prime \prime}$ & $106^{\circ} 24^{\prime} 43^{\prime \prime}$ & 7,992 \\
\hline 22 & Eagle River below Cross Creek & EAGL-74.978 & $39^{\circ} 34^{\prime} 39^{\prime \prime}$ & $106^{\circ} 24^{\prime} 47^{\prime \prime}$ & 7,917 \\
\hline 23 & West Grouse Creek below pack trail crossing & WGRO-2.794 & $39^{\circ} 34 ' 30^{\prime \prime}$ & $106^{\circ} 27^{\prime} 51^{\prime \prime}$ & 9,391 \\
\hline 24 & Eagle River below Game Creek & EAGL-71.778 & $39^{\circ} 35^{\prime} 54^{\prime \prime}$ & $106^{\circ} 26^{\prime} 03^{\prime \prime}$ & 7,804 \\
\hline 25 & Eagle River above Gore Creek near Minturn & 393627106264000 & $39^{\circ} 36^{\prime} 27^{\prime \prime}$ & $106^{\circ} 26^{\prime} 40^{\prime \prime}$ & 7,730 \\
\hline 26 & Gore Creek near Red Buffalo Pass & GORE-R9-27.102 & $39^{\circ} 37^{\prime} 21^{\prime \prime}$ & $106^{\circ} 11^{\prime} 20^{\prime \prime}$ & 10,636 \\
\hline 27 & Gore Creek approximately 3.5 miles above wilderness boundary & GORE-R8-25.38 & $39^{\circ} 37^{\prime} 28^{\prime \prime}$ & $106^{\circ} 12^{\prime} 20^{\prime \prime}$ & 10,172 \\
\hline 27 & Gore Creek approximately 3.5 miles above wilderness boundary & GORE-R8-25.38 & $39^{\circ} 37^{\prime} 28^{\prime \prime}$ & $106^{\circ} 12^{\prime} 20^{\prime \prime}$ & 10,172 \\
\hline 27 & Gore Creek approximately 3.5 miles above wilderness boundary & GORE-R8-25.38 & $39^{\circ} 37^{\prime} 28^{\prime \prime}$ & $106^{\circ} 12^{\prime} 20^{\prime \prime}$ & 10,172 \\
\hline 30 & Black Gore Creek below Black Lake No. 2 & BGOR-R4-10.64 & $39^{\circ} 33^{\prime} 16^{\prime \prime}$ & $106^{\circ} 13^{\prime} 40^{\prime \prime}$ & 10,339 \\
\hline 30 & Black Gore Creek below Black Lake No. 2 & BGOR-R4-10.64 & $39^{\circ} 33^{\prime} 16^{\prime \prime}$ & $106^{\circ} 13^{\prime} 40^{\prime \prime}$ & 10,339 \\
\hline 30 & Black Gore Creek below Black Lake No. 2 & BGOR-R4-10.64 & $39^{\circ} 33^{\prime} 16^{\prime \prime}$ & $106^{\circ} 13^{\prime} 40^{\prime \prime}$ & 10,339 \\
\hline 31 & Black Gore Creek above Polk Creek & BGOR-R3-5.73 & $39^{\circ} 35^{\prime} 26^{\prime \prime}$ & $106^{\circ} 14^{\prime} 45^{\prime \prime}$ & 9,482 \\
\hline 31 & Black Gore Creek above Polk Creek & BGOR-R3-5.73 & $39^{\circ} 35^{\prime} 26^{\prime \prime}$ & $106^{\circ} 14^{\prime} 45^{\prime \prime}$ & 9,482 \\
\hline 31 & Black Gore Creek above Polk Creek & BGOR-R3-5.73 & $39^{\circ} 35^{\prime} 26^{\prime \prime}$ & $106^{\circ} 14^{\prime} 45^{\prime \prime}$ & 9,482 \\
\hline 31 & Black Gore Creek above Polk Creek & BGOR-R3-5.73 & $39^{\circ} 35^{\prime} 26^{\prime \prime}$ & $106^{\circ} 14^{\prime} 45^{\prime \prime}$ & 9,482 \\
\hline 32 & Polk Creek approximately 1.25 miles above wilderness boundary & POLK-R3-2.90 & $39^{\circ} 34^{\prime} 26^{\prime \prime}$ & $106^{\circ} 13^{\prime} 42^{\prime \prime}$ & 10,277 \\
\hline 32 & Polk Creek approximately 1.25 miles above wilderness boundary & POLK-R3-2.90 & $39^{\circ} 34^{\prime} 26^{\prime \prime}$ & $106^{\circ} 13^{\prime} 42^{\prime \prime}$ & 10,277 \\
\hline 32 & Polk Creek approximately 1.25 miles above wilderness boundary & POLK-R3-2.90 & $39^{\circ} 34^{\prime} 26^{\prime \prime}$ & $106^{\circ} 13^{\prime} 42^{\prime \prime}$ & 10,277 \\
\hline 33 & Polk Creek above wilderness boundary & POLK-R2-0.97 & $39^{\circ} 35^{\prime} 19^{\prime \prime}$ & $106^{\circ} 14^{\prime} 12^{\prime \prime}$ & 9,911 \\
\hline 33 & Polk Creek above wilderness boundary & POLK-R2-0.97 & $39^{\circ} 35^{\prime} 19^{\prime \prime}$ & $106^{\circ} 14^{\prime} 12^{\prime \prime}$ & 9,911 \\
\hline 33 & Polk Creek above wilderness boundary & POLK-R2-0.97 & $39^{\circ} 35^{\prime} 19^{\prime \prime}$ & $106^{\circ} 14^{\prime} 12^{\prime \prime}$ & 9,911 \\
\hline 33 & Polk Creek above wilderness boundary & POLK-R2-0.97 & $39^{\circ} 35^{\prime} 19^{\prime \prime}$ & $106^{\circ} 14^{\prime} 12^{\prime \prime}$ & 9,911 \\
\hline 34 & Black Gore Creek near Minturn & 09066000 & $39^{\circ} 35^{\prime} 47^{\prime \prime}$ & $106^{\circ} 15^{\prime} 52^{\prime \prime}$ & 9,150 \\
\hline 34 & Black Gore Creek near Minturn & 09066000 & $39^{\circ} 35^{\prime} 47^{\prime \prime}$ & $106^{\circ} 15^{\prime} 52^{\prime \prime}$ & 9,150 \\
\hline 34 & Black Gore Creek near Minturn & 09066000 & $39^{\circ} 35^{\prime} 47^{\prime \prime}$ & $106^{\circ} 15^{\prime} 52^{\prime \prime}$ & 9,150 \\
\hline 34 & Black Gore Creek near Minturn & 09066000 & $39^{\circ} 35^{\prime} 47^{\prime \prime}$ & $106^{\circ} 15^{\prime} 52^{\prime \prime}$ & 9,150 \\
\hline 34 & Black Gore Creek near Minturn & 09066000 & $39^{\circ} 35^{\prime} 47^{\prime \prime}$ & $106^{\circ} 15^{\prime} 52^{\prime \prime}$ & 9,150 \\
\hline 35 & Timber Creek at mouth & TIMBER-R1-01R-0.4444 & $39^{\circ} 35^{\prime} 58^{\prime \prime}$ & $106^{\circ} 16^{\prime} 11^{\prime \prime}$ & 9,119 \\
\hline 36 & Black Gore Creek at I-70 milepost 183 & BGOR-R1-1.83 & $39^{\circ} 36^{\prime} 37^{\prime \prime}$ & $106^{\circ} 16^{\prime} 34^{\prime \prime}$ & 8,921 \\
\hline 36 & Black Gore Creek at I-70 milepost 183 & BGOR-R1-1.83 & $39^{\circ} 36^{\prime} 37^{\prime \prime}$ & $106^{\circ} 16^{\prime} 34^{\prime \prime}$ & 8,921 \\
\hline 36 & Black Gore Creek at I-70 milepost 183 & BGOR-R1-1.83 & $39^{\circ} 36^{\prime} 37^{\prime \prime}$ & $106^{\circ} 16^{\prime} 34^{\prime \prime}$ & 8,921 \\
\hline 36 & Black Gore Creek at I-70 milepost 183 & BGOR-R1-1.83 & $39^{\circ} 36^{\prime} 37^{\prime \prime}$ & $106^{\circ} 16^{\prime} 34^{\prime \prime}$ & 8,921 \\
\hline
\end{tabular}


Table 1. Description of sites and macroinvertebrate data collected from selected sites the Eagle River watershed, Colorado, 2000-2007.-Continued

[ID, identification; NAVD, North American Vertical Datum of 1988; ft, feet; $\mathrm{mi}^{2}$, square miles; ${ }^{\circ}$, degrees; ', minutes; ", seconds; FS, U.S. Department of Agriculture Forest Service; USGS, U.S. Geological Survey]

\begin{tabular}{|c|c|c|c|c|c|}
\hline Site ID' & Station name & Station ID² & Latitude & Longitude & $\begin{array}{c}\text { Elevation } \\
\text { NAVD } 88 \\
\text { (ft) }\end{array}$ \\
\hline 37 & Black Gore Creek near Vail & 09066050 & $39^{\circ} 37^{\prime} 24^{\prime \prime}$ & $106^{\circ} 16^{\prime} 47^{\prime \prime}$ & 8,570 \\
\hline 37 & Black Gore Creek near Vail & 09066050 & $39^{\circ} 37^{\prime} 24^{\prime \prime}$ & $106^{\circ} 16^{\prime} 47^{\prime \prime}$ & 8,570 \\
\hline 38 & Gore Creek at Bighorn Park & GORE-R4-17.37 & $39^{\circ} 37^{\prime} 48^{\prime \prime}$ & $106^{\circ} 17^{\prime} 15^{\prime \prime}$ & 8,516 \\
\hline 38 & Gore Creek at Bighorn Park & GORE-R4-17.37 & $39^{\circ} 37^{\prime} 48^{\prime \prime}$ & $106^{\circ} 17^{\prime} 15^{\prime \prime}$ & 8,516 \\
\hline 38 & Gore Creek at Bighorn Park & GORE-R4-17.37 & $39^{\circ} 37^{\prime} 48^{\prime \prime}$ & $106^{\circ} 17^{\prime} 15^{\prime \prime}$ & 8,516 \\
\hline 39 & Gore Creek above Katsos & 393836106182500 & $39^{\circ} 38^{\prime} 36^{\prime \prime}$ & $106^{\circ} 18^{\prime} 25^{\prime \prime}$ & 8,355 \\
\hline 39 & Gore Creek above Katsos & 393836106182500 & $39^{\circ} 38^{\prime} 36^{\prime \prime}$ & $106^{\circ} 18^{\prime} 25^{\prime \prime}$ & 8,355 \\
\hline 39 & Gore Creek above Katsos & 393836106182500 & $39^{\circ} 38^{\prime} 36^{\prime \prime}$ & $106^{\circ} 18^{\prime} 25^{\prime \prime}$ & 8,355 \\
\hline 39 & Gore Creek above Katsos & 393836106182500 & $39^{\circ} 38^{\prime} 36^{\prime \prime}$ & $106^{\circ} 18^{\prime} 25^{\prime \prime}$ & 8,355 \\
\hline 39 & Gore Creek above Katsos & 393836106182500 & $39^{\circ} 38^{\prime} 36^{\prime \prime}$ & $106^{\circ} 18^{\prime} 25^{\prime \prime}$ & 8,355 \\
\hline 40 & Booth Creek approximately 1.0 miles above wilderness boundary & booth_R3_02R-2.5407 & $39^{\circ} 39^{\prime} 53^{\prime \prime}$ & $106^{\circ} 18^{\prime} 47^{\prime \prime}$ & 9,317 \\
\hline 41 & Gore Creek downstream of Pulis Bridge & $3938 \overline{25} 10 \overline{6} 213400$ & $39^{\circ} 38^{\prime} 25^{\prime \prime}$ & $106^{\circ} 21^{\prime} 34^{\prime \prime}$ & 8,236 \\
\hline 41 & Gore Creek downstream of Pulis Bridge & 393825106213400 & $39^{\circ} 38^{\prime} 25^{\prime \prime}$ & $106^{\circ} 21^{\prime} 34^{\prime \prime}$ & 8,236 \\
\hline 41 & Gore Creek downstream of Pulis Bridge & 393825106213400 & $39^{\circ} 38^{\prime} 25^{\prime \prime}$ & $106^{\circ} 21^{\prime} 34^{\prime \prime}$ & 8,236 \\
\hline 41 & Gore Creek downstream of Pulis Bridge & 393825106213400 & $39^{\circ} 38^{\prime} 25^{\prime \prime}$ & $106^{\circ} 21^{\prime} 34^{\prime \prime}$ & 8,236 \\
\hline 41 & Gore Creek downstream of Pulis Bridge & 393825106213400 & $39^{\circ} 38^{\prime} 25^{\prime \prime}$ & $106^{\circ} 21^{\prime} 34^{\prime \prime}$ & 8,236 \\
\hline 42 & Un-named Tributary to Mill Creek draining Northeast Bowl & NEBL-R1-0.374 & $39^{\circ} 37^{\prime} 17^{\prime \prime}$ & $106^{\circ} 21^{\prime} 01^{\prime \prime}$ & 9,548 \\
\hline 42 & Un-named Tributary to Mill Creek draining Northeast Bowl & NEBL-R1-0.374 & $39^{\circ} 37^{\prime} 17^{\prime \prime}$ & $106^{\circ} 21^{\prime} 01^{\prime \prime}$ & 9,548 \\
\hline 43 & Un-named Tributary to Mill Creek near Mid Vail & PTAR-R1-0.066 & $39^{\circ} 37^{\prime} 36^{\prime \prime}$ & $106^{\circ} 21^{\prime} 59^{\prime \prime}$ & 8,878 \\
\hline 44 & Mill Creek near Vail & 393824106221700 & $39^{\circ} 38^{\prime} 24^{\prime \prime}$ & $106^{\circ} 22^{\prime} 17^{\prime \prime}$ & 8,210 \\
\hline 44 & Mill Creek near Vail & 393824106221700 & $39^{\circ} 38^{\prime} 24^{\prime \prime}$ & $106^{\circ} 22^{\prime} 17^{\prime \prime}$ & 8,210 \\
\hline 45 & Middle Creek approximately 0.5 miles above wilderness boundary & MIDL-R4-1.211 & $39^{\circ} 39^{\prime} 08^{\prime \prime}$ & $106^{\circ} 22^{\prime} 44^{\prime \prime}$ & 8,644 \\
\hline 46 & Middle Creek above wilderness boundary & MIDL-R3-0.675 & $39^{\circ} 38^{\prime} 52^{\prime \prime}$ & $106^{\circ} 22^{\prime} 50^{\prime \prime}$ & 8,419 \\
\hline 47 & Gore Creek at Lower Station at Vail & 09066310 & $39^{\circ} 38^{\prime} 28^{\prime \prime}$ & $106^{\circ} 23^{\prime} 37^{\prime \prime}$ & 8,060 \\
\hline 48 & Red Sandstone Creek above South Fork Red Sandstone & RDSS-R3-7.588 & $39^{\circ} 41^{\prime} 57^{\prime \prime}$ & $106^{\circ} 23^{\prime} 35^{\prime \prime}$ & 9,629 \\
\hline 49 & Red Sandstone Creek below Sandstone Creek Road & RDSS-R2-5.338 & $39^{\circ} 40^{\prime} 55^{\prime \prime}$ & $106^{\circ} 24^{\prime} 07^{\prime \prime}$ & 9,206 \\
\hline 50 & Red Sandstone Creek at Town of Vail city limit & RDSS-R1-0.843 & $39^{\circ} 38^{\prime} 53^{\prime \prime}$ & $106^{\circ} 23^{\prime} 47^{\prime \prime}$ & 8,238 \\
\hline 51 & Gore Creek below WWTP & 393826106235300 & $39^{\circ} 38^{\prime} 26^{\prime \prime}$ & $106^{\circ} 23^{\prime} 53^{\prime \prime}$ & 8,050 \\
\hline 52 & Gore Creek at Stephens Park & 393715106253600 & $39^{\circ} 37^{\prime} 15^{\prime \prime}$ & $106^{\circ} 25^{\prime} 36^{\prime \prime}$ & 7,825 \\
\hline 52 & Gore Creek at Stephens Park & 393715106253600 & $39^{\circ} 37^{\prime} 15^{\prime \prime}$ & $106^{\circ} 25^{\prime} 36^{\prime \prime}$ & 7,825 \\
\hline 52 & Gore Creek at Stephens Park & 393715106253600 & $39^{\circ} 37^{\prime} 15^{\prime \prime}$ & $106^{\circ} 25^{\prime} 36^{\prime \prime}$ & 7,825 \\
\hline 52 & Gore Creek at Stephens Park & 393715106253600 & $39^{\circ} 37^{\prime} 15^{\prime \prime}$ & $106^{\circ} 25^{\prime} 36^{\prime \prime}$ & 7,825 \\
\hline 52 & Gore Creek at Stephens Park & 393715106253600 & $39^{\circ} 37^{\prime} 15^{\prime \prime}$ & $106^{\circ} 25^{\prime} 36^{\prime \prime}$ & 7,825 \\
\hline 53 & Gore Creek at mouth near Minturn & 09066510 & $39^{\circ} 36^{\prime} 34^{\prime \prime}$ & $106^{\circ} 26^{\prime} 50^{\prime \prime}$ & 7,730 \\
\hline 53 & Gore Creek at mouth near Minturn & 09066510 & $39^{\circ} 36^{\prime} 34^{\prime \prime}$ & $106^{\circ} 26^{\prime} 50^{\prime \prime}$ & 7,730 \\
\hline 54 & Beaver Creek below wilderness boundary & BVRC-R1-7.075 & $39^{\circ} 34^{\prime} 24^{\prime \prime}$ & $106^{\circ} 31^{\prime} 58^{\prime \prime}$ & 9,322 \\
\hline 55 & Beaver Creek above Avon & 393501106313200 & $39^{\circ} 35^{\prime} 01^{\prime \prime}$ & $106^{\circ} 31^{\prime} 32^{\prime \prime}$ & 8,840 \\
\hline 55 & Beaver Creek above Avon & 393501106313200 & $39^{\circ} 35^{\prime} 01^{\prime \prime}$ & $106^{\circ} 31^{\prime} 32^{\prime \prime}$ & 8,840 \\
\hline 56 & Beaver Creek at Avon & 09067000 & $39^{\circ} 37^{\prime} 47^{\prime \prime}$ & $106^{\circ} 31^{\prime} 20^{\prime \prime}$ & 7,453 \\
\hline 57 & Eagle River at Avon & 09067005 & $39^{\circ} 37^{\prime} 54^{\prime \prime}$ & $106^{\circ} 31^{\prime} 19^{\prime \prime}$ & 7,410 \\
\hline 57 & Eagle River at Avon & 09067005 & $39^{\circ} 37^{\prime} 54^{\prime \prime}$ & $106^{\circ} 31^{\prime} 19^{\prime \prime}$ & 7,410 \\
\hline 58 & June Creek above June Creek Ditch & JUNE-R1-3.430 & $39^{\circ} 40^{\prime} 07^{\prime \prime}$ & $106^{\circ} 33^{\prime} 11^{\prime \prime}$ & 7,996 \\
\hline 59 & Eagle River at Edwards & 393845106353000 & $39^{\circ} 38^{\prime} 45^{\prime \prime}$ & $106^{\circ} 35^{\prime} 30^{\prime \prime}$ & 7,180 \\
\hline 59 & Eagle River at Edwards & 393845106353000 & $39^{\circ} 38^{\prime} 45^{\prime \prime}$ & $106^{\circ} 35^{\prime} 30^{\prime \prime}$ & 7,180 \\
\hline 60 & Berry Creek above USFS road crossing & BERY-R1-2.841 & $39^{\circ} 39^{\prime} 59^{\prime \prime}$ & $106^{\circ} 34^{\prime} 40^{\prime \prime}$ & 7,719 \\
\hline 61 & West Lake Creek below wilderness boundary & WLAK-R1-11.324 & $39^{\circ} 32^{\prime} 16^{\prime \prime}$ & $106^{\circ} 36^{\prime} 56^{\prime \prime}$ & 9,592 \\
\hline 62 & West Lake Creek near Edwards & 393523106364700 & $39^{\circ} 35^{\prime} 23^{\prime \prime}$ & $106^{\circ} 36^{\prime} 47^{\prime \prime}$ & 8,300 \\
\hline 63 & Lake Creek near Edwards & 09067200 & $39^{\circ} 38^{\prime} 51^{\prime \prime}$ & $106^{\circ} 36^{\prime} 31^{\prime \prime}$ & 7,160 \\
\hline 63 & Lake Creek near Edwards & 09067200 & $39^{\circ} 38^{\prime} 51^{\prime \prime}$ & $106^{\circ} 36^{\prime} 31^{\prime \prime}$ & 7,160 \\
\hline 64 & Squaw Creek below wilderness boundary & SQAW-R3-12.28 & $39^{\circ} 33^{\prime} 52^{\prime \prime}$ & $106^{\circ} 38^{\prime} 17^{\prime \prime}$ & 9,357 \\
\hline 65 & Squaw Creek above Poison Gulch & SQAW-R1-8.75 & $39^{\circ} 35^{\prime} 31^{\prime \prime}$ & $106^{\circ} 38^{\prime} 57^{\prime \prime}$ & 8,512 \\
\hline 65 & Squaw Creek above Poison Gulch & SQAW-R1-8.75 & $39^{\circ} 35^{\prime} 31^{\prime \prime}$ & $106^{\circ} 38^{\prime} 57^{\prime \prime}$ & 8,512 \\
\hline 66 & Squaw Creek at mouth near Edwards & 393930106382001 & $39^{\circ} 39^{\prime} 30^{\prime \prime}$ & $106^{\circ} 38^{\prime} 20^{\prime \prime}$ & 7,120 \\
\hline 67 & Eagle River at Eagle Springs Golf Course near Wolcott & 394129106393300 & $39^{\circ} 41^{\prime 2} 29^{\prime \prime}$ & $106^{\circ} 39^{\prime} 33^{\prime \prime}$ & 6,980 \\
\hline 68 & Eagle River below Milk Creek near Wolcott & 394220106431500 & $39^{\circ} 42^{\prime} 18^{\prime \prime}$ & $106^{\circ} 43^{\prime} 33^{\prime \prime}$ & 6,820 \\
\hline 68 & Eagle River below Milk Creek near Wolcott & 394220106431500 & $39^{\circ} 42^{\prime} 18^{\prime \prime}$ & $106^{\circ} 43^{\prime} 33^{\prime \prime}$ & 6,820 \\
\hline 69 & Eagle River above Brush Creek at Eagle & 393852106503200 & $39^{\circ} 38^{\prime} 52^{\prime \prime}$ & $106^{\circ} 50^{\prime} 32^{\prime \prime}$ & 6,500 \\
\hline 70 & East Brush Creek above Confluence & 393221106450700 & $39^{\circ} 32^{\prime} 21^{\prime \prime}$ & $106^{\circ} 45^{\prime} 07^{\prime \prime}$ & 7,630 \\
\hline 71 & Brush Creek at mouth near Eagle & 393851106503400 & $39^{\circ} 38^{\prime} 51^{\prime \prime}$ & $106^{\circ} 50^{\prime} 34^{\prime \prime}$ & 6,500 \\
\hline 71 & Brush Creek at mouth near Eagle & 393851106503400 & $39^{\circ} 38^{\prime} 51^{\prime \prime}$ & $106^{\circ} 50^{\prime} 34^{\prime \prime}$ & 6,500 \\
\hline 72 & Eagle River at Gypsum & 09069000 & $39^{\circ} 39^{\prime} 00^{\prime \prime}$ & $106^{\circ} 57^{\prime} 06^{\prime \prime}$ & 6,276 \\
\hline 72 & Eagle River at Gypsum & 09069000 & $39^{\circ} 39^{\prime} 00^{\prime \prime}$ & $106^{\circ} 57^{\prime} 06^{\prime \prime}$ & 6,276 \\
\hline 73 & Gypsum Creek at mouth & 393858106570900 & $39^{\circ} 38^{\prime} 58^{\prime \prime}$ & $106^{\circ} 57^{\prime} 09^{\prime \prime}$ & 6,280 \\
\hline 73 & Gypsum Creek at mouth & 393858106570900 & $39^{\circ} 38^{\prime} 58^{\prime \prime}$ & $106^{\circ} 57^{\prime} 09^{\prime \prime}$ & 6,280 \\
\hline
\end{tabular}


Table 1. Description of sites and macroinvertebrate data collected from selected sites the Eagle River watershed, Colorado, 2000-2007.-Continued

[ID, identification; NAVD, North American Vertical Datum of 1988; ft, feet; $\mathrm{mi}^{2}$, square miles; ${ }^{\circ}$, degrees; ', minutes; ", seconds; FS, U.S. Department of Agriculture Forest Service; USGS, U.S. Geological Survey]

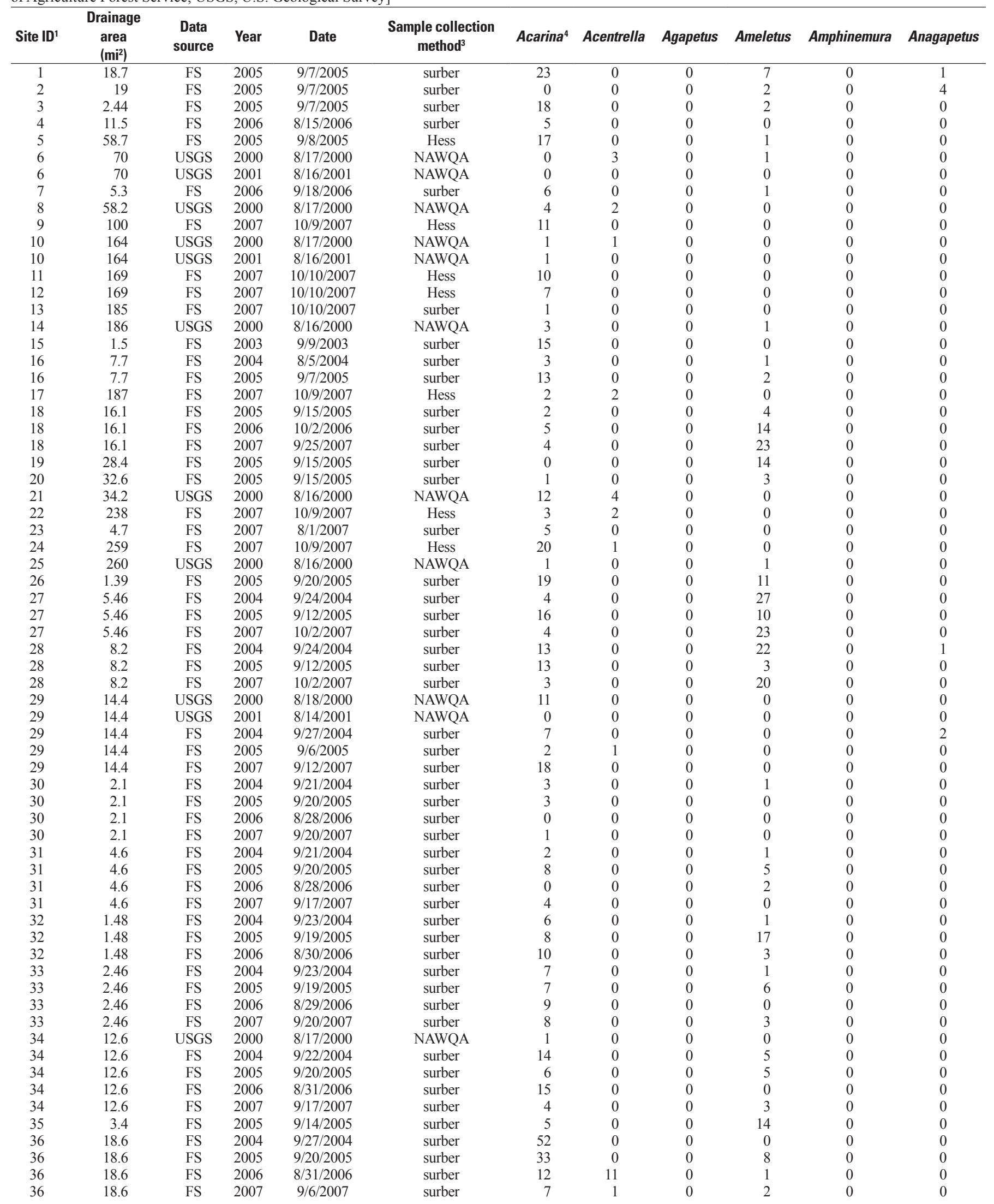


Table 1. Description of sites and macroinvertebrate data collected from selected sites the Eagle River watershed, Colorado, 2000-2007.-Continued

[ID, identification; NAVD, North American Vertical Datum of 1988; ft, feet; mi², square miles; ’ , degrees; ', minutes; ", seconds; FS, U.S. Department of Agriculture Forest Service; USGS, U.S. Geological Survey]

\begin{tabular}{|c|c|c|c|c|c|c|c|c|c|c|c|}
\hline Site ID' & $\begin{array}{c}\text { Drainage } \\
\text { area } \\
\left(\mathrm{mi}^{2}\right)\end{array}$ & $\begin{array}{c}\text { Data } \\
\text { source }\end{array}$ & Year & Date & $\begin{array}{l}\text { Sample collection } \\
\text { method }^{3}\end{array}$ & Acarina $^{4}$ & Acentrella & Agapetus & Ameletus & Amphinemura & Anagapetus \\
\hline 37 & 19.6 & USGS & 2000 & $8 / 17 / 2000$ & NAWQA & 1 & 4 & 0 & 0 & 0 & 0 \\
\hline 37 & 19.6 & USGS & 2001 & $8 / 17 / 2001$ & NAWQA & 2 & 1 & 0 & 0 & 0 & 0 \\
\hline 38 & 35.4 & FS & 2005 & $9 / 6 / 2005$ & surber & 9 & 1 & 0 & 0 & 0 & 0 \\
\hline 38 & 35.4 & FS & 2006 & $9 / 5 / 2006$ & surber & 29 & 0 & 0 & 0 & 0 & 0 \\
\hline 38 & 35.4 & FS & 2007 & $9 / 12 / 2007$ & surber & 2 & 0 & 0 & 0 & 0 & 0 \\
\hline 39 & 47.6 & USGS & 2000 & $8 / 18 / 2000$ & NAWQA & 3 & 2 & 0 & 0 & 0 & 0 \\
\hline 39 & 47.6 & FS & 2004 & $9 / 27 / 2004$ & surber & 27 & 0 & 0 & 0 & 0 & 0 \\
\hline 39 & 47.6 & FS & 2005 & $9 / 6 / 2005$ & surber & 17 & 0 & 0 & 0 & 0 & 0 \\
\hline 39 & 47.6 & FS & 2006 & $9 / 5 / 2006$ & surber & 33 & 0 & 0 & 0 & 0 & 0 \\
\hline 39 & 47.6 & FS & 2007 & $9 / 12 / 2007$ & surber & 7 & 0 & 0 & 0 & 0 & 0 \\
\hline 40 & 4.1 & FS & 2005 & $9 / 19 / 2005$ & surber & 70 & 0 & 0 & 15 & 0 & 0 \\
\hline 41 & 58.7 & USGS & 2000 & $8 / 18 / 2000$ & NAWQA & 6 & 8 & 0 & 0 & 0 & 0 \\
\hline 41 & 58.7 & FS & 2004 & $9 / 27 / 2004$ & surber & 35 & 0 & 0 & 0 & 0 & 0 \\
\hline 41 & 58.7 & FS & 2005 & $9 / 6 / 2005$ & surber & 31 & 0 & 0 & 0 & 0 & 0 \\
\hline 41 & 58.7 & FS & 2006 & $9 / 5 / 2006$ & surber & 48 & 0 & 0 & 0 & 0 & 0 \\
\hline 41 & 58.7 & FS & 2007 & $9 / 12 / 2007$ & surber & 39 & 0 & 0 & 0 & 0 & 0 \\
\hline 42 & 1.1 & FS & 2003 & $9 / 9 / 2003$ & surber & 1 & 0 & 0 & 2 & 0 & 0 \\
\hline 42 & 1.1 & FS & 2005 & $9 / 13 / 2005$ & surber & 3 & 0 & 0 & 2 & 0 & 0 \\
\hline 43 & 1.1 & FS & 2005 & $9 / 13 / 2005$ & surber & 16 & 0 & 0 & 0 & 0 & 0 \\
\hline 44 & 7.5 & USGS & 2000 & $8 / 17 / 2000$ & NAWQA & 16 & 0 & 0 & 0 & 0 & 0 \\
\hline 44 & 7.5 & USGS & 2001 & $8 / 17 / 2001$ & NAWQA & 0 & 0 & 0 & 0 & 0 & 0 \\
\hline 45 & 5.82 & FS & 2005 & $9 / 19 / 2005$ & surber & 10 & 0 & 0 & 1 & 0 & 0 \\
\hline 46 & 5.9 & FS & 2005 & $9 / 14 / 2005$ & surber & 5 & 0 & 0 & 0 & 0 & 0 \\
\hline 47 & 77.1 & USGS & 2000 & $8 / 18 / 2000$ & NAWQA & 4 & 0 & 0 & 0 & 0 & 0 \\
\hline 48 & 2.4 & FS & 2006 & $9 / 29 / 2006$ & surber & 19 & 0 & 0 & 2 & 0 & 1 \\
\hline 49 & 7.4 & FS & 2006 & $9 / 27 / 2006$ & surber & 6 & 0 & 0 & 2 & 0 & 0 \\
\hline 50 & 13.8 & FS & 2006 & $9 / 25 / 2006$ & surber & 15 & 0 & 0 & 0 & 0 & 1 \\
\hline 51 & 91.1 & USGS & 2000 & $8 / 18 / 2000$ & NAWQA & 2 & 0 & 0 & 0 & 0 & 0 \\
\hline 52 & 100 & USGS & 2000 & $8 / 18 / 2000$ & NAWQA & 6 & 1 & 0 & 0 & 0 & 0 \\
\hline 52 & 100 & FS & 2004 & $9 / 27 / 2004$ & surber & 16 & 0 & 0 & 0 & 0 & 0 \\
\hline 52 & 100 & FS & 2005 & $9 / 6 / 2005$ & surber & 27 & 0 & 0 & 0 & 0 & 0 \\
\hline 52 & 100 & FS & 2006 & $9 / 5 / 2006$ & surber & 21 & 0 & 0 & 0 & 0 & 0 \\
\hline 52 & 100 & FS & 2007 & $9 / 12 / 2007$ & surber & 12 & 0 & 0 & 0 & 0 & 0 \\
\hline 53 & 102 & USGS & 2000 & $8 / 17 / 2000$ & NAWQA & 1 & 7 & 0 & 0 & 0 & 0 \\
\hline 53 & 102 & USGS & 2001 & $8 / 16 / 2001$ & NAWQA & 0 & 3 & 0 & 0 & 0 & 0 \\
\hline 54 & 7.1 & FS & 2005 & $10 / 6 / 2005$ & surber & 6 & 0 & 0 & 0 & 0 & 3 \\
\hline 55 & 8.1 & USGS & 2000 & $8 / 16 / 2000$ & NAWQA & 0 & 0 & 0 & 0 & 0 & 0 \\
\hline 55 & 8.1 & USGS & 2001 & $8 / 16 / 2001$ & NAWQA & 1 & 0 & 0 & 0 & 0 & 0 \\
\hline 56 & 14.8 & USGS & 2000 & $8 / 16 / 2000$ & NAWQA & 0 & 0 & 0 & 0 & 0 & 0 \\
\hline 57 & 395 & USGS & 2000 & $8 / 16 / 2000$ & NAWQA & 2 & 0 & 0 & 0 & 0 & 0 \\
\hline 57 & 395 & USGS & 2001 & $8 / 16 / 2001$ & NAWQA & 0 & 0 & 0 & 0 & 0 & 0 \\
\hline 58 & 5.2 & FS & 2006 & $9 / 28 / 2006$ & surber & 0 & 0 & 0 & 7 & 10 & 0 \\
\hline 59 & 424 & USGS & 2000 & $8 / 15 / 2000$ & NAWQA & 0 & 0 & 0 & 0 & 0 & 0 \\
\hline 59 & 424 & USGS & 2001 & $8 / 16 / 2001$ & NAWQA & 0 & 0 & 0 & 0 & 0 & 0 \\
\hline 60 & 5 & FS & 2006 & $9 / 22 / 2006$ & surber & 3 & 0 & 0 & 0 & 0 & 0 \\
\hline 61 & 4.34 & FS & 2006 & $9 / 27 / 2006$ & surber & 9 & 0 & 0 & 1 & 0 & 0 \\
\hline 62 & 11 & USGS & 2000 & $8 / 15 / 2000$ & NAWQA & 0 & 0 & 0 & 0 & 0 & 0 \\
\hline 63 & 49 & USGS & 2000 & $8 / 15 / 2000$ & NAWQA & 0 & 0 & 0 & 0 & 2 & 0 \\
\hline 63 & 49 & USGS & 2001 & $8 / 15 / 2001$ & NAWQA & 0 & 0 & 2 & 0 & 0 & 0 \\
\hline 64 & 2.1 & FS & 2005 & $9 / 12 / 2005$ & surber & 14 & 0 & 0 & 4 & 0 & 0 \\
\hline 65 & 4.12 & FS & 2005 & $9 / 12 / 2005$ & surber & 0 & 0 & 0 & 1 & 0 & 0 \\
\hline 65 & 4.12 & FS & 2006 & $9 / 21 / 2006$ & surber & 4 & 0 & 0 & 0 & 0 & 0 \\
\hline 66 & 17.4 & USGS & 2000 & $8 / 15 / 2000$ & NAWQA & 0 & 0 & 0 & 0 & 1 & 0 \\
\hline 67 & 517 & USGS & 2000 & $8 / 15 / 2000$ & NAWQA & 2 & 0 & 0 & 0 & 0 & 0 \\
\hline 68 & 600 & USGS & 2000 & $8 / 15 / 2000$ & NAWQA & 3 & 0 & 0 & 0 & 0 & 0 \\
\hline 68 & 600 & USGS & 2001 & $8 / 15 / 2001$ & NAWQA & 1 & 0 & 1 & 0 & 0 & 0 \\
\hline 69 & 646 & USGS & 2000 & $8 / 14 / 2000$ & NAWQA & 0 & 0 & 0 & 0 & 0 & 0 \\
\hline 70 & 32.6 & USGS & 2000 & $8 / 14 / 2000$ & NAWQA & 0 & 0 & 0 & 0 & 0 & 0 \\
\hline 71 & 147 & USGS & 2000 & $8 / 14 / 2000$ & NAWQA & 0 & 0 & 1 & 0 & 0 & 0 \\
\hline 71 & 147 & USGS & 2001 & $8 / 15 / 2001$ & NAWQA & 0 & 0 & 0 & 0 & 0 & 0 \\
\hline 72 & 842 & USGS & 2000 & $8 / 14 / 2000$ & NAWQA & 3 & 0 & 0 & 0 & 0 & 0 \\
\hline 72 & 842 & USGS & 2001 & $8 / 15 / 2001$ & NAWQA & 0 & 0 & 0 & 0 & 0 & 0 \\
\hline 73 & 103 & USGS & 2000 & $8 / 14 / 2000$ & NAWQA & 0 & 0 & 0 & 0 & 0 & 0 \\
\hline 73 & 103 & USGS & 2001 & $8 / 15 / 2001$ & NAWQA & 1 & 0 & 0 & 0 & 0 & 0 \\
\hline
\end{tabular}


Table 1. Description of sites and macroinvertebrate data collected from selected sites the Eagle River watershed, Colorado, 2000-2007.-Continued

[ID, identification; NAVD, North American Vertical Datum of 1988; ft, feet; mi², square miles; ’, degrees; ', minutes; ", seconds; FS, U.S. Department of Agriculture Forest Service; USGS, U.S. Geological Survey]

\begin{tabular}{|c|c|c|c|c|c|c|c|c|c|c|}
\hline Site ID' & Antocha & Arctopsyche & Asellidae & Atherix & Attenella & Baetis & Blephariceridae & Brachycentrus & $\begin{array}{c}\text { Caloparyphus } \\
\text { Euparyphus }\end{array}$ & Capniidae \\
\hline 2 & 0 & 2 & 0 & 0 & 0 & 15 & 0 & 0 & 0 & 0 \\
\hline 3 & 0 & 0 & 0 & 0 & 0 & 20 & 0 & 0 & 0 & 0 \\
\hline 5 & 2 & 2 & 0 & 0 & 0 & 39 & 0 & 1 & 0 & 1 \\
\hline 6 & 0 & 12 & 0 & 0 & 0 & 130 & 0 & 2 & 0 & 0 \\
\hline 6 & 1 & 25 & 0 & 0 & 0 & 113 & 0 & 1 & 0 & 0 \\
\hline 10 & 0 & 5 & 0 & 0 & 0 & 29 & 0 & 0 & 0 & 0 \\
\hline 10 & 0 & 15 & 0 & 0 & 0 & 52 & 0 & 5 & 0 & 0 \\
\hline 11 & 41 & 6 & 0 & 13 & 0 & 11 & 0 & 14 & 0 & 0 \\
\hline 12 & 19 & 11 & 0 & 3 & 0 & 6 & 0 & 26 & 0 & 0 \\
\hline 13 & 25 & 8 & 0 & 2 & 0 & 3 & 0 & 34 & 0 & 1 \\
\hline 14 & 0 & 14 & 0 & 1 & 0 & 53 & 0 & 4 & 0 & 3 \\
\hline 18 & 0 & 12 & 0 & 0 & 0 & 46 & 0 & 0 & 0 & 3 \\
\hline 18 & 0 & 8 & 0 & 0 & 0 & 35 & 0 & 0 & 0 & 1 \\
\hline 19 & 0 & 2 & 0 & 0 & 0 & 106 & 0 & 0 & 0 & 2 \\
\hline 20 & 0 & 19 & 0 & 0 & 0 & 98 & 0 & 0 & 0 & 0 \\
\hline 21 & 0 & 5 & 0 & 0 & 0 & 60 & 0 & 27 & 0 & 0 \\
\hline 22 & 32 & 17 & 0 & 2 & 0 & 68 & 0 & 34 & 0 & 0 \\
\hline 23 & 0 & 0 & 0 & 0 & 0 & 50 & 0 & 0 & 0 & 0 \\
\hline 24 & 36 & 7 & 0 & 22 & 0 & 16 & 0 & 97 & 0 & 0 \\
\hline 25 & 1 & 35 & 0 & 5 & 0 & 24 & 0 & 68 & 0 & 0 \\
\hline 26 & 0 & 0 & 0 & 0 & 0 & 5 & 0 & 0 & 0 & 0 \\
\hline 27 & 0 & 2 & 0 & 0 & 0 & 33 & 0 & 0 & 0 & 8 \\
\hline 27 & 0 & 0 & 0 & 0 & 0 & 21 & 0 & 0 & 0 & 3 \\
\hline 27 & 0 & 0 & 0 & 0 & 0 & 64 & 0 & 0 & 0 & 2 \\
\hline 28 & 0 & 0 & 0 & 0 & 0 & 21 & 0 & 0 & 0 & 4 \\
\hline 30 & 0 & 0 & 0 & 0 & 0 & 12 & 0 & 0 & 0 & 1 \\
\hline 30 & 0 & 0 & 0 & 0 & 0 & 6 & 0 & 0 & 0 & 0 \\
\hline 31 & 0 & 0 & 0 & 0 & 0 & 15 & 0 & 0 & 0 & 5 \\
\hline 31 & 0 & 0 & 0 & 0 & 0 & 1 & 0 & 0 & 0 & 0 \\
\hline 31 & 0 & 0 & 0 & 0 & 0 & 230 & 0 & 0 & 0 & 0 \\
\hline 31 & 1 & 0 & 0 & 0 & 0 & 10 & 0 & 0 & 0 & 6 \\
\hline 32 & 0 & 0 & 0 & 0 & 0 & 2 & 0 & 0 & 0 & 0 \\
\hline 32 & 0 & 0 & 0 & 0 & 0 & 7 & 0 & 0 & 0 & 0 \\
\hline 32 & 0 & 0 & 0 & 0 & 0 & 82 & 0 & 0 & 0 & 1 \\
\hline 33 & 0 & 1 & 0 & 0 & 0 & 11 & 0 & 0 & 0 & 1 \\
\hline 33 & 0 & 0 & 0 & 0 & 0 & 22 & 1 & 0 & 0 & 1 \\
\hline 33 & 0 & 0 & 0 & 0 & 0 & 61 & 0 & 0 & 0 & 1 \\
\hline 33 & 0 & 0 & 0 & 0 & 0 & 26 & 0 & 0 & 0 & 1 \\
\hline 34 & 0 & 0 & 0 & 0 & 0 & 75 & 0 & 0 & 0 & 3 \\
\hline 34 & 0 & 0 & 0 & 0 & 0 & 7 & 0 & 0 & 0 & 2 \\
\hline 34 & 0 & 0 & 0 & 0 & 0 & 2 & 0 & 0 & 0 & 0 \\
\hline 34 & 0 & 0 & 0 & 0 & 0 & 66 & 0 & 0 & 0 & 3 \\
\hline 34 & 0 & 1 & 0 & 0 & 0 & 32 & 0 & 2 & 0 & 13 \\
\hline 35 & 0 & 0 & 0 & 0 & 0 & 28 & 0 & 0 & 0 & 0 \\
\hline 36 & 0 & 0 & 0 & 0 & 0 & 29 & 0 & 0 & 0 & 1 \\
\hline 36 & 0 & 1 & 0 & 0 & 0 & 35 & 0 & 0 & 0 & 1 \\
\hline 36 & 0 & 1 & 0 & 0 & 0 & 97 & 0 & 0 & 0 & 1 \\
\hline 36 & 0 & 1 & 0 & 0 & 0 & 52 & 0 & 0 & 0 & 2 \\
\hline
\end{tabular}


Table 1. Description of sites and macroinvertebrate data collected from selected sites the Eagle River watershed, Colorado, 2000-2007.-Continued

[ID, identification; NAVD, North American Vertical Datum of 1988; ft, feet; mi² , square miles; ${ }^{\circ}$, degrees; ', minutes; ", seconds; FS, U.S. Department of Agriculture Forest Service; USGS, U.S. Geological Survey]

\begin{tabular}{|c|c|c|c|c|c|c|c|c|c|c|}
\hline Site ID' & Antocha & Arctopsyche & Asellidae & Atherix & Attenella & Baetis & Blephariceridae & Brachycentrus & $\begin{array}{c}\text { Caloparyphus } \\
\text { Euparyphus }\end{array}$ & Capniidae \\
\hline 37 & 0 & 3 & 0 & 0 & 0 & 178 & 0 & 2 & 0 & 0 \\
\hline 38 & 0 & 0 & 0 & 0 & 0 & 30 & 0 & 0 & 0 & 0 \\
\hline 38 & 0 & 0 & 0 & 0 & 0 & 101 & 0 & 2 & 0 & 0 \\
\hline 39 & 0 & 11 & 0 & 0 & 0 & 100 & 0 & 1 & 0 & 0 \\
\hline 39 & 0 & 2 & 0 & 0 & 0 & 89 & 0 & 3 & 0 & 3 \\
\hline 39 & 0 & 0 & 0 & 0 & 0 & 169 & 0 & 3 & 0 & 0 \\
\hline 40 & 0 & 0 & 0 & 0 & 0 & 9 & 0 & 0 & 0 & 5 \\
\hline 41 & 0 & 16 & 0 & 0 & 0 & 51 & 0 & 39 & 0 & 0 \\
\hline 41 & 4 & 1 & 0 & 0 & 0 & 21 & 0 & 12 & 0 & 0 \\
\hline 41 & 2 & 7 & 0 & 0 & 0 & 14 & 0 & 30 & 0 & 0 \\
\hline 41 & 0 & 0 & 0 & 0 & 0 & 21 & 0 & 75 & 0 & 0 \\
\hline 41 & 1 & 0 & 0 & 0 & 0 & 47 & 0 & 63 & 0 & 0 \\
\hline 44 & 0 & 0 & 0 & 0 & 0 & 33 & 0 & 0 & 0 & 0 \\
\hline 45 & 0 & 0 & 0 & 0 & 0 & 9 & 0 & 0 & 0 & 0 \\
\hline 46 & 0 & 0 & 0 & 0 & 0 & 29 & 0 & 0 & 0 & 0 \\
\hline 47 & 0 & 1 & 0 & 0 & 0 & 15 & 0 & 6 & 0 & 0 \\
\hline 48 & 0 & 0 & 0 & 0 & 0 & 3 & 0 & 0 & 0 & 0 \\
\hline 49 & 0 & 1 & 0 & 0 & 0 & 24 & 0 & 0 & 0 & 0 \\
\hline 50 & 1 & 10 & 0 & 0 & 0 & 36 & 0 & 5 & 0 & 7 \\
\hline 51 & 0 & 1 & 0 & 0 & 0 & 18 & 0 & 0 & 0 & 0 \\
\hline 52 & 0 & 0 & 0 & 0 & 0 & 21 & 0 & 2 & 0 & 0 \\
\hline 52 & 1 & 0 & 0 & 0 & 0 & 105 & 0 & 21 & 0 & 0 \\
\hline 52 & 5 & 0 & 0 & 0 & 0 & 86 & 0 & 25 & 0 & 0 \\
\hline 52 & 0 & 0 & 0 & 0 & 0 & 83 & 0 & 44 & 0 & 0 \\
\hline 52 & 0 & 0 & 0 & 0 & 0 & 43 & 0 & 40 & 0 & 0 \\
\hline 59 & 0 & 14 & 0 & 0 & 0 & 20 & 0 & 34 & 0 & 0 \\
\hline 59 & 1 & 7 & 0 & 0 & 0 & 26 & 0 & 52 & 0 & 0 \\
\hline 60 & 2 & 19 & 0 & 0 & 0 & 32 & 0 & 1 & 1 & 0 \\
\hline 61 & 0 & 0 & 0 & 0 & 0 & 1 & 0 & 0 & 0 & 0 \\
\hline 62 & 0 & 0 & 0 & 0 & 0 & 53 & 0 & 0 & 0 & 2 \\
\hline 63 & 0 & 9 & 0 & 0 & 0 & 168 & 0 & 0 & 0 & 0 \\
\hline 63 & 0 & 0 & 0 & 0 & 0 & 33 & 0 & 5 & 0 & 0 \\
\hline 64 & 0 & 0 & 0 & 0 & 0 & 3 & 0 & 0 & 0 & 0 \\
\hline 65 & 0 & 0 & 0 & 0 & 0 & 17 & 0 & 0 & 0 & 0 \\
\hline 65 & 1 & 0 & 0 & 0 & 0 & 8 & 0 & 0 & 0 & 3 \\
\hline 66 & 0 & 0 & 0 & 0 & 0 & 101 & 0 & 0 & 0 & 0 \\
\hline 67 & 0 & 3 & 0 & 2 & 0 & 52 & 0 & 45 & 0 & 0 \\
\hline 68 & 0 & 12 & 0 & 2 & 0 & 82 & 0 & 31 & 0 & 0 \\
\hline 68 & 0 & 3 & 0 & 1 & 2 & 88 & 0 & 43 & 0 & 0 \\
\hline 69 & 0 & 2 & 0 & 4 & 1 & 25 & 0 & 94 & 0 & 0 \\
\hline 70 & 0 & 1 & 0 & 0 & 0 & 40 & 0 & 0 & 0 & 0 \\
\hline 71 & 5 & 6 & 0 & 1 & 0 & 32 & 0 & 7 & 0 & 0 \\
\hline 71 & 0 & 3 & 0 & 1 & 0 & 12 & 0 & 42 & 0 & 0 \\
\hline 72 & 1 & 0 & 0 & 3 & 0 & 12 & 0 & 106 & 0 & 0 \\
\hline 72 & 0 & 0 & 0 & 0 & 2 & 24 & 0 & 163 & 0 & 0 \\
\hline 73 & 0 & 2 & 0 & 2 & 0 & 30 & 0 & 49 & 0 & 0 \\
\hline 73 & 1 & 1 & 0 & 0 & 0 & 34 & 0 & 47 & 1 & 0 \\
\hline
\end{tabular}


Table 1. Description of sites and macroinvertebrate data collected from selected sites the Eagle River watershed, Colorado, 2000-2007.-Continued

[ID, identification; NAVD, North American Vertical Datum of 1988; ft, feet; $\mathrm{mi}^{2}$, square miles; ${ }^{\circ}$, degrees; ', minutes; ", seconds; FS, U.S. Department of Agriculture Forest Service; USGS, U.S. Geological Survey]

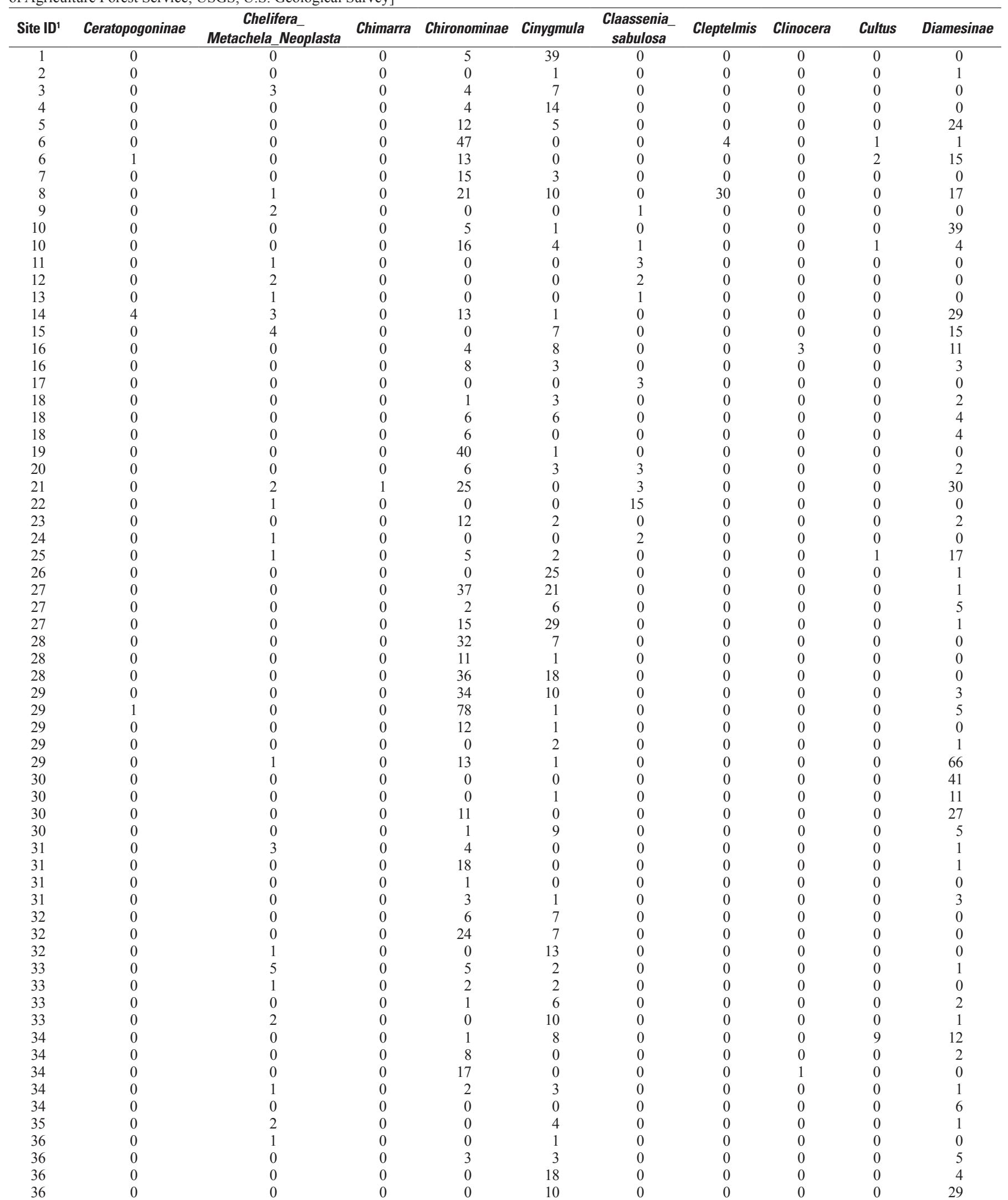


Table 1. Description of sites and macroinvertebrate data collected from selected sites the Eagle River watershed, Colorado, 2000-2007.-Continued

[ID, identification; NAVD, North American Vertical Datum of 1988; ft, feet; mi², square miles; ’, degrees; ', minutes; ", seconds; FS, U.S. Department of Agriculture Forest Service; USGS, U.S. Geological Survey]

\begin{tabular}{|c|c|c|c|c|c|c|c|c|c|c|}
\hline Site ID ${ }^{1}$ & Ceratopogoninae & $\begin{array}{c}\text { Chelifera_ } \\
\text { Metachela_Neoplasta }\end{array}$ & Chimarra & Chironominae & Cinygmula & $\begin{array}{c}\text { Claassenia_ } \\
\text { sabulosa }\end{array}$ & Cleptelmis & Clinocera & Cultus & Diamesinae \\
\hline 37 & 0 & 0 & 0 & 0 & 3 & 0 & 0 & 0 & 0 & 78 \\
\hline 37 & 0 & 0 & 0 & 1 & 2 & 0 & 0 & 0 & 4 & 27 \\
\hline 38 & 0 & 0 & 0 & 4 & 0 & 0 & 0 & 0 & 0 & 17 \\
\hline 38 & 0 & 0 & 0 & 3 & 0 & 0 & 0 & 1 & 0 & 64 \\
\hline 38 & 0 & 0 & 0 & 5 & 0 & 0 & 0 & 0 & 0 & 18 \\
\hline 39 & 0 & 0 & 0 & 1 & 1 & 0 & 0 & 0 & 1 & 33 \\
\hline 39 & 0 & 0 & 0 & 17 & 0 & 0 & 0 & 0 & 0 & 7 \\
\hline 39 & 0 & 0 & 0 & 17 & 0 & 0 & 0 & 1 & 0 & 20 \\
\hline 39 & 0 & 2 & 0 & 6 & 0 & 0 & 0 & 0 & 0 & 61 \\
\hline 39 & 0 & 0 & 0 & 2 & 0 & 0 & 0 & 0 & 0 & 62 \\
\hline 40 & 0 & 2 & 0 & 0 & 2 & 0 & 0 & 0 & 0 & 0 \\
\hline 41 & 0 & 0 & 0 & 8 & 2 & 0 & 0 & 0 & 0 & 22 \\
\hline 41 & 0 & 0 & 0 & 14 & 0 & 0 & 0 & 0 & 0 & 3 \\
\hline 41 & 0 & 0 & 0 & 24 & 0 & 0 & 0 & 1 & 0 & 31 \\
\hline 41 & 0 & 2 & 0 & 2 & 0 & 0 & 0 & 1 & 0 & 51 \\
\hline 41 & 0 & 0 & 0 & 2 & 0 & 0 & 0 & 0 & 0 & 49 \\
\hline 42 & 0 & 0 & 0 & 1 & 12 & 0 & 0 & 1 & 0 & 18 \\
\hline 42 & 0 & 11 & 0 & 0 & 5 & 0 & 0 & 0 & 0 & 18 \\
\hline 43 & 0 & 2 & 0 & 0 & 0 & 0 & 0 & 0 & 0 & 20 \\
\hline 44 & 0 & 0 & 0 & 5 & 1 & 0 & 1 & 0 & 0 & 66 \\
\hline 44 & 0 & 0 & 0 & 0 & 0 & 0 & 0 & 0 & 0 & 154 \\
\hline 45 & 0 & 0 & 0 & 0 & 7 & 0 & 0 & 0 & 0 & 2 \\
\hline 46 & 0 & 0 & 0 & 1 & 3 & 0 & 0 & 0 & 0 & 1 \\
\hline 47 & 1 & 0 & 0 & 0 & 1 & 0 & 0 & 0 & 0 & 75 \\
\hline 48 & 0 & 0 & 0 & 11 & 0 & 0 & 0 & 0 & 0 & 6 \\
\hline 49 & 0 & 0 & 0 & 5 & 0 & 0 & 0 & 0 & 0 & 2 \\
\hline 50 & 0 & 2 & 0 & 5 & 2 & 0 & 0 & 0 & 0 & 2 \\
\hline 51 & 0 & 0 & 0 & 0 & 0 & 0 & 0 & 0 & 0 & 127 \\
\hline 52 & 0 & 1 & 0 & 12 & 0 & 0 & 0 & 0 & 0 & 40 \\
\hline 52 & 0 & 0 & 0 & 112 & 0 & 0 & 0 & 0 & 0 & 1 \\
\hline 52 & 0 & 0 & 0 & 27 & 0 & 0 & 0 & 0 & 0 & 38 \\
\hline 52 & 0 & 0 & 0 & 1 & 0 & 0 & 0 & 0 & 0 & 6 \\
\hline 52 & 0 & 0 & 0 & 5 & 0 & 0 & 0 & 0 & 0 & 6 \\
\hline 53 & 0 & 0 & 0 & 9 & 0 & 0 & 0 & 0 & 0 & 31 \\
\hline 53 & 0 & 1 & 0 & 35 & 0 & 0 & 0 & 0 & 0 & 50 \\
\hline 54 & 0 & 0 & 0 & 6 & 3 & 0 & 0 & 0 & 0 & 1 \\
\hline 55 & 0 & 0 & 0 & 0 & 6 & 0 & 11 & 0 & 0 & 10 \\
\hline 55 & 0 & 0 & 0 & 36 & 4 & 0 & 0 & 0 & 0 & 8 \\
\hline 56 & 0 & 0 & 0 & 17 & 0 & 0 & 0 & 0 & 0 & 117 \\
\hline 57 & 0 & 0 & 0 & 8 & 0 & 0 & 0 & 0 & 0 & 34 \\
\hline 57 & 0 & 1 & 0 & 14 & 0 & 0 & 1 & 0 & 0 & 43 \\
\hline 58 & 0 & 0 & 0 & 10 & 8 & 0 & 0 & 0 & 0 & 2 \\
\hline 59 & 0 & 0 & 0 & 39 & 0 & 0 & 0 & 0 & 0 & 41 \\
\hline 59 & 0 & 0 & 0 & 51 & 0 & 0 & 0 & 0 & 0 & 32 \\
\hline 60 & 0 & 11 & 0 & 0 & 4 & 0 & 0 & 0 & 0 & 5 \\
\hline 61 & 0 & 0 & 0 & 14 & 71 & 0 & 0 & 0 & 0 & 8 \\
\hline 62 & 0 & 1 & 0 & 13 & 14 & 0 & 0 & 0 & 2 & 1 \\
\hline 63 & 0 & 0 & 0 & 5 & 0 & 0 & 1 & 0 & 0 & 62 \\
\hline 63 & 0 & 0 & 0 & 2 & 0 & 0 & 0 & 0 & 0 & 71 \\
\hline 64 & 0 & 0 & 0 & 15 & 10 & 0 & 0 & 0 & 0 & 13 \\
\hline 65 & 0 & 0 & 0 & 0 & 7 & 0 & 0 & 0 & 0 & 0 \\
\hline 65 & 0 & 0 & 0 & 8 & 1 & 0 & 0 & 0 & 0 & 4 \\
\hline 66 & 0 & 0 & 0 & 4 & 0 & 0 & 10 & 0 & 0 & 1 \\
\hline 67 & 0 & 0 & 0 & 25 & 0 & 0 & 15 & 0 & 0 & 26 \\
\hline 68 & 0 & 0 & 0 & 11 & 0 & 1 & 0 & 0 & 0 & 1 \\
\hline 68 & 0 & 0 & 0 & 9 & 0 & 0 & 0 & 0 & 0 & 9 \\
\hline 69 & 0 & 0 & 0 & 28 & 0 & 0 & 0 & 0 & 0 & 5 \\
\hline 70 & 0 & 0 & 0 & 2 & 2 & 0 & 0 & 0 & 0 & 9 \\
\hline 71 & 0 & 0 & 0 & 18 & 0 & 0 & 0 & 0 & 0 & 12 \\
\hline 71 & 0 & 0 & 0 & 11 & 0 & 0 & 0 & 0 & 0 & 27 \\
\hline 72 & 0 & 0 & 0 & 35 & 0 & 1 & 0 & 0 & 0 & 0 \\
\hline 72 & 0 & 0 & 0 & 11 & 0 & 1 & 0 & 0 & 2 & 2 \\
\hline 73 & 0 & 3 & 0 & 2 & 0 & 0 & 13 & 0 & 0 & 1 \\
\hline 73 & 0 & 0 & 0 & 1 & 0 & 0 & 18 & 0 & 0 & 41 \\
\hline
\end{tabular}


Table 1. Description of sites and macroinvertebrate data collected from selected sites the Eagle River watershed, Colorado, 2000-2007.-Continued

[ID, identification; NAVD, North American Vertical Datum of 1988; ft, feet; mi², square miles; ’, degrees; ', minutes; ", seconds; FS, U.S. Department of Agriculture Forest Service; USGS, U.S. Geological Survey]

\begin{tabular}{|c|c|c|c|c|c|c|c|c|c|c|}
\hline Site ID ${ }^{1}$ & Dicosmoecus & Dicranota & Diphetor & Diura & Dixa & Dolophilodes & $\begin{array}{c}\text { Drunella_ } \\
\text { coloradensis_flavilinea }\end{array}$ & $\begin{array}{r}\text { Drunella } \\
\text { doddsi }\end{array}$ & $\begin{array}{c}\text { Drunella_ } \\
\text { grandis }\end{array}$ & Epeorus \\
\hline 1 & 0 & 0 & 0 & 0 & 0 & 0 & 1 & 6 & 2 & 12 \\
\hline 2 & 0 & 0 & 1 & 0 & 0 & 0 & 0 & 0 & 0 & 0 \\
\hline 3 & 0 & 0 & 0 & 0 & 0 & 0 & 0 & 1 & 0 & 1 \\
\hline 4 & 0 & 0 & 0 & 0 & 0 & 3 & 2 & 9 & 4 & 10 \\
\hline 5 & 0 & 0 & 0 & 0 & 0 & 0 & 0 & 4 & 4 & 0 \\
\hline 6 & 0 & 1 & 0 & 0 & 0 & 0 & 4 & 5 & 0 & 4 \\
\hline 6 & 0 & 0 & 0 & 0 & 0 & 2 & 1 & 1 & 0 & 3 \\
\hline 7 & 0 & 1 & 5 & 0 & 0 & 0 & 0 & 18 & 0 & 0 \\
\hline 8 & 0 & 0 & 0 & 0 & 0 & 0 & 8 & 3 & 0 & 3 \\
\hline 9 & 27 & 0 & 0 & 0 & 0 & 0 & 0 & 0 & 0 & 16 \\
\hline 10 & 0 & 0 & 0 & 0 & 0 & 0 & 1 & 7 & 2 & 7 \\
\hline 10 & 0 & 0 & 0 & 0 & 0 & 1 & 0 & 31 & 2 & 8 \\
\hline 11 & 11 & 0 & 0 & 0 & 0 & 0 & 0 & 0 & 0 & 64 \\
\hline 12 & 11 & 0 & 0 & 0 & 2 & 0 & 0 & 0 & 0 & 94 \\
\hline 13 & 6 & 0 & 0 & 0 & 2 & 0 & 0 & 0 & 0 & 130 \\
\hline 14 & 0 & 0 & 0 & 0 & 0 & 0 & 0 & 58 & 2 & 1 \\
\hline 15 & 0 & 0 & 0 & 0 & 0 & 0 & 0 & 1 & 0 & 0 \\
\hline 16 & 0 & 0 & 0 & 0 & 0 & 0 & 4 & 0 & 0 & 4 \\
\hline 16 & 0 & 0 & 0 & 0 & 0 & 1 & 0 & 6 & 0 & 4 \\
\hline 17 & 13 & 0 & 0 & 0 & 0 & 0 & 0 & 0 & 0 & 36 \\
\hline 18 & 0 & 2 & 0 & 0 & 0 & 0 & 0 & 3 & 0 & 0 \\
\hline 18 & 0 & 0 & 0 & 0 & 0 & 0 & 0 & 6 & 0 & 0 \\
\hline 18 & 0 & 0 & 0 & 1 & 0 & 0 & 0 & 2 & 0 & 0 \\
\hline 19 & 0 & 0 & 0 & 0 & 0 & 0 & 0 & 1 & 1 & 0 \\
\hline 20 & 0 & 1 & 0 & 0 & 0 & 2 & 0 & 17 & 2 & 1 \\
\hline 21 & 0 & 0 & 0 & 0 & 0 & 0 & 0 & 3 & 5 & 1 \\
\hline 22 & 20 & 0 & 0 & 0 & 0 & 0 & 0 & 0 & 0 & 19 \\
\hline 23 & 0 & 0 & 0 & 0 & 0 & 0 & 6 & 2 & 0 & 4 \\
\hline 24 & 14 & 0 & 0 & 0 & 0 & 0 & 0 & 0 & 0 & 7 \\
\hline 25 & 0 & 0 & 0 & 0 & 0 & 0 & 0 & 84 & 1 & 2 \\
\hline 26 & 0 & 0 & 0 & 0 & 0 & 0 & 3 & 7 & 0 & 1 \\
\hline 27 & 0 & 0 & 0 & 0 & 0 & 0 & 0 & 9 & 0 & 1 \\
\hline 27 & 0 & 0 & 0 & 0 & 0 & 0 & 0 & 44 & 0 & 5 \\
\hline 27 & 0 & 1 & 0 & 0 & 0 & 0 & 2 & 8 & 0 & 0 \\
\hline 28 & 0 & 0 & 0 & 0 & 0 & 0 & 0 & 27 & 0 & 0 \\
\hline 28 & 0 & 0 & 0 & 0 & 0 & 6 & 0 & 32 & 0 & 21 \\
\hline 28 & 0 & 0 & 0 & 0 & 0 & 0 & 0 & 13 & 0 & 0 \\
\hline 29 & 0 & 0 & 0 & 0 & 0 & 0 & 1 & 35 & 0 & 24 \\
\hline 29 & 0 & 0 & 0 & 0 & 0 & 1 & 0 & 10 & 3 & 11 \\
\hline 29 & 0 & 0 & 0 & 0 & 0 & 3 & 0 & 31 & 0 & 5 \\
\hline 29 & 0 & 0 & 0 & 0 & 0 & 7 & 1 & 38 & 1 & 27 \\
\hline 29 & 0 & 0 & 0 & 0 & 0 & 0 & 0 & 12 & 0 & 3 \\
\hline 30 & 0 & 2 & 5 & 0 & 0 & 0 & 0 & 0 & 1 & 1 \\
\hline 30 & 0 & 0 & 32 & 0 & 0 & 0 & 0 & 1 & 1 & 0 \\
\hline 30 & 0 & 1 & 4 & 0 & 0 & 0 & 0 & 0 & 0 & 0 \\
\hline 30 & 0 & 2 & 12 & 0 & 0 & 0 & 0 & 1 & 1 & 0 \\
\hline 31 & 0 & 2 & 0 & 0 & 0 & 0 & 0 & 1 & 0 & 0 \\
\hline 31 & 0 & 1 & 0 & 0 & 0 & 0 & 0 & 0 & 0 & 0 \\
\hline 31 & 0 & 0 & 0 & 0 & 0 & 0 & 0 & 0 & 0 & 1 \\
\hline 31 & 0 & 0 & 0 & 0 & 0 & 0 & 0 & 0 & 0 & 1 \\
\hline 32 & 0 & 0 & 0 & 0 & 0 & 0 & 0 & 21 & 0 & 0 \\
\hline 32 & 0 & 0 & 0 & 0 & 0 & 0 & 0 & 8 & 0 & 0 \\
\hline 32 & 0 & 0 & 0 & 0 & 0 & 0 & 2 & 28 & 0 & 7 \\
\hline 33 & 0 & 0 & 0 & 0 & 0 & 0 & 0 & 7 & 0 & 0 \\
\hline 33 & 0 & 0 & 0 & 0 & 0 & 0 & 0 & 6 & 0 & 0 \\
\hline 33 & 1 & 0 & 0 & 0 & 0 & 0 & 1 & 23 & 0 & 36 \\
\hline 33 & 0 & 0 & 0 & 0 & 0 & 0 & 0 & 9 & 0 & 0 \\
\hline 34 & 0 & 0 & 0 & 0 & 0 & 0 & 9 & 18 & 0 & 7 \\
\hline 34 & 5 & 0 & 0 & 3 & 0 & 0 & 0 & 0 & 0 & 0 \\
\hline 34 & 0 & 0 & 0 & 0 & 0 & 0 & 0 & 0 & 0 & 0 \\
\hline 34 & 0 & 1 & 0 & 0 & 0 & 0 & 0 & 6 & 0 & 4 \\
\hline 34 & 0 & 0 & 0 & 0 & 0 & 0 & 0 & 3 & 0 & 0 \\
\hline 35 & 0 & 0 & 0 & 0 & 0 & 0 & 0 & 0 & 0 & 4 \\
\hline 36 & 1 & 1 & 0 & 0 & 0 & 0 & 0 & 4 & 1 & 0 \\
\hline 36 & 0 & 0 & 0 & 0 & 0 & 0 & 0 & 0 & 1 & 0 \\
\hline 36 & 0 & 0 & 0 & 0 & 0 & 0 & 0 & 18 & 1 & 13 \\
\hline 36 & 0 & 0 & 0 & 0 & 0 & 0 & 0 & 5 & 0 & 0 \\
\hline
\end{tabular}


Table 1. Description of sites and macroinvertebrate data collected from selected sites the Eagle River watershed, Colorado, 2000-2007.-Continued

[ID, identification; NAVD, North American Vertical Datum of 1988; ft, feet; mi², square miles; ’, degrees; ', minutes; ", seconds; FS, U.S. Department of Agriculture Forest Service; USGS, U.S. Geological Survey]

\begin{tabular}{|c|c|c|c|c|c|c|c|c|c|c|}
\hline Site ID & Dicosmoecus & Dicranota & Diphetor & Diura & Dixa & Dolophilodes & $\begin{array}{c}\text { Drunella_ } \\
\text { coloradensis_flavilinea }\end{array}$ & $\begin{array}{l}\text { Drunella } \\
\text { doddsi }\end{array}$ & $\begin{array}{c}\text { Drunella_ } \\
\text { grandis }\end{array}$ & Epeorus \\
\hline 37 & 0 & 0 & 0 & 0 & 0 & 0 & 4 & 4 & 0 & 34 \\
\hline 37 & 0 & 0 & 0 & 0 & 0 & 0 & 2 & 0 & 1 & 34 \\
\hline 38 & 0 & 0 & 0 & 0 & 0 & 0 & 0 & 0 & 0 & 0 \\
\hline 38 & 0 & 0 & 0 & 0 & 0 & 0 & 0 & 0 & 1 & 0 \\
\hline 38 & 0 & 0 & 0 & 0 & 0 & 0 & 0 & 0 & 0 & 0 \\
\hline 39 & 0 & 0 & 0 & 0 & 0 & 0 & 2 & 7 & 0 & 12 \\
\hline 39 & 0 & 0 & 0 & 0 & 0 & 0 & 0 & 0 & 2 & 0 \\
\hline 39 & 0 & 0 & 0 & 0 & 0 & 0 & 0 & 0 & 0 & 0 \\
\hline 39 & 0 & 0 & 0 & 0 & 0 & 0 & 0 & 0 & 0 & 0 \\
\hline 39 & 0 & 0 & 0 & 0 & 0 & 0 & 0 & 0 & 0 & 0 \\
\hline 40 & 0 & 0 & 0 & 0 & 0 & 0 & 0 & 23 & 0 & 3 \\
\hline 41 & 0 & 0 & 0 & 0 & 0 & 0 & 0 & 2 & 6 & 13 \\
\hline 41 & 0 & 4 & 0 & 0 & 0 & 0 & 0 & 0 & 0 & 0 \\
\hline 41 & 0 & 0 & 0 & 0 & 0 & 0 & 0 & 0 & 0 & 0 \\
\hline 41 & 0 & 0 & 0 & 0 & 0 & 0 & 0 & 0 & 0 & 0 \\
\hline 41 & 0 & 0 & 0 & 0 & 0 & 0 & 0 & 0 & 1 & 0 \\
\hline 42 & 0 & 0 & 0 & 0 & 0 & 0 & 0 & 0 & 0 & 0 \\
\hline 42 & 0 & 4 & 0 & 0 & 0 & 0 & 0 & 0 & 0 & 0 \\
\hline 43 & 0 & 0 & 0 & 0 & 0 & 0 & 0 & 0 & 0 & 0 \\
\hline 44 & 0 & 0 & 0 & 0 & 0 & 0 & 13 & 1 & 0 & 1 \\
\hline 44 & 0 & 0 & 0 & 0 & 0 & 0 & 0 & 0 & 0 & 3 \\
\hline 45 & 0 & 0 & 0 & 0 & 0 & 0 & 0 & 18 & 0 & 8 \\
\hline 46 & 0 & 0 & 0 & 0 & 1 & 0 & 2 & 7 & 0 & 10 \\
\hline 47 & 0 & 0 & 0 & 0 & 0 & 0 & 0 & 1 & 10 & 9 \\
\hline 48 & 0 & 0 & 0 & 0 & 0 & 1 & 0 & 4 & 0 & 0 \\
\hline 49 & 0 & 0 & 0 & 0 & 0 & 1 & 0 & 6 & 0 & 0 \\
\hline 50 & 1 & 2 & 0 & 1 & 0 & 0 & 0 & 1 & 0 & 0 \\
\hline 51 & 0 & 0 & 0 & 0 & 0 & 0 & 7 & 0 & 0 & 0 \\
\hline 52 & 0 & 0 & 0 & 0 & 0 & 0 & 5 & 7 & 0 & 4 \\
\hline 52 & 0 & 0 & 0 & 0 & 0 & 0 & 0 & 0 & 0 & 0 \\
\hline 52 & 0 & 0 & 0 & 0 & 0 & 0 & 0 & 0 & 0 & 0 \\
\hline 52 & 0 & 0 & 0 & 0 & 0 & 0 & 0 & 0 & 0 & 0 \\
\hline 52 & 0 & 0 & 0 & 0 & 0 & 0 & 0 & 0 & 0 & 0 \\
\hline 53 & 0 & 0 & 0 & 0 & 0 & 0 & 0 & 1 & 4 & 4 \\
\hline 53 & 0 & 0 & 0 & 0 & 0 & 0 & 0 & 16 & 7 & 8 \\
\hline 54 & 0 & 1 & 0 & 0 & 0 & 0 & 0 & 2 & 0 & 0 \\
\hline 55 & 0 & 0 & 0 & 0 & 0 & 0 & 0 & 2 & 0 & 14 \\
\hline 55 & 0 & 0 & 0 & 0 & 0 & 2 & 8 & 3 & 0 & 9 \\
\hline 56 & 0 & 0 & 0 & 0 & 0 & 0 & 1 & 4 & 0 & 6 \\
\hline 57 & 0 & 0 & 0 & 0 & 0 & 0 & 7 & 29 & 0 & 0 \\
\hline 57 & 0 & 0 & 0 & 0 & 0 & 0 & 0 & 72 & 4 & 0 \\
\hline 58 & 0 & 3 & 1 & 0 & 0 & 0 & 0 & 0 & 0 & 0 \\
\hline 59 & 0 & 0 & 0 & 0 & 0 & 0 & 0 & 86 & 0 & 0 \\
\hline 59 & 0 & 0 & 0 & 0 & 0 & 0 & 0 & 27 & 5 & 0 \\
\hline 60 & 0 & 1 & 0 & 0 & 0 & 7 & 5 & 0 & 0 & 0 \\
\hline 61 & 0 & 0 & 0 & 0 & 0 & 0 & 0 & 31 & 0 & 0 \\
\hline 62 & 0 & 0 & 0 & 0 & 0 & 0 & 0 & 25 & 0 & 19 \\
\hline 63 & 0 & 0 & 0 & 0 & 0 & 0 & 14 & 0 & 0 & 0 \\
\hline 63 & 0 & 0 & 0 & 0 & 0 & 0 & 0 & 0 & 14 & 0 \\
\hline 64 & 0 & 0 & 0 & 0 & 0 & 0 & 1 & 0 & 0 & 0 \\
\hline 65 & 0 & 0 & 0 & 0 & 0 & 1 & 0 & 6 & 0 & 1 \\
\hline 65 & 0 & 0 & 0 & 0 & 0 & 1 & 0 & 5 & 0 & 0 \\
\hline 66 & 0 & 0 & 0 & 0 & 0 & 0 & 0 & 0 & 0 & 0 \\
\hline 67 & 0 & 0 & 0 & 0 & 0 & 0 & 0 & 8 & 4 & 0 \\
\hline 68 & 0 & 0 & 0 & 0 & 0 & 0 & 0 & 0 & 0 & 0 \\
\hline 68 & 0 & 0 & 0 & 0 & 0 & 0 & 0 & 0 & 4 & 0 \\
\hline 69 & 0 & 0 & 0 & 0 & 0 & 0 & 0 & 0 & 2 & 0 \\
\hline 70 & 0 & 0 & 0 & 0 & 0 & 2 & 3 & 7 & 0 & 1 \\
\hline 71 & 0 & 0 & 0 & 0 & 0 & 0 & 0 & 0 & 0 & 0 \\
\hline 71 & 0 & 0 & 0 & 0 & 0 & 0 & 0 & 0 & 0 & 0 \\
\hline 72 & 0 & 0 & 0 & 0 & 0 & 0 & 0 & 0 & 0 & 0 \\
\hline 72 & 0 & 0 & 0 & 0 & 0 & 0 & 2 & 0 & 0 & 0 \\
\hline 73 & 0 & 1 & 0 & 0 & 0 & 0 & 0 & 0 & 0 & 0 \\
\hline 73 & 0 & 0 & 0 & 0 & 0 & 0 & 0 & 0 & 0 & 0 \\
\hline
\end{tabular}


Table 1. Description of sites and macroinvertebrate data collected from selected sites the Eagle River watershed, Colorado, 2000-2007.-Continued

[ID, identification; NAVD, North American Vertical Datum of 1988; ft, feet; $\mathrm{mi}^{2}$, square miles; ${ }^{\circ}$, degrees; ', minutes; ", seconds; FS, U.S. Department of Agriculture Forest Service; USGS, U.S. Geological Survey]

Site ID' Erpobdellidae Gammarus Glossosoma Helichus Hemerodromia Hesperoconopa Hesperoperla Heterlimnius Hexatoma Homophylax Hy

\begin{tabular}{|c|c|c|c|c|c|c|c|c|c|c|c|}
\hline 1 & 0 & 0 & 1 & 0 & 0 & 0 & 0 & 1 & 1 & 0 & 0 \\
\hline 2 & 0 & 0 & 0 & 0 & 0 & 0 & 4 & 57 & 0 & 0 & 0 \\
\hline 3 & 0 & 0 & 0 & 0 & 0 & 0 & 0 & 5 & 0 & 0 & 0 \\
\hline 4 & 0 & 0 & 6 & 0 & 0 & 0 & 0 & 39 & 0 & 0 & 0 \\
\hline 5 & 0 & 0 & 1 & 0 & 0 & 0 & 0 & 110 & 0 & 0 & 0 \\
\hline 6 & 0 & 0 & 4 & 0 & 0 & 0 & 0 & 18 & 0 & 0 & 0 \\
\hline 6 & 0 & 0 & 7 & 0 & 0 & 0 & 0 & 41 & 1 & 0 & 0 \\
\hline 7 & 0 & 0 & 0 & 0 & 0 & 0 & 1 & 51 & 6 & 0 & 0 \\
\hline 8 & 0 & 0 & 5 & 0 & 0 & 0 & 3 & 0 & 0 & 0 & 0 \\
\hline 9 & 0 & 0 & 0 & 0 & 0 & 0 & 0 & 0 & 0 & 38 & 0 \\
\hline 10 & 0 & 0 & 14 & 0 & 0 & 0 & 1 & 9 & 1 & 0 & 0 \\
\hline 10 & 0 & 0 & 14 & 0 & 0 & 0 & 0 & 7 & 0 & 0 & 0 \\
\hline 11 & 0 & 0 & 0 & 12 & 0 & 0 & 0 & 0 & 0 & 23 & 0 \\
\hline 12 & 0 & 0 & 0 & 7 & 0 & 0 & 0 & 0 & 0 & 19 & 0 \\
\hline 13 & 0 & 0 & 0 & 7 & 0 & 0 & 0 & 0 & 0 & 15 & 0 \\
\hline 14 & 0 & 0 & 0 & 0 & 0 & 0 & 0 & 15 & 0 & 0 & 0 \\
\hline 15 & 0 & 0 & 0 & 0 & 0 & 0 & 0 & 1 & 0 & 0 & 0 \\
\hline 16 & 0 & 0 & 0 & 0 & 0 & 0 & 0 & 4 & 0 & 0 & 0 \\
\hline 16 & 0 & 0 & 0 & 0 & 0 & 0 & 0 & 16 & 0 & 0 & 0 \\
\hline 17 & 0 & 0 & 0 & 0 & 0 & 1 & 0 & 0 & 0 & 3 & 0 \\
\hline 18 & 0 & 0 & 0 & 0 & 0 & 0 & 11 & 14 & 0 & 0 & 0 \\
\hline 18 & 0 & 0 & 0 & 0 & 0 & 0 & 8 & 21 & 0 & 0 & 0 \\
\hline 18 & 0 & 0 & 0 & 0 & 0 & 0 & 6 & 85 & 0 & 0 & 0 \\
\hline 19 & 0 & 0 & 0 & 0 & 0 & 0 & 3 & 38 & 0 & 0 & 0 \\
\hline 20 & 0 & 0 & 0 & 0 & 0 & 0 & 4 & 35 & 0 & 0 & 0 \\
\hline 21 & 0 & 0 & 16 & 0 & 0 & 0 & 4 & 12 & 0 & 0 & 0 \\
\hline 22 & 0 & 0 & 1 & 0 & 0 & 2 & 0 & 0 & 0 & 7 & 0 \\
\hline 23 & 0 & 0 & 0 & 0 & 0 & 0 & 0 & 0 & 0 & 0 & 0 \\
\hline 24 & 0 & 0 & 0 & 5 & 0 & 0 & 0 & 0 & 0 & 9 & 0 \\
\hline 25 & 0 & 0 & 0 & 0 & 0 & 0 & 0 & 2 & 0 & 0 & 0 \\
\hline 26 & 0 & 0 & 0 & 0 & 0 & 0 & 0 & 1 & 0 & 0 & 0 \\
\hline 27 & 0 & 0 & 0 & 0 & 0 & 0 & 7 & 7 & 0 & 0 & 0 \\
\hline 27 & 0 & 0 & 0 & 0 & 0 & 0 & 11 & 10 & 0 & 0 & 0 \\
\hline 27 & 0 & 0 & 0 & 0 & 0 & 0 & 6 & 14 & 1 & 0 & 0 \\
\hline 28 & 0 & 0 & 0 & 0 & 0 & 0 & 1 & 20 & 3 & 0 & 0 \\
\hline 28 & 0 & 0 & 5 & 0 & 0 & 0 & 1 & 15 & 1 & 0 & 0 \\
\hline 28 & 0 & 0 & 1 & 0 & 0 & 0 & 0 & 20 & 3 & 0 & 0 \\
\hline 29 & 0 & 0 & 0 & 0 & 0 & 0 & 0 & 0 & 0 & 0 & 16 \\
\hline 29 & 0 & 0 & 0 & 0 & 0 & 0 & 0 & 7 & 0 & 0 & 0 \\
\hline 29 & 0 & 0 & 0 & 0 & 0 & 0 & 3 & 9 & 0 & 0 & 0 \\
\hline 29 & 0 & 0 & 0 & 0 & 0 & 0 & 4 & 9 & 0 & 0 & 0 \\
\hline 29 & 0 & 0 & 0 & 0 & 0 & 0 & 2 & 30 & 0 & 0 & 0 \\
\hline 30 & 0 & 0 & 0 & 0 & 0 & 0 & 0 & 44 & 1 & 0 & 0 \\
\hline 30 & 0 & 0 & 0 & 0 & 0 & 0 & 0 & 53 & 1 & 0 & 0 \\
\hline 30 & 0 & 0 & 0 & 0 & 0 & 0 & 0 & 11 & 0 & 0 & 0 \\
\hline 30 & 0 & 0 & 0 & 0 & 0 & 0 & 0 & 84 & 0 & 0 & 0 \\
\hline 31 & 0 & 0 & 0 & 0 & 0 & 0 & 0 & 71 & 0 & 0 & 0 \\
\hline 31 & 0 & 0 & 0 & 0 & 0 & 0 & 0 & 30 & 1 & 0 & 0 \\
\hline 31 & 0 & 0 & 0 & 0 & 0 & 0 & 0 & 22 & 0 & 0 & 0 \\
\hline 31 & 0 & 0 & 0 & 0 & 0 & 0 & 0 & 59 & 0 & 0 & 0 \\
\hline 32 & 0 & 0 & 0 & 0 & 0 & 0 & 0 & 39 & 1 & 0 & 0 \\
\hline 32 & 0 & 0 & 0 & 0 & 0 & 0 & 0 & 25 & 1 & 0 & 0 \\
\hline 32 & 0 & 0 & 0 & 0 & 0 & 0 & 0 & 42 & 1 & 0 & 0 \\
\hline 33 & 0 & 0 & 0 & 0 & 0 & 0 & 0 & 50 & 1 & 0 & 0 \\
\hline 33 & 0 & 0 & 0 & 0 & 0 & 0 & 0 & 12 & 0 & 0 & 0 \\
\hline 33 & 0 & 0 & 0 & 0 & 0 & 0 & 0 & 30 & 2 & 0 & 0 \\
\hline 33 & 0 & 0 & 0 & 0 & 0 & 0 & 0 & 56 & 1 & 0 & 0 \\
\hline 34 & 0 & 0 & 0 & 0 & 0 & 0 & 0 & 24 & 1 & 0 & 0 \\
\hline 34 & 0 & 0 & 0 & 0 & 0 & 0 & 0 & 92 & 0 & 0 & 0 \\
\hline 34 & 0 & 0 & 0 & 0 & 0 & 0 & 0 & 8 & 0 & 0 & 0 \\
\hline 34 & 0 & 0 & 0 & 0 & 0 & 0 & 0 & 58 & 1 & 0 & 0 \\
\hline 34 & 0 & 0 & 0 & 0 & 0 & 0 & 0 & 43 & 0 & 0 & 0 \\
\hline 35 & 0 & 0 & 0 & 0 & 0 & 0 & 0 & 22 & 0 & 0 & 0 \\
\hline 36 & 0 & 0 & 0 & 0 & 0 & 0 & 0 & 56 & 1 & 0 & 0 \\
\hline 36 & 0 & 0 & 0 & 0 & 0 & 0 & 0 & 64 & 1 & 0 & 0 \\
\hline 36 & 0 & 0 & 0 & 0 & 0 & 0 & 0 & 29 & 0 & 0 & 0 \\
\hline 36 & 0 & 0 & 0 & 0 & 0 & 0 & 0 & 107 & 0 & 0 & 0 \\
\hline
\end{tabular}


Table 1. Description of sites and macroinvertebrate data collected from selected sites the Eagle River watershed, Colorado, 2000-2007.-Continued

[ID, identification; NAVD, North American Vertical Datum of 1988; ft, feet; mi², square miles; ’, degrees; ', minutes; ", seconds; FS, U.S. Department of Agriculture Forest Service; USGS, U.S. Geological Survey]

\begin{tabular}{|c|c|c|c|c|c|c|c|c|c|c|c|}
\hline Site ID' & Erpobdellidae & Gammarus & Glossosoma & Helichus & Hemerodromia & Hesperoconopa & Hesperoperla & Heterlimnius & Hexatoma & Homophylax & $\begin{array}{c}\text { Hydropsyche } \\
\text { Ceratopsyche }\end{array}$ \\
\hline 37 & 0 & 0 & 0 & 0 & 0 & 0 & 0 & 12 & 0 & 0 & 0 \\
\hline 37 & 0 & 0 & 0 & 0 & 0 & 0 & 0 & 13 & 0 & 0 & 0 \\
\hline 38 & 0 & 0 & 0 & 0 & 0 & 0 & 0 & 2 & 0 & 0 & 0 \\
\hline 38 & 0 & 0 & 0 & 0 & 0 & 0 & 0 & 12 & 0 & 0 & 0 \\
\hline 38 & 0 & 0 & 0 & 0 & 0 & 0 & 0 & 6 & 0 & 0 & 0 \\
\hline 39 & 0 & 0 & 0 & 0 & 0 & 0 & 0 & 6 & 1 & 0 & 0 \\
\hline 39 & 0 & 0 & 0 & 0 & 0 & 0 & 0 & 4 & 0 & 0 & 0 \\
\hline 39 & 0 & 0 & 0 & 0 & 0 & 0 & 0 & 5 & 0 & 0 & 0 \\
\hline 39 & 0 & 0 & 0 & 0 & 0 & 0 & 0 & 3 & 1 & 0 & 0 \\
\hline 39 & 0 & 0 & 0 & 0 & 0 & 0 & 0 & 7 & 0 & 0 & 0 \\
\hline 40 & 0 & 0 & 0 & 0 & 0 & 0 & 0 & 11 & 0 & 0 & 0 \\
\hline 41 & 0 & 0 & 0 & 0 & 0 & 0 & 0 & 11 & 0 & 0 & 0 \\
\hline 41 & 0 & 0 & 0 & 0 & 0 & 0 & 0 & 1 & 0 & 0 & 0 \\
\hline 41 & 0 & 0 & 0 & 0 & 0 & 0 & 0 & 2 & 0 & 0 & 0 \\
\hline 41 & 0 & 0 & 0 & 0 & 0 & 0 & 0 & 7 & 0 & 0 & 0 \\
\hline 41 & 0 & 0 & 0 & 0 & 0 & 0 & 0 & 13 & 0 & 0 & 0 \\
\hline 42 & 0 & 0 & 0 & 0 & 0 & 0 & 0 & 2 & 0 & 1 & 0 \\
\hline 42 & 0 & 0 & 0 & 0 & 0 & 0 & 0 & 0 & 0 & 0 & 0 \\
\hline 43 & 0 & 0 & 0 & 0 & 0 & 0 & 0 & 0 & 0 & 0 & 0 \\
\hline 44 & 0 & 0 & 0 & 0 & 0 & 0 & 0 & 1 & 0 & 0 & 0 \\
\hline 44 & 0 & 0 & 0 & 0 & 0 & 0 & 0 & 0 & 0 & 0 & 0 \\
\hline 45 & 0 & 0 & 0 & 0 & 0 & 0 & 0 & 13 & 0 & 0 & 0 \\
\hline 46 & 0 & 0 & 0 & 0 & 0 & 0 & 0 & 3 & 0 & 0 & 0 \\
\hline 47 & 0 & 0 & 0 & 0 & 0 & 0 & 0 & 2 & 0 & 0 & 0 \\
\hline 48 & 0 & 0 & 0 & 0 & 0 & 0 & 0 & 24 & 1 & 0 & 0 \\
\hline 49 & 0 & 0 & 0 & 0 & 0 & 0 & 0 & 11 & 0 & 0 & 0 \\
\hline 50 & 0 & 0 & 0 & 0 & 0 & 0 & 0 & 53 & 0 & 0 & 0 \\
\hline 51 & 0 & 0 & 0 & 0 & 0 & 0 & 0 & 2 & 0 & 0 & 0 \\
\hline 52 & 0 & 0 & 0 & 0 & 0 & 0 & 0 & 1 & 0 & 0 & 0 \\
\hline 52 & 0 & 0 & 0 & 0 & 0 & 0 & 0 & 2 & 0 & 0 & 0 \\
\hline 52 & 0 & 0 & 0 & 0 & 0 & 0 & 0 & 0 & 0 & 0 & 0 \\
\hline 52 & 0 & 0 & 0 & 0 & 0 & 0 & 0 & 2 & 0 & 0 & 0 \\
\hline 52 & 0 & 0 & 0 & 0 & 0 & 0 & 0 & 1 & 0 & 0 & 0 \\
\hline 53 & 0 & 0 & 0 & 0 & 0 & 0 & 0 & 0 & 0 & 0 & 0 \\
\hline 53 & 0 & 0 & 0 & 0 & 0 & 0 & 0 & 1 & 0 & 0 & 0 \\
\hline 54 & 0 & 0 & 0 & 0 & 0 & 0 & 5 & 10 & 0 & 0 & 0 \\
\hline 55 & 0 & 0 & 0 & 0 & 1 & 0 & 0 & 0 & 0 & 0 & 0 \\
\hline 55 & 0 & 0 & 0 & 0 & 0 & 0 & 0 & 11 & 0 & 0 & 0 \\
\hline 56 & 0 & 0 & 0 & 0 & 0 & 0 & 0 & 59 & 0 & 0 & 0 \\
\hline 57 & 0 & 0 & 32 & 0 & 0 & 0 & 0 & 4 & 0 & 0 & 0 \\
\hline 57 & 0 & 0 & 5 & 0 & 0 & 0 & 0 & 4 & 1 & 0 & 1 \\
\hline 58 & 0 & 0 & 0 & 0 & 0 & 0 & 4 & 1 & 1 & 0 & 0 \\
\hline 59 & 0 & 0 & 7 & 0 & 0 & 0 & 0 & 0 & 0 & 0 & 19 \\
\hline 59 & 0 & 0 & 19 & 0 & 0 & 0 & 1 & 0 & 0 & 0 & 8 \\
\hline 60 & 0 & 0 & 0 & 0 & 0 & 0 & 0 & 51 & 0 & 0 & 1 \\
\hline 61 & 0 & 0 & 0 & 0 & 0 & 0 & 0 & 1 & 0 & 0 & 0 \\
\hline 62 & 0 & 0 & 0 & 0 & 0 & 0 & 0 & 31 & 0 & 0 & 0 \\
\hline 63 & 0 & 0 & 0 & 0 & 0 & 0 & 0 & 6 & 1 & 0 & 0 \\
\hline 63 & 0 & 0 & 3 & 0 & 0 & 0 & 0 & 2 & 0 & 0 & 2 \\
\hline 64 & 0 & 0 & 0 & 0 & 0 & 0 & 0 & 15 & 0 & 0 & 0 \\
\hline 65 & 0 & 0 & 0 & 0 & 0 & 0 & 12 & 35 & 0 & 0 & 0 \\
\hline 65 & 0 & 0 & 0 & 0 & 0 & 0 & 11 & 26 & 0 & 0 & 0 \\
\hline 66 & 0 & 0 & 0 & 0 & 0 & 0 & 1 & 4 & 1 & 0 & 26 \\
\hline 67 & 0 & 0 & 27 & 0 & 0 & 0 & 0 & 0 & 0 & 0 & 51 \\
\hline 68 & 0 & 0 & 20 & 0 & 0 & 0 & 0 & 0 & 0 & 0 & 84 \\
\hline 68 & 0 & 0 & 19 & 0 & 0 & 0 & 0 & 0 & 1 & 0 & 46 \\
\hline 69 & 0 & 0 & 43 & 0 & 0 & 0 & 2 & 0 & 3 & 0 & 41 \\
\hline 70 & 0 & 0 & 3 & 0 & 0 & 0 & 0 & 4 & 1 & 0 & 0 \\
\hline 71 & 1 & 1 & 0 & 0 & 0 & 0 & 0 & 0 & 0 & 0 & 53 \\
\hline 71 & 0 & 0 & 0 & 0 & 0 & 0 & 0 & 0 & 0 & 0 & 15 \\
\hline 72 & 0 & 0 & 57 & 0 & 0 & 0 & 2 & 0 & 2 & 0 & 23 \\
\hline 72 & 0 & 0 & 25 & 0 & 0 & 0 & 0 & 0 & 2 & 0 & 13 \\
\hline 73 & 0 & 3 & 0 & 0 & 0 & 0 & 0 & 14 & 0 & 0 & 3 \\
\hline 73 & 0 & 38 & 0 & 0 & 0 & 0 & 0 & 0 & 0 & 0 & 1 \\
\hline
\end{tabular}


Table 1. Description of sites and macroinvertebrate data collected from selected sites the Eagle River watershed, Colorado, 2000-2007.-Continued

[ID, identification; NAVD, North American Vertical Datum of 1988; ft, feet; mi², square miles; ’, degrees; ', minutes; ", seconds; FS, U.S. Department of Agriculture Forest Service; USGS, U.S. Geological Survey]

\begin{tabular}{|c|c|c|c|c|c|c|c|c|c|c|c|}
\hline Site ID' & Hydroptila & Isogenoides & Isoperla & Kogotus & Lepidoptera & Lepidostoma & Leuctridae & Limnophila & Limonia & Megarcys & Micrasema \\
\hline 1 & 0 & 0 & 0 & 0 & 0 & 0 & 0 & 0 & 0 & 1 & 0 \\
\hline 2 & 0 & 0 & 0 & 0 & 0 & 0 & 0 & 0 & 0 & 0 & 69 \\
\hline 3 & 0 & 0 & 0 & 0 & 0 & 0 & 3 & 0 & 0 & 4 & 0 \\
\hline 4 & 0 & 0 & 0 & 0 & 0 & 0 & 0 & 0 & 0 & 3 & 8 \\
\hline 5 & 0 & 0 & 0 & 0 & 0 & 0 & 0 & 0 & 0 & 0 & 6 \\
\hline 6 & 0 & 0 & 0 & 0 & 0 & 2 & 0 & 0 & 2 & 0 & 0 \\
\hline 6 & 0 & 0 & 5 & 0 & 0 & 0 & 0 & 0 & 0 & 1 & 9 \\
\hline 7 & 0 & 0 & 0 & 0 & 0 & 0 & 1 & 0 & 0 & 0 & 0 \\
\hline 8 & 0 & 0 & 0 & 0 & 0 & 2 & 0 & 0 & 0 & 0 & 0 \\
\hline 9 & 0 & 0 & 0 & 7 & 0 & 12 & 3 & 0 & 0 & 0 & 2 \\
\hline 10 & 0 & 0 & 0 & 0 & 0 & 0 & 0 & 0 & 0 & 3 & 2 \\
\hline 10 & 0 & 0 & 2 & 0 & 0 & 0 & 0 & 0 & 0 & 0 & 1 \\
\hline 11 & 0 & 0 & 0 & 1 & 0 & 37 & 1 & 0 & 0 & 0 & 0 \\
\hline 12 & 0 & 0 & 0 & 1 & 0 & 67 & 1 & 0 & 0 & 0 & 0 \\
\hline 13 & 0 & 0 & 0 & 1 & 0 & 38 & 0 & 0 & 0 & 0 & 0 \\
\hline 14 & 0 & 0 & 0 & 0 & 0 & 1 & 0 & 0 & 0 & 0 & 0 \\
\hline 15 & 0 & 0 & 0 & 0 & 0 & 0 & 0 & 0 & 0 & 6 & 0 \\
\hline 16 & 0 & 0 & 0 & 0 & 0 & 0 & 0 & 0 & 0 & 1 & 0 \\
\hline 16 & 0 & 0 & 0 & 1 & 0 & 0 & 3 & 0 & 0 & 4 & 0 \\
\hline 17 & 0 & 0 & 0 & 1 & 0 & 9 & 0 & 0 & 0 & 0 & 0 \\
\hline 18 & 0 & 0 & 0 & 0 & 0 & 0 & 0 & 0 & 0 & 0 & 9 \\
\hline 18 & 0 & 0 & 1 & 0 & 0 & 0 & 0 & 0 & 0 & 0 & 2 \\
\hline 18 & 1 & 0 & 0 & 0 & 0 & 2 & 1 & 0 & 0 & 0 & 0 \\
\hline 19 & 0 & 0 & 0 & 0 & 0 & 0 & 0 & 0 & 0 & 0 & 24 \\
\hline 20 & 0 & 0 & 0 & 0 & 0 & 1 & 0 & 0 & 0 & 1 & 7 \\
\hline 21 & 0 & 0 & 3 & 0 & 0 & 0 & 0 & 0 & 0 & 0 & 0 \\
\hline 22 & 0 & 0 & 0 & 0 & 0 & 7 & 1 & 0 & 0 & 0 & 0 \\
\hline 23 & 0 & 0 & 0 & 0 & 0 & 0 & 0 & 0 & 0 & 0 & 0 \\
\hline 24 & 0 & 0 & 1 & 1 & 0 & 13 & 0 & 0 & 0 & 0 & 0 \\
\hline 25 & 0 & 1 & 4 & 0 & 0 & 2 & 0 & 0 & 0 & 0 & 0 \\
\hline 26 & 0 & 0 & 0 & 0 & 0 & 0 & 2 & 0 & 0 & 3 & 0 \\
\hline 27 & 0 & 0 & 0 & 0 & 0 & 0 & 4 & 0 & 0 & 1 & 0 \\
\hline 27 & 0 & 0 & 0 & 0 & 0 & 0 & 0 & 0 & 0 & 14 & 0 \\
\hline 27 & 0 & 0 & 0 & 0 & 0 & 0 & 3 & 0 & 0 & 5 & 0 \\
\hline 28 & 0 & 0 & 0 & 0 & 0 & 0 & 5 & 0 & 0 & 2 & 0 \\
\hline 28 & 0 & 0 & 0 & 0 & 0 & 0 & 1 & 0 & 0 & 4 & 0 \\
\hline 28 & 0 & 0 & 0 & 0 & 0 & 0 & 2 & 0 & 0 & 1 & 0 \\
\hline 29 & 0 & 0 & 0 & 0 & 1 & 0 & 3 & 0 & 0 & 0 & 0 \\
\hline 29 & 0 & 0 & 0 & 0 & 0 & 0 & 0 & 0 & 0 & 0 & 0 \\
\hline 29 & 0 & 0 & 0 & 0 & 0 & 0 & 1 & 0 & 0 & 1 & 0 \\
\hline 29 & 0 & 0 & 0 & 0 & 0 & 0 & 1 & 0 & 0 & 7 & 0 \\
\hline 29 & 0 & 0 & 0 & 0 & 0 & 0 & 0 & 0 & 0 & 5 & 0 \\
\hline 30 & 3 & 0 & 1 & 0 & 0 & 0 & 0 & 0 & 0 & 0 & 5 \\
\hline 30 & 30 & 0 & 0 & 0 & 0 & 1 & 0 & 0 & 0 & 1 & 1 \\
\hline 30 & 3 & 0 & 1 & 0 & 0 & 0 & 0 & 0 & 0 & 0 & 1 \\
\hline 30 & 6 & 0 & 0 & 0 & 0 & 0 & 0 & 1 & 0 & 0 & 2 \\
\hline 31 & 0 & 0 & 3 & 0 & 0 & 0 & 2 & 0 & 0 & 37 & 0 \\
\hline 31 & 1 & 0 & 0 & 0 & 0 & 0 & 0 & 0 & 0 & 2 & 0 \\
\hline 31 & 0 & 0 & 0 & 0 & 0 & 0 & 0 & 0 & 0 & 12 & 0 \\
\hline 31 & 0 & 0 & 2 & 0 & 0 & 0 & 0 & 0 & 0 & 28 & 0 \\
\hline 32 & 0 & 0 & 0 & 0 & 0 & 0 & 1 & 0 & 0 & 1 & 0 \\
\hline 32 & 0 & 0 & 0 & 0 & 0 & 0 & 0 & 0 & 0 & 1 & 0 \\
\hline 32 & 0 & 0 & 0 & 0 & 0 & 0 & 3 & 0 & 0 & 2 & 0 \\
\hline 33 & 0 & 0 & 0 & 0 & 0 & 0 & 4 & 0 & 0 & 0 & 0 \\
\hline 33 & 0 & 0 & 0 & 0 & 0 & 0 & 0 & 0 & 0 & 0 & 1 \\
\hline 33 & 0 & 0 & 0 & 0 & 0 & 0 & 0 & 0 & 0 & 5 & 1 \\
\hline 33 & 0 & 0 & 0 & 0 & 0 & 0 & 0 & 0 & 0 & 2 & 0 \\
\hline 34 & 0 & 0 & 0 & 1 & 0 & 0 & 2 & 0 & 0 & 1 & 0 \\
\hline 34 & 0 & 0 & 0 & 0 & 0 & 0 & 0 & 0 & 0 & 2 & 0 \\
\hline 34 & 0 & 0 & 0 & 0 & 0 & 0 & 0 & 0 & 0 & 0 & 0 \\
\hline 34 & 0 & 0 & 0 & 1 & 0 & 0 & 1 & 0 & 0 & 5 & 0 \\
\hline 34 & 0 & 0 & 0 & 0 & 0 & 0 & 0 & 0 & 0 & 11 & 0 \\
\hline 35 & 0 & 0 & 0 & 0 & 0 & 0 & 0 & 0 & 0 & 2 & 0 \\
\hline 36 & 0 & 0 & 0 & 0 & 0 & 0 & 1 & 0 & 0 & 2 & 0 \\
\hline 36 & 0 & 0 & 0 & 0 & 0 & 0 & 1 & 0 & 0 & 1 & 0 \\
\hline 36 & 0 & 0 & 0 & 1 & 0 & 0 & 1 & 0 & 0 & 6 & 0 \\
\hline 36 & 0 & 0 & 0 & 0 & 0 & 0 & 2 & 0 & 0 & 6 & 0 \\
\hline
\end{tabular}


Table 1. Description of sites and macroinvertebrate data collected from selected sites the Eagle River watershed, Colorado, 2000-2007.-Continued

[ID, identification; NAVD, North American Vertical Datum of 1988; ft, feet; mi², square miles; ’, degrees; ', minutes; ", seconds; FS, U.S. Department of Agriculture Forest Service; USGS, U.S. Geological Survey]

\begin{tabular}{|c|c|c|c|c|c|c|c|c|c|c|c|}
\hline Site ID' & Hydroptila & Isogenoides & Isoperla & Kogotus & Lepidoptera & Lepidostoma & Leuctridae & Limnophila & Limonia & Megarcys & Micrasema \\
\hline 37 & 0 & 0 & 0 & 0 & 0 & 0 & 1 & 0 & 0 & 1 & 0 \\
\hline 37 & 0 & 0 & 1 & 1 & 0 & 0 & 1 & 0 & 0 & 3 & 0 \\
\hline 38 & 0 & 0 & 0 & 0 & 0 & 0 & 0 & 0 & 0 & 0 & 0 \\
\hline 38 & 0 & 0 & 0 & 0 & 0 & 0 & 2 & 0 & 0 & 4 & 0 \\
\hline 38 & 0 & 0 & 0 & 0 & 0 & 0 & 0 & 0 & 0 & 0 & 0 \\
\hline 39 & 0 & 0 & 0 & 0 & 0 & 0 & 0 & 0 & 0 & 2 & 0 \\
\hline 39 & 0 & 0 & 0 & 0 & 0 & 0 & 0 & 0 & 0 & 0 & 0 \\
\hline 39 & 0 & 0 & 0 & 0 & 0 & 0 & 0 & 0 & 0 & 1 & 0 \\
\hline 39 & 0 & 0 & 0 & 0 & 0 & 0 & 0 & 0 & 0 & 0 & 0 \\
\hline 39 & 0 & 0 & 0 & 0 & 0 & 0 & 0 & 0 & 0 & 0 & 0 \\
\hline 40 & 0 & 0 & 0 & 0 & 0 & 0 & 1 & 0 & 0 & 1 & 0 \\
\hline 41 & 0 & 0 & 0 & 0 & 0 & 3 & 0 & 0 & 0 & 0 & 0 \\
\hline 41 & 0 & 0 & 0 & 0 & 0 & 1 & 0 & 0 & 0 & 0 & 0 \\
\hline 41 & 0 & 0 & 0 & 0 & 0 & 0 & 0 & 0 & 0 & 0 & 0 \\
\hline 41 & 0 & 0 & 0 & 0 & 0 & 0 & 0 & 0 & 0 & 0 & 0 \\
\hline 41 & 0 & 0 & 0 & 0 & 0 & 0 & 0 & 0 & 0 & 0 & 0 \\
\hline 42 & 0 & 0 & 0 & 0 & 0 & 0 & 0 & 0 & 0 & 0 & 0 \\
\hline 42 & 0 & 0 & 0 & 0 & 0 & 0 & 0 & 0 & 0 & 6 & 0 \\
\hline 43 & 0 & 0 & 0 & 0 & 0 & 0 & 0 & 0 & 0 & 1 & 0 \\
\hline 44 & 0 & 0 & 0 & 0 & 0 & 0 & 0 & 0 & 0 & 0 & 0 \\
\hline 44 & 0 & 0 & 0 & 0 & 0 & 0 & 0 & 0 & 0 & 0 & 0 \\
\hline 45 & 0 & 0 & 0 & 0 & 0 & 0 & 0 & 0 & 0 & 0 & 0 \\
\hline 46 & 0 & 0 & 0 & 0 & 0 & 0 & 0 & 0 & 0 & 0 & 0 \\
\hline 47 & 0 & 0 & 0 & 0 & 0 & 0 & 0 & 0 & 0 & 2 & 0 \\
\hline 48 & 0 & 0 & 0 & 0 & 0 & 0 & 3 & 0 & 0 & 0 & 0 \\
\hline 49 & 0 & 0 & 0 & 0 & 0 & 0 & 0 & 0 & 0 & 1 & 0 \\
\hline 50 & 0 & 0 & 0 & 0 & 0 & 0 & 1 & 0 & 0 & 3 & 15 \\
\hline 51 & 0 & 0 & 0 & 0 & 0 & 0 & 0 & 0 & 0 & 0 & 0 \\
\hline 52 & 0 & 0 & 0 & 0 & 0 & 149 & 0 & 0 & 0 & 0 & 0 \\
\hline 52 & 0 & 0 & 0 & 0 & 0 & 0 & 0 & 0 & 0 & 0 & 0 \\
\hline 52 & 0 & 0 & 0 & 0 & 0 & 2 & 0 & 0 & 0 & 0 & 0 \\
\hline 52 & 0 & 0 & 0 & 0 & 0 & 0 & 0 & 0 & 0 & 0 & 0 \\
\hline 52 & 0 & 0 & 0 & 0 & 0 & 1 & 0 & 0 & 0 & 0 & 0 \\
\hline 53 & 0 & 0 & 0 & 0 & 0 & 0 & 0 & 0 & 0 & 0 & 0 \\
\hline 53 & 0 & 0 & 0 & 0 & 0 & 5 & 0 & 0 & 0 & 0 & 0 \\
\hline 54 & 0 & 0 & 0 & 0 & 0 & 0 & 1 & 0 & 0 & 0 & 0 \\
\hline 55 & 0 & 0 & 0 & 0 & 0 & 112 & 0 & 0 & 0 & 0 & 0 \\
\hline 55 & 0 & 0 & 1 & 0 & 0 & 0 & 0 & 0 & 0 & 4 & 0 \\
\hline 56 & 0 & 0 & 0 & 0 & 0 & 1 & 0 & 0 & 0 & 1 & 0 \\
\hline 57 & 0 & 0 & 0 & 0 & 0 & 20 & 0 & 0 & 0 & 0 & 0 \\
\hline 57 & 0 & 1 & 0 & 0 & 0 & 38 & 0 & 0 & 0 & 0 & 0 \\
\hline 58 & 0 & 0 & 0 & 0 & 0 & 0 & 0 & 1 & 0 & 0 & 0 \\
\hline 59 & 0 & 1 & 0 & 0 & 0 & 2 & 0 & 0 & 0 & 0 & 0 \\
\hline 59 & 0 & 0 & 0 & 0 & 0 & 53 & 0 & 0 & 0 & 0 & 0 \\
\hline 60 & 0 & 0 & 0 & 0 & 0 & 0 & 0 & 0 & 0 & 17 & 7 \\
\hline 61 & 0 & 0 & 0 & 0 & 0 & 0 & 4 & 0 & 0 & 1 & 0 \\
\hline 62 & 0 & 0 & 0 & 0 & 0 & 0 & 0 & 0 & 0 & 0 & 1 \\
\hline 63 & 0 & 0 & 0 & 0 & 0 & 4 & 0 & 0 & 0 & 0 & 0 \\
\hline 63 & 0 & 0 & 0 & 0 & 0 & 147 & 0 & 0 & 0 & 0 & 0 \\
\hline 64 & 0 & 0 & 0 & 0 & 0 & 0 & 2 & 0 & 0 & 1 & 0 \\
\hline 65 & 0 & 0 & 0 & 0 & 0 & 0 & 2 & 0 & 0 & 0 & 18 \\
\hline 65 & 0 & 0 & 0 & 0 & 0 & 0 & 1 & 0 & 0 & 0 & 8 \\
\hline 66 & 0 & 0 & 0 & 0 & 0 & 0 & 0 & 0 & 0 & 0 & 0 \\
\hline 67 & 0 & 0 & 0 & 0 & 0 & 19 & 0 & 0 & 0 & 0 & 0 \\
\hline 68 & 0 & 1 & 0 & 0 & 0 & 16 & 0 & 0 & 0 & 0 & 0 \\
\hline 68 & 0 & 1 & 0 & 0 & 0 & 2 & 0 & 0 & 0 & 0 & 0 \\
\hline 69 & 0 & 0 & 0 & 0 & 0 & 2 & 0 & 0 & 0 & 0 & 0 \\
\hline 70 & 0 & 0 & 0 & 0 & 0 & 0 & 0 & 0 & 0 & 1 & 0 \\
\hline 71 & 0 & 0 & 0 & 0 & 0 & 1 & 0 & 0 & 0 & 0 & 0 \\
\hline 71 & 0 & 0 & 0 & 0 & 0 & 0 & 0 & 0 & 0 & 0 & 0 \\
\hline 72 & 0 & 1 & 0 & 0 & 0 & 4 & 0 & 0 & 0 & 0 & 0 \\
\hline 72 & 0 & 0 & 0 & 0 & 0 & 0 & 0 & 0 & 0 & 0 & 0 \\
\hline 73 & 0 & 0 & 0 & 0 & 0 & 0 & 0 & 0 & 0 & 0 & 0 \\
\hline 73 & 1 & 0 & 0 & 0 & 0 & 0 & 0 & 0 & 0 & 0 & 0 \\
\hline
\end{tabular}


Table 1. Description of sites and macroinvertebrate data collected from selected sites the Eagle River watershed, Colorado, 2000-2007.-Continued

[ID, identification; NAVD, North American Vertical Datum of 1988; ft, feet; mi², square miles; ’, degrees; ', minutes; ", seconds; FS, U.S. Department of Agriculture Forest Service; USGS, U.S. Geological Survey]

Site ID' Muscidae Narpus Nematoda Neothremma Ochrotrichia Oligophlebodes Optioservus Oreodytes Oreogeton Orthocladiinae

Other_

\begin{tabular}{|c|c|c|c|c|c|c|c|c|c|c|c|}
\hline & & & & & & & & & & & Chloroperlida \\
\hline 1 & 0 & 0 & 0 & 0 & 0 & 1 & 0 & 0 & 0 & 43 & 0 \\
\hline 2 & 0 & 0 & 0 & 0 & 0 & 7 & 0 & 0 & 0 & 14 & 0 \\
\hline 3 & 0 & 0 & 0 & 15 & 0 & 0 & 0 & 0 & 0 & 74 & 10 \\
\hline 4 & 0 & 0 & 0 & 0 & 0 & 8 & 0 & 0 & 0 & 8 & 5 \\
\hline 5 & 0 & 0 & 0 & 0 & 0 & 0 & 0 & 0 & 0 & 22 & 14 \\
\hline 6 & 0 & 0 & 0 & 0 & 0 & 0 & 0 & 0 & 0 & 1 & 6 \\
\hline 6 & 0 & 0 & 0 & 0 & 0 & 0 & 0 & 0 & 1 & 4 & 10 \\
\hline 7 & 0 & 0 & 0 & 0 & 0 & 0 & 0 & 0 & 0 & 11 & 5 \\
\hline 8 & 0 & 0 & 1 & 0 & 0 & 0 & 0 & 0 & 0 & 14 & 7 \\
\hline 9 & 0 & 2 & 0 & 1 & 0 & 0 & 0 & 0 & 0 & 10 & 1 \\
\hline 10 & 0 & 0 & 1 & 0 & 0 & 0 & 0 & 0 & 0 & 22 & 8 \\
\hline 10 & 0 & 0 & 0 & 0 & 0 & 0 & 1 & 0 & 0 & 10 & 4 \\
\hline 11 & 0 & 0 & 0 & 0 & 0 & 0 & 0 & 0 & 0 & 2 & 1 \\
\hline 12 & 0 & 0 & 0 & 0 & 0 & 0 & 0 & 0 & 0 & 4 & 0 \\
\hline 13 & 0 & 0 & 0 & 0 & 0 & 0 & 0 & 0 & 0 & 3 & 0 \\
\hline 14 & 0 & 4 & 1 & 0 & 0 & 0 & 0 & 0 & 0 & 41 & 10 \\
\hline 15 & 0 & 0 & 0 & 2 & 0 & 0 & 1 & 0 & 2 & 113 & 2 \\
\hline 16 & 0 & 0 & 0 & 11 & 0 & 0 & 0 & 0 & 1 & 85 & 1 \\
\hline 16 & 0 & 0 & 0 & 33 & 0 & 13 & 1 & 0 & 2 & 11 & 9 \\
\hline 17 & 0 & 0 & 0 & 1 & 0 & 0 & 0 & 0 & 0 & 4 & 1 \\
\hline 18 & 0 & 0 & 0 & 1 & 0 & 0 & 0 & 0 & 0 & 32 & 0 \\
\hline 18 & 0 & 0 & 0 & 0 & 0 & 0 & 0 & 0 & 0 & 12 & 6 \\
\hline 18 & 0 & 0 & 0 & 0 & 0 & 0 & 0 & 0 & 0 & 49 & 9 \\
\hline 19 & 0 & 0 & 0 & 0 & 0 & 2 & 0 & 0 & 0 & 3 & 2 \\
\hline 20 & 0 & 0 & 0 & 0 & 0 & 0 & 0 & 0 & 0 & 3 & 1 \\
\hline 21 & 0 & 0 & 0 & 0 & 0 & 0 & 0 & 0 & 0 & 11 & 13 \\
\hline 22 & 0 & 6 & 0 & 1 & 0 & 0 & 0 & 0 & 0 & 16 & 4 \\
\hline 23 & 0 & 0 & 0 & 129 & 0 & 0 & 1 & 0 & 0 & 34 & 2 \\
\hline 24 & 0 & 0 & 0 & 0 & 0 & 0 & 0 & 0 & 0 & 13 & 2 \\
\hline 25 & 0 & 0 & 0 & 0 & 0 & 0 & 1 & 0 & 0 & 17 & 3 \\
\hline 26 & 0 & 0 & 0 & 0 & 0 & 0 & 0 & 0 & 0 & 13 & 15 \\
\hline 27 & 0 & 0 & 0 & 0 & 0 & 2 & 0 & 0 & 0 & 15 & 38 \\
\hline 27 & 0 & 0 & 0 & 0 & 0 & 2 & 0 & 0 & 0 & 15 & 15 \\
\hline 27 & 0 & 0 & 0 & 0 & 0 & 3 & 0 & 0 & 1 & 17 & 27 \\
\hline 28 & 0 & 0 & 0 & 0 & 0 & 3 & 0 & 0 & 0 & 3 & 29 \\
\hline 28 & 0 & 0 & 0 & 0 & 0 & 0 & 0 & 0 & 4 & 15 & 4 \\
\hline 28 & 0 & 0 & 0 & 0 & 0 & 3 & 0 & 0 & 2 & 7 & 19 \\
\hline 29 & 0 & 0 & 0 & 0 & 0 & 0 & 0 & 0 & 0 & 9 & 0 \\
\hline 29 & 0 & 0 & 0 & 0 & 0 & 0 & 0 & 0 & 0 & 33 & 5 \\
\hline 29 & 0 & 0 & 0 & 0 & 0 & 0 & 0 & 0 & 1 & 13 & 6 \\
\hline 29 & 0 & 0 & 0 & 0 & 0 & 0 & 0 & 0 & 0 & 16 & 1 \\
\hline 29 & 0 & 0 & 0 & 0 & 0 & 0 & 0 & 0 & 3 & 11 & 9 \\
\hline 30 & 0 & 0 & 0 & 0 & 0 & 0 & 1 & 0 & 0 & 36 & 9 \\
\hline 30 & 0 & 0 & 0 & 0 & 0 & 0 & 0 & 0 & 1 & 54 & 3 \\
\hline 30 & 0 & 0 & 0 & 0 & 0 & 0 & 0 & 0 & 0 & 133 & 0 \\
\hline 30 & 0 & 0 & 0 & 0 & 0 & 1 & 0 & 0 & 0 & 9 & 4 \\
\hline 31 & 0 & 0 & 0 & 0 & 0 & 2 & 0 & 0 & 0 & 41 & 16 \\
\hline 31 & 0 & 0 & 0 & 0 & 0 & 10 & 0 & 0 & 0 & 197 & 6 \\
\hline 31 & 0 & 0 & 0 & 0 & 0 & 0 & 0 & 0 & 0 & 3 & 5 \\
\hline 31 & 0 & 0 & 0 & 0 & 0 & 1 & 0 & 0 & 0 & 7 & 8 \\
\hline 32 & 0 & 0 & 0 & 1 & 0 & 56 & 0 & 0 & 0 & 2 & 34 \\
\hline 32 & 0 & 0 & 0 & 0 & 0 & 88 & 0 & 0 & 0 & 10 & 9 \\
\hline 32 & 0 & 0 & 0 & 0 & 0 & 2 & 0 & 0 & 0 & 5 & 24 \\
\hline 33 & 0 & 0 & 0 & 0 & 0 & 41 & 0 & 0 & 0 & 57 & 14 \\
\hline 33 & 0 & 0 & 0 & 3 & 0 & 149 & 0 & 0 & 0 & 29 & 1 \\
\hline 33 & 0 & 0 & 0 & 1 & 0 & 7 & 0 & 0 & 0 & 23 & 9 \\
\hline 33 & 0 & 0 & 0 & 1 & 0 & 43 & 0 & 0 & 0 & 13 & 3 \\
\hline 34 & 0 & 0 & 0 & 0 & 0 & 1 & 0 & 0 & 1 & 25 & 38 \\
\hline 34 & 0 & 0 & 0 & 0 & 0 & 71 & 0 & 0 & 0 & 26 & 1 \\
\hline 34 & 0 & 0 & 0 & 0 & 0 & 8 & 0 & 0 & 0 & 8 & 0 \\
\hline 34 & 0 & 0 & 0 & 0 & 0 & 42 & 0 & 0 & 0 & 21 & 13 \\
\hline 34 & 0 & 0 & 0 & 0 & 0 & 28 & 0 & 0 & 0 & 50 & 22 \\
\hline 35 & 0 & 0 & 0 & 8 & 0 & 111 & 0 & 0 & 0 & 2 & 7 \\
\hline 36 & 0 & 0 & 0 & 0 & 0 & 25 & 0 & 0 & 0 & 14 & 10 \\
\hline 36 & 0 & 0 & 0 & 0 & 0 & 13 & 0 & 0 & 0 & 62 & 0 \\
\hline 36 & 0 & 0 & 0 & 0 & 0 & 2 & 0 & 0 & 0 & 24 & 6 \\
\hline 36 & 0 & 0 & 0 & 1 & 0 & 8 & 0 & 0 & 0 & 5 & 9 \\
\hline
\end{tabular}


Table 1. Description of sites and macroinvertebrate data collected from selected sites the Eagle River watershed, Colorado, 2000-2007.-Continued

[ID, identification; NAVD, North American Vertical Datum of 1988; ft, feet; mi², square miles; ${ }^{\circ}$, degrees; ', minutes; ", seconds; FS, U.S. Department of Agriculture Forest Service; USGS, U.S. Geological Survey]

\begin{tabular}{|c|c|c|c|c|c|c|c|c|c|c|c|}
\hline Site ID' & Muscidae & Narpus & Nematoda & Neothremma & Ochrotrichia & Oligophlebodes & Optioservus & Oreodytes & Oreogeton & Orthocladiinae & $\begin{array}{c}\text { Other }_{-} \\
\text {Chloroperlidae }\end{array}$ \\
\hline 37 & 0 & 0 & 4 & 0 & 0 & 0 & 0 & 0 & 0 & 2 & 1 \\
\hline 37 & 0 & 0 & 0 & 0 & 0 & 0 & 0 & 0 & 0 & 1 & 5 \\
\hline 38 & 0 & 0 & 0 & 0 & 0 & 0 & 0 & 0 & 0 & 201 & 0 \\
\hline 38 & 0 & 0 & 0 & 0 & 0 & 0 & 0 & 0 & 0 & 30 & 1 \\
\hline 39 & 0 & 0 & 0 & 0 & 0 & 0 & 0 & 0 & 0 & 9 & 15 \\
\hline 39 & 0 & 0 & 0 & 0 & 0 & 0 & 0 & 0 & 0 & 52 & 11 \\
\hline 39 & 0 & 0 & 0 & 0 & 0 & 0 & 0 & 0 & 0 & 15 & 0 \\
\hline 40 & 0 & 0 & 0 & 1 & 0 & 4 & 0 & 0 & 5 & 11 & 10 \\
\hline 41 & 0 & 0 & 1 & 0 & 0 & 0 & 0 & 0 & 0 & 16 & 32 \\
\hline 41 & 1 & 0 & 0 & 0 & 0 & 0 & 0 & 0 & 0 & 164 & 1 \\
\hline 41 & 0 & 0 & 0 & 0 & 0 & 0 & 0 & 0 & 0 & 97 & 0 \\
\hline 41 & 0 & 0 & 0 & 0 & 0 & 0 & 0 & 0 & 0 & 51 & 4 \\
\hline 41 & 0 & 0 & 0 & 0 & 0 & 0 & 0 & 0 & 0 & 32 & 7 \\
\hline 44 & 0 & 0 & 0 & 0 & 0 & 0 & 0 & 0 & 0 & 82 & 0 \\
\hline 45 & 0 & 0 & 0 & 174 & 0 & 0 & 0 & 0 & 0 & 0 & 3 \\
\hline 46 & 0 & 0 & 0 & 95 & 0 & 0 & 0 & 0 & 0 & 5 & 4 \\
\hline 47 & 0 & 0 & 1 & 0 & 0 & 0 & 0 & 0 & 0 & 19 & 9 \\
\hline 48 & 0 & 0 & 0 & 48 & 0 & 20 & 0 & 0 & 1 & 49 & 7 \\
\hline 49 & 0 & 0 & 0 & 70 & 0 & 0 & 0 & 0 & 1 & 67 & 4 \\
\hline 50 & 0 & 0 & 0 & 21 & 0 & 5 & 0 & 0 & 1 & 43 & 4 \\
\hline 51 & 0 & 0 & 0 & 0 & 0 & 0 & 0 & 0 & 0 & 120 & 1 \\
\hline 52 & 0 & 0 & 0 & 0 & 0 & 0 & 0 & 1 & 0 & 15 & 0 \\
\hline 52 & 0 & 0 & 0 & 0 & 0 & 0 & 0 & 0 & 0 & 18 & 0 \\
\hline 52 & 0 & 0 & 0 & 0 & 0 & 0 & 0 & 0 & 0 & 39 & 0 \\
\hline 52 & 0 & 0 & 0 & 0 & 1 & 0 & 0 & 0 & 0 & 25 & 1 \\
\hline 52 & 2 & 0 & 0 & 0 & 0 & 0 & 0 & 0 & 0 & 96 & 0 \\
\hline 53 & 0 & 0 & 0 & 0 & 0 & 0 & 0 & 0 & 0 & 0 & 4 \\
\hline 59 & 0 & 0 & 0 & 0 & 0 & 0 & 1 & 0 & 0 & 29 & 0 \\
\hline 59 & 0 & 2 & 0 & 0 & 0 & 0 & 1 & 0 & 0 & 9 & 1 \\
\hline 60 & 0 & 0 & 0 & 35 & 0 & 12 & 0 & 0 & 0 & 12 & 1 \\
\hline 61 & 0 & 0 & 0 & 36 & 0 & 18 & 0 & 0 & 0 & 15 & 6 \\
\hline 62 & 0 & 0 & 0 & 69 & 0 & 1 & 0 & 0 & 0 & 18 & 1 \\
\hline 63 & 0 & 0 & 0 & 0 & 0 & 0 & 0 & 0 & 0 & 6 & 3 \\
\hline 63 & 0 & 0 & 0 & 0 & 0 & 0 & 3 & 0 & 0 & 3 & 2 \\
\hline 64 & 0 & 0 & 0 & 114 & 0 & 0 & 0 & 0 & 1 & 28 & 10 \\
\hline 65 & 0 & 0 & 0 & 150 & 0 & 0 & 0 & 0 & 0 & 8 & 4 \\
\hline 65 & 0 & 0 & 0 & 107 & 0 & 0 & 0 & 0 & 0 & 33 & 3 \\
\hline 66 & 0 & 0 & 0 & 0 & 0 & 0 & 88 & 2 & 0 & 26 & 0 \\
\hline 67 & 0 & 0 & 1 & 0 & 0 & 0 & 0 & 0 & 0 & 8 & 0 \\
\hline 68 & 0 & 0 & 0 & 0 & 0 & 0 & 14 & 0 & 0 & 5 & 4 \\
\hline 68 & 0 & 1 & 0 & 0 & 0 & 0 & 57 & 0 & 0 & 3 & 1 \\
\hline 69 & 0 & 0 & 0 & 0 & 0 & 0 & 23 & 0 & 0 & 6 & 3 \\
\hline 70 & 0 & 0 & 0 & 0 & 0 & 29 & 0 & 0 & 0 & 1 & 0 \\
\hline 71 & 0 & 0 & 0 & 0 & 0 & 0 & 66 & 1 & 0 & 74 & 0 \\
\hline 71 & 0 & 0 & 0 & 0 & 0 & 0 & 153 & 0 & 0 & 17 & 0 \\
\hline 72 & 0 & 0 & 0 & 0 & 0 & 0 & 16 & 0 & 0 & 5 & 2 \\
\hline 72 & 0 & 0 & 0 & 0 & 0 & 0 & 27 & 0 & 0 & 4 & 0 \\
\hline 73 & 0 & 0 & 0 & 0 & 0 & 0 & 0 & 0 & 0 & 134 & 0 \\
\hline 73 & 0 & 0 & 0 & 0 & 0 & 0 & 94 & 0 & 0 & 15 & 0 \\
\hline
\end{tabular}


Table 1. Description of sites and macroinvertebrate data collected from selected sites the Eagle River watershed, Colorado, 2000-2007.-Continued

[ID, identification; NAVD, North American Vertical Datum of 1988; ft, feet; mi², square miles; ’, degrees; ', minutes; ", seconds; FS, U.S. Department of Agriculture Forest Service; USGS, U.S. Geological Survey]

\begin{tabular}{|c|c|c|c|c|c|c|c|c|c|}
\hline Site ID' & $\begin{array}{c}\text { Other__ } \\
\text { Ephemerella }\end{array}$ & $\begin{array}{c}\text { Other_- } \\
\text { Oligochaeta }\end{array}$ & Paraleptophlebia & Paraperla & Parapsyche & Pedicia & $\begin{array}{c}\text { Pericoma_ } \\
\text { Telmatoscopus }\end{array}$ & Physa_Physella & Pisidiidae \\
\hline 2 & 0 & 2 & 0 & 0 & 0 & 0 & 0 & 0 & 99 \\
\hline 3 & 0 & 4 & 0 & 0 & 1 & 0 & 2 & 0 & 0 \\
\hline 5 & 4 & 3 & 12 & 0 & 0 & 0 & 1 & 0 & 2 \\
\hline 6 & 0 & 3 & 3 & 0 & 0 & 0 & 5 & 0 & 0 \\
\hline 6 & 0 & 0 & 3 & 0 & 0 & 0 & 0 & 0 & 0 \\
\hline 9 & 0 & 26 & 0 & 0 & 0 & 0 & 0 & 0 & 0 \\
\hline 10 & 1 & 18 & 2 & 0 & 0 & 0 & 1 & 0 & 0 \\
\hline 10 & 1 & 20 & 2 & 0 & 0 & 0 & 0 & 0 & 0 \\
\hline 11 & 0 & 38 & 0 & 0 & 0 & 0 & 0 & 0 & 0 \\
\hline 12 & 0 & 13 & 0 & 0 & 0 & 0 & 0 & 0 & 0 \\
\hline 13 & 0 & 13 & 0 & 0 & 0 & 0 & 0 & 0 & 0 \\
\hline 14 & 6 & 10 & 0 & 0 & 0 & 0 & 1 & 0 & 0 \\
\hline 18 & 7 & 23 & 0 & 0 & 0 & 0 & 0 & 0 & 0 \\
\hline 18 & 0 & 12 & 0 & 0 & 0 & 0 & 0 & 0 & 0 \\
\hline 19 & 4 & 2 & 1 & 0 & 0 & 0 & 0 & 0 & 0 \\
\hline 20 & 38 & 11 & 11 & 0 & 0 & 0 & 0 & 0 & 0 \\
\hline 21 & 27 & 1 & 5 & 0 & 0 & 0 & 0 & 0 & 0 \\
\hline 22 & 0 & 26 & 0 & 0 & 0 & 0 & 0 & 0 & 0 \\
\hline 23 & 0 & 0 & 0 & 0 & 2 & 0 & 0 & 0 & 0 \\
\hline 24 & 0 & 5 & 0 & 0 & 0 & 0 & 0 & 0 & 0 \\
\hline 25 & 0 & 0 & 0 & 0 & 0 & 0 & 0 & 0 & 0 \\
\hline 26 & 0 & 5 & 0 & 0 & 0 & 0 & 0 & 0 & 0 \\
\hline 27 & 0 & 10 & 0 & 0 & 0 & 0 & 0 & 0 & 0 \\
\hline 27 & 0 & 2 & 0 & 0 & 0 & 0 & 0 & 0 & 0 \\
\hline 27 & 0 & 9 & 0 & 0 & 0 & 0 & 1 & 0 & 1 \\
\hline 28 & 1 & 0 & 0 & 0 & 0 & 0 & 18 & 0 & 0 \\
\hline 30 & 55 & 1 & 23 & 0 & 0 & 0 & 1 & 0 & 0 \\
\hline 30 & 71 & 5 & 24 & 0 & 0 & 0 & 0 & 0 & 0 \\
\hline 31 & 1 & 11 & 0 & 0 & 0 & 0 & 9 & 0 & 0 \\
\hline 31 & 0 & 4 & 1 & 0 & 0 & 0 & 1 & 0 & 0 \\
\hline 31 & 0 & 8 & 0 & 0 & 0 & 0 & 0 & 0 & 0 \\
\hline 31 & 1 & 64 & 0 & 0 & 0 & 1 & 5 & 0 & 0 \\
\hline 32 & 24 & 0 & 1 & 0 & 0 & 0 & 12 & 0 & 0 \\
\hline 32 & 14 & 0 & 4 & 0 & 0 & 0 & 36 & 0 & 0 \\
\hline 32 & 9 & 0 & 2 & 0 & 0 & 0 & 0 & 0 & 0 \\
\hline 33 & 22 & 0 & 4 & 0 & 0 & 0 & 0 & 0 & 0 \\
\hline 33 & 12 & 0 & 1 & 0 & 0 & 0 & 0 & 0 & 0 \\
\hline 33 & 0 & 0 & 2 & 0 & 0 & 0 & 0 & 0 & 0 \\
\hline 33 & 4 & 0 & 3 & 0 & 0 & 0 & 7 & 0 & 0 \\
\hline 34 & 0 & 2 & 0 & 0 & 0 & 0 & 12 & 0 & 0 \\
\hline 34 & 11 & 1 & 0 & 0 & 0 & 0 & 37 & 0 & 0 \\
\hline 34 & 0 & 5 & 0 & 0 & 0 & 0 & 232 & 0 & 0 \\
\hline 34 & 1 & 8 & 0 & 0 & 0 & 0 & 0 & 0 & 0 \\
\hline 34 & 4 & 13 & 0 & 0 & 0 & 0 & 4 & 0 & 0 \\
\hline 35 & 0 & 11 & 0 & 0 & 0 & 0 & 0 & 0 & 0 \\
\hline 36 & 8 & 4 & 0 & 0 & 0 & 0 & 16 & 0 & 0 \\
\hline 36 & 1 & 3 & 0 & 0 & 0 & 0 & 49 & 0 & 0 \\
\hline 36 & 2 & 2 & 0 & 0 & 0 & 0 & 0 & 0 & 0 \\
\hline 36 & 4 & 6 & 0 & 0 & 0 & 0 & 5 & 0 & 0 \\
\hline
\end{tabular}


Table 1. Description of sites and macroinvertebrate data collected from selected sites the Eagle River watershed, Colorado, 2000-2007.-Continued

[ID, identification; NAVD, North American Vertical Datum of 1988; ft, feet; mi² , square miles; ${ }^{\circ}$, degrees; ', minutes; ", seconds; FS, U.S. Department of Agriculture Forest Service; USGS, U.S. Geological Survey]

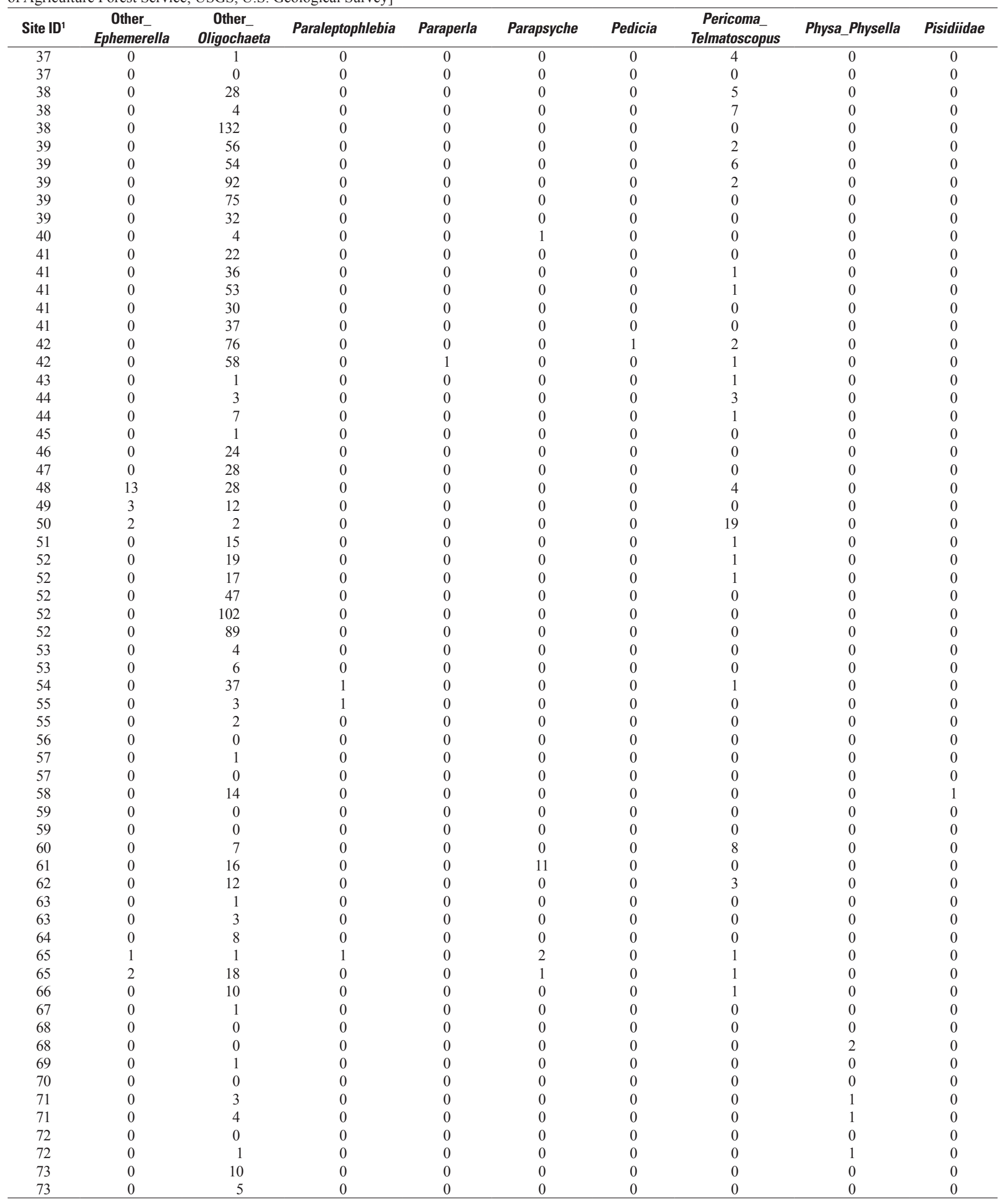


Table 1. Description of sites and macroinvertebrate data collected from selected sites the Eagle River watershed, Colorado, 2000-2007.-Continued

[ID, identification; NAVD, North American Vertical Datum of 1988; ft, feet; $\mathrm{mi}^{2}$, square miles; ${ }^{\circ}$, degrees; ', minutes; ", seconds; FS, U.S. Department of Agriculture Forest Service; USGS, U.S. Geological Survey]

Site ID' Podmosta Prodiamesinae Psychoglypha Pteronarcella Rhabdomastix Rhithrogena

Rhyacophila_ Rhyacophila_ Rhyacophila

Site Podmosta Prodiamesinae Psychoglypha Pteronarcella Rhabdomastix Rhithrogena alberta_group angelita_group brunnea_vemna_groups

\begin{tabular}{|c|c|c|c|c|c|c|c|c|c|}
\hline & & & & & & & & & \\
\hline 1 & 0 & 0 & 0 & 0 & 0 & 25 & 0 & 0 & 0 \\
\hline 2 & 0 & 0 & 0 & 0 & 0 & 0 & 0 & 0 & 2 \\
\hline 3 & 0 & 0 & 0 & 0 & 0 & 6 & 41 & 0 & 0 \\
\hline 4 & 0 & 0 & 0 & 0 & 0 & 0 & 0 & 0 & 3 \\
\hline 5 & 0 & 0 & 0 & 0 & 0 & 0 & 0 & 0 & 1 \\
\hline 6 & 0 & 0 & 0 & 0 & 0 & 1 & 0 & 9 & 7 \\
\hline 6 & 0 & 0 & 0 & 0 & 0 & 3 & 0 & 0 & 7 \\
\hline 7 & 0 & 0 & 0 & 0 & 0 & 15 & 0 & 0 & 1 \\
\hline 8 & 0 & 0 & 0 & 0 & 0 & 0 & 0 & 4 & 4 \\
\hline 9 & 1 & 0 & 0 & 0 & 0 & 0 & 0 & 0 & 0 \\
\hline 10 & 0 & 0 & 0 & 0 & 0 & 1 & 0 & 0 & 2 \\
\hline 10 & 0 & 0 & 0 & 0 & 0 & 7 & 0 & 0 & 3 \\
\hline 11 & 0 & 0 & 0 & 0 & 0 & 0 & 0 & 0 & 0 \\
\hline 12 & 1 & 0 & 0 & 0 & 0 & 0 & 0 & 0 & 0 \\
\hline 13 & 0 & 0 & 0 & 0 & 0 & 0 & 0 & 0 & 0 \\
\hline 14 & 0 & 0 & 0 & 1 & 0 & 10 & 0 & 0 & 0 \\
\hline 15 & 0 & 0 & 0 & 0 & 0 & 0 & 41 & 0 & 0 \\
\hline 16 & 0 & 0 & 0 & 0 & 0 & 2 & 0 & 0 & 1 \\
\hline 16 & 0 & 0 & 0 & 0 & 0 & 11 & 0 & 0 & 3 \\
\hline 17 & 0 & 0 & 0 & 0 & 0 & 0 & 0 & 0 & 0 \\
\hline 18 & 0 & 0 & 0 & 0 & 0 & 4 & 0 & 0 & 2 \\
\hline 18 & 0 & 0 & 0 & 0 & 0 & 20 & 0 & 0 & 1 \\
\hline 18 & 0 & 0 & 0 & 0 & 0 & 7 & 0 & 0 & 1 \\
\hline 19 & 0 & 0 & 0 & 0 & 0 & 2 & 0 & 0 & 1 \\
\hline 20 & 0 & 0 & 0 & 0 & 0 & 4 & 0 & 0 & 0 \\
\hline 21 & 0 & 0 & 0 & 1 & 0 & 6 & 0 & 0 & 1 \\
\hline 22 & 0 & 0 & 0 & 0 & 0 & 0 & 0 & 0 & 0 \\
\hline 23 & 0 & 0 & 0 & 0 & 0 & 3 & 0 & 0 & 3 \\
\hline 24 & 0 & 1 & 0 & 0 & 0 & 0 & 0 & 0 & 0 \\
\hline 25 & 0 & 0 & 0 & 7 & 0 & 9 & 0 & 0 & 1 \\
\hline 26 & 0 & 0 & 0 & 0 & 0 & 35 & 25 & 0 & 0 \\
\hline 27 & 0 & 0 & 0 & 0 & 0 & 30 & 0 & 0 & 4 \\
\hline 27 & 0 & 0 & 0 & 0 & 0 & 68 & 0 & 0 & 5 \\
\hline 27 & 0 & 0 & 0 & 0 & 0 & 12 & 0 & 0 & 4 \\
\hline 28 & 0 & 0 & 0 & 0 & 0 & 12 & 0 & 0 & 5 \\
\hline 28 & 0 & 0 & 0 & 0 & 0 & 22 & 0 & 0 & 12 \\
\hline 28 & 0 & 0 & 0 & 0 & 0 & 13 & 0 & 0 & 1 \\
\hline 29 & 0 & 0 & 0 & 5 & 0 & 0 & 0 & 9 & 10 \\
\hline 29 & 0 & 0 & 0 & 0 & 0 & 2 & 0 & 0 & 10 \\
\hline 29 & 0 & 0 & 0 & 0 & 0 & 13 & 0 & 0 & 17 \\
\hline 29 & 0 & 0 & 0 & 0 & 0 & 19 & 0 & 0 & 6 \\
\hline 29 & 0 & 0 & 0 & 0 & 0 & 3 & 0 & 0 & 7 \\
\hline 30 & 0 & 0 & 0 & 0 & 0 & 0 & 0 & 0 & 0 \\
\hline 30 & 0 & 0 & 0 & 0 & 0 & 0 & 0 & 0 & 0 \\
\hline 30 & 0 & 0 & 0 & 0 & 0 & 0 & 0 & 0 & 0 \\
\hline 30 & 0 & 0 & 0 & 0 & 0 & 0 & 0 & 0 & 1 \\
\hline 31 & 0 & 0 & 0 & 0 & 0 & 0 & 0 & 0 & 11 \\
\hline 31 & 0 & 0 & 0 & 0 & 0 & 0 & 0 & 0 & 0 \\
\hline 31 & 0 & 0 & 0 & 0 & 0 & 0 & 0 & 0 & 1 \\
\hline 31 & 0 & 0 & 0 & 0 & 0 & 0 & 0 & 0 & 0 \\
\hline 32 & 0 & 0 & 0 & 0 & 0 & 12 & 0 & 0 & 6 \\
\hline 32 & 0 & 0 & 0 & 0 & 0 & 9 & 0 & 0 & 0 \\
\hline 32 & 0 & 0 & 0 & 0 & 0 & 24 & 0 & 0 & 3 \\
\hline 33 & 0 & 0 & 0 & 0 & 0 & 6 & 0 & 0 & 14 \\
\hline 33 & 0 & 0 & 0 & 0 & 0 & 9 & 0 & 0 & 7 \\
\hline 33 & 0 & 0 & 0 & 0 & 1 & 17 & 0 & 0 & 10 \\
\hline 33 & 0 & 0 & 0 & 0 & 0 & 3 & 0 & 0 & 13 \\
\hline 34 & 0 & 0 & 0 & 0 & 0 & 8 & 0 & 0 & 6 \\
\hline 34 & 0 & 0 & 0 & 0 & 0 & 0 & 0 & 0 & 1 \\
\hline 34 & 0 & 2 & 0 & 0 & 0 & 0 & 0 & 0 & 0 \\
\hline 34 & 0 & 0 & 0 & 0 & 0 & 6 & 0 & 0 & 7 \\
\hline 34 & 1 & 0 & 0 & 0 & 0 & 4 & 0 & 0 & 3 \\
\hline 35 & 0 & 0 & 0 & 0 & 0 & 13 & 2 & 0 & 2 \\
\hline 36 & 0 & 0 & 0 & 0 & 0 & 9 & 0 & 0 & 1 \\
\hline 36 & 0 & 0 & 0 & 0 & 0 & 0 & 0 & 0 & 1 \\
\hline 36 & 0 & 0 & 0 & 0 & 0 & 7 & 0 & 0 & 7 \\
\hline 36 & 0 & 0 & 0 & 0 & 1 & 7 & 0 & 0 & 2 \\
\hline
\end{tabular}


Table 1. Description of sites and macroinvertebrate data collected from selected sites the Eagle River watershed, Colorado, 2000-2007.-Continued

[ID, identification; NAVD, North American Vertical Datum of 1988; ft, feet; mi², square miles; ${ }^{\circ}$, degrees; ', minutes; ", seconds; FS, U.S. Department of Agriculture Forest Service; USGS, U.S. Geological Survey]

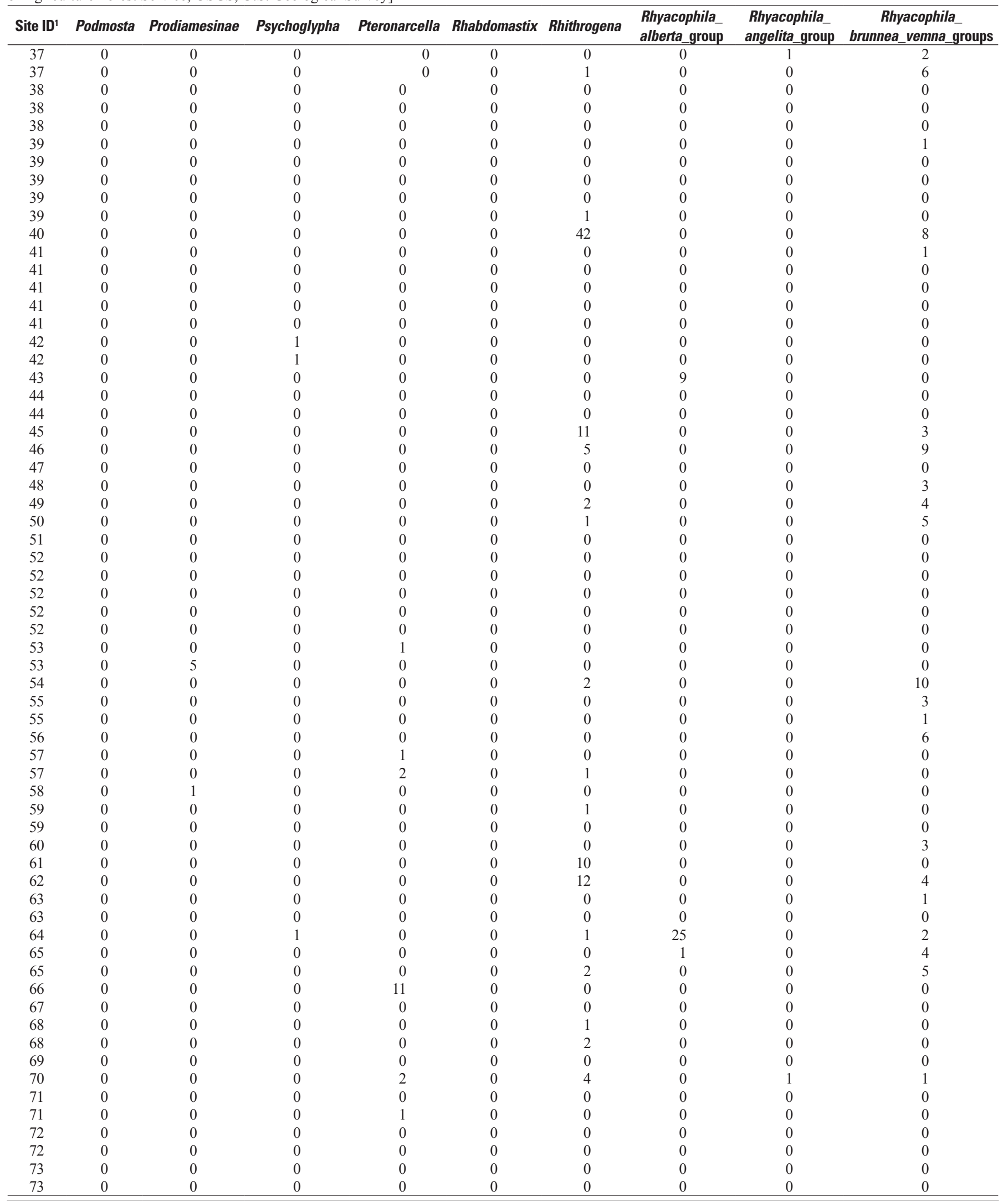


Table 1. Description of sites and macroinvertebrate data collected from selected sites the Eagle River watershed, Colorado, 2000-2007.-Continued

[ID, identification; NAVD, North American Vertical Datum of 1988; ft, feet; mi², square miles; ’, degrees; ', minutes; ", seconds; FS, U.S. Department of Agriculture Forest Service; USGS, U.S. Geological Survey]

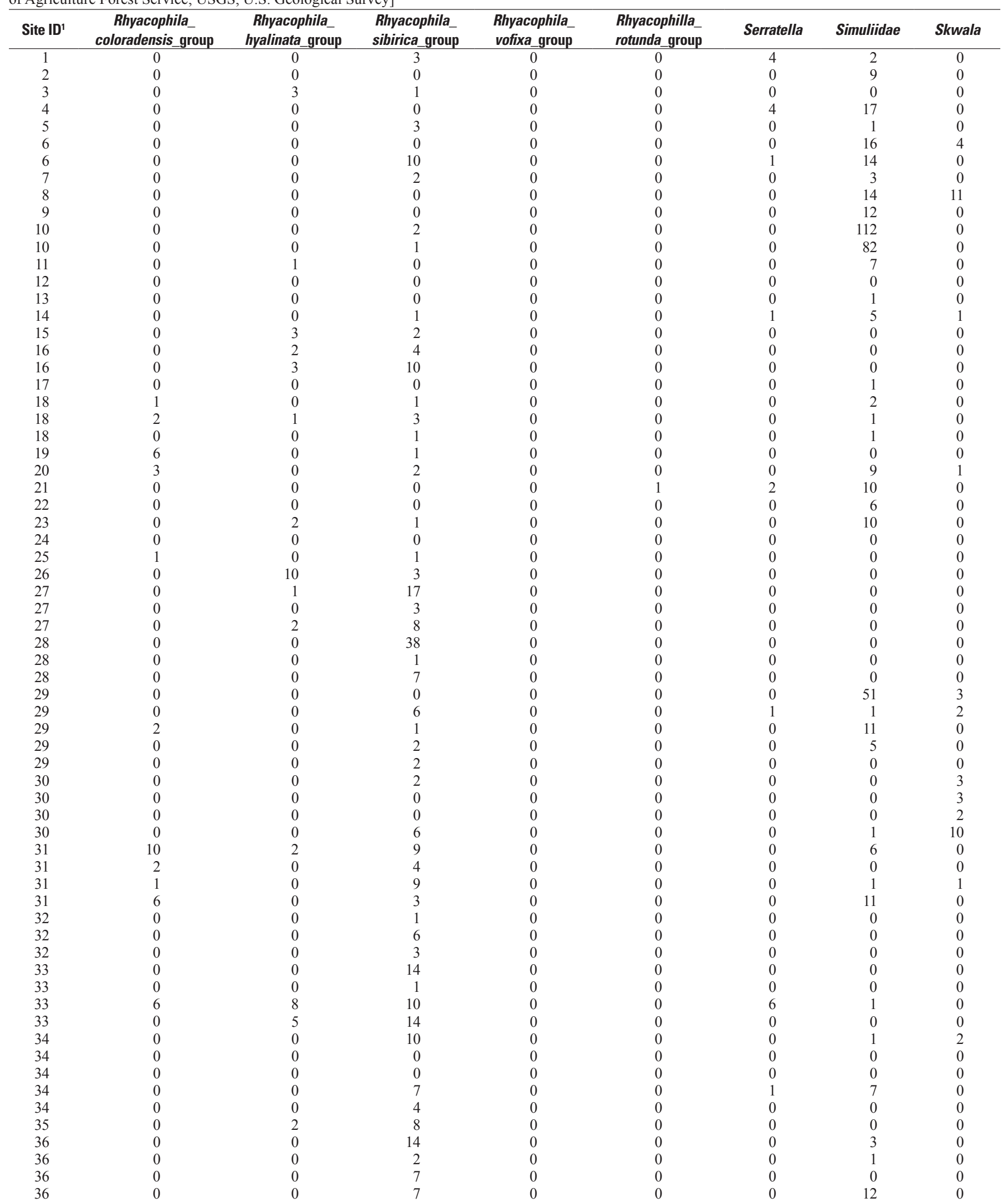


Table 1. Description of sites and macroinvertebrate data collected from selected sites the Eagle River watershed, Colorado, 2000-2007.-Continued

[ID, identification; NAVD, North American Vertical Datum of 1988; ft, feet; mi² , square miles; ${ }^{\circ}$, degrees; ', minutes; ", seconds; FS, U.S. Department of Agriculture Forest Service; USGS, U.S. Geological Survey]

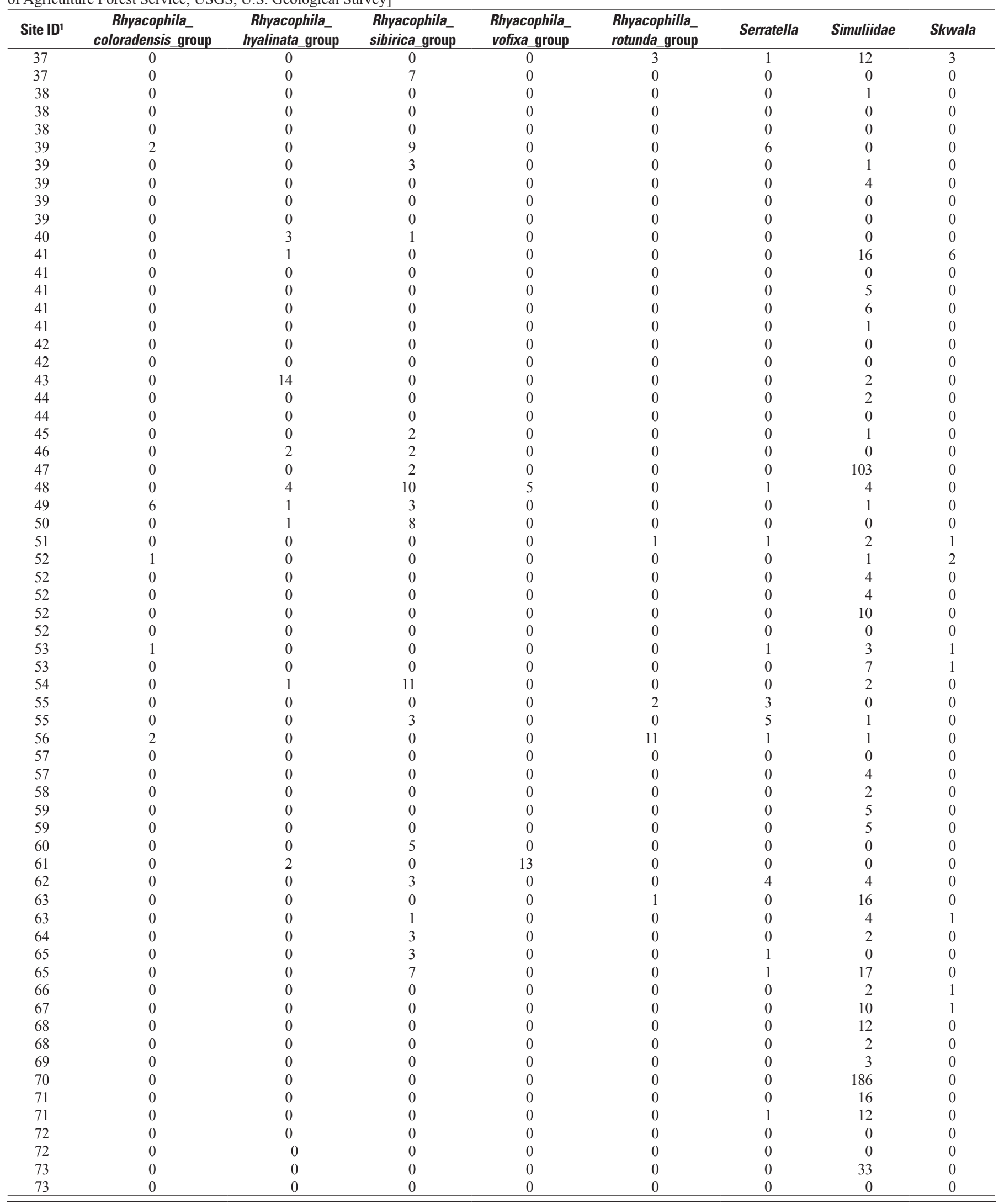


Table 1. Description of sites and macroinvertebrate data collected from selected sites the Eagle River watershed, Colorado, 2000-2007.-Continued

[ID, identification; NAVD, North American Vertical Datum of 1988; ft, feet; $\mathrm{mi}^{2}$, square miles; ${ }^{\circ}$, degrees; ', minutes; ", seconds; FS, U.S. Department of Agriculture Forest Service; USGS, U.S. Geological Survey]

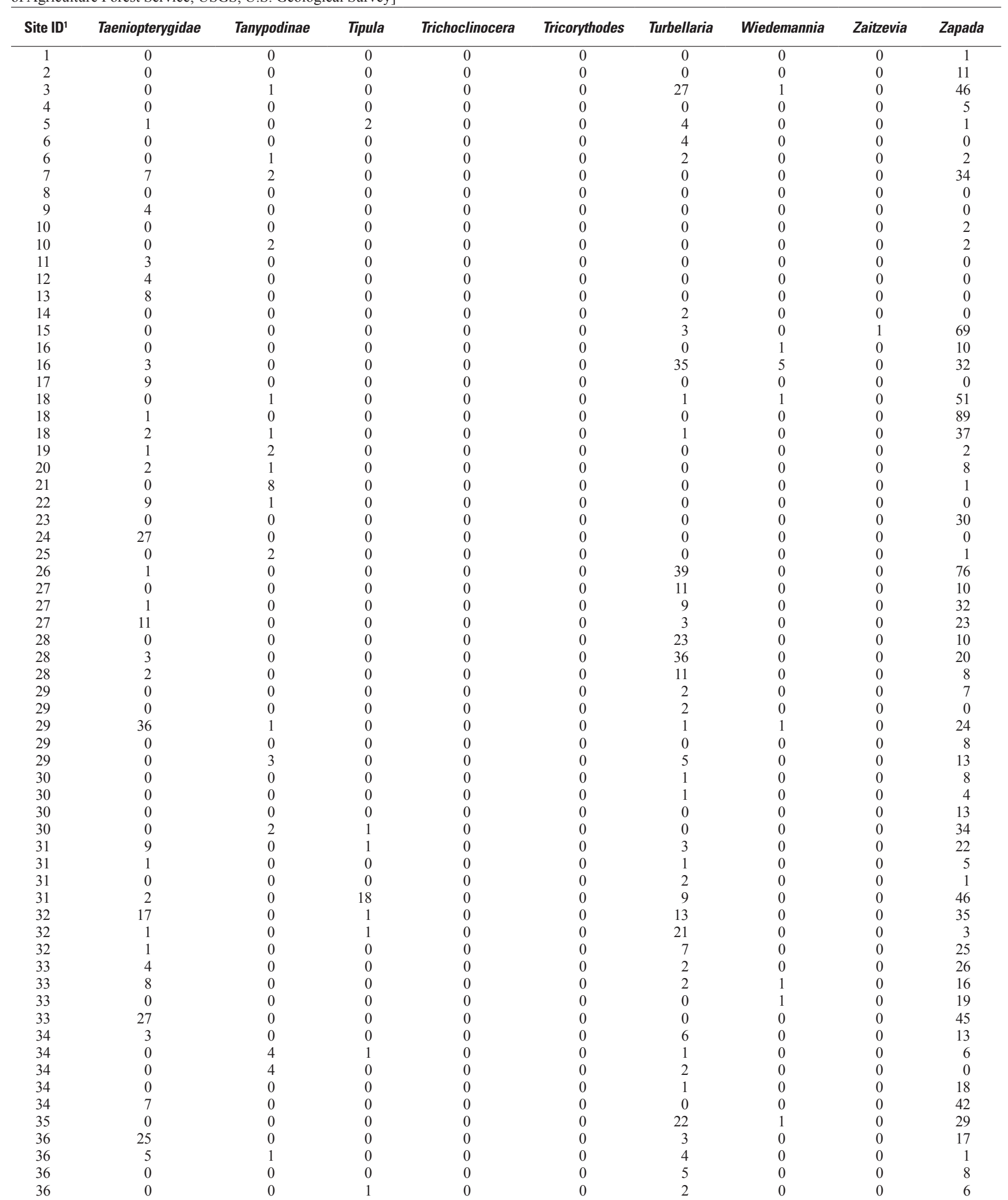


Table 1. Description of sites and macroinvertebrate data collected from selected sites the Eagle River watershed, Colorado, 2000-2007.-Continued

[ID, identification; NAVD, North American Vertical Datum of 1988; ft, feet; mi² , square miles; ${ }^{\circ}$, degrees; ', minutes; ", seconds; FS, U.S. Department of Agriculture Forest Service; USGS, U.S. Geological Survey]

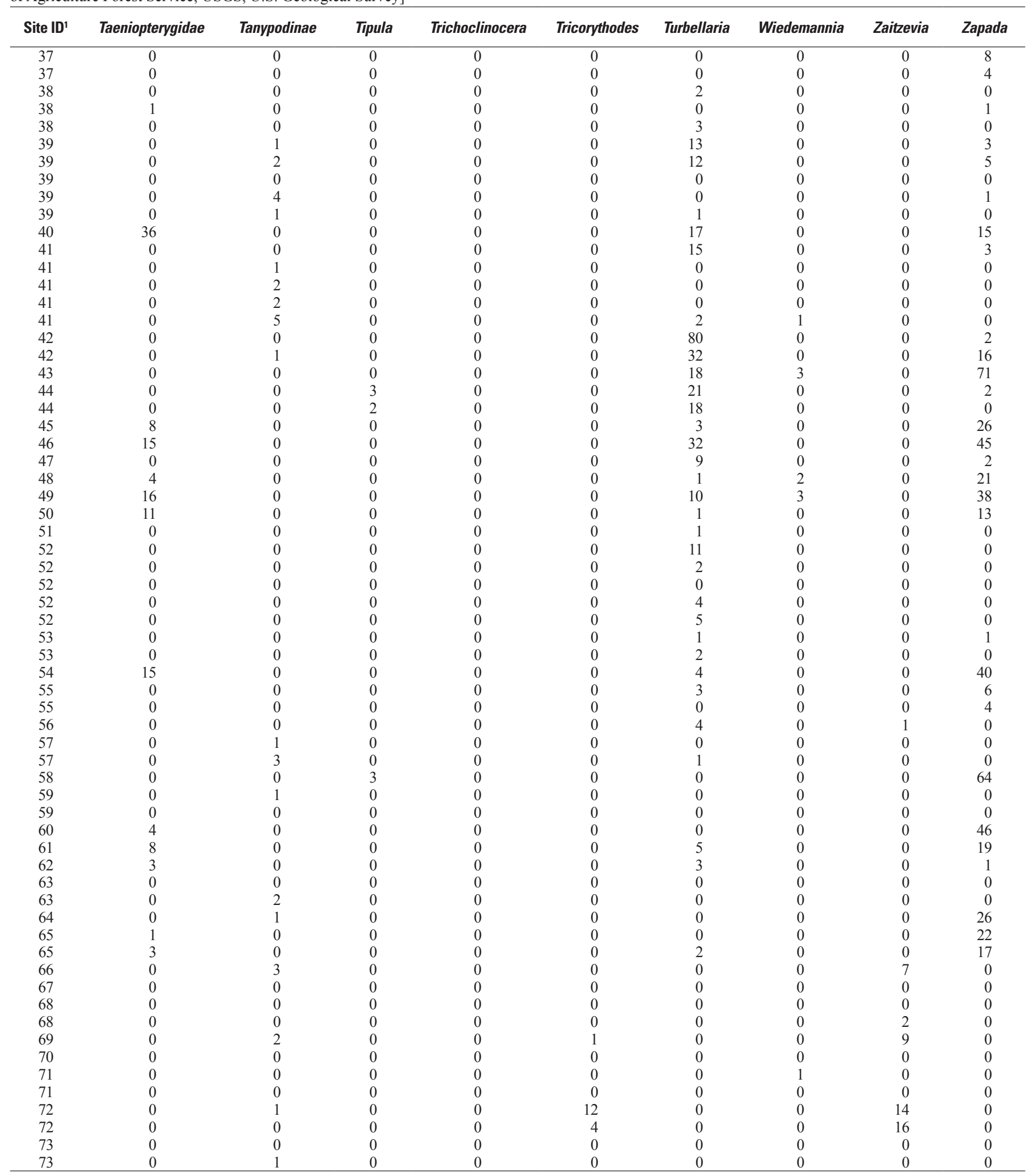

${ }^{1}$ See figure 1.

${ }^{2}$ Station ID is either a USGS station number or a FS station ID.

${ }^{3}$ See text for description of sampling methods.

${ }^{4}$ Values in the taxa columns indicate the number of organisms. See text for description of macroinvertebrate data preparation. 
Table 2. Description of sites and algal data collected from selected sites the Eagle River watershed, Colorado, $2000-2001$.

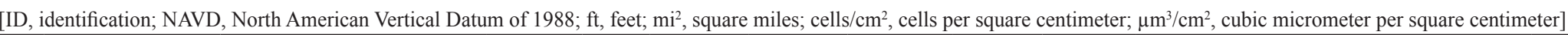

\begin{tabular}{|c|c|c|c|c|c|c|c|c|c|c|c|c|}
\hline $\begin{array}{l}\text { Site } \\
\text { ID }^{1}\end{array}$ & $\begin{array}{l}\text { USGS } \\
\text { station } \\
\text { number }\end{array}$ & Station name & $\begin{array}{c}\text { Replicate } \\
\text { sample } \\
\text { number }\end{array}$ & Year & $\begin{array}{l}\text { Collection } \\
\text { date }\end{array}$ & Latitude & Longitude & $\begin{array}{c}\text { Elevation } \\
\text { NAVD } 88 \\
\text { (ft) }\end{array}$ & $\begin{array}{c}\text { Drainage } \\
\text { area } \\
\left(\mathrm{mi}^{2}\right)\end{array}$ & Algal taxon name & $\begin{array}{c}\text { Total } \\
\text { density } \\
\text { (number of } \\
\text { cells/cm²) }\end{array}$ & $\begin{array}{c}\text { Total } \\
\text { biovolume } \\
\left(\mu \mathrm{m}^{3} / \mathrm{cm}^{2}\right)\end{array}$ \\
\hline 6 & 09063000 & Eagle River at Red Cliff & 1 & 2000 & $8 / 17 / 2000$ & $39^{\circ} 30^{\prime} 30^{\prime \prime}$ & $106^{\circ} 21^{\prime} 58^{\prime \prime}$ & 8,654 & 70 & $\begin{array}{l}\text { Achnanthidium minutissimum (Kützing) } \\
\text { Czarnecki }\end{array}$ & 10,461 & 576,109 \\
\hline 6 & 09063000 & Eagle River at Red Cliff & 1 & 2000 & $8 / 17 / 2000$ & $39^{\circ} 30^{\prime} 30^{\prime \prime}$ & $106^{\circ} 21^{\prime} 58^{\prime \prime}$ & 8,654 & 70 & $\begin{array}{l}\text { Achnanthidium pyrenaicum (Hustedt) } \\
\text { Kobayasi }\end{array}$ & 206 & 25,890 \\
\hline 6 & 09063000 & Eagle River at Red Cliff & 1 & 2000 & $8 / 17 / 2000$ & $39^{\circ} 30^{\prime} 30^{\prime \prime}$ & $106^{\circ} 21^{\prime} 58^{\prime \prime}$ & 8,654 & 70 & Amphora pediculus (Kützing) Grunow & 34 & 3,246 \\
\hline 6 & 09063000 & Eagle River at Red Cliff & 1 & 2000 & $8 / 17 / 2000$ & $39^{\circ} 30^{\prime} 30^{\prime \prime}$ & $106^{\circ} 21^{\prime} 58^{\prime \prime}$ & 8,654 & 70 & $\begin{array}{l}\text { Cocconeis placentula var. euglypta } \\
\text { (Ehrenberg) Grunow }\end{array}$ & 34 & 20,663 \\
\hline 6 & 09063000 & Eagle River at Red Cliff & 1 & 2000 & $8 / 17 / 2000$ & $39^{\circ} 30^{\prime} 30^{\prime \prime}$ & $106^{\circ} 21^{\prime} 58^{\prime \prime}$ & 8,654 & 70 & $\begin{array}{l}\text { Cocconeis placentula var. lineata (Ehrenberg) } \\
\text { Van Heurck }\end{array}$ & 377 & 395,299 \\
\hline 6 & 09063000 & Eagle River at Red Cliff & 1 & 2000 & $8 / 17 / 2000$ & $39^{\circ} 30^{\prime} 30^{\prime \prime}$ & $106^{\circ} 21^{\prime} 58^{\prime \prime}$ & 8,654 & 70 & $\begin{array}{l}\text { Craticula molestiformis (Hustedt) } \\
\text { Lange-Bertalot }\end{array}$ & 34 & 4,238 \\
\hline 6 & 09063000 & Eagle River at Red Cliff & 1 & 2000 & $8 / 17 / 2000$ & $39^{\circ} 30^{\prime} 30^{\prime \prime}$ & $106^{\circ} 21^{\prime} 58^{\prime \prime}$ & 8,654 & 70 & Diatoma tenuis Agardh & 34 & 3,861 \\
\hline 6 & 09063000 & Eagle River at Red Cliff & 1 & 2000 & $8 / 17 / 2000$ & $39^{\circ} 30^{\prime} 30^{\prime \prime}$ & $106^{\circ} 21^{\prime} 58^{\prime \prime}$ & 8,654 & 70 & Encyonema brehmii (Hustedt) Mann & 17 & 473 \\
\hline 6 & 09063000 & Eagle River at Red Cliff & 1 & 2000 & $8 / 17 / 2000$ & $39^{\circ} 30^{\prime} 30^{\prime \prime}$ & $106^{\circ} 21^{\prime} 58^{\prime \prime}$ & 8,654 & 70 & Encyonema silesiacum (Bleisch) Mann & 326 & 153,420 \\
\hline 6 & 09063000 & Eagle River at Red Cliff & 1 & 2000 & $8 / 17 / 2000$ & $39^{\circ} 30^{\prime} 30^{\prime \prime}$ & $106^{\circ} 21^{\prime} 58^{\prime \prime}$ & 8,654 & 70 & Fragilaria vaucheriae (Kützing) Petersen & 17 & 3,548 \\
\hline 6 & 09063000 & Eagle River at Red Cliff & 1 & 2000 & $8 / 17 / 2000$ & $39^{\circ} 30^{\prime} 30^{\prime \prime}$ & $106^{\circ} 21^{\prime} 58^{\prime \prime}$ & 8,654 & 70 & Gomphonema olivaceoides Hustedt & 34 & 5,247 \\
\hline 6 & 09063000 & Eagle River at Red Cliff & 1 & 2000 & $8 / 17 / 2000$ & $39^{\circ} 30^{\prime} 30^{\prime \prime}$ & $106^{\circ} 21^{\prime} 58^{\prime \prime}$ & 8,654 & 70 & $\begin{array}{l}\text { Homoeothrix janthina (Bornet et Flahault) } \\
\text { Starmach }\end{array}$ & 17,139 & 555,460 \\
\hline 6 & 09063000 & Eagle River at Red Cliff & 1 & 2000 & $8 / 17 / 2000$ & $39^{\circ} 30^{\prime} 30^{\prime \prime}$ & $106^{\circ} 21^{\prime} 58^{\prime \prime}$ & 8,654 & 70 & $\begin{array}{l}\text { Navicula cryptotenella Lange-Bertalot } \\
\text { ex Krammer et Lange-Bertalot }\end{array}$ & 34 & 12,413 \\
\hline 6 & 09063000 & Eagle River at Red Cliff & 1 & 2000 & $8 / 17 / 2000$ & $39^{\circ} 30^{\prime} 30^{\prime \prime}$ & $106^{\circ} 21^{\prime} 58^{\prime \prime}$ & 8,654 & 70 & Nitzschia dissipata (Kützing) Grunow & 34 & 8,919 \\
\hline 6 & 09063000 & Eagle River at Red Cliff & 1 & 2000 & $8 / 17 / 2000$ & $39^{\circ} 30^{\prime} 30^{\prime \prime}$ & $106^{\circ} 21^{\prime} 58^{\prime \prime}$ & 8,654 & 70 & Phormidium autumnale (Agardh) Gomont & 10,672 & $1,045,073$ \\
\hline 6 & 09063000 & Eagle River at Red Cliff & 1 & 2000 & $8 / 17 / 2000$ & $39^{\circ} 30^{\prime} 30^{\prime \prime}$ & $106^{\circ} 21^{\prime} 58^{\prime \prime}$ & 8,654 & 70 & $\begin{array}{l}\text { Reimeria sinuata (Gregory) } \\
\text { Kociolek et Stoermer }\end{array}$ & 137 & 22,684 \\
\hline 6 & 09063000 & Eagle River at Red Cliff & 1 & 2000 & $8 / 17 / 2000$ & $39^{\circ} 30^{\prime} 30^{\prime \prime}$ & $106^{\circ} 21^{\prime} 58^{\prime \prime}$ & 8,654 & 70 & $\begin{array}{l}\text { Staurosirella leptostauron (Ehrenberg) } \\
\text { Williams et Round }\end{array}$ & 69 & 33,505 \\
\hline 6 & 09063000 & Eagle River at Red Cliff & 1 & 2000 & $8 / 17 / 2000$ & $39^{\circ} 30^{\prime} 30^{\prime \prime}$ & $106^{\circ} 21^{\prime} 58^{\prime \prime}$ & 8,654 & 70 & $\begin{array}{l}\text { Staurosirella pinnata (Ehrenberg) } \\
\text { Williams et Round }\end{array}$ & 34 & 3,302 \\
\hline 6 & 09063000 & Eagle River at Red Cliff & 1 & 2000 & $8 / 17 / 2000$ & $39^{\circ} 30^{\prime} 30^{\prime \prime}$ & $106^{\circ} 21^{\prime} 58^{\prime \prime}$ & 8,654 & 70 & $\begin{array}{l}\text { Unknown Cyanophyte Oscillatoriales } \\
\text { (no sheath) }\end{array}$ & 5,174 & 83,901 \\
\hline 6 & 09063000 & Eagle River at Red Cliff & 1 & 2000 & $8 / 17 / 2000$ & $39^{\circ} 30^{\prime} 30^{\prime \prime}$ & $106^{\circ} 21^{\prime} 58^{\prime \prime}$ & 8,654 & 70 & $\begin{array}{l}\text { Unknown Rhodophyte Florideophycidae } \\
\text { (chantransia) }\end{array}$ & 19,727 & $69,815,603$ \\
\hline 6 & 09063000 & Eagle River at Red Cliff & 1 & 2001 & $8 / 16 / 2001$ & $39^{\circ} 30^{\prime} 30^{\prime \prime}$ & $106^{\circ} 21^{\prime} 58^{\prime \prime}$ & 8,654 & 70 & $\begin{array}{l}\text { Achnanthidium minutissimum (Kützing) } \\
\text { Czarnecki }\end{array}$ & 78,669 & $4,265,488$ \\
\hline 6 & 09063000 & Eagle River at Red Cliff & 1 & 2001 & $8 / 16 / 2001$ & $39^{\circ} 30^{\prime} 30^{\prime \prime}$ & $106^{\circ} 21^{\prime} 58^{\prime \prime}$ & 8,654 & 70 & $\begin{array}{l}\text { Achnanthidium pyrenaicum (Hustedt) } \\
\text { Kobayasi }\end{array}$ & 3,304 & 417,459 \\
\hline 6 & 09063000 & Eagle River at Red Cliff & 1 & 2001 & $8 / 16 / 2001$ & $39^{\circ} 30^{\prime} 30^{\prime \prime}$ & $106^{\circ} 21^{\prime} 58^{\prime \prime}$ & 8,654 & 70 & Amphipleura pellucida (Kützing) Kützing & 619 & 481,923 \\
\hline 6 & 09063000 & Eagle River at Red Cliff & 1 & 2001 & $8 / 16 / 2001$ & $39^{\circ} 30^{\prime} 30^{\prime \prime}$ & $106^{\circ} 21^{\prime} 58^{\prime \prime}$ & 8,654 & 70 & Amphora pediculus (Kützing) Grunow & 1,032 & 99,818 \\
\hline 6 & 09063000 & Eagle River at Red Cliff & 1 & 2001 & $8 / 16 / 2001$ & $39^{\circ} 30^{\prime} 30^{\prime \prime}$ & $106^{\circ} 21^{\prime} 58^{\prime \prime}$ & 8,654 & 70 & Caloneis bacillum (Grunow) Cleve & 413 & 177,641 \\
\hline 6 & 09063000 & Eagle River at Red Cliff & 1 & 2001 & $8 / 16 / 2001$ & $39^{\circ} 30^{\prime} 30^{\prime \prime}$ & $106^{\circ} 21^{\prime} 58^{\prime \prime}$ & 8,654 & 70 & $\begin{array}{l}\text { Chamaepinnularia soehrensis var. hassiaca } \\
\text { (Krasske) Lange-Bertalot }\end{array}$ & 413 & $3,097,606$ \\
\hline 6 & 09063000 & Eagle River at Red Cliff & 1 & 2001 & $8 / 16 / 2001$ & $39^{\circ} 30^{\prime} 30^{\prime \prime}$ & $106^{\circ} 21^{\prime} 58^{\prime \prime}$ & 8,654 & 70 & Closterium moniliferum Ehrenberg & 745 & $88,557,668$ \\
\hline 6 & 09063000 & Eagle River at Red Cliff & 1 & 2001 & $8 / 16 / 2001$ & $39^{\circ} 30^{\prime} 30^{\prime \prime}$ & $106^{\circ} 21^{\prime} 58^{\prime \prime}$ & 8,654 & 70 & Cocconeis pediculus Ehrenberg & 1,032 & $3,222,716$ \\
\hline 6 & 09063000 & Eagle River at Red Cliff & 1 & 2001 & $8 / 16 / 2001$ & $39^{\circ} 30^{\prime} 30^{\prime \prime}$ & $106^{\circ} 21^{\prime} 58^{\prime \prime}$ & 8,654 & 70 & $\begin{array}{l}\text { Cocconeis placentula var. euglypta } \\
\text { (Ehrenberg) Grunow }\end{array}$ & 619 & 368,064 \\
\hline 6 & 09063000 & Eagle River at Red Cliff & 1 & 2001 & $8 / 16 / 2001$ & $39^{\circ} 30^{\prime} 30^{\prime \prime}$ & $106^{\circ} 21^{\prime} 58^{\prime \prime}$ & 8,654 & 70 & $\begin{array}{l}\text { Cocconeis placentula var. lineata (Ehrenberg) } \\
\text { Van Heurck }\end{array}$ & 10,117 & $10,669,839$ \\
\hline
\end{tabular}


Table 2. Description of sites and algal data collected from selected sites the Eagle River watershed, Colorado, 2000-2001.—Continued

[ID, identification; NAVD, North American Vertical Datum of 1988; ft, feet; $\mathrm{mi}^{2}$, square miles; cells $/ \mathrm{cm}^{2}$, cells per square centimeter; $\mu \mathrm{m}^{3} / \mathrm{cm}^{2}$, cubic micrometer per square centimeter]

\begin{tabular}{|c|c|c|c|c|c|c|c|c|c|c|c|c|}
\hline $\begin{array}{l}\text { Site } \\
\text { ID' }\end{array}$ & $\begin{array}{l}\text { USGS } \\
\text { station } \\
\text { number }\end{array}$ & Station name & $\begin{array}{c}\text { Replicate } \\
\text { sample } \\
\text { number }\end{array}$ & Year & $\begin{array}{l}\text { Collection } \\
\text { date }\end{array}$ & Latitude & Longitude & $\begin{array}{c}\text { Elevation } \\
\text { NAVD } 88 \\
\text { (ft) }\end{array}$ & $\begin{array}{c}\text { Drainage } \\
\text { area } \\
\left(\mathrm{mi}^{2}\right)\end{array}$ & Algal taxon name & $\begin{array}{c}\text { Total } \\
\text { density } \\
\text { (number of } \\
\text { cells } / \mathrm{cm}^{2} \text { ) }\end{array}$ & $\begin{array}{c}\text { Total } \\
\text { biovolume } \\
\left(\mu \mathrm{m}^{3} / \mathrm{cm}^{2}\right)\end{array}$ \\
\hline 6 & 09063000 & Eagle River at Red Cliff & 1 & 2001 & $8 / 16 / 2001$ & $39^{\circ} 30^{\prime} 30^{\prime \prime}$ & $106^{\circ} 21^{\prime} 58^{\prime \prime}$ & 8,654 & 70 & Encyonema brehmii (Hustedt) Mann & 3,097 & 85,394 \\
\hline 6 & 09063000 & Eagle River at Red Cliff & 1 & 2001 & $8 / 16 / 2001$ & $39^{\circ} 30^{\prime} 30^{\prime \prime}$ & $106^{\circ} 21^{\prime} 58^{\prime \prime}$ & 8,654 & 70 & Encyonema minutum (Hilse) Mann & 2,065 & 445,652 \\
\hline 6 & 09063000 & Eagle River at Red Cliff & 1 & 2001 & $8 / 16 / 2001$ & $39^{\circ} 30^{\prime} 30^{\prime \prime}$ & $106^{\circ} 21^{\prime} 58^{\prime \prime}$ & 8,654 & 70 & Encyonema silesiacum (Bleisch) Mann & 5,368 & $2,549,730$ \\
\hline 6 & 09063000 & Eagle River at Red Cliff & 1 & 2001 & $8 / 16 / 2001$ & $39^{\circ} 30^{\prime} 30^{\prime \prime}$ & $106^{\circ} 21^{\prime} 58^{\prime \prime}$ & 8,654 & 70 & $\begin{array}{l}\text { Encyonopsis microcephala (Grunow) } \\
\text { Krammer }\end{array}$ & 826 & 52,565 \\
\hline 6 & 09063000 & Eagle River at Red Cliff & 1 & 2001 & $8 / 16 / 2001$ & $39^{\circ} 30^{\prime} 30^{\prime \prime}$ & $106^{\circ} 21^{\prime} 58^{\prime \prime}$ & 8,654 & 70 & Fragilaria vaucheriae (Kützing) Petersen & 826 & 162,715 \\
\hline 6 & 09063000 & Eagle River at Red Cliff & 1 & 2001 & $8 / 16 / 2001$ & $39^{\circ} 30^{\prime} 30^{\prime \prime}$ & $106^{\circ} 21^{\prime} 58^{\prime \prime}$ & 8,654 & 70 & Gomphonema minutum (Agardh) Agardh & 1,652 & 134,964 \\
\hline 6 & 09063000 & Eagle River at Red Cliff & 1 & 2001 & $8 / 16 / 2001$ & $39^{\circ} 30^{\prime} 30^{\prime \prime}$ & $106^{\circ} 21^{\prime} 58^{\prime \prime}$ & 8,654 & 70 & Gomphonema olivaceum (Lyngbye) Kützing & 206 & 78,243 \\
\hline 6 & 09063000 & Eagle River at Red Cliff & 1 & 2001 & $8 / 16 / 2001$ & $39^{\circ} 30^{\prime} 30^{\prime \prime}$ & $106^{\circ} 21^{\prime} 58^{\prime \prime}$ & 8,654 & 70 & Hannaea arcus (Ehrenberg) Patrick & 1,239 & $2,484,136$ \\
\hline 6 & 09063000 & Eagle River at Red Cliff & 1 & 2001 & $8 / 16 / 2001$ & $39^{\circ} 30^{\prime} 30^{\prime \prime}$ & $106^{\circ} 21^{\prime} 58^{\prime \prime}$ & 8,654 & 70 & $\begin{array}{l}\text { Homoeothrix janthina (Bornet et Flahault) } \\
\text { Starmach }\end{array}$ & 199,693 & $3,437,440$ \\
\hline 6 & 09063000 & Eagle River at Red Cliff & 1 & 2001 & $8 / 16 / 2001$ & $39^{\circ} 30^{\prime} 30^{\prime \prime}$ & $106^{\circ} 21^{\prime} 58^{\prime \prime}$ & 8,654 & 70 & Navicula cryptocephala Kützing & 1,239 & 453,976 \\
\hline 6 & 09063000 & Eagle River at Red Cliff & 1 & 2001 & $8 / 16 / 2001$ & $39^{\circ} 30^{\prime} 30^{\prime \prime}$ & $106^{\circ} 21^{\prime} 58^{\prime \prime}$ & 8,654 & 70 & $\begin{array}{l}\text { Navicula cryptotenella Lange-Bertalot } \\
\text { ex Krammer et Lange-Bertalot }\end{array}$ & 1,858 & 493,609 \\
\hline 6 & 09063000 & Eagle River at Red Cliff & 1 & 2001 & $8 / 16 / 2001$ & $39^{\circ} 30^{\prime} 30^{\prime \prime}$ & $106^{\circ} 21^{\prime} 58^{\prime \prime}$ & 8,654 & 70 & Navicula tripunctata (Müller) Bory & 3,717 & $3,379,660$ \\
\hline 6 & 09063000 & Eagle River at Red Cliff & 1 & 2001 & $8 / 16 / 2001$ & $39^{\circ} 30^{\prime} 30^{\prime \prime}$ & $106^{\circ} 21^{\prime} 58^{\prime \prime}$ & 8,654 & 70 & Navicula veneta Kützing & 2,065 & 455,870 \\
\hline 6 & 09063000 & Eagle River at Red Cliff & 1 & 2001 & $8 / 16 / 2001$ & $39^{\circ} 30^{\prime} 30^{\prime \prime}$ & $106^{\circ} 21^{\prime} 58^{\prime \prime}$ & 8,654 & 70 & Nitzschia agnita Hustedt & 413 & 41,442 \\
\hline 6 & 09063000 & Eagle River at Red Cliff & 1 & 2001 & $8 / 16 / 2001$ & $39^{\circ} 30^{\prime} 30^{\prime \prime}$ & $106^{\circ} 21^{\prime} 58^{\prime \prime}$ & 8,654 & 70 & Nitzschia dissipata (Kützing) Grunow & 413 & 106,475 \\
\hline 6 & 09063000 & Eagle River at Red Cliff & 1 & 2001 & $8 / 16 / 2001$ & $39^{\circ} 30^{\prime} 30^{\prime \prime}$ & $106^{\circ} 21^{\prime} 58^{\prime \prime}$ & 8,654 & 70 & Nitzschia fonticola Grunow & 413 & 41,079 \\
\hline 6 & 09063000 & Eagle River at Red Cliff & 1 & 2001 & $8 / 16 / 2001$ & $39^{\circ} 30^{\prime} 30^{\prime \prime}$ & $106^{\circ} 21^{\prime} 58^{\prime \prime}$ & 8,654 & 70 & Nitzschia inconspicua Grunow & 826 & 44,604 \\
\hline 6 & 09063000 & Eagle River at Red Cliff & 1 & 2001 & $8 / 16 / 2001$ & $39^{\circ} 30^{\prime} 30^{\prime \prime}$ & $106^{\circ} 21^{\prime} 58^{\prime \prime}$ & 8,654 & 70 & Nitzschia lacuum Lange-Bertalot & 413 & $4,837,402$ \\
\hline 6 & 09063000 & Eagle River at Red Cliff & 1 & 2001 & $8 / 16 / 2001$ & $39^{\circ} 30^{\prime} 30^{\prime \prime}$ & $106^{\circ} 21^{\prime} 58^{\prime \prime}$ & 8,654 & 70 & $\begin{array}{l}\text { Planothidium dubium (Grunow) } \\
\text { Round et Bukhtiyarova }\end{array}$ & 619 & 49,841 \\
\hline 6 & 09063000 & Eagle River at Red Cliff & 1 & 2001 & $8 / 16 / 2001$ & $39^{\circ} 30^{\prime} 30^{\prime \prime}$ & $106^{\circ} 21^{\prime} 58^{\prime \prime}$ & 8,654 & 70 & $\begin{array}{l}\text { Planothidium lanceolatum } \\
\text { (Brébisson ex Kützing) Lange-Bertalot }\end{array}$ & 826 & 113,139 \\
\hline 6 & 09063000 & Eagle River at Red Cliff & 1 & 2001 & $8 / 16 / 2001$ & $39^{\circ} 30^{\prime} 30^{\prime \prime}$ & $106^{\circ} 21^{\prime} 58^{\prime \prime}$ & 8,654 & 70 & $\begin{array}{l}\text { Pseudostaurosira brevistriata var. inflata } \\
\text { (Pantocsek) Edlund }\end{array}$ & 413 & 52,137 \\
\hline 6 & 09063000 & Eagle River at Red Cliff & 1 & 2001 & $8 / 16 / 2001$ & $39^{\circ} 30^{\prime} 30^{\prime \prime}$ & $106^{\circ} 21^{\prime} 58^{\prime \prime}$ & 8,654 & 70 & $\begin{array}{l}\text { Reimeria sinuata (Gregory) } \\
\text { Kociolek et Stoermer }\end{array}$ & 2,065 & 348,000 \\
\hline 6 & 09063000 & Eagle River at Red Cliff & 1 & 2001 & $8 / 16 / 2001$ & $39^{\circ} 30^{\prime} 30^{\prime \prime}$ & $106^{\circ} 21^{\prime} 58^{\prime \prime}$ & 8,654 & 70 & $\begin{array}{l}\text { Staurosira construens var. venter (Ehrenberg) } \\
\text { Hamilton }\end{array}$ & 6,194 & 743,976 \\
\hline 6 & 09063000 & Eagle River at Red Cliff & 1 & 2001 & $8 / 16 / 2001$ & $39^{\circ} 30^{\prime} 30^{\prime \prime}$ & $106^{\circ} 21^{\prime} 58^{\prime \prime}$ & 8,654 & 70 & $\begin{array}{l}\text { Staurosirella leptostauron (Ehrenberg) } \\
\text { Williams et Round }\end{array}$ & 2,478 & $1,210,209$ \\
\hline 6 & 09063000 & Eagle River at Red Cliff & 1 & 2001 & $8 / 16 / 2001$ & $39^{\circ} 30^{\prime} 30^{\prime \prime}$ & $106^{\circ} 21^{\prime} 58^{\prime \prime}$ & 8,654 & 70 & $\begin{array}{l}\text { Staurosirella pinnata (Ehrenberg) } \\
\text { Williams et Round }\end{array}$ & 1,652 & 159,515 \\
\hline 6 & 09063000 & Eagle River at Red Cliff & 1 & 2001 & $8 / 16 / 2001$ & $39^{\circ} 30^{\prime} 30^{\prime \prime}$ & $106^{\circ} 21^{\prime} 58^{\prime \prime}$ & 8,654 & 70 & $\begin{array}{l}\text { Unknown Cyanophyte Oscillatoriales } \\
\text { (no sheath) }\end{array}$ & 143,063 & $2,122,424$ \\
\hline 6 & 09063000 & Eagle River at Red Cliff & 1 & 2001 & $8 / 16 / 2001$ & $39^{\circ} 30^{\prime} 30^{\prime \prime}$ & $106^{\circ} 21^{\prime} 58^{\prime \prime}$ & 8,654 & 70 & $\begin{array}{l}\text { Unknown Rhodophyte Florideophycidae } \\
\text { (chantransia) }\end{array}$ & 418,013 & $2,675,488,317$ \\
\hline 8 & 09064500 & $\begin{array}{l}\text { Homestake Creek near } \\
\text { Red Cliff }\end{array}$ & 1 & 2000 & $8 / 17 / 2000$ & $39^{\circ} 28^{\prime} 24^{\prime \prime}$ & $106^{\circ} 22^{\prime} 02^{\prime \prime}$ & 8,783 & 58.2 & Achnanthes levanderi Hustedt & 26 & 38,493 \\
\hline 8 & 09064500 & $\begin{array}{l}\text { Homestake Creek near } \\
\text { Red Cliff }\end{array}$ & 1 & 2000 & $8 / 17 / 2000$ & $39^{\circ} 28^{\prime} 24^{\prime \prime}$ & $106^{\circ} 22^{\prime} 02^{\prime \prime}$ & 8,783 & 58.2 & $\begin{array}{l}\text { Achnanthidium minutissimum (Kützing) } \\
\text { Czarnecki }\end{array}$ & 4,486 & 247,059 \\
\hline 8 & 09064500 & $\begin{array}{l}\text { Homestake Creek near } \\
\text { Red Cliff }\end{array}$ & 1 & 2000 & $8 / 17 / 2000$ & $39^{\circ} 28^{\prime} 24^{\prime \prime}$ & $106^{\circ} 22^{\prime} 02^{\prime \prime}$ & 8,783 & 58.2 & Aulacoseira distans (Ehrenberg) Simonsen & 400 & 159,670 \\
\hline 8 & 09064500 & $\begin{array}{l}\text { Homestake Creek near } \\
\text { Red Cliff }\end{array}$ & 1 & 2000 & $8 / 17 / 2000$ & $39^{\circ} 28^{\prime} 24^{\prime \prime}$ & $106^{\circ} 22^{\prime} 02^{\prime \prime}$ & 8,783 & 58.2 & Brachysira microcephala (Grunow) Compère & 26 & 5,150 \\
\hline
\end{tabular}


Table 2. Description of sites and algal data collected from selected sites the Eagle River watershed, Colorado, 2000-2001.—Continued

[ID, identification; NAVD, North American Vertical Datum of 1988; ft, feet; $\mathrm{mi}^{2}$, square miles; cells $/ \mathrm{cm}^{2}$, cells per square centimeter; $\mu \mathrm{m}^{3} / \mathrm{cm}^{2}$, cubic micrometer per square centimeter]

\begin{tabular}{|c|c|c|c|c|c|c|c|c|c|c|c|c|}
\hline $\begin{array}{l}\text { Site } \\
\text { ID' }\end{array}$ & $\begin{array}{l}\text { USGS } \\
\text { station } \\
\text { number }\end{array}$ & Station name & $\begin{array}{c}\text { Replicate } \\
\text { sample } \\
\text { number }\end{array}$ & Year & $\begin{array}{l}\text { Collection } \\
\text { date }\end{array}$ & Latitude & Longitude & $\begin{array}{c}\text { Elevation } \\
\text { NAVD } 88 \\
\text { (ft) }\end{array}$ & $\begin{array}{c}\text { Drainage } \\
\text { area } \\
\left(\mathrm{mi}^{2}\right)\end{array}$ & Algal taxon name & $\begin{array}{c}\text { Total } \\
\text { density } \\
\text { (number of } \\
\text { cells } / \mathrm{cm}^{2} \text { ) }\end{array}$ & $\begin{array}{c}\text { Total } \\
\text { biovolume } \\
\left(\mu \mathrm{m}^{3} / \mathrm{cm}^{2}\right)\end{array}$ \\
\hline 8 & 09064500 & $\begin{array}{l}\text { Homestake Creek near } \\
\text { Red Cliff }\end{array}$ & 1 & 2000 & $8 / 17 / 2000$ & $39^{\circ} 28^{\prime} 24^{\prime \prime}$ & $106^{\circ} 22^{\prime} 02^{\prime \prime}$ & 8,783 & 58.2 & $\begin{array}{l}\text { Cocconeis placentula var. lineata (Ehrenberg) } \\
\text { Van Heurck }\end{array}$ & 13 & 13,507 \\
\hline 8 & 09064500 & $\begin{array}{l}\text { Homestake Creek near } \\
\text { Red Cliff }\end{array}$ & 1 & 2000 & $8 / 17 / 2000$ & $39^{\circ} 28^{\prime} 24^{\prime \prime}$ & $106^{\circ} 22^{\prime} 02^{\prime \prime}$ & 8,783 & 58.2 & Cosmarium sp. & 197 & 16,757 \\
\hline 8 & 09064500 & $\begin{array}{l}\text { Homestake Creek near } \\
\text { Red Cliff }\end{array}$ & 1 & 2000 & $8 / 17 / 2000$ & $39^{\circ} 28^{\prime} 24^{\prime \prime}$ & $106^{\circ} 22^{\prime} 02^{\prime \prime}$ & 8,783 & 58.2 & Cosmarium subcrenatum Hantzsch & 197 & 16,757 \\
\hline 8 & 09064500 & $\begin{array}{l}\text { Homestake Creek near } \\
\text { Red Cliff }\end{array}$ & 1 & 2000 & $8 / 17 / 2000$ & $39^{\circ} 28^{\prime} 24^{\prime \prime}$ & $106^{\circ} 22^{\prime} 02^{\prime \prime}$ & 8,783 & 58.2 & Encyonema minutum (Hilse) Mann & 90 & 19,309 \\
\hline 8 & 09064500 & $\begin{array}{l}\text { Homestake Creek near } \\
\text { Red Cliff }\end{array}$ & 1 & 2000 & $8 / 17 / 2000$ & $39^{\circ} 28^{\prime} 24^{\prime \prime}$ & $106^{\circ} 22^{\prime} 02^{\prime \prime}$ & 8,783 & 58.2 & Encyonema silesiacum (Bleisch) Mann & 142 & 66,768 \\
\hline 8 & 09064500 & $\begin{array}{l}\text { Homestake Creek near } \\
\text { Red Cliff }\end{array}$ & 1 & 2000 & $8 / 17 / 2000$ & $39^{\circ} 28^{\prime} 24^{\prime \prime}$ & $106^{\circ} 22^{\prime} 02^{\prime \prime}$ & 8,783 & 58.2 & Encyonopsis cesatii (Rabenhorst) Krammer & 26 & 47,800 \\
\hline 8 & 09064500 & $\begin{array}{l}\text { Homestake Creek near } \\
\text { Red Cliff }\end{array}$ & 1 & 2000 & $8 / 17 / 2000$ & $39^{\circ} 28^{\prime} 24^{\prime \prime}$ & $106^{\circ} 22^{\prime} 02^{\prime \prime}$ & 8,783 & 58.2 & $\begin{array}{l}\text { Encyonopsis microcephala (Grunow) } \\
\text { Krammer }\end{array}$ & 39 & 2,411 \\
\hline 8 & 09064500 & $\begin{array}{l}\text { Homestake Creek near } \\
\text { Red Cliff }\end{array}$ & 1 & 2000 & $8 / 17 / 2000$ & $39^{\circ} 28^{\prime} 24^{\prime \prime}$ & $106^{\circ} 22^{\prime} 02^{\prime \prime}$ & 8,783 & 58.2 & Eucocconeis laevis (Østrup) Lange-Bertalot & 168 & 250,204 \\
\hline 8 & 09064500 & $\begin{array}{l}\text { Homestake Creek near } \\
\text { Red Cliff }\end{array}$ & 1 & 2000 & $8 / 17 / 2000$ & $39^{\circ} 28^{\prime} 24^{\prime \prime}$ & $106^{\circ} 22^{\prime} 02^{\prime \prime}$ & 8,783 & 58.2 & Eunotia flexuosa Brébisson ex Kützing & 13 & 29,856 \\
\hline 8 & 09064500 & $\begin{array}{l}\text { Homestake Creek near } \\
\text { Red Cliff }\end{array}$ & 1 & 2000 & $8 / 17 / 2000$ & $39^{\circ} 28^{\prime} 24^{\prime \prime}$ & $106^{\circ} 22^{\prime} 02^{\prime \prime}$ & 8,783 & 58.2 & $\begin{array}{l}\text { Eunotia implicata Nörpel, } \\
\text { Lange-Bertalot et Alles }\end{array}$ & 77 & 95,015 \\
\hline 8 & 09064500 & $\begin{array}{l}\text { Homestake Creek near } \\
\text { Red Cliff }\end{array}$ & 1 & 2000 & $8 / 17 / 2000$ & $39^{\circ} 28^{\prime} 24^{\prime \prime}$ & $106^{\circ} 22^{\prime} 02^{\prime \prime}$ & 8,783 & 58.2 & Eunotia incisa Smith ex Gregory & 52 & 24,383 \\
\hline 8 & 09064500 & $\begin{array}{l}\text { Homestake Creek near } \\
\text { Red Cliff }\end{array}$ & 1 & 2000 & $8 / 17 / 2000$ & $39^{\circ} 28^{\prime} 24^{\prime \prime}$ & $106^{\circ} 22^{\prime} 02^{\prime \prime}$ & 8,783 & 58.2 & $\begin{array}{l}\text { Fragilaria capucina var. fragilarioides } \\
\text { (Grunow) Ludwig et Flores }\end{array}$ & 155 & 15,850 \\
\hline 8 & 09064500 & $\begin{array}{l}\text { Homestake Creek near } \\
\text { Red Cliff }\end{array}$ & 1 & 2000 & $8 / 17 / 2000$ & $39^{\circ} 28^{\prime} 24^{\prime \prime}$ & $106^{\circ} 22^{\prime} 02^{\prime \prime}$ & 8,783 & 58.2 & Fragilaria vaucheriae (Kützing) Petersen & 361 & 74,667 \\
\hline 8 & 09064500 & $\begin{array}{l}\text { Homestake Creek near } \\
\text { Red Cliff }\end{array}$ & 1 & 2000 & $8 / 17 / 2000$ & $39^{\circ} 28^{\prime} 24^{\prime \prime}$ & $106^{\circ} 22^{\prime} 02^{\prime \prime}$ & 8,783 & 58.2 & $\begin{array}{l}\text { Fragilariforma virescens (Ralfs) } \\
\text { Williams et Round }\end{array}$ & 26 & 7,709 \\
\hline 8 & 09064500 & $\begin{array}{l}\text { Homestake Creek near } \\
\text { Red Cliff }\end{array}$ & 1 & 2000 & $8 / 17 / 2000$ & $39^{\circ} 28^{\prime} 24^{\prime \prime}$ & $106^{\circ} 22^{\prime} 02^{\prime \prime}$ & 8,783 & 58.2 & Frustulia saxonica Rabenhorst & 13 & 22,548 \\
\hline 8 & 09064500 & $\begin{array}{l}\text { Homestake Creek near } \\
\text { Red Cliff }\end{array}$ & 1 & 2000 & $8 / 17 / 2000$ & $39^{\circ} 28^{\prime} 24^{\prime \prime}$ & $106^{\circ} 22^{\prime} 02^{\prime \prime}$ & 8,783 & 58.2 & $\begin{array}{l}\text { Gomphonema exilissimum (Grunow) } \\
\text { Lange-Bertalot }\end{array}$ & 284 & 369,254 \\
\hline 8 & 09064500 & $\begin{array}{l}\text { Homestake Creek near } \\
\text { Red Cliff }\end{array}$ & 1 & 2000 & $8 / 17 / 2000$ & $39^{\circ} 28^{\prime} 24^{\prime \prime}$ & $106^{\circ} 22^{\prime} 02^{\prime \prime}$ & 8,783 & 58.2 & Gomphonema subclavatum (Grunow) Grunow & 26 & 20,584 \\
\hline 8 & 09064500 & $\begin{array}{l}\text { Homestake Creek near } \\
\text { Red Cliff }\end{array}$ & 1 & 2000 & $8 / 17 / 2000$ & $39^{\circ} 28^{\prime} 24^{\prime \prime}$ & $106^{\circ} 22^{\prime} 02^{\prime \prime}$ & 8,783 & 58.2 & $\begin{array}{l}\text { Homoeothrix janthina (Bornet et Flahault) } \\
\text { Starmach }\end{array}$ & 53,228 & $1,725,027$ \\
\hline 8 & 09064500 & $\begin{array}{l}\text { Homestake Creek near } \\
\text { Red Cliff }\end{array}$ & 1 & 2000 & $8 / 17 / 2000$ & $39^{\circ} 28^{\prime} 24^{\prime \prime}$ & $106^{\circ} 22^{\prime} 02^{\prime \prime}$ & 8,783 & 58.2 & Navicula radiosa Kützing & 26 & 26,621 \\
\hline 8 & 09064500 & $\begin{array}{l}\text { Homestake Creek near } \\
\text { Red Cliff }\end{array}$ & 1 & 2000 & $8 / 17 / 2000$ & $39^{\circ} 28^{\prime} 24^{\prime \prime}$ & $106^{\circ} 22^{\prime} 02^{\prime \prime}$ & 8,783 & 58.2 & Navicula rhynchocephala Kützing & 39 & 23,888 \\
\hline 8 & 09064500 & $\begin{array}{l}\text { Homestake Creek near } \\
\text { Red Cliff }\end{array}$ & 1 & 2000 & $8 / 17 / 2000$ & $39^{\circ} 28^{\prime} 24^{\prime \prime}$ & $106^{\circ} 22^{\prime} 02^{\prime \prime}$ & 8,783 & 58.2 & Oedogonium sp. & 591 & $24,237,411$ \\
\hline 8 & 09064500 & $\begin{array}{l}\text { Homestake Creek near } \\
\text { Red Cliff }\end{array}$ & 1 & 2000 & $8 / 17 / 2000$ & $39^{\circ} 28^{\prime} 24^{\prime \prime}$ & $106^{\circ} 22^{\prime} 02^{\prime \prime}$ & 8,783 & 58.2 & Phormidium autumnale (Agardh) Gomont & 8,083 & 791,538 \\
\hline 8 & 09064500 & $\begin{array}{l}\text { Homestake Creek near } \\
\text { Red Cliff }\end{array}$ & 1 & 2000 & $8 / 17 / 2000$ & $39^{\circ} 28^{\prime} 24^{\prime \prime}$ & $106^{\circ} 22^{\prime} 02^{\prime \prime}$ & 8,783 & 58.2 & Pinnularia subcapitata Gregory & 26 & 19,743 \\
\hline
\end{tabular}


Table 2. Description of sites and algal data collected from selected sites the Eagle River watershed, Colorado, 2000-2001.—Continued

[ID, identification; NAVD, North American Vertical Datum of 1988; ft, feet; $\mathrm{mi}^{2}$, square miles; cells $/ \mathrm{cm}^{2}$, cells per square centimeter; $\mu \mathrm{m}^{3} / \mathrm{cm}^{2}$, cubic micrometer per square centimeter]

\begin{tabular}{|c|c|c|c|c|c|c|c|c|c|c|c|c|}
\hline $\begin{array}{l}\text { Site } \\
\text { ID }^{1}\end{array}$ & $\begin{array}{l}\text { USGS } \\
\text { station } \\
\text { number }\end{array}$ & Station name & $\begin{array}{c}\text { Replicate } \\
\text { sample } \\
\text { number }\end{array}$ & Year & $\begin{array}{l}\text { Collection } \\
\text { date }\end{array}$ & Latitude & Longitude & $\begin{array}{c}\text { Elevation } \\
\text { NAVD } 88 \\
\text { (ft) }\end{array}$ & $\begin{array}{c}\text { Drainage } \\
\text { area } \\
\left(\mathrm{mi}^{2}\right)\end{array}$ & Algal taxon name & $\begin{array}{c}\text { Total } \\
\text { density } \\
\text { (number of } \\
\text { cells } / \mathrm{cm}^{2} \text { ) }\end{array}$ & $\begin{array}{c}\text { Total } \\
\text { biovolume } \\
\left(\mu \mathrm{m}^{3} / \mathrm{cm}^{2}\right)\end{array}$ \\
\hline 8 & 09064500 & $\begin{array}{l}\text { Homestake Creek near } \\
\text { Red Cliff }\end{array}$ & 1 & 2000 & $8 / 17 / 2000$ & $39^{\circ} 28^{\prime} 24^{\prime \prime}$ & $106^{\circ} 22^{\prime} 02^{\prime \prime}$ & 8,783 & 58.2 & $\begin{array}{l}\text { Reimeria sinuata (Gregory) } \\
\text { Kociolek et Stoermer }\end{array}$ & 142 & 23,446 \\
\hline 8 & 09064500 & $\begin{array}{l}\text { Homestake Creek near } \\
\text { Red Cliff }\end{array}$ & 1 & 2000 & $8 / 17 / 2000$ & $39^{\circ} 28^{\prime} 24^{\prime \prime}$ & $106^{\circ} 22^{\prime} 02^{\prime \prime}$ & 8,783 & 58.2 & $\begin{array}{l}\text { Rossithidium pusillum (Grunow) } \\
\text { Round et Bukhtiyarova }\end{array}$ & 64 & 5,850 \\
\hline 8 & 09064500 & $\begin{array}{l}\text { Homestake Creek near } \\
\text { Red Cliff }\end{array}$ & 1 & 2000 & $8 / 17 / 2000$ & $39^{\circ} 28^{\prime} 24^{\prime \prime}$ & $106^{\circ} 22^{\prime} 02^{\prime \prime}$ & 8,783 & 58.2 & Sellaphora pupula (Kützing) Meresckowsky & 13 & 8,202 \\
\hline 8 & 09064500 & $\begin{array}{l}\text { Homestake Creek near } \\
\text { Red Cliff }\end{array}$ & 1 & 2000 & $8 / 17 / 2000$ & $39^{\circ} 28^{\prime} 24^{\prime \prime}$ & $106^{\circ} 22^{\prime} 02^{\prime \prime}$ & 8,783 & 58.2 & Spirogyra sp. & 789 & $86,632,411$ \\
\hline 8 & 09064500 & $\begin{array}{l}\text { Homestake Creek near } \\
\text { Red Cliff }\end{array}$ & 1 & 2000 & $8 / 17 / 2000$ & $39^{\circ} 28^{\prime} 24^{\prime \prime}$ & $106^{\circ} 22^{\prime} 02^{\prime \prime}$ & 8,783 & 58.2 & $\begin{array}{l}\text { Stauroforma exiguiformis (Lange-Bertalot) } \\
\text { Flower, Jones et Round }\end{array}$ & 129 & 7,077 \\
\hline 8 & 09064500 & $\begin{array}{l}\text { Homestake Creek near } \\
\text { Red Cliff }\end{array}$ & 1 & 2000 & $8 / 17 / 2000$ & $39^{\circ} 28^{\prime} 24^{\prime \prime}$ & $106^{\circ} 22^{\prime} 02^{\prime \prime}$ & 8,783 & 58.2 & Staurosira construens Ehrenberg & 13 & 2,495 \\
\hline 8 & 09064500 & $\begin{array}{l}\text { Homestake Creek near } \\
\text { Red Cliff }\end{array}$ & 1 & 2000 & $8 / 17 / 2000$ & $39^{\circ} 28^{\prime} 24^{\prime \prime}$ & $106^{\circ} 22^{\prime} 02^{\prime \prime}$ & 8,783 & 58.2 & $\begin{array}{l}\text { Staurosira construens var. venter } \\
\text { (Ehrenberg) Hamilton }\end{array}$ & 1,109 & 133,153 \\
\hline 8 & 09064500 & $\begin{array}{l}\text { Homestake Creek near } \\
\text { Red Cliff }\end{array}$ & 1 & 2000 & $8 / 17 / 2000$ & $39^{\circ} 28^{\prime} 24^{\prime \prime}$ & $106^{\circ} 22^{\prime} 02^{\prime \prime}$ & 8,783 & 58.2 & $\begin{array}{l}\text { Staurosirella pinnata (Ehrenberg) } \\
\text { Williams et Round }\end{array}$ & 13 & 1,241 \\
\hline 8 & 09064500 & $\begin{array}{l}\text { Homestake Creek near } \\
\text { Red Cliff }\end{array}$ & 1 & 2000 & $8 / 17 / 2000$ & $39^{\circ} 28^{\prime} 24^{\prime \prime}$ & $106^{\circ} 22^{\prime} 02^{\prime \prime}$ & 8,783 & 58.2 & Synedra acus Kützing & 26 & 49,798 \\
\hline 8 & 09064500 & $\begin{array}{l}\text { Homestake Creek near } \\
\text { Red Cliff }\end{array}$ & 1 & 2000 & $8 / 17 / 2000$ & $39^{\circ} 28^{\prime} 24^{\prime \prime}$ & $106^{\circ} 22^{\prime} 02^{\prime \prime}$ & 8,783 & 58.2 & Synedra ulna (Nitzsch) Ehrenberg & 39 & 253,566 \\
\hline 8 & 09064500 & $\begin{array}{l}\text { Homestake Creek near } \\
\text { Red Cliff }\end{array}$ & 1 & 2000 & $8 / 17 / 2000$ & $39^{\circ} 28^{\prime} 24^{\prime \prime}$ & $106^{\circ} 22^{\prime} 02^{\prime \prime}$ & 8,783 & 58.2 & Tabellaria flocculosa (Roth) Kützing & 26 & 222,269 \\
\hline 10 & 393030106224700 & $\begin{array}{l}\text { Eagle River below Homestake } \\
\text { Creek near Red Cliff }\end{array}$ & 1 & 2000 & $8 / 17 / 2000$ & $39^{\circ} 30^{\prime} 30^{\prime \prime}$ & $106^{\circ} 22^{\prime} 47^{\prime \prime}$ & 8,820 & 164 & $\begin{array}{l}\text { Achnanthidium minutissimum (Kützing) } \\
\text { Czarnecki }\end{array}$ & 39,465 & $2,173,434$ \\
\hline 10 & 393030106224700 & $\begin{array}{l}\text { Eagle River below Homestake } \\
\text { Creek near Red Cliff }\end{array}$ & 1 & 2000 & $8 / 17 / 2000$ & $39^{\circ} 30^{\prime} 30^{\prime \prime}$ & $106^{\circ} 22^{\prime} 47^{\prime \prime}$ & 8,820 & 164 & $\begin{array}{l}\text { Achnanthidium pyrenaicum (Hustedt) } \\
\text { Kobayasi }\end{array}$ & 3,174 & 399,257 \\
\hline 10 & 393030106224700 & $\begin{array}{l}\text { Eagle River below Homestake } \\
\text { Creek near Red Cliff }\end{array}$ & 1 & 2000 & $8 / 17 / 2000$ & $39^{\circ} 30^{\prime} 30^{\prime \prime}$ & $106^{\circ} 22^{\prime} 47^{\prime \prime}$ & 8,820 & 164 & Amphipleura pellucida (Kützing) Kützing & 81 & 92,045 \\
\hline 10 & 393030106224700 & $\begin{array}{l}\text { Eagle River below Homestake } \\
\text { Creek near Red Cliff }\end{array}$ & 1 & 2000 & $8 / 17 / 2000$ & $39^{\circ} 30^{\prime} 30^{\prime \prime}$ & $106^{\circ} 22^{\prime} 47^{\prime \prime}$ & 8,820 & 164 & Aulacoseira distans (Ehrenberg) Simonsen & 81 & 32,512 \\
\hline 10 & 393030106224700 & $\begin{array}{l}\text { Eagle River below Homestake } \\
\text { Creek near Red Cliff }\end{array}$ & 1 & 2000 & $8 / 17 / 2000$ & $39^{\circ} 30^{\prime} 30^{\prime \prime}$ & $106^{\circ} 22^{\prime} 47^{\prime \prime}$ & 8,820 & 164 & Cocconeis pediculus Ehrenberg & 163 & 562,969 \\
\hline 10 & 393030106224700 & $\begin{array}{l}\text { Eagle River below Homestake } \\
\text { Creek near Red Cliff }\end{array}$ & 1 & 2000 & $8 / 17 / 2000$ & $39^{\circ} 30^{\prime} 30^{\prime \prime}$ & $106^{\circ} 22^{\prime} 47^{\prime \prime}$ & 8,820 & 164 & $\begin{array}{l}\text { Cocconeis placentula var. euglypta } \\
\text { (Ehrenberg) Grunow }\end{array}$ & 244 & 147,067 \\
\hline 10 & 393030106224700 & $\begin{array}{l}\text { Eagle River below Homestake } \\
\text { Creek near Red Cliff }\end{array}$ & 1 & 2000 & $8 / 17 / 2000$ & $39^{\circ} 30^{\prime} 30^{\prime \prime}$ & $106^{\circ} 22^{\prime} 47^{\prime \prime}$ & 8,820 & 164 & $\begin{array}{l}\text { Cocconeis placentula var. lineata (Ehrenberg) } \\
\text { Van Heurck }\end{array}$ & 1,139 & $1,193,606$ \\
\hline 10 & 393030106224700 & $\begin{array}{l}\text { Eagle River below Homestake } \\
\text { Creek near Red Cliff }\end{array}$ & 1 & 2000 & $8 / 17 / 2000$ & $39^{\circ} 30^{\prime} 30^{\prime \prime}$ & $106^{\circ} 22^{\prime} 47^{\prime \prime}$ & 8,820 & 164 & Cosmarium subcrenatum Hantzsch & 349 & 29,696 \\
\hline 10 & 393030106224700 & $\begin{array}{l}\text { Eagle River below Homestake } \\
\text { Creek near Red Cliff }\end{array}$ & 1 & 2000 & $8 / 17 / 2000$ & $39^{\circ} 30^{\prime} 30^{\prime \prime}$ & $106^{\circ} 22^{\prime} 47^{\prime \prime}$ & 8,820 & 164 & Cymbella affinis Kützing & 163 & 82,366 \\
\hline 10 & 393030106224700 & $\begin{array}{l}\text { Eagle River below Homestake } \\
\text { Creek near Red Cliff }\end{array}$ & 1 & 2000 & $8 / 17 / 2000$ & $39^{\circ} 30^{\prime} 30^{\prime \prime}$ & $106^{\circ} 22^{\prime} 47^{\prime \prime}$ & 8,820 & 164 & Cymbella sp. 5 ANS WRC & 488 & 905,182 \\
\hline 10 & 393030106224700 & $\begin{array}{l}\text { Eagle River below Homestake } \\
\text { Creek near Red Cliff }\end{array}$ & 1 & 2000 & $8 / 17 / 2000$ & $39^{\circ} 30^{\prime} 30^{\prime \prime}$ & $106^{\circ} 22^{\prime} 47^{\prime \prime}$ & 8,820 & 164 & Diatoma vulgaris Bory & 244 & 901,988 \\
\hline 10 & 393030106224700 & $\begin{array}{l}\text { Eagle River below Homestake } \\
\text { Creek near Red Cliff }\end{array}$ & 1 & 2000 & $8 / 17 / 2000$ & $39^{\circ} 30^{\prime} 30^{\prime \prime}$ & $106^{\circ} 22^{\prime} 47^{\prime \prime}$ & 8,820 & 164 & Encyonema brehmii (Hustedt) Mann & 570 & 15,705 \\
\hline
\end{tabular}


Table 2. Description of sites and algal data collected from selected sites the Eagle River watershed, Colorado, 2000-2001.—Continued

[ID, identification; NAVD, North American Vertical Datum of 1988; ft, feet; $\mathrm{mi}^{2}$, square miles; cells $/ \mathrm{cm}^{2}$, cells per square centimeter; $\mu \mathrm{m}^{3} / \mathrm{cm}^{2}$, cubic micrometer per square centimeter

\begin{tabular}{|c|c|c|c|c|c|c|c|c|c|c|c|c|}
\hline $\begin{array}{l}\text { Site } \\
\text { ID }^{1}\end{array}$ & $\begin{array}{l}\text { USGS } \\
\text { station } \\
\text { number }\end{array}$ & Station name & $\begin{array}{l}\text { Replicate } \\
\text { sample } \\
\text { number }\end{array}$ & Year & $\begin{array}{l}\text { Collection } \\
\text { date }\end{array}$ & Latitude & Longitude & $\begin{array}{c}\text { Elevation } \\
\text { NAVD } 88 \\
\text { (ft) }\end{array}$ & $\begin{array}{c}\text { Drainage } \\
\text { area } \\
\left(\mathrm{mi}^{2}\right)\end{array}$ & Algal taxon name & $\begin{array}{c}\text { Total } \\
\text { density } \\
\text { (number of } \\
\text { cells/cm²) }\end{array}$ & $\begin{array}{c}\text { Total } \\
\text { biovolume } \\
\left(\mu \mathbf{m}^{3} / \mathrm{cm}^{2}\right)\end{array}$ \\
\hline 10 & 393030106224700 & $\begin{array}{l}\text { Eagle River below Homestake } \\
\text { Creek near Red Cliff }\end{array}$ & 1 & 2000 & $8 / 17 / 2000$ & $39^{\circ} 30^{\prime} 30^{\prime \prime}$ & $106^{\circ} 22^{\prime} 47^{\prime \prime}$ & 8,820 & 164 & Encyonema minutum (Hilse) Mann & 488 & 104,474 \\
\hline 10 & 393030106224700 & $\begin{array}{l}\text { Eagle River below Homestake } \\
\text { Creek near Red Cliff }\end{array}$ & 1 & 2000 & $8 / 17 / 2000$ & $39^{\circ} 30^{\prime} 30^{\prime \prime}$ & $106^{\circ} 22^{\prime} 47^{\prime \prime}$ & 8,820 & 164 & Encyonema silesiacum (Bleisch) Mann & 3,499 & $1,647,506$ \\
\hline 10 & 393030106224700 & $\begin{array}{l}\text { Eagle River below Homestake } \\
\text { Creek near Red Cliff }\end{array}$ & 1 & 2000 & $8 / 17 / 2000$ & $39^{\circ} 30^{\prime} 30^{\prime \prime}$ & $106^{\circ} 22^{\prime} 47^{\prime \prime}$ & 8,820 & 164 & $\begin{array}{l}\text { Encyonopsis microcephala (Grunow) } \\
\text { Krammer }\end{array}$ & 163 & 10,144 \\
\hline 10 & 393030106224700 & $\begin{array}{l}\text { Eagle River below Homestake } \\
\text { Creek near Red Cliff }\end{array}$ & 1 & 2000 & $8 / 17 / 2000$ & $39^{\circ} 30^{\prime} 30^{\prime \prime}$ & $106^{\circ} 22^{\prime} 47^{\prime \prime}$ & 8,820 & 164 & Eucocconeis laevis (Østrup) Lange-Bertalot & 244 & 364,465 \\
\hline 10 & 393030106224700 & $\begin{array}{l}\text { Eagle River below Homestake } \\
\text { Creek near Red Cliff }\end{array}$ & 1 & 2000 & $8 / 17 / 2000$ & $39^{\circ} 30^{\prime} 30^{\prime \prime}$ & $106^{\circ} 22^{\prime} 47^{\prime \prime}$ & 8,820 & 164 & $\begin{array}{l}\text { Fragilaria capucina var. fragilarioides } \\
\text { (Grunow) Ludwig et Flores }\end{array}$ & 488 & 50,023 \\
\hline 10 & 393030106224700 & $\begin{array}{l}\text { Eagle River below Homestake } \\
\text { Creek near Red Cliff }\end{array}$ & 1 & 2000 & $8 / 17 / 2000$ & $39^{\circ} 30^{\prime} 30^{\prime \prime}$ & $106^{\circ} 22^{\prime} 47^{\prime \prime}$ & 8,820 & 164 & Fragilaria vaucheriae (Kützing) Petersen & 570 & 117,829 \\
\hline 10 & 393030106224700 & $\begin{array}{l}\text { Eagle River below Homestake } \\
\text { Creek near Red Cliff }\end{array}$ & 1 & 2000 & $8 / 17 / 2000$ & $39^{\circ} 30^{\prime} 30^{\prime \prime}$ & $106^{\circ} 22^{\prime} 47^{\prime \prime}$ & 8,820 & 164 & $\begin{array}{l}\text { Gomphonema exilissimum (Grunow) } \\
\text { Lange-Bertalot }\end{array}$ & 163 & 211,893 \\
\hline 10 & 393030106224700 & $\begin{array}{l}\text { Eagle River below Homestake } \\
\text { Creek near Red Cliff }\end{array}$ & 1 & 2000 & $8 / 17 / 2000$ & $39^{\circ} 30^{\prime} 30^{\prime \prime}$ & $106^{\circ} 22^{\prime} 47^{\prime \prime}$ & 8,820 & 164 & Gomphonema olivaceoides Hustedt & 244 & 37,344 \\
\hline 10 & 393030106224700 & $\begin{array}{l}\text { Eagle River below Homestake } \\
\text { Creek near Red Cliff }\end{array}$ & 1 & 2000 & $8 / 17 / 2000$ & $39^{\circ} 30^{\prime} 30^{\prime \prime}$ & $106^{\circ} 22^{\prime} 47^{\prime \prime}$ & 8,820 & 164 & Gomphonema parvulum (Kützing) Kützing & 163 & 36,349 \\
\hline 10 & 393030106224700 & $\begin{array}{l}\text { Eagle River below Homestake } \\
\text { Creek near Red Cliff }\end{array}$ & 1 & 2000 & $8 / 17 / 2000$ & $39^{\circ} 30^{\prime} 30^{\prime \prime}$ & $106^{\circ} 22^{\prime} 47^{\prime \prime}$ & 8,820 & 164 & Gomphonema subclavatum (Grunow) Grunow & 488 & 389,789 \\
\hline 10 & 393030106224700 & $\begin{array}{l}\text { Eagle River below Homestake } \\
\text { Creek near Red Cliff }\end{array}$ & 1 & 2000 & $8 / 17 / 2000$ & $39^{\circ} 30^{\prime} 30^{\prime \prime}$ & $106^{\circ} 22^{\prime} 47^{\prime \prime}$ & 8,820 & 164 & $\begin{array}{l}\text { Homoeothrix janthina (Bornet et Flahault) } \\
\text { Starmach }\end{array}$ & 463,605 & $15,024,677$ \\
\hline 10 & 393030106224700 & $\begin{array}{l}\text { Eagle River below Homestake } \\
\text { Creek near Red Cliff }\end{array}$ & 1 & 2000 & $8 / 17 / 2000$ & $39^{\circ} 30^{\prime} 30^{\prime \prime}$ & $106^{\circ} 22^{\prime} 47^{\prime \prime}$ & 8,820 & 164 & $\begin{array}{l}\text { Navicula cryptotenella Lange-Bertalot } \\
\text { ex Krammer et Lange-Bertalot }\end{array}$ & 814 & 294,503 \\
\hline 10 & 393030106224700 & $\begin{array}{l}\text { Eagle River below Homestake } \\
\text { Creek near Red Cliff }\end{array}$ & 1 & 2000 & $8 / 17 / 2000$ & $39^{\circ} 30^{\prime} 30^{\prime \prime}$ & $106^{\circ} 22^{\prime} 47^{\prime \prime}$ & 8,820 & 164 & Navicula expecta Van Landingham & 163 & $1,220,742$ \\
\hline 10 & 393030106224700 & $\begin{array}{l}\text { Eagle River below Homestake } \\
\text { Creek near Red Cliff }\end{array}$ & 1 & 2000 & $8 / 17 / 2000$ & $39^{\circ} 30^{\prime} 30^{\prime \prime}$ & $106^{\circ} 22^{\prime} 47^{\prime \prime}$ & 8,820 & 164 & Navicula incertata Hustedt & 163 & 8,414 \\
\hline 10 & 393030106224700 & $\begin{array}{l}\text { Eagle River below Homestake } \\
\text { Creek near Red Cliff }\end{array}$ & 1 & 2000 & $8 / 17 / 2000$ & $39^{\circ} 30^{\prime} 30^{\prime \prime}$ & $106^{\circ} 22^{\prime} 47^{\prime \prime}$ & 8,820 & 164 & Nitzschia dissipata (Kützing) Grunow & 325 & 84,640 \\
\hline 10 & 393030106224700 & $\begin{array}{l}\text { Eagle River below Homestake } \\
\text { Creek near Red Cliff }\end{array}$ & 1 & 2000 & $8 / 17 / 2000$ & $39^{\circ} 30^{\prime} 30^{\prime \prime}$ & $106^{\circ} 22^{\prime} 47^{\prime \prime}$ & 8,820 & 164 & Nitzschia fonticola Grunow & 163 & 16,161 \\
\hline 10 & 393030106224700 & $\begin{array}{l}\text { Eagle River below Homestake } \\
\text { Creek near Red Cliff }\end{array}$ & 1 & 2000 & $8 / 17 / 2000$ & $39^{\circ} 30^{\prime} 30^{\prime \prime}$ & $106^{\circ} 22^{\prime} 47^{\prime \prime}$ & 8,820 & 164 & Phormidium autumnale (Agardh) Gomont & 278,093 & $27,233,456$ \\
\hline 10 & 393030106224700 & $\begin{array}{l}\text { Eagle River below Homestake } \\
\text { Creek near Red Cliff }\end{array}$ & 1 & 2000 & $8 / 17 / 2000$ & $39^{\circ} 30^{\prime} 30^{\prime \prime}$ & $106^{\circ} 22^{\prime} 47^{\prime \prime}$ & 8,820 & 164 & $\begin{array}{l}\text { Planothidium dubium (Grunow) } \\
\text { Round et Bukhtiyarova }\end{array}$ & 163 & 13,172 \\
\hline 10 & 393030106224700 & $\begin{array}{l}\text { Eagle River below Homestake } \\
\text { Creek near Red Cliff }\end{array}$ & 1 & 2000 & $8 / 17 / 2000$ & $39^{\circ} 30^{\prime} 30^{\prime \prime}$ & $106^{\circ} 22^{\prime} 47^{\prime \prime}$ & 8,820 & 164 & $\begin{array}{l}\text { Reimeria sinuata (Gregory) } \\
\text { Kociolek et Stoermer }\end{array}$ & 814 & 134,543 \\
\hline 10 & 393030106224700 & $\begin{array}{l}\text { Eagle River below Homestake } \\
\text { Creek near Red Cliff }\end{array}$ & 1 & 2000 & $8 / 17 / 2000$ & $39^{\circ} 30^{\prime} 30^{\prime \prime}$ & $106^{\circ} 22^{\prime} 47^{\prime \prime}$ & 8,820 & 164 & $\begin{array}{l}\text { Rossithidium pusillum (Grunow) } \\
\text { Round et Bukhtiyarova }\end{array}$ & 244 & 22,158 \\
\hline 10 & 393030106224700 & $\begin{array}{l}\text { Eagle River below Homestake } \\
\text { Creek near Red Cliff }\end{array}$ & 1 & 2000 & $8 / 17 / 2000$ & $39^{\circ} 30^{\prime} 30^{\prime \prime}$ & $106^{\circ} 22^{\prime} 47^{\prime \prime}$ & 8,820 & 164 & $\begin{array}{l}\text { Staurosira construens var. venter (Ehrenberg) } \\
\text { Hamilton }\end{array}$ & 1,546 & 185,690 \\
\hline 10 & 393030106224700 & $\begin{array}{l}\text { Eagle River below Homestake } \\
\text { Creek near Red Cliff }\end{array}$ & 1 & 2000 & $8 / 17 / 2000$ & $39^{\circ} 30^{\prime} 30^{\prime \prime}$ & $106^{\circ} 22^{\prime} 47^{\prime \prime}$ & 8,820 & 164 & $\begin{array}{l}\text { Staurosirella leptostauron (Ehrenberg) } \\
\text { Williams et Round }\end{array}$ & 163 & 79,489 \\
\hline 10 & 393030106224700 & $\begin{array}{l}\text { Eagle River below Homestake } \\
\text { Creek near Red Cliff }\end{array}$ & 1 & 2000 & $8 / 17 / 2000$ & $39^{\circ} 30^{\prime} 30^{\prime \prime}$ & $106^{\circ} 22^{\prime} 47^{\prime \prime}$ & 8,820 & 164 & $\begin{array}{l}\text { Staurosirella pinnata (Ehrenberg) } \\
\text { Williams et Round }\end{array}$ & 1,139 & 109,679 \\
\hline
\end{tabular}


Table 2. Description of sites and algal data collected from selected sites the Eagle River watershed, Colorado, 2000-2001.—Continued

[ID, identification; NAVD, North American Vertical Datum of 1988; ft, feet; $\mathrm{mi}^{2}$, square miles; cells $/ \mathrm{cm}^{2}$, cells per square centimeter; $\mu \mathrm{m}^{3} / \mathrm{cm}^{2}$, cubic micrometer per square centimeter]

\begin{tabular}{|c|c|c|c|c|c|c|c|c|c|c|c|c|}
\hline $\begin{array}{l}\text { Site } \\
\text { ID' }\end{array}$ & $\begin{array}{l}\text { USGS } \\
\text { station } \\
\text { number }\end{array}$ & Station name & $\begin{array}{l}\text { Replicate } \\
\text { sample } \\
\text { number }\end{array}$ & Year & $\begin{array}{l}\text { Collection } \\
\text { date }\end{array}$ & Latitude & Longitude & $\begin{array}{c}\text { Elevation } \\
\text { NAVD } 88 \\
\text { (ft) }\end{array}$ & $\begin{array}{c}\text { Drainage } \\
\text { area } \\
\left(\mathrm{mi}^{2}\right)\end{array}$ & Algal taxon name & $\begin{array}{c}\text { Total } \\
\text { density } \\
\text { (number of } \\
\text { cells/cm²) }\end{array}$ & $\begin{array}{c}\text { Total } \\
\text { biovolume } \\
\left(\mu \mathrm{m}^{3} / \mathrm{cm}^{2}\right)\end{array}$ \\
\hline 10 & 393030106224700 & $\begin{array}{l}\text { Eagle River below Homestake } \\
\text { Creek near Red Cliff }\end{array}$ & 1 & 2000 & $8 / 17 / 2000$ & $39^{\circ} 30^{\prime} 30^{\prime \prime}$ & $106^{\circ} 22^{\prime} 47^{\prime \prime}$ & 8,820 & 164 & Synedra ulna (Nitzsch) Ehrenberg & 325 & $2,134,089$ \\
\hline 10 & 393030106224700 & $\begin{array}{l}\text { Eagle River below Homestake } \\
\text { Creek near Red Cliff }\end{array}$ & 1 & 2000 & $8 / 17 / 2000$ & $39^{\circ} 30^{\prime} 30^{\prime \prime}$ & $106^{\circ} 22^{\prime} 47^{\prime \prime}$ & 8,820 & 164 & $\begin{array}{l}\text { Unknown Rhodophyte Florideophycidae } \\
\text { (chantransia) }\end{array}$ & 14,673 & $51,931,262$ \\
\hline 10 & 393030106224700 & $\begin{array}{l}\text { Eagle River below Homestake } \\
\text { Creek near Red Cliff }\end{array}$ & 1 & 2001 & $8 / 16 / 2001$ & $39^{\circ} 30^{\prime} 30^{\prime \prime}$ & $106^{\circ} 22^{\prime} 47^{\prime \prime}$ & 8,820 & 164 & $\begin{array}{l}\text { Achnanthidium minutissimum (Kützing) } \\
\text { Czarnecki }\end{array}$ & 41,115 & $2,229,308$ \\
\hline 10 & 393030106224700 & $\begin{array}{l}\text { Eagle River below Homestake } \\
\text { Creek near Red Cliff }\end{array}$ & 1 & 2001 & $8 / 16 / 2001$ & $39^{\circ} 30^{\prime} 30^{\prime \prime}$ & $106^{\circ} 22^{\prime} 47^{\prime \prime}$ & 8,820 & 164 & $\begin{array}{l}\text { Achnanthidium pyrenaicum (Hustedt) } \\
\text { Kobayasi }\end{array}$ & 1,759 & 222,264 \\
\hline 10 & 393030106224700 & $\begin{array}{l}\text { Eagle River below Homestake } \\
\text { Creek near Red Cliff }\end{array}$ & 1 & 2001 & $8 / 16 / 2001$ & $39^{\circ} 30^{\prime} 30^{\prime \prime}$ & $106^{\circ} 22^{\prime} 47^{\prime \prime}$ & 8,820 & 164 & Adlafia bryophila (Petersen) Lange-Bertalot & 440 & 18,757 \\
\hline 10 & 393030106224700 & $\begin{array}{l}\text { Eagle River below Homestake } \\
\text { Creek near Red Cliff }\end{array}$ & 1 & 2001 & $8 / 16 / 2001$ & $39^{\circ} 30^{\prime} 30^{\prime \prime}$ & $106^{\circ} 22^{\prime} 47^{\prime \prime}$ & 8,820 & 164 & Amphipleura pellucida (Kützing) Kützing & 660 & 513,171 \\
\hline 10 & 393030106224700 & $\begin{array}{l}\text { Eagle River below Homestake } \\
\text { Creek near Red Cliff }\end{array}$ & 1 & 2001 & $8 / 16 / 2001$ & $39^{\circ} 30^{\prime} 30^{\prime \prime}$ & $106^{\circ} 22^{\prime} 47^{\prime \prime}$ & 8,820 & 164 & Amphora pediculus (Kützing) Grunow & 440 & 42,516 \\
\hline 10 & 393030106224700 & $\begin{array}{l}\text { Eagle River below Homestake } \\
\text { Creek near Red Cliff }\end{array}$ & 1 & 2001 & $8 / 16 / 2001$ & $39^{\circ} 30^{\prime} 30^{\prime \prime}$ & $106^{\circ} 22^{\prime} 47^{\prime \prime}$ & 8,820 & 164 & Aulacoseira ambigua (Grunow) Simonsen & 440 & 148,014 \\
\hline 10 & 393030106224700 & $\begin{array}{l}\text { Eagle River below Homestake } \\
\text { Creek near Red Cliff }\end{array}$ & 1 & 2001 & $8 / 16 / 2001$ & $39^{\circ} 30^{\prime} 30^{\prime \prime}$ & $106^{\circ} 22^{\prime} 47^{\prime \prime}$ & 8,820 & 164 & Aulacoseira distans (Ehrenberg) Simonsen & 1,539 & 933,561 \\
\hline 10 & 393030106224700 & $\begin{array}{l}\text { Eagle River below Homestake } \\
\text { Creek near Red Cliff }\end{array}$ & 1 & 2001 & $8 / 16 / 2001$ & $39^{\circ} 30^{\prime} 30^{\prime \prime}$ & $106^{\circ} 22^{\prime} 47^{\prime \prime}$ & 8,820 & 164 & Aulacoseira valida (Grunow) Krammer & 220 & 298,398 \\
\hline 10 & 393030106224700 & $\begin{array}{l}\text { Eagle River below Homestake } \\
\text { Creek near Red Cliff }\end{array}$ & 1 & 2001 & $8 / 16 / 2001$ & $39^{\circ} 30^{\prime} 30^{\prime \prime}$ & $106^{\circ} 22^{\prime} 47^{\prime \prime}$ & 8,820 & 164 & Bulbochaete sp. & 2,539 & 215,809 \\
\hline 10 & 393030106224700 & $\begin{array}{l}\text { Eagle River below Homestake } \\
\text { Creek near Red Cliff }\end{array}$ & 1 & 2001 & $8 / 16 / 2001$ & $39^{\circ} 30^{\prime} 30^{\prime \prime}$ & $106^{\circ} 22^{\prime} 47^{\prime \prime}$ & 8,820 & 164 & Chlamydomonas sp. & 1,904 & $3,768,896$ \\
\hline 10 & 393030106224700 & $\begin{array}{l}\text { Eagle River below Homestake } \\
\text { Creek near Red Cliff }\end{array}$ & 1 & 2001 & $8 / 16 / 2001$ & $39^{\circ} 30^{\prime} 30^{\prime \prime}$ & $106^{\circ} 22^{\prime} 47^{\prime \prime}$ & 8,820 & 164 & Closterium moniliferum Ehrenberg & 635 & $75,437,790$ \\
\hline 10 & 393030106224700 & $\begin{array}{l}\text { Eagle River below Homestake } \\
\text { Creek near Red Cliff }\end{array}$ & 1 & 2001 & $8 / 16 / 2001$ & $39^{\circ} 30^{\prime} 30^{\prime \prime}$ & $106^{\circ} 22^{\prime} 47^{\prime \prime}$ & 8,820 & 164 & Cocconeis pediculus Ehrenberg & 10,554 & $32,944,118$ \\
\hline 10 & 393030106224700 & $\begin{array}{l}\text { Eagle River below Homestake } \\
\text { Creek near Red Cliff }\end{array}$ & 1 & 2001 & $8 / 16 / 2001$ & $39^{\circ} 30^{\prime} 30^{\prime \prime}$ & $106^{\circ} 22^{\prime} 47^{\prime \prime}$ & 8,820 & 164 & $\begin{array}{l}\text { Cocconeis placentula var. euglypta } \\
\text { (Ehrenberg) Grunow }\end{array}$ & 440 & 261,286 \\
\hline 10 & 393030106224700 & $\begin{array}{l}\text { Eagle River below Homestake } \\
\text { Creek near Red Cliff }\end{array}$ & 1 & 2001 & $8 / 16 / 2001$ & $39^{\circ} 30^{\prime} 30^{\prime \prime}$ & $106^{\circ} 22^{\prime} 47^{\prime \prime}$ & 8,820 & 164 & $\begin{array}{l}\text { Cocconeis placentula var. lineata (Ehrenberg) } \\
\text { Van Heurck }\end{array}$ & 8,135 & $8,579,226$ \\
\hline 10 & 393030106224700 & $\begin{array}{l}\text { Eagle River below Homestake } \\
\text { Creek near Red Cliff }\end{array}$ & 1 & 2001 & $8 / 16 / 2001$ & $39^{\circ} 30^{\prime} 30^{\prime \prime}$ & $106^{\circ} 22^{\prime} 47^{\prime \prime}$ & 8,820 & 164 & Cymbella affinis Kützing & 440 & 223,804 \\
\hline 10 & 393030106224700 & $\begin{array}{l}\text { Eagle River below Homestake } \\
\text { Creek near Red Cliff }\end{array}$ & 1 & 2001 & $8 / 16 / 2001$ & $39^{\circ} 30^{\prime} 30^{\prime \prime}$ & $106^{\circ} 22^{\prime} 47^{\prime \prime}$ & 8,820 & 164 & Cymbella sp. 5 ANS WRC & 440 & 815,270 \\
\hline 10 & 393030106224700 & $\begin{array}{l}\text { Eagle River below Homestake } \\
\text { Creek near Red Cliff }\end{array}$ & 1 & 2001 & $8 / 16 / 2001$ & $39^{\circ} 30^{\prime} 30^{\prime \prime}$ & $106^{\circ} 22^{\prime} 47^{\prime \prime}$ & 8,820 & 164 & Diatoma mesodon (Ehrenberg) Kützing & 220 & 198,472 \\
\hline 10 & 393030106224700 & $\begin{array}{l}\text { Eagle River below Homestake } \\
\text { Creek near Red Cliff }\end{array}$ & 1 & 2001 & $8 / 16 / 2001$ & $39^{\circ} 30^{\prime} 30^{\prime \prime}$ & $106^{\circ} 22^{\prime} 47^{\prime \prime}$ & 8,820 & 164 & Diatoma vulgaris Bory & 440 & $1,624,787$ \\
\hline 10 & 393030106224700 & $\begin{array}{l}\text { Eagle River below Homestake } \\
\text { Creek near Red Cliff }\end{array}$ & 1 & 2001 & $8 / 16 / 2001$ & $39^{\circ} 30^{\prime} 30^{\prime \prime}$ & $106^{\circ} 22^{\prime} 47^{\prime \prime}$ & 8,820 & 164 & Encyonema brehmii (Hustedt) Mann & 879 & 24,248 \\
\hline 10 & 393030106224700 & $\begin{array}{l}\text { Eagle River below Homestake } \\
\text { Creek near Red Cliff }\end{array}$ & 1 & 2001 & $8 / 16 / 2001$ & $39^{\circ} 30^{\prime} 30^{\prime \prime}$ & $106^{\circ} 22^{\prime} 47^{\prime \prime}$ & 8,820 & 164 & Encyonema minutum (Hilse) Mann & 3,078 & 664,368 \\
\hline 10 & 393030106224700 & $\begin{array}{l}\text { Eagle River below Homestake } \\
\text { Creek near Red Cliff }\end{array}$ & 1 & 2001 & $8 / 16 / 2001$ & $39^{\circ} 30^{\prime} 30^{\prime \prime}$ & $106^{\circ} 22^{\prime} 47^{\prime \prime}$ & 8,820 & 164 & Encyonema silesiacum (Bleisch) Mann & 14,951 & $7,100,916$ \\
\hline
\end{tabular}


Table 2. Description of sites and algal data collected from selected sites the Eagle River watershed, Colorado, 2000-2001.—Continued

[ID, identification; NAVD, North American Vertical Datum of 1988; ft, feet; $\mathrm{mi}^{2}$, square miles; cells $/ \mathrm{cm}^{2}$, cells per square centimeter; $\mu \mathrm{m}^{3} / \mathrm{cm}^{2}$, cubic micrometer per square centimeter

\begin{tabular}{|c|c|c|c|c|c|c|c|c|c|c|c|c|}
\hline $\begin{array}{l}\text { Site } \\
\text { ID' }\end{array}$ & $\begin{array}{l}\text { USGS } \\
\text { station } \\
\text { number }\end{array}$ & Station name & $\begin{array}{c}\text { Replicate } \\
\text { sample } \\
\text { number }\end{array}$ & Year & $\begin{array}{l}\text { Collection } \\
\text { date }\end{array}$ & Latitude & Longitude & $\begin{array}{c}\text { Elevation } \\
\text { NAVD } 88 \\
\text { (ft) }\end{array}$ & $\begin{array}{c}\text { Drainage } \\
\text { area } \\
\left(\mathrm{mi}^{2}\right)\end{array}$ & Algal taxon name & $\begin{array}{c}\text { Total } \\
\text { density } \\
\text { (number of } \\
\text { cells } / \mathrm{cm}^{2} \text { ) }\end{array}$ & $\begin{array}{c}\text { Total } \\
\text { biovolume } \\
\left(\mu \mathrm{m}^{3} / \mathrm{cm}^{2}\right)\end{array}$ \\
\hline 10 & 393030106224700 & $\begin{array}{l}\text { Eagle River below Homestake } \\
\text { Creek near Red Cliff }\end{array}$ & 1 & 2001 & $8 / 16 / 2001$ & $39^{\circ} 30^{\prime} 30^{\prime \prime}$ & $106^{\circ} 22^{\prime} 47^{\prime \prime}$ & 8,820 & 164 & $\begin{array}{l}\text { Encyonopsis microcephala (Grunow) } \\
\text { Krammer }\end{array}$ & 440 & 27,987 \\
\hline 10 & 393030106224700 & $\begin{array}{l}\text { Eagle River below Homestake } \\
\text { Creek near Red Cliff }\end{array}$ & 1 & 2001 & $8 / 16 / 2001$ & $39^{\circ} 30^{\prime} 30^{\prime \prime}$ & $106^{\circ} 22^{\prime} 47^{\prime \prime}$ & 8,820 & 164 & $\begin{array}{l}\text { Eunotia implicata Nörpel, } \\
\text { Lange-Bertalot et Alles }\end{array}$ & 440 & 473,714 \\
\hline 10 & 393030106224700 & $\begin{array}{l}\text { Eagle River below Homestake } \\
\text { Creek near Red Cliff }\end{array}$ & 1 & 2001 & $8 / 16 / 2001$ & $39^{\circ} 30^{\prime} 30^{\prime \prime}$ & $106^{\circ} 22^{\prime} 47^{\prime \prime}$ & 8,820 & 164 & Fragilaria capucina Desmazières & 3,738 & 675,990 \\
\hline 10 & 393030106224700 & $\begin{array}{l}\text { Eagle River below Homestake } \\
\text { Creek near Red Cliff }\end{array}$ & 1 & 2001 & $8 / 16 / 2001$ & $39^{\circ} 30^{\prime} 30^{\prime \prime}$ & $106^{\circ} 22^{\prime} 47^{\prime \prime}$ & 8,820 & 164 & Fragilaria pinnata var. acuminata Mayer & 440 & 376,853 \\
\hline 10 & 393030106224700 & $\begin{array}{l}\text { Eagle River below Homestake } \\
\text { Creek near Red Cliff }\end{array}$ & 1 & 2001 & $8 / 16 / 2001$ & $39^{\circ} 30^{\prime} 30^{\prime \prime}$ & $106^{\circ} 22^{\prime} 47^{\prime \prime}$ & 8,820 & 164 & Fragilaria sp. 3 ANS WRC & 440 & 376,853 \\
\hline 10 & 393030106224700 & $\begin{array}{l}\text { Eagle River below Homestake } \\
\text { Creek near Red Cliff }\end{array}$ & 1 & 2001 & $8 / 16 / 2001$ & $39^{\circ} 30^{\prime} 30^{\prime \prime}$ & $106^{\circ} 22^{\prime} 47^{\prime \prime}$ & 8,820 & 164 & Fragilaria vaucheriae (Kützing) Petersen & 5,497 & $1,082,912$ \\
\hline 10 & 393030106224700 & $\begin{array}{l}\text { Eagle River below Homestake } \\
\text { Creek near Red Cliff }\end{array}$ & 1 & 2001 & $8 / 16 / 2001$ & $39^{\circ} 30^{\prime} 30^{\prime \prime}$ & $106^{\circ} 22^{\prime} 47^{\prime \prime}$ & 8,820 & 164 & $\begin{array}{l}\text { Geissleria acceptata (Hustedt) } \\
\text { Lange-Bertalot et Metzeltin }\end{array}$ & 440 & 45,139 \\
\hline 10 & 393030106224700 & $\begin{array}{l}\text { Eagle River below Homestake } \\
\text { Creek near Red Cliff }\end{array}$ & 1 & 2001 & $8 / 16 / 2001$ & $39^{\circ} 30^{\prime} 30^{\prime \prime}$ & $106^{\circ} 22^{\prime} 47^{\prime \prime}$ & 8,820 & 164 & Gomphonema minutum (Agardh) Agardh & 440 & 35,929 \\
\hline 10 & 393030106224700 & $\begin{array}{l}\text { Eagle River below Homestake } \\
\text { Creek near Red Cliff }\end{array}$ & 1 & 2001 & $8 / 16 / 2001$ & $39^{\circ} 30^{\prime} 30^{\prime \prime}$ & $106^{\circ} 22^{\prime} 47^{\prime \prime}$ & 8,820 & 164 & $\begin{array}{l}\text { Gomphonema parvulius (Lange-Bertalot } \\
\text { et Reichardt) Lange-Bertalot et Reichardt }\end{array}$ & 440 & 153,799 \\
\hline 10 & 393030106224700 & $\begin{array}{l}\text { Eagle River below Homestake } \\
\text { Creek near Red Cliff }\end{array}$ & 1 & 2001 & $8 / 16 / 2001$ & $39^{\circ} 30^{\prime} 30^{\prime \prime}$ & $106^{\circ} 22^{\prime} 47^{\prime \prime}$ & 8,820 & 164 & Gomphonema parvulum (Kützing) Kützing & 440 & 96,092 \\
\hline 10 & 393030106224700 & $\begin{array}{l}\text { Eagle River below Homestake } \\
\text { Creek near Red Cliff }\end{array}$ & 1 & 2001 & $8 / 16 / 2001$ & $39^{\circ} 30^{\prime} 30^{\prime \prime}$ & $106^{\circ} 22^{\prime} 47^{\prime \prime}$ & 8,820 & 164 & Hannaea arcus (Ehrenberg) Patrick & 220 & 440,868 \\
\hline 10 & 393030106224700 & $\begin{array}{l}\text { Eagle River below Homestake } \\
\text { Creek near Red Cliff }\end{array}$ & 1 & 2001 & $8 / 16 / 2001$ & $39^{\circ} 30^{\prime} 30^{\prime \prime}$ & $106^{\circ} 22^{\prime} 47^{\prime \prime}$ & 8,820 & 164 & Meridion circulare (Greville) Agardh & 220 & 142,703 \\
\hline 10 & 393030106224700 & $\begin{array}{l}\text { Eagle River below Homestake } \\
\text { Creek near Red Cliff }\end{array}$ & 1 & 2001 & $8 / 16 / 2001$ & $39^{\circ} 30^{\prime} 30^{\prime \prime}$ & $106^{\circ} 22^{\prime} 47^{\prime \prime}$ & 8,820 & 164 & $\begin{array}{l}\text { Navicula cryptotenella Lange-Bertalot } \\
\text { ex Krammer et Lange-Bertalot }\end{array}$ & 4,397 & $1,168,033$ \\
\hline 10 & 393030106224700 & $\begin{array}{l}\text { Eagle River below Homestake } \\
\text { Creek near Red Cliff }\end{array}$ & 1 & 2001 & $8 / 16 / 2001$ & $39^{\circ} 30^{\prime} 30^{\prime \prime}$ & $106^{\circ} 22^{\prime} 47^{\prime \prime}$ & 8,820 & 164 & Navicula libonensis Schoeman & 440 & 120,874 \\
\hline 10 & 393030106224700 & $\begin{array}{l}\text { Eagle River below Homestake } \\
\text { Creek near Red Cliff }\end{array}$ & 1 & 2001 & $8 / 16 / 2001$ & $39^{\circ} 30^{\prime} 30^{\prime \prime}$ & $106^{\circ} 22^{\prime} 47^{\prime \prime}$ & 8,820 & 164 & Navicula lundii Reichardt & 220 & 139,958 \\
\hline 10 & 393030106224700 & $\begin{array}{l}\text { Eagle River below Homestake } \\
\text { Creek near Red Cliff }\end{array}$ & 1 & 2001 & $8 / 16 / 2001$ & $39^{\circ} 30^{\prime} 30^{\prime \prime}$ & $106^{\circ} 22^{\prime} 47^{\prime \prime}$ & 8,820 & 164 & Navicula tripunctata (Müller) Bory & 5,277 & $4,798,400$ \\
\hline 10 & 393030106224700 & $\begin{array}{l}\text { Eagle River below Homestake } \\
\text { Creek near Red Cliff }\end{array}$ & 1 & 2001 & $8 / 16 / 2001$ & $39^{\circ} 30^{\prime} 30^{\prime \prime}$ & $106^{\circ} 22^{\prime} 47^{\prime \prime}$ & 8,820 & 164 & Navicula veneta Kützing & 440 & 97,086 \\
\hline 10 & 393030106224700 & $\begin{array}{l}\text { Eagle River below Homestake } \\
\text { Creek near Red Cliff }\end{array}$ & 1 & 2001 & $8 / 16 / 2001$ & $39^{\circ} 30^{\prime} 30^{\prime \prime}$ & $106^{\circ} 22^{\prime} 47^{\prime \prime}$ & 8,820 & 164 & Nitzschia dissipata (Kützing) Grunow & 440 & 113,379 \\
\hline 10 & 393030106224700 & $\begin{array}{l}\text { Eagle River below Homestake } \\
\text { Creek near Red Cliff }\end{array}$ & 1 & 2001 & $8 / 16 / 2001$ & $39^{\circ} 30^{\prime} 30^{\prime \prime}$ & $106^{\circ} 22^{\prime} 47^{\prime \prime}$ & 8,820 & 164 & Nitzschia inconspicua Grunow & 440 & 23,748 \\
\hline 10 & 393030106224700 & $\begin{array}{l}\text { Eagle River below Homestake } \\
\text { Creek near Red Cliff }\end{array}$ & 1 & 2001 & $8 / 16 / 2001$ & $39^{\circ} 30^{\prime} 30^{\prime \prime}$ & $106^{\circ} 22^{\prime} 47^{\prime \prime}$ & 8,820 & 164 & $\begin{array}{l}\text { Nitzschia linearis (Agardh ex Wm. Smith) } \\
\text { Wm. Smith }\end{array}$ & 220 & 634,732 \\
\hline 10 & 393030106224700 & $\begin{array}{l}\text { Eagle River below Homestake } \\
\text { Creek near Red Cliff }\end{array}$ & 1 & 2001 & $8 / 16 / 2001$ & $39^{\circ} 30^{\prime} 30^{\prime \prime}$ & $106^{\circ} 22^{\prime} 47^{\prime \prime}$ & 8,820 & 164 & $\begin{array}{l}\text { Nitzschia vermicularis (Kützing) } \\
\text { Hantzsch ex Rabenhorst }\end{array}$ & 220 & $1,005,886$ \\
\hline 10 & 393030106224700 & $\begin{array}{l}\text { Eagle River below Homestake } \\
\text { Creek near Red Cliff }\end{array}$ & 1 & 2001 & $8 / 16 / 2001$ & $39^{\circ} 30^{\prime} 30^{\prime \prime}$ & $106^{\circ} 22^{\prime} 47^{\prime \prime}$ & 8,820 & 164 & Phormidium autumnale (Agardh) Gomont & 396,072 & $38,401,268$ \\
\hline 10 & 393030106224700 & $\begin{array}{l}\text { Eagle River below Homestake } \\
\text { Creek near Red Cliff }\end{array}$ & 1 & 2001 & $8 / 16 / 2001$ & $39^{\circ} 30^{\prime} 30^{\prime \prime}$ & $106^{\circ} 22^{\prime} 47^{\prime \prime}$ & 8,820 & 164 & $\begin{array}{l}\text { Planothidium dubium (Grunow) } \\
\text { Round et Bukhtiyarova }\end{array}$ & 440 & 35,382 \\
\hline
\end{tabular}


Table 2. Description of sites and algal data collected from selected sites the Eagle River watershed, Colorado, 2000-2001.—Continued

[ID, identification; NAVD, North American Vertical Datum of 1988; ft, feet; $\mathrm{mi}^{2}$, square miles; cells $/ \mathrm{cm}^{2}$, cells per square centimeter; $\mu \mathrm{m}^{3} / \mathrm{cm}^{2}$, cubic micrometer per square centimeter]

\begin{tabular}{|c|c|c|c|c|c|c|c|c|c|c|c|c|}
\hline $\begin{array}{l}\text { Site } \\
\text { ID' }\end{array}$ & $\begin{array}{l}\text { USGS } \\
\text { station } \\
\text { number }\end{array}$ & Station name & $\begin{array}{c}\text { Replicate } \\
\text { sample } \\
\text { number }\end{array}$ & Year & $\begin{array}{l}\text { Collection } \\
\text { date }\end{array}$ & Latitude & Longitude & $\begin{array}{c}\text { Elevation } \\
\text { NAVD } 88 \\
\text { (ft) }\end{array}$ & $\begin{array}{c}\text { Drainage } \\
\text { area } \\
\left(\mathrm{mi}^{2}\right)\end{array}$ & Algal taxon name & $\begin{array}{c}\text { Total } \\
\text { density } \\
\text { (number of } \\
\text { cells } / \mathrm{cm}^{2} \text { ) }\end{array}$ & $\begin{array}{c}\text { Total } \\
\text { biovolume } \\
\left(\mu \mathrm{m}^{3} / \mathrm{cm}^{2}\right)\end{array}$ \\
\hline 10 & 393030106224700 & $\begin{array}{l}\text { Eagle River below Homestake } \\
\text { Creek near Red Cliff }\end{array}$ & 1 & 2001 & $8 / 16 / 2001$ & $39^{\circ} 30^{\prime} 30^{\prime \prime}$ & $106^{\circ} 22^{\prime} 47^{\prime \prime}$ & 8,820 & 164 & $\begin{array}{l}\text { Reimeria sinuata (Gregory) } \\
\text { Kociolek et Stoermer }\end{array}$ & 5,936 & $1,000,524$ \\
\hline 10 & 393030106224700 & $\begin{array}{l}\text { Eagle River below Homestake } \\
\text { Creek near Red Cliff }\end{array}$ & 1 & 2001 & $8 / 16 / 2001$ & $39^{\circ} 30^{\prime} 30^{\prime \prime}$ & $106^{\circ} 22^{\prime} 47^{\prime \prime}$ & 8,820 & 164 & Sellaphora disjuncta (Hustedt) Mann & 440 & 63,322 \\
\hline 10 & 393030106224700 & $\begin{array}{l}\text { Eagle River below Homestake } \\
\text { Creek near Red Cliff }\end{array}$ & 1 & 2001 & $8 / 16 / 2001$ & $39^{\circ} 30^{\prime} 30^{\prime \prime}$ & $106^{\circ} 22^{\prime} 47^{\prime \prime}$ & 8,820 & 164 & Stauroneis anceps Ehrenberg & 220 & $1,484,107$ \\
\hline 10 & 393030106224700 & $\begin{array}{l}\text { Eagle River below Homestake } \\
\text { Creek near Red Cliff }\end{array}$ & 1 & 2001 & $8 / 16 / 2001$ & $39^{\circ} 30^{\prime} 30^{\prime \prime}$ & $106^{\circ} 22^{\prime} 47^{\prime \prime}$ & 8,820 & 164 & $\begin{array}{l}\text { Staurosira construens var. venter (Ehrenberg) } \\
\text { Hamilton }\end{array}$ & 13,412 & $1,610,839$ \\
\hline 10 & 393030106224700 & $\begin{array}{l}\text { Eagle River below Homestake } \\
\text { Creek near Red Cliff }\end{array}$ & 1 & 2001 & $8 / 16 / 2001$ & $39^{\circ} 30^{\prime} 30^{\prime \prime}$ & $106^{\circ} 22^{\prime} 47^{\prime \prime}$ & 8,820 & 164 & $\begin{array}{l}\text { Staurosirella leptostauron (Ehrenberg) } \\
\text { Williams et Round }\end{array}$ & 3,738 & $1,825,630$ \\
\hline 10 & 393030106224700 & $\begin{array}{l}\text { Eagle River below Homestake } \\
\text { Creek near Red Cliff }\end{array}$ & 1 & 2001 & $8 / 16 / 2001$ & $39^{\circ} 30^{\prime} 30^{\prime \prime}$ & $106^{\circ} 22^{\prime} 47^{\prime \prime}$ & 8,820 & 164 & $\begin{array}{l}\text { Staurosirella pinnata (Ehrenberg) } \\
\text { Williams et Round }\end{array}$ & 3,738 & 360,948 \\
\hline 10 & 393030106224700 & $\begin{array}{l}\text { Eagle River below Homestake } \\
\text { Creek near Red Cliff }\end{array}$ & 1 & 2001 & $8 / 16 / 2001$ & $39^{\circ} 30^{\prime} 30^{\prime \prime}$ & $106^{\circ} 22^{\prime} 47^{\prime \prime}$ & 8,820 & 164 & Synedra rumpens Kützing & 879 & 105,679 \\
\hline 10 & 393030106224700 & $\begin{array}{l}\text { Eagle River below Homestake } \\
\text { Creek near Red Cliff }\end{array}$ & 1 & 2001 & $8 / 16 / 2001$ & $39^{\circ} 30^{\prime} 30^{\prime \prime}$ & $106^{\circ} 22^{\prime} 47^{\prime \prime}$ & 8,820 & 164 & $\begin{array}{l}\text { Unknown Cyanophyte Oscillatoriales } \\
\text { (no sheath) }\end{array}$ & 104,096 & $1,544,321$ \\
\hline 10 & 393030106224700 & $\begin{array}{l}\text { Eagle River below Homestake } \\
\text { Creek near Red Cliff }\end{array}$ & 1 & 2001 & $8 / 16 / 2001$ & $39^{\circ} 30^{\prime} 30^{\prime \prime}$ & $106^{\circ} 22^{\prime} 47^{\prime \prime}$ & 8,820 & 164 & $\begin{array}{l}\text { Unknown Rhodophyte Florideophycidae } \\
\text { (chantransia) }\end{array}$ & 67,916 & $434,697,119$ \\
\hline 14 & 09064600 & Eagle River near Minturn & 1 & 2000 & $8 / 16 / 2000$ & 39॰33'14" & $106^{\circ} 24^{\prime} 07^{\prime \prime}$ & 8,078 & 186 & $\begin{array}{l}\text { Achnanthidium minutissimum (Kützing) } \\
\text { Czarnecki }\end{array}$ & 61,854 & $3,406,419$ \\
\hline 14 & 09064600 & Eagle River near Minturn & 1 & 2000 & $8 / 16 / 2000$ & $39^{\circ} 33^{\prime} 14^{\prime \prime}$ & $106^{\circ} 24^{\prime} 07^{\prime \prime}$ & 8,078 & 186 & $\begin{array}{l}\text { Achnanthidium pyrenaicum (Hustedt) } \\
\text { Kobayasi }\end{array}$ & 786 & 98,862 \\
\hline 14 & 09064600 & Eagle River near Minturn & 1 & 2000 & $8 / 16 / 2000$ & 39³3'14" & $106^{\circ} 24^{\prime} 07^{\prime \prime}$ & 8,078 & 186 & $\begin{array}{l}\text { Cocconeis placentula var. lineata (Ehrenberg) } \\
\text { Van Heurck }\end{array}$ & 112 & 117,618 \\
\hline 14 & 09064600 & Eagle River near Minturn & 1 & 2000 & $8 / 16 / 2000$ & $39^{\circ} 33^{\prime} 14^{\prime \prime}$ & $106^{\circ} 24^{\prime} 07^{\prime \prime}$ & 8,078 & 186 & Encyonema minutum (Hilse) Mann & 786 & 168,149 \\
\hline 14 & 09064600 & Eagle River near Minturn & 1 & 2000 & $8 / 16 / 2000$ & $39^{\circ} 33^{\prime} 14^{\prime \prime}$ & $106^{\circ} 24^{\prime} 07^{\prime \prime}$ & 8,078 & 186 & Encyonema silesiacum (Bleisch) Mann & 7,297 & $3,435,688$ \\
\hline 14 & 09064600 & Eagle River near Minturn & 1 & 2000 & $8 / 16 / 2000$ & $39^{\circ} 33^{\prime} 14^{\prime \prime}$ & $106^{\circ} 24^{\prime} 07^{\prime \prime}$ & 8,078 & 186 & $\begin{array}{l}\text { Fragilaria capucina var. fragilarioides } \\
\text { (Grunow) Ludwig et Flores }\end{array}$ & 2,133 & 218,533 \\
\hline 14 & 09064600 & Eagle River near Minturn & 1 & 2000 & $8 / 16 / 2000$ & 39³3'14" & $106^{\circ} 24^{\prime} 07^{\prime \prime}$ & 8,078 & 186 & Fragilaria vaucheriae (Kützing) Petersen & 6,511 & $1,346,867$ \\
\hline 14 & 09064600 & Eagle River near Minturn & 1 & 2000 & $8 / 16 / 2000$ & $39^{\circ} 33^{\prime} 14^{\prime \prime}$ & $106^{\circ} 24^{\prime} 07^{\prime \prime}$ & 8,078 & 186 & Gomphonema olivaceoides Hustedt & 1,572 & 240,419 \\
\hline 14 & 09064600 & Eagle River near Minturn & 1 & 2000 & $8 / 16 / 2000$ & $39^{\circ} 33^{\prime} 14^{\prime \prime}$ & $106^{\circ} 24^{\prime} 07^{\prime \prime}$ & 8,078 & 186 & Hannaea arcus (Ehrenberg) Patrick & 337 & 817,732 \\
\hline 14 & 09064600 & Eagle River near Minturn & 1 & 2000 & $8 / 16 / 2000$ & $39^{\circ} 33^{\prime} 14^{\prime \prime}$ & $106^{\circ} 24^{\prime} 07^{\prime \prime}$ & 8,078 & 186 & $\begin{array}{l}\text { Homoeothrix janthina (Bornet et Flahault) } \\
\text { Starmach }\end{array}$ & 159,141 & $5,157,509$ \\
\hline 14 & 09064600 & Eagle River near Minturn & 1 & 2000 & $8 / 16 / 2000$ & $39^{\circ} 33^{\prime} 14^{\prime \prime}$ & $106^{\circ} 24^{\prime} 07^{\prime \prime}$ & 8,078 & 186 & Phormidium autumnale (Agardh) Gomont & 92,437 & $9,052,328$ \\
\hline 14 & 09064600 & Eagle River near Minturn & 1 & 2000 & $8 / 16 / 2000$ & $39^{\circ} 33^{\prime} 14^{\prime \prime}$ & $106^{\circ} 24^{\prime} 07^{\prime \prime}$ & 8,078 & 186 & $\begin{array}{l}\text { Reimeria sinuata (Gregory) } \\
\text { Kociolek et Stoermer }\end{array}$ & 337 & 55,683 \\
\hline 14 & 09064600 & Eagle River near Minturn & 1 & 2000 & $8 / 16 / 2000$ & 39॰33'14" & $106^{\circ} 24^{\prime} 07^{\prime \prime}$ & 8,078 & 186 & $\begin{array}{l}\text { Staurosira construens var. venter (Ehrenberg) } \\
\text { Hamilton }\end{array}$ & 1,235 & 148,310 \\
\hline 14 & 09064600 & Eagle River near Minturn & 1 & 2000 & $8 / 16 / 2000$ & $39^{\circ} 33^{\prime} 14^{\prime \prime}$ & $106^{\circ} 24^{\prime} 07^{\prime \prime}$ & 8,078 & 186 & Synedra ulna (Nitzsch) Ehrenberg & 337 & $2,208,085$ \\
\hline 14 & 09064600 & Eagle River near Minturn & 1 & 2000 & $8 / 16 / 2000$ & $39^{\circ} 33^{\prime} 14^{\prime \prime}$ & $106^{\circ} 24^{\prime} 07^{\prime \prime}$ & 8,078 & 186 & $\begin{array}{l}\text { Unknown Cyanophyte Oscillatoriales } \\
\text { (no sheath) }\end{array}$ & 44,695 & 724,745 \\
\hline 14 & 09064600 & Eagle River near Minturn & 2 & 2000 & $8 / 16 / 2000$ & 39॰33'14" & $106^{\circ} 24^{\prime} 07^{\prime \prime}$ & 8,078 & 186 & $\begin{array}{l}\text { Achnanthidium minutissimum (Kützing) } \\
\text { Czarnecki }\end{array}$ & 28,167 & $1,551,236$ \\
\hline 14 & 09064600 & Eagle River near Minturn & 2 & 2000 & $8 / 16 / 2000$ & $39^{\circ} 33^{\prime} 14^{\prime \prime}$ & $106^{\circ} 24^{\prime} 07^{\prime \prime}$ & 8,078 & 186 & $\begin{array}{l}\text { Cocconeis placentula var. lineata (Ehrenberg) } \\
\text { Van Heurck }\end{array}$ & 54 & 56,864 \\
\hline 14 & 09064600 & Eagle River near Minturn & 2 & 2000 & $8 / 16 / 2000$ & 39³3'14" & $106^{\circ} 24^{\prime} 07^{\prime \prime}$ & 8,078 & 186 & Encyonema minutum (Hilse) Mann & 326 & 603,729 \\
\hline 14 & 09064600 & Eagle River near Minturn & 2 & 2000 & $8 / 16 / 2000$ & $39^{\circ} 33^{\prime} 14^{\prime \prime}$ & $106^{\circ} 24^{\prime} 07^{\prime \prime}$ & 8,078 & 186 & Encyonema silesiacum (Bleisch) Mann & 2,334 & $1,098,836$ \\
\hline
\end{tabular}


[ID, identification; NAVD, North American Vertical Datum of 1988; ft, feet; $\mathrm{mi}^{2}$, square miles; cells $/ \mathrm{cm}^{2}$, cells per square centimeter; $\mu \mathrm{m}^{3} / \mathrm{cm}^{2}$, cubic micrometer per square centimeter]

\begin{tabular}{|c|c|c|c|c|c|c|c|c|c|c|c|c|}
\hline $\begin{array}{l}\text { Site } \\
\text { ID' }\end{array}$ & $\begin{array}{l}\text { USGS } \\
\text { station } \\
\text { number }\end{array}$ & Station name & $\begin{array}{c}\text { Replicate } \\
\text { sample } \\
\text { number }\end{array}$ & Year & $\begin{array}{l}\text { Collection } \\
\text { date }\end{array}$ & Latitude & Longitude & $\begin{array}{c}\text { Elevation } \\
\text { NAVD } 88 \\
\text { (ft) }\end{array}$ & $\begin{array}{c}\text { Drainage } \\
\text { area } \\
\left(\mathrm{mi}^{2}\right)\end{array}$ & Algal taxon name & $\begin{array}{c}\text { Total } \\
\text { density } \\
\text { (number of } \\
\text { cells/cm²) }\end{array}$ & $\begin{array}{c}\text { Total } \\
\text { biovolume } \\
\left(\mu^{3} / \mathrm{cm}^{2}\right)\end{array}$ \\
\hline 14 & 09064600 & Eagle River near Minturn & 2 & 2000 & $8 / 16 / 2000$ & $39^{\circ} 33^{\prime} 14^{\prime \prime}$ & $106^{\circ} 24^{\prime} 07^{\prime \prime}$ & 8,078 & 186 & $\begin{array}{l}\text { Fragilaria capucina var. fragilarioides } \\
\text { (Grunow) Ludwig et Flores }\end{array}$ & 814 & 83,410 \\
\hline 14 & 09064600 & Eagle River near Minturn & 2 & 2000 & $8 / 16 / 2000$ & $39^{\circ} 33^{\prime} 14^{\prime \prime}$ & $106^{\circ} 24^{\prime} 07^{\prime \prime}$ & 8,078 & 186 & Fragilaria vaucheriae (Kützing) Petersen & 2,279 & 471,531 \\
\hline 14 & 09064600 & Eagle River near Minturn & 2 & 2000 & $8 / 16 / 2000$ & $39^{\circ} 33^{\prime} 14^{\prime \prime}$ & $106^{\circ} 24^{\prime} 07^{\prime \prime}$ & 8,078 & 186 & $\begin{array}{l}\text { Gomphonema exilissimum (Grunow) } \\
\text { Lange-Bertalot }\end{array}$ & 109 & 141,326 \\
\hline 14 & 09064600 & Eagle River near Minturn & 2 & 2000 & $8 / 16 / 2000$ & $39^{\circ} 33^{\prime} 14^{\prime \prime}$ & $106^{\circ} 24^{\prime} 07^{\prime \prime}$ & 8,078 & 186 & Gomphonema olivaceoides Hustedt & 1,248 & 190,956 \\
\hline 14 & 09064600 & Eagle River near Minturn & 2 & 2000 & $8 / 16 / 2000$ & $39^{\circ} 33^{\prime} 14^{\prime \prime}$ & $106^{\circ} 24^{\prime} 07^{\prime \prime}$ & 8,078 & 186 & Gomphonema olivaceum (Lyngbye) Kützing & 163 & 56,021 \\
\hline 14 & 09064600 & Eagle River near Minturn & 2 & 2000 & $8 / 16 / 2000$ & $39^{\circ} 33^{\prime} 14^{\prime \prime}$ & $106^{\circ} 24^{\prime} 07^{\prime \prime}$ & 8,078 & 186 & $\begin{array}{l}\text { Gomphonema pumilum (Grunow) } \\
\text { Reichardt et Lange-Bertalot }\end{array}$ & 54 & 15,836 \\
\hline 14 & 09064600 & Eagle River near Minturn & 2 & 2000 & $8 / 16 / 2000$ & $39^{\circ} 33^{\prime} 14^{\prime \prime}$ & $106^{\circ} 24^{\prime} 07^{\prime \prime}$ & 8,078 & 186 & Hannaea arcus (Ehrenberg) Patrick & 380 & 922,470 \\
\hline 14 & 09064600 & Eagle River near Minturn & 2 & 2000 & $8 / 16 / 2000$ & $39^{\circ} 33^{\prime} 14^{\prime \prime}$ & $106^{\circ} 24^{\prime} 07^{\prime \prime}$ & 8,078 & 186 & $\begin{array}{l}\text { Homoeothrix janthina (Bornet et Flahault) } \\
\text { Starmach }\end{array}$ & 42,866 & $1,389,206$ \\
\hline 14 & 09064600 & Eagle River near Minturn & 2 & 2000 & $8 / 16 / 2000$ & $39^{\circ} 33^{\prime} 14^{\prime \prime}$ & $106^{\circ} 24^{\prime} 07^{\prime \prime}$ & 8,078 & 186 & Meridion circulare (Greville) Agardh & 54 & 35,225 \\
\hline 14 & 09064600 & Eagle River near Minturn & 2 & 2000 & $8 / 16 / 2000$ & $39^{\circ} 33^{\prime} 14^{\prime \prime}$ & $106^{\circ} 24^{\prime} 07^{\prime \prime}$ & 8,078 & 186 & Nitzschia fonticola Grunow & 109 & 10,779 \\
\hline 14 & 09064600 & Eagle River near Minturn & 2 & 2000 & $8 / 16 / 2000$ & $39^{\circ} 33^{\prime} 14^{\prime \prime}$ & $106^{\circ} 24^{\prime} 07^{\prime \prime}$ & 8,078 & 186 & Nitzschia inconspicua Grunow & 163 & 5,887 \\
\hline 14 & 09064600 & Eagle River near Minturn & 2 & 2000 & $8 / 16 / 2000$ & $39^{\circ} 33^{\prime} 14^{\prime \prime}$ & $106^{\circ} 24^{\prime} 07^{\prime \prime}$ & 8,078 & 186 & $\begin{array}{l}\text { Psammothidium subatomoides (Hustedt) } \\
\text { Bukhtiyarova et Round }\end{array}$ & 109 & 162,058 \\
\hline 14 & 09064600 & Eagle River near Minturn & 2 & 2000 & $8 / 16 / 2000$ & $39^{\circ} 33^{\prime} 14^{\prime \prime}$ & $106^{\circ} 24^{\prime} 07^{\prime \prime}$ & 8,078 & 186 & $\begin{array}{l}\text { Reimeria sinuata (Gregory) } \\
\text { Kociolek et Stoermer }\end{array}$ & 326 & 53,842 \\
\hline 14 & 09064600 & Eagle River near Minturn & 2 & 2000 & $8 / 16 / 2000$ & $39^{\circ} 33^{\prime} 14^{\prime \prime}$ & $106^{\circ} 24^{\prime} 07^{\prime \prime}$ & 8,078 & 186 & $\begin{array}{l}\text { Staurosira construens var. venter (Ehrenberg) } \\
\text { Hamilton }\end{array}$ & 488 & 58,666 \\
\hline 14 & 09064600 & Eagle River near Minturn & 2 & 2000 & $8 / 16 / 2000$ & $39^{\circ} 33^{\prime} 14^{\prime \prime}$ & $106^{\circ} 24^{\prime} 07^{\prime \prime}$ & 8,078 & 186 & Stigeoclonium lubricum (Dillwyn) Kützing & 926 & $1,374,606$ \\
\hline 14 & 09064600 & Eagle River near Minturn & 2 & 2000 & $8 / 16 / 2000$ & $39^{\circ} 33^{\prime} 14^{\prime \prime}$ & $106^{\circ} 24^{\prime} 07^{\prime \prime}$ & 8,078 & 186 & $\begin{array}{l}\text { Unknown Cyanophyte Oscillatoriales } \\
\text { (no sheath) }\end{array}$ & 19,581 & 317,506 \\
\hline 14 & 09064600 & Eagle River near Minturn & 3 & 2000 & $8 / 16 / 2000$ & $39^{\circ} 33^{\prime} 14^{\prime \prime}$ & $106^{\circ} 24^{\prime} 07^{\prime \prime}$ & 8,078 & 186 & $\begin{array}{l}\text { Achnanthidium minutissimum (Kützing) } \\
\text { Czarnecki }\end{array}$ & 23,166 & $1,275,806$ \\
\hline 14 & 09064600 & Eagle River near Minturn & 3 & 2000 & $8 / 16 / 2000$ & $39^{\circ} 33^{\prime} 14^{\prime \prime}$ & $106^{\circ} 24^{\prime} 07^{\prime \prime}$ & 8,078 & 186 & Amphora pediculus (Kützing) Grunow & 46 & 4,367 \\
\hline 14 & 09064600 & Eagle River near Minturn & 3 & 2000 & $8 / 16 / 2000$ & $39^{\circ} 33^{\prime} 14^{\prime \prime}$ & $106^{\circ} 24^{\prime} 07^{\prime \prime}$ & 8,078 & 186 & $\begin{array}{l}\text { Cocconeis placentula var. lineata (Ehrenberg) } \\
\text { Van Heurck }\end{array}$ & 46 & 48,351 \\
\hline 14 & 09064600 & Eagle River near Minturn & 3 & 2000 & $8 / 16 / 2000$ & $39^{\circ} 33^{\prime} 14^{\prime \prime}$ & $106^{\circ} 24^{\prime} 07^{\prime \prime}$ & 8,078 & 186 & Cymbella affinis Kützing & 92 & 46,711 \\
\hline 14 & 09064600 & Eagle River near Minturn & 3 & 2000 & $8 / 16 / 2000$ & $39^{\circ} 33^{\prime} 14^{\prime \prime}$ & $106^{\circ} 24^{\prime} 07^{\prime \prime}$ & 8,078 & 186 & Diatoma moniliformis Kützing & 46 & 6,955 \\
\hline 14 & 09064600 & Eagle River near Minturn & 3 & 2000 & $8 / 16 / 2000$ & $39^{\circ} 33^{\prime} 14^{\prime \prime}$ & $106^{\circ} 24^{\prime} 07^{\prime \prime}$ & 8,078 & 186 & Encyonema minutum (Hilse) Mann & 185 & 39,500 \\
\hline 14 & 09064600 & Eagle River near Minturn & 3 & 2000 & $8 / 16 / 2000$ & $39^{\circ} 33^{\prime} 14^{\prime \prime}$ & $106^{\circ} 24^{\prime} 07^{\prime \prime}$ & 8,078 & 186 & Encyonema silesiacum (Bleisch) Mann & 3,000 & $1,412,369$ \\
\hline 14 & 09064600 & Eagle River near Minturn & 3 & 2000 & $8 / 16 / 2000$ & $39^{\circ} 33^{\prime} 14^{\prime \prime}$ & $106^{\circ} 24^{\prime} 07^{\prime \prime}$ & 8,078 & 186 & $\begin{array}{l}\text { Fragilaria capucina var. fragilarioides } \\
\text { (Grunow) Ludwig et Flores }\end{array}$ & 738 & 75,652 \\
\hline 14 & 09064600 & Eagle River near Minturn & 3 & 2000 & $8 / 16 / 2000$ & $39^{\circ} 33^{\prime} 14^{\prime \prime}$ & $106^{\circ} 24^{\prime} 07^{\prime \prime}$ & 8,078 & 186 & Fragilaria vaucheriae (Kützing) Petersen & 2,815 & 582,319 \\
\hline 14 & 09064600 & Eagle River near Minturn & 3 & 2000 & $8 / 16 / 2000$ & $39^{\circ} 33^{\prime} 14^{\prime \prime}$ & $106^{\circ} 24^{\prime} 07^{\prime \prime}$ & 8,078 & 186 & $\begin{array}{l}\text { Gomphonema exilissimum (Grunow) } \\
\text { Lange-Bertalot }\end{array}$ & 92 & 120,169 \\
\hline 14 & 09064600 & Eagle River near Minturn & 3 & 2000 & $8 / 16 / 2000$ & $39^{\circ} 33^{\prime} 14^{\prime \prime}$ & $106^{\circ} 24^{\prime} 07^{\prime \prime}$ & 8,078 & 186 & Gomphonema olivaceoides Hustedt & 138 & 21,179 \\
\hline 14 & 09064600 & Eagle River near Minturn & 3 & 2000 & $8 / 16 / 2000$ & $39^{\circ} 33^{\prime} 14^{\prime \prime}$ & $106^{\circ} 24^{\prime} 07^{\prime \prime}$ & 8,078 & 186 & Hannaea arcus (Ehrenberg) Patrick & 138 & 336,160 \\
\hline 14 & 09064600 & Eagle River near Minturn & 3 & 2000 & $8 / 16 / 2000$ & $39^{\circ} 33^{\prime} 14^{\prime \prime}$ & $106^{\circ} 24^{\prime} 07^{\prime \prime}$ & 8,078 & 186 & $\begin{array}{l}\text { Homoeothrix janthina (Bornet et Flahault) } \\
\text { Starmach }\end{array}$ & 67,130 & $2,175,570$ \\
\hline 14 & 09064600 & Eagle River near Minturn & 3 & 2000 & $8 / 16 / 2000$ & $39^{\circ} 33^{\prime} 14^{\prime \prime}$ & $106^{\circ} 24^{\prime} 07^{\prime \prime}$ & 8,078 & 186 & Navicula minima Grunow & 92 & 4,902 \\
\hline 14 & 09064600 & Eagle River near Minturn & 3 & 2000 & $8 / 16 / 2000$ & $39^{\circ} 33^{\prime} 14^{\prime \prime}$ & $106^{\circ} 24^{\prime} 07^{\prime \prime}$ & 8,078 & 186 & Navicula tripunctata (Müller) Bory & 92 & 87,326 \\
\hline 14 & 09064600 & Eagle River near Minturn & 3 & 2000 & $8 / 16 / 2000$ & $39^{\circ} 33^{\prime} 14^{\prime \prime}$ & $106^{\circ} 24^{\prime} 07^{\prime \prime}$ & 8,078 & 186 & Nitzschia palea (Kützing) Smith & 92 & 15,996 \\
\hline 14 & 09064600 & Eagle River near Minturn & 3 & 2000 & $8 / 16 / 2000$ & $39^{\circ} 33^{\prime} 14^{\prime \prime}$ & $106^{\circ} 24^{\prime} 07^{\prime \prime}$ & 8,078 & 186 & Nitzschia pura Hustedt & 92 & 29,227 \\
\hline 14 & 09064600 & Eagle River near Minturn & 3 & 2000 & $8 / 16 / 2000$ & $39^{\circ} 33^{\prime} 14^{\prime \prime}$ & $106^{\circ} 24^{\prime} 07^{\prime \prime}$ & 8,078 & 186 & Phormidium autumnale (Agardh) Gomont & 7,962 & 779,736 \\
\hline
\end{tabular}


Table 2. Description of sites and algal data collected from selected sites the Eagle River watershed, Colorado, 2000-2001.—Continued

[ID, identification; NAVD, North American Vertical Datum of 1988; ft, feet; $\mathrm{mi}^{2}$, square miles; cells $/ \mathrm{cm}^{2}$, cells per square centimeter; $\mu \mathrm{m}^{3} / \mathrm{cm}^{2}$, cubic micrometer per square centimeter]

\begin{tabular}{|c|c|c|c|c|c|c|c|c|c|c|c|c|}
\hline $\begin{array}{l}\text { Site } \\
\text { ID' }\end{array}$ & $\begin{array}{l}\text { USGS } \\
\text { station } \\
\text { number }\end{array}$ & Station name & $\begin{array}{c}\text { Replicate } \\
\text { sample } \\
\text { number }\end{array}$ & Year & $\begin{array}{l}\text { Collection } \\
\text { date }\end{array}$ & Latitude & Longitude & $\begin{array}{c}\text { Elevation } \\
\text { NAVD } 88 \\
\text { (ft) }\end{array}$ & $\begin{array}{c}\text { Drainage } \\
\text { area } \\
\left(\mathrm{mi}^{2}\right)\end{array}$ & Algal taxon name & $\begin{array}{c}\text { Total } \\
\text { density } \\
\text { (number of } \\
\text { cells } / \mathrm{cm}^{2} \text { ) }\end{array}$ & $\begin{array}{c}\text { Total } \\
\text { biovolume } \\
\left(\mu \mathrm{m}^{3} / \mathrm{cm}^{2}\right)\end{array}$ \\
\hline 14 & 09064600 & Eagle River near Minturn & 3 & 2000 & $8 / 16 / 2000$ & $39^{\circ} 33^{\prime} 14^{\prime \prime}$ & $106^{\circ} 24^{\prime} 07^{\prime \prime}$ & 8,078 & 186 & $\begin{array}{l}\text { Planothidium lanceolatum } \\
\text { (Brébisson ex Kützing) Lange-Bertalot }\end{array}$ & 92 & 13,184 \\
\hline 14 & 09064600 & Eagle River near Minturn & 3 & 2000 & $8 / 16 / 2000$ & $39^{\circ} 33^{\prime} 14^{\prime \prime}$ & $106^{\circ} 24^{\prime} 07^{\prime \prime}$ & 8,078 & 186 & $\begin{array}{l}\text { Reimeria sinuata (Gregory) } \\
\text { Kociolek et Stoermer }\end{array}$ & 231 & 38,151 \\
\hline 14 & 09064600 & Eagle River near Minturn & 3 & 2000 & $8 / 16 / 2000$ & $39^{\circ} 33^{\prime} 14^{\prime \prime}$ & $106^{\circ} 24^{\prime} 07^{\prime \prime}$ & 8,078 & 186 & $\begin{array}{l}\text { Staurosira construens var. venter (Ehrenberg) } \\
\text { Hamilton }\end{array}$ & 1,246 & 149,650 \\
\hline 14 & 09064600 & Eagle River near Minturn & 3 & 2000 & $8 / 16 / 2000$ & $39^{\circ} 33^{\prime} 14^{\prime \prime}$ & $106^{\circ} 24^{\prime} 07^{\prime \prime}$ & 8,078 & 186 & Synedra ulna (Nitzsch) Ehrenberg & 231 & $1,512,861$ \\
\hline 14 & 09064600 & Eagle River near Minturn & 3 & 2000 & $8 / 16 / 2000$ & $39^{\circ} 33^{\prime} 14^{\prime \prime}$ & $106^{\circ} 24^{\prime} 07^{\prime \prime}$ & 8,078 & 186 & $\begin{array}{l}\text { Unknown Cyanophyte Oscillatoriales } \\
\text { (no sheath) }\end{array}$ & 35,144 & 569,867 \\
\hline 21 & 09065100 & Cross Creek near Minturn & 1 & 2000 & $8 / 16 / 2000$ & $39^{\circ} 34^{\prime} 05^{\prime \prime}$ & $106^{\circ} 24^{\prime} 43^{\prime \prime}$ & 7,992 & 34.2 & $\begin{array}{l}\text { Achnanthidium minutissimum (Kützing) } \\
\text { Czarnecki }\end{array}$ & 15,699 & 864,577 \\
\hline 21 & 09065100 & Cross Creek near Minturn & 1 & 2000 & $8 / 16 / 2000$ & $39^{\circ} 34^{\prime} 05^{\prime \prime}$ & $106^{\circ} 24^{\prime} 43^{\prime \prime}$ & 7,992 & 34.2 & Aulacoseira ambigua (Grunow) Simonsen & 62 & 20,639 \\
\hline 21 & 09065100 & Cross Creek near Minturn & 1 & 2000 & $8 / 16 / 2000$ & $39^{\circ} 34^{\prime} 05^{\prime \prime}$ & $106^{\circ} 24^{\prime} 43^{\prime \prime}$ & 7,992 & 34.2 & Aulacoseira distans (Ehrenberg) Simonsen & 31 & 12,372 \\
\hline 21 & 09065100 & Cross Creek near Minturn & 1 & 2000 & $8 / 16 / 2000$ & $39^{\circ} 34^{\prime} 05^{\prime \prime}$ & $106^{\circ} 24^{\prime} 43^{\prime \prime}$ & 7,992 & 34.2 & Closterium venus Kützing & 132 & 11,238 \\
\hline 21 & 09065100 & Cross Creek near Minturn & 1 & 2000 & $8 / 16 / 2000$ & $39^{\circ} 34^{\prime} 05^{\prime \prime}$ & $106^{\circ} 24^{\prime} 43^{\prime \prime}$ & 7,992 & 34.2 & $\begin{array}{l}\text { Cocconeis placentula var. euglypta } \\
\text { (Ehrenberg) Grunow }\end{array}$ & 248 & 149,237 \\
\hline 21 & 09065100 & Cross Creek near Minturn & 1 & 2000 & $8 / 16 / 2000$ & $39^{\circ} 34^{\prime} 05^{\prime \prime}$ & $106^{\circ} 24^{\prime} 43^{\prime \prime}$ & 7,992 & 34.2 & $\begin{array}{l}\text { Cocconeis placentula var. lineata (Ehrenberg) } \\
\text { Van Heurck }\end{array}$ & 31 & 32,443 \\
\hline 21 & 09065100 & Cross Creek near Minturn & 1 & 2000 & $8 / 16 / 2000$ & $39^{\circ} 34^{\prime} 05^{\prime \prime}$ & $106^{\circ} 24^{\prime} 43^{\prime \prime}$ & 7,992 & 34.2 & Cosmarium subcrenatum Hantzsch & 132 & 11,238 \\
\hline 21 & 09065100 & Cross Creek near Minturn & 1 & 2000 & $8 / 16 / 2000$ & $39^{\circ} 34^{\prime} 05^{\prime \prime}$ & $106^{\circ} 24^{\prime} 43^{\prime \prime}$ & 7,992 & 34.2 & Cymbella cistula (Ehrenberg) Kirchner & 31 & 37,412 \\
\hline 21 & 09065100 & Cross Creek near Minturn & 1 & 2000 & $8 / 16 / 2000$ & $39^{\circ} 34^{\prime} 05^{\prime \prime}$ & $106^{\circ} 24^{\prime} 43^{\prime \prime}$ & 7,992 & 34.2 & Denticula tenuis Kützing & 31 & 11,774 \\
\hline 21 & 09065100 & Cross Creek near Minturn & 1 & 2000 & $8 / 16 / 2000$ & $39^{\circ} 34^{\prime} 05^{\prime \prime}$ & $106^{\circ} 24^{\prime} 43^{\prime \prime}$ & 7,992 & 34.2 & Diatoma anceps (Ehrenberg) Kirchner & 31 & 12,935 \\
\hline 21 & 09065100 & Cross Creek near Minturn & 1 & 2000 & $8 / 16 / 2000$ & $39^{\circ} 34^{\prime} 05^{\prime \prime}$ & $106^{\circ} 24^{\prime} 43^{\prime \prime}$ & 7,992 & 34.2 & Encyonema minutum (Hilse) Mann & 248 & 459,267 \\
\hline 21 & 09065100 & Cross Creek near Minturn & 1 & 2000 & $8 / 16 / 2000$ & $39^{\circ} 34^{\prime} 05^{\prime \prime}$ & $106^{\circ} 24^{\prime} 43^{\prime \prime}$ & 7,992 & 34.2 & Encyonema silesiacum (Bleisch) Mann & 341 & 160,377 \\
\hline 21 & 09065100 & Cross Creek near Minturn & 1 & 2000 & $8 / 16 / 2000$ & $39^{\circ} 34^{\prime} 05^{\prime \prime}$ & $106^{\circ} 24^{\prime} 43^{\prime \prime}$ & 7,992 & 34.2 & Eucocconeis laevis (Østrup) Lange-Bertalot & 124 & 184,921 \\
\hline 21 & 09065100 & Cross Creek near Minturn & 1 & 2000 & $8 / 16 / 2000$ & $39^{\circ} 34^{\prime} 05^{\prime \prime}$ & $106^{\circ} 24^{\prime} 43^{\prime \prime}$ & 7,992 & 34.2 & $\begin{array}{l}\text { Eunotia implicata Nörpel, } \\
\text { Lange-Bertalot et Alles }\end{array}$ & 93 & 114,113 \\
\hline 21 & 09065100 & Cross Creek near Minturn & 1 & 2000 & $8 / 16 / 2000$ & $39^{\circ} 34^{\prime} 05^{\prime \prime}$ & $106^{\circ} 24^{\prime} 43^{\prime \prime}$ & 7,992 & 34.2 & Eunotia praerupta Ehrenberg & 31 & 106,828 \\
\hline 21 & 09065100 & Cross Creek near Minturn & 1 & 2000 & $8 / 16 / 2000$ & $39^{\circ} 34^{\prime} 05^{\prime \prime}$ & $106^{\circ} 24^{\prime} 43^{\prime \prime}$ & 7,992 & 34.2 & $\begin{array}{l}\text { Fragilaria capucina var. fragilarioide } \\
\text { (Grunow) Ludwig et Flores }\end{array}$ & 310 & 31,726 \\
\hline 21 & 09065100 & Cross Creek near Minturn & 1 & 2000 & $8 / 16 / 2000$ & $39^{\circ} 34^{\prime} 05^{\prime \prime}$ & $106^{\circ} 24^{\prime} 43^{\prime \prime}$ & 7,992 & 34.2 & Fragilaria vaucheriae (Kützing) Petersen & 1,331 & 275,432 \\
\hline 21 & 09065100 & Cross Creek near Minturn & 1 & 2000 & $8 / 16 / 2000$ & $39^{\circ} 34^{\prime} 05^{\prime \prime}$ & $106^{\circ} 24^{\prime} 43^{\prime \prime}$ & 7,992 & 34.2 & Gomphonema consector Hohn et Hellermann & 31 & 40,316 \\
\hline 21 & 09065100 & Cross Creek near Minturn & 1 & 2000 & $8 / 16 / 2000$ & $39^{\circ} 34^{\prime} 05^{\prime \prime}$ & $106^{\circ} 24^{\prime} 43^{\prime \prime}$ & 7,992 & 34.2 & Gomphonema olivaceoides Hustedt & 62 & 9,474 \\
\hline 21 & 09065100 & Cross Creek near Minturn & 1 & 2000 & $8 / 16 / 2000$ & $39^{\circ} 34^{\prime} 05^{\prime \prime}$ & $106^{\circ} 24^{\prime} 43^{\prime \prime}$ & 7,992 & 34.2 & Hannaea arcus (Ehrenberg) Patrick & 93 & 225,559 \\
\hline 21 & 09065100 & Cross Creek near Minturn & 1 & 2000 & $8 / 16 / 2000$ & $39^{\circ} 34^{\prime} 05^{\prime \prime}$ & $106^{\circ} 24^{\prime} 43^{\prime \prime}$ & 7,992 & 34.2 & $\begin{array}{l}\text { Homoeothrix janthina (Bornet et Flahault) } \\
\text { Starmach }\end{array}$ & 56,060 & $1,816,813$ \\
\hline 21 & 09065100 & Cross Creek near Minturn & 1 & 2000 & $8 / 16 / 2000$ & $39^{\circ} 34^{\prime} 05^{\prime \prime}$ & $106^{\circ} 24^{\prime} 43^{\prime \prime}$ & 7,992 & 34.2 & Melosira varians Agardh & 31 & 168,115 \\
\hline 21 & 09065100 & Cross Creek near Minturn & 1 & 2000 & $8 / 16 / 2000$ & $39^{\circ} 34^{\prime} 05^{\prime \prime}$ & $106^{\circ} 24^{\prime} 43^{\prime \prime}$ & 7,992 & 34.2 & Meridion circulare (Greville) Agardh & 31 & 20,097 \\
\hline 21 & 09065100 & Cross Creek near Minturn & 1 & 2000 & $8 / 16 / 2000$ & $39^{\circ} 34^{\prime} 05^{\prime \prime}$ & $106^{\circ} 24^{\prime} 43^{\prime \prime}$ & 7,992 & 34.2 & Navicula minima Grunow & 31 & 1,645 \\
\hline 21 & 09065100 & Cross Creek near Minturn & 1 & 2000 & $8 / 16 / 2000$ & $39^{\circ} 34^{\prime} 05^{\prime \prime}$ & $106^{\circ} 24^{\prime} 43^{\prime \prime}$ & 7,992 & 34.2 & Navicula tripunctata (Müller) Bory & 62 & 58,595 \\
\hline 21 & 09065100 & Cross Creek near Minturn & 1 & 2000 & $8 / 16 / 2000$ & $39^{\circ} 34^{\prime} 05^{\prime \prime}$ & $106^{\circ} 24^{\prime} 43^{\prime \prime}$ & 7,992 & 34.2 & Nitzschia dissipata (Kützing) Grunow & 124 & 32,208 \\
\hline 21 & 09065100 & Cross Creek near Minturn & 1 & 2000 & $8 / 16 / 2000$ & $39^{\circ} 34^{\prime} 05^{\prime \prime}$ & $106^{\circ} 24^{\prime} 43^{\prime \prime}$ & 7,992 & 34.2 & Nitzschia inconspicua Grunow & 62 & 3,324 \\
\hline 21 & 09065100 & Cross Creek near Minturn & 1 & 2000 & $8 / 16 / 2000$ & $39^{\circ} 34^{\prime} 05^{\prime \prime}$ & $106^{\circ} 24^{\prime} 43^{\prime \prime}$ & 7,992 & 34.2 & Nitzschia palea (Kützing) Smith & 62 & 10,733 \\
\hline 21 & 09065100 & Cross Creek near Minturn & 1 & 2000 & $8 / 16 / 2000$ & $39^{\circ} 34^{\prime} 05^{\prime \prime}$ & $106^{\circ} 24^{\prime} 43^{\prime \prime}$ & 7,992 & 34.2 & Phormidium autumnale (Agardh) Gomont & 104,451 & $10,228,851$ \\
\hline 21 & 09065100 & Cross Creek near Minturn & 1 & 2000 & $8 / 16 / 2000$ & $39^{\circ} 34^{\prime} 05^{\prime \prime}$ & $106^{\circ} 24^{\prime} 43^{\prime \prime}$ & 7,992 & 34.2 & $\begin{array}{l}\text { Psammothidium chlidanos } \\
\text { (Hohn et Hellerman) Lange-Bertalot }\end{array}$ & 62 & 21,533 \\
\hline 21 & 09065100 & Cross Creek near Minturn & 1 & 2000 & $8 / 16 / 2000$ & $39^{\circ} 34^{\prime} 05^{\prime \prime}$ & $106^{\circ} 24^{\prime} 43^{\prime \prime}$ & 7,992 & 34.2 & Psammothidium scoticum (Flower et Jones) & 62 & 92,460 \\
\hline
\end{tabular}


Table 2. Description of sites and algal data collected from selected sites the Eagle River watershed, Colorado, 2000-2001.—Continued

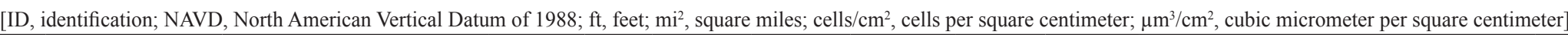

\begin{tabular}{|c|c|c|c|c|c|c|c|c|c|c|c|c|}
\hline $\begin{array}{l}\text { Site } \\
\text { ID }^{1}\end{array}$ & $\begin{array}{l}\text { USGS } \\
\text { station } \\
\text { number }\end{array}$ & Station name & $\begin{array}{c}\text { Replicate } \\
\text { sample } \\
\text { number }\end{array}$ & Year & $\begin{array}{l}\text { Collection } \\
\text { date }\end{array}$ & Latitude & Longitude & $\begin{array}{c}\text { Elevation } \\
\text { NAVD } 88 \\
\text { (ft) }\end{array}$ & $\begin{array}{c}\text { Drainage } \\
\text { area } \\
\left(\mathrm{mi}^{2}\right)\end{array}$ & Algal taxon name & $\begin{array}{c}\text { Total } \\
\text { density } \\
\text { (number of } \\
\text { cells/cm²) }\end{array}$ & $\begin{array}{c}\text { Total } \\
\text { biovolume } \\
\left(\mu^{3} / \mathrm{cm}^{2}\right)\end{array}$ \\
\hline 21 & 09065100 & Cross Creek near Minturn & 1 & 2000 & $8 / 16 / 2000$ & $39^{\circ} 34^{\prime} 05^{\prime \prime}$ & $106^{\circ} 24^{\prime} 43^{\prime \prime}$ & 7,992 & 34.2 & $\begin{array}{l}\text { Psammothidium subatomoides (Hustedt) } \\
\text { Bukhtiyarova et Round }\end{array}$ & 62 & 92,460 \\
\hline 21 & 09065100 & Cross Creek near Minturn & 1 & 2000 & $8 / 16 / 2000$ & $39^{\circ} 34^{\prime} 05^{\prime \prime}$ & $106^{\circ} 24^{\prime} 43^{\prime \prime}$ & 7,992 & 34.2 & $\begin{array}{l}\text { Pseudostaurosira brevistriata var. inflata } \\
\text { (Pantocsek) Edlund }\end{array}$ & 31 & 3,862 \\
\hline 21 & 09065100 & Cross Creek near Minturn & 1 & 2000 & $8 / 16 / 2000$ & $39^{\circ} 34^{\prime} 05^{\prime \prime}$ & $106^{\circ} 24^{\prime} 43^{\prime \prime}$ & 7,992 & 34.2 & $\begin{array}{l}\text { Reimeria sinuata (Gregory) } \\
\text { Kociolek et Stoermer }\end{array}$ & 341 & 56,318 \\
\hline 21 & 09065100 & Cross Creek near Minturn & 1 & 2000 & $8 / 16 / 2000$ & $39^{\circ} 34^{\prime} 05^{\prime \prime}$ & $106^{\circ} 24^{\prime} 43^{\prime \prime}$ & 7,992 & 34.2 & $\begin{array}{l}\text { Rossithidium petersennii (Hustedt) } \\
\text { Round et Bukhtiyarova }\end{array}$ & 31 & 8,643 \\
\hline 21 & 09065100 & Cross Creek near Minturn & 1 & 2000 & $8 / 16 / 2000$ & $39^{\circ} 34^{\prime} 05^{\prime \prime}$ & $106^{\circ} 24^{\prime} 43^{\prime \prime}$ & 7,992 & 34.2 & $\begin{array}{l}\text { Stauroforma exiguiformis (Lange-Bertalot) } \\
\text { Flower, Jones et Round }\end{array}$ & 31 & 1,700 \\
\hline 21 & 09065100 & Cross Creek near Minturn & 1 & 2000 & $8 / 16 / 2000$ & $39^{\circ} 34^{\prime} 05^{\prime \prime}$ & $106^{\circ} 24^{\prime} 43^{\prime \prime}$ & 7,992 & 34.2 & $\begin{array}{l}\text { Staurosira construens var. venter (Ehrenberg) } \\
\text { Hamilton }\end{array}$ & 1,548 & 185,950 \\
\hline 21 & 09065100 & Cross Creek near Minturn & 1 & 2000 & $8 / 16 / 2000$ & $39^{\circ} 34^{\prime} 05^{\prime \prime}$ & $106^{\circ} 24^{\prime} 43^{\prime \prime}$ & 7,992 & 34.2 & Staurosirella oldenburgiana (Hustedt) Morales & 31 & 26,537 \\
\hline 21 & 09065100 & Cross Creek near Minturn & 1 & 2000 & $8 / 16 / 2000$ & $39^{\circ} 34^{\prime} 05^{\prime \prime}$ & $106^{\circ} 24^{\prime} 43^{\prime \prime}$ & 7,992 & 34.2 & $\begin{array}{l}\text { Staurosirella pinnata (Ehrenberg) } \\
\text { Williams et Round }\end{array}$ & 31 & 2,981 \\
\hline 21 & 09065100 & Cross Creek near Minturn & 1 & 2000 & $8 / 16 / 2000$ & $39^{\circ} 34^{\prime} 05^{\prime \prime}$ & $106^{\circ} 24^{\prime} 43^{\prime \prime}$ & 7,992 & 34.2 & Synedra ulna (Nitzsch) Ehrenberg & 62 & 406,045 \\
\hline 21 & 09065100 & Cross Creek near Minturn & 1 & 2000 & $8 / 16 / 2000$ & $39^{\circ} 34^{\prime} 05^{\prime \prime}$ & $106^{\circ} 24^{\prime} 43^{\prime \prime}$ & 7,992 & 34.2 & Synedra ulna var. contracta Østrup & 31 & 49,226 \\
\hline 21 & 09065100 & Cross Creek near Minturn & 1 & 2000 & $8 / 16 / 2000$ & $39^{\circ} 34^{\prime} 05^{\prime \prime}$ & $106^{\circ} 24^{\prime} 43^{\prime \prime}$ & 7,992 & 34.2 & $\begin{array}{l}\text { Unknown Rhodophyte Florideophycidae } \\
\text { (chantransia) }\end{array}$ & 29,088 & $102,946,676$ \\
\hline 25 & 393627106264000 & $\begin{array}{l}\text { Eagle River above Gore Creek } \\
\text { near Minturn }\end{array}$ & 1 & 2000 & $8 / 16 / 2000$ & $39^{\circ} 36^{\prime} 27^{\prime \prime}$ & $106^{\circ} 26^{\prime} 40^{\prime \prime}$ & 7,730 & 260 & $\begin{array}{l}\text { Achnanthidium minutissimum (Kützing) } \\
\text { Czarnecki }\end{array}$ & 149,507 & $8,233,649$ \\
\hline 25 & 393627106264000 & $\begin{array}{l}\text { Eagle River above Gore Creek } \\
\text { near Minturn }\end{array}$ & 1 & 2000 & $8 / 16 / 2000$ & $39^{\circ} 36^{\prime} 27^{\prime \prime}$ & $106^{\circ} 26^{\prime} 40^{\prime \prime}$ & 7,730 & 260 & $\begin{array}{l}\text { Achnanthidium pyrenaicum (Hustedt) } \\
\text { Kobayasi }\end{array}$ & 43,846 & $5,516,230$ \\
\hline 25 & 393627106264000 & $\begin{array}{l}\text { Eagle River above Gore Creek } \\
\text { near Minturn }\end{array}$ & 1 & 2000 & $8 / 16 / 2000$ & $39^{\circ} 36^{\prime} 27^{\prime \prime}$ & $106^{\circ} 26^{\prime} 40^{\prime \prime}$ & 7,730 & 260 & Brachysira microcephala (Grunow) Compère & 3,594 & 717,946 \\
\hline 25 & 393627106264000 & $\begin{array}{l}\text { Eagle River above Gore Creek } \\
\text { near Minturn }\end{array}$ & 1 & 2000 & $8 / 16 / 2000$ & $39^{\circ} 36^{\prime} 27^{\prime \prime}$ & $106^{\circ} 26^{\prime} 40^{\prime \prime}$ & 7,730 & 260 & Chlamydomonas sp. & 1,121 & 95,326 \\
\hline 25 & 393627106264000 & $\begin{array}{l}\text { Eagle River above Gore Creek } \\
\text { near Minturn }\end{array}$ & 1 & 2000 & $8 / 16 / 2000$ & $39^{\circ} 36^{\prime 2} 27^{\prime \prime}$ & $106^{\circ} 26^{\prime} 40^{\prime \prime}$ & 7,730 & 260 & $\begin{array}{l}\text { Cymbella naviculiformis } \\
\text { Auerswald ex Héribaud }\end{array}$ & 719 & $1,332,628$ \\
\hline 25 & 393627106264000 & $\begin{array}{l}\text { Eagle River above Gore Creek } \\
\text { near Minturn }\end{array}$ & 1 & 2000 & $8 / 16 / 2000$ & $39^{\circ} 36^{\prime} 27^{\prime \prime}$ & $106^{\circ} 26^{\prime} 40^{\prime \prime}$ & 7,730 & 260 & Denticula tenuis Kützing & 359 & 136,659 \\
\hline 25 & 393627106264000 & $\begin{array}{l}\text { Eagle River above Gore Creek } \\
\text { near Minturn }\end{array}$ & 1 & 2000 & $8 / 16 / 2000$ & $39^{\circ} 36^{\prime 2} 27^{\prime \prime}$ & $106^{\circ} 26^{\prime} 40^{\prime \prime}$ & 7,730 & 260 & Diatoma moniliformis Kützing & 359 & 54,166 \\
\hline 25 & 393627106264000 & $\begin{array}{l}\text { Eagle River above Gore Creek } \\
\text { near Minturn }\end{array}$ & 1 & 2000 & $8 / 16 / 2000$ & $39^{\circ} 36^{\prime} 27^{\prime \prime}$ & $106^{\circ} 26^{\prime} 40^{\prime \prime}$ & 7,730 & 260 & Encyonema minutum (Hilse) Mann & 719 & 153,808 \\
\hline 25 & 393627106264000 & $\begin{array}{l}\text { Eagle River above Gore Creek } \\
\text { near Minturn }\end{array}$ & 1 & 2000 & $8 / 16 / 2000$ & $39^{\circ} 36^{\prime} 27^{\prime \prime}$ & $106^{\circ} 26^{\prime} 40^{\prime \prime}$ & 7,730 & 260 & Encyonema silesiacum (Bleisch) Mann & 26,236 & $12,353,095$ \\
\hline 25 & 393627106264000 & $\begin{array}{l}\text { Eagle River above Gore Creek } \\
\text { near Minturn }\end{array}$ & 1 & 2000 & $8 / 16 / 2000$ & $39^{\circ} 36^{\prime 2} 27^{\prime \prime}$ & $106^{\circ} 26^{\prime} 40^{\prime \prime}$ & 7,730 & 260 & $\begin{array}{l}\text { Fragilaria capucina var. fragilarioides } \\
\text { (Grunow) Ludwig et Flores }\end{array}$ & 8,625 & 883,746 \\
\hline 25 & 393627106264000 & $\begin{array}{l}\text { Eagle River above Gore Creek } \\
\text { near Minturn }\end{array}$ & 1 & 2000 & $8 / 16 / 2000$ & $39^{\circ} 36^{\prime} 27^{\prime \prime}$ & $106^{\circ} 26^{\prime} 40^{\prime \prime}$ & 7,730 & 260 & Fragilaria vaucheriae (Kützing) Petersen & 18,329 & $3,791,572$ \\
\hline 25 & 393627106264000 & $\begin{array}{l}\text { Eagle River above Gore Creek } \\
\text { near Minturn }\end{array}$ & 1 & 2000 & $8 / 16 / 2000$ & $39^{\circ} 36^{\prime} 27^{\prime \prime}$ & $106^{\circ} 26^{\prime} 40^{\prime \prime}$ & 7,730 & 260 & Gomphonema olivaceoides Hustedt & 7,188 & $1,099,571$ \\
\hline 25 & 393627106264000 & $\begin{array}{l}\text { Eagle River above Gore Creek } \\
\text { near Minturn }\end{array}$ & 1 & 2000 & $8 / 16 / 2000$ & $39^{\circ} 36^{\prime} 27^{\prime \prime}$ & $106^{\circ} 26^{\prime} 40^{\prime \prime}$ & 7,730 & 260 & $\begin{array}{l}\text { Gomphonema pumilum (Grunow) } \\
\text { Reichardt et Lange-Bertalot }\end{array}$ & 1,438 & 419,457 \\
\hline 25 & 393627106264000 & $\begin{array}{l}\text { Eagle River above Gore Creek } \\
\text { near Minturn }\end{array}$ & 1 & 2000 & $8 / 16 / 2000$ & $39^{\circ} 36^{\prime} 27^{\prime \prime}$ & $106^{\circ} 26^{\prime} 40^{\prime \prime}$ & 7,730 & 260 & Hannaea arcus (Ehrenberg) Patrick & 719 & $1,745,310$ \\
\hline
\end{tabular}


Table 2. Description of sites and algal data collected from selected sites the Eagle River watershed, Colorado, 2000-2001.—Continued

[ID, identification; NAVD, North American Vertical Datum of 1988; ft, feet; $\mathrm{mi}^{2}$, square miles; cells $/ \mathrm{cm}^{2}$, cells per square centimeter; $\mu \mathrm{m}^{3} / \mathrm{cm}^{2}$, cubic micrometer per square centimeter]

\begin{tabular}{|c|c|c|c|c|c|c|c|c|c|c|c|c|}
\hline $\begin{array}{l}\text { Site } \\
\text { ID }^{1}\end{array}$ & $\begin{array}{l}\text { USGS } \\
\text { station } \\
\text { number }\end{array}$ & Station name & $\begin{array}{l}\text { Replicate } \\
\text { sample } \\
\text { number }\end{array}$ & Year & $\begin{array}{l}\text { Collection } \\
\text { date }\end{array}$ & Latitude & Longitude & $\begin{array}{c}\text { Elevation } \\
\text { NAVD } 88 \\
\text { (ft) }\end{array}$ & $\begin{array}{c}\text { Drainage } \\
\text { area } \\
\left(\mathrm{mi}^{2}\right)\end{array}$ & Algal taxon name & $\begin{array}{c}\text { Total } \\
\text { density } \\
\text { (number of } \\
\text { cells/cm²) }\end{array}$ & $\begin{array}{c}\text { Total } \\
\text { biovolume } \\
\left(\mu \mathrm{m}^{3} / \mathrm{cm}^{2}\right)\end{array}$ \\
\hline 25 & 393627106264000 & $\begin{array}{l}\text { Eagle River above Gore Creek } \\
\text { near Minturn }\end{array}$ & 1 & 2000 & $8 / 16 / 2000$ & $39^{\circ} 36^{\prime} 27^{\prime \prime}$ & $106^{\circ} 26^{\prime} 40^{\prime \prime}$ & 7,730 & 260 & $\begin{array}{l}\text { Homoeothrix janthina (Bornet et Flahault) } \\
\text { Starmach }\end{array}$ & 700,924 & $22,715,776$ \\
\hline 25 & 393627106264000 & $\begin{array}{l}\text { Eagle River above Gore Creek } \\
\text { near Minturn }\end{array}$ & 1 & 2000 & $8 / 16 / 2000$ & $39^{\circ} 36^{\prime} 27^{\prime \prime}$ & $106^{\circ} 26^{\prime} 40^{\prime \prime}$ & 7,730 & 260 & Navicula minima Grunow & 1,078 & 57,263 \\
\hline 25 & 393627106264000 & $\begin{array}{l}\text { Eagle River above Gore Creek } \\
\text { near Minturn }\end{array}$ & 1 & 2000 & $8 / 16 / 2000$ & $39^{\circ} 36^{\prime} 27^{\prime \prime}$ & $106^{\circ} 26^{\prime} 40^{\prime \prime}$ & 7,730 & 260 & Nitzschia inconspicua Grunow & 2,516 & 135,013 \\
\hline 25 & 393627106264000 & $\begin{array}{l}\text { Eagle River above Gore Creek } \\
\text { near Minturn }\end{array}$ & 1 & 2000 & $8 / 16 / 2000$ & $39^{\circ} 36^{\prime} 27^{\prime \prime}$ & $106^{\circ} 26^{\prime} 40^{\prime \prime}$ & 7,730 & 260 & Nitzschia palea (Kützing) Smith & 719 & 124,574 \\
\hline 25 & 393627106264000 & $\begin{array}{l}\text { Eagle River above Gore Creek } \\
\text { near Minturn }\end{array}$ & 1 & 2000 & $8 / 16 / 2000$ & $39^{\circ} 36^{\prime} 27^{\prime \prime}$ & $106^{\circ} 26^{\prime} 40^{\prime \prime}$ & 7,730 & 260 & Phormidium autumnale (Agardh) Gomont & 98,690 & $9,664,641$ \\
\hline 25 & 393627106264000 & $\begin{array}{l}\text { Eagle River above Gore Creek } \\
\text { near Minturn }\end{array}$ & 1 & 2000 & $8 / 16 / 2000$ & $39^{\circ} 36^{\prime} 27^{\prime \prime}$ & $106^{\circ} 26^{\prime} 40^{\prime \prime}$ & 7,730 & 260 & $\begin{array}{l}\text { Reimeria sinuata (Gregory) } \\
\text { Kociolek et Stoermer }\end{array}$ & 2,516 & 415,962 \\
\hline 25 & 393627106264000 & $\begin{array}{l}\text { Eagle River above Gore Creek } \\
\text { near Minturn }\end{array}$ & 1 & 2000 & $8 / 16 / 2000$ & $39^{\circ} 36^{\prime} 27^{\prime \prime}$ & $106^{\circ} 26^{\prime} 40^{\prime \prime}$ & 7,730 & 260 & Synedra ulna (Nitzsch) Ehrenberg & 9,704 & $63,622,501$ \\
\hline 25 & 393627106264000 & $\begin{array}{l}\text { Eagle River above Gore Creek } \\
\text { near Minturn }\end{array}$ & 1 & 2000 & $8 / 16 / 2000$ & $39^{\circ} 36^{\prime} 27^{\prime \prime}$ & $106^{\circ} 26^{\prime} 40^{\prime \prime}$ & 7,730 & 260 & Synedra ulna var. contracta Østrup & 1,078 & $1,714,026$ \\
\hline 25 & 393627106264000 & $\begin{array}{l}\text { Eagle River above Gore Creek } \\
\text { near Minturn }\end{array}$ & 1 & 2000 & $8 / 16 / 2000$ & $39^{\circ} 36^{\prime} 27^{\prime \prime}$ & $106^{\circ} 26^{\prime} 40^{\prime \prime}$ & 7,730 & 260 & $\begin{array}{l}\text { Unknown Rhodophyte Florideophycidae } \\
\text { (chantransia) }\end{array}$ & 217,567 & $770,006,963$ \\
\hline 29 & 09065500 & $\begin{array}{l}\text { Gore Creek at Upper Station } \\
\text { near Minturn }\end{array}$ & 1 & 2000 & $8 / 18 / 2000$ & $39^{\circ} 37^{\prime} 33^{\prime \prime}$ & $106^{\circ} 16^{\prime} 39^{\prime \prime}$ & 8,600 & 14.4 & $\begin{array}{l}\text { Achnanthidium minutissimum (Kützing) } \\
\text { Czarnecki }\end{array}$ & 35,309 & $1,944,538$ \\
\hline 29 & 09065500 & $\begin{array}{l}\text { Gore Creek at Upper Station } \\
\text { near Minturn }\end{array}$ & 1 & 2000 & $8 / 18 / 2000$ & $39^{\circ} 37^{\prime} 33^{\prime \prime}$ & $106^{\circ} 16^{\prime} 39^{\prime \prime}$ & 8,600 & 14.4 & $\begin{array}{l}\text { Achnanthidium pyrenaicum (Hustedt) } \\
\text { Kobayasi }\end{array}$ & 2,269 & 285,511 \\
\hline 29 & 09065500 & $\begin{array}{l}\text { Gore Creek at Upper Station } \\
\text { near Minturn }\end{array}$ & 1 & 2000 & $8 / 18 / 2000$ & $39^{\circ} 37^{\prime} 33^{\prime \prime}$ & $106^{\circ} 16^{\prime} 39^{\prime \prime}$ & 8,600 & 14.4 & $\begin{array}{l}\text { Cocconeis placentula var. lineata (Ehrenberg) } \\
\text { Van Heurck }\end{array}$ & 334 & 349,671 \\
\hline 29 & 09065500 & $\begin{array}{l}\text { Gore Creek at Upper Station } \\
\text { near Minturn }\end{array}$ & 1 & 2000 & $8 / 18 / 2000$ & $39^{\circ} 37^{\prime} 33^{\prime \prime}$ & $106^{\circ} 16^{\prime} 39^{\prime \prime}$ & 8,600 & 14.4 & Cymbella cistula (Ehrenberg) Kirchner & 67 & 80,644 \\
\hline 29 & 09065500 & $\begin{array}{l}\text { Gore Creek at Upper Station } \\
\text { near Minturn }\end{array}$ & 1 & 2000 & $8 / 18 / 2000$ & $39^{\circ} 37^{\prime} 33^{\prime \prime}$ & $106^{\circ} 16^{\prime} 39^{\prime \prime}$ & 8,600 & 14.4 & Diatoma mesodon (Ehrenberg) Kützing & 67 & 71,074 \\
\hline 29 & 09065500 & $\begin{array}{l}\text { Gore Creek at Upper Station } \\
\text { near Minturn }\end{array}$ & 1 & 2000 & $8 / 18 / 2000$ & $39^{\circ} 37^{\prime} 33^{\prime \prime}$ & $106^{\circ} 16^{\prime} 39^{\prime \prime}$ & 8,600 & 14.4 & Encyonema brehmii (Hustedt) Mann & 200 & 5,521 \\
\hline 29 & 09065500 & $\begin{array}{l}\text { Gore Creek at Upper Station } \\
\text { near Minturn }\end{array}$ & 1 & 2000 & $8 / 18 / 2000$ & $39^{\circ} 37^{\prime} 33^{\prime \prime}$ & $106^{\circ} 16^{\prime} 39^{\prime \prime}$ & 8,600 & 14.4 & Encyonema minutum (Hilse) Mann & 67 & 123,749 \\
\hline 29 & 09065500 & $\begin{array}{l}\text { Gore Creek at Upper Station } \\
\text { near Minturn }\end{array}$ & 1 & 2000 & $8 / 18 / 2000$ & $39^{\circ} 37^{\prime} 33^{\prime \prime}$ & $106^{\circ} 16^{\prime} 39^{\prime \prime}$ & 8,600 & 14.4 & Encyonema silesiacum (Bleisch) Mann & 400 & 188,567 \\
\hline 29 & 09065500 & $\begin{array}{l}\text { Gore Creek at Upper Station } \\
\text { near Minturn }\end{array}$ & 1 & 2000 & $8 / 18 / 2000$ & $39^{\circ} 37^{\prime} 33^{\prime \prime}$ & $106^{\circ} 16^{\prime} 39^{\prime \prime}$ & 8,600 & 14.4 & $\begin{array}{l}\text { Fragilaria capucina var. fragilarioides } \\
\text { (Grunow) Ludwig et Flores }\end{array}$ & 267 & 27,355 \\
\hline 29 & 09065500 & $\begin{array}{l}\text { Gore Creek at Upper Station } \\
\text { near Minturn }\end{array}$ & 1 & 2000 & $8 / 18 / 2000$ & $39^{\circ} 37^{\prime} 33^{\prime \prime}$ & $106^{\circ} 16^{\prime} 39^{\prime \prime}$ & 8,600 & 14.4 & Fragilaria vaucheriae (Kützing) Petersen & 2,403 & 497,065 \\
\hline 29 & 09065500 & $\begin{array}{l}\text { Gore Creek at Upper Station } \\
\text { near Minturn }\end{array}$ & 1 & 2000 & $8 / 18 / 2000$ & $39^{\circ} 37^{\prime} 33^{\prime \prime}$ & $106^{\circ} 16^{\prime} 39^{\prime \prime}$ & 8,600 & 14.4 & $\begin{array}{l}\text { Gomphonema angustatum (Kützing) } \\
\text { Rabenhorst }\end{array}$ & 67 & 27,595 \\
\hline 29 & 09065500 & $\begin{array}{l}\text { Gore Creek at Upper Station } \\
\text { near Minturn }\end{array}$ & 1 & 2000 & $8 / 18 / 2000$ & $39^{\circ} 37^{\prime} 33^{\prime \prime}$ & $106^{\circ} 16^{\prime} 39^{\prime \prime}$ & 8,600 & 14.4 & Gomphonema olivaceoides Hustedt & 4,339 & 663,695 \\
\hline 29 & 09065500 & $\begin{array}{l}\text { Gore Creek at Upper Station } \\
\text { near Minturn }\end{array}$ & 1 & 2000 & $8 / 18 / 2000$ & $39^{\circ} 37^{\prime} 33^{\prime \prime}$ & $106^{\circ} 16^{\prime} 39^{\prime \prime}$ & 8,600 & 14.4 & $\begin{array}{l}\text { Gomphonema pumilum (Grunow) } \\
\text { Reichardt et Lange-Bertalot }\end{array}$ & 1,802 & 525,839 \\
\hline 29 & 09065500 & $\begin{array}{l}\text { Gore Creek at Upper Station } \\
\text { near Minturn }\end{array}$ & 1 & 2000 & $8 / 18 / 2000$ & $39^{\circ} 37^{\prime} 33^{\prime \prime}$ & $106^{\circ} 16^{\prime} 39^{\prime \prime}$ & 8,600 & 14.4 & Hannaea arcus (Ehrenberg) Patrick & 801 & $1,944,847$ \\
\hline
\end{tabular}


Table 2. Description of sites and algal data collected from selected sites the Eagle River watershed, Colorado, 2000-2001.—Continued

[ID, identification; NAVD, North American Vertical Datum of 1988; ft, feet; $\mathrm{mi}^{2}$, square miles; cells $/ \mathrm{cm}^{2}$, cells per square centimeter; $\mu \mathrm{m}^{3} / \mathrm{cm}^{2}$, cubic micrometer per square centimeter]

\begin{tabular}{|c|c|c|c|c|c|c|c|c|c|c|c|c|}
\hline $\begin{array}{l}\text { Site } \\
\text { ID }^{1}\end{array}$ & $\begin{array}{l}\text { USGS } \\
\text { station } \\
\text { number }\end{array}$ & Station name & $\begin{array}{c}\text { Replicate } \\
\text { sample } \\
\text { number }\end{array}$ & Year & $\begin{array}{l}\text { Collection } \\
\text { date }\end{array}$ & Latitude & Longitude & $\begin{array}{c}\text { Elevation } \\
\text { NAVD } 88 \\
\text { (ft) }\end{array}$ & $\begin{array}{c}\text { Drainage } \\
\text { area } \\
\left(\mathrm{mi}^{2}\right)\end{array}$ & Algal taxon name & $\begin{array}{c}\text { Total } \\
\text { density } \\
\text { (number of } \\
\text { cells } / \mathrm{cm}^{2} \text { ) }\end{array}$ & $\begin{array}{c}\text { Total } \\
\text { biovolume } \\
\left(\mu \mathbf{m}^{3} / \mathrm{cm}^{2}\right)\end{array}$ \\
\hline 29 & 09065500 & $\begin{array}{l}\text { Gore Creek at Upper Station } \\
\text { near Minturn }\end{array}$ & 1 & 2000 & $8 / 18 / 2000$ & $39^{\circ} 37^{\prime} 33^{\prime \prime}$ & $106^{\circ} 16^{\prime} 39^{\prime \prime}$ & 8,600 & 14.4 & $\begin{array}{l}\text { Homoeothrix janthina (Bornet et Flahault) } \\
\text { Starmach }\end{array}$ & 231,888 & $7,515,109$ \\
\hline 29 & 09065500 & $\begin{array}{l}\text { Gore Creek at Upper Station } \\
\text { near Minturn }\end{array}$ & 1 & 2000 & $8 / 18 / 2000$ & $39^{\circ} 37^{\prime} 33^{\prime \prime}$ & $106^{\circ} 16^{\prime} 39^{\prime \prime}$ & 8,600 & 14.4 & Phormidium autumnale (Agardh) Gomont & 69,422 & $6,798,423$ \\
\hline 29 & 09065500 & $\begin{array}{l}\text { Gore Creek at Upper Station } \\
\text { near Minturn }\end{array}$ & 1 & 2000 & $8 / 18 / 2000$ & $39^{\circ} 37^{\prime} 33^{\prime \prime}$ & $106^{\circ} 16^{\prime} 39^{\prime \prime}$ & 8,600 & 14.4 & $\begin{array}{l}\text { Psammothidium chlidanos } \\
\text { (Hohn et Hellerman) Lange-Bertalot }\end{array}$ & 67 & 23,208 \\
\hline 29 & 09065500 & $\begin{array}{l}\text { Gore Creek at Upper Station } \\
\text { near Minturn }\end{array}$ & 1 & 2000 & $8 / 18 / 2000$ & $39^{\circ} 37^{\prime} 33^{\prime \prime}$ & $106^{\circ} 16^{\prime} 39^{\prime \prime}$ & 8,600 & 14.4 & $\begin{array}{l}\text { Reimeria sinuata (Gregory) } \\
\text { Kociolek et Stoermer }\end{array}$ & 1,068 & 176,578 \\
\hline 29 & 09065500 & $\begin{array}{l}\text { Gore Creek at Upper Station } \\
\text { near Minturn }\end{array}$ & 1 & 2000 & $8 / 18 / 2000$ & $39^{\circ} 37^{\prime} 33^{\prime \prime}$ & $106^{\circ} 16^{\prime} 39^{\prime \prime}$ & 8,600 & 14.4 & $\begin{array}{l}\text { Staurosirella pinnata (Ehrenberg) } \\
\text { Williams et Round }\end{array}$ & 67 & 6,426 \\
\hline 29 & 09065500 & $\begin{array}{l}\text { Gore Creek at Upper Station } \\
\text { near Minturn }\end{array}$ & 1 & 2000 & $8 / 18 / 2000$ & $39^{\circ} 37^{\prime} 33^{\prime \prime}$ & $106^{\circ} 16^{\prime} 39^{\prime \prime}$ & 8,600 & 14.4 & Stigeoclonium lubricum (Dillwyn) Kützing & 5,785 & $8,586,771$ \\
\hline 29 & 09065500 & $\begin{array}{l}\text { Gore Creek at Upper Station } \\
\text { near Minturn }\end{array}$ & 1 & 2000 & $8 / 18 / 2000$ & $39^{\circ} 37^{\prime} 33^{\prime \prime}$ & $106^{\circ} 16^{\prime} 39^{\prime \prime}$ & 8,600 & 14.4 & Synedra mazamaensis Sovereign & 200 & 37,424 \\
\hline 29 & 09065500 & $\begin{array}{l}\text { Gore Creek at Upper Station } \\
\text { near Minturn }\end{array}$ & 1 & 2000 & $8 / 18 / 2000$ & $39^{\circ} 37^{\prime} 33^{\prime \prime}$ & $106^{\circ} 16^{\prime} 39^{\prime \prime}$ & 8,600 & 14.4 & Synedra ulna (Nitzsch) Ehrenberg & 1,068 & $7,002,107$ \\
\hline 29 & 09065500 & $\begin{array}{l}\text { Gore Creek at Upper Station } \\
\text { near Minturn }\end{array}$ & 1 & 2000 & $8 / 18 / 2000$ & $39^{\circ} 37^{\prime} 33^{\prime \prime}$ & $106^{\circ} 16^{\prime} 39^{\prime \prime}$ & 8,600 & 14.4 & $\begin{array}{l}\text { Unknown Rhodophyte Florideophycidae } \\
\text { (chantransia) }\end{array}$ & 3,857 & $13,649,777$ \\
\hline 29 & 09065500 & $\begin{array}{l}\text { Gore Creek at Upper Station } \\
\text { near Minturn }\end{array}$ & 2 & 2000 & $8 / 18 / 2000$ & $39^{\circ} 37^{\prime} 33^{\prime \prime}$ & $106^{\circ} 16^{\prime} 39^{\prime \prime}$ & 8,600 & 14.4 & $\begin{array}{l}\text { Achnanthidium minutissimum (Kützing) } \\
\text { Czarnecki }\end{array}$ & 16,873 & 929,223 \\
\hline 29 & 09065500 & $\begin{array}{l}\text { Gore Creek at Upper Station } \\
\text { near Minturn }\end{array}$ & 2 & 2000 & $8 / 18 / 2000$ & $39^{\circ} 37^{\prime} 33^{\prime \prime}$ & $106^{\circ} 16^{\prime} 39^{\prime \prime}$ & 8,600 & 14.4 & $\begin{array}{l}\text { Achnanthidium pyrenaicum (Hustedt) } \\
\text { Kobayasi }\end{array}$ & 646 & 81,229 \\
\hline 29 & 09065500 & $\begin{array}{l}\text { Gore Creek at Upper Station } \\
\text { near Minturn }\end{array}$ & 2 & 2000 & $8 / 18 / 2000$ & $39^{\circ} 37^{\prime} 33^{\prime \prime}$ & $106^{\circ} 16^{\prime} 39^{\prime \prime}$ & 8,600 & 14.4 & Amphora pediculus (Kützing) Grunow & 43 & 4,073 \\
\hline 29 & 09065500 & $\begin{array}{l}\text { Gore Creek at Upper Station } \\
\text { near Minturn }\end{array}$ & 2 & 2000 & $8 / 18 / 2000$ & $39^{\circ} 37^{\prime} 33^{\prime \prime}$ & $106^{\circ} 16^{\prime} 39^{\prime \prime}$ & 8,600 & 14.4 & $\begin{array}{l}\text { Cocconeis placentula var. lineata (Ehrenberg) } \\
\text { Van Heurck }\end{array}$ & 430 & 450,985 \\
\hline 29 & 09065500 & $\begin{array}{l}\text { Gore Creek at Upper Station } \\
\text { near Minturn }\end{array}$ & 2 & 2000 & $8 / 18 / 2000$ & $39^{\circ} 37^{\prime} 33^{\prime \prime}$ & $106^{\circ} 16^{\prime} 39^{\prime \prime}$ & 8,600 & 14.4 & Cosmarium subcrenatum Hantzsch & 201 & 17,083 \\
\hline 29 & 09065500 & $\begin{array}{l}\text { Gore Creek at Upper Station } \\
\text { near Minturn }\end{array}$ & 2 & 2000 & $8 / 18 / 2000$ & $39^{\circ} 37^{\prime} 33^{\prime \prime}$ & $106^{\circ} 16^{\prime} 39^{\prime \prime}$ & 8,600 & 14.4 & Encyonema brehmii (Hustedt) Mann & 1,550 & 42,723 \\
\hline 29 & 09065500 & $\begin{array}{l}\text { Gore Creek at Upper Station } \\
\text { near Minturn }\end{array}$ & 2 & 2000 & $8 / 18 / 2000$ & $39^{\circ} 37^{\prime} 33^{\prime \prime}$ & $106^{\circ} 16^{\prime} 39^{\prime \prime}$ & 8,600 & 14.4 & Encyonema silesiacum (Bleisch) Mann & 430 & 202,669 \\
\hline 29 & 09065500 & $\begin{array}{l}\text { Gore Creek at Upper Station } \\
\text { near Minturn }\end{array}$ & 2 & 2000 & $8 / 18 / 2000$ & $39^{\circ} 37^{\prime} 33^{\prime \prime}$ & $106^{\circ} 16^{\prime} 39^{\prime \prime}$ & 8,600 & 14.4 & Eucocconeis laevis (Østrup) Lange-Bertalot & 86 & 128,527 \\
\hline 29 & 09065500 & $\begin{array}{l}\text { Gore Creek at Upper Station } \\
\text { near Minturn }\end{array}$ & 2 & 2000 & $8 / 18 / 2000$ & $39^{\circ} 37^{\prime} 33^{\prime \prime}$ & $106^{\circ} 16^{\prime} 39^{\prime \prime}$ & 8,600 & 14.4 & $\begin{array}{l}\text { Fragilaria capucina var. fragilarioides } \\
\text { (Grunow) Ludwig et Flores }\end{array}$ & 86 & 8,820 \\
\hline 29 & 09065500 & $\begin{array}{l}\text { Gore Creek at Upper Station } \\
\text { near Minturn }\end{array}$ & 2 & 2000 & $8 / 18 / 2000$ & $39^{\circ} 37^{\prime} 33^{\prime \prime}$ & $106^{\circ} 16^{\prime} 39^{\prime \prime}$ & 8,600 & 14.4 & Fragilaria vaucheriae (Kützing) Petersen & 775 & 160,272 \\
\hline 29 & 09065500 & $\begin{array}{l}\text { Gore Creek at Upper Station } \\
\text { near Minturn }\end{array}$ & 2 & 2000 & $8 / 18 / 2000$ & $39^{\circ} 377^{\prime \prime}$ & $106^{\circ} 16^{\prime} 39^{\prime \prime}$ & 8,600 & 14.4 & $\begin{array}{l}\text { Gomphonema angustatum (Kützing) } \\
\text { Rabenhorst }\end{array}$ & 43 & 17,795 \\
\hline 29 & 09065500 & $\begin{array}{l}\text { Gore Creek at Upper Station } \\
\text { near Minturn }\end{array}$ & 2 & 2000 & $8 / 18 / 2000$ & $39^{\circ} 37^{\prime} 33^{\prime \prime}$ & $106^{\circ} 16^{\prime} 39^{\prime \prime}$ & 8,600 & 14.4 & Gomphonema olivaceoides Hustedt & 3,702 & 566,274 \\
\hline 29 & 09065500 & $\begin{array}{l}\text { Gore Creek at Upper Station } \\
\text { near Minturn }\end{array}$ & 2 & 2000 & $8 / 18 / 2000$ & $39^{\circ} 37^{\prime} 33^{\prime \prime}$ & $106^{\circ} 16^{\prime} 39^{\prime \prime}$ & 8,600 & 14.4 & $\begin{array}{l}\text { Gomphonema pumilum (Grunow) } \\
\text { Reichardt et Lange-Bertalot }\end{array}$ & 344 & 100,474 \\
\hline 29 & 09065500 & $\begin{array}{l}\text { Gore Creek at Upper Station } \\
\text { near Minturn }\end{array}$ & 2 & 2000 & $8 / 18 / 2000$ & $39^{\circ} 37^{\prime} 33^{\prime \prime}$ & $106^{\circ} 16^{\prime} 39^{\prime \prime}$ & 8,600 & 14.4 & Hannaea arcus (Ehrenberg) Patrick & 344 & 836,118 \\
\hline
\end{tabular}


Table 2. Description of sites and algal data collected from selected sites the Eagle River watershed, Colorado, 2000-2001.—Continued

[ID, identification; NAVD, North American Vertical Datum of 1988; ft, feet; $\mathrm{mi}^{2}$, square miles; cells $/ \mathrm{cm}^{2}$, cells per square centimeter; $\mu \mathrm{m}^{3} / \mathrm{cm}^{2}$, cubic micrometer per square centimeter]

\begin{tabular}{|c|c|c|c|c|c|c|c|c|c|c|c|c|}
\hline $\begin{array}{l}\text { Site } \\
\text { ID' }\end{array}$ & $\begin{array}{l}\text { USGS } \\
\text { station } \\
\text { number }\end{array}$ & Station name & $\begin{array}{l}\text { Replicate } \\
\text { sample } \\
\text { number }\end{array}$ & Year & $\begin{array}{l}\text { Collection } \\
\text { date }\end{array}$ & Latitude & Longitude & $\begin{array}{c}\text { Elevation } \\
\text { NAVD } 88 \\
\text { (ft) }\end{array}$ & $\begin{array}{c}\text { Drainage } \\
\text { area } \\
\left(\mathrm{mi}^{2}\right)\end{array}$ & Algal taxon name & $\begin{array}{c}\text { Total } \\
\text { density } \\
\text { (number of } \\
\text { cells/cm²) }\end{array}$ & $\begin{array}{c}\text { Total } \\
\text { biovolume } \\
\left(\mu \mathrm{m}^{3} / \mathrm{cm}^{2}\right)\end{array}$ \\
\hline 29 & 09065500 & $\begin{array}{l}\text { Gore Creek at Upper Station } \\
\text { near Minturn }\end{array}$ & 2 & 2000 & $8 / 18 / 2000$ & $39^{\circ} 37^{\prime} 33^{\prime \prime}$ & $106^{\circ} 16^{\prime} 39^{\prime \prime}$ & 8,600 & 14.4 & $\begin{array}{l}\text { Homoeothrix janthina (Bornet et Flahault) } \\
\text { Starmach }\end{array}$ & 500,820 & $16,230,753$ \\
\hline 29 & 09065500 & $\begin{array}{l}\text { Gore Creek at Upper Station } \\
\text { near Minturn }\end{array}$ & 2 & 2000 & $8 / 18 / 2000$ & $39^{\circ} 37^{\prime} 33^{\prime \prime}$ & $106^{\circ} 16^{\prime} 39^{\prime \prime}$ & 8,600 & 14.4 & Navicula schmassmanni Hustedt & 86 & 645,733 \\
\hline 29 & 09065500 & $\begin{array}{l}\text { Gore Creek at Upper Station } \\
\text { near Minturn }\end{array}$ & 2 & 2000 & $8 / 18 / 2000$ & $39^{\circ} 37^{\prime} 33^{\prime \prime}$ & $106^{\circ} 16^{\prime} 39^{\prime \prime}$ & 8,600 & 14.4 & Phormidium autumnale (Agardh) Gomont & 43,611 & $4,270,767$ \\
\hline 29 & 09065500 & $\begin{array}{l}\text { Gore Creek at Upper Station } \\
\text { near Minturn }\end{array}$ & 2 & 2000 & $8 / 18 / 2000$ & $39^{\circ} 37^{\prime} 33^{\prime \prime}$ & $106^{\circ} 16^{\prime} 39^{\prime \prime}$ & 8,600 & 14.4 & $\begin{array}{l}\text { Reimeria sinuata (Gregory) } \\
\text { Kociolek et Stoermer }\end{array}$ & 1,851 & 306,026 \\
\hline 29 & 09065500 & $\begin{array}{l}\text { Gore Creek at Upper Station } \\
\text { near Minturn }\end{array}$ & 2 & 2000 & $8 / 18 / 2000$ & $39^{\circ} 37^{\prime} 33^{\prime \prime}$ & $106^{\circ} 16^{\prime} 39^{\prime \prime}$ & 8,600 & 14.4 & $\begin{array}{l}\text { Staurosira construens var. venter (Ehrenberg) } \\
\text { Hamilton }\end{array}$ & 258 & 31,018 \\
\hline 29 & 09065500 & $\begin{array}{l}\text { Gore Creek at Upper Station } \\
\text { near Minturn }\end{array}$ & 2 & 2000 & $8 / 18 / 2000$ & $39^{\circ} 37^{\prime} 33^{\prime \prime}$ & $106^{\circ} 16^{\prime} 39^{\prime \prime}$ & 8,600 & 14.4 & Stigeoclonium lubricum (Dillwyn) Kützing & 4,019 & $5,965,943$ \\
\hline 29 & 09065500 & $\begin{array}{l}\text { Gore Creek at Upper Station } \\
\text { near Minturn }\end{array}$ & 2 & 2000 & $8 / 18 / 2000$ & $39^{\circ} 37^{\prime} 33^{\prime \prime}$ & $106^{\circ} 16^{\prime} 39^{\prime \prime}$ & 8,600 & 14.4 & Synedra mazamaensis Sovereign & 43 & 8,044 \\
\hline 29 & 09065500 & $\begin{array}{l}\text { Gore Creek at Upper Station } \\
\text { near Minturn }\end{array}$ & 2 & 2000 & $8 / 18 / 2000$ & $39^{\circ} 37^{\prime} 33^{\prime \prime}$ & $106^{\circ} 16^{\prime} 39^{\prime \prime}$ & 8,600 & 14.4 & Synedra ulna (Nitzsch) Ehrenberg & 344 & $2,257,729$ \\
\hline 29 & 09065500 & $\begin{array}{l}\text { Gore Creek at Upper Station } \\
\text { near Minturn }\end{array}$ & 2 & 2000 & $8 / 18 / 2000$ & $39^{\circ} 37^{\prime} 33^{\prime \prime}$ & $106^{\circ} 16^{\prime} 39^{\prime \prime}$ & 8,600 & 14.4 & Ulothrix sp. & 1,407 & 119,578 \\
\hline 29 & 09065500 & $\begin{array}{l}\text { Gore Creek at Upper Station } \\
\text { near Minturn }\end{array}$ & 2 & 2000 & $8 / 18 / 2000$ & $39^{\circ} 37^{\prime} 33^{\prime \prime}$ & $106^{\circ} 16^{\prime} 39^{\prime \prime}$ & 8,600 & 14.4 & $\begin{array}{l}\text { Unknown Rhodophyte Florideophycidae } \\
\text { (chantransia) }\end{array}$ & 2,010 & $7,112,725$ \\
\hline 29 & 09065500 & $\begin{array}{l}\text { Gore Creek at Upper Station } \\
\text { near Minturn }\end{array}$ & 3 & 2000 & $8 / 18 / 2000$ & $39^{\circ} 37^{\prime} 33^{\prime \prime}$ & $106^{\circ} 16^{\prime} 39^{\prime \prime}$ & 8,600 & 14.4 & $\begin{array}{l}\text { Achnanthidium minutissimum (Kützing) } \\
\text { Czarnecki }\end{array}$ & 18,588 & $1,023,695$ \\
\hline 29 & 09065500 & $\begin{array}{l}\text { Gore Creek at Upper Station } \\
\text { near Minturn }\end{array}$ & 3 & 2000 & $8 / 18 / 2000$ & $39^{\circ} 37^{\prime} 33^{\prime \prime}$ & $106^{\circ} 16^{\prime} 39^{\prime \prime}$ & 8,600 & 14.4 & $\begin{array}{l}\text { Achnanthidium pyrenaicum (Hustedt) } \\
\text { Kobayasi }\end{array}$ & 669 & 84,189 \\
\hline 29 & 09065500 & $\begin{array}{l}\text { Gore Creek at Upper Station } \\
\text { near Minturn }\end{array}$ & 3 & 2000 & $8 / 18 / 2000$ & $39^{\circ} 37^{\prime} 33^{\prime \prime}$ & $106^{\circ} 16^{\prime} 39^{\prime \prime}$ & 8,600 & 14.4 & $\begin{array}{l}\text { Cocconeis placentula var. lineata (Ehrenberg) } \\
\text { Van Heurck }\end{array}$ & 37 & 38,952 \\
\hline 29 & 09065500 & $\begin{array}{l}\text { Gore Creek at Upper Station } \\
\text { near Minturn }\end{array}$ & 3 & 2000 & $8 / 18 / 2000$ & $39^{\circ} 37^{\prime} 33^{\prime \prime}$ & $106^{\circ} 16^{\prime} 39^{\prime \prime}$ & 8,600 & 14.4 & Diatoma mesodon (Ehrenberg) Kützing & 74 & 79,174 \\
\hline 29 & 09065500 & $\begin{array}{l}\text { Gore Creek at Upper Station } \\
\text { near Minturn }\end{array}$ & 3 & 2000 & $8 / 18 / 2000$ & $39^{\circ} 37^{\prime} 33^{\prime \prime}$ & $106^{\circ} 16^{\prime} 39^{\prime \prime}$ & 8,600 & 14.4 & Encyonema brehmii (Hustedt) Mann & 37 & 1,025 \\
\hline 29 & 09065500 & $\begin{array}{l}\text { Gore Creek at Upper Station } \\
\text { near Minturn }\end{array}$ & 3 & 2000 & $8 / 18 / 2000$ & $39^{\circ} 37^{\prime} 33^{\prime \prime}$ & $106^{\circ} 16^{\prime} 39^{\prime \prime}$ & 8,600 & 14.4 & Encyonema minutum (Hilse) Mann & 74 & 137,851 \\
\hline 29 & 09065500 & $\begin{array}{l}\text { Gore Creek at Upper Station } \\
\text { near Minturn }\end{array}$ & 3 & 2000 & $8 / 18 / 2000$ & $39^{\circ} 37^{\prime} 33^{\prime \prime}$ & $106^{\circ} 16^{\prime} 39^{\prime \prime}$ & 8,600 & 14.4 & Encyonema silesiacum (Bleisch) Mann & 372 & 175,047 \\
\hline 29 & 09065500 & $\begin{array}{l}\text { Gore Creek at Upper Station } \\
\text { near Minturn }\end{array}$ & 3 & 2000 & $8 / 18 / 2000$ & $39^{\circ} 37^{\prime} 33^{\prime \prime}$ & $106^{\circ} 16^{\prime} 39^{\prime \prime}$ & 8,600 & 14.4 & Eucocconeis laevis (Østrup) Lange-Bertalot & 74 & 111,010 \\
\hline 29 & 09065500 & $\begin{array}{l}\text { Gore Creek at Upper Station } \\
\text { near Minturn }\end{array}$ & 3 & 2000 & $8 / 18 / 2000$ & $39^{\circ} 37^{\prime} 33^{\prime \prime}$ & $106^{\circ} 16^{\prime} 39^{\prime \prime}$ & 8,600 & 14.4 & $\begin{array}{l}\text { Fragilaria capucina var. fragilarioides } \\
\text { (Grunow) Ludwig et Flores }\end{array}$ & 74 & 7,618 \\
\hline 29 & 09065500 & $\begin{array}{l}\text { Gore Creek at Upper Station } \\
\text { near Minturn }\end{array}$ & 3 & 2000 & $8 / 18 / 2000$ & $39^{\circ} 37^{\prime} 33^{\prime \prime}$ & $106^{\circ} 16^{\prime} 39^{\prime \prime}$ & 8,600 & 14.4 & Fragilaria vaucheriae (Kützing) Petersen & 297 & 61,523 \\
\hline 29 & 09065500 & $\begin{array}{l}\text { Gore Creek at Upper Station } \\
\text { near Minturn }\end{array}$ & 3 & 2000 & $8 / 18 / 2000$ & $39^{\circ} 37^{\prime} 33^{\prime \prime}$ & $106^{\circ} 16^{\prime} 39^{\prime \prime}$ & 8,600 & 14.4 & $\begin{array}{l}\text { Gomphonema angustatum (Kützing) } \\
\text { Rabenhorst }\end{array}$ & 74 & 30,740 \\
\hline 29 & 09065500 & $\begin{array}{l}\text { Gore Creek at Upper Station } \\
\text { near Minturn }\end{array}$ & 3 & 2000 & $8 / 18 / 2000$ & $39^{\circ} 37^{\prime} 33^{\prime \prime}$ & $106^{\circ} 16^{\prime} 39^{\prime \prime}$ & 8,600 & 14.4 & Gomphonema olivaceoides Hustedt & 2,863 & 437,911 \\
\hline 29 & 09065500 & $\begin{array}{l}\text { Gore Creek at Upper Station } \\
\text { near Minturn }\end{array}$ & 3 & 2000 & $8 / 18 / 2000$ & $39^{\circ} 37^{\prime} 33^{\prime \prime}$ & $106^{\circ} 16^{\prime} 39^{\prime \prime}$ & 8,600 & 14.4 & Hannaea arcus (Ehrenberg) Patrick & 335 & 812,431 \\
\hline
\end{tabular}


Table 2. Description of sites and algal data collected from selected sites the Eagle River watershed, Colorado, 2000-2001.—Continued

[ID, identification; NAVD, North American Vertical Datum of 1988; ft, feet; $\mathrm{mi}^{2}$, square miles; cells $/ \mathrm{cm}^{2}$, cells per square centimeter; $\mu \mathrm{m}^{3} / \mathrm{cm}^{2}$, cubic micrometer per square centimeter]

\begin{tabular}{|c|c|c|c|c|c|c|c|c|c|c|c|c|}
\hline $\begin{array}{l}\text { Site } \\
\text { ID }^{1}\end{array}$ & $\begin{array}{l}\text { USGS } \\
\text { station } \\
\text { number }\end{array}$ & Station name & $\begin{array}{c}\text { Replicate } \\
\text { sample } \\
\text { number }\end{array}$ & Year & $\begin{array}{l}\text { Collection } \\
\text { date }\end{array}$ & Latitude & Longitude & $\begin{array}{c}\text { Elevation } \\
\text { NAVD } 88 \\
\text { (ft) }\end{array}$ & $\begin{array}{c}\text { Drainage } \\
\text { area } \\
\left(\mathrm{mi}^{2}\right)\end{array}$ & Algal taxon name & $\begin{array}{c}\text { Total } \\
\text { density } \\
\text { (number of } \\
\text { cells } / \mathbf{c m}^{2} \text { ) }\end{array}$ & $\begin{array}{c}\text { Total } \\
\text { biovolume } \\
\left(\mu^{3} / \mathrm{cm}^{2}\right)\end{array}$ \\
\hline 29 & 09065500 & $\begin{array}{l}\text { Gore Creek at Upper Station } \\
\text { near Minturn }\end{array}$ & 3 & 2000 & $8 / 18 / 2000$ & $39^{\circ} 37^{\prime} 33^{\prime \prime}$ & $106^{\circ} 16^{\prime} 39^{\prime \prime}$ & 8,600 & 14.4 & $\begin{array}{l}\text { Homoeothrix janthina (Bornet et Flahault) } \\
\text { Starmach }\end{array}$ & 119,029 & $3,857,516$ \\
\hline 29 & 09065500 & $\begin{array}{l}\text { Gore Creek at Upper Station } \\
\text { near Minturn }\end{array}$ & 3 & 2000 & $8 / 18 / 2000$ & $39^{\circ} 37^{\prime} 33^{\prime \prime}$ & $106^{\circ} 16^{\prime} 39^{\prime \prime}$ & 8,600 & 14.4 & Phormidium autumnale (Agardh) Gomont & 15,037 & $1,472,602$ \\
\hline 29 & 09065500 & $\begin{array}{l}\text { Gore Creek at Upper Station } \\
\text { near Minturn }\end{array}$ & 3 & 2000 & $8 / 18 / 2000$ & $39^{\circ} 37^{\prime} 33^{\prime \prime}$ & $106^{\circ} 16^{\prime} 39^{\prime \prime}$ & 8,600 & 14.4 & $\begin{array}{l}\text { Reimeria sinuata (Gregory) } \\
\text { Kociolek et Stoermer }\end{array}$ & 335 & 55,322 \\
\hline 29 & 09065500 & $\begin{array}{l}\text { Gore Creek at Upper Station } \\
\text { near Minturn }\end{array}$ & 3 & 2000 & $8 / 18 / 2000$ & $39^{\circ} 37^{\prime} 33^{\prime \prime}$ & $106^{\circ} 16^{\prime} 39^{\prime \prime}$ & 8,600 & 14.4 & $\begin{array}{l}\text { Rossithidium pusillum (Grunow) } \\
\text { Round et Bukhtiyarova }\end{array}$ & 37 & 3,374 \\
\hline 29 & 09065500 & $\begin{array}{l}\text { Gore Creek at Upper Station } \\
\text { near Minturn }\end{array}$ & 3 & 2000 & $8 / 18 / 2000$ & $39^{\circ} 37^{\prime} 33^{\prime \prime}$ & $106^{\circ} 16^{\prime} 39^{\prime \prime}$ & 8,600 & 14.4 & Sellaphora disjuncta (Hustedt) Mann & 74 & 8,030 \\
\hline 29 & 09065500 & $\begin{array}{l}\text { Gore Creek at Upper Station } \\
\text { near Minturn }\end{array}$ & 3 & 2000 & $8 / 18 / 2000$ & $39^{\circ} 37^{\prime} 33^{\prime \prime}$ & $106^{\circ} 16^{\prime} 39^{\prime \prime}$ & 8,600 & 14.4 & Sellaphora seminulum (Grunow) Mann & 37 & 4,706 \\
\hline 29 & 09065500 & $\begin{array}{l}\text { Gore Creek at Upper Station } \\
\text { near Minturn }\end{array}$ & 3 & 2000 & $8 / 18 / 2000$ & $39^{\circ} 37^{\prime} 33^{\prime \prime}$ & $106^{\circ} 16^{\prime} 39^{\prime \prime}$ & 8,600 & 14.4 & $\begin{array}{l}\text { Staurosirella pinnata (Ehrenberg) } \\
\text { Williams et Round }\end{array}$ & 149 & 14,317 \\
\hline 29 & 09065500 & $\begin{array}{l}\text { Gore Creek at Upper Station } \\
\text { near Minturn }\end{array}$ & 3 & 2000 & $8 / 18 / 2000$ & $39^{\circ} 37^{\prime} 33^{\prime \prime}$ & $106^{\circ} 16^{\prime} 39^{\prime \prime}$ & 8,600 & 14.4 & Synedra ulna (Nitzsch) Ehrenberg & 260 & $1,706,266$ \\
\hline 29 & 09065500 & $\begin{array}{l}\text { Gore Creek at Upper Station } \\
\text { near Minturn }\end{array}$ & 3 & 2000 & $8 / 18 / 2000$ & $39^{\circ} 37^{\prime} 33^{\prime \prime}$ & $106^{\circ} 16^{\prime} 39^{\prime \prime}$ & 8,600 & 14.4 & $\begin{array}{l}\text { Unknown Rhodophyte Florideophycidae } \\
\text { (chantransia) }\end{array}$ & 1,377 & $4,872,257$ \\
\hline 29 & 09065500 & $\begin{array}{l}\text { Gore Creek at Upper Station } \\
\text { near Minturn }\end{array}$ & 1 & 2001 & $8 / 14 / 2001$ & $39^{\circ} 37^{\prime} 33^{\prime \prime}$ & $106^{\circ} 16^{\prime} 39^{\prime \prime}$ & 8,600 & 14.4 & $\begin{array}{l}\text { Achnanthidium minutissimum (Kützing) } \\
\text { Czarnecki }\end{array}$ & 26,430 & $1,433,038$ \\
\hline 29 & 09065500 & $\begin{array}{l}\text { Gore Creek at Upper Station } \\
\text { near Minturn }\end{array}$ & 1 & 2001 & $8 / 14 / 2001$ & $39^{\circ} 37^{\prime} 33^{\prime \prime}$ & $106^{\circ} 16^{\prime} 39^{\prime \prime}$ & 8,600 & 14.4 & $\begin{array}{l}\text { Achnanthidium pyrenaicum (Hustedt) } \\
\text { Kobayasi }\end{array}$ & 936 & 118,300 \\
\hline 29 & 09065500 & $\begin{array}{l}\text { Gore Creek at Upper Station } \\
\text { near Minturn }\end{array}$ & 1 & 2001 & $8 / 14 / 2001$ & $39^{\circ} 37^{\prime} 33^{\prime \prime}$ & $106^{\circ} 16^{\prime} 39^{\prime \prime}$ & 8,600 & 14.4 & $\begin{array}{l}\text { Cocconeis placentula var. euglypta } \\
\text { (Ehrenberg) Grunow }\end{array}$ & 72 & 42,791 \\
\hline 29 & 09065500 & $\begin{array}{l}\text { Gore Creek at Upper Station } \\
\text { near Minturn }\end{array}$ & 1 & 2001 & $8 / 14 / 2001$ & $39^{\circ} 37^{\prime} 33^{\prime \prime}$ & $106^{\circ} 16^{\prime} 39^{\prime \prime}$ & 8,600 & 14.4 & $\begin{array}{l}\text { Cocconeis placentula var. lineata (Ehrenberg) } \\
\text { Van Heurck }\end{array}$ & 4,897 & $5,164,383$ \\
\hline 29 & 09065500 & $\begin{array}{l}\text { Gore Creek at Upper Station } \\
\text { near Minturn }\end{array}$ & 1 & 2001 & $8 / 14 / 2001$ & $39^{\circ} 37^{\prime} 33^{\prime \prime}$ & $106^{\circ} 16^{\prime} 39^{\prime \prime}$ & 8,600 & 14.4 & Didymosphenia geminata (Lyngbye) Schmidt & 72 & $4,405,904$ \\
\hline 29 & 09065500 & $\begin{array}{l}\text { Gore Creek at Upper Station } \\
\text { near Minturn }\end{array}$ & 1 & 2001 & $8 / 14 / 2001$ & $39^{\circ} 37^{\prime} 33^{\prime \prime}$ & $106^{\circ} 16^{\prime} 39^{\prime \prime}$ & 8,600 & 14.4 & Encyonema brehmii (Hustedt) Mann & 576 & 15,885 \\
\hline 29 & 09065500 & $\begin{array}{l}\text { Gore Creek at Upper Station } \\
\text { near Minturn }\end{array}$ & 1 & 2001 & $8 / 14 / 2001$ & $39^{\circ} 37^{\prime} 33^{\prime \prime}$ & $106^{\circ} 16^{\prime} 39^{\prime \prime}$ & 8,600 & 14.4 & Encyonema silesiacum (Bleisch) Mann & 936 & 444,644 \\
\hline 29 & 09065500 & $\begin{array}{l}\text { Gore Creek at Upper Station } \\
\text { near Minturn }\end{array}$ & 1 & 2001 & $8 / 14 / 2001$ & $39^{\circ} 37^{\prime} 33^{\prime \prime}$ & $106^{\circ} 16^{\prime} 39^{\prime \prime}$ & 8,600 & 14.4 & Eucocconeis laevis (Østrup) Lange-Bertalot & 72 & 107,519 \\
\hline 29 & 09065500 & $\begin{array}{l}\text { Gore Creek at Upper Station } \\
\text { near Minturn }\end{array}$ & 1 & 2001 & $8 / 14 / 2001$ & $39^{\circ} 37^{\prime} 33^{\prime \prime}$ & $106^{\circ} 16^{\prime} 39^{\prime \prime}$ & 8,600 & 14.4 & Fragilaria vaucheriae (Kützing) Petersen & 1,224 & 241,193 \\
\hline 29 & 09065500 & $\begin{array}{l}\text { Gore Creek at Upper Station } \\
\text { near Minturn }\end{array}$ & 1 & 2001 & $8 / 14 / 2001$ & $39^{\circ} 37^{\prime} 33^{\prime \prime}$ & $106^{\circ} 16^{\prime} 39^{\prime \prime}$ & 8,600 & 14.4 & Gomphonema olivaceoides Hustedt & 720 & 108,430 \\
\hline 29 & 09065500 & $\begin{array}{l}\text { Gore Creek at Upper Station } \\
\text { near Minturn }\end{array}$ & 1 & 2001 & $8 / 14 / 2001$ & $39^{\circ} 37^{\prime} 33^{\prime \prime}$ & $106^{\circ} 16^{\prime} 39^{\prime \prime}$ & 8,600 & 14.4 & $\begin{array}{l}\text { Gomphonema pumilum (Grunow) } \\
\text { Reichardt et Lange-Bertalot }\end{array}$ & 3,961 & 864,448 \\
\hline 29 & 09065500 & $\begin{array}{l}\text { Gore Creek at Upper Station } \\
\text { near Minturn }\end{array}$ & 1 & 2001 & $8 / 14 / 2001$ & $39^{\circ} 37^{\prime} 33^{\prime \prime}$ & $106^{\circ} 16^{\prime} 39^{\prime \prime}$ & 8,600 & 14.4 & Hannaea arcus (Ehrenberg) Patrick & 72 & 144,402 \\
\hline 29 & 09065500 & $\begin{array}{l}\text { Gore Creek at Upper Station } \\
\text { near Minturn }\end{array}$ & 1 & 2001 & $8 / 14 / 2001$ & $39^{\circ} 37^{\prime} 33^{\prime \prime}$ & $106^{\circ} 16^{\prime} 39^{\prime \prime}$ & 8,600 & 14.4 & $\begin{array}{l}\text { Homoeothrix janthina (Bornet et Flahault) } \\
\text { Starmach }\end{array}$ & 452,433 & $7,788,033$ \\
\hline 29 & 09065500 & $\begin{array}{l}\text { Gore Creek at Upper Station } \\
\text { near Minturn }\end{array}$ & 1 & 2001 & $8 / 14 / 2001$ & $39^{\circ} 37^{\prime} 33^{\prime \prime}$ & $106^{\circ} 16^{\prime} 39^{\prime \prime}$ & 8,600 & 14.4 & Nitzschia dissipata (Kützing) Grunow & 72 & 18,568 \\
\hline
\end{tabular}


Table 2. Description of sites and algal data collected from selected sites the Eagle River watershed, Colorado, 2000-2001.—Continued

[ID, identification; NAVD, North American Vertical Datum of 1988; ft, feet; $\mathrm{mi}^{2}$, square miles; cells $/ \mathrm{cm}^{2}$, cells per square centimeter; $\mu \mathrm{m}^{3} / \mathrm{cm}^{2}$, cubic micrometer per square centimeter]

\begin{tabular}{|c|c|c|c|c|c|c|c|c|c|c|c|c|}
\hline $\begin{array}{l}\text { Site } \\
\text { ID' }\end{array}$ & $\begin{array}{l}\text { USGS } \\
\text { station } \\
\text { number }\end{array}$ & Station name & $\begin{array}{l}\text { Replicate } \\
\text { sample } \\
\text { number }\end{array}$ & Year & $\begin{array}{l}\text { Collection } \\
\text { date }\end{array}$ & Latitude & Longitude & $\begin{array}{c}\text { Elevation } \\
\text { NAVD } 88 \\
\text { (ft) }\end{array}$ & $\begin{array}{c}\text { Drainage } \\
\text { area } \\
\left(\mathrm{mi}^{2}\right)\end{array}$ & Algal taxon name & $\begin{array}{c}\text { Total } \\
\text { density } \\
\text { (number of } \\
\text { cells } / \mathrm{cm}^{2} \text { ) }\end{array}$ & $\begin{array}{c}\text { Total } \\
\text { biovolume } \\
\left(\mu \mathrm{m}^{3} / \mathrm{cm}^{2}\right)\end{array}$ \\
\hline 29 & 09065500 & $\begin{array}{l}\text { Gore Creek at Upper Station } \\
\text { near Minturn }\end{array}$ & 1 & 2001 & $8 / 14 / 2001$ & $39^{\circ} 37^{\prime} 33^{\prime \prime}$ & $106^{\circ} 16^{\prime} 39^{\prime \prime}$ & 8,600 & 14.4 & Phormidium autumnale (Agardh) Gomont & 9,014 & 873,986 \\
\hline 29 & 09065500 & $\begin{array}{l}\text { Gore Creek at Upper Station } \\
\text { near Minturn }\end{array}$ & 1 & 2001 & $8 / 14 / 2001$ & $39^{\circ} 37^{\prime} 33^{\prime \prime}$ & $106^{\circ} 16^{\prime} 39^{\prime \prime}$ & 8,600 & 14.4 & $\begin{array}{l}\text { Reimeria sinuata (Gregory) } \\
\text { Kociolek et Stoermer }\end{array}$ & 3,529 & 594,734 \\
\hline 29 & 09065500 & $\begin{array}{l}\text { Gore Creek at Upper Station } \\
\text { near Minturn }\end{array}$ & 1 & 2001 & $8 / 14 / 2001$ & $39^{\circ} 37^{\prime} 33^{\prime \prime}$ & $106^{\circ} 16^{\prime} 39^{\prime \prime}$ & 8,600 & 14.4 & Unknown alga flagellate $(<10 \mu)$ & 644 & 61,879 \\
\hline 29 & 09065500 & $\begin{array}{l}\text { Gore Creek at Upper Station } \\
\text { near Minturn }\end{array}$ & 1 & 2001 & $8 / 14 / 2001$ & $39^{\circ} 37^{\prime} 33^{\prime \prime}$ & $106^{\circ} 16^{\prime} 39^{\prime \prime}$ & 8,600 & 14.4 & $\begin{array}{l}\text { Unknown Cyanophyte Oscillatoriales } \\
\text { (no sheath) }\end{array}$ & 24,038 & 356,620 \\
\hline 29 & 09065500 & $\begin{array}{l}\text { Gore Creek at Upper Station } \\
\text { near Minturn }\end{array}$ & 1 & 2001 & $8 / 14 / 2001$ & $39^{\circ} 37^{\prime} 33^{\prime \prime}$ & $106^{\circ} 16^{\prime} 39^{\prime \prime}$ & 8,600 & 14.4 & $\begin{array}{l}\text { Unknown Rhodophyte Florideophycidae } \\
\text { (chantransia) }\end{array}$ & 13,092 & $83,796,693$ \\
\hline 34 & 09066000 & $\begin{array}{l}\text { Black Gore Creek near } \\
\text { Minturn }\end{array}$ & 1 & 2000 & $8 / 17 / 2000$ & $39^{\circ} 35^{\prime} 47^{\prime \prime}$ & $106^{\circ} 15^{\prime} 52^{\prime \prime}$ & 9,150 & 12.6 & $\begin{array}{l}\text { Achnanthidium minutissimum (Kützing) } \\
\text { Czarnecki }\end{array}$ & 39,586 & $2,180,050$ \\
\hline 34 & 09066000 & $\begin{array}{l}\text { Black Gore Creek near } \\
\text { Minturn }\end{array}$ & 1 & 2000 & $8 / 17 / 2000$ & $39^{\circ} 35^{\prime} 47^{\prime \prime}$ & $106^{\circ} 15^{\prime} 52^{\prime \prime}$ & 9,150 & 12.6 & $\begin{array}{l}\text { Achnanthidium pyrenaicum (Hustedt) } \\
\text { Kobayasi }\end{array}$ & 1,991 & 250,515 \\
\hline 34 & 09066000 & $\begin{array}{l}\text { Black Gore Creek near } \\
\text { Minturn }\end{array}$ & 1 & 2000 & $8 / 17 / 2000$ & $39^{\circ} 35^{\prime} 47^{\prime \prime}$ & $106^{\circ} 15^{\prime} 52^{\prime \prime}$ & 9,150 & 12.6 & Amphora pediculus (Kützing) Grunow & 80 & 7,537 \\
\hline 34 & 09066000 & $\begin{array}{l}\text { Black Gore Creek near } \\
\text { Minturn }\end{array}$ & 1 & 2000 & $8 / 17 / 2000$ & $39^{\circ} 35^{\prime} 47^{\prime \prime}$ & $106^{\circ} 15^{\prime} 52^{\prime \prime}$ & 9,150 & 12.6 & Chlamydomonas sp. & 749 & 63,665 \\
\hline 34 & 09066000 & $\begin{array}{l}\text { Black Gore Creek near } \\
\text { Minturn }\end{array}$ & 1 & 2000 & $8 / 17 / 2000$ & $39^{\circ} 35^{\prime} 47^{\prime \prime}$ & $106^{\circ} 15^{\prime} 52^{\prime \prime}$ & 9,150 & 12.6 & $\begin{array}{l}\text { Cocconeis placentula var. lineata (Ehrenberg) } \\
\text { Van Heurck }\end{array}$ & 478 & 500,714 \\
\hline 34 & 09066000 & $\begin{array}{l}\text { Black Gore Creek near } \\
\text { Minturn }\end{array}$ & 1 & 2000 & $8 / 17 / 2000$ & $39^{\circ} 35^{\prime} 47^{\prime \prime}$ & $106^{\circ} 15^{\prime} 52^{\prime \prime}$ & 9,150 & 12.6 & Cymbella affinis Kützing & 1,115 & 564,352 \\
\hline 34 & 09066000 & $\begin{array}{l}\text { Black Gore Creek near } \\
\text { Minturn }\end{array}$ & 1 & 2000 & $8 / 17 / 2000$ & $39^{\circ} 35^{\prime} 47^{\prime \prime}$ & $106^{\circ} 15^{\prime} 52^{\prime \prime}$ & 9,150 & 12.6 & Encyonema brehmii (Hustedt) Mann & 1,593 & 43,921 \\
\hline 34 & 09066000 & $\begin{array}{l}\text { Black Gore Creek near } \\
\text { Minturn }\end{array}$ & 1 & 2000 & $8 / 17 / 2000$ & $39^{\circ} 35^{\prime} 47^{\prime \prime}$ & $106^{\circ} 15^{\prime} 52^{\prime \prime}$ & 9,150 & 12.6 & Encyonema silesiacum (Bleisch) Mann & 7,328 & $3,450,259$ \\
\hline 34 & 09066000 & $\begin{array}{l}\text { Black Gore Creek near } \\
\text { Minturn }\end{array}$ & 1 & 2000 & $8 / 17 / 2000$ & $39^{\circ} 35^{\prime} 47^{\prime \prime}$ & $106^{\circ} 15^{\prime} 52^{\prime \prime}$ & 9,150 & 12.6 & $\begin{array}{l}\text { Fragilaria capucina var. fragilarioides } \\
\text { (Grunow) Ludwig et Flores }\end{array}$ & 478 & 48,964 \\
\hline 34 & 09066000 & $\begin{array}{l}\text { Black Gore Creek near } \\
\text { Minturn }\end{array}$ & 1 & 2000 & $8 / 17 / 2000$ & $39^{\circ} 35^{\prime} 47^{\prime \prime}$ & $106^{\circ} 15^{\prime} 52^{\prime \prime}$ & 9,150 & 12.6 & Fragilaria vaucheriae (Kützing) Petersen & 637 & 131,811 \\
\hline 34 & 09066000 & $\begin{array}{l}\text { Black Gore Creek near } \\
\text { Minturn }\end{array}$ & 1 & 2000 & $8 / 17 / 2000$ & $39^{\circ} 35^{\prime} 47^{\prime \prime}$ & $106^{\circ} 15^{\prime} 52^{\prime \prime}$ & 9,150 & 12.6 & Gomphonema olivaceoides Hustedt & 159 & 24,369 \\
\hline 34 & 09066000 & $\begin{array}{l}\text { Black Gore Creek near } \\
\text { Minturn }\end{array}$ & 1 & 2000 & $8 / 17 / 2000$ & $39^{\circ} 35^{\prime} 47^{\prime \prime}$ & $106^{\circ} 15^{\prime} 52^{\prime \prime}$ & 9,150 & 12.6 & Gomphonema olivaceum (Lyngbye) Kützing & 796 & 274,047 \\
\hline 34 & 09066000 & $\begin{array}{l}\text { Black Gore Creek near } \\
\text { Minturn }\end{array}$ & 1 & 2000 & $8 / 17 / 2000$ & $39^{\circ} 35^{\prime} 47^{\prime \prime}$ & $106^{\circ} 15^{\prime} 52^{\prime \prime}$ & 9,150 & 12.6 & $\begin{array}{l}\text { Gomphonema pumilum (Grunow) } \\
\text { Reichardt et Lange-Bertalot }\end{array}$ & 1,832 & 534,523 \\
\hline 34 & 09066000 & $\begin{array}{l}\text { Black Gore Creek near } \\
\text { Minturn }\end{array}$ & 1 & 2000 & $8 / 17 / 2000$ & $39^{\circ} 35^{\prime} 47^{\prime \prime}$ & $106^{\circ} 15^{\prime} 52^{\prime \prime}$ & 9,150 & 12.6 & Hannaea arcus (Ehrenberg) Patrick & 159 & 386,797 \\
\hline 34 & 09066000 & $\begin{array}{l}\text { Black Gore Creek near } \\
\text { Minturn }\end{array}$ & 1 & 2000 & $8 / 17 / 2000$ & $39^{\circ} 35^{\prime} 47^{\prime \prime}$ & $106^{\circ} 15^{\prime} 52^{\prime \prime}$ & 9,150 & 12.6 & $\begin{array}{l}\text { Homoeothrix janthina (Bornet et Flahault) } \\
\text { Starmach }\end{array}$ & $1,213,750$ & $39,335,610$ \\
\hline 34 & 09066000 & $\begin{array}{l}\text { Black Gore Creek near } \\
\text { Minturn }\end{array}$ & 1 & 2000 & $8 / 17 / 2000$ & $39^{\circ} 35^{\prime} 47^{\prime \prime}$ & $106^{\circ} 15^{\prime} 52^{\prime \prime}$ & 9,150 & 12.6 & Meridion circulare (Greville) Agardh & 80 & 51,695 \\
\hline 34 & 09066000 & $\begin{array}{l}\text { Black Gore Creek near } \\
\text { Minturn }\end{array}$ & 1 & 2000 & $8 / 17 / 2000$ & $39^{\circ} 35^{\prime} 47^{\prime \prime}$ & $106^{\circ} 15^{\prime} 52^{\prime \prime}$ & 9,150 & 12.6 & Navicula gregaria Donkin & 319 & 79,642 \\
\hline 34 & 09066000 & Black Gore Creek near Minturn & 1 & 2000 & $8 / 17 / 2000$ & $39^{\circ} 35^{\prime} 47^{\prime \prime}$ & $106^{\circ} 15^{\prime} 52^{\prime \prime}$ & 9,150 & 12.6 & Nitzschia dissipata (Kützing) Grunow & 319 & 82,847 \\
\hline 34 & 09066000 & Black Gore Creek near Minturn & 1 & 2000 & $8 / 17 / 2000$ & $39^{\circ} 35^{\prime} 47^{\prime \prime}$ & $106^{\circ} 15^{\prime} 52^{\prime \prime}$ & 9,150 & 12.6 & Nitzschia fonticola Grunow & 319 & 31,638 \\
\hline 34 & 09066000 & Black Gore Creek near Minturn & 1 & 2000 & $8 / 17 / 2000$ & $39^{\circ} 35^{\prime} 47^{\prime \prime}$ & $106^{\circ} 15^{\prime} 52^{\prime \prime}$ & 9,150 & 12.6 & Nitzschia inconspicua Grunow & 159 & 8,549 \\
\hline
\end{tabular}


Table 2. Description of sites and algal data collected from selected sites the Eagle River watershed, Colorado, 2000-2001.—Continued

[ID, identification; NAVD, North American Vertical Datum of 1988; ft, feet; $\mathrm{mi}^{2}$, square miles; cells $/ \mathrm{cm}^{2}$, cells per square centimeter; $\mu \mathrm{m}^{3} / \mathrm{cm}^{2}$, cubic micrometer per square centimeter]

\begin{tabular}{|c|c|c|c|c|c|c|c|c|c|c|c|c|}
\hline $\begin{array}{l}\text { Site } \\
\text { ID }^{1}\end{array}$ & $\begin{array}{l}\text { USGS } \\
\text { station } \\
\text { number }\end{array}$ & Station name & $\begin{array}{l}\text { Replicate } \\
\text { sample } \\
\text { number }\end{array}$ & Year & $\begin{array}{l}\text { Collection } \\
\text { date }\end{array}$ & Latitude & Longitude & $\begin{array}{c}\text { Elevation } \\
\text { NAVD } 88 \\
\text { (ft) }\end{array}$ & $\begin{array}{c}\text { Drainage } \\
\text { area } \\
\left(\mathrm{mi}^{2}\right)\end{array}$ & Algal taxon name & $\begin{array}{c}\text { Total } \\
\text { density } \\
\text { (number of } \\
\text { cells/cm²) }\end{array}$ & $\begin{array}{c}\text { Total } \\
\text { biovolume } \\
\left(\mu \mathrm{m}^{3} / \mathrm{cm}^{2}\right)\end{array}$ \\
\hline 34 & 09066000 & Black Gore Creek near Minturn & 1 & 2000 & $8 / 17 / 2000$ & $39^{\circ} 35^{\prime} 47^{\prime \prime}$ & $106^{\circ} 15^{\prime} 52^{\prime \prime}$ & 9,150 & 12.6 & Phormidium autumnale (Agardh) Gomont & 139,313 & $13,642,855$ \\
\hline 34 & 09066000 & Black Gore Creek near Minturn & 1 & 2000 & $8 / 17 / 2000$ & $39^{\circ} 35^{\prime} 47^{\prime \prime}$ & $106^{\circ} 15^{\prime} 52^{\prime \prime}$ & 9,150 & 12.6 & $\begin{array}{l}\text { Reimeria sinuata (Gregory) } \\
\text { Kociolek et Stoermer }\end{array}$ & 2,071 & 342,405 \\
\hline 34 & 09066000 & Black Gore Creek near Minturn & 1 & 2000 & $8 / 17 / 2000$ & $39^{\circ} 35^{\prime} 47^{\prime \prime}$ & $106^{\circ} 15^{\prime} 52^{\prime \prime}$ & 9,150 & 12.6 & $\begin{array}{l}\text { Staurosirella pinnata (Ehrenberg) } \\
\text { Williams et Round }\end{array}$ & 319 & 30,673 \\
\hline 34 & 09066000 & Black Gore Creek near Minturn & 1 & 2000 & $8 / 17 / 2000$ & $39^{\circ} 35^{\prime} 47^{\prime \prime}$ & $106^{\circ} 15^{\prime} 52^{\prime \prime}$ & 9,150 & 12.6 & Stigeoclonium lubricum (Dillwyn) Kützing & 4,119 & $6,114,458$ \\
\hline 34 & 09066000 & Black Gore Creek near Minturn & 1 & 2000 & $8 / 17 / 2000$ & $39^{\circ} 35^{\prime} 47^{\prime \prime}$ & $106^{\circ} 15^{\prime} 52^{\prime \prime}$ & 9,150 & 12.6 & Synedra ulna (Nitzsch) Ehrenberg & 478 & $3,133,352$ \\
\hline 37 & 09066050 & Black Gore Creek near Vail & 1 & 2001 & $8 / 17 / 2001$ & $39^{\circ} 37^{\prime} 24^{\prime \prime}$ & $106^{\circ} 16^{\prime} 47^{\prime \prime}$ & 8,570 & 19.6 & $\begin{array}{l}\text { Achnanthidium minutissimum (Kützing) } \\
\text { Czarnecki }\end{array}$ & 14,096 & 764,299 \\
\hline 37 & 09066050 & Black Gore Creek near Vail & 1 & 2001 & $8 / 17 / 2001$ & $39^{\circ} 37^{\prime} 24^{\prime \prime}$ & $106^{\circ} 16^{\prime} 47^{\prime \prime}$ & 8,570 & 19.6 & $\begin{array}{l}\text { Achnanthidium pyrenaicum (Hustedt) } \\
\text { Kobayasi }\end{array}$ & 1,122 & 141,787 \\
\hline 37 & 09066050 & Black Gore Creek near Vail & 1 & 2001 & $8 / 17 / 2001$ & $39^{\circ} 37^{\prime} 24^{\prime \prime}$ & $106^{\circ} 16^{\prime} 47^{\prime \prime}$ & 8,570 & 19.6 & Adlafia minuscula (Grunow) Lange-Bertalot & 140 & 11,670 \\
\hline 37 & 09066050 & Black Gore Creek near Vail & 1 & 2001 & $8 / 17 / 2001$ & $39^{\circ} 37^{\prime} 24^{\prime \prime}$ & $106^{\circ} 16^{\prime} 47^{\prime \prime}$ & 8,570 & 19.6 & Amphipleura pellucida (Kützing) Kützing & 70 & 54,561 \\
\hline 37 & 09066050 & Black Gore Creek near Vail & 1 & 2001 & $8 / 17 / 2001$ & $39^{\circ} 37^{\prime 2} 24^{\prime \prime}$ & $106^{\circ} 16^{\prime} 47^{\prime \prime}$ & 8,570 & 19.6 & $\begin{array}{l}\text { Cocconeis placentula var. euglypta } \\
\text { (Ehrenberg) Grunow }\end{array}$ & 5,260 & $3,125,263$ \\
\hline 37 & 09066050 & Black Gore Creek near Vail & 1 & 2001 & $8 / 17 / 2001$ & $39^{\circ} 37^{\prime} 24^{\prime \prime}$ & $106^{\circ} 16^{\prime} 47^{\prime \prime}$ & 8,570 & 19.6 & $\begin{array}{l}\text { Cocconeis placentula var. lineata (Ehrenberg) } \\
\text { Van Heurck }\end{array}$ & 3,226 & $3,402,070$ \\
\hline 37 & 09066050 & Black Gore Creek near Vail & 1 & 2001 & $8 / 17 / 2001$ & $39^{\circ} 37^{\prime} 24^{\prime \prime}$ & $106^{\circ} 16^{\prime} 47^{\prime \prime}$ & 8,570 & 19.6 & $\begin{array}{l}\text { Cocconeis placentula var. } \\
\text { pseudolineata Geitler }\end{array}$ & 70 & 139,358 \\
\hline 37 & 09066050 & Black Gore Creek near Vail & 1 & 2001 & $8 / 17 / 2001$ & $39^{\circ} 37^{\prime} 24^{\prime \prime}$ & $106^{\circ} 16^{\prime} 47^{\prime \prime}$ & 8,570 & 19.6 & Cymbella affinis Kützing & 842 & 428,309 \\
\hline 37 & 09066050 & Black Gore Creek near Vail & 1 & 2001 & $8 / 17 / 2001$ & $39^{\circ} 37^{\prime} 24^{\prime \prime}$ & $106^{\circ} 16^{\prime} 47^{\prime \prime}$ & 8,570 & 19.6 & Diatoma vulgaris Bory & 210 & 777,368 \\
\hline 37 & 09066050 & Black Gore Creek near Vail & 1 & 2001 & $8 / 17 / 2001$ & $39^{\circ} 37^{\prime} 24^{\prime \prime}$ & $106^{\circ} 16^{\prime} 47^{\prime \prime}$ & 8,570 & 19.6 & Encyonema brehmii (Hustedt) Mann & 140 & 3,867 \\
\hline 37 & 09066050 & Black Gore Creek near Vail & 1 & 2001 & $8 / 17 / 2001$ & $39^{\circ} 37^{\prime} 24^{\prime \prime}$ & $106^{\circ} 16^{\prime} 47^{\prime \prime}$ & 8,570 & 19.6 & Encyonema silesiacum (Bleisch) Mann & 10,379 & $4,929,539$ \\
\hline 37 & 09066050 & Black Gore Creek near Vail & 1 & 2001 & $8 / 17 / 2001$ & $39^{\circ} 37^{\prime} 24^{\prime \prime}$ & $106^{\circ} 16^{\prime} 47^{\prime \prime}$ & 8,570 & 19.6 & Fragilaria vaucheriae (Kützing) Petersen & 1,473 & 290,143 \\
\hline 37 & 09066050 & Black Gore Creek near Vail & 1 & 2001 & $8 / 17 / 2001$ & $39^{\circ} 37^{\prime} 24^{\prime \prime}$ & $106^{\circ} 16^{\prime} 47^{\prime \prime}$ & 8,570 & 19.6 & $\begin{array}{l}\text { Geissleria acceptata (Hustedt) } \\
\text { Lange-Bertalot et Metzeltin }\end{array}$ & 140 & 14,398 \\
\hline 37 & 09066050 & Black Gore Creek near Vail & 1 & 2001 & $8 / 17 / 2001$ & $39^{\circ} 37^{\prime} 24^{\prime \prime}$ & $106^{\circ} 16^{\prime} 47^{\prime \prime}$ & 8,570 & 19.6 & Gomphonema minutum (Agardh) Agardh & 70 & 5,730 \\
\hline 37 & 09066050 & Black Gore Creek near Vail & 1 & 2001 & $8 / 17 / 2001$ & $39^{\circ} 37^{\prime} 24^{\prime \prime}$ & $106^{\circ} 16^{\prime} 47^{\prime \prime}$ & 8,570 & 19.6 & Gomphonema olivaceoides Hustedt & 421 & 63,355 \\
\hline 37 & 09066050 & Black Gore Creek near Vail & 1 & 2001 & $8 / 17 / 2001$ & $39^{\circ} 37^{\prime} 24^{\prime \prime}$ & $106^{\circ} 16^{\prime} 47^{\prime \prime}$ & 8,570 & 19.6 & Gomphonema olivaceum (Lyngbye) Kützing & 1,262 & 478,346 \\
\hline 37 & 09066050 & Black Gore Creek near Vail & 1 & 2001 & $8 / 17 / 2001$ & $39^{\circ} 37^{\prime} 24^{\prime \prime}$ & $106^{\circ} 16^{\prime} 47^{\prime \prime}$ & 8,570 & 19.6 & $\begin{array}{l}\text { Gomphonema pumilum (Grunow) } \\
\text { Reichardt et Lange-Bertalot }\end{array}$ & 140 & 30,611 \\
\hline 37 & 09066050 & Black Gore Creek near Vail & 1 & 2001 & $8 / 17 / 2001$ & $39^{\circ} 37^{\prime} 24^{\prime \prime}$ & $106^{\circ} 16^{\prime} 47^{\prime \prime}$ & 8,570 & 19.6 & Hannaea arcus (Ehrenberg) Patrick & 491 & 984,342 \\
\hline 37 & 09066050 & Black Gore Creek near Vail & 1 & 2001 & $8 / 17 / 2001$ & $39^{\circ} 37^{\prime} 24^{\prime \prime}$ & $106^{\circ} 16^{\prime} 47^{\prime \prime}$ & 8,570 & 19.6 & $\begin{array}{l}\text { Homoeothrix janthina (Bornet et Flahault) } \\
\text { Starmach }\end{array}$ & 616,132 & $10,605,889$ \\
\hline 37 & 09066050 & Black Gore Creek & 1 & 2001 & $8 / 17 / 2001$ & $39^{\circ} 37^{\prime} 24^{\prime \prime}$ & $106^{\circ} 16^{\prime} 47^{\prime \prime}$ & 8,570 & 19.6 & Meridion circulare (Greville) Agardh & 140 & 91,034 \\
\hline 37 & 09066050 & Black Gore Creek near Vail & 1 & 2001 & $8 / 17 / 2001$ & $39^{\circ} 37^{\prime} 24^{\prime \prime}$ & $106^{\circ} 16^{\prime} 47^{\prime \prime}$ & 8,570 & 19.6 & Navicula cryptocephala Kützing & 140 & 51,397 \\
\hline 37 & 09066050 & Black Gore Creek near Vail & 1 & 2001 & $8 / 17 / 2001$ & $39^{\circ} 37^{\prime} 24^{\prime \prime}$ & $106^{\circ} 16^{\prime} 47^{\prime \prime}$ & 8,570 & 19.6 & $\begin{array}{l}\text { Navicula cryptotenella Lange-Bertalot } \\
\text { ex Krammer et Lange-Bertalot }\end{array}$ & 140 & 37,256 \\
\hline 37 & 09066050 & Black Gore Creek near Vail & 1 & 2001 & $8 / 17 / 2001$ & $39^{\circ} 37^{\prime} 24^{\prime \prime}$ & $106^{\circ} 16^{\prime} 47^{\prime \prime}$ & 8,570 & 19.6 & Navicula gregaria Donkin & 70 & 17,600 \\
\hline 37 & 09066050 & Black Gore Creek near Vail & 1 & 2001 & $8 / 17 / 2001$ & $39^{\circ} 37^{\prime} 24^{\prime \prime}$ & $106^{\circ} 16^{\prime} 47^{\prime \prime}$ & 8,570 & 19.6 & Navicula incertata Hustedt & 210 & 12,530 \\
\hline 37 & 09066050 & Black Gore Creek near Vail & 1 & 2001 & $8 / 17 / 2001$ & $39^{\circ} 37^{\prime} 24^{\prime \prime}$ & $106^{\circ} 16^{\prime} 47^{\prime \prime}$ & 8,570 & 19.6 & Navicula minima Grunow & 140 & 6,313 \\
\hline 37 & 09066050 & Black Gore Creek near Vail & 1 & 2001 & $8 / 17 / 2001$ & $39^{\circ} 37^{\prime} 24^{\prime \prime}$ & $106^{\circ} 16^{\prime} 47^{\prime \prime}$ & 8,570 & 19.6 & Navicula tripunctata (Müller) Bory & 421 & 382,627 \\
\hline 37 & 09066050 & Black Gore Creek near Vail & 1 & 2001 & $8 / 17 / 2001$ & $39^{\circ} 37^{\prime} 24^{\prime \prime}$ & $106^{\circ} 16^{\prime} 47^{\prime \prime}$ & 8,570 & 19.6 & Navicula veneta Kützing & 140 & 30,967 \\
\hline 37 & 09066050 & Black Gore Creek near Vail & 1 & 2001 & $8 / 17 / 2001$ & $39^{\circ} 37^{\prime} 24^{\prime \prime}$ & $106^{\circ} 16^{\prime} 47^{\prime \prime}$ & 8,570 & 19.6 & $\begin{array}{l}\text { Nitzschia } \text { cf. tubicola } \\
\text { Grunow ex Cleve et Grunow }\end{array}$ & 140 & 45,771 \\
\hline 37 & 09066050 & Black Gore Creek near Vail & 1 & 2001 & $8 / 17 / 2001$ & $39^{\circ} 37^{\prime} 24^{\prime \prime}$ & $106^{\circ} 16^{\prime} 47^{\prime \prime}$ & 8,570 & 19.6 & Nitzschia dissipata (Kützing) Grunow & 70 & 18,082 \\
\hline 37 & 09066050 & Black Gore Creek near Vail & 1 & 2001 & $8 / 17 / 2001$ & $39^{\circ} 37^{\prime} 24^{\prime \prime}$ & $106^{\circ} 16^{\prime} 47^{\prime \prime}$ & 8,570 & 19.6 & Nitzschia inconspicua Grunow & 491 & 26,512 \\
\hline 37 & 09066050 & Black Gore Creek near Vail & 1 & 2001 & $8 / 17 / 2001$ & $39^{\circ} 37^{\prime} 24^{\prime \prime}$ & $106^{\circ} 16^{\prime} 47^{\prime \prime}$ & 8,570 & 19.6 & Nitzschia supralitorea Lange-Bertalot & 70 & 5,624 \\
\hline
\end{tabular}


Table 2. Description of sites and algal data collected from selected sites the Eagle River watershed, Colorado, 2000-2001.—Continued

[ID, identification; NAVD, North American Vertical Datum of 1988; ft, feet; $\mathrm{mi}^{2}$, square miles; cells $/ \mathrm{cm}^{2}$, cells per square centimeter; $\mu \mathrm{m}^{3} / \mathrm{cm}^{2}$, cubic micrometer per square centimeter]

\begin{tabular}{|c|c|c|c|c|c|c|c|c|c|c|c|c|}
\hline $\begin{array}{l}\text { Site } \\
\text { ID }^{1}\end{array}$ & $\begin{array}{l}\text { USGS } \\
\text { station } \\
\text { number }\end{array}$ & Station name & $\begin{array}{l}\text { Replicate } \\
\text { sample } \\
\text { number }\end{array}$ & Year & $\begin{array}{l}\text { Collection } \\
\text { date }\end{array}$ & Latitude & Longitude & $\begin{array}{c}\text { Elevation } \\
\text { NAVD } 88 \\
\text { (ft) }\end{array}$ & $\begin{array}{c}\text { Drainage } \\
\text { area } \\
\left(\mathrm{mi}^{2}\right)\end{array}$ & Algal taxon name & $\begin{array}{c}\text { Total } \\
\text { density } \\
\text { (number of } \\
\text { cells/cm²) }\end{array}$ & $\begin{array}{c}\text { Total } \\
\text { biovolume } \\
\left(\mu^{3} / \mathrm{cm}^{2}\right)\end{array}$ \\
\hline 37 & 09066050 & Black Gore Creek near Vail & 1 & 2001 & $8 / 17 / 2001$ & $39^{\circ} 37^{\prime} 24^{\prime \prime}$ & $106^{\circ} 16^{\prime} 47^{\prime \prime}$ & 8,570 & 19.6 & $\begin{array}{l}\text { Planothidium lanceolatum (Brébisson } \\
\text { ex Kützing) Lange-Bertalot }\end{array}$ & 210 & 28,820 \\
\hline 37 & 09066050 & Black Gore Creek near Vail & 1 & 2001 & $8 / 17 / 2001$ & $39^{\circ} 37^{\prime} 24^{\prime \prime}$ & $106^{\circ} 16^{\prime} 47^{\prime \prime}$ & 8,570 & 19.6 & $\begin{array}{l}\text { Reimeria sinuata (Gregory) } \\
\text { Kociolek et Stoermer }\end{array}$ & 421 & 70,918 \\
\hline 37 & 09066050 & Black Gore Creek near Vail & 1 & 2001 & $8 / 17 / 2001$ & $39^{\circ} 37^{\prime} 24^{\prime \prime}$ & $106^{\circ} 16^{\prime} 47^{\prime \prime}$ & 8,570 & 19.6 & $\begin{array}{l}\text { Staurosira construens var. venter (Ehrenberg) } \\
\text { Hamilton }\end{array}$ & 70 & 8,423 \\
\hline 37 & 09066050 & Black Gore Creek near Vail & 1 & 2001 & $8 / 17 / 2001$ & $39^{\circ} 37^{\prime} 24^{\prime \prime}$ & $106^{\circ} 16^{\prime} 47^{\prime \prime}$ & 8,570 & 19.6 & $\begin{array}{l}\text { Staurosirella pinnata (Ehrenberg) } \\
\text { Williams et Round }\end{array}$ & 70 & 6,772 \\
\hline 37 & 09066050 & Black Gore Creek near Vail & 1 & 2001 & $8 / 17 / 2001$ & $39^{\circ} 37^{\prime} 24^{\prime \prime}$ & $106^{\circ} 16^{\prime} 47^{\prime \prime}$ & 8,570 & 19.6 & Synedra ulna (Nitzsch) Ehrenberg & 281 & $1,708,027$ \\
\hline 37 & 09066050 & Black Gore Creek near Vail & 1 & 2001 & $8 / 17 / 2001$ & $39^{\circ} 37^{\prime} 24^{\prime \prime}$ & $106^{\circ} 16^{\prime} 47^{\prime \prime}$ & 8,570 & 19.6 & Ulothrix sp. & 3,445 & 292,849 \\
\hline 37 & 09066050 & Black Gore Creek near Vail & 1 & 2001 & $8 / 17 / 2001$ & $39^{\circ} 37^{\prime} 24^{\prime \prime}$ & $106^{\circ} 16^{\prime} 47^{\prime \prime}$ & 8,570 & 19.6 & Unknown alga flagellate $(<10 \mu)$ & 1,723 & 165,550 \\
\hline 37 & 09066050 & Black Gore Creek near Vail & 1 & 2001 & $8 / 17 / 2001$ & $39^{\circ} 37^{\prime} 24^{\prime \prime}$ & $106^{\circ} 16^{\prime} 47^{\prime \prime}$ & 8,570 & 19.6 & $\begin{array}{l}\text { Unknown Cyanophyte Oscillatoriales } \\
\text { (no sheath) }\end{array}$ & 24,978 & 370,567 \\
\hline 37 & 09066050 & Black Gore Creek near Vail & 1 & 2001 & $8 / 17 / 2001$ & $39^{\circ} 37^{\prime} 24^{\prime \prime}$ & $106^{\circ} 16^{\prime} 47^{\prime \prime}$ & 8,570 & 19.6 & $\begin{array}{l}\text { Unknown Rhodophyte Florideophycidae } \\
\text { (chantransia) }\end{array}$ & 5,742 & $36,752,527$ \\
\hline 44 & 393824106221700 & Mill Creek near Vail & 1 & 2000 & $8 / 17 / 2000$ & $39^{\circ} 38^{\prime} 24^{\prime \prime}$ & $106^{\circ} 22^{\prime} 17^{\prime \prime}$ & 8,210 & 7.5 & $\begin{array}{l}\text { Achnanthidium minutissimum (Kützing) } \\
\text { Czarnecki }\end{array}$ & 378,376 & $20,837,890$ \\
\hline 44 & 393824106221700 & Mill Creek near Vail & 1 & 2000 & $8 / 17 / 2000$ & $39^{\circ} 38^{\prime} 24^{\prime \prime}$ & $106^{\circ} 22^{\prime} 17^{\prime \prime}$ & 8,210 & 7.5 & $\begin{array}{l}\text { Achnanthidium pyrenaicum (Hustedt) } \\
\text { Kobayasi }\end{array}$ & 33,454 & $4,208,830$ \\
\hline 44 & 393824106221700 & Mill Creek near Vail & 1 & 2000 & $8 / 17 / 2000$ & $39^{\circ} 38^{\prime} 24^{\prime \prime}$ & $106^{\circ} 22^{\prime} 17^{\prime \prime}$ & 8,210 & 7.5 & Amphora pediculus (Kützing) Grunow & 2,307 & 218,327 \\
\hline 44 & 393824106221700 & Mill Creek near Vail & 1 & 2000 & $8 / 17 / 2000$ & $39^{\circ} 38^{\prime} 24^{\prime \prime}$ & $106^{\circ} 22^{\prime} 17^{\prime \prime}$ & 8,210 & 7.5 & $\begin{array}{l}\text { Cocconeis placentula var. lineata (Ehrenberg) } \\
\text { Van Heurck }\end{array}$ & 1,154 & $1,208,671$ \\
\hline 44 & 393824106221700 & Mill Creek near Vail & 1 & 2000 & $8 / 17 / 2000$ & $39^{\circ} 38^{\prime} 24^{\prime \prime}$ & $106^{\circ} 22^{\prime} 17^{\prime \prime}$ & 8,210 & 7.5 & Cymbella affinis Kützing & 2,307 & $1,167,676$ \\
\hline 44 & 393824106221700 & Mill Creek near Vail & 1 & 2000 & $8 / 17 / 2000$ & $39^{\circ} 38^{\prime} 24^{\prime \prime}$ & $106^{\circ} 22^{\prime} 17^{\prime \prime}$ & 8,210 & 7.5 & Diatoma mesodon (Ehrenberg) Kützing & 11,536 & $12,283,781$ \\
\hline 44 & 393824106221700 & Mill Creek near Vail & 1 & 2000 & $8 / 17 / 2000$ & $39^{\circ} 38^{\prime} 24^{\prime \prime}$ & $106^{\circ} 22^{\prime} 17^{\prime \prime}$ & 8,210 & 7.5 & Encyonema brehmii (Hustedt) Mann & 2,307 & 63,612 \\
\hline 44 & 393824106221700 & Mill Creek near Vail & 1 & 2000 & $8 / 17 / 2000$ & $39^{\circ} 38^{\prime} 24^{\prime \prime}$ & $106^{\circ} 22^{\prime} 17^{\prime \prime}$ & 8,210 & 7.5 & Encyonema minutum (Hilse) Mann & 12,689 & $2,715,334$ \\
\hline 44 & 393824106221700 & Mill Creek near Vail & 1 & 2000 & $8 / 17 / 2000$ & $39^{\circ} 38^{\prime} 24^{\prime \prime}$ & $106^{\circ} 22^{\prime} 17^{\prime \prime}$ & 8,210 & 7.5 & Encyonema silesiacum (Bleisch) Mann & 220,335 & $103,744,996$ \\
\hline 44 & 393824106221700 & Mill Creek near Vail & 1 & 2000 & $8 / 17 / 2000$ & $39^{\circ} 38^{\prime} 24^{\prime \prime}$ & $106^{\circ} 22^{\prime} 17^{\prime \prime}$ & 8,210 & 7.5 & Fragilaria vaucheriae (Kützing) Petersen & 24,225 & $5,011,287$ \\
\hline 44 & 393824106221700 & Mill Creek near Vail & 1 & 2000 & $8 / 17 / 2000$ & $39^{\circ} 38^{\prime} 24^{\prime \prime}$ & $106^{\circ} 22^{\prime} 17^{\prime \prime}$ & 8,210 & 7.5 & $\begin{array}{l}\text { Gomphonema angustatum (Kützing) } \\
\text { Rabenhorst }\end{array}$ & 36,915 & $15,261,664$ \\
\hline 44 & 393824106221700 & Mill Creek near Vail & 1 & 2000 & $8 / 17 / 2000$ & $39^{\circ} 38^{\prime} 24^{\prime \prime}$ & $106^{\circ} 22^{\prime} 17^{\prime \prime}$ & 8,210 & 7.5 & Gomphonema olivaceum (Lyngbye) Kützing & 21,918 & $7,541,343$ \\
\hline 44 & 393824106221700 & Mill Creek near Vail & 1 & 2000 & $8 / 17 / 2000$ & $39^{\circ} 38^{\prime} 24^{\prime \prime}$ & $106^{\circ} 22^{\prime} 17^{\prime \prime}$ & 8,210 & 7.5 & Hannaea arcus (Ehrenberg) Patrick & 68,062 & $165,262,909$ \\
\hline 44 & 393824106221700 & Mill Creek near Vail & 1 & 2000 & $8 / 17 / 2000$ & $39^{\circ} 38^{\prime} 24^{\prime \prime}$ & $106^{\circ} 22^{\prime} 17^{\prime \prime}$ & 8,210 & 7.5 & $\begin{array}{l}\text { Homoeothrix janthina (Bornet et Flahault) } \\
\text { Starmach }\end{array}$ & $2,071,775$ & $67,142,766$ \\
\hline 44 & 393824106221700 & Mill Creek near Vail & 1 & 2000 & $8 / 17 / 2000$ & $39^{\circ} 38^{\prime} 24^{\prime \prime}$ & $106^{\circ} 22^{\prime} 17^{\prime \prime}$ & 8,210 & 7.5 & $\begin{array}{l}\text { Navicula cryptotenella Lange-Bertalot } \\
\text { ex Krammer et Lange-Bertalot }\end{array}$ & 2,307 & 835,016 \\
\hline 44 & 393824106221700 & Mill Creek near Vail & 1 & 2000 & $8 / 17 / 2000$ & $39^{\circ} 38^{\prime} 24^{\prime \prime}$ & $106^{\circ} 22^{\prime} 17^{\prime \prime}$ & 8,210 & 7.5 & Navicula tripunctata (Müller) Bory & 1,154 & $1,091,477$ \\
\hline 44 & 393824106221700 & Mill Creek near Vail & 1 & 2000 & $8 / 17 / 2000$ & $39^{\circ} 38^{\prime} 24^{\prime \prime}$ & $106^{\circ} 22^{\prime} 17^{\prime \prime}$ & 8,210 & 7.5 & $\begin{array}{l}\text { Nitzschia cf. tubicola } \\
\text { Grunow ex Cleve et Grunow }\end{array}$ & 2,307 & 564,680 \\
\hline 44 & 393824106221700 & Mill Creek near Vail & 1 & 2000 & $8 / 17 / 2000$ & $39^{\circ} 38^{\prime} 24^{\prime \prime}$ & $106^{\circ} 22^{\prime} 17^{\prime \prime}$ & 8,210 & 7.5 & Nitzschia fonticola Grunow & 2,307 & 229,110 \\
\hline 44 & 393824106221700 & Mill Creek near Vail & 1 & 2000 & $8 / 17 / 2000$ & $39^{\circ} 38^{\prime} 24^{\prime \prime}$ & $106^{\circ} 22^{\prime} 17^{\prime \prime}$ & 8,210 & 7.5 & Phormidium autumnale (Agardh) Gomont & $1,119,475$ & $109,629,265$ \\
\hline 44 & 393824106221700 & Mill Creek near Vail & 1 & 2000 & $8 / 17 / 2000$ & $39^{\circ} 38^{\prime} 24^{\prime \prime}$ & $106^{\circ} 22^{\prime} 17^{\prime \prime}$ & 8,210 & 7.5 & $\begin{array}{l}\text { Reimeria sinuata (Gregory) } \\
\text { Kociolek et Stoermer }\end{array}$ & 9,229 & $1,525,900$ \\
\hline 44 & 393824106221700 & Mill Creek near Vail & 1 & 2000 & $8 / 17 / 2000$ & $39^{\circ} 38^{\prime} 24^{\prime \prime}$ & $106^{\circ} 22^{\prime} 17^{\prime \prime}$ & 8,210 & 7.5 & Stigeoclonium lubricum (Dillwyn) Kützing & 95,529 & $141,790,844$ \\
\hline 44 & 393824106221700 & Mill Creek near Vail & 1 & 2001 & $8 / 17 / 2001$ & $39^{\circ} 38^{\prime} 24^{\prime \prime}$ & $106^{\circ} 22^{\prime} 17^{\prime \prime}$ & 8,210 & 7.5 & $\begin{array}{l}\text { Achnanthidium minutissimum (Kützing) } \\
\text { Czarnecki }\end{array}$ & $3,313,311$ & $179,650,738$ \\
\hline 44 & 393824106221700 & Mill Creek near Vail & 1 & 2001 & $8 / 17 / 2001$ & $39^{\circ} 38^{\prime} 24^{\prime \prime}$ & $106^{\circ} 22^{\prime} 17^{\prime \prime}$ & 8,210 & 7.5 & $\begin{array}{l}\text { Achnanthidium pyrenaicum (Hustedt) } \\
\text { Kobayasi }\end{array}$ & 541,119 & $68,376,853$ \\
\hline
\end{tabular}




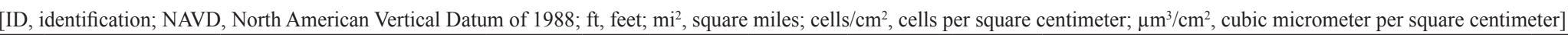

\begin{tabular}{|c|c|c|c|c|c|c|c|c|c|c|c|c|}
\hline $\begin{array}{l}\text { Site } \\
\text { ID }^{1}\end{array}$ & $\begin{array}{l}\text { USGS } \\
\text { station } \\
\text { number }\end{array}$ & Station name & $\begin{array}{c}\text { Replicate } \\
\text { sample } \\
\text { number }\end{array}$ & Year & $\begin{array}{l}\text { Collection } \\
\text { date }\end{array}$ & Latitude & Longitude & $\begin{array}{c}\text { Elevation } \\
\text { NAVD } 88 \\
\text { (ft) }\end{array}$ & $\begin{array}{c}\text { Drainage } \\
\text { area } \\
\left(\mathrm{mi}^{2}\right)\end{array}$ & Algal taxon name & $\begin{array}{c}\text { Total } \\
\text { density } \\
\text { (number of } \\
\text { cells } / \mathrm{cm}^{2} \text { ) }\end{array}$ & $\begin{array}{c}\text { Total } \\
\text { biovolume } \\
\left(\mu \mathrm{m}^{3} / \mathrm{cm}^{2}\right)\end{array}$ \\
\hline 44 & 393824106221700 & Mill Creek near Vail & 1 & 2001 & $8 / 17 / 2001$ & $39^{\circ} 38^{\prime} 24^{\prime \prime}$ & $106^{\circ} 22^{\prime} 17^{\prime \prime}$ & 8,210 & 7.5 & Adlafia minuscula (Grunow) Lange-Bertalot & 16,650 & $1,385,282$ \\
\hline 44 & 393824106221700 & Mill Creek near Vail & 1 & 2001 & $8 / 17 / 2001$ & $39^{\circ} 38^{\prime} 24^{\prime \prime}$ & $106^{\circ} 22^{\prime} 17^{\prime \prime}$ & 8,210 & 7.5 & Amphora pediculus (Kützing) Grunow & 41,625 & $4,024,511$ \\
\hline 44 & 393824106221700 & Mill Creek near Vail & 1 & 2001 & $8 / 17 / 2001$ & $39^{\circ} 38^{\prime} 24^{\prime \prime}$ & $106^{\circ} 22^{\prime} 17^{\prime \prime}$ & 8,210 & 7.5 & Caloneis bacillum (Grunow) Cleve & 16,650 & $7,162,190$ \\
\hline 44 & 393824106221700 & Mill Creek near Vail & 1 & 2001 & $8 / 17 / 2001$ & $39^{\circ} 38^{\prime} 24^{\prime \prime}$ & $106^{\circ} 22^{\prime} 17^{\prime \prime}$ & 8,210 & 7.5 & $\begin{array}{l}\text { Cocconeis placentula var. lineata (Ehrenberg) } \\
\text { Van Heurck }\end{array}$ & 16,650 & $17,558,764$ \\
\hline 44 & 393824106221700 & Mill Creek near Vail & 1 & 2001 & $8 / 17 / 2001$ & $39^{\circ} 38^{\prime} 24^{\prime \prime}$ & $106^{\circ} 22^{\prime} 17^{\prime \prime}$ & 8,210 & 7.5 & Cymbella affinis Kützing & 66,599 & $33,895,685$ \\
\hline 44 & 393824106221700 & Mill Creek near Vail & 1 & 2001 & $8 / 17 / 2001$ & $39^{\circ} 38^{\prime} 24^{\prime \prime}$ & $106^{\circ} 22^{\prime} 17^{\prime \prime}$ & 8,210 & 7.5 & Encyonema minutum (Hilse) Mann & 83,249 & $17,967,946$ \\
\hline 44 & 393824106221700 & Mill Creek near Vail & 1 & 2001 & $8 / 17 / 2001$ & $39^{\circ} 38^{\prime} 24^{\prime \prime}$ & $106^{\circ} 22^{\prime} 17^{\prime \prime}$ & 8,210 & 7.5 & Encyonema silesiacum (Bleisch) Mann & 449,545 & $213,509,298$ \\
\hline 44 & 393824106221700 & Mill Creek near Vail & 1 & 2001 & $8 / 17 / 2001$ & $39^{\circ} 38^{\prime} 24^{\prime \prime}$ & $106^{\circ} 22^{\prime} 17^{\prime \prime}$ & 8,210 & 7.5 & Fragilaria vaucheriae (Kützing) Petersen & 83,249 & $16,401,010$ \\
\hline 44 & 393824106221700 & Mill Creek near Vail & 1 & 2001 & $8 / 17 / 2001$ & $39^{\circ} 38^{\prime} 24^{\prime \prime}$ & $106^{\circ} 22^{\prime} 17^{\prime \prime}$ & 8,210 & 7.5 & Gomphonema minutum (Agardh) Agardh & 16,650 & $1,360,376$ \\
\hline 44 & 393824106221700 & Mill Creek near Vail & 1 & 2001 & $8 / 17 / 2001$ & $39^{\circ} 38^{\prime} 24^{\prime \prime}$ & $106^{\circ} 22^{\prime} 17^{\prime \prime}$ & 8,210 & 7.5 & Gomphonema olivaceum (Lyngbye) Kützing & 24,975 & $9,463,881$ \\
\hline 44 & 393824106221700 & Mill Creek near Vail & 1 & 2001 & $8 / 17 / 2001$ & $39^{\circ} 38^{\prime} 24^{\prime \prime}$ & $106^{\circ} 22^{\prime} 17^{\prime \prime}$ & 8,210 & 7.5 & Gomphonema parvulum (Kützing) Kützing & 41,625 & $9,095,863$ \\
\hline 44 & 393824106221700 & Mill Creek near Vail & 1 & 2001 & $8 / 17 / 2001$ & $39^{\circ} 38^{\prime} 24^{\prime \prime}$ & $106^{\circ} 22^{\prime} 17^{\prime \prime}$ & 8,210 & 7.5 & Hannaea arcus (Ehrenberg) Patrick & 33,300 & $66,770,749$ \\
\hline 44 & 393824106221700 & Mill Creek near Vail & 1 & 2001 & $8 / 17 / 2001$ & $39^{\circ} 38^{\prime} 24^{\prime \prime}$ & $106^{\circ} 22^{\prime} 17^{\prime \prime}$ & 8,210 & 7.5 & $\begin{array}{l}\text { Homoeothrix janthina (Bornet et Flahault) } \\
\text { Starmach }\end{array}$ & $35,633,323$ & $613,379,816$ \\
\hline 44 & 393824106221700 & Mill Creek near Vail & 1 & 2001 & $8 / 17 / 2001$ & $39^{\circ} 38^{\prime} 24^{\prime \prime}$ & $106^{\circ} 22^{\prime} 17^{\prime \prime}$ & 8,210 & 7.5 & $\begin{array}{l}\text { Navicula cryptotenella Lange-Bertalot } \\
\text { ex Krammer et Lange-Bertalot }\end{array}$ & 66,599 & $17,690,195$ \\
\hline 44 & 393824106221700 & Mill Creek near Vail & 1 & 2001 & $8 / 17 / 2001$ & $39^{\circ} 38^{\prime} 24^{\prime \prime}$ & $106^{\circ} 22^{\prime} 17^{\prime \prime}$ & 8,210 & 7.5 & Navicula minima Grunow & 33,300 & $1,498,707$ \\
\hline 44 & 393824106221700 & Mill Creek near Vail & 1 & 2001 & $8 / 17 / 2001$ & $39^{\circ} 38^{\prime} 24^{\prime \prime}$ & $106^{\circ} 22^{\prime} 17^{\prime \prime}$ & 8,210 & 7.5 & Navicula tripunctata (Müller) Bory & 33,300 & $30,280,478$ \\
\hline 44 & 393824106221700 & Mill Creek near Vail & 1 & 2001 & $8 / 17 / 2001$ & $39^{\circ} 38^{\prime} 24^{\prime \prime}$ & $106^{\circ} 22^{\prime} 17^{\prime \prime}$ & 8,210 & 7.5 & $\begin{array}{l}\text { Nitzschia } \text { cf. tubicola } \\
\text { Grunow ex Cleve et Grunow }\end{array}$ & 58,274 & $19,016,851$ \\
\hline 44 & 393824106221700 & Mill Creek near Vail & 1 & 2001 & $8 / 17 / 2001$ & $39^{\circ} 38^{\prime} 24^{\prime \prime}$ & $106^{\circ} 22^{\prime} 17^{\prime \prime}$ & 8,210 & 7.5 & Nitzschia dissipata (Kützing) Grunow & 33,300 & $8,585,804$ \\
\hline 44 & 393824106221700 & Mill Creek near Vail & 1 & 2001 & $8 / 17 / 2001$ & $39^{\circ} 38^{\prime} 24^{\prime \prime}$ & $106^{\circ} 22^{\prime} 17^{\prime \prime}$ & 8,210 & 7.5 & Nitzschia fonticola Grunow & 49,949 & $4,968,754$ \\
\hline 44 & 393824106221700 & Mill Creek near Vail & 1 & 2001 & $8 / 17 / 2001$ & $39^{\circ} 38^{\prime} 24^{\prime \prime}$ & $106^{\circ} 22^{\prime} 17^{\prime \prime}$ & 8,210 & 7.5 & Nitzschia inconspicua Grunow & 99,899 & $3,518,121$ \\
\hline 44 & 393824106221700 & Mill Creek near Vail & 1 & 2001 & $8 / 17 / 2001$ & $39^{\circ} 38^{\prime} 24^{\prime \prime}$ & $106^{\circ} 22^{\prime} 17^{\prime \prime}$ & 8,210 & 7.5 & Phormidium autumnale (Agardh) Gomont & $8,479,235$ & $822,105,660$ \\
\hline 44 & 393824106221700 & Mill Creek near Vail & 1 & 2001 & $8 / 17 / 2001$ & $39^{\circ} 38^{\prime} 24^{\prime \prime}$ & $106^{\circ} 22^{\prime} 17^{\prime \prime}$ & 8,210 & 7.5 & Unknown alga flagellate $(<10 \mu)$ & 102,690 & $9,868,732$ \\
\hline 47 & 09066310 & $\begin{array}{l}\text { Gore Creek at Lower Station } \\
\text { at Vail }\end{array}$ & 1 & 2000 & $8 / 17 / 2000$ & $39^{\circ} 38^{\prime} 28^{\prime \prime}$ & $106^{\circ} 23^{\prime} 37^{\prime \prime}$ & 8,060 & 77.1 & $\begin{array}{l}\text { Achnanthidium minutissimum (Kützing) } \\
\text { Czarnecki }\end{array}$ & 15,413 & 848,840 \\
\hline 47 & 09066310 & $\begin{array}{l}\text { Gore Creek at Lower Station } \\
\text { at Vail }\end{array}$ & 1 & 2000 & $8 / 17 / 2000$ & $39^{\circ} 38^{\prime} 28^{\prime \prime}$ & $106^{\circ} 23^{\prime} 37^{\prime \prime}$ & 8,060 & 77.1 & $\begin{array}{l}\text { Achnanthidium pyrenaicum (Hustedt) } \\
\text { Kobayasi }\end{array}$ & 75 & 9,444 \\
\hline 47 & 09066310 & $\begin{array}{l}\text { Gore Creek at Lower Station } \\
\text { at Vail }\end{array}$ & 1 & 2000 & $8 / 17 / 2000$ & $39^{\circ} 38^{\prime} 28^{\prime \prime}$ & $106^{\circ} 23^{\prime} 37^{\prime \prime}$ & 8,060 & 77.1 & $\begin{array}{l}\text { Cocconeis placentula var. euglypta } \\
\text { (Ehrenberg) Grunow }\end{array}$ & 425 & 256,261 \\
\hline 47 & 09066310 & $\begin{array}{l}\text { Gore Creek at Lower Station } \\
\text { at Vail }\end{array}$ & 1 & 2000 & $8 / 17 / 2000$ & $39^{\circ} 38^{\prime} 28^{\prime \prime}$ & $106^{\circ} 23^{\prime} 37^{\prime \prime}$ & 8,060 & 77.1 & $\begin{array}{l}\text { Cocconeis placentula var. lineata (Ehrenberg) } \\
\text { Van Heurck }\end{array}$ & 225 & 235,948 \\
\hline 47 & 09066310 & $\begin{array}{l}\text { Gore Creek at Lower Station } \\
\text { at Vail }\end{array}$ & 1 & 2000 & $8 / 17 / 2000$ & $39^{\circ} 38^{\prime} 28^{\prime \prime}$ & $106^{\circ} 23^{\prime} 37^{\prime \prime}$ & 8,060 & 77.1 & Cymbella affinis Kützing & 50 & 25,327 \\
\hline 47 & 09066310 & $\begin{array}{l}\text { Gore Creek at Lower Station } \\
\text { at Vail }\end{array}$ & 1 & 2000 & $8 / 17 / 2000$ & $39^{\circ} 38^{\prime} 28^{\prime \prime}$ & $106^{\circ} 23^{\prime} 37^{\prime \prime}$ & 8,060 & 77.1 & Diatoma mesodon (Ehrenberg) Kützing & 25 & 26,644 \\
\hline 47 & 09066310 & $\begin{array}{l}\text { Gore Creek at Lower Station } \\
\text { at Vail }\end{array}$ & 1 & 2000 & $8 / 17 / 2000$ & $39^{\circ} 38^{\prime} 28^{\prime \prime}$ & $106^{\circ} 23^{\prime} 37^{\prime \prime}$ & 8,060 & 77.1 & Encyonema brehmii (Hustedt) Mann & 50 & 1,380 \\
\hline 47 & 09066310 & $\begin{array}{l}\text { Gore Creek at Lower Station } \\
\text { at Vail }\end{array}$ & 1 & 2000 & $8 / 17 / 2000$ & $39^{\circ} 38^{\prime} 28^{\prime \prime}$ & $106^{\circ} 23^{\prime} 37^{\prime \prime}$ & 8,060 & 77.1 & Encyonema silesiacum (Bleisch) Mann & 776 & 365,225 \\
\hline 47 & 09066310 & $\begin{array}{l}\text { Gore Creek at Lower Station } \\
\text { at Vail }\end{array}$ & 1 & 2000 & $8 / 17 / 2000$ & $39^{\circ} 38^{\prime} 28^{\prime \prime}$ & $106^{\circ} 23^{\prime} 37^{\prime \prime}$ & 8,060 & 77.1 & $\begin{array}{l}\text { Fragilaria capucina var. fragilarioides } \\
\text { (Grunow) Ludwig et Flores }\end{array}$ & 50 & 5,127 \\
\hline 47 & 09066310 & $\begin{array}{l}\text { Gore Creek at Lower Station } \\
\text { at Vail }\end{array}$ & 1 & 2000 & $8 / 17 / 2000$ & $39^{\circ} 38^{\prime} 28^{\prime \prime}$ & $106^{\circ} 23^{\prime} 37^{\prime \prime}$ & 8,060 & 77.1 & Fragilaria vaucheriae (Kützing) Petersen & 300 & 62,112 \\
\hline 47 & 09066310 & $\begin{array}{l}\text { Gore Creek at Lower Station } \\
\text { at Vail }\end{array}$ & 1 & 2000 & $8 / 17 / 2000$ & $39^{\circ} 38^{\prime} 28^{\prime \prime}$ & $106^{\circ} 23^{\prime} 37^{\prime \prime}$ & 8,060 & 77.1 & $\begin{array}{l}\text { Gomphonema angustatum (Kützing) } \\
\text { Rabenhorst }\end{array}$ & 100 & 41,379 \\
\hline
\end{tabular}


Table 2. Description of sites and algal data collected from selected sites the Eagle River watershed, Colorado, 2000-2001.—Continued

[ID, identification; NAVD, North American Vertical Datum of 1988; ft, feet; $\mathrm{mi}^{2}$, square miles; cells $/ \mathrm{cm}^{2}$, cells per square centimeter; $\mu \mathrm{m}^{3} / \mathrm{cm}^{2}$, cubic micrometer per square centimeter]

\begin{tabular}{|c|c|c|c|c|c|c|c|c|c|c|c|c|}
\hline $\begin{array}{l}\text { Site } \\
\text { ID' }\end{array}$ & $\begin{array}{l}\text { USGS } \\
\text { station } \\
\text { number }\end{array}$ & Station name & $\begin{array}{l}\text { Replicate } \\
\text { sample } \\
\text { number }\end{array}$ & Year & $\begin{array}{l}\text { Collection } \\
\text { date }\end{array}$ & Latitude & Longitude & $\begin{array}{c}\text { Elevation } \\
\text { NAVD } 88 \\
\text { (ft) }\end{array}$ & $\begin{array}{c}\text { Drainage } \\
\text { area } \\
\left(\mathrm{mi}^{2}\right)\end{array}$ & Algal taxon name & $\begin{array}{c}\text { Total } \\
\text { density } \\
\text { (number of } \\
\text { cells/cm²) }\end{array}$ & $\begin{array}{c}\text { Total } \\
\text { biovolume } \\
\left(\mu \mathrm{m}^{3} / \mathrm{cm}^{2}\right)\end{array}$ \\
\hline 47 & 09066310 & $\begin{array}{l}\text { Gore Creek at Lower Station } \\
\text { at Vail }\end{array}$ & 1 & 2000 & $8 / 17 / 2000$ & $39^{\circ} 38^{\prime} 28^{\prime \prime}$ & $106^{\circ} 23^{\prime} 37^{\prime \prime}$ & 8,060 & 77.1 & Gomphonema olivaceum (Lyngbye) Kützing & 475 & 163,574 \\
\hline 47 & 09066310 & $\begin{array}{l}\text { Gore Creek at Lower Station } \\
\text { at Vail }\end{array}$ & 1 & 2000 & $8 / 17 / 2000$ & $39^{\circ} 38^{\prime} 28^{\prime \prime}$ & $106^{\circ} 23^{\prime} 37^{\prime \prime}$ & 8,060 & 77.1 & $\begin{array}{l}\text { Gomphonema pumilum (Grunow) } \\
\text { Reichardt et Lange-Bertalot }\end{array}$ & 325 & 94,911 \\
\hline 47 & 09066310 & $\begin{array}{l}\text { Gore Creek at Lower Station } \\
\text { at Vail }\end{array}$ & 1 & 2000 & $8 / 17 / 2000$ & $39^{\circ} 38^{\prime} 28^{\prime \prime}$ & $106^{\circ} 23^{\prime} 37^{\prime \prime}$ & 8,060 & 77.1 & Hannaea arcus (Ehrenberg) Patrick & 100 & 243,024 \\
\hline 47 & 09066310 & $\begin{array}{l}\text { Gore Creek at Lower Station } \\
\text { at Vail }\end{array}$ & 1 & 2000 & $8 / 17 / 2000$ & $39^{\circ} 38^{\prime} 28^{\prime \prime}$ & $106^{\circ} 23^{\prime} 37^{\prime \prime}$ & 8,060 & 77.1 & $\begin{array}{l}\text { Homoeothrix janthina (Bornet et Flahault) } \\
\text { Starmach }\end{array}$ & 189,844 & $6,152,540$ \\
\hline 47 & 09066310 & $\begin{array}{l}\text { Gore Creek at Lower Station } \\
\text { at Vail }\end{array}$ & 1 & 2000 & $8 / 17 / 2000$ & $39^{\circ} 38^{\prime} 28^{\prime \prime}$ & $106^{\circ} 23^{\prime} 37^{\prime \prime}$ & 8,060 & 77.1 & Navicula incertata Hustedt & 50 & 2,587 \\
\hline 47 & 09066310 & $\begin{array}{l}\text { Gore Creek at Lower Station } \\
\text { at Vail }\end{array}$ & 1 & 2000 & $8 / 17 / 2000$ & $39^{\circ} 38^{\prime} 28^{\prime \prime}$ & $106^{\circ} 23^{\prime} 37^{\prime \prime}$ & 8,060 & 77.1 & Nitzschia fonticola Grunow & 100 & 9,939 \\
\hline 47 & 09066310 & $\begin{array}{l}\text { Gore Creek at Lower Station } \\
\text { at Vail }\end{array}$ & 1 & 2000 & $8 / 17 / 2000$ & $39^{\circ} 38^{\prime} 28^{\prime \prime}$ & $106^{\circ} 23^{\prime} 37^{\prime \prime}$ & 8,060 & 77.1 & Phormidium autumnale (Agardh) Gomont & 19,024 & $1,863,039$ \\
\hline 47 & 09066310 & $\begin{array}{l}\text { Gore Creek at Lower Station } \\
\text { at Vail }\end{array}$ & 1 & 2000 & $8 / 17 / 2000$ & $39^{\circ} 38^{\prime} 28^{\prime \prime}$ & $106^{\circ} 23^{\prime} 37^{\prime \prime}$ & 8,060 & 77.1 & $\begin{array}{l}\text { Planothidium lanceolatum } \\
\text { (Brébisson ex Kützing) Lange-Bertalot }\end{array}$ & 25 & 3,574 \\
\hline 47 & 09066310 & $\begin{array}{l}\text { Gore Creek at Lower Station } \\
\text { at Vail }\end{array}$ & 1 & 2000 & $8 / 17 / 2000$ & $39^{\circ} 38^{\prime} 28^{\prime \prime}$ & $106^{\circ} 23^{\prime} 37^{\prime \prime}$ & 8,060 & 77.1 & $\begin{array}{l}\text { Reimeria sinuata (Gregory) } \\
\text { Kociolek et Stoermer }\end{array}$ & 75 & 12,411 \\
\hline 47 & 09066310 & $\begin{array}{l}\text { Gore Creek at Lower Station } \\
\text { at Vail }\end{array}$ & 1 & 2000 & $8 / 17 / 2000$ & $39^{\circ} 38^{\prime} 28^{\prime \prime}$ & $106^{\circ} 23^{\prime} 37^{\prime \prime}$ & 8,060 & 77.1 & $\begin{array}{l}\text { Staurosira construens var. venter (Ehrenberg) } \\
\text { Hamilton }\end{array}$ & 50 & 6,010 \\
\hline 47 & 09066310 & $\begin{array}{l}\text { Gore Creek at Lower Station } \\
\text { at Vail }\end{array}$ & 1 & 2000 & $8 / 17 / 2000$ & $39^{\circ} 38^{\prime} 28^{\prime \prime}$ & $106^{\circ} 23^{\prime} 37^{\prime \prime}$ & 8,060 & 77.1 & Stigeoclonium lubricum (Dillwyn) Kützing & 2,528 & $3,751,824$ \\
\hline 47 & 09066310 & $\begin{array}{l}\text { Gore Creek at Lower Station } \\
\text { at Vail }\end{array}$ & 1 & 2000 & $8 / 17 / 2000$ & $39^{\circ} 38^{\prime} 28^{\prime \prime}$ & $106^{\circ} 23^{\prime} 37^{\prime \prime}$ & 8,060 & 77.1 & Synedra ulna (Nitzsch) Ehrenberg & 200 & $1,312,450$ \\
\hline 47 & 09066310 & $\begin{array}{l}\text { Gore Creek at Lower Station } \\
\text { at Vail }\end{array}$ & 1 & 2000 & $8 / 17 / 2000$ & $39^{\circ} 38^{\prime} 28^{\prime \prime}$ & $106^{\circ} 23^{\prime} 37^{\prime \prime}$ & 8,060 & 77.1 & $\begin{array}{l}\text { Unknown Rhodophyte Florideophycidae } \\
\text { (chantransia) }\end{array}$ & 3,592 & $12,712,752$ \\
\hline 47 & 09066310 & $\begin{array}{l}\text { Gore Creek at Lower Station } \\
\text { at Vail }\end{array}$ & 2 & 2000 & $8 / 18 / 2000$ & $39^{\circ} 38^{\prime} 28^{\prime \prime}$ & $106^{\circ} 23^{\prime} 37^{\prime \prime}$ & 8,060 & 77.1 & $\begin{array}{l}\text { Achnanthidium minutissimum (Kützing) } \\
\text { Czarnecki }\end{array}$ & 305,012 & $16,797,569$ \\
\hline 47 & 09066310 & $\begin{array}{l}\text { Gore Creek at Lower Station } \\
\text { at Vail }\end{array}$ & 2 & 2000 & $8 / 18 / 2000$ & $39^{\circ} 38^{\prime} 28^{\prime \prime}$ & $106^{\circ} 23^{\prime} 37^{\prime \prime}$ & 8,060 & 77.1 & $\begin{array}{l}\text { Achnanthidium pyrenaicum (Hustedt) } \\
\text { Kobayasi }\end{array}$ & 122,354 & $15,393,330$ \\
\hline 47 & 09066310 & $\begin{array}{l}\text { Gore Creek at Lower Station } \\
\text { at Vail }\end{array}$ & 2 & 2000 & $8 / 18 / 2000$ & $39^{\circ} 38^{\prime} 28^{\prime \prime}$ & $106^{\circ} 23^{\prime} 37^{\prime \prime}$ & 8,060 & 77.1 & Amphora pediculus (Kützing) Grunow & 1,748 & 165,405 \\
\hline 47 & 09066310 & $\begin{array}{l}\text { Gore Creek at Lower Station } \\
\text { at Vail }\end{array}$ & 2 & 2000 & $8 / 18 / 2000$ & $39^{\circ} 38^{\prime} 28^{\prime \prime}$ & $106^{\circ} 23^{\prime} 37^{\prime \prime}$ & 8,060 & 77.1 & Chlamydomonas sp. & 4,760 & 404,624 \\
\hline 47 & 09066310 & $\begin{array}{l}\text { Gore Creek at Lower Station } \\
\text { at Vail }\end{array}$ & 2 & 2000 & $8 / 18 / 2000$ & $39^{\circ} 38^{\prime} 28^{\prime \prime}$ & $106^{\circ} 23^{\prime} 37^{\prime \prime}$ & 8,060 & 77.1 & $\begin{array}{l}\text { Cocconeis placentula var. lineata (Ehrenberg) } \\
\text { Van Heurck }\end{array}$ & 1,748 & $1,831,384$ \\
\hline 47 & 09066310 & $\begin{array}{l}\text { Gore Creek at Lower Station } \\
\text { at Vail }\end{array}$ & 2 & 2000 & $8 / 18 / 2000$ & $39^{\circ} 38^{\prime} 28^{\prime \prime}$ & $106^{\circ} 23^{\prime} 37^{\prime \prime}$ & 8,060 & 77.1 & Diatoma moniliformis Kützing & 27,967 & $4,214,982$ \\
\hline 47 & 09066310 & $\begin{array}{l}\text { Gore Creek at Lower Station } \\
\text { at Vail }\end{array}$ & 2 & 2000 & $8 / 18 / 2000$ & $39^{\circ} 38^{\prime} 28^{\prime \prime}$ & $106^{\circ} 23^{\prime} 37^{\prime \prime}$ & 8,060 & 77.1 & Diatoma vulgaris Bory & 15,731 & $58,125,740$ \\
\hline 47 & 09066310 & $\begin{array}{l}\text { Gore Creek at Lower Station } \\
\text { at Vail }\end{array}$ & 2 & 2000 & $8 / 18 / 2000$ & $39^{\circ} 38^{\prime} 28^{\prime \prime}$ & $106^{\circ} 23^{\prime} 37^{\prime \prime}$ & 8,060 & 77.1 & Encyonema brehmii (Hustedt) Mann & 1,748 & 48,193 \\
\hline 47 & 09066310 & $\begin{array}{l}\text { Gore Creek at Lower Station } \\
\text { at Vail }\end{array}$ & 2 & 2000 & $8 / 18 / 2000$ & $39^{\circ} 38^{\prime} 28^{\prime \prime}$ & $106^{\circ} 23^{\prime} 37^{\prime \prime}$ & 8,060 & 77.1 & Encyonema minutum (Hilse) Mann & 1,748 & 374,026 \\
\hline 47 & 09066310 & Gore Creek at Lower Station & 2 & 2000 & $8 / 18 / 2000$ & $39^{\circ} 38^{\prime} 28^{\prime \prime}$ & $106^{\circ} 23^{\prime} 37^{\prime \prime}$ & 8,060 & 77.1 & Encyonema silesiacum (Bleisch) Mann & 105,749 & $49,792,080$ \\
\hline
\end{tabular}


Table 2. Description of sites and algal data collected from selected sites the Eagle River watershed, Colorado, 2000-2001. - Continued

[ID, identification; NAVD, North American Vertical Datum of 1988; ft, feet; $\mathrm{mi}^{2}$, square miles; cells $/ \mathrm{cm}^{2}$, cells per square centimeter; $\mu \mathrm{m}^{3} / \mathrm{cm}^{2}$, cubic micrometer per square centimeter

\begin{tabular}{|c|c|c|c|c|c|c|c|c|c|c|c|c|}
\hline $\begin{array}{l}\text { Site } \\
\text { ID' }^{1}\end{array}$ & $\begin{array}{l}\text { USGS } \\
\text { station } \\
\text { number }\end{array}$ & Station name & $\begin{array}{l}\text { Replicate } \\
\text { sample } \\
\text { number }\end{array}$ & Year & $\begin{array}{l}\text { Collection } \\
\text { date }\end{array}$ & Latitude & Longitude & $\begin{array}{c}\text { Elevation } \\
\text { NAVD } 88 \\
\text { (ft) }\end{array}$ & $\begin{array}{c}\text { Drainage } \\
\text { area } \\
\left(\mathrm{mi}^{2}\right)\end{array}$ & Algal taxon name & $\begin{array}{c}\text { Total } \\
\text { density } \\
\text { (number of } \\
\text { cells/cm²) }\end{array}$ & $\begin{array}{c}\text { Total } \\
\text { biovolume } \\
\left(\mu \mathrm{m}^{3} / \mathrm{cm}^{2}\right)\end{array}$ \\
\hline 47 & 09066310 & $\begin{array}{l}\text { Gore Creek at Lower Station } \\
\text { at Vail }\end{array}$ & 2 & 2000 & $8 / 18 / 2000$ & $39^{\circ} 38^{\prime} 28^{\prime \prime}$ & $106^{\circ} 23^{\prime} 37^{\prime \prime}$ & 8,060 & 77.1 & Eucocconeis laevis (Østrup) Lange-Bertalot & 1,748 & $2,609,642$ \\
\hline 47 & 09066310 & $\begin{array}{l}\text { Gore Creek at Lower Station } \\
\text { at Vail }\end{array}$ & 2 & 2000 & $8 / 18 / 2000$ & $39^{\circ} 38^{\prime} 28^{\prime \prime}$ & $106^{\circ} 23^{\prime} 37^{\prime \prime}$ & 8,060 & 77.1 & Fragilaria vaucheriae (Kützing) Petersen & 27,093 & $5,604,448$ \\
\hline 47 & 09066310 & $\begin{array}{l}\text { Gore Creek at Lower Station } \\
\text { at Vail }\end{array}$ & 2 & 2000 & $8 / 18 / 2000$ & $39^{\circ} 38^{\prime} 28^{\prime \prime}$ & $106^{\circ} 23^{\prime} 37^{\prime \prime}$ & 8,060 & 77.1 & Gomphonema olivaceum (Lyngbye) Kützing & 33,210 & $11,426,673$ \\
\hline 47 & 09066310 & $\begin{array}{l}\text { Gore Creek at Lower Station } \\
\text { at Vail }\end{array}$ & 2 & 2000 & $8 / 18 / 2000$ & $39^{\circ} 38^{\prime} 28^{\prime \prime}$ & $106^{\circ} 23^{\prime} 37^{\prime \prime}$ & 8,060 & 77.1 & Hannaea arcus (Ehrenberg) Patrick & 3,496 & $8,488,374$ \\
\hline 47 & 09066310 & $\begin{array}{l}\text { Gore Creek at Lower Station } \\
\text { at Vail }\end{array}$ & 2 & 2000 & $8 / 18 / 2000$ & $39^{\circ} 38^{\prime} 28^{\prime \prime}$ & $106^{\circ} 23^{\prime} 3$ & 8,060 & 77.1 & $\begin{array}{l}\text { Homoeothrix janthina (Bornet et Flahault) } \\
\text { Starmach }\end{array}$ & 1,14 & 8,388 \\
\hline 47 & 09066310 & $\begin{array}{l}\text { Gore Creek at Lower Station } \\
\text { at Vail }\end{array}$ & 2 & 2000 & $8 / 18 / 2000$ & $39^{\circ} 38^{\prime} 28^{\prime \prime}$ & $106^{\circ} 23^{\prime} 37^{\prime \prime}$ & 8,060 & 77.1 & $\begin{array}{l}\text { Navicula cryptotenella Lange-Bertalot } \\
\text { ex Krammer et Lange-Bertalot }\end{array}$ & 3,496 & $1,265,220$ \\
\hline 47 & 09066310 & $\begin{array}{l}\text { Gore Creek at Lower Station } \\
\text { at Vail }\end{array}$ & 2 & 2000 & $8 / 18 / 2000$ & $39^{\circ} 38^{\prime} 28^{\prime \prime}$ & $106^{\circ} 23^{\prime} 37^{\prime \prime}$ & 8,060 & 77.1 & Nitzschia fonticola Grunow & 3,496 & 347,148 \\
\hline 47 & 09066310 & $\begin{array}{l}\text { Gore Creek at Lower Station } \\
\text { at Vail }\end{array}$ & 2 & 2000 & $8 / 18 / 2000$ & $39^{\circ} 38^{\prime} 28^{\prime \prime}$ & $106^{\circ} 23^{\prime} 37^{\prime \prime}$ & 8,060 & 77.1 & Phormidium autumnale (Agardh) Gomont & 211,833 & 20,7 \\
\hline 47 & 09066310 & $\begin{array}{l}\text { Gore Creek at Lower Station } \\
\text { at Vail }\end{array}$ & 2 & 2000 & $8 / 18 / 2000$ & $39^{\circ} 38^{\prime} 28^{\prime \prime}$ & $106^{\circ} 23^{\prime} 37^{\prime \prime}$ & 8,060 & 77.1 & $\begin{array}{l}\text { Reimeria sinuata (Gregory) } \\
\text { Kociolek et Stoermer }\end{array}$ & 7,866 & $1,300,528$ \\
\hline 47 & 09066310 & $\begin{array}{l}\text { Gore Creek at Lower Station } \\
\text { at Vail }\end{array}$ & 2 & 2000 & $8 / 18 / 2000$ & $39^{\circ} 38^{\prime} 28^{\prime \prime}$ & $106^{\circ} 23^{\prime} 37^{\prime \prime}$ & 8,060 & 77.1 & $\begin{array}{l}\text { Rossithidium pusillum (Grunow) } \\
\text { Round et Bukhtiyarova }\end{array}$ & 1,748 & 158,653 \\
\hline 47 & 09066310 & $\begin{array}{l}\text { Gore Creek at Lower Station } \\
\text { at Vail }\end{array}$ & 2 & 2000 & $8 / 18 / 2000$ & $39^{\circ} 38^{\prime} 28^{\prime \prime}$ & $106^{\circ} 23^{\prime} 37^{\prime \prime}$ & 8,060 & 77.1 & Synedra ulna (Nitzsch) Ehrenberg & 5,244 & $34,381,135$ \\
\hline 47 & 09066310 & $\begin{array}{l}\text { Gore Creek at Lower Station } \\
\text { at Vail }\end{array}$ & 2 & 2000 & $8 / 18 / 2000$ & $39^{\circ} 38^{\prime} 28^{\prime \prime}$ & $106^{\circ} 23^{\prime} 37^{\prime \prime}$ & 8,060 & 77.1 & $\begin{array}{l}\text { Unknown Rhodophyte Florideophycidae } \\
\text { (chantransia) }\end{array}$ & 40,462 & $143,203,711$ \\
\hline 51 & 393826106235300 & Gore Creek below WWTP & 1 & 2000 & $8 / 18 / 2000$ & $39^{\circ} 38^{\prime} 26^{\prime \prime}$ & $106^{\circ} 23^{\prime} 53^{\prime \prime}$ & 8,050 & 91.1 & $\begin{array}{l}\text { Achnanthidium minutissimum (Kützing) } \\
\text { Czarnecki }\end{array}$ & 230,483 & $12,693,138$ \\
\hline 51 & 393826106235300 & Gore Creek below WWTP & 1 & 2000 & $8 / 18 / 2000$ & $39^{\circ} 38^{\prime} 26^{\prime \prime}$ & $106^{\circ} 23^{\prime} 53^{\prime \prime}$ & 8,050 & 91.1 & $\begin{array}{l}\text { Achnanthidium pyrenaicum (Hustedt) } \\
\text { Kobayasi }\end{array}$ & 80,598 & $10,140,042$ \\
\hline 51 & 393826106 & ГР & 1 & 00 & $8 / 2000$ & 8'26" & & 0 & 1 & Chlan & 4,510 & 383,367 \\
\hline 51 & 393826106235300 & ow WWTP & 1 & 2000 & $8 / 18 / 2000$ & $39^{\circ} 38^{\prime} 26^{\prime \prime}$ & $106^{\circ} 23^{\prime} 53^{\prime \prime}$ & 8,050 & 91.1 & oniliformis Kützing & 28,280 & $4,262,223$ \\
\hline 51 & 393826106235300 & Gore Creek below WWTP & 1 & 2000 & $8 / 18 / 2000$ & $39^{\circ} 38^{\prime} 26^{\prime \prime}$ & $106^{\circ} 23^{\prime} 53^{\prime \prime}$ & 8,050 & 91.1 & Diatomella balfouriana (Smith) Greville & 14,140 & $11,511,085$ \\
\hline 51 & 393826106 & WWWTP & 1 & 2000 & $8 / 18 / 2000$ & $39^{\circ} 38^{\prime} 26^{\prime \prime}$ & & & & Mann & & 389,862 \\
\hline 51 & 393826106235300 & w WWTP & 1 & 2000 & $8 / 18 / 2000$ & $39^{\circ} 38^{\prime} 26^{\prime \prime}$ & $106^{\circ} 23^{\prime} 53^{\prime \prime}$ & 8,050 & 91.1 & minutum (Hilse) Mann & 26,866 & $5,748,911$ \\
\hline 51 & 393826106235300 & Gore Creek below WWTP & 1 & 2000 & $8 / 18 / 2000$ & $39^{\circ} 38^{\prime} 26^{\prime \prime}$ & $106^{\circ} 23^{\prime} 53^{\prime \prime}$ & 8,050 & 91.1 & Encyonema silesiacum (Bleisch) Mann & 199,375 & $93,875,958$ \\
\hline 51 & 39382610 & WUTTD & 1 & 2000 & $8 / 18 / 2000$ & & & & & Fragilaria & & $11,115,144$ \\
\hline 51 & 393826106235300 & $\mathrm{~W}$ & $x^{2}$ & 2000 & $8 / 18 / 2000$ & $39^{\circ} 38^{\prime} 26^{\prime \prime}$ & $106^{\circ} 23^{\prime} 53^{\prime \prime}$ & $80,-3$ & 91.1 & zing & 11,312 & $3,892,123$ \\
\hline 51 & 393826106235300 & Gore Creek below WWTP & 1 & 2000 & $8 / 18 / 2000$ & $39^{\circ} 38^{\prime} 26^{\prime \prime}$ & $106^{\circ} 23^{\prime} 53^{\prime \prime}$ & 8,050 & 91.1 & Gomphonema parvulum (Kützing) Kützing & 2,828 & 631,647 \\
\hline 51 & 393826106235300 & Gore Creek below WWTP & 1 & 2000 & $8 / 18 / 2000$ & $39^{\circ} 38^{\prime} 26^{\prime \prime}$ & $106^{\circ} 23^{\prime} 53^{\prime \prime}$ & 8,050 & 91.1 & Hannaea arcus (Ehrenberg) Patrick & 1,414 & $3,433,404$ \\
\hline 51 & 393826106235300 & Gore Creek below WWTP & 1 & 2000 & $8 / 18 / 2000$ & $39^{\circ} 38^{\prime} 26^{\prime \prime}$ & $106^{\circ} 23^{\prime} 53^{\prime \prime}$ & 8,050 & 91.1 & $\begin{array}{l}\text { Homoeothrix janthina (Bornet et Flahault) } \\
\text { Starmach }\end{array}$ & $1,639,456$ & $53,132,027$ \\
\hline 51 & 393826106235300 & Gore Creek below WWTP & 1 & 2000 & $8 / 18 / 2000$ & $39^{\circ} 38^{\prime} 26^{\prime \prime}$ & $106^{\circ} 23^{\prime} 53^{\prime \prime}$ & 8,050 & 91.1 & $\begin{array}{l}\text { Navicula cryptotenella Lange-Bertalot } \\
\text { ex Krammer et Lange-Bertalot }\end{array}$ & 26,866 & $9,723,444$ \\
\hline 51 & 39382610 & S & 1 & 000 & & 39 & & 8,0 & & Navicula incertata Hustedt & 55,1 & \\
\hline 51 & 39382610 & & 1 & 2000 & $3 / 2000$ & $39^{\circ} 38^{\prime} 26^{\prime \prime}$ & 3'53" & & & Müller) Bory & 8,484 & $8,027,258$ \\
\hline 51 & 393826106235300 & Gore Creek below WWTP & 1 & 2000 & $8 / 18 / 2000$ & $39^{\circ} 38^{\prime} 26^{\prime \prime}$ & $106^{\circ} 23^{\prime} 53^{\prime \prime}$ & 8,050 & 91.1 & Navicula veneta Kützing & 14,140 & $3,066,126$ \\
\hline 51 & 393826106235300 & Gore Creek below WWTP & 1 & 2000 & $8 / 18 / 2000$ & $39^{\circ} 38^{\prime} 26^{\prime \prime}$ & $106^{\circ} 23^{\prime} 53^{\prime \prime}$ & 8,050 & 91.1 & Nitzschia dissipata (Kützing) Grunow & 2,828 & 735,395 \\
\hline 51 & 393826106 & Gore $\mathrm{C}$ & 1 & 2000 & & $39^{\circ} 38^{\prime} 26^{\prime \prime}$ & $106^{\circ} 23^{\prime} 53^{\prime \prime}$ & 8,050 & 91.1 & Nitzschia fonticola Grunow & 131,503 & $13,058,658$ \\
\hline 51 & 393826106235300 & Gore Creek below WWTP & 1 & 2000 & $8 / 18 / 2000$ & $39^{\circ} 38^{\prime} 26^{\prime \prime}$ & $106^{\circ} 23^{\prime} 53^{\prime \prime}$ & 8,050 & 91.1 & Nitzschia inconspicua Grunow & 31,108 & $1,124,825$ \\
\hline
\end{tabular}


Table 2. Description of sites and algal data collected from selected sites the Eagle River watershed, Colorado, 2000-2001.—Continued

[ID, identification; NAVD, North American Vertical Datum of 1988; ft, feet; $\mathrm{mi}^{2}$, square miles; cells $/ \mathrm{cm}^{2}$, cells per square centimeter; $\mu \mathrm{m}^{3} / \mathrm{cm}^{2}$, cubic micrometer per square centimeter]

\begin{tabular}{|c|c|c|c|c|c|c|c|c|c|c|c|c|}
\hline $\begin{array}{l}\text { Site } \\
\text { ID }^{1}\end{array}$ & $\begin{array}{l}\text { USGS } \\
\text { station } \\
\text { number }\end{array}$ & Station name & $\begin{array}{c}\text { Replicate } \\
\text { sample } \\
\text { number }\end{array}$ & Year & $\begin{array}{l}\text { Collection } \\
\text { date }\end{array}$ & Latitude & Longitude & $\begin{array}{c}\text { Elevation } \\
\text { NAVD } 88 \\
\text { (ft) }\end{array}$ & $\begin{array}{c}\text { Drainage } \\
\text { area } \\
\left(\mathrm{mi}^{2}\right)\end{array}$ & Algal taxon name & $\begin{array}{c}\text { Total } \\
\text { density } \\
\text { (number of } \\
\text { cells/cm²) }\end{array}$ & $\begin{array}{c}\text { Total } \\
\text { biovolume } \\
\left(\mu \mathrm{m}^{3} / \mathrm{cm}^{2}\right)\end{array}$ \\
\hline 51 & 393826106235300 & Gore Creek below WWTP & 1 & 2000 & $8 / 18 / 2000$ & $39^{\circ} 38^{\prime} 26^{\prime \prime}$ & $106^{\circ} 23^{\prime} 53^{\prime \prime}$ & 8,050 & 91.1 & Phormidium autumnale (Agardh) Gomont & $1,062,151$ & $104,015,572$ \\
\hline 51 & 393826106235300 & Gore Creek below WWTP & 1 & 2000 & $8 / 18 / 2000$ & $39^{\circ} 38^{\prime} 26^{\prime \prime}$ & $106^{\circ} 23^{\prime} 53^{\prime \prime}$ & 8,050 & 91.1 & $\begin{array}{l}\text { Planothidium lanceolatum } \\
\text { (Brébisson ex Kützing) Lange-Bertalot }\end{array}$ & 5,656 & 807,916 \\
\hline 51 & 393826106235300 & Gore Creek below WWTP & 1 & 2000 & $8 / 18 / 2000$ & $39^{\circ} 38^{\prime} 26^{\prime \prime}$ & $106^{\circ} 23^{\prime} 53^{\prime \prime}$ & 8,050 & 91.1 & $\begin{array}{l}\text { Reimeria sinuata (Gregory) } \\
\text { Kociolek et Stoermer }\end{array}$ & 97,566 & $16,131,943$ \\
\hline 51 & 393826106235300 & Gore Creek below WWTP & 1 & 2000 & $8 / 18 / 2000$ & $39^{\circ} 38^{\prime} 26^{\prime \prime}$ & $106^{\circ} 23^{\prime} 53^{\prime \prime}$ & 8,050 & 91.1 & Stigeoclonium lubricum (Dillwyn) Kützing & 31,571 & $46,860,667$ \\
\hline 51 & 393826106235300 & Gore Creek below WWTP & 1 & 2000 & $8 / 18 / 2000$ & $39^{\circ} 38^{\prime} 26^{\prime \prime}$ & $106^{\circ} 23^{\prime} 53^{\prime \prime}$ & 8,050 & 91.1 & Synedra ulna (Nitzsch) Ehrenberg & 8,484 & $55,626,351$ \\
\hline 51 & 393826106235300 & Gore Creek below WWTP & 1 & 2000 & $8 / 18 / 2000$ & $39^{\circ} 38^{\prime} 26^{\prime \prime}$ & $106^{\circ} 23^{\prime} 53^{\prime \prime}$ & 8,050 & 91.1 & Synedra ulna var. contracta Østrup & 1,414 & $2,247,908$ \\
\hline 53 & 09066510 & $\begin{array}{l}\text { Gore Creek at mouth near } \\
\text { Minturn }\end{array}$ & 1 & 2000 & $8 / 17 / 2000$ & $39^{\circ} 36^{\prime} 34^{\prime \prime}$ & $106^{\circ} 26^{\prime} 50^{\prime \prime}$ & 7,730 & 102 & $\begin{array}{l}\text { Achnanthidium minutissimum (Kützing) } \\
\text { Czarnecki }\end{array}$ & 124,853 & $6,875,898$ \\
\hline 53 & 09066510 & $\begin{array}{l}\text { Gore Creek at mouth near } \\
\text { Minturn }\end{array}$ & 1 & 2000 & $8 / 17 / 2000$ & $39^{\circ} 36^{\prime} 34^{\prime \prime}$ & $106^{\circ} 26^{\prime} 50^{\prime \prime}$ & 7,730 & 102 & $\begin{array}{l}\text { Achnanthidium pyrenaicum (Hustedt) } \\
\text { Kobayasi }\end{array}$ & 62,427 & $7,853,857$ \\
\hline 53 & 09066510 & $\begin{array}{l}\text { Gore Creek at mouth near } \\
\text { Minturn }\end{array}$ & 1 & 2000 & $8 / 17 / 2000$ & $39^{\circ} 36^{\prime} 34^{\prime \prime}$ & $106^{\circ} 26^{\prime} 50^{\prime \prime}$ & 7,730 & 102 & Amphora pediculus (Kützing) Grunow & 4,802 & 454,417 \\
\hline 53 & 09066510 & $\begin{array}{l}\text { Gore Creek at mouth near } \\
\text { Minturn }\end{array}$ & 1 & 2000 & $8 / 17 / 2000$ & $39^{\circ} 36^{\prime} 34^{\prime \prime}$ & $106^{\circ} 26^{\prime} 50^{\prime \prime}$ & 7,730 & 102 & $\begin{array}{l}\text { Cocconeis placentula var. euglypta } \\
\text { (Ehrenberg) Grunow }\end{array}$ & 1,201 & 723,245 \\
\hline 53 & 09066510 & $\begin{array}{l}\text { Gore Creek at mouth near } \\
\text { Minturn }\end{array}$ & 1 & 2000 & $8 / 17 / 2000$ & $39^{\circ} 36^{\prime} 34^{\prime \prime}$ & $106^{\circ} 26^{\prime} 50^{\prime \prime}$ & 7,730 & 102 & Diatoma vulgaris Bory & 7,203 & $26,614,746$ \\
\hline 53 & 09066510 & $\begin{array}{l}\text { Gore Creek at mouth near } \\
\text { Minturn }\end{array}$ & 1 & 2000 & $8 / 17 / 2000$ & $39^{\circ} 36^{\prime} 34^{\prime \prime}$ & $106^{\circ} 26^{\prime} 50^{\prime \prime}$ & 7,730 & 102 & Encyonema brehmii (Hustedt) Mann & 14,406 & 397,198 \\
\hline 53 & 09066510 & $\begin{array}{l}\text { Gore Creek at mouth near } \\
\text { Minturn }\end{array}$ & 1 & 2000 & $8 / 17 / 2000$ & $39^{\circ} 36^{\prime} 34^{\prime \prime}$ & $106^{\circ} 26^{\prime} 50^{\prime \prime}$ & 7,730 & 102 & Encyonema minutum (Hilse) Mann & 22,810 & $4,880,905$ \\
\hline 53 & 09066510 & $\begin{array}{l}\text { Gore Creek at mouth near } \\
\text { Minturn }\end{array}$ & 1 & 2000 & $8 / 17 / 2000$ & $39^{\circ} 36^{\prime} 34^{\prime \prime}$ & $106^{\circ} 26^{\prime} 50^{\prime \prime}$ & 7,730 & 102 & Encyonema silesiacum (Bleisch) Mann & 140,460 & $66,135,683$ \\
\hline 53 & 09066510 & $\begin{array}{l}\text { Gore Creek at mouth near } \\
\text { Minturn }\end{array}$ & 1 & 2000 & $8 / 17 / 2000$ & $39^{\circ} 36^{\prime} 34^{\prime \prime}$ & $106^{\circ} 26^{\prime} 50^{\prime \prime}$ & 7,730 & 102 & $\begin{array}{l}\text { Geissleria acceptata (Hustedt) } \\
\text { Lange-Bertalot et Metzeltin }\end{array}$ & 2,401 & 246,467 \\
\hline 53 & 09066510 & $\begin{array}{l}\text { Gore Creek at mouth near } \\
\text { Minturn }\end{array}$ & 1 & 2000 & $8 / 17 / 2000$ & $39^{\circ} 36^{\prime} 34^{\prime \prime}$ & $106^{\circ} 26^{\prime} 50^{\prime \prime}$ & 7,730 & 102 & Gomphonema minutum (Agardh) Agardh & 1,201 & 208,241 \\
\hline 53 & 09066510 & $\begin{array}{l}\text { Gore Creek at mouth near } \\
\text { Minturn }\end{array}$ & 1 & 2000 & $8 / 17 / 2000$ & $39^{\circ} 36^{\prime} 34^{\prime \prime}$ & $106^{\circ} 26^{\prime} 50^{\prime \prime}$ & 7,730 & 102 & $\begin{array}{l}\text { Homoeothrix janthina (Bornet et Flahault) } \\
\text { Starmach }\end{array}$ & $5,606,642$ & $181,701,943$ \\
\hline 53 & 09066510 & $\begin{array}{l}\text { Gore Creek at mouth near } \\
\text { Minturn }\end{array}$ & 1 & 2000 & $8 / 17 / 2000$ & $39^{\circ} 36^{\prime} 34^{\prime \prime}$ & $106^{\circ} 26^{\prime} 50^{\prime \prime}$ & 7,730 & 102 & $\begin{array}{l}\text { Navicula cryptotenella Lange-Bertalot } \\
\text { ex Krammer et Lange-Bertalot }\end{array}$ & 6,003 & $2,172,457$ \\
\hline 53 & 09066510 & $\begin{array}{l}\text { Gore Creek at mouth near } \\
\text { Minturn }\end{array}$ & 1 & 2000 & $8 / 17 / 2000$ & $39^{\circ} 36^{\prime} 34^{\prime \prime}$ & $106^{\circ} 26^{\prime} 50^{\prime \prime}$ & 7,730 & 102 & Navicula incertata Hustedt & 36,015 & $1,862,105$ \\
\hline 53 & 09066510 & $\begin{array}{l}\text { Gore Creek at mouth near } \\
\text { Minturn }\end{array}$ & 1 & 2000 & $8 / 17 / 2000$ & $39^{\circ} 36^{\prime} 34^{\prime \prime}$ & $106^{\circ} 26^{\prime} 50^{\prime \prime}$ & 7,730 & 102 & Navicula tripunctata (Müller) Bory & 9,604 & $9,087,003$ \\
\hline 53 & 09066510 & $\begin{array}{l}\text { Gore Creek at mouth near } \\
\text { Minturn }\end{array}$ & 1 & 2000 & $8 / 17 / 2000$ & $39^{\circ} 36^{\prime} 34^{\prime \prime}$ & $106^{\circ} 26^{\prime} 50^{\prime \prime}$ & 7,730 & 102 & Nitzschia dissipata (Kützing) Grunow & 4,802 & $1,248,720$ \\
\hline 53 & 09066510 & $\begin{array}{l}\text { Gore Creek at mouth } \\
\text { near Minturn }\end{array}$ & 1 & 2000 & $8 / 17 / 2000$ & $39^{\circ} 36^{\prime} 34^{\prime \prime}$ & $106^{\circ} 26^{\prime} 50^{\prime \prime}$ & 7,730 & 102 & Nitzschia fonticola Grunow & 46,820 & $4,649,379$ \\
\hline 53 & 09066510 & $\begin{array}{l}\text { Gore Creek at mouth } \\
\text { near Minturn }\end{array}$ & 1 & 2000 & $8 / 17 / 2000$ & $39^{\circ} 36^{\prime} 34^{\prime \prime}$ & $106^{\circ} 26^{\prime} 50^{\prime \prime}$ & 7,730 & 102 & Nitzschia inconspicua Grunow & 34,815 & $1,258,853$ \\
\hline 53 & 09066510 & $\begin{array}{l}\text { Gore Creek at mouth } \\
\text { near Minturn }\end{array}$ & 1 & 2000 & $8 / 17 / 2000$ & $39^{\circ} 36^{\prime} 34^{\prime \prime}$ & $106^{\circ} 26^{\prime} 50^{\prime \prime}$ & 7,730 & 102 & Phormidium autumnale (Agardh) Gomont & $1,117,723$ & $109,457,708$ \\
\hline 53 & 09066510 & $\begin{array}{l}\text { Gore Creek at mouth } \\
\text { near Minturn }\end{array}$ & 1 & 2000 & $8 / 17 / 2000$ & $39^{\circ} 36^{\prime} 34^{\prime \prime}$ & $106^{\circ} 26^{\prime} 50^{\prime \prime}$ & 7,730 & 102 & $\begin{array}{l}\text { Reimeria sinuata (Gregory) } \\
\text { Kociolek et Stoermer }\end{array}$ & 286,922 & $47,440,602$ \\
\hline
\end{tabular}


Table 2. Description of sites and algal data collected from selected sites the Eagle River watershed, Colorado, 2000-2001.—Continued

[ID, identification; NAVD, North American Vertical Datum of 1988; ft, feet; $\mathrm{mi}^{2}$, square miles; cells $/ \mathrm{cm}^{2}$, cells per square centimeter; $\mu \mathrm{m}^{3} / \mathrm{cm}^{2}$, cubic micrometer per square centimeter]

\begin{tabular}{|c|c|c|c|c|c|c|c|c|c|c|c|c|}
\hline $\begin{array}{l}\text { Site } \\
\text { ID' }\end{array}$ & $\begin{array}{l}\text { USGS } \\
\text { station } \\
\text { number }\end{array}$ & Station name & $\begin{array}{c}\text { Replicate } \\
\text { sample } \\
\text { number }\end{array}$ & Year & $\begin{array}{l}\text { Collection } \\
\text { date }\end{array}$ & Latitude & Longitude & $\begin{array}{c}\text { Elevation } \\
\text { NAVD } 88 \\
\text { (ft) }\end{array}$ & $\begin{array}{c}\text { Drainage } \\
\text { area } \\
\left(\mathrm{mi}^{2}\right)\end{array}$ & Algal taxon name & $\begin{array}{c}\text { Total } \\
\text { density } \\
\text { (number of } \\
\text { cells } / \mathrm{cm}^{2} \text { ) }\end{array}$ & $\begin{array}{c}\text { Total } \\
\text { biovolume } \\
\left(\mu \mathrm{m}^{3} / \mathrm{cm}^{2}\right)\end{array}$ \\
\hline 53 & 09066510 & $\begin{array}{l}\text { Gore Creek at mouth } \\
\text { near Minturn }\end{array}$ & 1 & 2000 & $8 / 17 / 2000$ & $39^{\circ} 36^{\prime} 34^{\prime \prime}$ & $106^{\circ} 26^{\prime} 50^{\prime \prime}$ & 7,730 & 102 & Stigeoclonium lubricum (Dillwyn) Kützing & 54,083 & $80,274,736$ \\
\hline 53 & 09066510 & $\begin{array}{l}\text { Gore Creek at mouth } \\
\text { near Minturn }\end{array}$ & 1 & 2000 & $8 / 17 / 2000$ & $39^{\circ} 36^{\prime} 34^{\prime \prime}$ & $106^{\circ} 26^{\prime} 50^{\prime \prime}$ & 7,730 & 102 & $\begin{array}{l}\text { Unknown Rhodophyte Florideophycidae } \\
\text { (chantransia) }\end{array}$ & 67,604 & $239,263,151$ \\
\hline 53 & 09066510 & $\begin{array}{l}\text { Gore Creek at mouth } \\
\text { near Minturn }\end{array}$ & 1 & 2001 & $8 / 16 / 2001$ & $39^{\circ} 36^{\prime} 34^{\prime \prime}$ & $106^{\circ} 26^{\prime} 50^{\prime \prime}$ & 7,730 & 102 & $\begin{array}{l}\text { Achnanthidium minutissimum (Kützing) } \\
\text { Czarnecki }\end{array}$ & 56,525 & $3,064,839$ \\
\hline 53 & 09066510 & $\begin{array}{l}\text { Gore Creek at mouth } \\
\text { near Minturn }\end{array}$ & 1 & 2001 & $8 / 16 / 2001$ & $39^{\circ} 36^{\prime} 34^{\prime \prime}$ & $106^{\circ} 26^{\prime} 50^{\prime \prime}$ & 7,730 & 102 & $\begin{array}{l}\text { Achnanthidium pyrenaicum (Hustedt) } \\
\text { Kobayasi }\end{array}$ & 37,683 & $4,761,747$ \\
\hline 53 & 09066510 & $\begin{array}{l}\text { Gore Creek at mouth } \\
\text { near Minturn }\end{array}$ & 1 & 2001 & $8 / 16 / 2001$ & $39^{\circ} 36^{\prime} 34^{\prime \prime}$ & $106^{\circ} 26^{\prime} 50^{\prime \prime}$ & 7,730 & 102 & Amphora pediculus (Kützing) Grunow & 3,426 & 331,223 \\
\hline 53 & 09066510 & $\begin{array}{l}\text { Gore Creek at mouth } \\
\text { near Minturn }\end{array}$ & 1 & 2001 & $8 / 16 / 2001$ & $39^{\circ} 36^{\prime} 34^{\prime \prime}$ & $106^{\circ} 26^{\prime} 50^{\prime \prime}$ & 7,730 & 102 & Caloneis bacillum (Grunow) Cleve & 1,713 & 736,824 \\
\hline 53 & 09066510 & $\begin{array}{l}\text { Gore Creek at mouth } \\
\text { near Minturn }\end{array}$ & 1 & 2001 & $8 / 16 / 2001$ & $39^{\circ} 36^{\prime} 34^{\prime \prime}$ & $106^{\circ} 26^{\prime} 50^{\prime \prime}$ & 7,730 & 102 & $\begin{array}{l}\text { Cocconeis placentula var. euglypta } \\
\text { (Ehrenberg) Grunow }\end{array}$ & 2,569 & $1,526,662$ \\
\hline 53 & 09066510 & $\begin{array}{l}\text { Gore Creek at mouth } \\
\text { near Minturn }\end{array}$ & 1 & 2001 & $8 / 16 / 2001$ & $39^{\circ} 36^{\prime} 34^{\prime \prime}$ & $106^{\circ} 26^{\prime} 50^{\prime \prime}$ & 7,730 & 102 & $\begin{array}{l}\text { Cocconeis placentula var. lineata (Ehrenberg) } \\
\text { Van Heurck }\end{array}$ & 5,139 & $5,419,173$ \\
\hline 53 & 09066510 & $\begin{array}{l}\text { Gore Creek at mouth } \\
\text { near Minturn }\end{array}$ & 1 & 2001 & $8 / 16 / 2001$ & $39^{\circ} 36^{\prime} 34^{\prime \prime}$ & $106^{\circ} 26^{\prime} 50^{\prime \prime}$ & 7,730 & 102 & Diatoma vulgaris Bory & 5,995 & $22,151,333$ \\
\hline 53 & 09066510 & $\begin{array}{l}\text { Gore Creek at mouth } \\
\text { near Minturn }\end{array}$ & 1 & 2001 & $8 / 16 / 2001$ & $39^{\circ} 36^{\prime} 34^{\prime \prime}$ & $106^{\circ} 26^{\prime} 50^{\prime \prime}$ & 7,730 & 102 & Encyonema brehmii (Hustedt) Mann & 11,990 & 330,586 \\
\hline 53 & 09066510 & $\begin{array}{l}\text { Gore Creek at mouth } \\
\text { near Minturn }\end{array}$ & 1 & 2001 & $8 / 16 / 2001$ & $39^{\circ} 36^{\prime} 34^{\prime \prime}$ & $106^{\circ} 26^{\prime} 50^{\prime \prime}$ & 7,730 & 102 & Encyonema minutum (Hilse) Mann & 20,555 & $4,436,367$ \\
\hline 53 & 09066510 & $\begin{array}{l}\text { Gore Creek at mouth } \\
\text { near Minturn }\end{array}$ & 1 & 2001 & $8 / 16 / 2001$ & $39^{\circ} 36^{\prime} 34^{\prime \prime}$ & $106^{\circ} 26^{\prime} 50^{\prime \prime}$ & 7,730 & 102 & Encyonema silesiacum (Bleisch) Mann & 164,436 & $78,098,394$ \\
\hline 53 & 09066510 & $\begin{array}{l}\text { Gore Creek at mouth } \\
\text { near Minturn }\end{array}$ & 1 & 2001 & $8 / 16 / 2001$ & $39^{\circ} 36^{\prime} 34^{\prime \prime}$ & $106^{\circ} 26^{\prime} 50^{\prime \prime}$ & 7,730 & 102 & Fragilaria vaucheriae (Kützing) Petersen & 6,852 & $1,349,828$ \\
\hline 53 & 09066510 & $\begin{array}{l}\text { Gore Creek at mouth } \\
\text { near Minturn }\end{array}$ & 1 & 2001 & $8 / 16 / 2001$ & $39^{\circ} 36^{\prime} 34^{\prime \prime}$ & $106^{\circ} 26^{\prime} 50^{\prime \prime}$ & 7,730 & 102 & Gomphonema minutum (Agardh) Agardh & 10,277 & 839,707 \\
\hline 53 & 09066510 & $\begin{array}{l}\text { Gore Creek at mouth } \\
\text { near Minturn }\end{array}$ & 1 & 2001 & $8 / 16 / 2001$ & $39^{\circ} 36^{\prime} 34^{\prime \prime}$ & $106^{\circ} 26^{\prime} 50^{\prime \prime}$ & 7,730 & 102 & Gomphonema olivaceum (Lyngbye) Kützing & 2,569 & 973,615 \\
\hline 53 & 09066510 & $\begin{array}{l}\text { Gore Creek at mouth } \\
\text { near Minturn }\end{array}$ & 1 & 2001 & $8 / 16 / 2001$ & $39^{\circ} 36^{\prime} 34^{\prime \prime}$ & $106^{\circ} 26^{\prime} 50^{\prime \prime}$ & 7,730 & 102 & $\begin{array}{l}\text { Homoeothrix janthina (Bornet et Flahault) } \\
\text { Starmach }\end{array}$ & $4,770,777$ & $82,122,520$ \\
\hline 53 & 09066510 & $\begin{array}{l}\text { Gore Creek at mouth } \\
\text { near Minturn }\end{array}$ & 1 & 2001 & $8 / 16 / 2001$ & $39^{\circ} 36^{\prime} 34^{\prime \prime}$ & $106^{\circ} 26{ }^{\prime} 50^{\prime \prime}$ & 7,730 & 102 & Mayamaea atomus (Kützing) Lange-Bertalot & 856 & 24,593 \\
\hline 53 & 09066510 & $\begin{array}{l}\text { Gore Creek at mouth } \\
\text { near Minturn }\end{array}$ & 1 & 2001 & $8 / 16 / 2001$ & $39^{\circ} 36^{\prime} 34^{\prime \prime}$ & $106^{\circ} 26^{\prime} 50^{\prime \prime}$ & 7,730 & 102 & Navicula gregaria Donkin & 1,713 & 429,867 \\
\hline 53 & 09066510 & $\begin{array}{l}\text { Gore Creek at mouth } \\
\text { near Minturn }\end{array}$ & 1 & 2001 & $8 / 16 / 2001$ & $39^{\circ} 36^{\prime} 34^{\prime \prime}$ & $106^{\circ} 26^{\prime} 50^{\prime \prime}$ & 7,730 & 102 & Navicula incertata Hustedt & 4,282 & 255,031 \\
\hline 53 & 09066510 & $\begin{array}{l}\text { Gore Creek at mouth } \\
\text { near Minturn }\end{array}$ & 1 & 2001 & $8 / 16 / 2001$ & $39^{\circ} 36^{\prime} 34^{\prime \prime}$ & $106^{\circ} 266^{\prime \prime}$ & 7,730 & 102 & Navicula tripunctata (Müller) Bory & 8,564 & $7,787,904$ \\
\hline 53 & 09066510 & $\begin{array}{l}\text { Gore Creek at mouth } \\
\text { near Minturn }\end{array}$ & 1 & 2001 & $8 / 16 / 2001$ & $39^{\circ} 36^{\prime} 34^{\prime \prime}$ & $106^{\circ} 26^{\prime} 50^{\prime \prime}$ & 7,730 & 102 & Navicula veneta Kützing & 856 & 189,087 \\
\hline 53 & 09066510 & $\begin{array}{l}\text { Gore Creek at mouth } \\
\text { near Minturn }\end{array}$ & 1 & 2001 & $8 / 16 / 2001$ & $39^{\circ} 36^{\prime} 34^{\prime \prime}$ & $106^{\circ} 26^{\prime} 50^{\prime \prime}$ & 7,730 & 102 & Nitzschia fonticola Grunow & 120,758 & $12,012,494$ \\
\hline 53 & 09066510 & $\begin{array}{l}\text { Gore Creek at mouth } \\
\text { near Minturn }\end{array}$ & 1 & 2001 & $8 / 16 / 2001$ & $39^{\circ} 36^{\prime} 34^{\prime \prime}$ & $106^{\circ} 26^{\prime} 50^{\prime \prime}$ & 7,730 & 102 & Nitzschia inconspicua Grunow & 3,426 & 120,644 \\
\hline
\end{tabular}


Table 2. Description of sites and algal data collected from selected sites the Eagle River watershed, Colorado, 2000-2001.—Continued

[ID, identification; NAVD, North American Vertical Datum of 1988; ft, feet; $\mathrm{mi}^{2}$, square miles; cells $/ \mathrm{cm}^{2}$, cells per square centimeter; $\mu \mathrm{m}^{3} / \mathrm{cm}^{2}$, cubic micrometer per square centimeter]

\begin{tabular}{|c|c|c|c|c|c|c|c|c|c|c|c|c|}
\hline $\begin{array}{l}\text { Site } \\
\text { ID' }\end{array}$ & $\begin{array}{l}\text { USGS } \\
\text { station } \\
\text { number }\end{array}$ & Station name & $\begin{array}{c}\text { Replicate } \\
\text { sample } \\
\text { number }\end{array}$ & Year & $\begin{array}{l}\text { Collection } \\
\text { date }\end{array}$ & Latitude & Longitude & $\begin{array}{c}\text { Elevation } \\
\text { NAVD } 88 \\
\text { (ft) }\end{array}$ & $\begin{array}{c}\text { Drainage } \\
\text { area } \\
\left(\mathrm{mi}^{2}\right)\end{array}$ & Algal taxon name & $\begin{array}{c}\text { Total } \\
\text { density } \\
\text { (number of } \\
\text { cells/cm²) }\end{array}$ & $\begin{array}{c}\text { Total } \\
\text { biovolume } \\
\left(\mu \mathrm{m}^{3} / \mathrm{cm}^{2}\right)\end{array}$ \\
\hline 53 & 09066510 & $\begin{array}{l}\text { Gore Creek at mouth } \\
\text { near Minturn }\end{array}$ & 1 & 2001 & $8 / 16 / 2001$ & $39^{\circ} 36^{\prime} 34^{\prime \prime}$ & $106^{\circ} 26^{\prime} 50^{\prime \prime}$ & 7,730 & 102 & Nitzschia paleacea Grunow ex Van Heurck & 1,713 & 89,324 \\
\hline 53 & 09066510 & $\begin{array}{l}\text { Gore Creek at mouth } \\
\text { near Minturn }\end{array}$ & 1 & 2001 & $8 / 16 / 2001$ & $39^{\circ} 36^{\prime} 34^{\prime \prime}$ & $106^{\circ} 26^{\prime} 50^{\prime \prime}$ & 7,730 & 102 & Phormidium autumnale (Agardh) Gomont & 456,067 & $44,218,007$ \\
\hline 53 & 09066510 & $\begin{array}{l}\text { Gore Creek at mouth } \\
\text { near Minturn }\end{array}$ & 1 & 2001 & $8 / 16 / 2001$ & $39^{\circ} 36^{\prime} 34^{\prime \prime}$ & $106^{\circ} 26^{\prime} 50^{\prime \prime}$ & 7,730 & 102 & $\begin{array}{l}\text { Planothidium lanceolatum } \\
\text { (Brébisson ex Kützing) Lange-Bertalot }\end{array}$ & 856 & 117,320 \\
\hline 53 & 09066510 & $\begin{array}{l}\text { Gore Creek at mouth } \\
\text { near Minturn }\end{array}$ & 1 & 2001 & $8 / 16 / 2001$ & $39^{\circ} 36^{\prime} 34^{\prime \prime}$ & $106^{\circ} 26^{\prime} 50^{\prime \prime}$ & 7,730 & 102 & $\begin{array}{l}\text { Reimeria sinuata (Gregory) } \\
\text { Kociolek et Stoermer }\end{array}$ & 48,817 & $8,227,611$ \\
\hline 53 & 09066510 & $\begin{array}{l}\text { Gore Creek at mouth } \\
\text { near Minturn }\end{array}$ & 1 & 2001 & $8 / 16 / 2001$ & $39^{\circ} 36^{\prime} 34^{\prime \prime}$ & $106^{\circ} 26^{\prime} 50^{\prime \prime}$ & 7,730 & 102 & Scenedesmus ecornis (Ralfs) Chodat & 4,944 & 115,111 \\
\hline 53 & 09066510 & $\begin{array}{l}\text { Gore Creek at mouth } \\
\text { near Minturn }\end{array}$ & 1 & 2001 & $8 / 16 / 2001$ & $39^{\circ} 36^{\prime} 34^{\prime \prime}$ & $106^{\circ} 26^{\prime} 50^{\prime \prime}$ & 7,730 & 102 & Stigeoclonium lubricum (Dillwyn) Kützing & 12,360 & $21,860,534$ \\
\hline 53 & 09066510 & $\begin{array}{l}\text { Gore Creek at mouth } \\
\text { near Minturn }\end{array}$ & 1 & 2001 & $8 / 16 / 2001$ & $39^{\circ} 36^{\prime} 34^{\prime \prime}$ & $106^{\circ} 26^{\prime} 50^{\prime \prime}$ & 7,730 & 102 & Unknown alga flagellate $(<10 \mu)$ & 2,472 & 237,556 \\
\hline 53 & 09066510 & $\begin{array}{l}\text { Gore Creek at mouth } \\
\text { near Minturn }\end{array}$ & 1 & 2001 & $8 / 16 / 2001$ & $39^{\circ} 36^{\prime} 34^{\prime \prime}$ & $106^{\circ} 26^{\prime} 50^{\prime \prime}$ & 7,730 & 102 & $\begin{array}{l}\text { Unknown Cyanophyte Oscillatoriales } \\
\text { (no sheath) }\end{array}$ & 79,101 & $1,173,507$ \\
\hline 53 & 09066510 & $\begin{array}{l}\text { Gore Creek at mouth } \\
\text { near Minturn }\end{array}$ & 1 & 2001 & $8 / 16 / 2001$ & $39^{\circ} 36^{\prime} 34^{\prime \prime}$ & $106^{\circ} 26^{\prime} 50^{\prime \prime}$ & 7,730 & 102 & $\begin{array}{l}\text { Unknown Rhodophyte Florideophycidae } \\
\text { (chantransia) }\end{array}$ & 8,652 & $55,374,886$ \\
\hline 55 & 393501106313200 & Beaver Creek above Avon & 1 & 2000 & $8 / 16 / 2000$ & $39^{\circ} 35^{\prime} 01^{\prime \prime}$ & $106^{\circ} 31^{\prime} 32^{\prime \prime}$ & 8,840 & 8.1 & Achnanthes nodosa Cleve & 186 & 278,416 \\
\hline 55 & 393501106313200 & Beaver Creek above Avon & 1 & 2000 & $8 / 16 / 2000$ & $39^{\circ} 35^{\prime} 01^{\prime \prime}$ & $106^{\circ} 31^{\prime} 32^{\prime \prime}$ & 8,840 & 8.1 & $\begin{array}{l}\text { Achnanthidium minutissimum (Kützing) } \\
\text { Czarnecki }\end{array}$ & 26,853 & $1,478,859$ \\
\hline 55 & 393501106313200 & Beaver Creek above Avon & 1 & 2000 & $8 / 16 / 2000$ & $39^{\circ} 35^{\prime} 01^{\prime \prime}$ & $106^{\circ} 31^{\prime} 32^{\prime \prime}$ & 8,840 & 8.1 & $\begin{array}{l}\text { Achnanthidium pyrenaicum (Hustedt) } \\
\text { Kobayasi }\end{array}$ & 186 & 23,461 \\
\hline 55 & 393501106313200 & Beaver Creek above Avon & 1 & 2000 & $8 / 16 / 2000$ & $39^{\circ} 35^{\prime} 01^{\prime \prime}$ & $106^{\circ} 31^{\prime} 32^{\prime \prime}$ & 8,840 & 8.1 & Adlafia minuscula (Grunow) Lange-Bertalot & 186 & 9,569 \\
\hline 55 & 393501106313200 & Beaver Creek above Avon & 1 & 2000 & $8 / 16 / 2000$ & $39^{\circ} 35^{\prime} 01^{\prime \prime}$ & $106^{\circ} 31^{\prime} 32^{\prime \prime}$ & 8,840 & 8.1 & Amphora pediculus (Kützing) Grunow & 559 & 52,940 \\
\hline 55 & 393501106313200 & Beaver Creek above Avon & 1 & 2000 & $8 / 16 / 2000$ & $39^{\circ} 35^{\prime} 01^{\prime \prime}$ & $106^{\circ} 31^{\prime} 32^{\prime \prime}$ & 8,840 & 8.1 & Chlamydomonas sp. & 1,488 & 126,484 \\
\hline 55 & 393501106313200 & Beaver Creek above Avon & 1 & 2000 & $8 / 16 / 2000$ & $39^{\circ} 35^{\prime} 01^{\prime \prime}$ & $106^{\circ} 31^{\prime} 32^{\prime \prime}$ & 8,840 & 8.1 & $\begin{array}{l}\text { Cocconeis placentula var. euglypta } \\
\text { (Ehrenberg) Grunow }\end{array}$ & 93 & 56,172 \\
\hline 55 & 393501106313200 & Beaver Creek above Avon & 1 & 2000 & $8 / 16 / 2000$ & $39^{\circ} 35^{\prime} 01^{\prime \prime}$ & $106^{\circ} 31^{\prime} 32^{\prime \prime}$ & 8,840 & 8.1 & $\begin{array}{l}\text { Cocconeis placentula var. lineata (Ehrenberg) } \\
\text { Van Heurck }\end{array}$ & 3,823 & $4,005,405$ \\
\hline 55 & 393501106313200 & Beaver Creek above Avon & 1 & 2000 & $8 / 16 / 2000$ & $39^{\circ} 35^{\prime} 01^{\prime \prime}$ & $106^{\circ} 31^{\prime} 32^{\prime \prime}$ & 8,840 & 8.1 & Diatoma mesodon (Ehrenberg) Kützing & 93 & 99,286 \\
\hline 55 & 393501106313200 & Beaver Creek above Avon & 1 & 2000 & $8 / 16 / 2000$ & $39^{\circ} 35^{\prime} 01^{\prime \prime}$ & $106^{\circ} 31^{\prime} 32^{\prime \prime}$ & 8,840 & 8.1 & Discostella stelligera (Hustedt) Houk et Klee & 93 & 24,486 \\
\hline 55 & 393501106313200 & Beaver Creek above Avon & 1 & 2000 & $8 / 16 / 2000$ & $39^{\circ} 35^{\prime} 01^{\prime \prime}$ & $106^{\circ} 31^{\prime} 32^{\prime \prime}$ & 8,840 & 8.1 & Encyonema brehmii (Hustedt) Mann & 4,476 & 123,397 \\
\hline 55 & 393501106313200 & Beaver Creek above Avon & 1 & 2000 & $8 / 16 / 2000$ & $39^{\circ} 35^{\prime} 01^{\prime \prime}$ & $106^{\circ} 31^{\prime} 32^{\prime \prime}$ & 8,840 & 8.1 & Encyonema minutum (Hilse) Mann & 186 & 39,904 \\
\hline 55 & 393501106313200 & Beaver Creek above Avon & 1 & 2000 & $8 / 16 / 2000$ & $39^{\circ} 35^{\prime} 01^{\prime \prime}$ & $106^{\circ} 31^{\prime} 32^{\prime \prime}$ & 8,840 & 8.1 & Encyonema silesiacum (Bleisch) Mann & 4,942 & $2,326,826$ \\
\hline 55 & 393501106313200 & Beaver Creek above Avon & 1 & 2000 & $8 / 16 / 2000$ & $39^{\circ} 35^{\prime} 01^{\prime \prime}$ & $106^{\circ} 31^{\prime} 32^{\prime \prime}$ & 8,840 & 8.1 & Fragilaria capucina Desmazières & 559 & 104,516 \\
\hline 55 & 393501106313200 & Beaver Creek above Avon & 1 & 2000 & $8 / 16 / 2000$ & $39^{\circ} 35^{\prime} 01^{\prime \prime}$ & $106^{\circ} 31^{\prime} 32^{\prime \prime}$ & 8,840 & 8.1 & Fragilaria vaucheriae (Kützing) Petersen & 1,119 & 231,454 \\
\hline 55 & 393501106313200 & Beaver Creek above Avon & 1 & 2000 & $8 / 16 / 2000$ & $39^{\circ} 35^{\prime} 01^{\prime \prime}$ & $106^{\circ} 31^{\prime} 32^{\prime \prime}$ & 8,840 & 8.1 & $\begin{array}{l}\text { Geissleria acceptata (Hustedt) } \\
\text { Lange-Bertalot et Metzeltin }\end{array}$ & 186 & 19,142 \\
\hline 55 & 393501106313200 & Beaver Creek above Avon & 1 & 2000 & $8 / 16 / 2000$ & $39^{\circ} 35^{\prime} 01^{\prime \prime}$ & $106^{\circ} 31^{\prime} 32^{\prime \prime}$ & 8,840 & 8.1 & Gomphonema olivaceoides Hustedt & 93 & 14,264 \\
\hline 55 & 393501106313200 & Beaver Creek above Avon & 1 & 2000 & $8 / 16 / 2000$ & $39^{\circ} 35^{\prime} 01^{\prime \prime}$ & $106^{\circ} 31^{\prime} 32^{\prime \prime}$ & 8,840 & 8.1 & $\begin{array}{l}\text { Gomphonema olivaceoides var. } \\
\text { hutchinsoniana } \text { Patrick }\end{array}$ & 186 & 28,249 \\
\hline 55 & 393501106313200 & Beaver Creek above Avon & 1 & 2000 & $8 / 16 / 2000$ & $39^{\circ} 35^{\prime} 01^{\prime \prime}$ & $106^{\circ} 31^{\prime} 32^{\prime \prime}$ & 8,840 & 8.1 & $\begin{array}{l}\text { Gomphonema pumilum (Grunow) } \\
\text { Reichardt et Lange-Bertalot }\end{array}$ & 9,231 & $2,693,381$ \\
\hline 55 & 393501106313200 & Beaver Creek above Avon & 1 & 2000 & $8 / 16 / 2000$ & $39^{\circ} 35^{\prime} 01^{\prime \prime}$ & $106^{\circ} 31^{\prime} 32^{\prime \prime}$ & 8,840 & 8.1 & Gomphonema subclavatum (Grunow) Grunow & 932 & 744,402 \\
\hline 55 & 393501106313200 & Beaver Creek above Avon & 1 & 2000 & $8 / 16 / 2000$ & $39^{\circ} 35^{\prime} 01^{\prime \prime}$ & $106^{\circ} 31^{\prime} 32^{\prime \prime}$ & 8,840 & 8.1 & Hannaea arcus (Ehrenberg) Patrick & 373 & 905,603 \\
\hline
\end{tabular}




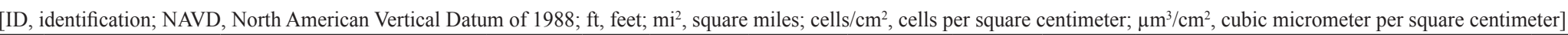

\begin{tabular}{|c|c|c|c|c|c|c|c|c|c|c|c|c|}
\hline $\begin{array}{l}\text { Site } \\
\text { ID }^{1}\end{array}$ & $\begin{array}{l}\text { USGS } \\
\text { station } \\
\text { number }\end{array}$ & Station name & $\begin{array}{c}\text { Replicate } \\
\text { sample } \\
\text { number }\end{array}$ & Year & $\begin{array}{c}\text { Collection } \\
\text { date }\end{array}$ & Latitude & Longitude & $\begin{array}{c}\text { Elevation } \\
\text { NAVD } 88 \\
\text { (ft) }\end{array}$ & $\begin{array}{c}\text { Drainage } \\
\text { area } \\
\left(\mathrm{mi}^{2}\right)\end{array}$ & Algal taxon name & $\begin{array}{c}\text { Total } \\
\text { density } \\
\text { (number of } \\
\text { cells } / \mathbf{c m}^{2} \text { ) }\end{array}$ & $\begin{array}{c}\text { Total } \\
\text { biovolume } \\
\left(\mu \mathrm{m}^{3} / \mathrm{cm}^{2}\right)\end{array}$ \\
\hline 55 & 393501106313200 & Beaver Creek above Avon & 1 & 2000 & $8 / 16 / 2000$ & $39^{\circ} 35^{\prime} 01^{\prime \prime}$ & $106^{\circ} 31^{\prime} 32^{\prime \prime}$ & 8,840 & 8.1 & $\begin{array}{l}\text { Homoeothrix janthina (Bornet et Flahault) } \\
\text { Starmach }\end{array}$ & 239,079 & $7,748,141$ \\
\hline 55 & 393501106313200 & Beaver Creek above Avon & 1 & 2000 & $8 / 16 / 2000$ & $39^{\circ} 35^{\prime} 01^{\prime \prime}$ & $106^{\circ} 31^{\prime} 32^{\prime \prime}$ & 8,840 & 8.1 & Karayevia clevei (Grunow) Bukhtiyarova & 93 & 20,234 \\
\hline 55 & 393501106313200 & Beaver Creek above Avon & 1 & 2000 & $8 / 16 / 2000$ & $39^{\circ} 35^{\prime} 01^{\prime \prime}$ & $106^{\circ} 31^{\prime} 32^{\prime \prime}$ & 8,840 & 8.1 & Navicula cryptocephala Kützing & 186 & 70,651 \\
\hline 55 & 393501106313200 & Beaver Creek above Avon & 1 & 2000 & $8 / 16 / 2000$ & $39^{\circ} 35^{\prime} 01^{\prime \prime}$ & $106^{\circ} 31^{\prime} 32^{\prime \prime}$ & 8,840 & 8.1 & $\begin{array}{l}\text { Navicula cryptotenella Lange-Bertalot } \\
\text { ex Krammer et Lange-Bertalot }\end{array}$ & 1,492 & 539,932 \\
\hline 55 & 393501106313200 & Beaver Creek above Avon & 1 & 2000 & $8 / 16 / 2000$ & $39^{\circ} 35^{\prime} 01^{\prime \prime}$ & $106^{\circ} 31^{\prime} 32^{\prime \prime}$ & 8,840 & 8.1 & Navicula incertata Hustedt & 2,984 & 154,266 \\
\hline 55 & 393501106313200 & Beaver Creek above Avon & 1 & 2000 & $8 / 16 / 2000$ & $39^{\circ} 35^{\prime} 01^{\prime \prime}$ & $106^{\circ} 31^{\prime} 32^{\prime \prime}$ & 8,840 & 8.1 & Navicula veneta Kützing & 932 & 202,182 \\
\hline 55 & 393501106313200 & Beaver Creek above Avon & 1 & 2000 & $8 / 16 / 2000$ & $39^{\circ} 35^{\prime} 01^{\prime \prime}$ & $106^{\circ} 31^{\prime} 32^{\prime \prime}$ & 8,840 & 8.1 & Nitzschia inconspicua Grunow & 373 & 20,016 \\
\hline 55 & 393501106313200 & Beaver Creek above Avon & 1 & 2000 & $8 / 16 / 2000$ & $39^{\circ} 35^{\prime} 01^{\prime \prime}$ & $106^{\circ} 31^{\prime} 32^{\prime \prime}$ & 8,840 & 8.1 & Nitzschia palea (Kützing) Smith & 186 & 32,319 \\
\hline 55 & 393501106313200 & Beaver Creek above Avon & 1 & 2000 & $8 / 16 / 2000$ & $39^{\circ} 35^{\prime} 01^{\prime \prime}$ & $106^{\circ} 31 ' 32^{\prime \prime}$ & 8,840 & 8.1 & Phormidium autumnale (Agardh) Gomont & 889,849 & $87,142,173$ \\
\hline 55 & 393501106313200 & Beaver Creek above Avon & 1 & 2000 & $8 / 16 / 2000$ & $39^{\circ} 35^{\prime} 01^{\prime \prime}$ & $106^{\circ} 31^{\prime} 32^{\prime \prime}$ & 8,840 & 8.1 & $\begin{array}{l}\text { Planothidium lanceolatum } \\
\text { (Brébisson ex Kützing) Lange-Bertalot }\end{array}$ & 559 & 79,912 \\
\hline 55 & 393501106313200 & Beaver Creek above Avon & 1 & 2000 & $8 / 16 / 2000$ & $39^{\circ} 35^{\prime} 01^{\prime \prime}$ & $106^{\circ} 31^{\prime} 32^{\prime \prime}$ & 8,840 & 8.1 & $\begin{array}{l}\text { Reimeria sinuata (Gregory) } \\
\text { Kociolek et Stoermer }\end{array}$ & 11,562 & $1,911,666$ \\
\hline 55 & 393501106313200 & Beaver Creek above Avon & 1 & 2000 & $8 / 16 / 2000$ & $39^{\circ} 35^{\prime} 01^{\prime \prime}$ & $106^{\circ} 31^{\prime} 32^{\prime \prime}$ & 8,840 & 8.1 & $\begin{array}{l}\text { Staurosira construens var. venter (Ehrenberg) } \\
\text { Hamilton }\end{array}$ & 186 & 22,397 \\
\hline 55 & 393501106313200 & Beaver Creek above Avon & 1 & 2001 & $8 / 16 / 2001$ & $39^{\circ} 35^{\prime} 01^{\prime \prime}$ & $106^{\circ} 31 ' 32^{\prime \prime}$ & 8,840 & 8.1 & Achnanthes levanderi Hustedt & 116 & 173,474 \\
\hline 55 & 393501106313200 & Beaver Creek above Avon & 1 & 2001 & $8 / 16 / 2001$ & $39^{\circ} 35^{\prime} 01^{\prime \prime}$ & $106^{\circ} 31^{\prime} 32^{\prime \prime}$ & 8,840 & 8.1 & $\begin{array}{l}\text { Achnanthidium minutissimum (Kützing) } \\
\text { Czarnecki }\end{array}$ & 52,635 & $2,853,898$ \\
\hline 55 & 393501106313200 & Beaver Creek above Avon & 1 & 2001 & $8 / 16 / 2001$ & $39^{\circ} 35^{\prime} 01^{\prime \prime}$ & $106^{\circ} 31^{\prime} 32^{\prime \prime}$ & 8,840 & 8.1 & Adlafia minuscula (Grunow) Lange-Bertalot & 232 & 19,334 \\
\hline 55 & 393501106313200 & Beaver Creek above Avon & 1 & 2001 & $8 / 16 / 2001$ & $39^{\circ} 35^{\prime} 01^{\prime \prime}$ & $106^{\circ} 31^{\prime} 32^{\prime \prime}$ & 8,840 & 8.1 & Aulacoseira distans (Ehrenberg) Simonsen & 232 & 140,957 \\
\hline 55 & 393501106313200 & Beaver Creek above Avon & 1 & 2001 & $8 / 16 / 2001$ & $39^{\circ} 35^{\prime} 01^{\prime \prime}$ & $106^{\circ} 31^{\prime} 32^{\prime \prime}$ & 8,840 & 8.1 & $\begin{array}{l}\text { Cocconeis placentula var. lineata (Ehrenberg) } \\
\text { Van Heurck }\end{array}$ & 2,091 & $2,205,620$ \\
\hline 55 & 393501106313200 & Beaver Creek above Avon & 1 & 2001 & $8 / 16 / 2001$ & $39^{\circ} 35^{\prime} 01^{\prime \prime}$ & $106^{\circ} 31^{\prime} 32^{\prime \prime}$ & 8,840 & 8.1 & Diatoma mesodon (Ehrenberg) Kützing & 1,627 & $1,468,384$ \\
\hline 55 & 393501106313200 & Beaver Creek above Avon & 1 & 2001 & $8 / 16 / 2001$ & $39^{\circ} 35^{\prime} 01^{\prime \prime}$ & $106^{\circ} 31^{\prime} 32^{\prime \prime}$ & 8,840 & 8.1 & Encyonema brehmii (Hustedt) Mann & 1,046 & 28,832 \\
\hline 55 & 393501106313200 & Beaver Creek above Avon & 1 & 2001 & $8 / 16 / 2001$ & $39^{\circ} 35^{\prime} 01^{\prime \prime}$ & $106^{\circ} 31^{\prime} 32^{\prime \prime}$ & 8,840 & 8.1 & Encyonema silesiacum (Bleisch) Mann & 4,531 & $2,152,197$ \\
\hline 55 & 393501106313200 & Beaver Creek above Avon & 1 & 2001 & $8 / 16 / 2001$ & $39^{\circ} 35^{\prime} 01^{\prime \prime}$ & $106^{\circ} 31^{\prime} 32^{\prime \prime}$ & 8,840 & 8.1 & Fragilaria vaucheriae (Kützing) Petersen & 930 & 183,128 \\
\hline 55 & 393501106313200 & Beaver Creek above Avon & 1 & 2001 & $8 / 16 / 2001$ & $39^{\circ} 35^{\prime} 01^{\prime \prime}$ & $106^{\circ} 31^{\prime} 32^{\prime \prime}$ & 8,840 & 8.1 & Gomphonema minutum (Agardh) Agardh & 349 & 28,480 \\
\hline 55 & 393501106313200 & Beaver Creek above Avon & 1 & 2001 & $8 / 16 / 2001$ & $39^{\circ} 35^{\prime} 01^{\prime \prime}$ & $106^{\circ} 31^{\prime} 32^{\prime \prime}$ & 8,840 & 8.1 & Gomphonema parvulum (Kützing) Kützing & 581 & 126,952 \\
\hline 55 & 393501106313200 & Beaver Creek above Avon & 1 & 2001 & $8 / 16 / 2001$ & $39^{\circ} 35^{\prime} 01^{\prime \prime}$ & $106^{\circ} 31^{\prime} 32^{\prime \prime}$ & 8,840 & 8.1 & $\begin{array}{l}\text { Gomphonema pumilum (Grunow) } \\
\text { Reichardt et Lange-Bertalot }\end{array}$ & 2,440 & 532,530 \\
\hline 55 & 393501106313200 & Beaver Creek above Avon & 1 & 2001 & $8 / 16 / 2001$ & $39^{\circ} 35^{\prime} 01^{\prime \prime}$ & $106^{\circ} 31 ' 32^{\prime \prime}$ & 8,840 & 8.1 & Hannaea arcus (Ehrenberg) Patrick & 232 & 465,962 \\
\hline 55 & 393501106313200 & Beaver Creek above Avon & 1 & 2001 & $8 / 16 / 2001$ & $39^{\circ} 35^{\prime} 01^{\prime \prime}$ & $106^{\circ} 31^{\prime} 32^{\prime \prime}$ & 8,840 & 8.1 & $\begin{array}{l}\text { Homoeothrix janthina (Bornet et Flahault) } \\
\text { Starmach }\end{array}$ & $15,634,095$ & $269,119,952$ \\
\hline 55 & 393501106313200 & Beaver Creek above Avon & 1 & 2001 & $8 / 16 / 2001$ & $39^{\circ} 35^{\prime} 01^{\prime \prime}$ & $106^{\circ} 31^{\prime} 32^{\prime \prime}$ & 8,840 & 8.1 & Mayamaea atomus (Kützing) Lange-Bertalot & 581 & 16,682 \\
\hline 55 & 393501106313200 & Beaver Creek above Avon & 1 & 2001 & $8 / 16 / 2001$ & $39^{\circ} 35^{\prime} 01^{\prime \prime}$ & $106^{\circ} 31^{\prime} 32^{\prime \prime}$ & 8,840 & 8.1 & Meridion circulare (Greville) Agardh & 232 & 150,826 \\
\hline 55 & 393501106313200 & Beaver Creek above Avon & 1 & 2001 & $8 / 16 / 2001$ & $39^{\circ} 35^{\prime} 01^{\prime \prime}$ & $106^{\circ} 31^{\prime} 32^{\prime \prime}$ & 8,840 & 8.1 & $\begin{array}{l}\text { Navicula cryptotenella Lange-Bertalot } \\
\text { ex Krammer et Lange-Bertalot }\end{array}$ & 697 & 185,177 \\
\hline 55 & 393501106313200 & Beaver Creek above Avon & 1 & 2001 & $8 / 16 / 2001$ & $39^{\circ} 35^{\prime} 01^{\prime \prime}$ & $106^{\circ} 31^{\prime} 32^{\prime \prime}$ & 8,840 & 8.1 & Navicula incertata Hustedt & 349 & 20,760 \\
\hline 55 & 393501106313200 & Beaver Creek above Avon & 1 & 2001 & $8 / 16 / 2001$ & $39^{\circ} 35^{\prime} 01^{\prime \prime}$ & $106^{\circ} 31^{\prime} 32^{\prime \prime}$ & 8,840 & 8.1 & Navicula tripunctata (Müller) Bory & 232 & 211,313 \\
\hline 55 & 393501106313200 & Beaver Creek above Avon & 1 & 2001 & $8 / 16 / 2001$ & $39^{\circ} 35^{\prime} 01^{\prime \prime}$ & $106^{\circ} 31^{\prime} 32^{\prime \prime}$ & 8,840 & 8.1 & $\begin{array}{l}\text { Nitzschia } \text { cf. tubicola } \\
\text { Grunow ex Cleve et Grunow }\end{array}$ & 232 & 75,834 \\
\hline 55 & 393501106313200 & Beaver Creek above Avon & 1 & 2001 & $8 / 16 / 2001$ & $39^{\circ} 35^{\prime} 01^{\prime \prime}$ & $106^{\circ} 31^{\prime} 32^{\prime \prime}$ & 8,840 & 8.1 & Nitzschia fonticola Grunow & 232 & 23,116 \\
\hline 55 & 393501106313200 & Beaver Creek above Avon & 1 & 2001 & $8 / 16 / 2001$ & $39^{\circ} 35^{\prime} 01^{\prime \prime}$ & $106^{\circ} 31^{\prime} 32^{\prime \prime}$ & 8,840 & 8.1 & Nitzschia inconspicua Grunow & 465 & 16,368 \\
\hline 55 & 393501106313200 & Beaver Creek above Avon & 1 & 2001 & $8 / 16 / 2001$ & $39^{\circ} 35^{\prime} 01^{\prime \prime}$ & $106^{\circ} 31^{\prime} 32^{\prime \prime}$ & 8,840 & 8.1 & $\begin{array}{l}\text { Nitzschia linearis (Agardh ex Wm. Smith) } \\
\text { Wm. Smith }\end{array}$ & 232 & 670,860 \\
\hline 55 & 393501106313200 & Beaver Creek above Avon & 1 & 2001 & $8 / 16 / 2001$ & $39^{\circ} 35^{\prime} 01^{\prime \prime}$ & $106^{\circ} 31^{\prime} 32^{\prime \prime}$ & 8,840 & 8.1 & Nitzschia paleacea Grunow ex Van Heurck & 232 & 12,118 \\
\hline
\end{tabular}


Table 2. Description of sites and algal data collected from selected sites the Eagle River watershed, Colorado, 2000-2001.—Continued

[ID, identification; NAVD, North American Vertical Datum of 1988; ft, feet; $\mathrm{mi}^{2}$, square miles; cells $/ \mathrm{cm}^{2}$, cells per square centimeter; $\mu \mathrm{m}^{3} / \mathrm{cm}^{2}$, cubic micrometer per square centimeter]

\begin{tabular}{|c|c|c|c|c|c|c|c|c|c|c|c|c|}
\hline $\begin{array}{l}\text { Site } \\
\text { ID' }\end{array}$ & $\begin{array}{l}\text { USGS } \\
\text { station } \\
\text { number }\end{array}$ & Station name & $\begin{array}{l}\text { Replicate } \\
\text { sample } \\
\text { number }\end{array}$ & Year & $\begin{array}{l}\text { Collection } \\
\text { date }\end{array}$ & Latitude & Longitude & $\begin{array}{c}\text { Elevation } \\
\text { NAVD } 88 \\
\text { (ft) }\end{array}$ & $\begin{array}{c}\text { Drainage } \\
\text { area } \\
\left(\mathrm{mi}^{2}\right)\end{array}$ & Algal taxon name & $\begin{array}{c}\text { Total } \\
\text { density } \\
\text { (number of } \\
\text { cells } / \mathrm{cm}^{2} \text { ) }\end{array}$ & $\begin{array}{c}\text { Total } \\
\text { biovolume } \\
\left(\mu \mathrm{m}^{3} / \mathrm{cm}^{2}\right)\end{array}$ \\
\hline 55 & 393501106313200 & Beaver Creek above Avon & 1 & 2001 & $8 / 16 / 2001$ & $39^{\circ} 35^{\prime} 01^{\prime \prime}$ & $106^{\circ} 31^{\prime} 32^{\prime \prime}$ & 8,840 & 8.1 & $\begin{array}{l}\text { Planothidium lanceolatum } \\
\text { (Brébisson ex Kützing) Lange-Bertalot }\end{array}$ & 581 & 79,583 \\
\hline 55 & 393501106313200 & Beaver Creek above Avon & 1 & 2001 & $8 / 16 / 2001$ & $39^{\circ} 35^{\prime} 01^{\prime \prime}$ & $106^{\circ} 31^{\prime} 32^{\prime \prime}$ & 8,840 & 8.1 & $\begin{array}{l}\text { Reimeria sinuata (Gregory) } \\
\text { Kociolek et Stoermer }\end{array}$ & 1,975 & 332,908 \\
\hline 55 & 393501106313200 & Beaver Creek above Avon & 1 & 2001 & $8 / 16 / 2001$ & $39^{\circ} 35^{\prime} 01^{\prime \prime}$ & $106^{\circ} 31^{\prime} 32^{\prime \prime}$ & 8,840 & 8.1 & $\begin{array}{l}\text { Staurosirella pinnata (Ehrenberg) } \\
\text { Williams et Round }\end{array}$ & 232 & 22,441 \\
\hline 55 & 393501106313200 & Beaver Creek above Avon & 1 & 2001 & $8 / 16 / 2001$ & $39^{\circ} 35^{\prime} 01^{\prime \prime}$ & $106^{\circ} 31^{\prime} 32^{\prime \prime}$ & 8,840 & 8.1 & Synedra ulna var. contracta Østrup & 116 & 196,935 \\
\hline 55 & 393501106313200 & Beaver Creek above Avon & 1 & 2001 & $8 / 16 / 2001$ & $39^{\circ} 35^{\prime} 01^{\prime \prime}$ & $106^{\circ} 31^{\prime} 32^{\prime \prime}$ & 8,840 & 8.1 & Unknown alga flagellate $(<10 \mu)$ & 5,330 & 512,207 \\
\hline 55 & 393501106313200 & Beaver Creek above Avon & 1 & 2001 & $8 / 16 / 2001$ & $39^{\circ} 35^{\prime} 01^{\prime \prime}$ & $106^{\circ} 31^{\prime} 32^{\prime \prime}$ & 8,840 & 8.1 & $\begin{array}{l}\text { Unknown Cyanophyte Oscillatoriales } \\
\text { (no sheath) }\end{array}$ & 74,025 & $1,098,203$ \\
\hline 55 & 393501106313200 & Beaver Creek above Avon & 1 & 2001 & $8 / 16 / 2001$ & $39^{\circ} 35^{\prime} 01^{\prime \prime}$ & $106^{\circ} 31^{\prime} 32^{\prime \prime}$ & 8,840 & 8.1 & $\begin{array}{l}\text { Unknown Rhodophyte Florideophycidae } \\
\text { (chantransia) }\end{array}$ & 6,514 & $41,694,090$ \\
\hline 56 & 09067000 & Beaver Creek at Avon & 1 & 2000 & $8 / 16 / 2000$ & $39^{\circ} 37^{\prime} 47^{\prime \prime}$ & $106^{\circ} 31^{\prime} 20^{\prime \prime}$ & 7,453 & 14.8 & $\begin{array}{l}\text { Achnanthidium minutissimum (Kützing) } \\
\text { Czarnecki }\end{array}$ & 369,438 & $20,345,640$ \\
\hline 56 & 09067000 & Beaver Creek at Avon & 1 & 2000 & $8 / 16 / 2000$ & $39^{\circ} 37^{\prime} 47^{\prime \prime}$ & $106^{\circ} 31^{\prime 2} 20^{\prime \prime}$ & 7,453 & 14.8 & Amphora pediculus (Kützing) Grunow & 6,987 & 661,179 \\
\hline 56 & 09067000 & Beaver Creek at Avon & 1 & 2000 & $8 / 16 / 2000$ & $39^{\circ} 37^{\prime} 47^{\prime \prime}$ & $106^{\circ} 31^{\prime 2} 20^{\prime \prime}$ & 7,453 & 14.8 & Caloneis bacillum (Grunow) Cleve & 3,494 & $1,502,788$ \\
\hline 56 & 09067000 & Beaver Creek at Avon & 1 & 2000 & $8 / 16 / 2000$ & $39^{\circ} 37^{\prime} 47^{\prime \prime}$ & $106^{\circ} 31^{\prime 2} 20^{\prime \prime}$ & 7,453 & 14.8 & Chlamydomonas sp. & 4,277 & 363,558 \\
\hline 56 & 09067000 & Beaver Creek at Avon & 1 & 2000 & $8 / 16 / 2000$ & $39^{\circ} 37^{\prime} 47^{\prime \prime}$ & $106^{\circ} 31^{\prime 2} 20^{\prime \prime}$ & 7,453 & 14.8 & Cladophora glomerata (Linnaeus) Kützing & 19,247 & $104,483,445,625$ \\
\hline 56 & 09067000 & Beaver Creek at Avon & 1 & 2000 & $8 / 16 / 2000$ & $39^{\circ} 37^{\prime} 47^{\prime \prime}$ & $106^{\circ} 31^{\prime 2} 20^{\prime \prime}$ & 7,453 & 14.8 & Cocconeis pediculus Ehrenberg & 3,494 & $12,084,841$ \\
\hline 56 & 09067000 & Beaver Creek at Avon & 1 & 2000 & $8 / 16 / 2000$ & $39^{\circ} 37^{\prime} 47^{\prime \prime}$ & $106^{\circ} 31^{\prime} 20^{\prime \prime}$ & 7,453 & 14.8 & $\begin{array}{l}\text { Cocconeis placentula var. englypta } \\
\text { (Ehrenberg) Grunow }\end{array}$ & 7,860 & $4,735,467$ \\
\hline 56 & 09067000 & Beaver Creek at Avon & 1 & 2000 & $8 / 16 / 2000$ & $39^{\circ} 37^{\prime} 47^{\prime \prime}$ & $106^{\circ} 31^{\prime} 20^{\prime \prime}$ & 7,453 & 14.8 & $\begin{array}{l}\text { Cocconeis placentula var. lineata (Ehrenberg) } \\
\text { Van Heurck }\end{array}$ & 6,987 & $7,320,645$ \\
\hline 56 & 09067000 & Beaver Creek at Avon & 1 & 2000 & $8 / 16 / 2000$ & $39^{\circ} 37^{\prime} 47^{\prime \prime}$ & $106^{\circ} 31^{\prime 2} 20^{\prime \prime}$ & 7,453 & 14.8 & Diatoma vulgaris Bory & 1,747 & $6,454,104$ \\
\hline 56 & 09067000 & Beaver Creek at Avon & 1 & 2000 & $8 / 16 / 2000$ & $39^{\circ} 37^{\prime} 47^{\prime \prime}$ & $106^{\circ} 31^{\prime 2} 20^{\prime \prime}$ & 7,453 & 14.8 & Encyonema brehmii (Hustedt) Mann & 13,101 & 361,204 \\
\hline 56 & 09067000 & Beaver Creek at Avon & 1 & 2000 & $8 / 16 / 2000$ & $39^{\circ} 37^{\prime} 47^{\prime \prime}$ & $106^{\circ} 31^{\prime 2} 20^{\prime \prime}$ & 7,453 & 14.8 & Encyonema minиtum (Hilse) Mann & 24,455 & $5,232,867$ \\
\hline 56 & 09067000 & Beaver Creek at Avon & 1 & 2000 & $8 / 16 / 2000$ & $39^{\circ} 37^{\prime} 47^{\prime \prime}$ & $106^{\circ} 31^{\prime 2} 20^{\prime \prime}$ & 7,453 & 14.8 & Encyonema silesiacum (Bleisch) Mann & 65,503 & $30,842,256$ \\
\hline 56 & 09067000 & Beaver Creek at Avon & 1 & 2000 & $8 / 16 / 2000$ & $39^{\circ} 37^{\prime} 47^{\prime \prime}$ & $106^{\circ} 31^{\prime 2} 20^{\prime \prime}$ & 7,453 & 14.8 & Fallacia pygmaea (Kützing) Stickle et Mann & 1,747 & $2,007,862$ \\
\hline 56 & 09067000 & Beaver Creek at Avon & 1 & 2000 & $8 / 16 / 2000$ & $39^{\circ} 37^{\prime} 47^{\prime \prime}$ & $106^{\circ} 31^{\prime 2} 20^{\prime \prime}$ & 7,453 & 14.8 & Fragilaria capucina Desmazières & 5,240 & 978,991 \\
\hline 56 & 09067000 & Beaver Creek at Avon & 1 & 2000 & $8 / 16 / 2000$ & $39^{\circ} 37^{\prime} 47^{\prime \prime}$ & $106^{\circ} 31^{\prime 2} 20^{\prime \prime}$ & 7,453 & 14.8 & Fragilaria vaucheriae (Kützing) Petersen & 1,747 & 361,336 \\
\hline 56 & 09067000 & Beaver Creek at Avon & 1 & 2000 & $8 / 16 / 2000$ & $39^{\circ} 37^{\prime} 47^{\prime \prime}$ & $106^{\circ} 31^{\prime 2} 20^{\prime \prime}$ & 7,453 & 14.8 & Gomphonema subclavatum (Grunow) Grunow & 27,948 & $22,312,807$ \\
\hline 56 & 09067000 & Beaver Creek at Avon & 1 & 2000 & $8 / 16 / 2000$ & $39^{\circ} 37^{\prime} 47^{\prime \prime}$ & $106^{\circ} 31^{\prime} 20^{\prime \prime}$ & 7,453 & 14.8 & $\begin{array}{l}\text { Homoeothrix janthina (Bornet et Flahault) } \\
\text { Starmach }\end{array}$ & 190,333 & $6,168,379$ \\
\hline 56 & 09067000 & Beaver Creek at Avon & 1 & 2000 & $8 / 16 / 2000$ & $39^{\circ} 37^{\prime} 47^{\prime \prime}$ & $106^{\circ} 31^{\prime 2} 20^{\prime \prime}$ & 7,453 & 14.8 & Navicula cryptocephala Kützing & 1,747 & 661,782 \\
\hline 56 & 09067000 & Beaver Creek at Avon & 1 & 2000 & $8 / 16 / 2000$ & $39^{\circ} 37^{\prime} 47^{\prime \prime}$ & $106^{\circ} 31^{\prime} 20^{\prime \prime}$ & 7,453 & 14.8 & $\begin{array}{l}\text { Navicula cryptotenella Lange-Bertalot } \\
\text { ex Krammer et Lange-Bertalot }\end{array}$ & 20,961 & $7,586,254$ \\
\hline 56 & 09067000 & Beaver Creek at Avon & 1 & 2000 & $8 / 16 / 2000$ & $39^{\circ} 37^{\prime} 47^{\prime \prime}$ & $106^{\circ} 31^{\prime 2} 20^{\prime \prime}$ & 7,453 & 14.8 & Navicula incertata Hustedt & 3,494 & 180,625 \\
\hline 56 & 09067000 & Beaver Creek at Avon & 1 & 2000 & $8 / 16 / 2000$ & $39^{\circ} 37^{\prime} 47^{\prime \prime}$ & $106^{\circ} 31^{\prime 2} 20^{\prime \prime}$ & 7,453 & 14.8 & Navicula lanceolata (Agardh) Ehrenberg & 3,494 & $4,391,612$ \\
\hline 56 & 09067000 & Beaver Creek at Avon & 1 & 2000 & $8 / 16 / 2000$ & $39^{\circ} 37^{\prime} 47^{\prime \prime}$ & $106^{\circ} 31^{\prime 2} 20^{\prime \prime}$ & 7,453 & 14.8 & Navicula tripunctata (Müller) Bory & 6,987 & $6,610,824$ \\
\hline 56 & 09067000 & Beaver Creek at Avon & 1 & 2000 & $8 / 16 / 2000$ & $39^{\circ} 37^{\prime} 47^{\prime \prime}$ & $106^{\circ} 31^{\prime 2} 20^{\prime \prime}$ & 7,453 & 14.8 & Navicula veneta Kützing & 3,494 & 757,530 \\
\hline 56 & 09067000 & Beaver Creek at Avon & 1 & 2000 & $8 / 16 / 2000$ & $39^{\circ} 37^{\prime} 47^{\prime \prime}$ & $106^{\circ} 31^{\prime 2} 20^{\prime \prime}$ & 7,453 & 14.8 & Nitzschia fonticola Grunow & 18,341 & $1,821,313$ \\
\hline 56 & 09067000 & Beaver Creek at Avon & 1 & 2000 & $8 / 16 / 2000$ & $39^{\circ} 37^{\prime} 47^{\prime \prime}$ & $106^{\circ} 31^{\prime 2} 20^{\prime \prime}$ & 7,453 & 14.8 & Nitzschia heufleriana Grunow & 5,240 & $61,384,339$ \\
\hline 56 & 09067000 & Beaver Creek at Avon & 1 & 2000 & $8 / 16 / 2000$ & $39^{\circ} 37^{\prime} 47^{\prime \prime}$ & $106^{\circ} 31^{\prime 2} 20^{\prime \prime}$ & 7,453 & 14.8 & Nitzschia inconspicua Grunow & 1,747 & 93,743 \\
\hline 56 & 09067000 & Beaver Creek at Avon & 1 & 2000 & $8 / 16 / 2000$ & $39^{\circ} 37^{\prime} 47^{\prime \prime}$ & $106^{\circ} 31^{\prime 2} 20^{\prime \prime}$ & 7,453 & 14.8 & Nitzschia palea (Kützing) Smith & 1,747 & 302,732 \\
\hline 56 & 09067000 & Beaver Creek at Avon & 1 & 2000 & $8 / 16 / 2000$ & $39^{\circ} 37^{\prime} 47^{\prime \prime}$ & $106^{\circ} 31^{\prime 2} 20^{\prime \prime}$ & 7,453 & 14.8 & Nitzschia recta Hantzsch ex Rabenhorst & 5,240 & $9,093,487$ \\
\hline 56 & 09067000 & Beaver Creek at Avon & 1 & 2000 & $8 / 16 / 2000$ & $39^{\circ} 37^{\prime} 47^{\prime \prime}$ & $106^{\circ} 31^{\prime 2} 20^{\prime \prime}$ & 7,453 & 14.8 & Oedogonium sp. & 6,416 & $262,926,920$ \\
\hline 56 & 09067000 & Beaver Creek at Avon & 1 & 2000 & $8 / 16 / 2000$ & $39^{\circ} 37^{\prime} 47^{\prime \prime}$ & $106^{\circ} 31^{\prime 2} 20^{\prime \prime}$ & 7,453 & 14.8 & Planothidium lanceolatum & 1,747 & 249,509 \\
\hline
\end{tabular}




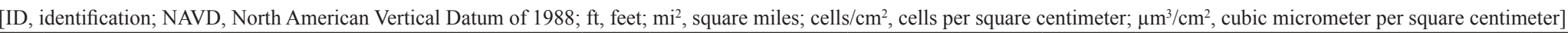

\begin{tabular}{|c|c|c|c|c|c|c|c|c|c|c|c|c|}
\hline $\begin{array}{l}\text { Site } \\
\text { ID }^{1}\end{array}$ & $\begin{array}{l}\text { USGS } \\
\text { station } \\
\text { number }\end{array}$ & Station name & $\begin{array}{c}\text { Replicate } \\
\text { sample } \\
\text { number }\end{array}$ & Year & $\begin{array}{l}\text { Collection } \\
\text { date }\end{array}$ & Latitude & Longitude & $\begin{array}{c}\text { Elevation } \\
\text { NAVD } 88 \\
\text { (ft) }\end{array}$ & $\begin{array}{c}\text { Drainage } \\
\text { area } \\
\left(\mathrm{mi}^{2}\right)\end{array}$ & Algal taxon name & $\begin{array}{c}\text { Total } \\
\text { density } \\
\text { (number of } \\
\text { cells/cm²) }\end{array}$ & $\begin{array}{c}\text { Total } \\
\text { biovolume } \\
\left(\mu \mathrm{m}^{3} / \mathrm{cm}^{2}\right)\end{array}$ \\
\hline 56 & 09067000 & Beaver Creek at Avon & 1 & 2000 & $8 / 16 / 2000$ & $39^{\circ} 37^{\prime} 47^{\prime \prime}$ & $106^{\circ} 31^{\prime} 20^{\prime \prime}$ & 7,453 & 14.8 & $\begin{array}{l}\text { Rhoicosphenia curvata (Kützing) } \\
\text { Grunow ex Rabenhorst }\end{array}$ & 6,987 & $3,720,861$ \\
\hline 56 & 09067000 & Beaver Creek at Avon & 1 & 2000 & $8 / 16 / 2000$ & $39^{\circ} 37^{\prime} 47^{\prime \prime}$ & $106^{\circ} 31^{\prime 2} 20^{\prime \prime}$ & 7,453 & 14.8 & Surirella angusta Kützing & 1,747 & $1,978,540$ \\
\hline 56 & 09067000 & Beaver Creek at Avon & 1 & 2000 & $8 / 16 / 2000$ & $39^{\circ} 37^{\prime} 47^{\prime \prime}$ & $106^{\circ} 31^{\prime 2} 20^{\prime \prime}$ & 7,453 & 14.8 & Surirella minuta Brébisson & 1,747 & $1,648,834$ \\
\hline 57 & 09067005 & Eagle River at Avon & 1 & 2000 & $8 / 18 / 2000$ & $39^{\circ} 37^{\prime} 54^{\prime \prime}$ & $106^{\circ} 31^{\prime} 19^{\prime \prime}$ & 7,410 & 395 & $\begin{array}{l}\text { Achnanthidium minutissimum (Kützing) } \\
\text { Czarnecki }\end{array}$ & 90,944 & $5,008,483$ \\
\hline 57 & 09067005 & Eagle River at Avon & 1 & 2000 & $8 / 18 / 2000$ & $39^{\circ} 37^{\prime} 54^{\prime \prime}$ & $106^{\circ} 31^{\prime} 19^{\prime \prime}$ & 7,410 & 395 & $\begin{array}{l}\text { Achnanthidium pyrenaicum (Hustedt) } \\
\text { Kobayasi }\end{array}$ & 3,163 & 397,971 \\
\hline 57 & 09067005 & Eagle River at Avon & 1 & 2000 & $8 / 18 / 2000$ & $39^{\circ} 37 ' 54^{\prime \prime}$ & $106^{\circ} 31^{\prime} 19^{\prime \prime}$ & 7,410 & 395 & Brachysira microcephala (Grunow) Compère & 1,582 & 315,959 \\
\hline 57 & 09067005 & Eagle River at Avon & 1 & 2000 & $8 / 18 / 2000$ & $39^{\circ} 37 ' 54^{\prime \prime}$ & $106^{\circ} 31^{\prime} 19^{\prime \prime}$ & 7,410 & 395 & Diatoma moniliformis Kützing & 4,745 & 715,129 \\
\hline 57 & 09067005 & Eagle River at Avon & 1 & 2000 & $8 / 18 / 2000$ & $39^{\circ} 377^{\prime \prime}$ & $106^{\circ} 31^{\prime} 19^{\prime \prime}$ & 7,410 & 395 & Encyonema brehmii (Hustedt) Mann & 14,235 & 392,474 \\
\hline 57 & 09067005 & Eagle River at Avon & 1 & 2000 & $8 / 18 / 2000$ & $39^{\circ} 377^{\prime \prime}$ & $106^{\circ} 31^{\prime} 19^{\prime \prime}$ & 7,410 & 395 & Encyonema minutum (Hilse) Mann & 1,582 & 338,446 \\
\hline 57 & 09067005 & Eagle River at Avon & 1 & 2000 & $8 / 18 / 2000$ & $39^{\circ} 374^{\prime \prime}$ & $106^{\circ} 31^{\prime} 19^{\prime \prime}$ & 7,410 & 395 & Encyonema silesiacum (Bleisch) Mann & 174,772 & $82,291,416$ \\
\hline 57 & 09067005 & Eagle River at Avon & 1 & 2000 & $8 / 18 / 2000$ & $39^{\circ} 37^{\prime} 54^{\prime \prime}$ & $106^{\circ} 31^{\prime} 19^{\prime \prime}$ & 7,410 & 395 & $\begin{array}{l}\text { Fragilaria capucina var. fragilarioides } \\
\text { (Grunow) Ludwig et Flores }\end{array}$ & 791 & 81,026 \\
\hline 57 & 09067005 & Eagle River at Avon & 1 & 2000 & $8 / 18 / 2000$ & $39^{\circ} 37 ' 54^{\prime \prime}$ & $106^{\circ} 31^{\prime} 19^{\prime \prime}$ & 7,410 & 395 & Fragilaria vaucheriae (Kützing) Petersen & 19,771 & $4,089,766$ \\
\hline 57 & 09067005 & Eagle River at Avon & 1 & 2000 & $8 / 18 / 2000$ & $39^{\circ} 37^{\prime} 54^{\prime \prime}$ & $106^{\circ} 31^{\prime} 19^{\prime \prime}$ & 7,410 & 395 & $\begin{array}{l}\text { Geissleria acceptata (Hustedt) } \\
\text { Lange-Bertalot et Metzeltin }\end{array}$ & 1,582 & 162,357 \\
\hline 57 & 09067005 & Eagle River at Avon & 1 & 2000 & $8 / 18 / 2000$ & $39^{\circ} 374^{\prime \prime}$ & $106^{\circ} 31^{\prime} 19^{\prime \prime}$ & 7,410 & 395 & Gomphonema minutum (Agardh) Agardh & 791 & 137,176 \\
\hline 57 & 09067005 & Eagle River at Avon & 1 & 2000 & $8 / 18 / 2000$ & $39^{\circ} 37 ' 54^{\prime \prime}$ & $106^{\circ} 31^{\prime} 19^{\prime \prime}$ & 7,410 & 395 & Gomphonema olivaceum (Lyngbye) Kützing & 3,163 & $1,088,388$ \\
\hline 57 & 09067005 & Eagle River at Avon & 1 & 2000 & $8 / 18 / 2000$ & $39^{\circ} 374^{\prime \prime}$ & $106^{\circ} 31^{\prime} 19^{\prime \prime}$ & 7,410 & 395 & Hannaea arcus (Ehrenberg) Patrick & 6,327 & $15,361,790$ \\
\hline 57 & 09067005 & Eagle River at Avon & 1 & 2000 & $8 / 18 / 2000$ & $39^{\circ} 37^{\prime} 54^{\prime \prime}$ & $106^{\circ} 31^{\prime} 19^{\prime \prime}$ & 7,410 & 395 & $\begin{array}{l}\text { Homoeothrix janthina (Bornet et Flahault) } \\
\text { Starmach }\end{array}$ & $2,920,894$ & $94,661,306$ \\
\hline 57 & 09067005 & Eagle River at Avon & 1 & 2000 & $8 / 18 / 2000$ & $39^{\circ} 37^{\prime} 54^{\prime \prime}$ & $106^{\circ} 31^{\prime} 19^{\prime \prime}$ & 7,410 & 395 & Mayamaea atomus (Kützing) Lange-Bertalot & 3,954 & 103,272 \\
\hline 57 & 09067005 & Eagle River at Avon & 1 & 2000 & $8 / 18 / 2000$ & $39^{\circ} 37 ' 54^{\prime \prime}$ & $106^{\circ} 31^{\prime} 19^{\prime \prime}$ & 7,410 & 395 & Melosira varians Agardh & 6,327 & $34,348,573$ \\
\hline 57 & 09067005 & Eagle River at Avon & 1 & 2000 & $8 / 18 / 2000$ & $39^{\circ} 374^{\prime \prime}$ & $106^{\circ} 31^{\prime} 19^{\prime \prime}$ & 7,410 & 395 & Navicula incertata Hustedt & 5,536 & 286,216 \\
\hline 57 & 09067005 & Eagle River at Avon & 1 & 2000 & $8 / 18 / 2000$ & $39^{\circ} 37 ' 54^{\prime \prime}$ & $106^{\circ} 31^{\prime} 19^{\prime \prime}$ & 7,410 & 395 & Navicula minima Grunow & 1,582 & 84,002 \\
\hline 57 & 09067005 & Eagle River at Avon & 1 & 2000 & $8 / 18 / 2000$ & $39^{\circ} 374^{\prime \prime}$ & $106^{\circ} 31^{\prime} 19^{\prime \prime}$ & 7,410 & 395 & Navicula tenelloides Hustedt & 1,582 & 257,197 \\
\hline 57 & 09067005 & Eagle River at Avon & 1 & 2000 & $8 / 18 / 2000$ & $39^{\circ} 37^{\prime} 54^{\prime \prime}$ & $106^{\circ} 31^{\prime} 19^{\prime \prime}$ & 7,410 & 395 & Nitzschia fonticola Grunow & 9,490 & 942,375 \\
\hline 57 & 09067005 & Eagle River at Avon & 1 & 2000 & $8 / 18 / 2000$ & $39^{\circ} 37 ' 54^{\prime \prime}$ & $106^{\circ} 31^{\prime} 19^{\prime \prime}$ & 7,410 & 395 & Nitzschia frustulum (Kützing) Grunow & 3,163 & 236,345 \\
\hline 57 & 09067005 & Eagle River at Avon & 1 & 2000 & $8 / 18 / 2000$ & $39^{\circ} 374^{\prime \prime}$ & $106^{\circ} 31^{\prime} 19^{\prime \prime}$ & 7,410 & 395 & Nitzschia inconspicua Grunow & 3,163 & 114,380 \\
\hline 57 & 09067005 & Eagle River at Avon & 1 & 2000 & $8 / 18 / 2000$ & $39^{\circ} 37 ' 54^{\prime \prime}$ & $106^{\circ} 31^{\prime} 19^{\prime \prime}$ & 7,410 & 395 & Nitzschia palea (Kützing) Smith & 25,306 & $4,385,865$ \\
\hline 57 & 09067005 & Eagle River at Avon & 1 & 2000 & $8 / 18 / 2000$ & $39^{\circ} 37^{\prime} 54^{\prime \prime}$ & $106^{\circ} 31^{\prime} 19^{\prime \prime}$ & 7,410 & 395 & Nitzschia paleacea Grunow ex Van Heurck & 185,052 & $5,669,314$ \\
\hline 57 & 09067005 & Eagle River at Avon & 1 & 2000 & $8 / 18 / 2000$ & $39^{\circ} 37 ' 54^{\prime \prime}$ & $106^{\circ} 31^{\prime} 19^{\prime \prime}$ & 7,410 & 395 & Phormidium autumnale (Agardh) Gomont & 380,174 & $37,230,178$ \\
\hline 57 & 09067005 & Eagle River at Avon & 1 & 2000 & $8 / 18 / 2000$ & $39^{\circ} 37^{\prime} 54^{\prime \prime}$ & $106^{\circ} 31^{\prime} 19^{\prime \prime}$ & 7,410 & 395 & $\begin{array}{l}\text { Planothidium lanceolatum } \\
\text { (Brébisson ex Kützing) Lange-Bertalot }\end{array}$ & 1,582 & 225,924 \\
\hline 57 & 09067005 & Eagle River at Avon & 1 & 2000 & $8 / 18 / 2000$ & $39^{\circ} 37^{\prime} 54^{\prime \prime}$ & $106^{\circ} 31^{\prime} 19^{\prime \prime}$ & 7,410 & 395 & $\begin{array}{l}\text { Reimeria sinuata (Gregory) } \\
\text { Kociolek et Stoermer }\end{array}$ & 14,235 & $2,353,624$ \\
\hline 57 & 09067005 & Eagle River at Avon & 1 & 2000 & $8 / 18 / 2000$ & $39^{\circ} 37^{\prime} 54^{\prime \prime}$ & $106^{\circ} 31^{\prime} 19^{\prime \prime}$ & 7,410 & 395 & $\begin{array}{l}\text { Staurosira construens var. venter (Ehrenberg) } \\
\text { Hamilton }\end{array}$ & 1,582 & 189,963 \\
\hline 57 & 09067005 & Eagle River at Avon & 1 & 2000 & $8 / 18 / 2000$ & $39^{\circ} 37^{\prime} 54^{\prime \prime}$ & $106^{\circ} 31^{\prime} 19^{\prime \prime}$ & 7,410 & 395 & $\begin{array}{l}\text { Staurosirella pinnata (Ehrenberg) } \\
\text { Williams et Round }\end{array}$ & 791 & 76,137 \\
\hline 57 & 09067005 & Eagle River at Avon & 1 & 2000 & $8 / 18 / 2000$ & $39^{\circ} 377^{\prime \prime}$ & $106^{\circ} 31^{\prime} 19^{\prime \prime}$ & 7,410 & 395 & Surirella angusta Kützing & 1,582 & $1,791,522$ \\
\hline 57 & 09067005 & Eagle River at Avon & 1 & 2000 & $8 / 18 / 2000$ & $39^{\circ} 37^{\prime} 54^{\prime \prime}$ & $106^{\circ} 31^{\prime} 19^{\prime \prime}$ & 7,410 & 395 & $\begin{array}{l}\text { Surirella brebissonii } \\
\text { Krammer et Lange-Bertalot }\end{array}$ & 1,582 & $4,493,721$ \\
\hline 57 & 09067005 & Eagle River at Avon & 1 & 2000 & $8 / 18 / 2000$ & $39^{\circ} 37^{\prime} 54^{\prime \prime}$ & $106^{\circ} 31^{\prime} 19^{\prime \prime}$ & 7,410 & 395 & Synedra ulna (Nitzsch) Ehrenberg & 1,582 & $10,370,180$ \\
\hline 57 & 09067005 & Eagle River at Avon & 1 & 2000 & $8 / 18 / 2000$ & $39^{\circ} 37^{\prime} 54^{\prime \prime}$ & $106^{\circ} 31^{\prime} 19^{\prime \prime}$ & 7,410 & 395 & Tabellaria flocculosa (Roth) Kützing & 791 & $6,817,673$ \\
\hline
\end{tabular}


Table 2. Description of sites and algal data collected from selected sites the Eagle River watershed, Colorado, 2000-2001.—Continued

[ID, identification; NAVD, North American Vertical Datum of 1988; ft, feet; $\mathrm{mi}^{2}$, square miles; cells $/ \mathrm{cm}^{2}$, cells per square centimeter; $\mu \mathrm{m}^{3} / \mathrm{cm}^{2}$, cubic micrometer per square centimeter]

\begin{tabular}{|c|c|c|c|c|c|c|c|c|c|c|c|c|}
\hline $\begin{array}{l}\text { Site } \\
\text { ID' }\end{array}$ & $\begin{array}{l}\text { USGS } \\
\text { station } \\
\text { number }\end{array}$ & Station name & $\begin{array}{c}\text { Replicate } \\
\text { sample } \\
\text { number }\end{array}$ & Year & $\begin{array}{l}\text { Collection } \\
\text { date }\end{array}$ & Latitude & Longitude & $\begin{array}{c}\text { Elevation } \\
\text { NAVD } 88 \\
\text { (ft) }\end{array}$ & $\begin{array}{c}\text { Drainage } \\
\text { area } \\
\left(\mathrm{mi}^{2}\right)\end{array}$ & Algal taxon name & $\begin{array}{c}\text { Total } \\
\text { density } \\
\text { (number of } \\
\text { cells/cm²) }\end{array}$ & $\begin{array}{c}\text { Total } \\
\text { biovolume } \\
\left(\mu \mathrm{m}^{3} / \mathrm{cm}^{2}\right)\end{array}$ \\
\hline 57 & 09067005 & Eagle River at Avon & 1 & 2001 & $8 / 16 / 2001$ & $39^{\circ} 37^{\prime} 54^{\prime \prime}$ & $106^{\circ} 31^{\prime} 19^{\prime \prime}$ & 7,410 & 395 & $\begin{array}{l}\text { Achnanthidium minutissimum (Kützing) } \\
\text { Czarnecki }\end{array}$ & 14,503 & 786,369 \\
\hline 57 & 09067005 & Eagle River at Avon & 1 & 2001 & $8 / 16 / 2001$ & $39^{\circ} 37^{\prime} 54^{\prime \prime}$ & $106^{\circ} 31^{\prime} 19^{\prime \prime}$ & 7,410 & 395 & $\begin{array}{l}\text { Achnanthidium pyrenaicum (Hustedt) } \\
\text { Kobayasi }\end{array}$ & 594 & 75,108 \\
\hline 57 & 09067005 & Eagle River at Avon & 1 & 2001 & $8 / 16 / 2001$ & $39^{\circ} 37^{\prime} 54^{\prime \prime}$ & $106^{\circ} 31^{\prime} 19^{\prime \prime}$ & 7,410 & 395 & Adlafia bryophila (Petersen) Lange-Bertalot & 238 & 10,142 \\
\hline 57 & 09067005 & Eagle River at Avon & 1 & 2001 & $8 / 16 / 2001$ & $39^{\circ} 37^{\prime} 54^{\prime \prime}$ & $106^{\circ} 31^{\prime} 19^{\prime \prime}$ & 7,410 & 395 & Adlafia minuscula (Grunow) Lange-Bertalot & 119 & 9,891 \\
\hline 57 & 09067005 & Eagle River at Avon & 1 & 2001 & $8 / 16 / 2001$ & $39^{\circ} 37^{\prime} 54^{\prime \prime}$ & $106^{\circ} 31^{\prime} 19^{\prime \prime}$ & 7,410 & 395 & Amphora pediculus (Kützing) Grunow & 357 & 34,481 \\
\hline 57 & 09067005 & Eagle River at Avon & 1 & 2001 & $8 / 16 / 2001$ & $39^{\circ} 37^{\prime} 54^{\prime \prime}$ & $106^{\circ} 31^{\prime} 19^{\prime \prime}$ & 7,410 & 395 & Calothrix parientina (Nägeli) Thuret & 4,670 & 379,333 \\
\hline 57 & 09067005 & Eagle River at Avon & 1 & 2001 & $8 / 16 / 2001$ & $39^{\circ} 37^{\prime} 54^{\prime \prime}$ & $106^{\circ} 31^{\prime} 19^{\prime \prime}$ & 7,410 & 395 & Chlamydomonas sp. & 1,038 & $2,053,973$ \\
\hline 57 & 09067005 & Eagle River at Avon & 1 & 2001 & $8 / 16 / 2001$ & $39^{\circ} 37^{\prime} 54^{\prime \prime}$ & $106^{\circ} 31^{\prime} 19^{\prime \prime}$ & 7,410 & 395 & $\begin{array}{l}\text { Cocconeis placentula var. lineata (Ehrenberg) } \\
\text { Van Heurck }\end{array}$ & 238 & 250,735 \\
\hline 57 & 09067005 & Eagle River at Avon & 1 & 2001 & $8 / 16 / 2001$ & $39^{\circ} 37^{\prime} 54^{\prime \prime}$ & $106^{\circ} 31^{\prime} 19^{\prime \prime}$ & 7,410 & 395 & Diatoma moniliformis Kützing & 238 & 43,391 \\
\hline 57 & 09067005 & Eagle River at Avon & 1 & 2001 & $8 / 16 / 2001$ & $39^{\circ} 37^{\prime} 54^{\prime \prime}$ & $106^{\circ} 31^{\prime} 19^{\prime \prime}$ & 7,410 & 395 & Encyonema brehmii (Hustedt) Mann & 357 & 9,833 \\
\hline 57 & 09067005 & Eagle River at Avon & 1 & 2001 & $8 / 16 / 2001$ & $39^{\circ} 37^{\prime} 54^{\prime \prime}$ & $106^{\circ} 31^{\prime} 19^{\prime \prime}$ & 7,410 & 395 & Encyonema тіпитит (Hilse) Mann & 1,545 & 333,551 \\
\hline 57 & 09067005 & Eagle River at Avon & 1 & 2001 & $8 / 16 / 2001$ & $39^{\circ} 37^{\prime} 54^{\prime \prime}$ & $106^{\circ} 31^{\prime} 19^{\prime \prime}$ & 7,410 & 395 & Encyonema silesiacum (Bleisch) Mann & 38,397 & $18,236,689$ \\
\hline 57 & 09067005 & Eagle River at Avon & 1 & 2001 & $8 / 16 / 2001$ & $39^{\circ} 37^{\prime} 54^{\prime \prime}$ & $106^{\circ} 31^{\prime} 19^{\prime \prime}$ & 7,410 & 395 & Fragilaria vaucheriae (Kützing) Petersen & 5,231 & $1,030,490$ \\
\hline 57 & 09067005 & Eagle River at Avon & 1 & 2001 & $8 / 16 / 2001$ & $39^{\circ} 37^{\prime} 54^{\prime \prime}$ & $106^{\circ} 31^{\prime} 19^{\prime \prime}$ & 7,410 & 395 & Gomphonema minutum (Agardh) Agardh & 476 & 38,852 \\
\hline 57 & 09067005 & Eagle River at Avon & 1 & 2001 & $8 / 16 / 2001$ & $39^{\circ} 37^{\prime} 54^{\prime \prime}$ & $106^{\circ} 31^{\prime} 19^{\prime \prime}$ & 7,410 & 395 & $\begin{array}{l}\text { Homoeothrix janthina (Bornet et Flahault) } \\
\text { Starmach }\end{array}$ & $1,025,295$ & $17,649,077$ \\
\hline 57 & 09067005 & Eagle River at Avon & 1 & 2001 & $8 / 16 / 2001$ & $39^{\circ} 37^{\prime} 54^{\prime \prime}$ & $106^{\circ} 31^{\prime} 19^{\prime \prime}$ & 7,410 & 395 & Melosira varians Agardh & 2,853 & $14,744,783$ \\
\hline 57 & 09067005 & Eagle River at Avon & 1 & 2001 & $8 / 16 / 2001$ & $39^{\circ} 37^{\prime} 54^{\prime \prime}$ & $106^{\circ} 31^{\prime} 19^{\prime \prime}$ & 7,410 & 395 & Navicula tripunctata (Müller) Bory & 713 & 648,596 \\
\hline 57 & 09067005 & Eagle River at Avon & 1 & 2001 & $8 / 16 / 2001$ & $39^{\circ} 37^{\prime} 54^{\prime \prime}$ & $106^{\circ} 31^{\prime} 19^{\prime \prime}$ & 7,410 & 395 & Nitzschia dissipata (Kützing) Grunow & 713 & 183,905 \\
\hline 57 & 09067005 & Eagle River at Avon & 1 & 2001 & $8 / 16 / 2001$ & $39^{\circ} 37^{\prime} 54^{\prime \prime}$ & $106^{\circ} 31^{\prime} 19^{\prime \prime}$ & 7,410 & 395 & Nitzschia fonticola Grunow & 4,636 & 461,191 \\
\hline 57 & 09067005 & Eagle River at Avon & 1 & 2001 & $8 / 16 / 2001$ & $39^{\circ} 37^{\prime} 54^{\prime \prime}$ & $106^{\circ} 31^{\prime} 19^{\prime \prime}$ & 7,410 & 395 & $\begin{array}{l}\text { Nitzschia linearis (Agardh ex Wm. Smith) } \\
\text { Wm. Smith }\end{array}$ & 238 & 686,370 \\
\hline 57 & 09067005 & Eagle River at Avon & 1 & 2001 & $8 / 16 / 2001$ & $39^{\circ} 37^{\prime} 54^{\prime \prime}$ & $106^{\circ} 31^{\prime} 19^{\prime \prime}$ & 7,410 & 395 & Nitzschia paleacea Grunow ex Van Heurck & 1,427 & 74,391 \\
\hline 57 & 09067005 & Eagle River at Avon & 1 & 2001 & $8 / 16 / 2001$ & $39^{\circ} 37^{\prime} 54^{\prime \prime}$ & $106^{\circ} 31^{\prime} 19^{\prime \prime}$ & 7,410 & 395 & Phormidium autumnale (Agardh) Gomont & 10,896 & $1,056,458$ \\
\hline 57 & 09067005 & Eagle River at Avon & 1 & 2001 & $8 / 16 / 2001$ & $39^{\circ} 37^{\prime} 54^{\prime \prime}$ & $106^{\circ} 31^{\prime} 19^{\prime \prime}$ & 7,410 & 395 & $\begin{array}{l}\text { Planothidium lanceolatum } \\
\text { (Brébisson ex Kützing) Lange-Bertalot }\end{array}$ & 594 & 81,423 \\
\hline 57 & 09067005 & Eagle River at Avon & 1 & 2001 & $8 / 16 / 2001$ & $39^{\circ} 37^{\prime} 54^{\prime \prime}$ & $106^{\circ} 31^{\prime} 19^{\prime \prime}$ & 7,410 & 395 & $\begin{array}{l}\text { Reimeria sinuata (Gregory) } \\
\text { Kociolek et Stoermer }\end{array}$ & 2,378 & 400,711 \\
\hline 57 & 09067005 & Eagle River at Avon & 1 & 2001 & $8 / 16 / 2001$ & $39^{\circ} 37^{\prime} 54^{\prime \prime}$ & $106^{\circ} 31^{\prime} 19^{\prime \prime}$ & 7,410 & 395 & Staurosira construens Ehrenberg & 594 & 115,028 \\
\hline 57 & 09067005 & Eagle River at Avon & 1 & 2001 & $8 / 16 / 2001$ & $39^{\circ} 37^{\prime} 54^{\prime \prime}$ & $106^{\circ} 31^{\prime} 19^{\prime \prime}$ & 7,410 & 395 & $\begin{array}{l}\text { Staurosira construens var. venter (Ehrenberg) } \\
\text { Hamilton }\end{array}$ & 1,427 & 171,333 \\
\hline 57 & 09067005 & Eagle River at Avon & 1 & 2001 & $8 / 16 / 2001$ & $39^{\circ} 37^{\prime} 54^{\prime \prime}$ & $106^{\circ} 31^{\prime} 19^{\prime \prime}$ & 7,410 & 395 & $\begin{array}{l}\text { Staurosirella leptostauron (Ehrenberg) } \\
\text { Williams et Round }\end{array}$ & 713 & 348,380 \\
\hline 57 & 09067005 & Eagle River at Avon & 1 & 2001 & $8 / 16 / 2001$ & $39^{\circ} 37^{\prime} 54^{\prime \prime}$ & $106^{\circ} 31^{\prime} 19^{\prime \prime}$ & 7,410 & 395 & $\begin{array}{l}\text { Staurosirella pinnata (Ehrenberg) } \\
\text { Williams et Round }\end{array}$ & 476 & 45,919 \\
\hline 57 & 09067005 & Eagle River at Avon & 1 & 2001 & $8 / 16 / 2001$ & $39^{\circ} 37^{\prime} 54^{\prime \prime}$ & $106^{\circ} 31^{\prime} 19^{\prime \prime}$ & 7,410 & 395 & Synedra rumpens Kützing & 1,664 & 199,983 \\
\hline 57 & 09067005 & Eagle River at Avon & 1 & 2001 & $8 / 16 / 2001$ & $39^{\circ} 37^{\prime} 54^{\prime \prime}$ & $106^{\circ} 31^{\prime} 19^{\prime \prime}$ & 7,410 & 395 & Synedra ulna var. contracta Østrup & 1,783 & $3,022,312$ \\
\hline 57 & 09067005 & Eagle River at Avon & 1 & 2001 & $8 / 16 / 2001$ & $39^{\circ} 37^{\prime} 54^{\prime \prime}$ & $106^{\circ} 31^{\prime} 19^{\prime \prime}$ & 7,410 & 395 & $\begin{array}{l}\text { Unknown Cyanophyte Oscillatoriales } \\
\text { (no sheath) }\end{array}$ & 31,651 & 469,565 \\
\hline 57 & 09067005 & Eagle River at Avon & 1 & 2001 & $8 / 16 / 2001$ & $39^{\circ} 37^{\prime} 54^{\prime \prime}$ & $106^{\circ} 31^{\prime} 19^{\prime \prime}$ & 7,410 & 395 & $\begin{array}{l}\text { Unknown Rhodophyte Florideophycidae } \\
\text { (chantransia) }\end{array}$ & 1,557 & $9,963,138$ \\
\hline 57 & 09067005 & Eagle River at Avon & 2 & 2001 & $8 / 16 / 2001$ & $39^{\circ} 37^{\prime} 54^{\prime \prime}$ & $106^{\circ} 31^{\prime} 19^{\prime \prime}$ & 7,410 & 395 & $\begin{array}{l}\text { Achnanthidium minutissimum (Kützing) } \\
\text { Czarnecki }\end{array}$ & 14,169 & 768,267 \\
\hline 57 & 09067005 & Eagle River at Avon & 2 & 2001 & $8 / 16 / 2001$ & $39^{\circ} 37^{\prime} 54^{\prime \prime}$ & $106^{\circ} 31^{\prime} 19^{\prime \prime}$ & 7,410 & 395 & $\begin{array}{l}\text { Achnanthidium pyrenaicum (Hustedt) } \\
\text { Kobayasi }\end{array}$ & 114 & 14,439 \\
\hline
\end{tabular}




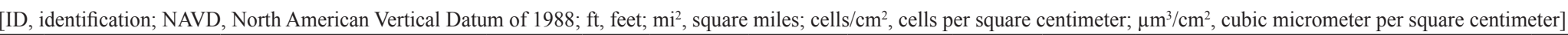

\begin{tabular}{|c|c|c|c|c|c|c|c|c|c|c|c|c|}
\hline $\begin{array}{l}\text { Site } \\
\text { ID }^{1}\end{array}$ & $\begin{array}{l}\text { USGS } \\
\text { station } \\
\text { number }\end{array}$ & Station name & $\begin{array}{c}\text { Replicate } \\
\text { sample } \\
\text { number }\end{array}$ & Year & $\begin{array}{l}\text { Collection } \\
\text { date }\end{array}$ & Latitude & Longitude & $\begin{array}{c}\text { Elevation } \\
\text { NAVD } 88 \\
\text { (ft) }\end{array}$ & $\begin{array}{c}\text { Drainage } \\
\text { area } \\
\left(\mathrm{mi}^{2}\right)\end{array}$ & Algal taxon name & $\begin{array}{c}\text { Total } \\
\text { density } \\
\text { (number of } \\
\text { cells/cm²) }\end{array}$ & $\begin{array}{c}\text { Total } \\
\text { biovolume } \\
\left(\mu \mathrm{m}^{3} / \mathrm{cm}^{2}\right)\end{array}$ \\
\hline 57 & 09067005 & Eagle River at Avon & 2 & 2001 & $8 / 16 / 2001$ & $39^{\circ} 37^{\prime} 54^{\prime \prime}$ & $106^{\circ} 31^{\prime} 19^{\prime \prime}$ & 7,410 & 395 & Amphora pediculus (Kützing) Grunow & 229 & 22,096 \\
\hline 57 & 09067005 & Eagle River at Avon & 2 & 2001 & $8 / 16 / 2001$ & $39^{\circ} 37^{\prime} 54^{\prime \prime}$ & $106^{\circ} 31^{\prime} 19^{\prime \prime}$ & 7,410 & 395 & Aulacoseira distans (Ehrenberg) Simonsen & 343 & 207,935 \\
\hline 57 & 09067005 & Eagle River at Avon & 2 & 2001 & $8 / 16 / 2001$ & $39^{\circ} 37^{\prime} 54^{\prime \prime}$ & $106^{\circ} 31^{\prime} 19^{\prime \prime}$ & 7,410 & 395 & Chlamydomonas sp. & 470 & 929,948 \\
\hline 57 & 09067005 & Eagle River at Avon & 2 & 2001 & $8 / 16 / 2001$ & $39^{\circ} 37^{\prime} 54^{\prime \prime}$ & $106^{\circ} 31^{\prime} 19^{\prime \prime}$ & 7,410 & 395 & $\begin{array}{l}\text { Cocconeis placentula var. lineata (Ehrenberg) } \\
\text { Van Heurck }\end{array}$ & 114 & 120,506 \\
\hline 57 & 09067005 & Eagle River at Avon & 2 & 2001 & $8 / 16 / 2001$ & $39^{\circ} 374^{\prime \prime}$ & $106^{\circ} 31^{\prime} 19^{\prime \prime}$ & 7,410 & 395 & Cymbella affinis Kützing & 229 & 116,313 \\
\hline 57 & 09067005 & Eagle River at Avon & 2 & 2001 & $8 / 16 / 2001$ & $39^{\circ} 377^{\prime \prime}$ & $106^{\circ} 31^{\prime} 19^{\prime \prime}$ & 7,410 & 395 & Encyonema minutum (Hilse) Mann & 229 & 49,326 \\
\hline 57 & 09067005 & Eagle River at Avon & 2 & 2001 & $8 / 16 / 2001$ & $39^{\circ} 377^{\prime \prime}$ & $106^{\circ} 31^{\prime} 19^{\prime \prime}$ & 7,410 & 395 & Encyonema silesiacum (Bleisch) Mann & 28,338 & $13,459,207$ \\
\hline 57 & 09067005 & Eagle River at Avon & 2 & 2001 & $8 / 16 / 2001$ & $39^{\circ} 377^{\prime \prime}$ & $106^{\circ} 31^{\prime} 19^{\prime \prime}$ & 7,410 & 395 & Encyonopsis cesatii (Rabenhorst) Krammer & 114 & 211,853 \\
\hline 57 & 09067005 & Eagle River at Avon & 2 & 2001 & $8 / 16 / 2001$ & $39^{\circ} 37 ' 54^{\prime \prime}$ & $106^{\circ} 31^{\prime} 19^{\prime \prime}$ & 7,410 & 395 & Fragilaria vaucheriae (Kützing) Petersen & 4,799 & 945,507 \\
\hline 57 & 09067005 & Eagle River at Avon & 2 & 2001 & $8 / 16 / 2001$ & $39^{\circ} 37 ' 54^{\prime \prime}$ & $106^{\circ} 31^{\prime} 19^{\prime \prime}$ & 7,410 & 395 & Gomphonema olivaceum (Lyngbye) Kützing & 343 & 129,901 \\
\hline 57 & 09067005 & Eagle River at Avon & 2 & 2001 & $8 / 16 / 2001$ & $39^{\circ} 377^{\prime \prime}$ & $106^{\circ} 31^{\prime} 19^{\prime \prime}$ & 7,410 & 395 & Gomphonema parvulum (Kützing) Kützing & 114 & 24,970 \\
\hline 57 & 09067005 & Eagle River at Avon & 2 & 2001 & $8 / 16 / 2001$ & $39^{\circ} 37^{\prime} 54^{\prime \prime}$ & $106^{\circ} 31^{\prime} 19^{\prime \prime}$ & 7,410 & 395 & $\begin{array}{l}\text { Gomphonema pumilum (Grunow) } \\
\text { Reichardt et Lange-Bertalot }\end{array}$ & 457 & 99,755 \\
\hline 57 & 09067005 & Eagle River at Avon & 2 & 2001 & $8 / 16 / 2001$ & $39^{\circ} 37^{\prime} 54^{\prime \prime}$ & $106^{\circ} 31^{\prime} 19^{\prime \prime}$ & 7,410 & 395 & Hannaea arcus (Ehrenberg) Patrick & 2,057 & $4,124,236$ \\
\hline 57 & 09067005 & Eagle River at Avon & 2 & 2001 & $8 / 16 / 2001$ & $39^{\circ} 37^{\prime} 54^{\prime \prime}$ & $106^{\circ} 31^{\prime} 19^{\prime \prime}$ & 7,410 & 395 & $\begin{array}{l}\text { Homoeothrix janthina (Bornet et Flahault) } \\
\text { Starmach }\end{array}$ & 763,031 & $13,134,549$ \\
\hline 57 & 09067005 & Eagle River at Avon & 2 & 2001 & $8 / 16 / 2001$ & $39^{\circ} 377^{\prime \prime}$ & $106^{\circ} 31^{\prime} 19^{\prime \prime}$ & 7,410 & 395 & Melosira varians Agardh & 11,884 & $61,416,464$ \\
\hline 57 & 09067005 & Eagle River at Avon & 2 & 2001 & $8 / 16 / 2001$ & $39^{\circ} 37^{\prime} 54^{\prime \prime}$ & $106^{\circ} 31^{\prime} 19^{\prime \prime}$ & 7,410 & 395 & $\begin{array}{l}\text { Navicula cryptotenella Lange-Bertalot } \\
\text { ex Krammer et Lange-Bertalot }\end{array}$ & 457 & 121,408 \\
\hline 57 & 09067005 & Eagle River at Avon & 2 & 2001 & $8 / 16 / 2001$ & $39^{\circ} 374^{\prime \prime}$ & $106^{\circ} 31^{\prime} 19^{\prime \prime}$ & 7,410 & 395 & Navicula minima Grunow & 229 & 10,286 \\
\hline 57 & 09067005 & Eagle River at Avon & 2 & 2001 & $8 / 16 / 2001$ & $39^{\circ} 37^{\prime} 54^{\prime \prime}$ & $106^{\circ} 31^{\prime} 19^{\prime \prime}$ & 7,410 & 395 & Navicula tripunctata (Müller) Bory & 229 & 207,815 \\
\hline 57 & 09067005 & Eagle River at Avon & 2 & 2001 & $8 / 16 / 2001$ & $39^{\circ} 377^{\prime \prime}$ & $106^{\circ} 31^{\prime} 19^{\prime \prime}$ & 7,410 & 395 & Nitzschia dissipata (Kützing) Grunow & 457 & 117,849 \\
\hline 57 & 09067005 & Eagle River at Avon & 2 & 2001 & $8 / 16 / 2001$ & $39^{\circ} 37^{\prime} 54^{\prime \prime}$ & $106^{\circ} 31^{\prime} 19^{\prime \prime}$ & 7,410 & 395 & Nitzschia fonticola Grunow & 2,971 & 295,539 \\
\hline 57 & 09067005 & Eagle River at Avon & 2 & 2001 & $8 / 16 / 2001$ & $39^{\circ} 37^{\prime} 54^{\prime \prime}$ & $106^{\circ} 31^{\prime} 19^{\prime \prime}$ & 7,410 & 395 & Nitzschia inconspicua Grunow & 229 & 12,342 \\
\hline 57 & 09067005 & Eagle River at Avon & 2 & 2001 & $8 / 16 / 2001$ & $39^{\circ} 37^{\prime} 54^{\prime \prime}$ & $106^{\circ} 31^{\prime} 19^{\prime \prime}$ & 7,410 & 395 & Nitzschia paleacea Grunow ex Van Heurck & 229 & 11,918 \\
\hline 57 & 09067005 & Eagle River at Avon & 2 & 2001 & $8 / 16 / 2001$ & $39^{\circ} 37 ' 54^{\prime \prime}$ & $106^{\circ} 31^{\prime} 19^{\prime \prime}$ & 7,410 & 395 & Pinnularia mesolepta (Ehrenberg) Smith & 229 & 816,996 \\
\hline 57 & 09067005 & Eagle River at Avon & 2 & 2001 & $8 / 16 / 2001$ & $39^{\circ} 37^{\prime} 54^{\prime \prime}$ & $106^{\circ} 31^{\prime} 19^{\prime \prime}$ & 7,410 & 395 & $\begin{array}{l}\text { Planothidium lanceolatum } \\
\text { (Brébisson ex Kützing) Lange-Bertalot }\end{array}$ & 229 & 31,306 \\
\hline 57 & 09067005 & Eagle River at Avon & 2 & 2001 & $8 / 16 / 2001$ & $39^{\circ} 37^{\prime} 54^{\prime \prime}$ & $106^{\circ} 31^{\prime} 19^{\prime \prime}$ & 7,410 & 395 & $\begin{array}{l}\text { Reimeria sinuata (Gregory) } \\
\text { Kociolek et Stoermer }\end{array}$ & 1,485 & 250,362 \\
\hline 57 & 09067005 & Eagle River at Avon & 2 & 2001 & $8 / 16 / 2001$ & $39^{\circ} 37^{\prime} 54^{\prime \prime}$ & $106^{\circ} 31^{\prime} 19^{\prime \prime}$ & 7,410 & 395 & $\begin{array}{l}\text { Staurosira construens var. venter (Ehrenberg) } \\
\text { Hamilton }\end{array}$ & 2,285 & 274,482 \\
\hline 57 & 09067005 & Eagle River at Avon & 2 & 2001 & $8 / 16 / 2001$ & $39^{\circ} 37^{\prime} 54^{\prime \prime}$ & $106^{\circ} 31^{\prime} 19^{\prime \prime}$ & 7,410 & 395 & $\begin{array}{l}\text { Staurosirella leptostauron (Ehrenberg) } \\
\text { Williams et Round }\end{array}$ & 229 & 111,624 \\
\hline 57 & 09067005 & Eagle River at Avon & 2 & 2001 & $8 / 16 / 2001$ & $39^{\circ} 37^{\prime} 54^{\prime \prime}$ & $106^{\circ} 31^{\prime} 19^{\prime \prime}$ & 7,410 & 395 & $\begin{array}{l}\text { Surirella brebissonii } \\
\text { Krammer et Lange-Bertalot }\end{array}$ & 343 & 568,017 \\
\hline 57 & 09067005 & Eagle River at Avon & 2 & 2001 & $8 / 16 / 2001$ & $39^{\circ} 37^{\prime} 54^{\prime \prime}$ & $106^{\circ} 31^{\prime} 19^{\prime \prime}$ & 7,410 & 395 & Surirella minuta Brébisson & 114 & 100,890 \\
\hline 57 & 09067005 & Eagle River at Avon & 2 & 2001 & $8 / 16 / 2001$ & $39^{\circ} 37^{\prime} 54^{\prime \prime}$ & $106^{\circ} 31^{\prime} 19^{\prime \prime}$ & 7,410 & 395 & Synedra ulna var. contracta Østrup & 2,400 & $4,067,164$ \\
\hline 57 & 09067005 & Eagle River at Avon & 2 & 2001 & $8 / 16 / 2001$ & $39^{\circ} 37^{\prime} 54^{\prime \prime}$ & $106^{\circ} 31^{\prime} 19^{\prime \prime}$ & 7,410 & 395 & Unknown alga flagellate $(<10 \mu)$ & 1,879 & 180,614 \\
\hline 57 & 09067005 & Eagle River at Avon & 3 & 2001 & $8 / 16 / 2001$ & $39^{\circ} 37^{\prime} 54^{\prime \prime}$ & $106^{\circ} 31^{\prime} 19^{\prime \prime}$ & 7,410 & 395 & $\begin{array}{l}\text { Achnanthidium minutissimum (Kützing) } \\
\text { Czarnecki }\end{array}$ & 56,127 & $3,043,233$ \\
\hline 57 & 09067005 & Eagle River at Avon & 3 & 2001 & $8 / 16 / 2001$ & $39^{\circ} 37^{\prime} 54^{\prime \prime}$ & $106^{\circ} 31^{\prime} 19^{\prime \prime}$ & 7,410 & 395 & $\begin{array}{l}\text { Caloneis ventricosa var. truncatula (Grunow) } \\
\text { Meister }\end{array}$ & 819 & 912,015 \\
\hline 57 & 09067005 & Eagle River at Avon & 3 & 2001 & $8 / 16 / 2001$ & $39^{\circ} 37^{\prime} 54^{\prime \prime}$ & $106^{\circ} 31^{\prime} 19^{\prime \prime}$ & 7,410 & 395 & $\begin{array}{l}\text { Cocconeis placentula var. lineata (Ehrenberg) } \\
\text { Van Heurck }\end{array}$ & 819 & 864,097 \\
\hline 57 & 09067005 & Eagle River at Avon & 3 & 2001 & $8 / 16 / 2001$ & $39^{\circ} 37^{\prime} 54^{\prime \prime}$ & $106^{\circ} 31^{\prime} 19^{\prime \prime}$ & 7,410 & 395 & Diatoma moniliformis Kützing & 2,048 & 373,844 \\
\hline 57 & 09067005 & Eagle River at Avon & 3 & 2001 & $8 / 16 / 2001$ & $39^{\circ} 37^{\prime} 54^{\prime \prime}$ & $106^{\circ} 31^{\prime} 19^{\prime \prime}$ & 7,410 & 395 & Encyonema brehmii (Hustedt) Mann & 2,458 & 67,773 \\
\hline
\end{tabular}


Table 2. Description of sites and algal data collected from selected sites the Eagle River watershed, Colorado, 2000-2001.—Continued

[ID, identification; NAVD, North American Vertical Datum of 1988; ft, feet; $\mathrm{mi}^{2}$, square miles; cells $/ \mathrm{cm}^{2}$, cells per square centimeter; $\mu \mathrm{m}^{3} / \mathrm{cm}^{2}$, cubic micrometer per square centimeter]

\begin{tabular}{|c|c|c|c|c|c|c|c|c|c|c|c|c|}
\hline $\begin{array}{l}\text { Site } \\
\text { ID' }\end{array}$ & $\begin{array}{l}\text { USGS } \\
\text { station } \\
\text { number }\end{array}$ & Station name & $\begin{array}{c}\text { Replicate } \\
\text { sample } \\
\text { number }\end{array}$ & Year & $\begin{array}{l}\text { Collection } \\
\text { date }\end{array}$ & Latitude & Longitude & $\begin{array}{c}\text { Elevation } \\
\text { NAVD } 88 \\
\text { (ft) }\end{array}$ & $\begin{array}{c}\text { Drainage } \\
\text { area } \\
\left(\mathrm{mi}^{2}\right)\end{array}$ & Algal taxon name & $\begin{array}{c}\text { Total } \\
\text { density } \\
\text { (number of } \\
\text { cells } / \mathrm{cm}^{2} \text { ) }\end{array}$ & $\begin{array}{c}\text { Total } \\
\text { biovolume } \\
\left(\mu \mathrm{m}^{3} / \mathrm{cm}^{2}\right)\end{array}$ \\
\hline 57 & 09067005 & Eagle River at Avon & 3 & 2001 & $8 / 16 / 2001$ & $39^{\circ} 37^{\prime} 54^{\prime \prime}$ & $106^{\circ} 31^{\prime} 19^{\prime \prime}$ & 7,410 & 395 & Encyonema minutum (Hilse) Mann & 2,868 & 618,964 \\
\hline 57 & 09067005 & Eagle River at Avon & 3 & 2001 & $8 / 16 / 2001$ & $39^{\circ} 37^{\prime} 54^{\prime \prime}$ & $106^{\circ} 31^{\prime} 19^{\prime \prime}$ & 7,410 & 395 & Encyonema silesiacum (Bleisch) Mann & 117,989 & $56,038,211$ \\
\hline 57 & 09067005 & Eagle River at Avon & 3 & 2001 & $8 / 16 / 2001$ & $39^{\circ} 37^{\prime} 54^{\prime \prime}$ & $106^{\circ} 31^{\prime} 19^{\prime \prime}$ & 7,410 & 395 & Euglena sp. & 797 & $1,195,427$ \\
\hline 57 & 09067005 & Eagle River at Avon & 3 & 2001 & $8 / 16 / 2001$ & $39^{\circ} 37^{\prime} 54^{\prime \prime}$ & $106^{\circ} 31^{\prime} 19^{\prime \prime}$ & 7,410 & 395 & Fragilaria vaucheriae (Kützing) Petersen & 9,423 & $1,856,381$ \\
\hline 57 & 09067005 & Eagle River at Avon & 3 & 2001 & $8 / 16 / 2001$ & $39^{\circ} 37^{\prime} 54^{\prime \prime}$ & $106^{\circ} 31^{\prime} 19^{\prime \prime}$ & 7,410 & 395 & Gomphonema minutum (Agardh) Agardh & 819 & 66,946 \\
\hline 57 & 09067005 & Eagle River at Avon & 3 & 2001 & $8 / 16 / 2001$ & $39^{\circ} 37^{\prime} 54^{\prime \prime}$ & $106^{\circ} 31^{\prime} 19^{\prime \prime}$ & 7,410 & 395 & Hannaea arcus (Ehrenberg) Patrick & 410 & 821,476 \\
\hline 57 & 09067005 & Eagle River at Avon & 3 & 2001 & $8 / 16 / 2001$ & $39^{\circ} 37^{\prime} 54^{\prime \prime}$ & $106^{\circ} 31^{\prime} 19^{\prime \prime}$ & 7,410 & 395 & $\begin{array}{l}\text { Homoeothrix janthina (Bornet et Flahault) } \\
\text { Starmach }\end{array}$ & $1,131,671$ & $19,480,201$ \\
\hline 57 & 09067005 & Eagle River at Avon & 3 & 2001 & $8 / 16 / 2001$ & $39^{\circ} 37^{\prime} 54^{\prime \prime}$ & $106^{\circ} 31^{\prime} 19^{\prime \prime}$ & 7,410 & 395 & Mayamaea atomus (Kützing) Lange-Bertalot & 819 & 23,528 \\
\hline 57 & 09067005 & Eagle River at Avon & 3 & 2001 & $8 / 16 / 2001$ & $39^{\circ} 37^{\prime} 54^{\prime \prime}$ & $106^{\circ} 31^{\prime} 19^{\prime \prime}$ & 7,410 & 395 & Melosira varians Agardh & 26,629 & $137,622,299$ \\
\hline 57 & 09067005 & Eagle River at Avon & 3 & 2001 & $8 / 16 / 2001$ & $39^{\circ} 37^{\prime} 54^{\prime \prime}$ & $106^{\circ} 31^{\prime} 19^{\prime \prime}$ & 7,410 & 395 & $\begin{array}{l}\text { Navicula cryptotenella Lange-Bertalot } \\
\text { ex Krammer et Lange-Bertalot }\end{array}$ & 819 & 217,641 \\
\hline 57 & 09067005 & Eagle River at Avon & 3 & 2001 & $8 / 16 / 2001$ & $39^{\circ} 37^{\prime} 54^{\prime \prime}$ & $106^{\circ} 31^{\prime} 19^{\prime \prime}$ & 7,410 & 395 & Navicula minima Grunow & 3,277 & 147,508 \\
\hline 57 & 09067005 & Eagle River at Avon & 3 & 2001 & $8 / 16 / 2001$ & $39^{\circ} 37^{\prime} 54^{\prime \prime}$ & $106^{\circ} 31^{\prime} 19^{\prime \prime}$ & 7,410 & 395 & Navicula veneta Kützing & 3,687 & 814,056 \\
\hline 57 & 09067005 & Eagle River at Avon & 3 & 2001 & $8 / 16 / 2001$ & $39^{\circ} 37^{\prime} 54^{\prime \prime}$ & $106^{\circ} 31^{\prime} 19^{\prime \prime}$ & 7,410 & 395 & Nitzschia dissipata (Kützing) Grunow & 819 & 211,261 \\
\hline 57 & 09067005 & Eagle River at Avon & 3 & 2001 & $8 / 16 / 2001$ & $39^{\circ} 37^{\prime} 54^{\prime \prime}$ & $106^{\circ} 31^{\prime} 19^{\prime \prime}$ & 7,410 & 395 & Nitzschia fonticola Grunow & 15,978 & $1,589,387$ \\
\hline 57 & 09067005 & Eagle River at Avon & 3 & 2001 & $8 / 16 / 2001$ & $39^{\circ} 37^{\prime} 54^{\prime \prime}$ & $106^{\circ} 31^{\prime} 19^{\prime \prime}$ & 7,410 & 395 & Nitzschia recta Hantzsch ex Rabenhorst & 819 & $1,247,345$ \\
\hline 57 & 09067005 & Eagle River at Avon & 3 & 2001 & $8 / 16 / 2001$ & $39^{\circ} 37^{\prime} 54^{\prime \prime}$ & $106^{\circ} 31^{\prime} 19^{\prime \prime}$ & 7,410 & 395 & $\begin{array}{l}\text { Nitzschia vermicularis (Kützing) Hantzsch } \\
\text { ex Rabenhorst }\end{array}$ & 819 & $3,748,564$ \\
\hline 57 & 09067005 & Eagle River at Avon & 3 & 2001 & $8 / 16 / 2001$ & $39^{\circ} 37^{\prime} 54^{\prime \prime}$ & $106^{\circ} 31^{\prime} 19^{\prime \prime}$ & 7,410 & 395 & Phormidium autumnale (Agardh) Gomont & 102,807 & $9,967,647$ \\
\hline 57 & 09067005 & Eagle River at Avon & 3 & 2001 & $8 / 16 / 2001$ & $39^{\circ} 37^{\prime} 54^{\prime \prime}$ & $106^{\circ} 31^{\prime} 19^{\prime \prime}$ & 7,410 & 395 & $\begin{array}{l}\text { Psammothidium chlidanos (Hohn et Heller- } \\
\text { man) Lange-Bertalot }\end{array}$ & 410 & 33,247 \\
\hline 57 & 09067005 & Eagle River at Avon & 3 & 2001 & $8 / 16 / 2001$ & $39^{\circ} 37^{\prime} 54^{\prime \prime}$ & $106^{\circ} 31^{\prime} 19^{\prime \prime}$ & 7,410 & 395 & $\begin{array}{l}\text { Reimeria sinuata (Gregory) Kociolek } \\
\text { et Stoermer }\end{array}$ & 5,326 & 897,621 \\
\hline 57 & 09067005 & Eagle River at Avon & 3 & 2001 & $8 / 16 / 2001$ & $39^{\circ} 37^{\prime} 54^{\prime \prime}$ & $106^{\circ} 31^{\prime} 19^{\prime \prime}$ & 7,410 & 395 & $\begin{array}{l}\text { Rhoicosphenia abbreviata (Agardh) } \\
\text { Lange-Bertalot }\end{array}$ & 819 & 424,014 \\
\hline 57 & 09067005 & Eagle River at Avon & 3 & 2001 & $8 / 16 / 2001$ & $39^{\circ} 37^{\prime} 54^{\prime \prime}$ & $106^{\circ} 31^{\prime} 19^{\prime \prime}$ & 7,410 & 395 & $\begin{array}{l}\text { Stauroforma exiguiformis (Lange-Bertalot) } \\
\text { Flower, Jones et Round }\end{array}$ & 410 & 22,492 \\
\hline 57 & 09067005 & Eagle River at Avon & 3 & 2001 & $8 / 16 / 2001$ & $39^{\circ} 37^{\prime} 54^{\prime \prime}$ & $106^{\circ} 31^{\prime} 19^{\prime \prime}$ & 7,410 & 395 & $\begin{array}{l}\text { Staurosira construens var. venter (Ehrenberg) } \\
\text { Hamilton }\end{array}$ & 3,277 & 393,639 \\
\hline 57 & 09067005 & Eagle River at Avon & 3 & 2001 & $8 / 16 / 2001$ & $39^{\circ} 37^{\prime} 54^{\prime \prime}$ & $106^{\circ} 31^{\prime} 19^{\prime \prime}$ & 7,410 & 395 & $\begin{array}{l}\text { Staurosirella leptostauron (Ehrenberg) Wil- } \\
\text { liams et Round }\end{array}$ & 819 & 400,203 \\
\hline 57 & 09067005 & Eagle River at Avon & 3 & 2001 & $8 / 16 / 2001$ & $39^{\circ} 37^{\prime} 54^{\prime \prime}$ & $106^{\circ} 31^{\prime} 19^{\prime \prime}$ & 7,410 & 395 & $\begin{array}{l}\text { Surirella brebissonii Krammer et Lange- } \\
\text { Bertalot }\end{array}$ & 819 & $1,357,670$ \\
\hline 57 & 09067005 & Eagle River at Avon & 3 & 2001 & $8 / 16 / 2001$ & $39^{\circ} 37^{\prime} 54^{\prime \prime}$ & $106^{\circ} 31^{\prime} 19^{\prime \prime}$ & 7,410 & 395 & Synedra ulna var. contracta Østrup & 2,868 & $4,860,651$ \\
\hline 57 & 09067005 & Eagle River at Avon & 3 & 2001 & $8 / 16 / 2001$ & $39^{\circ} 37^{\prime} 54^{\prime \prime}$ & $106^{\circ} 31^{\prime} 19^{\prime \prime}$ & 7,410 & 395 & Unknown alga flagellate $(<10 \mu)$ & 2,391 & 229,767 \\
\hline 57 & 09067005 & Eagle River at Avon & 3 & 2001 & $8 / 16 / 2001$ & $39^{\circ} 37^{\prime} 54^{\prime \prime}$ & $106^{\circ} 31^{\prime} 19^{\prime \prime}$ & 7,410 & 395 & $\begin{array}{l}\text { Unknown Cyanophyte Oscillatoriales } \\
\text { (no sheath) }\end{array}$ & 32,675 & 484,752 \\
\hline 59 & 393845106353000 & Eagle River at Edwards & 1 & 2000 & $8 / 15 / 2000$ & $39^{\circ} 38^{\prime} 45^{\prime \prime}$ & $106^{\circ} 35^{\prime} 30^{\prime \prime}$ & 7,180 & 424 & $\begin{array}{l}\text { Achnanthidium minutissimum (Kützing) } \\
\text { Czarnecki }\end{array}$ & 68,398 & $3,766,787$ \\
\hline 59 & 393845106353000 & Eagle River at Edwards & 1 & 2000 & $8 / 15 / 2000$ & $39^{\circ} 38^{\prime} 45^{\prime \prime}$ & $106^{\circ} 35^{\prime} 30^{\prime \prime}$ & 7,180 & 424 & $\begin{array}{l}\text { Achnanthidium pyrenaicum (Hustedt) } \\
\text { Kobayasi }\end{array}$ & 795 & 100,059 \\
\hline 59 & 393845106353000 & Eagle River at Edwards & 1 & 2000 & $8 / 15 / 2000$ & $39^{\circ} 38^{\prime} 45^{\prime \prime}$ & $106^{\circ} 35^{\prime} 30^{\prime \prime}$ & 7,180 & 424 & Caloneis bacillum (Grunow) Cleve & 1,591 & 684,242 \\
\hline 59 & 393845106353000 & Eagle River at Edwards & 1 & 2000 & $8 / 15 / 2000$ & $39^{\circ} 38^{\prime} 45^{\prime \prime}$ & $106^{\circ} 35^{\prime} 30^{\prime \prime}$ & 7,180 & 424 & Chlamydomonas sp. & 1,794 & 152,465 \\
\hline 59 & 393845106353000 & Eagle River at Edwards & 1 & 2000 & $8 / 15 / 2000$ & $39^{\circ} 38^{\prime} 45^{\prime \prime}$ & $106^{\circ} 35^{\prime} 30^{\prime \prime}$ & 7,180 & 424 & Diatoma moniliformis Kützing & 2,386 & 359,599 \\
\hline 59 & 393845106353000 & Eagle River at Edwards & 1 & 2000 & $8 / 15 / 2000$ & $39^{\circ} 38^{\prime} 45^{\prime \prime}$ & $106^{\circ} 35^{\prime} 30^{\prime \prime}$ & 7,180 & 424 & Diatoma tenuis Agardh & 795 & 89,540 \\
\hline 59 & 393845106353000 & Eagle River at Edwards & 1 & 2000 & $8 / 15 / 2000$ & $39^{\circ} 38^{\prime} 45^{\prime \prime}$ & $106^{\circ} 35^{\prime} 30^{\prime \prime}$ & 7,180 & 424 & Diatoma vulgaris Bory & 795 & $2,938,648$ \\
\hline 59 & 393845106353000 & Eagle River at Edwards & 1 & 2000 & $8 / 15 / 2000$ & $39^{\circ} 38^{\prime} 45^{\prime \prime}$ & $106^{\circ} 35^{\prime} 30^{\prime \prime}$ & 7,180 & 424 & Encyonema brehmii (Hustedt) Mann & 9,544 & 263,138 \\
\hline
\end{tabular}




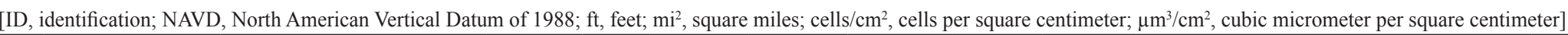

\begin{tabular}{|c|c|c|c|c|c|c|c|c|c|c|c|c|}
\hline $\begin{array}{l}\text { Site } \\
\text { ID }^{1}\end{array}$ & $\begin{array}{l}\text { USGS } \\
\text { station } \\
\text { number }\end{array}$ & Station name & $\begin{array}{c}\text { Replicate } \\
\text { sample } \\
\text { number }\end{array}$ & Year & $\begin{array}{c}\text { Collection } \\
\text { date }\end{array}$ & Latitude & Longitude & $\begin{array}{c}\text { Elevation } \\
\text { NAVD } 88 \\
\text { (ft) }\end{array}$ & $\begin{array}{c}\text { Drainage } \\
\text { area } \\
\left(\mathrm{mi}^{2}\right)\end{array}$ & Algal taxon name & $\begin{array}{c}\text { Total } \\
\text { density } \\
\text { (number of } \\
\text { cells } / \mathrm{cm}^{2} \text { ) }\end{array}$ & $\begin{array}{c}\text { Total } \\
\text { biovolume } \\
\left(\mu \mathrm{m}^{3} / \mathrm{cm}^{2}\right)\end{array}$ \\
\hline 59 & 393845106353000 & Eagle River at Edwards & 1 & 2000 & $8 / 15 / 2000$ & $39^{\circ} 38^{\prime} 45^{\prime \prime}$ & $106^{\circ} 35^{\prime} 30^{\prime \prime}$ & 7,180 & 424 & Encyonema minutum (Hilse) Mann & 1,591 & 340,372 \\
\hline 59 & 393845106353000 & Eagle River at Edwards & 1 & 2000 & $8 / 15 / 2000$ & $39^{\circ} 38^{\prime} 45^{\prime \prime}$ & $106^{\circ} 35^{\prime} 30^{\prime \prime}$ & 7,180 & 424 & Encyonema silesiacum (Bleisch) Mann & 187,696 & $88,376,844$ \\
\hline 59 & 393845106353000 & Eagle River at Edwards & 1 & 2000 & $8 / 15 / 2000$ & $39^{\circ} 38^{\prime} 45^{\prime \prime}$ & $106^{\circ} 35^{\prime} 30^{\prime \prime}$ & 7,180 & 424 & $\begin{array}{l}\text { Fistulifera pelliculosa (Brébisson ex Kützing) } \\
\text { Lange-Bertalot }\end{array}$ & 3,181 & 83,018 \\
\hline 59 & 393845106353000 & Eagle River at Edwards & 1 & 2000 & $8 / 15 / 2000$ & $39^{\circ} 38^{\prime} 45^{\prime \prime}$ & $106^{\circ} 35^{\prime} 30^{\prime \prime}$ & 7,180 & 424 & $\begin{array}{l}\text { Fragilaria capucina var. fragilarioides } \\
\text { (Grunow) Ludwig et Flores }\end{array}$ & 795 & 81,487 \\
\hline 59 & 393845106353000 & Eagle River at Edwards & 1 & 2000 & $8 / 15 / 2000$ & $39^{\circ} 38^{\prime} 45^{\prime \prime}$ & $106^{\circ} 35^{\prime} 30^{\prime \prime}$ & 7,180 & 424 & Fragilaria vaucheriae (Kützing) Petersen & 4,772 & 987,129 \\
\hline 59 & 393845106353000 & Eagle River at Edwards & 1 & 2000 & $8 / 15 / 2000$ & $39^{\circ} 38^{\prime} 45^{\prime \prime}$ & $106^{\circ} 35^{\prime} 30^{\prime \prime}$ & 7,180 & 424 & $\begin{array}{l}\text { Homoeothrix janthina (Bornet et Flahault) } \\
\text { Starmach }\end{array}$ & $2,286,972$ & $74,116,969$ \\
\hline 59 & 393845106353000 & Eagle River at Edwards & 1 & 2000 & $8 / 15 / 2000$ & $39^{\circ} 38^{\prime} 45^{\prime \prime}$ & $106^{\circ} 35^{\prime} 30^{\prime \prime}$ & 7,180 & 424 & Mayamaea atomus (Kützing) Lange-Bertalot & 37,380 & 976,284 \\
\hline 59 & 393845106353000 & Eagle River at Edwards & 1 & 2000 & $8 / 15 / 2000$ & $39^{\circ} 38^{\prime} 45^{\prime \prime}$ & $106^{\circ} 35^{\prime} 30^{\prime \prime}$ & 7,180 & 424 & Melosira varians Agardh & 5,567 & $30,226,021$ \\
\hline 59 & 393845106353000 & Eagle River at Edwards & 1 & 2000 & $8 / 15 / 2000$ & $39^{\circ} 38^{\prime} 45^{\prime \prime}$ & $106^{\circ} 35^{\prime} 30^{\prime \prime}$ & 7,180 & 424 & Navicula minima Grunow & 7,953 & 422,402 \\
\hline 59 & 393845106353000 & Eagle River at Edwards & 1 & 2000 & $8 / 15 / 2000$ & $39^{\circ} 38^{\prime} 45^{\prime \prime}$ & $106^{\circ} 35^{\prime} 30^{\prime \prime}$ & 7,180 & 424 & Navicula tantula Hustedt & 795 & 43,625 \\
\hline 59 & 393845106353000 & Eagle River at Edwards & 1 & 2000 & $8 / 15 / 2000$ & $39^{\circ} 38^{\prime} 45^{\prime \prime}$ & $106^{\circ} 35^{\prime} 30^{\prime \prime}$ & 7,180 & 424 & Nitzschia fonticola Grunow & 3,977 & 394,891 \\
\hline 59 & 393845106353000 & Eagle River at Edwards & 1 & 2000 & $8 / 15 / 2000$ & $39^{\circ} 38^{\prime} 45^{\prime \prime}$ & $106^{\circ} 35^{\prime} 30^{\prime \prime}$ & 7,180 & 424 & Nitzschia fruticosa Hustedt & 1,591 & 296,398 \\
\hline 59 & 393845106353000 & Eagle River at Edwards & 1 & 2000 & $8 / 15 / 2000$ & $39^{\circ} 38^{\prime} 45^{\prime \prime}$ & $106^{\circ} 35^{\prime} 30^{\prime \prime}$ & 7,180 & 424 & Nitzschia inconspicua Grunow & 13,520 & 725,605 \\
\hline 59 & 393845106353000 & Eagle River at Edwards & 1 & 2000 & $8 / 15 / 2000$ & $39^{\circ} 38^{\prime} 45^{\prime \prime}$ & $106^{\circ} 35^{\prime} 30^{\prime \prime}$ & 7,180 & 424 & Nitzschia palea (Kützing) Smith & 53,287 & $9,235,159$ \\
\hline 59 & 393845106353000 & Eagle River at Edwards & 1 & 2000 & $8 / 15 / 2000$ & $39^{\circ} 38^{\prime} 45^{\prime \prime}$ & $106^{\circ} 35^{\prime} 30^{\prime \prime}$ & 7,180 & 424 & Nitzschia paleacea Grunow ex Van Heurck & 148,725 & $4,556,385$ \\
\hline 59 & 393845106353000 & Eagle River at Edwards & 1 & 2000 & $8 / 15 / 2000$ & $39^{\circ} 38^{\prime} 45^{\prime \prime}$ & $106^{\circ} 35^{\prime} 30^{\prime \prime}$ & 7,180 & 424 & Phormidium autumnale (Agardh) Gomont & 846,628 & $82,909,623$ \\
\hline 59 & 393845106353000 & Eagle River at Edwards & 1 & 2000 & $8 / 15 / 2000$ & $39^{\circ} 38^{\prime} 45^{\prime \prime}$ & $106^{\circ} 35^{\prime} 30^{\prime \prime}$ & 7,180 & 424 & $\begin{array}{l}\text { Reimeria sinuata (Gregory) } \\
\text { Kociolek et Stoermer }\end{array}$ & 31,813 & $5,260,037$ \\
\hline 59 & 393845106353000 & Eagle River at Edwards & 1 & 2000 & $8 / 15 / 2000$ & $39^{\circ} 38^{\prime} 45^{\prime \prime}$ & $106^{\circ} 35^{\prime} 30^{\prime \prime}$ & 7,180 & 424 & Scenedesmus acutus Meyen & 28,699 & $2,606,262$ \\
\hline 59 & 393845106353000 & Eagle River at Edwards & 1 & 2000 & $8 / 15 / 2000$ & $39^{\circ} 38^{\prime} 45^{\prime \prime}$ & $106^{\circ} 35^{\prime} 30^{\prime \prime}$ & 7,180 & 424 & Synedra ulna var. contracta Østrup & 3,181 & $5,057,428$ \\
\hline 59 & 393845106353000 & Eagle River at Edwards & 2 & 2000 & $8 / 15 / 2000$ & $39^{\circ} 38^{\prime} 45^{\prime \prime}$ & $106^{\circ} 35^{\prime} 30^{\prime \prime}$ & 7,180 & 424 & $\begin{array}{l}\text { Achnanthidium minutissimum (Kützing) } \\
\text { Czarnecki }\end{array}$ & 78,334 & $4,313,981$ \\
\hline 59 & 393845106353000 & Eagle River at Edwards & 2 & 2000 & $8 / 15 / 2000$ & $39^{\circ} 38^{\prime} 45^{\prime \prime}$ & $106^{\circ} 35^{\prime} 30^{\prime \prime}$ & 7,180 & 424 & $\begin{array}{l}\text { Achnanthidium pyrenaicum (Hustedt) } \\
\text { Kobayasi }\end{array}$ & 7,121 & 895,920 \\
\hline 59 & 393845106353000 & Eagle River at Edwards & 2 & 2000 & $8 / 15 / 2000$ & $39^{\circ} 38^{\prime} 45^{\prime \prime}$ & $106^{\circ} 35^{\prime} 30^{\prime \prime}$ & 7,180 & 424 & Amphora pediculus (Kützing) Grunow & 3,561 & 336,941 \\
\hline 59 & 393845106353000 & Eagle River at Edwards & 2 & 2000 & $8 / 15 / 2000$ & $39^{\circ} 38^{\prime} 45^{\prime \prime}$ & $106^{\circ} 35^{\prime} 30^{\prime \prime}$ & 7,180 & 424 & $\begin{array}{l}\text { Cocconeis placentula var. lineata (Ehrenberg) } \\
\text { Van Heurck }\end{array}$ & 1,780 & $1,865,322$ \\
\hline 59 & 393845106353000 & Eagle River at Edwards & 2 & 2000 & $8 / 15 / 2000$ & $39^{\circ} 38^{\prime} 45^{\prime \prime}$ & $106^{\circ} 35^{\prime} 30^{\prime \prime}$ & 7,180 & 424 & Diatoma moniliformis Kützing & 3,561 & 536,637 \\
\hline 59 & 393845106353000 & Eagle River at Edwards & 2 & 2000 & $8 / 15 / 2000$ & $39^{\circ} 38^{\prime} 45^{\prime \prime}$ & $106^{\circ} 35^{\prime} 30^{\prime \prime}$ & 7,180 & 424 & Encyonema brehmii (Hustedt) Mann & 1,780 & 49,086 \\
\hline 59 & 393845106353000 & Eagle River at Edwards & 2 & 2000 & $8 / 15 / 2000$ & $39^{\circ} 38^{\prime} 45^{\prime \prime}$ & $106^{\circ} 35^{\prime} 30^{\prime \prime}$ & 7,180 & 424 & Encyonema minutum (Hilse) Mann & 24,924 & $5,333,400$ \\
\hline 59 & 393845106353000 & Eagle River at Edwards & 2 & 2000 & $8 / 15 / 2000$ & $39^{\circ} 38^{\prime} 45^{\prime \prime}$ & $106^{\circ} 35^{\prime} 30^{\prime \prime}$ & 7,180 & 424 & Encyonema silesiacum (Bleisch) Mann & 434,396 & $204,535,751$ \\
\hline 59 & 393845106353000 & Eagle River at Edwards & 2 & 2000 & $8 / 15 / 2000$ & $39^{\circ} 38^{\prime} 45^{\prime \prime}$ & $106^{\circ} 35^{\prime} 30^{\prime \prime}$ & 7,180 & 424 & Fragilaria vaucheriae (Kützing) Petersen & 19,583 & $4,051,057$ \\
\hline 59 & 393845106353000 & Eagle River at Edwards & 2 & 2000 & $8 / 15 / 2000$ & $39^{\circ} 38^{\prime} 45^{\prime \prime}$ & $106^{\circ} 35^{\prime} 30^{\prime \prime}$ & 7,180 & 424 & Hannaea arcus (Ehrenberg) Patrick & 7,121 & $17,291,353$ \\
\hline 59 & 393845106353000 & Eagle River at Edwards & 2 & 2000 & $8 / 15 / 2000$ & $39^{\circ} 38^{\prime} 45^{\prime \prime}$ & $106^{\circ} 35^{\prime} 30^{\prime \prime}$ & 7,180 & 424 & $\begin{array}{l}\text { Homoeothrix janthina (Bornet et Flahault) } \\
\text { Starmach }\end{array}$ & $37,969,578$ & $1,230,530,848$ \\
\hline 59 & 393845106353000 & Eagle River at Edwards & 2 & 2000 & $8 / 15 / 2000$ & $39^{\circ} 38^{\prime} 45^{\prime \prime}$ & $106^{\circ} 35^{\prime} 30^{\prime \prime}$ & 7,180 & 424 & Mayamaea atomus (Kützing) Lange-Bertalot & 359,623 & $9,392,532$ \\
\hline 59 & 393845106353000 & Eagle River at Edwards & 2 & 2000 & $8 / 15 / 2000$ & $39^{\circ} 38^{\prime} 45^{\prime \prime}$ & $106^{\circ} 35^{\prime} 30^{\prime \prime}$ & 7,180 & 424 & $\begin{array}{l}\text { Navicula cryptotenella Lange-Bertalot } \\
\text { ex Krammer et Lange-Bertalot }\end{array}$ & 1,780 & 644,333 \\
\hline 59 & 393845106353000 & Eagle Rive & 2 & 2000 & $8 / 15 / 2000$ & $39^{\circ} 38^{\prime} 45^{\prime \prime}$ & $106^{\circ} 35^{\prime} 30^{\prime \prime}$ & 7,180 & 424 & Navicula incertata Hustedt & 3,561 & 184,095 \\
\hline 59 & 393845106353000 & Eagle River at Edwards & 2 & 2000 & $8 / 15 / 2000$ & $39^{\circ} 38^{\prime} 45^{\prime \prime}$ & $106^{\circ} 35^{\prime} 30^{\prime \prime}$ & 7,180 & 424 & Nitzschia capitellata Hustedt & 3,561 & 892,675 \\
\hline 59 & 393845106353000 & Eagle River at Edwards & 2 & 2000 & $8 / 15 / 2000$ & $39^{\circ} 38^{\prime} 45^{\prime \prime}$ & $106^{\circ} 35^{\prime} 30^{\prime \prime}$ & 7,180 & 424 & Nitzschia fonticola Grunow & 44,508 & $4,419,771$ \\
\hline 59 & 393845106353000 & Eagle River at Edwards & 2 & 2000 & $8 / 15 / 2000$ & $39^{\circ} 38^{\prime} 45^{\prime \prime}$ & $106^{\circ} 35^{\prime} 30^{\prime \prime}$ & 7,180 & 424 & Nitzschia inconspicua Grunow & 10,682 & 386,240 \\
\hline 59 & 393845106353000 & Eagle River at Edwards & 2 & 2000 & $8 / 15 / 2000$ & $39^{\circ} 38^{\prime} 45^{\prime \prime}$ & $106^{\circ} 35^{\prime} 30^{\prime \prime}$ & 7,180 & 424 & Nitzschia palea (Kützing) Smith & 24,924 & $4,319,669$ \\
\hline 59 & 393845106353000 & Eagle River at Edwards & 2 & 2000 & $8 / 15 / 2000$ & $39^{\circ} 38^{\prime} 45^{\prime \prime}$ & $106^{\circ} 35^{\prime} 30^{\prime \prime}$ & 7,180 & 424 & Nitzschia paleacea Grunow ex Van Heurck & 423,714 & $12,981,017$ \\
\hline 59 & 393845106353000 & Eagle River at Edwards & 2 & 2000 & $8 / 15 / 2000$ & $39^{\circ} 38^{\prime} 45^{\prime \prime}$ & $106^{\circ} 35^{\prime} 30^{\prime \prime}$ & 7,180 & 424 & Phormidium autumnale (Agardh) Gomont & 564,803 & $55,310,742$ \\
\hline
\end{tabular}


Table 2. Description of sites and algal data collected from selected sites the Eagle River watershed, Colorado, 2000-2001.—Continued

[ID, identification; NAVD, North American Vertical Datum of 1988; ft, feet; $\mathrm{mi}^{2}$, square miles; cells $/ \mathrm{cm}^{2}$, cells per square centimeter; $\mu \mathrm{m}^{3} / \mathrm{cm}^{2}$, cubic micrometer per square centimeter]

\begin{tabular}{|c|c|c|c|c|c|c|c|c|c|c|c|c|}
\hline $\begin{array}{l}\text { Site } \\
\text { ID' }\end{array}$ & $\begin{array}{l}\text { USGS } \\
\text { station } \\
\text { number }\end{array}$ & Station name & $\begin{array}{l}\text { Replicate } \\
\text { sample } \\
\text { number }\end{array}$ & Year & $\begin{array}{l}\text { Collection } \\
\text { date }\end{array}$ & Latitude & Longitude & $\begin{array}{c}\text { Elevation } \\
\text { NAVD } 88 \\
\text { (ft) }\end{array}$ & $\begin{array}{c}\text { Drainage } \\
\text { area } \\
\left(\mathrm{mi}^{2}\right)\end{array}$ & Algal taxon name & $\begin{array}{c}\text { Total } \\
\text { density } \\
\text { (number of } \\
\text { cells } / \mathrm{cm}^{2} \text { ) }\end{array}$ & $\begin{array}{c}\text { Total } \\
\text { biovolume } \\
\left(\mu \mathbf{m}^{3} / \mathrm{cm}^{2}\right)\end{array}$ \\
\hline 59 & 393845106353000 & Eagle River at Edwards & 2 & 2000 & $8 / 15 / 2000$ & $39^{\circ} 38^{\prime} 45^{\prime \prime}$ & $106^{\circ} 35^{\prime} 30^{\prime \prime}$ & 7,180 & 424 & $\begin{array}{l}\text { Reimeria sinuata (Gregory) } \\
\text { Kociolek et Stoermer }\end{array}$ & 49,849 & $8,242,135$ \\
\hline 59 & 393845106353000 & Eagle River at Edwards & 2 & 2000 & $8 / 15 / 2000$ & $39^{\circ} 38^{\prime} 45^{\prime \prime}$ & $106^{\circ} 35^{\prime} 30^{\prime \prime}$ & 7,180 & 424 & Stigeoclonium lubricum (Dillwyn) Kützing & 779,967 & $1,157,687,008$ \\
\hline 59 & 393845106353000 & Eagle River at Edwards & 2 & 2000 & $8 / 15 / 2000$ & $39^{\circ} 38^{\prime} 45^{\prime \prime}$ & $106^{\circ} 35^{\prime} 30^{\prime \prime}$ & 7,180 & 424 & Synedra ulna (Nitzsch) Ehrenberg & 1,780 & $11,672,757$ \\
\hline 59 & 393845106353000 & Eagle River at Edwards & 3 & 2000 & $8 / 15 / 2000$ & $39^{\circ} 38^{\prime} 45^{\prime \prime}$ & $106^{\circ} 35^{\prime} 30^{\prime \prime}$ & 7,180 & 424 & $\begin{array}{l}\text { Achnanthidium minutissimum (Kützing) } \\
\text { Czarnecki }\end{array}$ & 84,261 & $4,640,409$ \\
\hline 59 & 393845106353000 & Eagle River at Edwards & 3 & 2000 & $8 / 15 / 2000$ & $39^{\circ} 38^{\prime} 45^{\prime \prime}$ & $106^{\circ} 35^{\prime} 30^{\prime \prime}$ & 7,180 & 424 & $\begin{array}{l}\text { Achnanthidium pyrenaicum (Hustedt) } \\
\text { Kobayasi }\end{array}$ & 8,548 & $1,075,446$ \\
\hline 59 & 393845106353000 & Eagle River at Edwards & 3 & 2000 & $8 / 15 / 2000$ & $39^{\circ} 38^{\prime} 45^{\prime \prime}$ & $106^{\circ} 35^{\prime} 30^{\prime \prime}$ & 7,180 & 424 & Chlamydomonas sp. & 3,060 & 260,140 \\
\hline 59 & 393845106353000 & Eagle River at Edwards & 3 & 2000 & $8 / 15 / 2000$ & $39^{\circ} 38^{\prime} 45^{\prime \prime}$ & $106^{\circ} 35^{\prime} 30^{\prime \prime}$ & 7,180 & 424 & Diatoma vulgaris Bory & 2,442 & $9,024,271$ \\
\hline 59 & 393845106353000 & Eagle River at Edwards & 3 & 2000 & $8 / 15 / 2000$ & $39^{\circ} 38^{\prime} 45^{\prime \prime}$ & $106^{\circ} 35^{\prime} 30^{\prime \prime}$ & 7,180 & 424 & Encyonema brehmii (Hustedt) Mann & 2,442 & 67,339 \\
\hline 59 & 393845106353000 & Eagle River at Edwards & 3 & 2000 & $8 / 15 / 2000$ & $39^{\circ} 38^{\prime} 45^{\prime \prime}$ & $106^{\circ} 35^{\prime} 30^{\prime \prime}$ & 7,180 & 424 & Encyonema minutum (Hilse) Mann & 17,096 & $3,658,355$ \\
\hline 59 & 393845106353000 & Eagle River at Edwards & 3 & 2000 & $8 / 15 / 2000$ & $39^{\circ} 38^{\prime} 45^{\prime \prime}$ & $106^{\circ} 35^{\prime} 30^{\prime \prime}$ & 7,180 & 424 & Encyonema silesiacum (Bleisch) Mann & 352,919 & $166,172,394$ \\
\hline 59 & 393845106353000 & Eagle River at Edwards & 3 & 2000 & $8 / 15 / 2000$ & $39^{\circ} 38^{\prime} 45^{\prime \prime}$ & $106^{\circ} 35^{\prime} 30^{\prime \prime}$ & 7,180 & 424 & $\begin{array}{l}\text { Fragilaria capucina var. fragilarioides } \\
\text { (Grunow) Ludwig et Flores }\end{array}$ & 1,221 & 125,119 \\
\hline 59 & 393845106353000 & Eagle River at Edwards & 3 & 2000 & $8 / 15 / 2000$ & $39^{\circ} 38^{\prime} 45^{\prime \prime}$ & $106^{\circ} 35^{\prime} 30^{\prime \prime}$ & 7,180 & 424 & Fragilaria vaucheriae (Kützing) Petersen & 3,664 & 757,842 \\
\hline 59 & 393845106353000 & Eagle River at Edwards & 3 & 2000 & $8 / 15 / 2000$ & $39^{\circ} 38^{\prime} 45^{\prime \prime}$ & $106^{\circ} 35^{\prime} 30^{\prime \prime}$ & 7,180 & 424 & Gomphonema olivaceum (Lyngbye) Kützing & 2,442 & 840,335 \\
\hline 59 & 393845106353000 & Eagle River at Edwards & 3 & 2000 & $8 / 15 / 2000$ & $39^{\circ} 38^{\prime} 45^{\prime \prime}$ & $106^{\circ} 35^{\prime} 30^{\prime \prime}$ & 7,180 & 424 & Hannaea arcus (Ehrenberg) Patrick & 1,221 & $2,965,177$ \\
\hline 59 & 393845106353000 & Eagle River at Edwards & 3 & 2000 & $8 / 15 / 2000$ & $39^{\circ} 38^{\prime} 45^{\prime \prime}$ & $106^{\circ} 35^{\prime} 30^{\prime \prime}$ & 7,180 & 424 & $\begin{array}{l}\text { Homoeothrix janthina (Bornet et Flahault) } \\
\text { Starmach }\end{array}$ & $4,382,595$ & $142,032,601$ \\
\hline 59 & 393845106353000 & Eagle River at Edwards & 3 & 2000 & $8 / 15 / 2000$ & $39^{\circ} 38^{\prime} 45^{\prime \prime}$ & $106^{\circ} 35^{\prime} 30^{\prime \prime}$ & 7,180 & 424 & Mayamaea atomus (Kützing) Lange-Bertalot & 28,087 & 733,569 \\
\hline 59 & 393845106353000 & Eagle River at Edwards & 3 & 2000 & $8 / 15 / 2000$ & $39^{\circ} 38^{\prime} 45^{\prime \prime}$ & $106^{\circ} 35^{\prime} 30^{\prime \prime}$ & 7,180 & 424 & Melosira varians Agardh & 8,548 & $46,410,423$ \\
\hline 59 & 393845106353000 & Eagle River at Edwards & 3 & 2000 & $8 / 15 / 2000$ & $39^{\circ} 38^{\prime} 45^{\prime \prime}$ & $106^{\circ} 35^{\prime} 30^{\prime \prime}$ & 7,180 & 424 & Navicula incertata Hustedt & 2,442 & 126,277 \\
\hline 59 & 393845106353000 & Eagle River at Edwards & 3 & 2000 & $8 / 15 / 2000$ & $39^{\circ} 38^{\prime} 45^{\prime \prime}$ & $106^{\circ} 35^{\prime} 30^{\prime \prime}$ & 7,180 & 424 & Navicula minima Grunow & 4,885 & 259,430 \\
\hline 59 & 393845106353000 & Eagle River at Edwards & 3 & 2000 & $8 / 15 / 2000$ & $39^{\circ} 38^{\prime} 45^{\prime \prime}$ & $106^{\circ} 35^{\prime} 30^{\prime \prime}$ & 7,180 & 424 & Nitzschia angustata (Smith) Grunow & 4,885 & $25,691,663$ \\
\hline 59 & 393845106353000 & Eagle River at Edwards & 3 & 2000 & $8 / 15 / 2000$ & $39^{\circ} 38^{\prime} 45^{\prime \prime}$ & $106^{\circ} 35^{\prime} 30^{\prime \prime}$ & 7,180 & 424 & Nitzschia dissipata (Kützing) Grunow & 2,442 & 635,106 \\
\hline 59 & 393845106353000 & Eagle River at Edwards & 3 & 2000 & $8 / 15 / 2000$ & $39^{\circ} 38^{\prime} 45^{\prime \prime}$ & $106^{\circ} 35^{\prime} 30^{\prime \prime}$ & 7,180 & 424 & Nitzschia fonticola Grunow & 23,202 & $2,304,066$ \\
\hline 59 & 393845106353000 & Eagle River at Edwards & 3 & 2000 & $8 / 15 / 2000$ & $39^{\circ} 38^{\prime} 45^{\prime \prime}$ & $106^{\circ} 35^{\prime} 30^{\prime \prime}$ & 7,180 & 424 & Nitzschia inconspicua Grunow & 2,442 & 88,312 \\
\hline 59 & 393845106353000 & Eagle River at Edwards & 3 & 2000 & $8 / 15 / 2000$ & $39^{\circ} 38^{\prime} 45^{\prime \prime}$ & $106^{\circ} 35^{\prime} 30^{\prime \prime}$ & 7,180 & 424 & Nitzschia palea (Kützing) Smith & 129,444 & $22,434,168$ \\
\hline 59 & 393845106353000 & Eagle River at Edwards & 3 & 2000 & $8 / 15 / 2000$ & $39^{\circ} 38^{\prime} 45^{\prime \prime}$ & $106^{\circ} 35^{\prime} 30^{\prime \prime}$ & 7,180 & 424 & Nitzschia paleacea Grunow ex Van Heurck & 275,985 & $8,455,160$ \\
\hline 59 & 393845106353000 & Eagle River at Edwards & 3 & 2000 & $8 / 15 / 2000$ & $39^{\circ} 38^{\prime} 45^{\prime \prime}$ & $106^{\circ} 35^{\prime} 30^{\prime \prime}$ & 7,180 & 424 & Phormidium autumnale (Agardh) Gomont & 73,451 & $7,193,028$ \\
\hline 59 & 393845106353000 & Eagle River at Edwards & 3 & 2000 & $8 / 15 / 2000$ & $39^{\circ} 38^{\prime} 45^{\prime \prime}$ & $106^{\circ} 35^{\prime} 30^{\prime \prime}$ & 7,180 & 424 & $\begin{array}{l}\text { Reimeria sinuata (Gregory) } \\
\text { Kociolek et Stoermer }\end{array}$ & 25,645 & $4,240,164$ \\
\hline 59 & 393845106353000 & Eagle River at Edwards & 3 & 2000 & $8 / 15 / 2000$ & $39^{\circ} 38^{\prime} 45^{\prime \prime}$ & $106^{\circ} 35^{\prime} 30^{\prime \prime}$ & 7,180 & 424 & Scenedesmus quadricauda (Turpin) Brébisson & 12,242 & $1,399,313$ \\
\hline 59 & 393845106353000 & Eagle River at Edwards & 3 & 2000 & $8 / 15 / 2000$ & $39^{\circ} 38^{\prime} 45^{\prime \prime}$ & $106^{\circ} 35^{\prime} 30^{\prime \prime}$ & 7,180 & 424 & Stigeoclonium lubricum (Dillwyn) Kützing & 91,814 & $136,277,679$ \\
\hline 59 & 393845106353000 & Eagle River at Edwards & 3 & 2000 & $8 / 15 / 2000$ & $39^{\circ} 38^{\prime} 45^{\prime \prime}$ & $106^{\circ} 35^{\prime} 30^{\prime \prime}$ & 7,180 & 424 & Synedra ulna (Nitzsch) Ehrenberg & 3,664 & $24,020,185$ \\
\hline 59 & 393845106353000 & Eagle River at Edwards & 3 & 2000 & $8 / 15 / 2000$ & $39^{\circ} 38^{\prime} 45^{\prime \prime}$ & $106^{\circ} 35^{\prime} 30^{\prime \prime}$ & 7,180 & 424 & Synedra ulna var. contracta Østrup & 3,664 & $5,824,056$ \\
\hline 59 & 393845106353000 & Eagle River at Edwards & 1 & 2001 & $8 / 16 / 2001$ & $39^{\circ} 38^{\prime} 45^{\prime \prime}$ & $106^{\circ} 35^{\prime} 30^{\prime \prime}$ & 7,180 & 424 & $\begin{array}{l}\text { Achnanthidium minutissimum (Kützing) } \\
\text { Czarnecki }\end{array}$ & 16,001 & 867,580 \\
\hline 59 & 393845106353000 & Eagle River at Edwards & 1 & 2001 & $8 / 16 / 2001$ & $39^{\circ} 38^{\prime} 45^{\prime \prime}$ & $106^{\circ} 35^{\prime} 30^{\prime \prime}$ & 7,180 & 424 & $\begin{array}{l}\text { Achnanthidium pyrenaicum (Hustedt) } \\
\text { Kobayasi }\end{array}$ & 314 & 39,645 \\
\hline 59 & 393845106353000 & Eagle River at Edwards & 1 & 2001 & $8 / 16 / 2001$ & $39^{\circ} 38^{\prime} 45^{\prime \prime}$ & $106^{\circ} 35^{\prime} 30^{\prime \prime}$ & 7,180 & 424 & Closterium lunula (Möller) Nitzsch & 1,201 & 102,115 \\
\hline 59 & 393845106353000 & Eagle River at Edwards & 1 & 2001 & $8 / 16 / 2001$ & $39^{\circ} 38^{\prime} 45^{\prime \prime}$ & $106^{\circ} 35^{\prime} 30^{\prime \prime}$ & 7,180 & 424 & Cocconeis pediculus Ehrenberg & 314 & 979,371 \\
\hline 59 & 393845106353000 & Eagle River at Edwards & 1 & 2001 & $8 / 16 / 2001$ & $39^{\circ} 38^{\prime} 45^{\prime \prime}$ & $106^{\circ} 35^{\prime} 30^{\prime \prime}$ & 7,180 & 424 & $\begin{array}{l}\text { Cocconeis placentula var. euglypta } \\
\text { (Ehrenberg) Grunow }\end{array}$ & 627 & 372,844 \\
\hline 59 & 353000 & Eagle & 1 & 2001 & 2001 & $39^{\circ} 38^{\prime} 45^{\prime \prime}$ & $106^{\circ} 35^{\prime} 30^{\prime \prime}$ & 7,180 & 424 & $\begin{array}{l}\text { Cocconeis placentula var. lineata (Ehrenberg) } \\
\text { Van Heurck }\end{array}$ & 1,569 & 4,349 \\
\hline 59 & 393845106353000 & Eagle River at Edwards & 1 & 2001 & $8 / 16 / 2001$ & $39^{\circ} 38^{\prime} 45^{\prime \prime}$ & $106^{\circ} 35^{\prime} 30^{\prime \prime}$ & 7,180 & 424 & Diatoma moniliformis Kützing & 314 & 57,259 \\
\hline
\end{tabular}


[ID, identification; NAVD, North American Vertical Datum of 1988; ft, feet; $\mathrm{mi}^{2}$, square miles; cells $/ \mathrm{cm}^{2}$, cells per square centimeter; $\mu \mathrm{m}^{3} / \mathrm{cm}^{2}$, cubic micrometer per square centimeter]

\begin{tabular}{|c|c|c|c|c|c|c|c|c|c|c|c|c|}
\hline $\begin{array}{l}\text { Site } \\
\text { ID' }\end{array}$ & $\begin{array}{l}\text { USGS } \\
\text { station } \\
\text { number }\end{array}$ & Station name & $\begin{array}{l}\text { Replicate } \\
\text { sample } \\
\text { number }\end{array}$ & Year & $\begin{array}{l}\text { Collection } \\
\text { date }\end{array}$ & Latitude & Longitude & $\begin{array}{l}\text { Elevation } \\
\text { NAVD } 88 \\
\text { (ft) }\end{array}$ & $\begin{array}{c}\text { Drainage } \\
\text { area } \\
\left(\mathrm{mi}^{2}\right)\end{array}$ & Algal taxon name & $\begin{array}{c}\text { Total } \\
\text { density } \\
\text { (number of } \\
\text { cells/cm²) }\end{array}$ & $\begin{array}{c}\text { Total } \\
\text { biovolume } \\
\left(\mu \mathrm{m}^{3} / \mathrm{cm}^{2}\right)\end{array}$ \\
\hline 59 & 393845106353000 & Eagle River at Edwards & 1 & 2001 & $8 / 16 / 2001$ & $39^{\circ} 38^{\prime} 45^{\prime \prime}$ & $106^{\circ} 35^{\prime} 30^{\prime \prime}$ & 7,180 & 424 & Encyonema brehmii (Hustedt) Mann & 2,510 & 69,203 \\
\hline 59 & 393845106353000 & Eagle River at Edwards & 1 & 2001 & $8 / 16 / 2001$ & $39^{\circ} 38^{\prime} 45^{\prime \prime}$ & $106^{\circ} 35^{\prime} 30^{\prime \prime}$ & 7,180 & 424 & Encyonema minutum (Hilse) Mann & 6,275 & $1,354,321$ \\
\hline 59 & 393845106353000 & Eagle River at Edwards & 1 & 2001 & $8 / 16 / 2001$ & $39^{\circ} 38^{\prime} 45^{\prime \prime}$ & $106^{\circ} 35^{\prime} 30^{\prime \prime}$ & 7,180 & 424 & Encyonema silesiacum (Bleisch) Mann & 67,141 & $31,888,198$ \\
\hline 59 & 393845106353000 & Eagle River at Edwards & 1 & 2001 & $8 / 16 / 2001$ & $39^{\circ} 38^{\prime} 45^{\prime \prime}$ & $106^{\circ} 35^{\prime} 30^{\prime \prime}$ & 7,180 & 424 & Fragilaria vaucheriae (Kützing) Petersen & 10,353 & $2,039,754$ \\
\hline 59 & 393845106353000 & Eagle River at Edwards & 1 & 2001 & $8 / 16 / 2001$ & $39^{\circ} 38^{\prime} 45^{\prime \prime}$ & $106^{\circ} 35^{\prime} 30^{\prime \prime}$ & 7,180 & 424 & Gomphonema minutum (Agardh) Agardh & 627 & 51,269 \\
\hline 59 & 393845106353000 & Eagle River at Edwards & 1 & 2001 & $8 / 16 / 2001$ & $39^{\circ} 38^{\prime} 45^{\prime \prime}$ & $106^{\circ} 35^{\prime} 30^{\prime \prime}$ & 7,180 & 424 & Gomphonema olivaceoides Hustedt & 314 & 47,239 \\
\hline 59 & 393845106353000 & Eagle River at Edwards & 1 & 2001 & $8 / 16 / 2001$ & $39^{\circ} 38^{\prime} 45^{\prime \prime}$ & $106^{\circ} 35^{\prime} 30^{\prime \prime}$ & 7,180 & 424 & Gomphonema parvulum (Kützing) Kützing & 314 & 68,559 \\
\hline 59 & 393845106353000 & Eagle River at Edwards & 1 & 2001 & $8 / 16 / 2001$ & $39^{\circ} 38^{\prime} 45^{\prime \prime}$ & $106^{\circ} 35^{\prime} 30^{\prime \prime}$ & 7,180 & 424 & Hannaea arcus (Ehrenberg) Patrick & 3,451 & $6,920,096$ \\
\hline 59 & 393845106353000 & Eagle River at Edwards & 1 & 2001 & $8 / 16 / 2001$ & $39^{\circ} 38^{\prime} 45^{\prime \prime}$ & $106^{\circ} 35^{\prime} 30^{\prime \prime}$ & 7,180 & 424 & $\begin{array}{l}\text { Homoeothrix janthina (Bornet et Flahault) } \\
\text { Starmach }\end{array}$ & $2,212,892$ & $38,091,964$ \\
\hline 59 & 393845106353000 & Eagle River at Edwards & 1 & 2001 & $8 / 16 / 2001$ & $39^{\circ} 38^{\prime} 45^{\prime \prime}$ & $106^{\circ} 35^{\prime} 30^{\prime \prime}$ & 7,180 & 424 & Mayamaea atomus (Kützing) Lange-Bertalot & 1,255 & 36,037 \\
\hline 59 & 393845106353000 & Eagle River at Edwards & 1 & 2001 & $8 / 16 / 2001$ & $39^{\circ} 38^{\prime} 45^{\prime \prime}$ & $106^{\circ} 35^{\prime} 30^{\prime \prime}$ & 7,180 & 424 & Melosira varians Agardh & 30,433 & $7,279,320$ \\
\hline 59 & 393845106353000 & Eagle River at Edwards & 1 & 2001 & $8 / 16 / 2001$ & $39^{\circ} 38^{\prime} 45^{\prime \prime}$ & $106^{\circ} 35^{\prime} 30^{\prime \prime}$ & 7,180 & 424 & Meridion circulare (Greville) Agardh & 314 & 203,631 \\
\hline 59 & 393845106353000 & Eagle River at Edwards & 1 & 2001 & $8 / 16 / 2001$ & $39^{\circ} 38^{\prime} 45^{\prime \prime}$ & $106^{\circ} 35^{\prime} 30^{\prime \prime}$ & 7,180 & 424 & Navicula incertata Hustedt & 1,255 & 74,741 \\
\hline 59 & 393845106353000 & Eagle River at Edwards & 1 & 2001 & $8 / 16 / 2001$ & $39^{\circ} 38^{\prime} 45^{\prime \prime}$ & $106^{\circ} 35^{\prime} 30^{\prime \prime}$ & 7,180 & 424 & Navicula minima Grunow & 1,255 & 56,482 \\
\hline 59 & 393845106353000 & Eagle River at Edwards & 1 & 2001 & $8 / 16 / 2001$ & $39^{\circ} 38^{\prime} 45^{\prime \prime}$ & $106^{\circ} 35^{\prime} 30^{\prime \prime}$ & 7,180 & 424 & Navicula tantula Hustedt & 1,255 & 68,838 \\
\hline 59 & 393845106353000 & Eagle River at Edwards & 1 & 2001 & $8 / 16 / 2001$ & $39^{\circ} 38^{\prime} 45^{\prime \prime}$ & $106^{\circ} 35^{\prime} 30^{\prime \prime}$ & 7,180 & 424 & Nitzschia dissipata (Kützing) Grunow & 3,137 & 808,936 \\
\hline 59 & 393845106353000 & Eagle River at Edwards & 1 & 2001 & $8 / 16 / 2001$ & $39^{\circ} 38^{\prime} 45^{\prime \prime}$ & $106^{\circ} 35^{\prime} 30^{\prime \prime}$ & 7,180 & 424 & Nitzschia fonticola Grunow & 11,608 & $1,154,758$ \\
\hline 59 & 393845106353000 & Eagle River at Edwards & 1 & 2001 & $8 / 16 / 2001$ & $39^{\circ} 38^{\prime} 45^{\prime \prime}$ & $106^{\circ} 35^{\prime} 30^{\prime \prime}$ & 7,180 & 424 & Nitzschia inconspicua Grunow & 1,569 & 55,245 \\
\hline 59 & 393845106353000 & Eagle River at Edwards & 1 & 2001 & $8 / 16 / 2001$ & $39^{\circ} 38^{\prime} 45^{\prime \prime}$ & $106^{\circ} 35^{\prime} 30^{\prime \prime}$ & 7,180 & 424 & $\begin{array}{l}\text { Nitzschia linearis (Agardh ex Wm. Smith) } \\
\text { Wm. Smith }\end{array}$ & 1,569 & $4,528,673$ \\
\hline 59 & 393845106353000 & Eagle River at Edwards & 1 & 2001 & $8 / 16 / 2001$ & $39^{\circ} 38^{\prime} 45^{\prime \prime}$ & $106^{\circ} 35^{\prime} 30^{\prime \prime}$ & 7,180 & 424 & Phormidium autumnale (Agardh) Gomont & 25,228 & $2,446,025$ \\
\hline 59 & 393845106353000 & Eagle River at Edwards & 1 & 2001 & $8 / 16 / 2001$ & $39^{\circ} 38^{\prime} 45^{\prime \prime}$ & $106^{\circ} 35^{\prime} 30^{\prime \prime}$ & 7,180 & 424 & $\begin{array}{l}\text { Planothidium lanceolatum } \\
\text { (Brébisson ex Kützing) Lange-Bertalot }\end{array}$ & 941 & 128,935 \\
\hline 59 & 393845106353000 & Eagle River at Edwards & 1 & 2001 & $8 / 16 / 2001$ & $39^{\circ} 38^{\prime} 45^{\prime \prime}$ & $106^{\circ} 35^{\prime} 30^{\prime \prime}$ & 7,180 & 424 & $\begin{array}{l}\text { Reimeria sinuata (Gregory) } \\
\text { Kociolek et Stoermer }\end{array}$ & 10,667 & $1,797,849$ \\
\hline 59 & 393845106353000 & Eagle River at Edwards & 1 & 2001 & $8 / 16 / 2001$ & $39^{\circ} 38^{\prime} 45^{\prime \prime}$ & $106^{\circ} 35^{\prime} 30^{\prime \prime}$ & 7,180 & 424 & Scenedesmus acutus Meyen & 4,805 & 103,239 \\
\hline 59 & 393845106353000 & Eagle River at Edwards & 1 & 2001 & $8 / 16 / 2001$ & $39^{\circ} 38^{\prime} 45^{\prime \prime}$ & $106^{\circ} 35^{\prime} 30^{\prime \prime}$ & 7,180 & 424 & Stauroneis sp. 1 ANS WRC & 627 & $4,706,754$ \\
\hline 59 & 393845106353000 & Eagle River at Edwards & 1 & 2001 & $8 / 16 / 2001$ & $39^{\circ} 38^{\prime} 45^{\prime \prime}$ & $106^{\circ} 35^{\prime} 30^{\prime \prime}$ & 7,180 & 424 & $\begin{array}{l}\text { Staurosira construens var. venter (Ehrenberg) } \\
\text { Hamilton }\end{array}$ & 6,275 & 753,638 \\
\hline 59 & 393845106353000 & Eagle River at Edwards & 1 & 2001 & $8 / 16 / 2001$ & $39^{\circ} 38^{\prime} 45^{\prime \prime}$ & $106^{\circ} 35^{\prime} 30^{\prime \prime}$ & 7,180 & 424 & $\begin{array}{l}\text { Staurosirella leptostauron (Ehrenberg) } \\
\text { Williams et Round }\end{array}$ & 1,255 & 612,963 \\
\hline 59 & 393845106353000 & Eagle River at Edwards & 1 & 2001 & $8 / 16 / 2001$ & $39^{\circ} 38^{\prime} 45^{\prime \prime}$ & $106^{\circ} 35^{\prime} 30^{\prime \prime}$ & 7,180 & 424 & Stigeoclonium lubricum (Dillwyn) Kützing & 22,826 & $40,372,269$ \\
\hline 59 & 393845106353000 & Eagle River at Edwards & 1 & 2001 & $8 / 16 / 2001$ & $39^{\circ} 38^{\prime} 45^{\prime \prime}$ & $106^{\circ} 35^{\prime} 30^{\prime \prime}$ & 7,180 & 424 & $\begin{array}{l}\text { Surirella brebissonii } \\
\text { Krammer et Lange-Bertalot }\end{array}$ & 314 & 519,863 \\
\hline 59 & 393845106353000 & Eagle River at Edwards & 1 & 2001 & $8 / 16 / 2001$ & $39^{\circ} 38^{\prime} 45^{\prime \prime}$ & $106^{\circ} 35^{\prime} 30^{\prime \prime}$ & 7,180 & 424 & Synedra ulna va & 5,961 & $10,103,559$ \\
\hline 59 & 393845106353000 & Eagle River at Edwards & 1 & 2001 & $8 / 16 / 2001$ & $39^{\circ} 38^{\prime} 45^{\prime \prime}$ & $106^{\circ} 35^{\prime} 30^{\prime \prime}$ & 7,180 & 424 & Unknown alga flagellate $(<10 \mu)$ & 3,604 & 346,359 \\
\hline 59 & 393845106353000 & Eagle River at Edwards & 1 & 2001 & $8 / 16 / 2001$ & $39^{\circ} 38^{\prime} 45^{\prime \prime}$ & $106^{\circ} 35^{\prime} 30^{\prime \prime}$ & 7,180 & 424 & $\begin{array}{l}\text { Unknown Cyanophyte Oscillatoriales } \\
\text { (no sheath) }\end{array}$ & 320,761 & $4,758,670$ \\
\hline 62 & 393523106364700 & West Lake Creek near Edwards & 1 & 2000 & $8 / 15 / 2000$ & $39^{\circ} 35^{\prime} 23^{\prime \prime}$ & $106^{\circ} 36^{\prime} 47^{\prime \prime}$ & 8,300 & 11 & $\begin{array}{l}\text { Achnanthidium minutissimum (Kützing) } \\
\text { Czarnecki }\end{array}$ & 6,367 & 350,646 \\
\hline 62 & 393523106364700 & West Lake Creek near Edwards & 1 & 2000 & $8 / 15 / 2000$ & $39^{\circ} 35^{\prime} 23^{\prime \prime}$ & $106^{\circ} 36^{\prime} 47^{\prime \prime}$ & 8,300 & 11 & $\begin{array}{l}\text { Achnanthidium pyrenaicum (Hustedt) } \\
\text { Kobayasi }\end{array}$ & 55 & 6,935 \\
\hline 62 & 393523106364700 & West Lake Creek near Edwards & 1 & 2000 & $8 / 15 / 2000$ & $39^{\circ} 35^{\prime} 23^{\prime \prime}$ & $106^{\circ} 36^{\prime} 47^{\prime \prime}$ & 8,300 & 11 & $\begin{array}{l}\text { Adlafia minuscula var. muralis (Grunow) } \\
\text { Lange-Bertalot }\end{array}$ & 14 & 625 \\
\hline 62 & 393523106364700 & West Lake Creek near Edwards & 1 & 2000 & $8 / 15 / 2000$ & $39^{\circ} 35^{\prime} 23^{\prime \prime}$ & $106^{\circ} 36^{\prime} 47^{\prime \prime}$ & 8,300 & 11 & Amphora pediculus (Kützing) Grunow & 28 & 2,608 \\
\hline 62 & 393523106364700 & West Lake Creek near Edwards & 1 & 2000 & $8 / 15 / 2000$ & $39^{\circ} 35^{\prime} 23^{\prime \prime}$ & $106^{\circ} 36^{\prime} 47^{\prime \prime}$ & 8,300 & 11 & Caloneis bacillum (Grunow) Cleve & 28 & 11,857 \\
\hline 62 & 393523106364700 & West Lake Creek near Edwards & 1 & 2000 & $8 / 15 / 2000$ & $39^{\circ} 35^{\prime} 23^{\prime \prime}$ & $106^{\circ} 36^{\prime} 47^{\prime \prime}$ & 8,300 & 11 & Chlamydomonas sp. & 98 & 8,321 \\
\hline
\end{tabular}


Table 2. Description of sites and algal data collected from selected sites the Eagle River watershed, Colorado, 2000-2001.—Continued

[ID, identification; NAVD, North American Vertical Datum of 1988; ft, feet; $\mathrm{mi}^{2}$, square miles; cells $/ \mathrm{cm}^{2}$, cells per square centimeter; $\mu \mathrm{m}^{3} / \mathrm{cm}^{2}$, cubic micrometer per square centimeter]

\begin{tabular}{|c|c|c|c|c|c|c|c|c|c|c|c|c|}
\hline $\begin{array}{l}\text { Site } \\
\text { ID' }\end{array}$ & $\begin{array}{l}\text { USGS } \\
\text { station } \\
\text { number }\end{array}$ & Station name & $\begin{array}{c}\text { Replicate } \\
\text { sample } \\
\text { number }\end{array}$ & Year & $\begin{array}{l}\text { Collection } \\
\text { date }\end{array}$ & Latitude & Longitude & $\begin{array}{c}\text { Elevation } \\
\text { NAVD } 88 \\
\text { (ft) }\end{array}$ & $\begin{array}{c}\text { Drainage } \\
\text { area } \\
\left(\mathrm{mi}^{2}\right)\end{array}$ & Algal taxon name & $\begin{array}{c}\text { Total } \\
\text { density } \\
\text { (number of } \\
\text { cells/cm²) }\end{array}$ & $\begin{array}{c}\text { Total } \\
\text { biovolume } \\
\left(\mu \mathrm{m}^{3} / \mathrm{cm}^{2}\right)\end{array}$ \\
\hline 62 & 393523106364700 & West Lake Creek near Edwards & 1 & 2000 & $8 / 15 / 2000$ & $39^{\circ} 35^{\prime} 23^{\prime \prime}$ & $106^{\circ} 36^{\prime} 47^{\prime \prime}$ & 8,300 & 11 & $\begin{array}{l}\text { Cocconeis placentula var. euglypta (Ehren- } \\
\text { berg) Grunow }\end{array}$ & 14 & 8,303 \\
\hline 62 & 393523106364700 & West Lake Creek near Edwards & 1 & 2000 & $8 / 15 / 2000$ & $39^{\circ} 35^{\prime} 23^{\prime \prime}$ & $106^{\circ} 36^{\prime} 47^{\prime \prime}$ & 8,300 & 11 & $\begin{array}{l}\text { Cocconeis placentula var. lineata (Ehrenberg) } \\
\text { Van Heurck }\end{array}$ & 841 & 880,815 \\
\hline 62 & 393523106364700 & West Lake Creek near Edwards & 1 & 2000 & $8 / 15 / 2000$ & $39^{\circ} 35^{\prime} 23^{\prime \prime}$ & $106^{\circ} 36^{\prime} 47^{\prime \prime}$ & 8,300 & 11 & $\begin{array}{l}\text { Cymbella cf. cymbiformis var. nonpunctata } \\
\text { Fontell }\end{array}$ & 14 & 25,551 \\
\hline 62 & 393523106364700 & West Lake Creek near Edwards & 1 & 2000 & $8 / 15 / 2000$ & $39^{\circ} 35^{\prime} 23^{\prime \prime}$ & $106^{\circ} 36^{\prime} 47^{\prime \prime}$ & 8,300 & 11 & Encyonema brehmii (Hustedt) Mann & 868 & 23,939 \\
\hline 62 & 393523106364700 & West Lake Creek near Edwards & 1 & 2000 & $8 / 15 / 2000$ & $39^{\circ} 35^{\prime} 23^{\prime \prime}$ & $106^{\circ} 36^{\prime} 47^{\prime \prime}$ & 8,300 & 11 & Encyonema minutum (Hilse) Mann & 28 & 5,898 \\
\hline 62 & 393523106364700 & West Lake Creek near Edwards & 1 & 2000 & $8 / 15 / 2000$ & $39^{\circ} 35^{\prime} 23^{\prime \prime}$ & $106^{\circ} 36^{\prime} 47^{\prime \prime}$ & 8,300 & 11 & Encyonema silesiacum (Bleisch) Mann & 165 & 77,868 \\
\hline 62 & 393523106364700 & West Lake Creek near Edwards & 1 & 2000 & $8 / 15 / 2000$ & $39^{\circ} 35^{\prime} 23^{\prime \prime}$ & $106^{\circ} 36^{\prime} 47^{\prime \prime}$ & 8,300 & 11 & Fragilaria capucina var. mesolepta Rabenhorst & 28 & 10,282 \\
\hline 62 & 393523106364700 & West Lake Creek near Edwards & 1 & 2000 & $8 / 15 / 2000$ & $39^{\circ} 35^{\prime} 23^{\prime \prime}$ & $106^{\circ} 36^{\prime} 47^{\prime \prime}$ & 8,300 & 11 & Fragilaria vaucheriae (Kützing) Petersen & 41 & 8,553 \\
\hline 62 & 393523106364700 & West Lake Creek near Edwards & 1 & 2000 & $8 / 15 / 2000$ & $39^{\circ} 35^{\prime} 23^{\prime \prime}$ & $106^{\circ} 36^{\prime} 47^{\prime \prime}$ & 8,300 & 11 & $\begin{array}{l}\text { Gomphonema angustatum (Kützing) } \\
\text { Rabenhorst }\end{array}$ & 28 & 11,395 \\
\hline 62 & 393523106364700 & West Lake Creek near Edwards & 1 & 2000 & $8 / 15 / 2000$ & $39^{\circ} 35^{\prime} 23^{\prime \prime}$ & $106^{\circ} 36^{\prime} 47^{\prime \prime}$ & 8,300 & 11 & $\begin{array}{l}\text { Gomphonema olivaceoides var. } \\
\text { hutchinsoniana Patrick }\end{array}$ & 14 & 2,088 \\
\hline 62 & 393523106364700 & West Lake Creek near Edwards & 1 & 2000 & $8 / 15 / 2000$ & $39^{\circ} 35^{\prime} 23^{\prime \prime}$ & $106^{\circ} 36^{\prime} 47^{\prime \prime}$ & 8,300 & 11 & Hannaea arcus (Ehrenberg) Patrick & 41 & 100,390 \\
\hline 62 & 393523106364700 & West Lake Creek near Edwards & 1 & 2000 & $8 / 15 / 2000$ & $39^{\circ} 35^{\prime} 23^{\prime \prime}$ & $106^{\circ} 36^{\prime} 47^{\prime \prime}$ & 8,300 & 11 & $\begin{array}{l}\text { Homoeothrix janthina (Bornet et Flahault) } \\
\text { Starmach }\end{array}$ & 76,257 & $2,471,373$ \\
\hline 62 & 393523106364700 & West Lake Creek near Edwards & 1 & 2000 & $8 / 15 / 2000$ & $39^{\circ} 35^{\prime} 23^{\prime \prime}$ & $106^{\circ} 36^{\prime} 47^{\prime \prime}$ & 8,300 & 11 & Navicula incertata Hustedt & 96 & 4,988 \\
\hline 62 & 393523106364700 & West Lake Creek near Edwards & 1 & 2000 & $8 / 15 / 2000$ & $39^{\circ} 35^{\prime} 23^{\prime \prime}$ & $106^{\circ} 36^{\prime} 47^{\prime \prime}$ & 8,300 & 11 & Navicula tripunctata (Müller) Bory & 41 & 39,119 \\
\hline 62 & 393523106364700 & West Lake Creek near Edwards & 1 & 2000 & $8 / 15 / 2000$ & $39^{\circ} 35^{\prime} 23^{\prime \prime}$ & $106^{\circ} 36^{\prime} 47^{\prime \prime}$ & 8,300 & 11 & Nitzschia dissipata (Kützing) Grunow & 41 & 10,751 \\
\hline 62 & 393523106364700 & West Lake Creek near Edwards & 1 & 2000 & $8 / 15 / 2000$ & $39^{\circ} 35^{\prime} 23^{\prime \prime}$ & $106^{\circ} 36^{\prime} 47^{\prime \prime}$ & 8,300 & 11 & Nitzschia inconspicua Grunow & 14 & 740 \\
\hline 62 & 393523106364700 & West Lake Creek near Edwards & 1 & 2000 & $8 / 15 / 2000$ & $39^{\circ} 35^{\prime} 23^{\prime \prime}$ & $106^{\circ} 36^{\prime} 47^{\prime \prime}$ & 8,300 & 11 & $\begin{array}{l}\text { Nitzschia vermicularis (Kützing) } \\
\text { Hantzsch ex Rabenhorst }\end{array}$ & 14 & 63,050 \\
\hline 62 & 393523106364700 & West Lake Creek near Edwards & 1 & 2000 & $8 / 15 / 2000$ & $39^{\circ} 35^{\prime} 23^{\prime \prime}$ & $106^{\circ} 36^{\prime} 47^{\prime \prime}$ & 8,300 & 11 & Phormidium autumnale (Agardh) Gomont & 55,309 & $5,416,327$ \\
\hline 62 & 393523106364700 & West Lake Creek near Edwards & 1 & 2000 & $8 / 15 / 2000$ & $39^{\circ} 35^{\prime} 23^{\prime \prime}$ & $106^{\circ} 36^{\prime} 47^{\prime \prime}$ & 8,300 & 11 & Placoneis elginensis (Gregory) Cox & 28 & 27,711 \\
\hline 62 & 393523106364700 & West Lake Creek near Edwards & 1 & 2000 & $8 / 15 / 2000$ & $39^{\circ} 35^{\prime} 23^{\prime \prime}$ & $106^{\circ} 36^{\prime} 47^{\prime \prime}$ & 8,300 & 11 & $\begin{array}{l}\text { Planothidium lanceolatum } \\
\text { (Brébisson ex Kützing) Lange-Bertalot }\end{array}$ & 28 & 3,937 \\
\hline 62 & 393523106364700 & West Lake Creek near Edwards & 1 & 2000 & $8 / 15 / 2000$ & $39^{\circ} 35^{\prime} 23^{\prime \prime}$ & $106^{\circ} 36^{\prime} 47^{\prime \prime}$ & 8,300 & 11 & $\begin{array}{l}\text { Reimeria sinuata (Gregory) } \\
\text { Kociolek et Stoermer }\end{array}$ & 537 & 88,868 \\
\hline 62 & 393523106364700 & West Lake Creek near Edwards & 1 & 2000 & $8 / 15 / 2000$ & $39^{\circ} 35^{\prime} 23^{\prime \prime}$ & $106^{\circ} 36^{\prime} 47^{\prime \prime}$ & 8,300 & 11 & $\begin{array}{l}\text { Rossithidium pusillum (Grunow) } \\
\text { Round et Bukhtiyarova }\end{array}$ & 41 & 3,753 \\
\hline 62 & 393523106364700 & West Lake Creek near Edwards & 1 & 2000 & $8 / 15 / 2000$ & $39^{\circ} 35^{\prime} 23^{\prime \prime}$ & $106^{\circ} 36^{\prime} 47^{\prime \prime}$ & 8,300 & 11 & $\begin{array}{l}\text { Staurosira construens var. venter (Ehrenberg) } \\
\text { Hamilton }\end{array}$ & 41 & 4,966 \\
\hline 62 & 393523106364700 & West Lake Creek near Edwards & 1 & 2000 & $8 / 15 / 2000$ & $39^{\circ} 35^{\prime} 23^{\prime \prime}$ & $106^{\circ} 36^{\prime} 47^{\prime \prime}$ & 8,300 & 11 & $\begin{array}{l}\text { Staurosirella leptostauron (Ehrenberg) } \\
\text { Williams et Round }\end{array}$ & 14 & 6,731 \\
\hline 62 & 393523106364700 & West Lake Creek near Edwards & 1 & 2000 & $8 / 15 / 2000$ & $39^{\circ} 35^{\prime} 23^{\prime \prime}$ & $106^{\circ} 36^{\prime} 47^{\prime \prime}$ & 8,300 & 11 & $\begin{array}{l}\text { Staurosirella pinnata (Ehrenberg) } \\
\text { Williams et Round }\end{array}$ & 28 & 2,654 \\
\hline 62 & 393523106364700 & West Lake Creek near Edwards & 1 & 2000 & $8 / 15 / 2000$ & $39^{\circ} 35^{\prime} 23^{\prime \prime}$ & $106^{\circ} 36^{\prime} 47^{\prime \prime}$ & 8,300 & 11 & $\begin{array}{l}\text { Unknown Cyanophyte Oscillatoriales } \\
\text { (no sheath) }\end{array}$ & 13,411 & 217,466 \\
\hline 62 & 393523106364700 & West Lake Creek near Edwards & 1 & 2000 & $8 / 15 / 2000$ & $39^{\circ} 35^{\prime} 23^{\prime \prime}$ & $106^{\circ} 36^{\prime} 47^{\prime \prime}$ & 8,300 & 11 & $\begin{array}{l}\text { Unknown Rhodophyte Florideophycidae } \\
\text { (chantransia) }\end{array}$ & 1,370 & $4,850,364$ \\
\hline 63 & 09067200 & Lake Creek near Edwards & 1 & 2000 & $8 / 15 / 2000$ & $39^{\circ} 38^{\prime} 51^{\prime \prime}$ & $106^{\circ} 36^{\prime} 31^{\prime \prime}$ & 7,160 & 49 & $\begin{array}{l}\text { Achnanthidium minutissimum (Kützing) } \\
\text { Czarnecki }\end{array}$ & 138,251 & $7,613,730$ \\
\hline 63 & 09067200 & Lake Creek near Edwards & 1 & 2000 & $8 / 15 / 2000$ & $39^{\circ} 38^{\prime} 51^{\prime \prime}$ & $106^{\circ} 36^{\prime} 31^{\prime \prime}$ & 7,160 & 49 & $\begin{array}{l}\text { Achnanthidium pyrenaicum (Hustedt) } \\
\text { Kobayasi }\end{array}$ & 27,473 & $3,456,353$ \\
\hline 63 & 09067200 & Lake Creek near Edwards & 1 & 2000 & $8 / 15 / 2000$ & $39^{\circ} 38^{\prime} 51^{\prime \prime}$ & $106^{\circ} 36^{\prime} 31^{\prime \prime}$ & 7,160 & 49 & Amphipleura pellucida (Kützing) Kützing & 591 & 668,306 \\
\hline
\end{tabular}




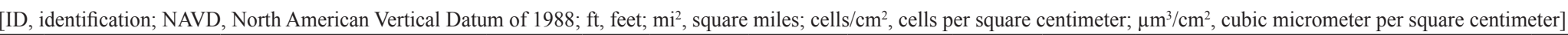

\begin{tabular}{|c|c|c|c|c|c|c|c|c|c|c|c|c|}
\hline $\begin{array}{l}\text { Site } \\
\text { ID' }^{1}\end{array}$ & $\begin{array}{l}\text { USGS } \\
\text { station } \\
\text { number }\end{array}$ & Station name & $\begin{array}{c}\text { Replicate } \\
\text { sample } \\
\text { number }\end{array}$ & Year & $\begin{array}{l}\text { Collection } \\
\text { date }\end{array}$ & Latitude & Longitude & $\begin{array}{c}\text { Elevation } \\
\text { NAVD } 88 \\
\text { (ft) }\end{array}$ & $\begin{array}{c}\text { Drainage } \\
\text { area } \\
\left(\mathrm{mi}^{2}\right)\end{array}$ & Algal taxon name & $\begin{array}{c}\text { Total } \\
\text { density } \\
\text { (number of } \\
\text { cells } / \mathbf{c m}^{2} \text { ) }\end{array}$ & $\begin{array}{c}\text { Total } \\
\text { biovolume } \\
\left(\mathrm{\mu m}^{3} / \mathrm{cm}^{2}\right)\end{array}$ \\
\hline 63 & 09067200 & Lake Creek near Edwards & 1 & 2000 & $8 / 15 / 2000$ & $39^{\circ} 38^{\prime} 51^{\prime \prime}$ & $106^{\circ} 36^{\prime} 31^{\prime \prime}$ & 7,160 & 49 & Amphora pediculus (Kützing) Grunow & 591 & 55,909 \\
\hline 63 & 09067200 & Lake Creek near Edwards & 1 & 2000 & $8 / 15 / 2000$ & $39^{\circ} 38^{\prime} 51^{\prime \prime}$ & $106^{\circ} 36^{\prime} 31^{\prime \prime}$ & 7,160 & 49 & Chlamydomonas sp. & 869 & 73,902 \\
\hline 63 & 09067200 & Lake Creek near Edwards & 1 & 2000 & $8 / 15 / 2000$ & $39^{\circ} 38^{\prime} 51^{\prime \prime}$ & $106^{\circ} 36^{\prime} 31^{\prime \prime}$ & 7,160 & 49 & Closterium sp. & 869 & 73,902 \\
\hline 63 & 09067200 & Lake Creek near Edwards & 1 & 2000 & $8 / 15 / 2000$ & $39^{\circ} 38^{\prime} 51^{\prime \prime}$ & $106^{\circ} 36^{\prime} 31^{\prime \prime}$ & 7,160 & 49 & Cocconeis pediculus Ehrenberg & 591 & $2,043,768$ \\
\hline 63 & 09067200 & Lake Creek near Edwards & 1 & 2000 & $8 / 15 / 2000$ & $39^{\circ} 38^{\prime} 51^{\prime \prime}$ & $106^{\circ} 36^{\prime} 31^{\prime \prime}$ & 7,160 & 49 & $\begin{array}{l}\text { Cocconeis placentula var. lineata (Ehrenberg) } \\
\text { Van Heurck }\end{array}$ & 1,772 & $1,857,083$ \\
\hline 63 & 09067200 & Lake Creek near Edwards & 1 & 2000 & $8 / 15 / 2000$ & $39^{\circ} 38^{\prime} 51^{\prime \prime}$ & $106^{\circ} 36^{\prime} 31^{\prime \prime}$ & 7,160 & 49 & Cymbella affinis Kützing & 2,363 & $1,196,063$ \\
\hline 63 & 09067200 & Lake Creek near Edwards & 1 & 2000 & $8 / 15 / 2000$ & $39^{\circ} 38^{\prime} 51^{\prime \prime}$ & $106^{\circ} 36^{\prime} 31^{\prime \prime}$ & 7,160 & 49 & Denticula tenuis Kützing & 295 & 112,329 \\
\hline 63 & 09067200 & Lake Creek near Edwards & 1 & 2000 & $8 / 15 / 2000$ & $39^{\circ} 38^{\prime} 51^{\prime \prime}$ & $106^{\circ} 36^{\prime} 31^{\prime \prime}$ & 7,160 & 49 & Diatoma tenuis Agardh & 886 & 99,774 \\
\hline 63 & 09067200 & Lake Creek near Edwards & 1 & 2000 & $8 / 15 / 2000$ & $39^{\circ} 38^{\prime} 51 "$ & $106^{\circ} 36^{\prime} 31^{\prime \prime}$ & 7,160 & 49 & Encyonema brehmii (Hustedt) Mann & 1,182 & 32,579 \\
\hline 63 & 09067200 & Lake Creek near Edwards & 1 & 2000 & $8 / 15 / 2000$ & $39^{\circ} 38^{\prime} 51^{\prime \prime}$ & $106^{\circ} 36^{\prime} 31 "$ & 7,160 & 49 & Encyonema minutum (Hilse) Mann & 1,772 & 379,274 \\
\hline 63 & 09067200 & Lake Creek near Edwards & 1 & 2000 & $8 / 15 / 2000$ & $39^{\circ} 38^{\prime} 51^{\prime \prime}$ & $106^{\circ} 36^{\prime} 31^{\prime \prime}$ & 7,160 & 49 & Encyonema silesiacum (Bleisch) Mann & 16,543 & $7,789,212$ \\
\hline 63 & 09067200 & Lake Creek near Edwards & 1 & 2000 & $8 / 15 / 2000$ & $39^{\circ} 38^{\prime} 51^{\prime \prime}$ & $106^{\circ} 36^{\prime} 31 "$ & 7,160 & 49 & $\begin{array}{l}\text { Encyonopsis microcephala (Grunow) } \\
\text { Krammer }\end{array}$ & 2,954 & 184,139 \\
\hline 63 & 09067200 & Lake Creek near Edwards & 1 & 2000 & $8 / 15 / 2000$ & $39^{\circ} 38^{\prime} 51^{\prime \prime}$ & $106^{\circ} 36^{\prime} 31^{\prime \prime}$ & 7,160 & 49 & Fragilaria capucina Desmazières & 6,499 & $1,214,145$ \\
\hline 63 & 09067200 & Lake Creek near Edwards & 1 & 2000 & $8 / 15 / 2000$ & $39^{\circ} 38^{\prime} 51^{\prime \prime}$ & $106^{\circ} 361^{\prime \prime}$ & 7,160 & 49 & Fragilaria vaucheriae (Kützing) Petersen & 4,431 & 916,628 \\
\hline 63 & 09067200 & Lake Creek near Edwards & 1 & 2000 & $8 / 15 / 2000$ & $39^{\circ} 38^{\prime} 51^{\prime \prime}$ & $106^{\circ} 36^{\prime} 31 "$ & 7,160 & 49 & Frustulia vulgaris (Thwaites) deToni & 591 & 917,241 \\
\hline 63 & 09067200 & Lake Creek near Edwards & 1 & 2000 & $8 / 15 / 2000$ & $39^{\circ} 38^{\prime} 51^{\prime \prime}$ & $106^{\circ} 36^{\prime} 31 "$ & 7,160 & 49 & $\begin{array}{l}\text { Gomphonema angustatum (Kützing) } \\
\text { Rabenhorst }\end{array}$ & 591 & 244,261 \\
\hline 63 & 09067200 & Lake Creek near Edwards & 1 & 2000 & $8 / 15 / 2000$ & $39^{\circ} 38^{\prime} 51^{\prime \prime}$ & $106^{\circ} 36^{\prime} 31^{\prime \prime}$ & 7,160 & 49 & Gomphonema olivaceum (Lyngbye) Kützing & 591 & 203,281 \\
\hline 63 & 09067200 & Lake Creek near Edwards & 1 & 2000 & $8 / 15 / 2000$ & $39^{\circ} 38^{\prime} 51^{\prime \prime}$ & $106^{\circ} 36^{\prime} 31^{\prime \prime}$ & 7,160 & 49 & Hannaea arcus (Ehrenberg) Patrick & 1,182 & $2,869,162$ \\
\hline 63 & 09067200 & Lake Creek near Edwards & 1 & 2000 & $8 / 15 / 2000$ & $39^{\circ} 38^{\prime} 51^{\prime \prime}$ & $106^{\circ} 36^{\prime} 31^{\prime \prime}$ & 7,160 & 49 & $\begin{array}{l}\text { Homoeothrix janthina (Bornet et Flahault) } \\
\text { Starmach }\end{array}$ & 159,977 & $5,184,578$ \\
\hline 63 & 09067200 & Lake Creek near Edwards & 1 & 2000 & $8 / 15 / 2000$ & $39^{\circ} 38^{\prime} 51^{\prime \prime}$ & $106^{\circ} 36^{\prime} 31 "$ & 7,160 & 49 & Melosira varians Agardh & 1,182 & $6,415,374$ \\
\hline 63 & 09067200 & Lake Creek near Edwards & 1 & 2000 & $8 / 15 / 2000$ & $39^{\circ} 38^{\prime} 51^{\prime \prime}$ & $106^{\circ} 36^{\prime} 31^{\prime \prime}$ & 7,160 & 49 & $\begin{array}{l}\text { Navicula cryptotenella Lange-Bertalot } \\
\text { ex Krammer et Lange-Bertalot }\end{array}$ & 2,068 & 748,402 \\
\hline 63 & 09067200 & Lake Creek near Edwards & 1 & 2000 & $8 / 15 / 2000$ & $39^{\circ} 38^{\prime} 51^{\prime \prime}$ & $106^{\circ} 36^{\prime} 31^{\prime \prime}$ & 7,160 & 49 & Navicula gregaria Donkin & 591 & 147,690 \\
\hline 63 & 09067200 & Lake Creek near Edwards & 1 & 2000 & $8 / 15 / 2000$ & $39^{\circ} 38^{\prime} 51^{\prime \prime}$ & $106^{\circ} 36^{\prime} 31^{\prime \prime}$ & 7,160 & 49 & Navicula tripunctata (Müller) Bory & 1,477 & $1,397,514$ \\
\hline 63 & 09067200 & Lake Creek near Edwards & 1 & 2000 & $8 / 15 / 2000$ & $39^{\circ} 38^{\prime} 51^{\prime \prime}$ & $106^{\circ} 36^{\prime} 31^{\prime \prime}$ & 7,160 & 49 & Navicula upsaliensis (Grunow) Peragallo & 591 & 111,539 \\
\hline 63 & 09067200 & Lake Creek near Edwards & 1 & 2000 & $8 / 15 / 2000$ & $39^{\circ} 38^{\prime} 51^{\prime \prime}$ & $106^{\circ} 36^{\prime} 31 "$ & 7,160 & 49 & Nitzschia dissipata (Kützing) Grunow & 591 & 153,635 \\
\hline 63 & 09067200 & Lake Creek near Edwards & 1 & 2000 & $8 / 15 / 2000$ & $39^{\circ} 38^{\prime} 51^{\prime \prime}$ & $106^{\circ} 36^{\prime} 31^{\prime \prime}$ & 7,160 & 49 & Nitzschia inconspicua Grunow & 1,182 & 63,415 \\
\hline 63 & 09067200 & Lake Creek near Edwards & 1 & 2000 & $8 / 15 / 2000$ & $39^{\circ} 38^{\prime} 51^{\prime \prime}$ & $106^{\circ} 36^{\prime} 31^{\prime \prime}$ & 7,160 & 49 & Nitzschia palea (Kützing) Smith & 591 & 102,395 \\
\hline 63 & 09067200 & Lake Creek near Edwards & 1 & 2000 & $8 / 15 / 2000$ & $39^{\circ} 38^{\prime} 51^{\prime \prime}$ & $106^{\circ} 36^{\prime} 31^{\prime \prime}$ & 7,160 & 49 & Phormidium autumnale (Agardh) Gomont & 123,460 & $12,090,365$ \\
\hline 63 & 09067200 & Lake Creek near Edwards & 1 & 2000 & $8 / 15 / 2000$ & $39^{\circ} 38^{\prime} 51^{\prime \prime}$ & $106^{\circ} 36^{\prime} 31^{\prime \prime}$ & 7,160 & 49 & $\begin{array}{l}\text { Reimeria sinuata (Gregory) } \\
\text { Kociolek et Stoermer }\end{array}$ & 2,659 & 439,593 \\
\hline 63 & 09067200 & Lake Creek near Edwards & 1 & 2000 & $8 / 15 / 2000$ & $39^{\circ} 38^{\prime} 51^{\prime \prime}$ & $106^{\circ} 36^{\prime} 31^{\prime \prime}$ & 7,160 & 49 & $\begin{array}{l}\text { Staurosira construens var. venter (Ehrenberg) } \\
\text { Hamilton }\end{array}$ & 7,090 & 851,518 \\
\hline 63 & 09067200 & Lake Creek near Edwards & 1 & 2000 & $8 / 15 / 2000$ & $39^{\circ} 38^{\prime} 51^{\prime \prime}$ & $106^{\circ} 36^{\prime} 31^{\prime \prime}$ & 7,160 & 49 & $\begin{array}{l}\text { Staurosirella leptostauron (Ehrenberg) } \\
\text { Williams et Round }\end{array}$ & 1,182 & 577,144 \\
\hline 63 & 09067200 & Lake Creek near Edwards & 1 & 2000 & $8 / 15 / 2000$ & $39^{\circ} 38^{\prime} 51 "$ & $106^{\circ} 36^{\prime} 31^{\prime \prime}$ & 7,160 & 49 & Synedra ulna (Nitzsch) Ehrenberg & 1,182 & $7,747,464$ \\
\hline 63 & 09067200 & Lake Creek near Edwards & 1 & 2000 & $8 / 15 / 2000$ & $39^{\circ} 38^{\prime} 51^{\prime \prime}$ & $106^{\circ} 36^{\prime} 31^{\prime \prime}$ & 7,160 & 49 & $\begin{array}{l}\text { Unknown Cyanophyte Oscillatoriales } \\
\text { (no sheath) }\end{array}$ & 493,841 & $8,007,796$ \\
\hline 63 & 09067200 & Lake Creek near Edwards & 1 & 2000 & $8 / 15 / 2000$ & $39^{\circ} 38^{\prime} 51^{\prime \prime}$ & $106^{\circ} 36^{\prime} 31^{\prime \prime}$ & 7,160 & 49 & $\begin{array}{l}\text { Unknown Rhodophyte Florideophycidae } \\
\text { (chantransia) }\end{array}$ & 6,086 & $21,539,667$ \\
\hline 63 & 09067200 & Lake Creek near Edwards & 1 & 2001 & $8 / 15 / 2001$ & $39^{\circ} 38^{\prime} 51^{\prime \prime}$ & $106^{\circ} 36^{\prime} 31^{\prime \prime}$ & 7,160 & 49 & $\begin{array}{l}\text { Achnanthidium minutissimum (Kützing) } \\
\text { Czarnecki }\end{array}$ & 93,730 & $5,082,135$ \\
\hline 63 & 09067200 & Lake Creek near Edwards & 1 & 2001 & $8 / 15 / 2001$ & $39^{\circ} 38^{\prime} 51^{\prime \prime}$ & $106^{\circ} 36^{\prime} 31^{\prime \prime}$ & 7,160 & 49 & $\begin{array}{l}\text { Achnanthidium pyrenaicum (Hustedt) } \\
\text { Kobayasi }\end{array}$ & 424 & 53,592 \\
\hline
\end{tabular}


Table 2. Description of sites and algal data collected from selected sites the Eagle River watershed, Colorado, 2000-2001.—Continued

[ID, identification; NAVD, North American Vertical Datum of 1988; ft, feet; $\mathrm{mi}^{2}$, square miles; cells $/ \mathrm{cm}^{2}$, cells per square centimeter; $\mu \mathrm{m}^{3} / \mathrm{cm}^{2}$, cubic micrometer per square centimeter]

\begin{tabular}{|c|c|c|c|c|c|c|c|c|c|c|c|c|}
\hline $\begin{array}{l}\text { Site } \\
\text { ID' }^{1}\end{array}$ & $\begin{array}{l}\text { USGS } \\
\text { station } \\
\text { number }\end{array}$ & Station name & $\begin{array}{c}\text { Replicate } \\
\text { sample } \\
\text { number }\end{array}$ & Year & $\begin{array}{l}\text { Collection } \\
\text { date }\end{array}$ & Latitude & Longitude & $\begin{array}{c}\text { Elevation } \\
\text { NAVD } 88 \\
\text { (ft) }\end{array}$ & $\begin{array}{c}\text { Drainage } \\
\text { area } \\
\left(\mathrm{mi}^{2}\right)\end{array}$ & Algal taxon name & $\begin{array}{c}\text { Total } \\
\text { density } \\
\text { (number of } \\
\text { cells } / \mathrm{cm}^{2} \text { ) }\end{array}$ & $\begin{array}{c}\text { Total } \\
\text { biovolume } \\
\left(\mu \mathrm{m}^{3} / \mathrm{cm}^{2}\right)\end{array}$ \\
\hline 63 & 09067200 & Lake Creek near Edwards & 1 & 2001 & $8 / 15 / 2001$ & $39^{\circ} 38^{\prime} 51^{\prime \prime}$ & $106^{\circ} 36^{\prime} 31^{\prime \prime}$ & 7,160 & 49 & Amphora pediculus (Kützing) Grunow & 424 & 41,006 \\
\hline 63 & 09067200 & Lake Creek near Edwards & 1 & 2001 & $8 / 15 / 2001$ & $39^{\circ} 38^{\prime} 51^{\prime \prime}$ & $106^{\circ} 36^{\prime} 31^{\prime \prime}$ & 7,160 & 49 & Chlamydomonas sp. & 625 & $1,237,280$ \\
\hline 63 & 09067200 & Lake Creek near Edwards & 1 & 2001 & $8 / 15 / 2001$ & $39^{\circ} 38^{\prime} 51 "$ & $106^{\circ} 36^{\prime} 31^{\prime \prime}$ & 7,160 & 49 & Cladophora glomerata (Linnaeus) Kützing & 1,875 & $7,372,435,079$ \\
\hline 63 & 09067200 & Lake Creek near Edwards & 1 & 2001 & $8 / 15 / 2001$ & $39^{\circ} 38^{\prime} 51^{\prime \prime}$ & $106^{\circ} 36^{\prime} 31^{\prime \prime}$ & 7,160 & 49 & $\begin{array}{l}\text { Cocconeis placentula var. lineata (Ehrenberg) } \\
\text { Van Heurck }\end{array}$ & 1,272 & $1,341,817$ \\
\hline 63 & 09067200 & Lake Creek near Edwards & 1 & 2001 & $8 / 15 / 2001$ & $39^{\circ} 38^{\prime} 51^{\prime \prime}$ & $106^{\circ} 361^{\prime \prime}$ & 7,160 & 49 & Diatoma vulgaris Bory & 212 & 783,541 \\
\hline 63 & 09067200 & Lake Creek near Edwards & 1 & 2001 & $8 / 15 / 2001$ & $39^{\circ} 38^{\prime} 51 "$ & $106^{\circ} 36^{\prime} 31^{\prime \prime}$ & 7,160 & 49 & Encyonema brehmii (Hustedt) Mann & 848 & 23,387 \\
\hline 63 & 09067200 & Lake Creek near Edwards & 1 & 2001 & $8 / 15 / 2001$ & $39^{\circ} 38^{\prime} 51 "$ & $106^{\circ} 36^{\prime} 31^{\prime \prime}$ & 7,160 & 49 & Encyonema latens (Krasske) Mann & 424 & 786,316 \\
\hline 63 & 09067200 & Lake Creek near Edwards & 1 & 2001 & $8 / 15 / 2001$ & $39^{\circ} 38^{\prime} 51 "$ & $106^{\circ} 36^{\prime} 31^{\prime \prime}$ & 7,160 & 49 & Encyonema minutum (Hilse) Mann & 1,060 & 228,848 \\
\hline 63 & 09067200 & Lake Creek near Edwards & 1 & 2001 & $8 / 15 / 2001$ & $39^{\circ} 38^{\prime} 51 "$ & $106^{\circ} 361^{\prime \prime}$ & 7,160 & 49 & Encyonema silesiacum (Bleisch) Mann & 20,146 & $9,568,076$ \\
\hline 63 & 09067200 & Lake Creek near Edwards & 1 & 2001 & $8 / 15 / 2001$ & $39^{\circ} 38^{\prime} 51 "$ & $106^{\circ} 36^{\prime} 31^{\prime \prime}$ & 7,160 & 49 & Eucocconeis laevis (Østrup) Lange-Bertalot & 424 & 633,209 \\
\hline 63 & 09067200 & Lake Creek near Edwards & 1 & 2001 & $8 / 15 / 2001$ & $39^{\circ} 38^{\prime} 51^{\prime \prime}$ & $106^{\circ} 36^{\prime} 31^{\prime \prime}$ & 7,160 & 49 & Fragilaria vaucheriae (Kützing) Petersen & 2,969 & 584,893 \\
\hline 63 & 09067200 & Lake Creek near Edwards & 1 & 2001 & $8 / 15 / 2001$ & $39^{\circ} 38^{\prime} 51^{\prime \prime}$ & $106^{\circ} 36 ' 31 "$ & 7,160 & 49 & $\begin{array}{l}\text { Homoeothrix janthina (Bornet et Flahault) } \\
\text { Starmach }\end{array}$ & 727,642 & $12,525,388$ \\
\hline 63 & 09067200 & Lake Creek near Edwards & 1 & 2001 & $8 / 15 / 2001$ & $39^{\circ} 38^{\prime} 51^{\prime \prime}$ & $106^{\circ} 36^{\prime} 31^{\prime \prime}$ & 7,160 & 49 & $\begin{array}{l}\text { Navicula cryptotenella Lange-Bertalot } \\
\text { ex Krammer et Lange-Bertalot }\end{array}$ & 2,545 & 675,930 \\
\hline 63 & 09067200 & Lake Creek near Edwards & 1 & 2001 & $8 / 15 / 2001$ & $39^{\circ} 38^{\prime} 51^{\prime \prime}$ & $106^{\circ} 361^{\prime \prime}$ & 7,160 & 49 & Navicula tripunctata (Müller) Bory & 2,333 & $2,121,160$ \\
\hline 63 & 09067200 & Lake Creek near Edwards & 1 & 2001 & $8 / 15 / 2001$ & $39^{\circ} 38^{\prime} 51 "$ & $106^{\circ} 36^{\prime} 31^{\prime \prime}$ & 7,160 & 49 & Nitzschia dissipata (Kützing) Grunow & 424 & 109,353 \\
\hline 63 & 09067200 & Lake Creek near Edwards & 1 & 2001 & $8 / 15 / 2001$ & $39^{\circ} 38^{\prime} 51^{\prime \prime}$ & $106^{\circ} 36^{\prime} 31^{\prime \prime}$ & 7,160 & 49 & Nitzschia fonticola Grunow & 848 & 84,379 \\
\hline 63 & 09067200 & Lake Creek near Edwards & 1 & 2001 & $8 / 15 / 2001$ & $39^{\circ} 38^{\prime} 51^{\prime \prime}$ & $106^{\circ} 36^{\prime} 31^{\prime \prime}$ & 7,160 & 49 & Nitzschia palea var. debilis (Kützing) Grunow & 424 & 73,867 \\
\hline 63 & 09067200 & Lake Creek near Edwards & 1 & 2001 & $8 / 15 / 2001$ & $39^{\circ} 38^{\prime} 51^{\prime \prime}$ & $106^{\circ} 36^{\prime} 31^{\prime \prime}$ & 7,160 & 49 & Nitzschia paleaeformis Hustedt & 424 & 75,921 \\
\hline 63 & 09067200 & Lake Creek near Edwards & 1 & 2001 & $8 / 15 / 2001$ & $39^{\circ} 38^{\prime} 51 "$ & $106^{\circ} 36^{\prime} 31^{\prime \prime}$ & 7,160 & 49 & Oscillatoria sp. & 8,752 & $1,137,814$ \\
\hline 63 & 09067200 & Lake Creek near Edwards & 1 & 2001 & $8 / 15 / 2001$ & $39^{\circ} 38^{\prime} 51^{\prime \prime}$ & $106^{\circ} 36^{\prime} 31^{\prime \prime}$ & 7,160 & 49 & Phormidium autumnale (Agardh) Gomont & 30,631 & $2,969,834$ \\
\hline 63 & 09067200 & Lake Creek near Edwards & 1 & 2001 & $8 / 15 / 2001$ & $39^{\circ} 38^{\prime} 51^{\prime \prime}$ & $106^{\circ} 36^{\prime} 31^{\prime \prime}$ & 7,160 & 49 & $\begin{array}{l}\text { Reimeria sinuata (Gregory) } \\
\text { Kociolek et Stoermer }\end{array}$ & 1,484 & 250,183 \\
\hline 63 & 09067200 & Lake Creek near Edwards & 1 & 2001 & $8 / 15 / 2001$ & $39^{\circ} 38^{\prime} 51 "$ & $106^{\circ} 361^{\prime \prime}$ & 7,160 & 49 & Scenedesmus ecornis (Ralfs) Chodat & 2,500 & 58,221 \\
\hline 63 & 09067200 & Lake Creek near Edwards & 1 & 2001 & $8 / 15 / 2001$ & $39^{\circ} 38^{\prime} 51^{\prime \prime}$ & $106^{\circ} 36^{\prime} 31^{\prime \prime}$ & 7,160 & 49 & $\begin{array}{l}\text { Staurosira construens var. venter (Ehrenberg) } \\
\text { Hamilton }\end{array}$ & 1,060 & 127,347 \\
\hline 63 & 09067200 & Lake Creek near Edwards & 1 & 2001 & $8 / 15 / 2001$ & $39^{\circ} 38^{\prime} 51^{\prime \prime}$ & $106^{\circ} 36^{\prime} 31^{\prime \prime}$ & 7,160 & 49 & $\begin{array}{l}\text { Staurosirella pinnata (Ehrenberg) } \\
\text { Williams et Round }\end{array}$ & 424 & 40,956 \\
\hline 63 & 09067200 & Lake Creek near Edwards & 1 & 2001 & $8 / 15 / 2001$ & $39^{\circ} 38^{\prime} 51^{\prime \prime}$ & $106^{\circ} 36^{\prime} 31^{\prime \prime}$ & 7,160 & 49 & Stigeoclonium lubricum (Dillwyn) Kützing & 11,877 & $21,007,657$ \\
\hline 63 & 09067200 & Lake Creek near Edwards & 1 & 2001 & $8 / 15 / 2001$ & $39^{\circ} 38^{\prime} 51 "$ & $106^{\circ} 36^{\prime} 31^{\prime \prime}$ & 7,160 & 49 & Unknown alga flagellate $(<10 \mu)$ & 1,250 & 120,152 \\
\hline 66 & 393930106382001 & $\begin{array}{l}\text { Squaw Creek at mouth } \\
\text { near Edwards }\end{array}$ & 1 & 2000 & $8 / 15 / 2000$ & $39^{\circ} 39^{\prime} 30^{\prime \prime}$ & $106^{\circ} 38^{\prime} 20^{\prime \prime}$ & 7,120 & 17.4 & $\begin{array}{l}\text { Achnanthidium minutissimum (Kützing) } \\
\text { Czarnecki }\end{array}$ & 9,701 & 534,261 \\
\hline 66 & 393930106382001 & $\begin{array}{l}\text { Squaw Creek at mouth } \\
\text { near Edwards }\end{array}$ & 1 & 2000 & $8 / 15 / 2000$ & $39^{\circ} 39^{\prime} 30^{\prime \prime}$ & $106^{\circ} 38^{\prime} 20^{\prime \prime}$ & 7,120 & 17.4 & Amphora pediculus (Kützing) Grunow & 21,976 & $2,079,596$ \\
\hline 66 & 393930106382001 & $\begin{array}{l}\text { Squaw Creek at mouth } \\
\text { near Edwards }\end{array}$ & 1 & 2000 & $8 / 15 / 2000$ & $39^{\circ} 39^{\prime} 30^{\prime \prime}$ & $106^{\circ} 38^{\prime} 20^{\prime \prime}$ & 7,120 & 17.4 & Amphora submontana Hustedt & 198 & 52,964 \\
\hline 66 & 393930106382001 & $\begin{array}{l}\text { Squaw Creek at mouth } \\
\text { near Edwards }\end{array}$ & 1 & 2000 & $8 / 15 / 2000$ & $39^{\circ} 39^{\prime} 30^{\prime \prime}$ & $106^{\circ} 38^{\prime} 20^{\prime \prime}$ & 7,120 & 17.4 & $\begin{array}{l}\text { Chamaepinnularia bremensis (Hustedt) } \\
\text { Lange-Bertalot }\end{array}$ & 198 & 4,633 \\
\hline 66 & 393930106382001 & $\begin{array}{l}\text { Squaw Creek at mouth } \\
\text { near Edwards }\end{array}$ & 1 & 2000 & $8 / 15 / 2000$ & $39^{\circ} 39^{\prime} 30^{\prime \prime}$ & $106^{\circ} 38^{\prime} 20^{\prime \prime}$ & 7,120 & 17.4 & Chlamydomonas sp. & 2,224 & 189,021 \\
\hline 66 & 393930106382001 & $\begin{array}{l}\text { Squaw Creek at mouth } \\
\text { near Edwards }\end{array}$ & 1 & 2000 & $8 / 15 / 2000$ & $39^{\circ} 39^{\prime} 30^{\prime \prime}$ & $106^{\circ} 38^{\prime} 20^{\prime \prime}$ & 7,120 & 17.4 & Cladophora glomerata (Linnaeus) Kützing & 4,448 & $24,143,551,235$ \\
\hline 66 & 393930106382001 & $\begin{array}{l}\text { Squaw Creek at mouth } \\
\text { near Edwards }\end{array}$ & 1 & 2000 & $8 / 15 / 2000$ & $39^{\circ} 39^{\prime} 30^{\prime \prime}$ & $106^{\circ} 38^{\prime} 20^{\prime \prime}$ & 7,120 & 17.4 & Cocconeis pediculus Ehrenberg & 10,691 & $36,982,943$ \\
\hline 66 & 393930106382001 & $\begin{array}{l}\text { Squaw Creek at mouth } \\
\text { near Edwards }\end{array}$ & 1 & 2000 & $8 / 15 / 2000$ & $39^{\circ} 39^{\prime} 30^{\prime \prime}$ & $106^{\circ} 38^{\prime} 20^{\prime \prime}$ & 7,120 & 17.4 & $\begin{array}{l}\text { Cocconeis placentula var. euglypta } \\
\text { (Ehrenberg) Grunow }\end{array}$ & 13,463 & $8,110,655$ \\
\hline
\end{tabular}

near Edwards 
Table 2. Description of sites and algal data collected from selected sites the Eagle River watershed, Colorado, 2000-2001.—Continued

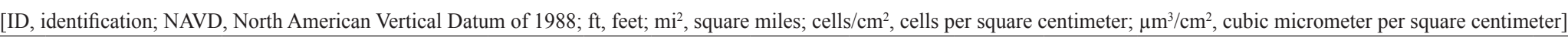

\begin{tabular}{|c|c|c|c|c|c|c|c|c|c|c|c|c|}
\hline $\begin{array}{l}\text { Site } \\
\text { ID }^{1}\end{array}$ & $\begin{array}{l}\text { USGS } \\
\text { station } \\
\text { number }\end{array}$ & Station name & $\begin{array}{c}\text { Replicate } \\
\text { sample } \\
\text { number }\end{array}$ & Year & $\begin{array}{l}\text { Collection } \\
\text { date }\end{array}$ & Latitude & Longitude & $\begin{array}{c}\text { Elevation } \\
\text { NAVD } 88 \\
\text { (ft) }\end{array}$ & $\begin{array}{c}\text { Drainage } \\
\text { area } \\
\left(\mathrm{mi}^{2}\right)\end{array}$ & Algal taxon name & $\begin{array}{c}\text { Total } \\
\text { density } \\
\text { (number of } \\
\text { cells/cm²) }\end{array}$ & $\begin{array}{c}\text { Total } \\
\text { biovolume } \\
\left(\mu \mathrm{m}^{3} / \mathrm{cm}^{2}\right)\end{array}$ \\
\hline 66 & 393930106382001 & $\begin{array}{l}\text { Squaw Creek at mouth } \\
\text { near Edwards }\end{array}$ & 1 & 2000 & $8 / 15 / 2000$ & $39^{\circ} 39^{\prime} 30^{\prime \prime}$ & $106^{\circ} 38^{\prime} 20^{\prime \prime}$ & 7,120 & 17.4 & $\begin{array}{l}\text { Cocconeis placentula var. lineata (Ehrenberg) } \\
\text { Van Heurck }\end{array}$ & 792 & 829,748 \\
\hline 66 & 393930106382001 & $\begin{array}{l}\text { Squaw Creek at mouth } \\
\text { near Edwards }\end{array}$ & 1 & 2000 & $8 / 15 / 2000$ & $39^{\circ} 39^{\prime} 30^{\prime \prime}$ & $106^{\circ} 38^{\prime} 20^{\prime \prime}$ & 7,120 & 17.4 & Gomphonema minutum (Agardh) Agardh & 792 & 137,369 \\
\hline 66 & 393930106382001 & $\begin{array}{l}\text { Squaw Creek at mouth } \\
\text { near Edwards }\end{array}$ & 1 & 2000 & $8 / 15 / 2000$ & $39^{\circ} 39^{\prime} 30^{\prime \prime}$ & $106^{\circ} 38^{\prime} 20^{\prime \prime}$ & 7,120 & 17.4 & Gomphonema olivaceum (Lyngbye) Kützing & 7,127 & $2,452,310$ \\
\hline 66 & 393930106382001 & $\begin{array}{l}\text { Squaw Creek at mouth } \\
\text { near Edwards }\end{array}$ & 1 & 2000 & $8 / 15 / 2000$ & $39^{\circ} 39^{\prime} 30^{\prime \prime}$ & $106^{\circ} 38^{\prime} 20^{\prime \prime}$ & 7,120 & 17.4 & $\begin{array}{l}\text { Hippodonta capitata } \text { (Ehrenberg) } \\
\text { Lange-Bertalot, Metzeltin et Witkowski }\end{array}$ & 396 & 313,457 \\
\hline 66 & 393930106382001 & $\begin{array}{l}\text { Squaw Creek at mouth } \\
\text { near Edwards }\end{array}$ & 1 & 2000 & $8 / 15 / 2000$ & $39^{\circ} 39^{\prime} 30^{\prime \prime}$ & $106^{\circ} 38^{\prime} 20^{\prime \prime}$ & 7,120 & 17.4 & $\begin{array}{l}\text { Homoeothrix janthina (Bornet et Flahault) } \\
\text { Starmach }\end{array}$ & 157,888 & $5,116,884$ \\
\hline 66 & 393930106382001 & $\begin{array}{l}\text { Squaw Creek at mouth } \\
\text { near Edwards }\end{array}$ & 1 & 2000 & $8 / 15 / 2000$ & $39^{\circ} 39^{\prime} 30^{\prime \prime}$ & $106^{\circ} 38^{\prime} 20^{\prime \prime}$ & 7,120 & 17.4 & Mayamaea atomus (Kützing) Lange-Bertalot & 396 & 10,342 \\
\hline 66 & 393930106382001 & $\begin{array}{l}\text { Squaw Creek at mouth } \\
\text { near Edwards }\end{array}$ & 1 & 2000 & $8 / 15 / 2000$ & $39^{\circ} 39^{\prime} 30^{\prime \prime}$ & $106^{\circ} 38^{\prime} 20^{\prime \prime}$ & 7,120 & 17.4 & Melosira varians Agardh & 1,386 & $7,524,300$ \\
\hline 66 & 393930106382001 & $\begin{array}{l}\text { Squaw Creek at mouth } \\
\text { near Edwards }\end{array}$ & 1 & 2000 & $8 / 15 / 2000$ & $39^{\circ} 39^{\prime} 30^{\prime \prime}$ & $106^{\circ} 38^{\prime} 20^{\prime \prime}$ & 7,120 & 17.4 & Navicula canalis Patrick & 396 & $2,970,141$ \\
\hline 66 & 393930106382001 & $\begin{array}{l}\text { Squaw Creek at mouth } \\
\text { near Edwards }\end{array}$ & 1 & 2000 & $8 / 15 / 2000$ & $39^{\circ} 39^{\prime} 30^{\prime \prime}$ & $106^{\circ} 38^{\prime} 20^{\prime \prime}$ & 7,120 & 17.4 & Navicula capitatoradiata Germain & 1,980 & 737,310 \\
\hline 66 & 393930106382001 & $\begin{array}{l}\text { Squaw Creek at mouth } \\
\text { near Edwards }\end{array}$ & 1 & 2000 & $8 / 15 / 2000$ & $39^{\circ} 39^{\prime} 30^{\prime \prime}$ & $106^{\circ} 38^{\prime} 20^{\prime \prime}$ & 7,120 & 17.4 & $\begin{array}{l}\text { Navicula cryptotenella Lange-Bertalot } \\
\text { ex Krammer et Lange-Bertalot }\end{array}$ & 13,265 & $4,800,845$ \\
\hline 66 & 393930106382001 & $\begin{array}{l}\text { Squaw Creek at mouth } \\
\text { near Edwards }\end{array}$ & 1 & 2000 & $8 / 15 / 2000$ & $39^{\circ} 39^{\prime} 30^{\prime \prime}$ & $106^{\circ} 38^{\prime} 20^{\prime \prime}$ & 7,120 & 17.4 & Navicula gregaria Donkin & 2,178 & 544,404 \\
\hline 66 & 393930106382001 & $\begin{array}{l}\text { Squaw Creek at mouth } \\
\text { near Edwards }\end{array}$ & 1 & 2000 & $8 / 15 / 2000$ & $39^{\circ} 39^{\prime} 30^{\prime \prime}$ & $106^{\circ} 38^{\prime} 20^{\prime \prime}$ & 7,120 & 17.4 & Navicula lanceolata (Agardh) Ehrenberg & 594 & 746,641 \\
\hline 66 & 393930106382001 & $\begin{array}{l}\text { Squaw Creek at mouth } \\
\text { near Edwards }\end{array}$ & 1 & 2000 & $8 / 15 / 2000$ & $39^{\circ} 39^{\prime} 30^{\prime \prime}$ & $106^{\circ} 38^{\prime} 20^{\prime \prime}$ & 7,120 & 17.4 & Navicula tripunctata (Müller) Bory & 13,265 & $12,550,677$ \\
\hline 66 & 393930106382001 & $\begin{array}{l}\text { Squaw Creek at mouth } \\
\text { near Edwards }\end{array}$ & 1 & 2000 & $8 / 15 / 2000$ & $39^{\circ} 39^{\prime} 30^{\prime \prime}$ & $106^{\circ} 38^{\prime} 20^{\prime \prime}$ & 7,120 & 17.4 & Navicula upsaliensis (Grunow) Peragallo & 198 & 37,377 \\
\hline 66 & 393930106382001 & $\begin{array}{l}\text { Squaw Creek at mouth } \\
\text { near Edwards }\end{array}$ & 1 & 2000 & $8 / 15 / 2000$ & $39^{\circ} 39^{\prime} 30^{\prime \prime}$ & $106^{\circ} 38^{\prime} 20^{\prime \prime}$ & 7,120 & 17.4 & Nitzschia capitellata Hustedt & 792 & 331,143 \\
\hline 66 & 393930106382001 & $\begin{array}{l}\text { Squaw Creek at mouth } \\
\text { near Edwards }\end{array}$ & 1 & 2000 & $8 / 15 / 2000$ & $39^{\circ} 39^{\prime} 30^{\prime \prime}$ & $106^{\circ} 38^{\prime} 20^{\prime \prime}$ & 7,120 & 17.4 & Nitzschia dissipata (Kützing) Grunow & 7,523 & $1,956,367$ \\
\hline 66 & 393930106382001 & $\begin{array}{l}\text { Squaw Creek at mouth } \\
\text { near Edwards }\end{array}$ & 1 & 2000 & $8 / 15 / 2000$ & $39^{\circ} 39^{\prime} 30^{\prime \prime}$ & $106^{\circ} 38^{\prime} 20^{\prime \prime}$ & 7,120 & 17.4 & $\begin{array}{l}\text { Nitzschia dissipata var. media (Hantzsch) } \\
\text { Grunow }\end{array}$ & 2,178 & $1,050,473$ \\
\hline 66 & 393930106382001 & $\begin{array}{l}\text { Squaw Creek at mouth } \\
\text { near Edwards }\end{array}$ & 1 & 2000 & $8 / 15 / 2000$ & $39^{\circ} 39^{\prime} 30^{\prime \prime}$ & $106^{\circ} 38^{\prime} 20^{\prime \prime}$ & 7,120 & 17.4 & Nitzschia flexoides Geitler & 396 & $4,638,345$ \\
\hline 66 & 393930106382001 & $\begin{array}{l}\text { Squaw Creek at mouth } \\
\text { near Edwards }\end{array}$ & 1 & 2000 & $8 / 15 / 2000$ & $39^{\circ} 39^{\prime} 30^{\prime \prime}$ & $106^{\circ} 38^{\prime} 20^{\prime \prime}$ & 7,120 & 17.4 & Nitzschia fonticola Grunow & 396 & 39,321 \\
\hline 66 & 393930106382001 & $\begin{array}{l}\text { Squaw Creek at mouth } \\
\text { near Edwards }\end{array}$ & 1 & 2000 & $8 / 15 / 2000$ & $39^{\circ} 39^{\prime} 30^{\prime \prime}$ & $106^{\circ} 38^{\prime} 20^{\prime \prime}$ & 7,120 & 17.4 & Nitzschia inconspicua Grunow & 792 & 42,501 \\
\hline 66 & 393930106382001 & $\begin{array}{l}\text { Squaw Creek at mouth } \\
\text { near Edwards }\end{array}$ & 1 & 2000 & $8 / 15 / 2000$ & $39^{\circ} 39^{\prime} 30^{\prime \prime}$ & $106^{\circ} 38^{\prime} 20^{\prime \prime}$ & 7,120 & 17.4 & $\begin{array}{l}\text { Nitzschia linearis (Agardh ex Wm. Smith) } \\
\text { Wm. Smith }\end{array}$ & 1,188 & $3,072,254$ \\
\hline 66 & 393930106382001 & $\begin{array}{l}\text { Squaw Creek at mouth } \\
\text { near Edwards }\end{array}$ & 1 & 2000 & $8 / 15 / 2000$ & $39^{\circ} 39^{\prime} 30^{\prime \prime}$ & $106^{\circ} 38^{\prime} 20^{\prime \prime}$ & 7,120 & 17.4 & Nitzschia palea (Kützing) Smith & 5,148 & 892,130 \\
\hline 66 & 393930106382001 & $\begin{array}{l}\text { Squaw Creek at mouth } \\
\text { near Edwards }\end{array}$ & 1 & 2000 & $8 / 15 / 2000$ & $39^{\circ} 39^{\prime} 30^{\prime \prime}$ & $106^{\circ} 38^{\prime} 20^{\prime \prime}$ & 7,120 & 17.4 & Nitzschia recta Hantzsch ex Rabenhorst & 594 & $1,030,688$ \\
\hline
\end{tabular}


Table 2. Description of sites and algal data collected from selected sites the Eagle River watershed, Colorado, 2000-2001.—Continued

[ID, identification; NAVD, North American Vertical Datum of 1988; ft, feet; $\mathrm{mi}^{2}$, square miles; cells $/ \mathrm{cm}^{2}$, cells per square centimeter; $\mu \mathrm{m}^{3} / \mathrm{cm}^{2}$, cubic micrometer per square centimeter]

\begin{tabular}{|c|c|c|c|c|c|c|c|c|c|c|c|c|}
\hline $\begin{array}{l}\text { Site } \\
\text { ID }^{1}\end{array}$ & $\begin{array}{l}\text { USGS } \\
\text { station } \\
\text { number }\end{array}$ & Station name & $\begin{array}{c}\text { Replicate } \\
\text { sample } \\
\text { number }\end{array}$ & Year & $\begin{array}{l}\text { Collection } \\
\text { date }\end{array}$ & Latitude & Longitude & $\begin{array}{c}\text { Elevation } \\
\text { NAVD } 88 \\
\text { (ft) }\end{array}$ & $\begin{array}{c}\text { Drainage } \\
\text { area } \\
\left(\mathrm{mi}^{2}\right)\end{array}$ & Algal taxon name & $\begin{array}{c}\text { Total } \\
\text { density } \\
\text { (number of } \\
\text { cells/cm²) }\end{array}$ & $\begin{array}{c}\text { Total } \\
\text { biovolume } \\
\left(\mu \mathrm{m}^{3} / \mathrm{cm}^{2}\right)\end{array}$ \\
\hline 66 & 393930106382001 & $\begin{array}{l}\text { Squaw Creek at mouth } \\
\text { near Edwards }\end{array}$ & 1 & 2000 & $8 / 15 / 2000$ & $39^{\circ} 39^{\prime} 30^{\prime \prime}$ & $106^{\circ} 38^{\prime} 20^{\prime \prime}$ & 7,120 & 17.4 & Phormidium autumnale (Agardh) Gomont & 849,481 & $83,189,029$ \\
\hline 66 & 393930106382001 & $\begin{array}{l}\text { Squaw Creek at mouth } \\
\text { near Edwards }\end{array}$ & 1 & 2000 & $8 / 15 / 2000$ & $39^{\circ} 39^{\prime} 30^{\prime \prime}$ & $106^{\circ} 38^{\prime} 20^{\prime \prime}$ & 7,120 & 17.4 & $\begin{array}{l}\text { Planothidium lanceolatum (Brébisson } \\
\text { ex Kützing) Lange-Bertalot }\end{array}$ & 1,584 & 226,242 \\
\hline 66 & 393930106382001 & $\begin{array}{l}\text { Squaw Creek at mouth } \\
\text { near Edwards }\end{array}$ & 1 & 2000 & $8 / 15 / 2000$ & $39^{\circ} 39^{\prime} 30^{\prime \prime}$ & $106^{\circ} 38^{\prime} 20^{\prime \prime}$ & 7,120 & 17.4 & $\begin{array}{l}\text { Reimeria sinuata (Gregory) } \\
\text { Kociolek et Stoermer }\end{array}$ & 396 & 65,470 \\
\hline 66 & 393930106382001 & $\begin{array}{l}\text { Squaw Creek at mouth } \\
\text { near Edwards }\end{array}$ & 1 & 2000 & $8 / 15 / 2000$ & $39^{\circ} 39^{\prime} 30^{\prime \prime}$ & $106^{\circ} 38^{\prime} 20^{\prime \prime}$ & 7,120 & 17.4 & Sellaphora hustedtii (Krasske) Lange-Bertalot & 594 & 77,207 \\
\hline 66 & 393930106382001 & $\begin{array}{l}\text { Squaw Creek at mouth } \\
\text { near Edwards }\end{array}$ & 1 & 2000 & $8 / 15 / 2000$ & $39^{\circ} 39^{\prime} 30^{\prime \prime}$ & $106^{\circ} 38^{\prime} 20^{\prime \prime}$ & 7,120 & 17.4 & Sellaphora pupula (Kützing) Meresckowsky & 1,980 & $1,259,648$ \\
\hline 66 & 393930106382001 & $\begin{array}{l}\text { Squaw Creek at mouth } \\
\text { near Edwards }\end{array}$ & 1 & 2000 & $8 / 15 / 2000$ & $39^{\circ} 39^{\prime} 30^{\prime \prime}$ & $106^{\circ} 38^{\prime} 20^{\prime \prime}$ & 7,120 & 17.4 & Surirella minuta Brébisson & 1,584 & $1,495,077$ \\
\hline 66 & 393930106382001 & $\begin{array}{l}\text { Squaw Creek at mouth } \\
\text { near Edwards }\end{array}$ & 1 & 2000 & $8 / 15 / 2000$ & $39^{\circ} 39^{\prime} 30^{\prime \prime}$ & $106^{\circ} 38^{\prime} 20^{\prime \prime}$ & 7,120 & 17.4 & Synedra ulna (Nitzsch) Ehrenberg & 396 & $2,596,185$ \\
\hline 66 & 393930106382001 & $\begin{array}{l}\text { Squaw Creek at mouth } \\
\text { near Edwards }\end{array}$ & 1 & 2000 & $8 / 15 / 2000$ & 39³9'30" & $106^{\circ} 38^{\prime} 20^{\prime \prime}$ & 7,120 & 17.4 & $\begin{array}{l}\text { Unknown Rhodophyte Florideophycidae } \\
\text { (chantransia) }\end{array}$ & 13,343 & $47,221,941$ \\
\hline 67 & 394129106393300 & $\begin{array}{l}\text { Eagle River at Eagle Springs } \\
\text { Golf Course near Wolcott }\end{array}$ & 1 & 2000 & $8 / 18 / 2000$ & $39^{\circ} 41^{\prime} 29^{\prime \prime}$ & $106^{\circ} 39^{\prime} 33^{\prime \prime}$ & 6,980 & 517 & $\begin{array}{l}\text { Achnanthidium minutissimum (Kützing) } \\
\text { Czarnecki }\end{array}$ & 15,911 & 876,243 \\
\hline 67 & 394129106393300 & $\begin{array}{l}\text { Eagle River at Eagle Springs } \\
\text { Golf Course near Wolcott }\end{array}$ & 1 & 2000 & $8 / 18 / 2000$ & $39^{\circ} 41^{\prime 2} 29^{\prime \prime}$ & $106^{\circ} 39^{\prime} 33^{\prime \prime}$ & 6,980 & 517 & $\begin{array}{l}\text { Achnanthidium pyrenaicum (Hustedt) } \\
\text { Kobayasi }\end{array}$ & 936 & 117,750 \\
\hline 67 & 394129106393300 & $\begin{array}{l}\text { Eagle River at Eagle Springs } \\
\text { Golf Course near Wolcott }\end{array}$ & 1 & 2000 & $8 / 18 / 2000$ & $39^{\circ} 41^{\prime} 29^{\prime \prime}$ & $106^{\circ} 39^{\prime} 33^{\prime \prime}$ & 6,980 & 517 & Amphora pediculus (Kützing) Grunow & 749 & 70,854 \\
\hline 67 & 394129106393300 & $\begin{array}{l}\text { Eagle River at Eagle Springs } \\
\text { Golf Course near Wolcott }\end{array}$ & 1 & 2000 & $8 / 18 / 2000$ & $39^{\circ} 41^{\prime} 29^{\prime \prime}$ & $106^{\circ} 39^{\prime} 33^{\prime \prime}$ & 6,980 & 517 & Aulacoseira distans (Ehrenberg) Simonsen & 562 & 224,371 \\
\hline 67 & 394129106393300 & $\begin{array}{l}\text { Eagle River at Eagle Springs } \\
\text { Golf Course near Wolcott }\end{array}$ & 1 & 2000 & $8 / 18 / 2000$ & $39^{\circ} 41^{\prime} 29^{\prime \prime}$ & $106^{\circ} 39^{\prime} 33^{\prime \prime}$ & 6,980 & 517 & Caloneis bacillum (Grunow) Cleve & 1,497 & 644,173 \\
\hline 67 & 394129106393300 & $\begin{array}{l}\text { Eagle River at Eagle Springs } \\
\text { Golf Course near Wolcott }\end{array}$ & 1 & 2000 & $8 / 18 / 2000$ & $39^{\circ} 41^{\prime} 29^{\prime \prime}$ & $106^{\circ} 39^{\prime} 33^{\prime \prime}$ & 6,980 & 517 & $\begin{array}{l}\text { Cocconeis placentula var. euglypta } \\
\text { (Ehrenberg) Grunow }\end{array}$ & 1,123 & 676,622 \\
\hline 67 & 394129106393300 & $\begin{array}{l}\text { Eagle River at Eagle Springs } \\
\text { Golf Course near Wolcott }\end{array}$ & 1 & 2000 & $8 / 18 / 2000$ & $39^{\circ} 41^{\prime 2} 29^{\prime \prime}$ & $106^{\circ} 39^{\prime} 33^{\prime \prime}$ & 6,980 & 517 & $\begin{array}{l}\text { Cocconeis placentula var. lineata (Ehrenberg) } \\
\text { Van Heurck }\end{array}$ & 187 & 196,125 \\
\hline 67 & 394129106393300 & $\begin{array}{l}\text { Eagle River at Eagle Springs } \\
\text { Golf Course near Wolcott }\end{array}$ & 1 & 2000 & $8 / 18 / 2000$ & $39^{\circ} 41^{\prime 2} 29^{\prime \prime}$ & $106^{\circ} 39^{\prime} 33^{\prime \prime}$ & 6,980 & 517 & Cyclotella meneghiniana Kützing & 374 & 285,582 \\
\hline 67 & 394129106393300 & $\begin{array}{l}\text { Eagle River at Eagle Springs } \\
\text { Golf Course near Wolcott }\end{array}$ & 1 & 2000 & $8 / 18 / 2000$ & $39^{\circ} 41^{\prime} 29^{\prime \prime}$ & $106^{\circ} 39^{\prime} 33^{\prime \prime}$ & 6,980 & 517 & Cymbella affinis Kützing & 749 & 378,947 \\
\hline 67 & 394129106393300 & $\begin{array}{l}\text { Eagle River at Eagle Springs } \\
\text { Golf Course near Wolcott }\end{array}$ & 1 & 2000 & $8 / 18 / 2000$ & $39^{\circ} 41^{\prime} 29^{\prime \prime}$ & $106^{\circ} 39^{\prime} 33^{\prime \prime}$ & 6,980 & 517 & Denticula tenuis Kützing & 374 & 142,356 \\
\hline 67 & 394129106393300 & $\begin{array}{l}\text { Eagle River at Eagle Springs } \\
\text { Golf Course near Wolcott }\end{array}$ & 1 & 2000 & $8 / 18 / 2000$ & $39^{\circ} 41^{\prime} 29^{\prime \prime}$ & $106^{\circ} 39^{\prime} 33^{\prime \prime}$ & 6,980 & 517 & Encyonema brehmii (Hustedt) Mann & 562 & 15,483 \\
\hline 67 & 394129106393300 & $\begin{array}{l}\text { Eagle River at Eagle Springs } \\
\text { Golf Course near Wolcott }\end{array}$ & 1 & 2000 & $8 / 18 / 2000$ & $39^{\circ} 41^{\prime} 29^{\prime \prime}$ & $106^{\circ} 39^{\prime} 33^{\prime \prime}$ & 6,980 & 517 & Encyonema minutum (Hilse) Mann & 1,872 & 400,550 \\
\hline 67 & 394129106393300 & $\begin{array}{l}\text { Eagle River at Eagle Springs } \\
\text { Golf Course near Wolcott }\end{array}$ & 1 & 2000 & $8 / 18 / 2000$ & $39^{\circ} 41^{\prime 2} 29^{\prime \prime}$ & $106^{\circ} 39^{\prime} 33^{\prime \prime}$ & 6,980 & 517 & Encyonema silesiacum (Bleisch) Mann & 52,600 & $24,766,569$ \\
\hline 67 & 394129106393300 & $\begin{array}{l}\text { Eagle River at Eagle Springs } \\
\text { Golf Course near Wolcott }\end{array}$ & 1 & 2000 & $8 / 18 / 2000$ & $39^{\circ} 41^{\prime} 29^{\prime \prime}$ & $106^{\circ} 39^{\prime} 33^{\prime \prime}$ & 6,980 & 517 & $\begin{array}{l}\text { Encyonopsis microcephala (Grunow) } \\
\text { Krammer }\end{array}$ & 374 & 23,336 \\
\hline 67 & 394129106393300 & Eagle River at Eagle Springs & 1 & 2000 & $8 / 18 / 2000$ & $39^{\circ} 41^{\prime 2} 29^{\prime \prime}$ & $106^{\circ} 39^{\prime} 33^{\prime \prime}$ & 6,980 & 517 & Fragilaria capucina var. fragilarioides & 374 & 38,358 \\
\hline
\end{tabular}


Table 2. Description of sites and algal data collected from selected sites the Eagle River watershed, Colorado, 2000-2001.—Continued

[ID, identification; NAVD, North American Vertical Datum of 1988; ft, feet; $\mathrm{mi}^{2}$, square miles; cells $/ \mathrm{cm}^{2}$, cells per square centimeter; $\mu \mathrm{m}^{3} / \mathrm{cm}^{2}$, cubic micrometer per square centimeter

\begin{tabular}{|c|c|c|c|c|c|c|c|c|c|c|c|c|}
\hline $\begin{array}{l}\text { Site } \\
\text { ID }^{1}\end{array}$ & $\begin{array}{l}\text { USGS } \\
\text { station } \\
\text { number }\end{array}$ & Station name & $\begin{array}{c}\text { Replicate } \\
\text { sample } \\
\text { number }\end{array}$ & Year & $\begin{array}{l}\text { Collection } \\
\text { date }\end{array}$ & Latitude & Longitude & $\begin{array}{c}\text { Elevation } \\
\text { NAVD } 88 \\
\text { (ft) }\end{array}$ & $\begin{array}{c}\text { Drainage } \\
\text { area } \\
\left(\mathrm{mi}^{2}\right)\end{array}$ & Algal taxon name & $\begin{array}{c}\text { Total } \\
\text { density } \\
\text { (number of } \\
\text { cells } / \mathrm{cm}^{2} \text { ) }\end{array}$ & $\begin{array}{c}\text { Total } \\
\text { biovolume } \\
\left(\mu \mathrm{m}^{3} / \mathrm{cm}^{2}\right)\end{array}$ \\
\hline 67 & 394129106393300 & $\begin{array}{l}\text { Eagle River at Eagle Springs } \\
\text { Golf Course near Wolcott }\end{array}$ & 1 & 2000 & $8 / 18 / 2000$ & $39^{\circ} 41^{\prime 2} 29^{\prime \prime}$ & $106^{\circ} 39^{\prime} 33^{\prime \prime}$ & 6,980 & 517 & Fragilaria vaucheriae (Kützing) Petersen & 2,059 & 425,940 \\
\hline 67 & 394129106393300 & $\begin{array}{l}\text { Eagle River at Eagle Springs } \\
\text { Golf Course near Wolcott }\end{array}$ & 1 & 2000 & $8 / 18 / 2000$ & $39^{\circ} 41^{\prime 2} 29^{\prime \prime}$ & $106^{\circ} 39^{\prime} 33^{\prime \prime}$ & 6,980 & 517 & $\begin{array}{l}\text { Geissleria acceptata (Hustedt) } \\
\text { Lange-Bertalot et Metzeltin }\end{array}$ & 374 & 38,430 \\
\hline 67 & 394129106393300 & $\begin{array}{l}\text { Eagle River at Eagle Springs } \\
\text { Golf Course near Wolcott }\end{array}$ & 1 & 2000 & $8 / 18 / 2000$ & $39^{\circ} 41^{\prime 2} 29^{\prime \prime}$ & $106^{\circ} 39^{\prime} 33^{\prime \prime}$ & 6,980 & 517 & Gomphonema olivaceoides Hustedt & 1,685 & 257,717 \\
\hline 67 & 394129106393300 & $\begin{array}{l}\text { Eagle River at Eagle Springs } \\
\text { Golf Course near Wolcott }\end{array}$ & 1 & 2000 & $8 / 18 / 2000$ & $39^{\circ} 41^{\prime 2} 29^{\prime \prime}$ & $106^{\circ} 39^{\prime} 33^{\prime \prime}$ & 6,980 & 517 & Hannaea arcus (Ehrenberg) Patrick & 562 & $1,363,548$ \\
\hline 67 & 394129106393300 & $\begin{array}{l}\text { Eagle River at Eagle Springs } \\
\text { Golf Course near Wolcott }\end{array}$ & 1 & 2000 & $8 / 18 / 2000$ & $39^{\circ} 41^{\prime 2} 29^{\prime \prime}$ & $106^{\circ} 39^{\prime} 33^{\prime \prime}$ & 6,980 & 517 & $\begin{array}{l}\text { Homoeothrix janthina (Bornet et Flahault) } \\
\text { Starmach }\end{array}$ & 294,472 & $9,543,331$ \\
\hline 67 & 394129106393300 & $\begin{array}{l}\text { Eagle River at Eagle Springs } \\
\text { Golf Course near Wolcott }\end{array}$ & 1 & 2000 & $8 / 18 / 2000$ & $39^{\circ} 41^{\prime 2} 29^{\prime \prime}$ & $106^{\circ} 39^{\prime} 33^{\prime \prime}$ & 6,980 & 517 & Mayamaea atomus (Kützing) Lange-Bertalot & 749 & 19,556 \\
\hline 67 & 394129106393300 & $\begin{array}{l}\text { Eagle River at Eagle Springs } \\
\text { Golf Course near Wolcott }\end{array}$ & 1 & 2000 & $8 / 18 / 2000$ & $39^{\circ} 41^{\prime 2} 29^{\prime \prime}$ & $106^{\circ} 39^{\prime} 33^{\prime \prime}$ & 6,980 & 517 & Melosira varians Agardh & 3,744 & $20,325,722$ \\
\hline 67 & 394129106393300 & $\begin{array}{l}\text { Eagle River at Eagle Springs } \\
\text { Golf Course near Wolcott }\end{array}$ & 1 & 2000 & $8 / 18 / 2000$ & $39^{\circ} 41^{\prime} 29^{\prime \prime}$ & $106^{\circ} 39^{\prime} 33^{\prime \prime}$ & 6,980 & 517 & Navicula gregaria Donkin & 4,305 & $1,076,228$ \\
\hline 67 & 394129106393300 & $\begin{array}{l}\text { Eagle River at Eagle Springs } \\
\text { Golf Course near Wolcott }\end{array}$ & 1 & 2000 & $8 / 18 / 2000$ & $39^{\circ} 41^{\prime 2} 29^{\prime \prime}$ & $106^{\circ} 39^{\prime} 33^{\prime \prime}$ & 6,980 & 517 & Navicula incertata Hustedt & 187 & 9,678 \\
\hline 67 & 394129106393300 & $\begin{array}{l}\text { Eagle River at Eagle Springs } \\
\text { Golf Course near Wolcott }\end{array}$ & 1 & 2000 & $8 / 18 / 2000$ & $39^{\circ} 41^{\prime 2} 29^{\prime \prime}$ & $106^{\circ} 39^{\prime} 33^{\prime \prime}$ & 6,980 & 517 & Navicula minima Grunow & 1,497 & 79,533 \\
\hline 67 & 394129106393300 & $\begin{array}{l}\text { Eagle River at Eagle Springs } \\
\text { Golf Course near Wolcott }\end{array}$ & 1 & 2000 & $8 / 18 / 2000$ & $39^{\circ} 41^{\prime} 29^{\prime \prime}$ & $106^{\circ} 39^{\prime} 33^{\prime \prime}$ & 6,980 & 517 & Navicula tripunctata (Müller) Bory & 374 & 354,218 \\
\hline 67 & 394129106393300 & $\begin{array}{l}\text { Eagle River at Eagle Springs } \\
\text { Golf Course near Wolcott }\end{array}$ & 1 & 2000 & $8 / 18 / 2000$ & $39^{\circ} 41^{\prime 2} 29^{\prime \prime}$ & $106^{\circ} 39^{\prime} 33^{\prime \prime}$ & 6,980 & 517 & Navicula veneta Kützing & 374 & 81,179 \\
\hline 67 & 394129106393300 & $\begin{array}{l}\text { Eagle River at Eagle Springs } \\
\text { Golf Course near Wolcott }\end{array}$ & 1 & 2000 & $8 / 18 / 2000$ & $39^{\circ} 41^{\prime 2} 29^{\prime \prime}$ & $106^{\circ} 39^{\prime} 33^{\prime \prime}$ & 6,980 & 517 & Nitzschia capitellata Hustedt & 2,059 & 516,222 \\
\hline 67 & 394129106393300 & $\begin{array}{l}\text { Eagle River at Eagle Springs } \\
\text { Golf Course near Wolcott }\end{array}$ & 1 & 2000 & $8 / 18 / 2000$ & $39^{\circ} 41^{\prime 2} 29^{\prime \prime}$ & $106^{\circ} 39^{\prime} 33^{\prime \prime}$ & 6,980 & 517 & Nitzschia dissipata (Kützing) Grunow & 936 & 243,380 \\
\hline 67 & 394129106393300 & $\begin{array}{l}\text { Eagle River at Eagle Springs } \\
\text { Golf Course near Wolcott }\end{array}$ & 1 & 2000 & $8 / 18 / 2000$ & $39^{\circ} 41^{\prime 2} 29^{\prime \prime}$ & $106^{\circ} 39^{\prime} 33^{\prime \prime}$ & 6,980 & 517 & Nitzschia fonticola Grunow & 13,290 & $1,319,770$ \\
\hline 67 & 394129106393300 & $\begin{array}{l}\text { Eagle River at Eagle Springs } \\
\text { Golf Course near Wolcott }\end{array}$ & 1 & 2000 & $8 / 18 / 2000$ & $39^{\circ} 41^{\prime 2} 29^{\prime \prime}$ & $106^{\circ} 39^{\prime} 33^{\prime \prime}$ & 6,980 & 517 & Nitzschia inconspicua Grunow & 1,497 & 54,147 \\
\hline 67 & 394129106393300 & $\begin{array}{l}\text { Eagle River at Eagle Springs } \\
\text { Golf Course near Wolcott }\end{array}$ & 1 & 2000 & $8 / 18 / 2000$ & $39^{\circ} 41^{\prime 2} 29^{\prime \prime}$ & $106^{\circ} 39^{\prime} 33^{\prime \prime}$ & 6,980 & 517 & $\begin{array}{l}\text { Nitzschia linearis (Agardh ex Wm. Smith) } \\
\text { Wm. Smith }\end{array}$ & 374 & 968,242 \\
\hline 67 & 394129106393300 & $\begin{array}{l}\text { Eagle River at Eagle Springs } \\
\text { Golf Course near Wolcott }\end{array}$ & 1 & 2000 & $8 / 18 / 2000$ & $39^{\circ} 41^{\prime} 29^{\prime \prime}$ & $106^{\circ} 39^{\prime} 33^{\prime \prime}$ & 6,980 & 517 & Nitzschia palea (Kützing) Smith & 749 & 129,766 \\
\hline 67 & 394129106393300 & $\begin{array}{l}\text { Eagle River at Eagle Springs } \\
\text { Golf Course near Wolcott }\end{array}$ & 1 & 2000 & $8 / 18 / 2000$ & $39^{\circ} 41^{\prime 2} 29^{\prime \prime}$ & $106^{\circ} 39^{\prime} 33^{\prime \prime}$ & 6,980 & 517 & Nitzschia paleacea Grunow ex Van Heurck & 3,369 & 103,225 \\
\hline 67 & 394129106393300 & $\begin{array}{l}\text { Eagle River at Eagle Springs } \\
\text { Golf Course near Wolcott }\end{array}$ & 1 & 2000 & $8 / 18 / 2000$ & $39^{\circ} 41^{\prime 2} 29^{\prime \prime}$ & $106^{\circ} 39^{\prime} 33^{\prime \prime}$ & 6,980 & 517 & Phormidium autumnale (Agardh) Gomont & 14,097 & $1,380,512$ \\
\hline 67 & 394129106393300 & $\begin{array}{l}\text { Eagle River at Eagle Springs } \\
\text { Golf Course near Wolcott }\end{array}$ & 1 & 2000 & $8 / 18 / 2000$ & $39^{\circ} 41^{\prime 2} 29^{\prime \prime}$ & $106^{\circ} 39^{\prime} 33^{\prime \prime}$ & 6,980 & 517 & $\begin{array}{l}\text { Planothidium lanceolatum (Brébisson } \\
\text { ex Kützing) Lange-Bertalot }\end{array}$ & 187 & 26,738 \\
\hline 67 & 394129106393300 & $\begin{array}{l}\text { Eagle River at Eagle Springs } \\
\text { Golf Course near Wolcott }\end{array}$ & 1 & 2000 & $8 / 18 / 2000$ & $39^{\circ} 41^{\prime 2} 29^{\prime \prime}$ & $106^{\circ} 39^{\prime} 33^{\prime \prime}$ & 6,980 & 517 & $\begin{array}{l}\text { Psammothidium subatomoides (Hustedt) } \\
\text { Bukhtiyarova et Round }\end{array}$ & 562 & 838,411 \\
\hline 67 & 394129106393300 & $\begin{array}{l}\text { Eagle River at Eagle Springs } \\
\text { Golf Course near Wolcott }\end{array}$ & 1 & 2000 & $8 / 18 / 2000$ & $39^{\circ} 41^{\prime 2} 29^{\prime \prime}$ & $106^{\circ} 39^{\prime} 33^{\prime \prime}$ & 6,980 & 517 & $\begin{array}{l}\text { Reimeria sinuata (Gregory) } \\
\text { Kociolek et Stoermer }\end{array}$ & 5,241 & 866,602 \\
\hline
\end{tabular}


Table 2. Description of sites and algal data collected from selected sites the Eagle River watershed, Colorado, 2000-2001.—Continued

[ID, identification; NAVD, North American Vertical Datum of 1988; ft, feet; $\mathrm{mi}^{2}$, square miles; cells $/ \mathrm{cm}^{2}$, cells per square centimeter; $\mu \mathrm{m}^{3} / \mathrm{cm}^{2}$, cubic micrometer per square centimeter]

\begin{tabular}{|c|c|c|c|c|c|c|c|c|c|c|c|c|}
\hline $\begin{array}{l}\text { Site } \\
\text { ID' }\end{array}$ & $\begin{array}{l}\text { USGS } \\
\text { station } \\
\text { number }\end{array}$ & Station name & $\begin{array}{l}\text { Replicate } \\
\text { sample } \\
\text { number }\end{array}$ & Year & $\begin{array}{l}\text { Collection } \\
\text { date }\end{array}$ & Latitude & Longitude & $\begin{array}{c}\text { Elevation } \\
\text { NAVD } 88 \\
\text { (ft) }\end{array}$ & $\begin{array}{c}\text { Drainage } \\
\text { area } \\
\left(\mathrm{mi}^{2}\right)\end{array}$ & Algal taxon name & $\begin{array}{c}\text { Total } \\
\text { density } \\
\text { (number of } \\
\text { cells/cm²) }\end{array}$ & $\begin{array}{c}\text { Total } \\
\text { biovolume } \\
\left(\mu \mathrm{m}^{3} / \mathrm{cm}^{2}\right)\end{array}$ \\
\hline 67 & 394129106393300 & $\begin{array}{l}\text { Eagle River at Eagle Springs } \\
\text { Golf Course near Wolcott }\end{array}$ & 1 & 2000 & $8 / 18 / 2000$ & $39^{\circ} 41^{\prime} 29^{\prime \prime}$ & $106^{\circ} 39^{\prime} 33^{\prime \prime}$ & 6,980 & 517 & $\begin{array}{l}\text { Rhoicosphenia abbreviata (Agardh) } \\
\text { Lange-Bertalot }\end{array}$ & 187 & 99,685 \\
\hline 67 & 394129106393300 & $\begin{array}{l}\text { Eagle River at Eagle Springs } \\
\text { Golf Course near Wolcott }\end{array}$ & 1 & 2000 & $8 / 18 / 2000$ & $39^{\circ} 41^{\prime 2} 29^{\prime \prime}$ & $106^{\circ} 39^{\prime} 33^{\prime \prime}$ & 6,980 & 517 & Scenedesmus acutus Meyen & 4,177 & 379,316 \\
\hline 67 & 394129106393300 & $\begin{array}{l}\text { Eagle River at Eagle Springs } \\
\text { Golf Course near Wolcott }\end{array}$ & 1 & 2000 & $8 / 18 / 2000$ & $39^{\circ} 41^{\prime} 29^{\prime \prime}$ & $106^{\circ} 39^{\prime} 33^{\prime \prime}$ & 6,980 & 517 & Scenedesmus quadricauda (Turpin) Brébisson & 2,088 & 238,721 \\
\hline 67 & 394129106393300 & $\begin{array}{l}\text { Eagle River at Eagle Springs } \\
\text { Golf Course near Wolcott }\end{array}$ & 1 & 2000 & $8 / 18 / 2000$ & $39^{\circ} 41^{\prime} 29^{\prime \prime}$ & $106^{\circ} 39^{\prime} 33^{\prime \prime}$ & 6,980 & 517 & $\begin{array}{l}\text { Staurosira construens var. venter (Ehrenberg) } \\
\text { Hamilton }\end{array}$ & 1,310 & 157,375 \\
\hline 67 & 394129106393300 & $\begin{array}{l}\text { Eagle River at Eagle Springs } \\
\text { Golf Course near Wolcott }\end{array}$ & 1 & 2000 & $8 / 18 / 2000$ & $39^{\circ} 41^{\prime} 29^{\prime \prime}$ & $106^{\circ} 39^{\prime} 33^{\prime \prime}$ & 6,980 & 517 & $\begin{array}{l}\text { Staurosirella leptostauron } \\
\text { (Ehrenberg) Williams et Round }\end{array}$ & 187 & 91,428 \\
\hline 67 & 394129106393300 & $\begin{array}{l}\text { Eagle River at Eagle Springs } \\
\text { Golf Course near Wolcott }\end{array}$ & 1 & 2000 & $8 / 18 / 2000$ & $39^{\circ} 41^{\prime} 29^{\prime \prime}$ & $106^{\circ} 39^{\prime} 33^{\prime \prime}$ & 6,980 & 517 & $\begin{array}{l}\text { Staurosirella pinnata (Ehrenberg) } \\
\text { Williams et Round }\end{array}$ & 749 & 72,087 \\
\hline 67 & 394129106393300 & $\begin{array}{l}\text { Eagle River at Eagle Springs } \\
\text { Golf Course near Wolcott }\end{array}$ & 1 & 2000 & $8 / 18 / 2000$ & $39^{\circ} 41^{\prime 2} 29^{\prime \prime}$ & $106^{\circ} 39^{\prime} 33^{\prime \prime}$ & 6,980 & 517 & Surirella angusta Kützing & 374 & 424,052 \\
\hline 67 & 394129106393300 & $\begin{array}{l}\text { Eagle River at Eagle Springs } \\
\text { Golf Course near Wolcott }\end{array}$ & 1 & 2000 & $8 / 18 / 2000$ & $39^{\circ} 41^{\prime} 29^{\prime \prime}$ & $106^{\circ} 39^{\prime} 33^{\prime \prime}$ & 6,980 & 517 & Synedra ulna (Nitzsch) Ehrenberg & 1,123 & $7,363,848$ \\
\hline 67 & 394129106393300 & $\begin{array}{l}\text { Eagle River at Eagle Springs } \\
\text { Golf Course near Wolcott }\end{array}$ & 1 & 2000 & $8 / 18 / 2000$ & $39^{\circ} 41^{\prime} 29^{\prime \prime}$ & $106^{\circ} 39^{\prime} 33^{\prime \prime}$ & 6,980 & 517 & $\begin{array}{l}\text { Unknown Cyanophyte Oscillatoriales } \\
\text { (no sheath) }\end{array}$ & 74,140 & $1,202,204$ \\
\hline 68 & 394220106431500 & $\begin{array}{l}\text { Eagle River below Milk Creek } \\
\text { near Wolcott }\end{array}$ & 1 & 2000 & $8 / 15 / 2000$ & $39^{\circ} 42^{\prime} 18^{\prime \prime}$ & $106^{\circ} 43^{\prime} 33^{\prime \prime}$ & 6,820 & 600 & $\begin{array}{l}\text { Achnanthidium minutissimum (Kützing) } \\
\text { Czarnecki }\end{array}$ & 5,585 & 307,588 \\
\hline 68 & 394220106431500 & $\begin{array}{l}\text { Eagle River below Milk Creek } \\
\text { near Wolcott }\end{array}$ & 1 & 2000 & $8 / 15 / 2000$ & $39^{\circ} 42^{\prime} 18^{\prime \prime}$ & $106^{\circ} 43^{\prime} 33^{\prime \prime}$ & 6,820 & 600 & $\begin{array}{l}\text { Achnanthidium pyrenaicum (Hustedt) } \\
\text { Kobayasi }\end{array}$ & 346 & 43,528 \\
\hline 68 & 394220106431500 & $\begin{array}{l}\text { Eagle River below Milk Creek } \\
\text { near Wolcott }\end{array}$ & 1 & 2000 & $8 / 15 / 2000$ & $39^{\circ} 42^{\prime} 18^{\prime \prime}$ & $106^{\circ} 43^{\prime} 33^{\prime \prime}$ & 6,820 & 600 & Amphora pediculus (Kützing) Grunow & 247 & 23,386 \\
\hline 68 & 394220106431500 & $\begin{array}{l}\text { Eagle River below Milk Creek } \\
\text { near Wolcott }\end{array}$ & 1 & 2000 & $8 / 15 / 2000$ & $39^{\circ} 42^{\prime} 18^{\prime \prime}$ & $106^{\circ} 43^{\prime} 33^{\prime \prime}$ & 6,820 & 600 & Amphora veneta Kützing & 99 & 56,300 \\
\hline 68 & 394220106431500 & $\begin{array}{l}\text { Eagle River below Milk Creek } \\
\text { near Wolcott }\end{array}$ & 1 & 2000 & $8 / 15 / 2000$ & $39^{\circ} 42^{\prime} 18^{\prime \prime}$ & $106^{\circ} 43^{\prime} 33^{\prime \prime}$ & 6,820 & 600 & Caloneis bacillum (Grunow) Cleve & 198 & 85,047 \\
\hline 68 & 394220106431500 & $\begin{array}{l}\text { Eagle River below Milk Creek } \\
\text { near Wolcott }\end{array}$ & 1 & 2000 & $8 / 15 / 2000$ & $39^{\circ} 42^{\prime} 18^{\prime \prime}$ & $106^{\circ} 43^{\prime} 33^{\prime \prime}$ & 6,820 & 600 & Chlamydomonas sp. & 142 & 12,062 \\
\hline 68 & 394220106431500 & $\begin{array}{l}\text { Eagle River below Milk Creek } \\
\text { near Wolcott }\end{array}$ & 1 & 2000 & $8 / 15 / 2000$ & $39^{\circ} 42^{\prime} 18^{\prime \prime}$ & $106^{\circ} 43^{\prime} 33^{\prime \prime}$ & 6,820 & 600 & $\begin{array}{l}\text { Cocconeis placentula var. euglypta } \\
\text { (Ehrenberg) Grunow }\end{array}$ & 1,582 & 952,863 \\
\hline 68 & 394220106431500 & $\begin{array}{l}\text { Eagle River below Milk Creek } \\
\text { near Wolcott }\end{array}$ & 1 & 2000 & $8 / 15 / 2000$ & $39^{\circ} 42^{\prime} 18^{\prime \prime}$ & $106^{\circ} 43^{\prime} 33^{\prime \prime}$ & 6,820 & 600 & $\begin{array}{l}\text { Cocconeis placentula var. lineata (Ehrenberg) } \\
\text { Van Heurck }\end{array}$ & 49 & 51,787 \\
\hline 68 & 394220106431500 & $\begin{array}{l}\text { Eagle River below Milk Creek } \\
\text { near Wolcott }\end{array}$ & 1 & 2000 & $8 / 15 / 2000$ & $39^{\circ} 42^{\prime} 18^{\prime \prime}$ & $106^{\circ} 43^{\prime} 33^{\prime \prime}$ & 6,820 & 600 & Cymbella affinis Kützing & 99 & 50,030 \\
\hline 68 & 394220106431500 & $\begin{array}{l}\text { Eagle River below Milk Creek } \\
\text { near Wolcott }\end{array}$ & 1 & 2000 & $8 / 15 / 2000$ & $39^{\circ} 42^{\prime} 18^{\prime \prime}$ & $106^{\circ} 43^{\prime} 33^{\prime \prime}$ & 6,820 & 600 & Encyonema brehmii (Hustedt) Mann & 890 & 24,530 \\
\hline 68 & 394220106431500 & $\begin{array}{l}\text { Eagle River below Milk Creek } \\
\text { near Wolcott }\end{array}$ & 1 & 2000 & $8 / 15 / 2000$ & $39^{\circ} 42^{\prime} 18^{\prime \prime}$ & $106^{\circ} 43^{\prime} 33^{\prime \prime}$ & 6,820 & 600 & Encyonema minutum (Hilse) Mann & 1,928 & 412,483 \\
\hline 68 & 394220106431500 & $\begin{array}{l}\text { Eagle River below Milk Creek } \\
\text { near Wolcott }\end{array}$ & 1 & 2000 & $8 / 15 / 2000$ & $39^{\circ} 42^{\prime} 18^{\prime \prime}$ & $106^{\circ} 43^{\prime} 33^{\prime \prime}$ & 6,820 & 600 & Encyonema silesiacum (Bleisch) Mann & 7,315 & $3,444,347$ \\
\hline 68 & 394220106431500 & $\begin{array}{l}\text { Eagle River below Milk Creek } \\
\text { near Wolcott }\end{array}$ & 1 & 2000 & $8 / 15 / 2000$ & $39^{\circ} 42^{\prime} 18^{\prime \prime}$ & $106^{\circ} 43^{\prime} 33^{\prime \prime}$ & 6,820 & 600 & Fragilaria vaucheriae (Kützing) Petersen & 247 & 51,122 \\
\hline 68 & 394220106431500 & $\begin{array}{l}\text { Eagle River below Milk Creek } \\
\text { near Wolcott }\end{array}$ & 1 & 2000 & $8 / 15 / 2000$ & $39^{\circ} 42^{\prime} 18^{\prime \prime}$ & $106^{\circ} 43^{\prime} 33^{\prime \prime}$ & 6,820 & 600 & Gomphonema olivaceum (Lyngbye) Kützing & 99 & 34,012 \\
\hline
\end{tabular}


Table 2. Description of sites and algal data collected from selected sites the Eagle River watershed, Colorado, 2000-2001.—Continued

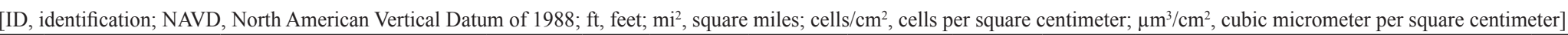

\begin{tabular}{|c|c|c|c|c|c|c|c|c|c|c|c|c|}
\hline $\begin{array}{l}\text { Site } \\
\text { ID' }^{1}\end{array}$ & $\begin{array}{l}\text { USGS } \\
\text { station } \\
\text { number }\end{array}$ & Station name & $\begin{array}{c}\text { Replicate } \\
\text { sample } \\
\text { number }\end{array}$ & Year & $\begin{array}{l}\text { Collection } \\
\text { date }\end{array}$ & Latitude & Longitude & $\begin{array}{c}\text { Elevation } \\
\text { NAVD } 88 \\
\text { (ft) }\end{array}$ & $\begin{array}{c}\text { Drainage } \\
\text { area } \\
\left(\mathrm{mi}^{2}\right)\end{array}$ & Algal taxon name & $\begin{array}{c}\text { Total } \\
\text { density } \\
\text { (number of } \\
\text { cells } / \mathrm{cm}^{2} \text { ) }\end{array}$ & $\begin{array}{c}\text { Total } \\
\text { biovolume } \\
\left(\mu^{3} \mathrm{~m}^{3} \mathrm{~cm}^{2}\right)\end{array}$ \\
\hline 68 & 394220106431500 & $\begin{array}{l}\text { Eagle River below Milk Creek } \\
\text { near Wolcott }\end{array}$ & 1 & 2000 & $8 / 15 / 2000$ & $39^{\circ} 42^{\prime} 18^{\prime \prime}$ & $106^{\circ} 43^{\prime} 33^{\prime \prime}$ & 6,820 & 600 & Hannaea arcus (Ehrenberg) Patrick & 247 & 600,074 \\
\hline 68 & 394220106431500 & $\begin{array}{l}\text { Eagle River below Milk Creek } \\
\text { near Wolcott }\end{array}$ & 1 & 2000 & $8 / 15 / 2000$ & $39^{\circ} 42^{\prime} 18^{\prime \prime}$ & $106^{\circ} 43^{\prime} 33^{\prime \prime}$ & 6,820 & 600 & $\begin{array}{l}\text { Homoeothrix janthina (Bornet et Flahault) } \\
\text { Starmach }\end{array}$ & 80,601 & $2,612,130$ \\
\hline 68 & 394220106431500 & $\begin{array}{l}\text { Eagle River below Milk Creek } \\
\text { near Wolcott }\end{array}$ & 1 & 2000 & $8 / 15 / 2000$ & $39^{\circ} 42^{\prime} 18^{\prime \prime}$ & $106^{\circ} 43^{\prime} 33^{\prime \prime}$ & 6,820 & 600 & Mayamaea atomus (Kützing) Lange-Bertalot & 6,129 & 160,073 \\
\hline 68 & 394220106431500 & $\begin{array}{l}\text { Eagle River below Milk Creek } \\
\text { near Wolcott }\end{array}$ & 1 & 2000 & $8 / 15 / 2000$ & $39^{\circ} 42^{\prime} 18^{\prime \prime}$ & $106^{\circ} 43^{\prime} 33^{\prime \prime}$ & 6,820 & 600 & Navicula gregaria Donkin & 445 & 111,200 \\
\hline 68 & 394220106431500 & $\begin{array}{l}\text { Eagle River below Milk Creek } \\
\text { near Wolcott }\end{array}$ & 1 & 2000 & $8 / 15 / 2000$ & $39^{\circ} 42^{\prime} 18^{\prime \prime}$ & $106^{\circ} 43^{\prime} 33^{\prime \prime}$ & 6,820 & 600 & Navicula minima Grunow & 643 & 34,126 \\
\hline 68 & 394220106431500 & $\begin{array}{l}\text { Eagle River below Milk Creek } \\
\text { near Wolcott }\end{array}$ & 1 & 2000 & $8 / 15 / 2000$ & $39^{\circ} 42^{\prime} 18^{\prime \prime}$ & $106^{\circ} 43^{\prime} 33^{\prime \prime}$ & 6,820 & 600 & Navicula tripunctata (Müller) Bory & 99 & 93,531 \\
\hline 68 & 394220106431500 & $\begin{array}{l}\text { Eagle River below Milk Creek } \\
\text { near Wolcott }\end{array}$ & 1 & 2000 & $8 / 15 / 2000$ & $39^{\circ} 42^{\prime} 18^{\prime \prime}$ & $106^{\circ} 43^{\prime} 33^{\prime \prime}$ & 6,820 & 600 & Nitzschia fonticola Grunow & 692 & 68,715 \\
\hline 68 & 394220106431500 & $\begin{array}{l}\text { Eagle River below Milk Creek } \\
\text { near Wolcott }\end{array}$ & 1 & 2000 & $8 / 15 / 2000$ & $39^{\circ} 42^{\prime} 18^{\prime \prime}$ & $106^{\circ} 43^{\prime} 33^{\prime \prime}$ & 6,820 & 600 & Nitzschia inconspicua Grunow & 890 & 32,170 \\
\hline 68 & 394220106431500 & $\begin{array}{l}\text { Eagle River below Milk Creek } \\
\text { near Wolcott }\end{array}$ & 1 & 2000 & $8 / 15 / 2000$ & $39^{\circ} 42^{\prime} 18^{\prime \prime}$ & $106^{\circ} 43^{\prime} 33^{\prime \prime}$ & 6,820 & 600 & Nitzschia palea (Kützing) Smith & 198 & 34,265 \\
\hline 68 & 394220106431500 & $\begin{array}{l}\text { Eagle River below Milk Creek } \\
\text { near Wolcott }\end{array}$ & 1 & 2000 & $8 / 15 / 2000$ & $39^{\circ} 42^{\prime} 18^{\prime \prime}$ & $106^{\circ} 43^{\prime} 33^{\prime \prime}$ & 6,820 & 600 & Nitzschia paleacea Grunow ex Van Heurck & 1,483 & 60,928 \\
\hline 68 & 394220106431500 & $\begin{array}{l}\text { Eagle River below Milk Creek } \\
\text { near Wolcott }\end{array}$ & 1 & 2000 & $8 / 15 / 2000$ & $39^{\circ} 42^{\prime} 18^{\prime \prime}$ & $106^{\circ} 43^{\prime} 33^{\prime \prime}$ & 6,820 & 600 & Phormidium autumnale (Agardh) Gomont & 8,798 & 861,576 \\
\hline 68 & 394220106431500 & $\begin{array}{l}\text { Eagle River below Milk Creek } \\
\text { near Wolcott }\end{array}$ & 1 & 2000 & $8 / 15 / 2000$ & $39^{\circ} 42^{\prime} 18^{\prime \prime}$ & $106^{\circ} 43^{\prime} 33^{\prime \prime}$ & 6,820 & 600 & $\begin{array}{l}\text { Planothidium lanceolatum } \\
\text { (Brébisson ex Kützing) Lange-Bertalot }\end{array}$ & 247 & 35,301 \\
\hline 68 & 394220106431500 & $\begin{array}{l}\text { Eagle River below Milk Creek } \\
\text { near Wolcott }\end{array}$ & 1 & 2000 & $8 / 15 / 2000$ & $39^{\circ} 42^{\prime} 18^{\prime \prime}$ & $106^{\circ} 43^{\prime} 33^{\prime \prime}$ & 6,820 & 600 & $\begin{array}{l}\text { Reimeria sinuata (Gregory) } \\
\text { Kociolek et Stoermer }\end{array}$ & 5,140 & 849,925 \\
\hline 68 & 394220106431500 & $\begin{array}{l}\text { Eagle River below Milk Creek } \\
\text { near Wolcott }\end{array}$ & 1 & 2000 & $8 / 15 / 2000$ & $39^{\circ} 42^{\prime} 18^{\prime \prime}$ & $106^{\circ} 43^{\prime} 33^{\prime \prime}$ & 6,820 & 600 & $\begin{array}{l}\text { Rhoicosphenia abbreviata (Agardh) } \\
\text { Lange-Bertalot }\end{array}$ & 198 & 105,287 \\
\hline 68 & 394220106431500 & $\begin{array}{l}\text { Eagle River below Milk Creek } \\
\text { near Wolcott }\end{array}$ & 1 & 2000 & $8 / 15 / 2000$ & $39^{\circ} 42^{\prime} 18^{\prime \prime}$ & $106^{\circ} 43^{\prime} 33^{\prime \prime}$ & 6,820 & 600 & $\begin{array}{l}\text { Staurosira construens var. venter (Ehrenberg) } \\
\text { Hamilton }\end{array}$ & 99 & 11,873 \\
\hline 68 & 394220106431500 & $\begin{array}{l}\text { Eagle River below Milk Creek } \\
\text { near Wolcott }\end{array}$ & 1 & 2001 & $8 / 15 / 2001$ & $39^{\circ} 42^{\prime} 18^{\prime \prime}$ & $106^{\circ} 43^{\prime} 33^{\prime \prime}$ & 6,820 & 600 & $\begin{array}{l}\text { Achnanthidium minutissimum (Kützing) } \\
\text { Czarnecki }\end{array}$ & 6,289 & 340,975 \\
\hline 68 & 394220106431500 & $\begin{array}{l}\text { Eagle River below Milk Creek } \\
\text { near Wolcott }\end{array}$ & 1 & 2001 & $8 / 15 / 2001$ & $39^{\circ} 42^{\prime} 18^{\prime \prime}$ & $106^{\circ} 43^{\prime} 33^{\prime \prime}$ & 6,820 & 600 & Adlafia minuscula (Grunow) Lange-Bertalot & 359 & 29,898 \\
\hline 68 & 394220106431500 & $\begin{array}{l}\text { Eagle River below Milk Creek } \\
\text { near Wolcott }\end{array}$ & 1 & 2001 & $8 / 15 / 2001$ & $39^{\circ} 42^{\prime} 18^{\prime \prime}$ & $106^{\circ} 43^{\prime} 33^{\prime \prime}$ & 6,820 & 600 & Amphora pediculus (Kützing) Grunow & 449 & 43,430 \\
\hline 68 & 394220106431500 & $\begin{array}{l}\text { Eagle River below Milk Creek } \\
\text { near Wolcott }\end{array}$ & 1 & 2001 & $8 / 15 / 2001$ & $39^{\circ} 42^{\prime} 18^{\prime \prime}$ & $106^{\circ} 43^{\prime} 33^{\prime \prime}$ & 6,820 & 600 & $\begin{array}{l}\text { Cocconeis placentula var. euglypta } \\
\text { (Ehrenberg) Grunow }\end{array}$ & 1,617 & 960,848 \\
\hline 68 & 394220106431500 & $\begin{array}{l}\text { Eagle River below Milk Creek } \\
\text { near Wolcott }\end{array}$ & 1 & 2001 & $8 / 15 / 2001$ & $39^{\circ} 42^{\prime} 18^{\prime \prime}$ & $106^{\circ} 43^{\prime} 33^{\prime \prime}$ & 6,820 & 600 & $\begin{array}{l}\text { Cocconeis placentula var. lineata (Ehrenberg) } \\
\text { Van Heurck }\end{array}$ & 6,019 & $6,347,709$ \\
\hline 68 & 394220106431500 & $\begin{array}{l}\text { Eagle River below Milk Creek } \\
\text { near Wolcott }\end{array}$ & 1 & 2001 & $8 / 15 / 2001$ & $39^{\circ} 42^{\prime} 18^{\prime \prime}$ & $106^{\circ} 43^{\prime} 33^{\prime \prime}$ & 6,820 & 600 & Cymbella affinis Kützing & 90 & 45,723 \\
\hline 68 & 394220106431500 & $\begin{array}{l}\text { Eagle River below Milk Creek } \\
\text { near Wolcott }\end{array}$ & 1 & 2001 & $8 / 15 / 2001$ & $39^{\circ} 42^{\prime} 18^{\prime \prime}$ & $106^{\circ} 43^{\prime} 33^{\prime \prime}$ & 6,820 & 600 & Diatoma moniliformis Kützing & 359 & 65,583 \\
\hline 68 & 394220106431500 & $\begin{array}{l}\text { Eagle River below Milk Creek } \\
\text { near Wolcott }\end{array}$ & 1 & 2001 & $8 / 15 / 2001$ & $39^{\circ} 42^{\prime} 18^{\prime \prime}$ & $106^{\circ} 43^{\prime} 33^{\prime \prime}$ & 6,820 & 600 & Encyonema brehmii (Hustedt) Mann & 1,797 & 49,539 \\
\hline
\end{tabular}


Table 2. Description of sites and algal data collected from selected sites the Eagle River watershed, Colorado, 2000-2001.—Continued

[ID, identification; NAVD, North American Vertical Datum of 1988; ft, feet; $\mathrm{mi}^{2}$, square miles; cells $/ \mathrm{cm}^{2}$, cells per square centimeter; $\mu \mathrm{m}^{3} / \mathrm{cm}^{2}$, cubic micrometer per square centimeter]

\begin{tabular}{|c|c|c|c|c|c|c|c|c|c|c|c|c|}
\hline $\begin{array}{l}\text { Site } \\
\text { ID }^{1}\end{array}$ & $\begin{array}{l}\text { USGS } \\
\text { station } \\
\text { number }\end{array}$ & Station name & $\begin{array}{l}\text { Replicate } \\
\text { sample } \\
\text { number }\end{array}$ & Year & $\begin{array}{l}\text { Collection } \\
\text { date }\end{array}$ & Latitude & Longitude & $\begin{array}{c}\text { Elevation } \\
\text { NAVD } 88 \\
\text { (ft) }\end{array}$ & $\begin{array}{c}\text { Drainage } \\
\text { area } \\
\left(\mathrm{mi}^{2}\right)\end{array}$ & Algal taxon name & $\begin{array}{c}\text { Total } \\
\text { density } \\
\text { (number of } \\
\text { cells } / \mathrm{cm}^{2} \text { ) }\end{array}$ & $\begin{array}{c}\text { Total } \\
\text { biovolume } \\
\left(\mathrm{\mu m}^{3} / \mathrm{cm}^{2}\right)\end{array}$ \\
\hline 68 & 394220106431500 & $\begin{array}{l}\text { Eagle River below Milk Creek } \\
\text { near Wolcott }\end{array}$ & 1 & 2001 & $8 / 15 / 2001$ & $39^{\circ} 42^{\prime} 18^{\prime \prime}$ & $106^{\circ} 43^{\prime} 33^{\prime \prime}$ & 6,820 & 600 & Encyonema minutum (Hilse) Mann & 4,133 & 891,938 \\
\hline 68 & 394220106431500 & $\begin{array}{l}\text { Eagle River below Milk Creek } \\
\text { near Wolcott }\end{array}$ & 1 & 2001 & $8 / 15 / 2001$ & $39^{\circ} 42^{\prime} 18^{\prime \prime}$ & $106^{\circ} 43^{\prime} 33^{\prime \prime}$ & 6,820 & 600 & Encyonema silesiacum (Bleisch) Mann & 11,589 & $5,504,159$ \\
\hline 68 & 394220106431500 & $\begin{array}{l}\text { Eagle River below Milk Creek } \\
\text { near Wolcott }\end{array}$ & 1 & 2001 & $8 / 15 / 2001$ & $39^{\circ} 42^{\prime} 18^{\prime \prime}$ & $106^{\circ} 43^{\prime} 33^{\prime \prime}$ & 6,820 & 600 & $\begin{array}{l}\text { Fragilaria capucina var. fragilarioides } \\
\text { (Grunow) Ludwig et Flores }\end{array}$ & 539 & 66,273 \\
\hline 68 & 394220106431500 & $\begin{array}{l}\text { Eagle River below Milk Creek } \\
\text { near Wolcott }\end{array}$ & 1 & 2001 & $8 / 15 / 2001$ & $39^{\circ} 42^{\prime} 18^{\prime \prime}$ & $106^{\circ} 43^{\prime} 33^{\prime \prime}$ & 6,820 & 600 & Fragilaria vaucheriae (Kützing) Petersen & 359 & 70,796 \\
\hline 68 & 394220106431500 & $\begin{array}{l}\text { Eagle River below Milk Creek } \\
\text { near Wolcott }\end{array}$ & 1 & 2001 & $8 / 15 / 2001$ & $39^{\circ} 42^{\prime} 18^{\prime \prime}$ & $106^{\circ} 43^{\prime} 33^{\prime \prime}$ & 6,820 & 600 & Gomphonema minutum (Agardh) Agardh & 180 & 14,680 \\
\hline 68 & 394220106431500 & $\begin{array}{l}\text { Eagle River below Milk Creek } \\
\text { near Wolcott }\end{array}$ & 1 & 2001 & $8 / 15 / 2001$ & $39^{\circ} 42^{\prime} 18^{\prime \prime}$ & $106^{\circ} 43^{\prime} 33^{\prime \prime}$ & 6,820 & 600 & Gomphonema parvulum (Kützing) Kützing & 90 & 19,631 \\
\hline 68 & 394220106431500 & $\begin{array}{l}\text { Eagle River below Milk Creek } \\
\text { near Wolcott }\end{array}$ & 1 & 2001 & $8 / 15 / 2001$ & $39^{\circ} 42^{\prime} 18^{\prime \prime}$ & $106^{\circ} 43^{\prime} 33^{\prime \prime}$ & 6,820 & 600 & $\begin{array}{l}\text { Homoeothrix janthina (Bornet et Flahault) } \\
\text { Starmach }\end{array}$ & 423,557 & $7,290,964$ \\
\hline 68 & 394220106431500 & $\begin{array}{l}\text { Eagle River below Milk Creek } \\
\text { near Wolcott }\end{array}$ & 1 & 2001 & $8 / 15 / 2001$ & $39^{\circ} 42^{\prime} 18^{\prime \prime}$ & $106^{\circ} 43^{\prime} 33^{\prime \prime}$ & 6,820 & 600 & Mayamaea atomus (Kützing) Lange-Bertalot & 719 & 20,638 \\
\hline 68 & 394220106431500 & $\begin{array}{l}\text { Eagle River below Milk Creek } \\
\text { near Wolcott }\end{array}$ & 1 & 2001 & $8 / 15 / 2001$ & $39^{\circ} 42^{\prime} 18^{\prime \prime}$ & $106^{\circ} 43^{\prime} 33^{\prime \prime}$ & 6,820 & 600 & Melosira varians Agardh & 1,168 & $6,035,709$ \\
\hline 68 & 394220106431500 & $\begin{array}{l}\text { Eagle River below Milk Creek } \\
\text { near Wolcott }\end{array}$ & 1 & 2001 & $8 / 15 / 2001$ & $39^{\circ} 42^{\prime} 18^{\prime \prime}$ & $106^{\circ} 43^{\prime} 33^{\prime \prime}$ & 6,820 & 600 & Microcystis sp. & 46,311 & $1,157,787$ \\
\hline 68 & 394220106431500 & $\begin{array}{l}\text { Eagle River below Milk Creek } \\
\text { near Wolcott }\end{array}$ & 1 & 2001 & $8 / 15 / 2001$ & $39^{\circ} 42^{\prime} 18^{\prime \prime}$ & $106^{\circ} 43^{\prime} 33^{\prime \prime}$ & 6,820 & 600 & Navicula gregaria Donkin & 1,168 & 293,095 \\
\hline 68 & 394220106431500 & $\begin{array}{l}\text { Eagle River below Milk Creek } \\
\text { near Wolcott }\end{array}$ & 1 & 2001 & $8 / 15 / 2001$ & $39^{\circ} 42^{\prime} 18^{\prime \prime}$ & $106^{\circ} 43^{\prime} 33^{\prime \prime}$ & 6,820 & 600 & Navicula minima Grunow & 719 & 32,346 \\
\hline 68 & 394220106431500 & $\begin{array}{l}\text { Eagle River below Milk Creek } \\
\text { near Wolcott }\end{array}$ & 1 & 2001 & $8 / 15 / 2001$ & $39^{\circ} 42^{\prime} 18^{\prime \prime}$ & $106^{\circ} 43^{\prime} 33^{\prime \prime}$ & 6,820 & 600 & Navicula tripunctata (Müller) Bory & 90 & 81,692 \\
\hline 68 & 394220106431500 & $\begin{array}{l}\text { Eagle River below Milk Creek } \\
\text { near Wolcott }\end{array}$ & 1 & 2001 & $8 / 15 / 2001$ & $39^{\circ} 42^{\prime} 18^{\prime \prime}$ & $106^{\circ} 43^{\prime} 33^{\prime \prime}$ & 6,820 & 600 & Navicula upsaliensis (Grunow) Peragallo & 180 & 33,921 \\
\hline 68 & 394220106431500 & $\begin{array}{l}\text { Eagle River below Milk Creek } \\
\text { near Wolcott }\end{array}$ & 1 & 2001 & $8 / 15 / 2001$ & $39^{\circ} 42^{\prime} 18^{\prime \prime}$ & $106^{\circ} 43^{\prime} 33^{\prime \prime}$ & 6,820 & 600 & Nitzschia archibaldii Lange-Bertalot & 3,054 & 133,352 \\
\hline 68 & 394220106431500 & $\begin{array}{l}\text { Eagle River below Milk Creek } \\
\text { near Wolcott }\end{array}$ & 1 & 2001 & $8 / 15 / 2001$ & $39^{\circ} 42^{\prime} 18^{\prime \prime}$ & $106^{\circ} 43^{\prime} 33^{\prime \prime}$ & 6,820 & 600 & Nitzschia dissipata (Kützing) Grunow & 539 & 138,979 \\
\hline 68 & 394220106431500 & $\begin{array}{l}\text { Eagle River below Milk Creek } \\
\text { near Wolcott }\end{array}$ & 1 & 2001 & $8 / 15 / 2001$ & $39^{\circ} 42^{\prime} 18^{\prime \prime}$ & $106^{\circ} 43^{\prime} 33^{\prime \prime}$ & 6,820 & 600 & Nitzschia fonticola Grunow & 2,695 & 268,099 \\
\hline 68 & 394220106431500 & $\begin{array}{l}\text { Eagle River below Milk Creek } \\
\text { near Wolcott }\end{array}$ & 1 & 2001 & $8 / 15 / 2001$ & $39^{\circ} 42^{\prime} 18^{\prime \prime}$ & $106^{\circ} 43^{\prime} 33^{\prime \prime}$ & 6,820 & 600 & Nitzschia inconspicua Grunow & 898 & 31,638 \\
\hline 68 & 394220106431500 & $\begin{array}{l}\text { Eagle River below Milk Creek } \\
\text { near Wolcott }\end{array}$ & 1 & 2001 & $8 / 15 / 2001$ & $39^{\circ} 42^{\prime} 18^{\prime \prime}$ & $106^{\circ} 43^{\prime} 33^{\prime \prime}$ & 6,820 & 600 & Nitzschia paleacea Grunow ex Van Heurck & 2,515 & 131,177 \\
\hline 68 & 394220106431500 & $\begin{array}{l}\text { Eagle River below Milk Creek } \\
\text { near Wolcott }\end{array}$ & 1 & 2001 & $8 / 15 / 2001$ & $39^{\circ} 42^{\prime} 18^{\prime \prime}$ & $106^{\circ} 43^{\prime} 33^{\prime \prime}$ & 6,820 & 600 & $\begin{array}{l}\text { Planothidium dubium (Grunow) } \\
\text { Round et Bukhtiyarova }\end{array}$ & 270 & 21,685 \\
\hline 68 & 394220106431500 & $\begin{array}{l}\text { Eagle River below Milk Creek } \\
\text { near Wolcott }\end{array}$ & 1 & 2001 & $8 / 15 / 2001$ & $39^{\circ} 42^{\prime} 18^{\prime \prime}$ & $106^{\circ} 43^{\prime} 33^{\prime \prime}$ & 6,820 & 600 & $\begin{array}{l}\text { Planothidium lanceolatum } \\
\text { (Brébisson ex Kützing) Lange-Bertalot }\end{array}$ & 270 & 36,919 \\
\hline 68 & 394220106431500 & $\begin{array}{l}\text { Eagle River below Milk Creek } \\
\text { near Wolcott }\end{array}$ & 1 & 2001 & $8 / 15 / 2001$ & $39^{\circ} 42^{\prime} 18^{\prime \prime}$ & $106^{\circ} 43^{\prime} 33^{\prime \prime}$ & 6,820 & 600 & $\begin{array}{l}\text { Reimeria sinuata (Gregory) } \\
\text { Kociolek et Stoermer }\end{array}$ & 3,593 & 605,647 \\
\hline 68 & 394220106431500 & $\begin{array}{l}\text { Eagle River below Milk Creek } \\
\text { near Wolcott }\end{array}$ & 1 & 2001 & $8 / 15 / 2001$ & $39^{\circ} 42^{\prime} 18^{\prime \prime}$ & $106^{\circ} 43^{\prime} 33^{\prime \prime}$ & 6,820 & 600 & $\begin{array}{l}\text { Rhoicosphenia abbreviata (Agardh) } \\
\text { Lange-Bertalot }\end{array}$ & 1,168 & 604,370 \\
\hline
\end{tabular}


Table 2. Description of sites and algal data collected from selected sites the Eagle River watershed, Colorado, 2000-2001.—Continued

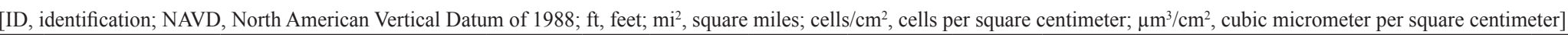

\begin{tabular}{|c|c|c|c|c|c|c|c|c|c|c|c|c|}
\hline $\begin{array}{l}\text { Site } \\
\text { ID' }\end{array}$ & $\begin{array}{l}\text { USGS } \\
\text { station } \\
\text { number }\end{array}$ & Station name & $\begin{array}{c}\text { Replicate } \\
\text { sample } \\
\text { number }\end{array}$ & Year & $\begin{array}{c}\text { Collection } \\
\text { date }\end{array}$ & Latitude & Longitude & $\begin{array}{c}\text { Elevation } \\
\text { NAVD } 88 \\
\text { (ft) }\end{array}$ & $\begin{array}{c}\text { Drainage } \\
\text { area } \\
\left(\mathbf{m i}^{2}\right)\end{array}$ & Algal taxon name & $\begin{array}{c}\text { Total } \\
\text { density } \\
\text { (number of } \\
\text { cells/cm²) }\end{array}$ & $\begin{array}{c}\text { Total } \\
\text { biovolume } \\
\left(\mu \mathrm{m}^{3} / \mathrm{cm}^{2}\right)\end{array}$ \\
\hline 68 & 394220106431500 & $\begin{array}{l}\text { Eagle River below Milk Creek } \\
\text { near Wolcott }\end{array}$ & 1 & 2001 & $8 / 15 / 2001$ & $39^{\circ} 42^{\prime} 18^{\prime \prime}$ & $106^{\circ} 43^{\prime} 33^{\prime \prime}$ & 6,820 & 600 & $\begin{array}{l}\text { Staurosira construens var. venter (Ehrenberg) } \\
\text { Hamilton }\end{array}$ & 359 & 43,160 \\
\hline 68 & 394220106431500 & $\begin{array}{l}\text { Eagle River below Milk Creek } \\
\text { near Wolcott }\end{array}$ & 1 & 2001 & $8 / 15 / 2001$ & $39^{\circ} 42^{\prime} 18^{\prime \prime}$ & $106^{\circ} 43^{\prime} 33^{\prime \prime}$ & 6,820 & 600 & $\begin{array}{l}\text { Surirella brebissonii } \\
\text { Krammer et Lange-Bertalot }\end{array}$ & 1,078 & $1,786,303$ \\
\hline 68 & 394220106431500 & $\begin{array}{l}\text { Eagle River below Milk Creek } \\
\text { near Wolcott }\end{array}$ & 1 & 2001 & $8 / 15 / 2001$ & $39^{\circ} 42^{\prime} 18^{\prime \prime}$ & $106^{\circ} 43^{\prime} 33^{\prime \prime}$ & 6,820 & 600 & Unknown alga flagellate $(<10 \mu)$ & 2,573 & 247,258 \\
\hline 68 & 394220106431500 & $\begin{array}{l}\text { Eagle River below Milk Creek } \\
\text { near Wolcott }\end{array}$ & 1 & 2001 & $8 / 15 / 2001$ & $39^{\circ} 42^{\prime} 18^{\prime \prime}$ & $106^{\circ} 43^{\prime} 33^{\prime \prime}$ & 6,820 & 600 & Unknown Cyanophyte (colonial coccoid) & 50,171 & $1,254,269$ \\
\hline 69 & 393852106503200 & $\begin{array}{l}\text { Eagle River above Brush } \\
\text { Creek at Eagle }\end{array}$ & 1 & 2000 & $8 / 14 / 2000$ & $39^{\circ} 38^{\prime} 52^{\prime \prime}$ & $106^{\circ} 50^{\prime} 32^{\prime \prime}$ & 6,500 & 646 & $\begin{array}{l}\text { Achnanthidium minutissimum (Kützing) } \\
\text { Czarnecki }\end{array}$ & 56,687 & $3,121,847$ \\
\hline 69 & 393852106503200 & $\begin{array}{l}\text { Eagle River above Brush } \\
\text { Creek at Eagle }\end{array}$ & 1 & 2000 & $8 / 14 / 2000$ & $39^{\circ} 38^{\prime} 52^{\prime \prime}$ & $106^{\circ} 50^{\prime} 32^{\prime \prime}$ & 6,500 & 646 & Amphora pediculus (Kützing) Grunow & 1,854 & 175,467 \\
\hline 69 & 393852106503200 & $\begin{array}{l}\text { Eagle River above Brush } \\
\text { Creek at Eagle }\end{array}$ & 1 & 2000 & $8 / 14 / 2000$ & $39^{\circ} 38^{\prime} 52^{\prime \prime}$ & $106^{\circ} 50^{\prime} 32^{\prime \prime}$ & 6,500 & 646 & Caloneis bacillum (Grunow) Cleve & 1,060 & 455,790 \\
\hline 69 & 393852106503200 & $\begin{array}{l}\text { Eagle River above Brush } \\
\text { Creek at Eagle }\end{array}$ & 1 & 2000 & $8 / 14 / 2000$ & $39^{\circ} 38^{\prime} 52^{\prime \prime}$ & $106^{\circ} 50^{\prime} 32^{\prime \prime}$ & 6,500 & 646 & Chlamydomonas sp. & 792 & 67,359 \\
\hline 69 & 393852106503200 & $\begin{array}{l}\text { Eagle River above Brush } \\
\text { Creek at Eagle }\end{array}$ & 1 & 2000 & $8 / 14 / 2000$ & $39^{\circ} 38^{\prime} 52^{\prime \prime}$ & $106^{\circ} 50^{\prime} 32^{\prime \prime}$ & 6,500 & 646 & $\begin{array}{l}\text { Cocconeis placentula var. euglypta } \\
\text { (Ehrenberg) Grunow }\end{array}$ & 6,093 & $3,670,414$ \\
\hline 69 & 393852106503200 & $\begin{array}{l}\text { Eagle River above Brush } \\
\text { Creek at Eagle }\end{array}$ & 1 & 2000 & $8 / 14 / 2000$ & $39^{\circ} 38^{\prime} 52^{\prime \prime}$ & $106^{\circ} 50^{\prime} 32^{\prime \prime}$ & 6,500 & 646 & $\begin{array}{l}\text { Cocconeis placentula var. lineata (Ehrenberg) } \\
\text { Van Heurck }\end{array}$ & 795 & 832,621 \\
\hline 69 & 393852106503200 & $\begin{array}{l}\text { Eagle River above Brush } \\
\text { Creek at Eagle }\end{array}$ & 1 & 2000 & $8 / 14 / 2000$ & $39^{\circ} 38^{\prime} 52^{\prime \prime}$ & $106^{\circ} 50^{\prime} 32^{\prime \prime}$ & 6,500 & 646 & Encyonema brehmii (Hustedt) Mann & 1,589 & 43,821 \\
\hline 69 & 393852106503200 & $\begin{array}{l}\text { Eagle River above Brush } \\
\text { Creek at Eagle }\end{array}$ & 1 & 2000 & $8 / 14 / 2000$ & $39^{\circ} 38^{\prime} 52^{\prime \prime}$ & $106^{\circ} 50^{\prime} 32^{\prime \prime}$ & 6,500 & 646 & Encyonema minutum (Hilse) Mann & 8,477 & $1,813,838$ \\
\hline 69 & 393852106503200 & $\begin{array}{l}\text { Eagle River above Brush } \\
\text { Creek at Eagle }\end{array}$ & 1 & 2000 & $8 / 14 / 2000$ & $39^{\circ} 38^{\prime} 52^{\prime \prime}$ & $106^{\circ} 50^{\prime} 32^{\prime \prime}$ & 6,500 & 646 & Encyonema silesiacum (Bleisch) Mann & 54,833 & $25,817,970$ \\
\hline 69 & 393852106503200 & $\begin{array}{l}\text { Eagle River above Brush } \\
\text { Creek at Eagle }\end{array}$ & 1 & 2000 & $8 / 14 / 2000$ & $39^{\circ} 38^{\prime} 52^{\prime \prime}$ & $106^{\circ} 50^{\prime} 32 "$ & 6,500 & 646 & Fragilaria vaucheriae (Kützing) Petersen & 265 & 54,796 \\
\hline 69 & 393852106503200 & $\begin{array}{l}\text { Eagle River above Brush } \\
\text { Creek at Eagle }\end{array}$ & 1 & 2000 & $8 / 14 / 2000$ & $39^{\circ} 38^{\prime} 52^{\prime \prime}$ & $106^{\circ} 50^{\prime} 32^{\prime \prime}$ & 6,500 & 646 & Gomphonema olivaceum (Lyngbye) Kützing & 795 & 273,423 \\
\hline 69 & 393852106503200 & $\begin{array}{l}\text { Eagle River above Brush } \\
\text { Creek at Eagle }\end{array}$ & 1 & 2000 & $8 / 14 / 2000$ & $39^{\circ} 38^{\prime} 52^{\prime \prime}$ & $106^{\circ} 50^{\prime} 32^{\prime \prime}$ & 6,500 & 646 & Gomphonema parvulum (Kützing) Kützing & 4,768 & $1,064,961$ \\
\hline 69 & 393852106503200 & $\begin{array}{l}\text { Eagle River above Brush } \\
\text { Creek at Eagle }\end{array}$ & 1 & 2000 & $8 / 14 / 2000$ & $39^{\circ} 38^{\prime} 52^{\prime \prime}$ & $106^{\circ} 50^{\prime} 32 "$ & 6,500 & 646 & $\begin{array}{l}\text { Homoeothrix janthina (Bornet et Flahault) } \\
\text { Starmach }\end{array}$ & $3,341,794$ & $108,301,997$ \\
\hline 69 & 393852106503200 & $\begin{array}{l}\text { Eagle River above Brush } \\
\text { Creek at Eagle }\end{array}$ & 1 & 2000 & $8 / 14 / 2000$ & $39^{\circ} 38^{\prime} 52^{\prime \prime}$ & $106^{\circ} 50^{\prime} 32^{\prime \prime}$ & 6,500 & 646 & Mayamaea atomus (Kützing) Lange-Bertalot & 13,245 & 345,918 \\
\hline 69 & 393852106503200 & $\begin{array}{l}\text { Eagle River above Brush } \\
\text { Creek at Eagle }\end{array}$ & 1 & 2000 & $8 / 14 / 2000$ & $39^{\circ} 38^{\prime} 52^{\prime \prime}$ & $106^{\circ} 50^{\prime} 32^{\prime \prime}$ & 6,500 & 646 & Melosira varians Agardh & 265 & $1,438,163$ \\
\hline 69 & 393852106503200 & $\begin{array}{l}\text { Eagle River above Brush } \\
\text { Creek at Eagle }\end{array}$ & 1 & 2000 & $8 / 14 / 2000$ & $39^{\circ} 38^{\prime} 52^{\prime \prime}$ & $106^{\circ} 50^{\prime} 32^{\prime \prime}$ & 6,500 & 646 & $\begin{array}{l}\text { Navicula cryptotenella Lange-Bertalot } \\
\text { ex Krammer et Lange-Bertalot }\end{array}$ & 530 & 191,740 \\
\hline 69 & 393852106503200 & $\begin{array}{l}\text { Eagle River above Brush } \\
\text { Creek at Eagle }\end{array}$ & 1 & 2000 & $8 / 14 / 2000$ & $39^{\circ} 38^{\prime} 52^{\prime \prime}$ & $106^{\circ} 50^{\prime} 32^{\prime \prime}$ & 6,500 & 646 & Navicula gregaria Donkin & 1,060 & 264,867 \\
\hline 69 & 393852106503200 & $\begin{array}{l}\text { Eagle River above Brush } \\
\text { Creek at Eagle }\end{array}$ & 1 & 2000 & $8 / 14 / 2000$ & $39^{\circ} 38^{\prime} 52^{\prime \prime}$ & $106^{\circ} 50^{\prime} 32^{\prime \prime}$ & 6,500 & 646 & Navicula minima Grunow & 1,060 & 56,274 \\
\hline 69 & 393852106503200 & $\begin{array}{l}\text { Eagle River above Brush } \\
\text { Creek at Eagle }\end{array}$ & 1 & 2000 & $8 / 14 / 2000$ & $39^{\circ} 38^{\prime} 52^{\prime \prime}$ & $106^{\circ} 50^{\prime} 32^{\prime \prime}$ & 6,500 & 646 & Navicula veneta Kützing & 1,589 & 344,634 \\
\hline
\end{tabular}


Table 2. Description of sites and algal data collected from selected sites the Eagle River watershed, Colorado, 2000-2001.—Continued

[ID, identification; NAVD, North American Vertical Datum of 1988; ft, feet; $\mathrm{mi}^{2}$, square miles; cells $/ \mathrm{cm}^{2}$, cells per square centimeter; $\mu \mathrm{m}^{3} / \mathrm{cm}^{2}$, cubic micrometer per square centimeter]

\begin{tabular}{|c|c|c|c|c|c|c|c|c|c|c|c|c|}
\hline $\begin{array}{l}\text { Site } \\
\text { ID' }\end{array}$ & $\begin{array}{l}\text { USGS } \\
\text { station } \\
\text { number }\end{array}$ & Station name & $\begin{array}{l}\text { Replicate } \\
\text { sample } \\
\text { number }\end{array}$ & Year & $\begin{array}{l}\text { Collection } \\
\text { date }\end{array}$ & Latitude & Longitude & $\begin{array}{c}\text { Elevation } \\
\text { NAVD } 88 \\
\text { (ft) }\end{array}$ & $\begin{array}{c}\text { Drainage } \\
\text { area } \\
\left(\mathrm{mi}^{2}\right)\end{array}$ & Algal taxon name & $\begin{array}{c}\text { Total } \\
\text { density } \\
\text { (number of } \\
\text { cells/cm²) }\end{array}$ & $\begin{array}{c}\text { Total } \\
\text { biovolume } \\
\left(\mu \mathrm{m}^{3} / \mathrm{cm}^{2}\right)\end{array}$ \\
\hline 69 & 393852106503200 & $\begin{array}{l}\text { Eagle River above Brush } \\
\text { Creek at Eagle }\end{array}$ & 1 & 2000 & $8 / 14 / 2000$ & $39^{\circ} 38^{\prime} 52^{\prime \prime}$ & $106^{\circ} 50^{\prime} 32^{\prime \prime}$ & 6,500 & 646 & Nitzschia fonticola Grunow & 2,119 & 210,437 \\
\hline 69 & 393852106503200 & $\begin{array}{l}\text { Eagle River above Brush } \\
\text { Creek at Eagle }\end{array}$ & 1 & 2000 & $8 / 14 / 2000$ & $39^{\circ} 38^{\prime} 52^{\prime \prime}$ & $106^{\circ} 50^{\prime} 32^{\prime \prime}$ & 6,500 & 646 & Nitzschia inconspicua Grunow & 5,033 & 270,104 \\
\hline 69 & 393852106503200 & $\begin{array}{l}\text { Eagle River above Brush } \\
\text { Creek at Eagle }\end{array}$ & 1 & 2000 & $8 / 14 / 2000$ & $39^{\circ} 38^{\prime} 52^{\prime \prime}$ & $106^{\circ} 50^{\prime} 32^{\prime \prime}$ & 6,500 & 646 & Nitzschia palea (Kützing) Smith & 2,119 & 367,269 \\
\hline 69 & 393852106503200 & $\begin{array}{l}\text { Eagle River above Brush } \\
\text { Creek at Eagle }\end{array}$ & 1 & 2000 & $8 / 14 / 2000$ & $39^{\circ} 38^{\prime} 52^{\prime \prime}$ & $106^{\circ} 50^{\prime} 32^{\prime \prime}$ & 6,500 & 646 & Nitzschia paleacea Grunow ex Van Heurck & 6,093 & 250,340 \\
\hline 69 & 393852106503200 & $\begin{array}{l}\text { Eagle River above Brush } \\
\text { Creek at Eagle }\end{array}$ & 1 & 2000 & $8 / 14 / 2000$ & $39^{\circ} 38^{\prime} 52^{\prime \prime}$ & $106^{\circ} 50^{\prime} 32^{\prime \prime}$ & 6,500 & 646 & Phormidium autumnale (Agardh) Gomont & 66,566 & $6,518,800$ \\
\hline 69 & 393852106503200 & $\begin{array}{l}\text { Eagle River above Brush } \\
\text { Creek at Eagle }\end{array}$ & 1 & 2000 & $8 / 14 / 2000$ & $39^{\circ} 38^{\prime} 52^{\prime \prime}$ & $106^{\circ} 50^{\prime} 32^{\prime \prime}$ & 6,500 & 646 & $\begin{array}{l}\text { Reimeria sinuata (Gregory) } \\
\text { Kociolek et Stoermer }\end{array}$ & 18,278 & $3,022,060$ \\
\hline 69 & 393852106503200 & $\begin{array}{l}\text { Eagle River above Brush } \\
\text { Creek at Eagle }\end{array}$ & 1 & 2000 & $8 / 14 / 2000$ & $39^{\circ} 38^{\prime} 52^{\prime \prime}$ & $106^{\circ} 50^{\prime} 32^{\prime \prime}$ & 6,500 & 646 & $\begin{array}{l}\text { Rhoicosphenia abbreviata (Agardh) } \\
\text { Lange-Bertalot }\end{array}$ & 530 & 282,131 \\
\hline 69 & 393852106503200 & $\begin{array}{l}\text { Eagle River above Brush } \\
\text { Creek at Eagle }\end{array}$ & 1 & 2000 & $8 / 14 / 2000$ & $39^{\circ} 38^{\prime} 52^{\prime \prime}$ & $106^{\circ} 50^{\prime} 32^{\prime \prime}$ & 6,500 & 646 & Staurosira construens Ehrenberg & 265 & 51,263 \\
\hline 69 & 393852106503200 & $\begin{array}{l}\text { Eagle River above Brush } \\
\text { Creek at Eagle }\end{array}$ & 1 & 2000 & $8 / 14 / 2000$ & $39^{\circ} 38^{\prime} 52^{\prime \prime}$ & $106^{\circ} 50^{\prime} 32^{\prime \prime}$ & 6,500 & 646 & Stigeoclonium lubricum (Dillwyn) Kützing & 5,547 & $8,233,592$ \\
\hline 69 & 393852106503200 & $\begin{array}{l}\text { Eagle River above Brush } \\
\text { Creek at Eagle }\end{array}$ & 2 & 2000 & $8 / 14 / 2000$ & $39^{\circ} 38^{\prime} 52^{\prime \prime}$ & $106^{\circ} 50^{\prime} 32^{\prime \prime}$ & 6,500 & 646 & $\begin{array}{l}\text { Achnanthidium minutissimum (Kützing) } \\
\text { Czarnecki }\end{array}$ & 45,658 & $2,514,467$ \\
\hline 69 & 393852106503200 & $\begin{array}{l}\text { Eagle River above Brush } \\
\text { Creek at Eagle }\end{array}$ & 2 & 2000 & $8 / 14 / 2000$ & $39^{\circ} 38^{\prime} 52^{\prime \prime}$ & $106^{\circ} 50^{\prime} 32^{\prime \prime}$ & 6,500 & 646 & $\begin{array}{l}\text { Achnanthidium pyrenaicum (Hustedt) } \\
\text { Kobayasi }\end{array}$ & 99 & 12,515 \\
\hline 69 & 393852106503200 & $\begin{array}{l}\text { Eagle River above Brush } \\
\text { Creek at Eagle }\end{array}$ & 2 & 2000 & $8 / 14 / 2000$ & $39^{\circ} 38^{\prime} 52^{\prime \prime}$ & $106^{\circ} 50^{\prime} 32^{\prime \prime}$ & 6,500 & 646 & Adlafia minuscula (Grunow) Lange-Bertalot & 199 & 10,209 \\
\hline 69 & 393852106503200 & $\begin{array}{l}\text { Eagle River above Brush } \\
\text { Creek at Eagle }\end{array}$ & 2 & 2000 & $8 / 14 / 2000$ & $39^{\circ} 38^{\prime} 52^{\prime \prime}$ & $106^{\circ} 50^{\prime} 32^{\prime \prime}$ & 6,500 & 646 & Amphora pediculus (Kützing) Grunow & 1,592 & 150,609 \\
\hline 69 & 393852106503200 & $\begin{array}{l}\text { Eagle River above Brush } \\
\text { Creek at Eagle }\end{array}$ & 2 & 2000 & $8 / 14 / 2000$ & $39^{\circ} 38^{\prime} 52^{\prime \prime}$ & $106^{\circ} 50^{\prime} 32^{\prime \prime}$ & 6,500 & 646 & Closterium lunula (Möller) Nitzsch & 785 & 66,764 \\
\hline 69 & 393852106503200 & $\begin{array}{l}\text { Eagle River above Brush } \\
\text { Creek at Eagle }\end{array}$ & 2 & 2000 & $8 / 14 / 2000$ & $39^{\circ} 38^{\prime} 52^{\prime \prime}$ & $106^{\circ} 50^{\prime} 32^{\prime \prime}$ & 6,500 & 646 & Closterium sp. & 393 & 33,382 \\
\hline 69 & 393852106503200 & $\begin{array}{l}\text { Eagle River above Brush } \\
\text { Creek at Eagle }\end{array}$ & 2 & 2000 & $8 / 14 / 2000$ & $39^{\circ} 38^{\prime} 52^{\prime \prime}$ & $106^{\circ} 50^{\prime} 32^{\prime \prime}$ & 6,500 & 646 & Cocconeis pediculus Ehrenberg & 199 & 688,198 \\
\hline 69 & 393852106503200 & $\begin{array}{l}\text { Eagle River above Brush } \\
\text { Creek at Eagle }\end{array}$ & 2 & 2000 & $8 / 14 / 2000$ & $39^{\circ} 38^{\prime} 52^{\prime \prime}$ & $106^{\circ} 50^{\prime} 32^{\prime \prime}$ & 6,500 & 646 & $\begin{array}{l}\text { Cocconeis placentula var. euglypta } \\
\text { (Ehrenberg) Grunow }\end{array}$ & 9,947 & $5,992,700$ \\
\hline 69 & 393852106503200 & $\begin{array}{l}\text { Eagle River above Brush } \\
\text { Creek at Eagle }\end{array}$ & 2 & 2000 & $8 / 14 / 2000$ & $39^{\circ} 38^{\prime} 52^{\prime \prime}$ & $106^{\circ} 50^{\prime} 32^{\prime \prime}$ & 6,500 & 646 & $\begin{array}{l}\text { Cocconeis placentula var. lineata (Ehrenberg) } \\
\text { Van Heurck }\end{array}$ & 1,492 & $1,563,338$ \\
\hline 69 & 393852106503200 & $\begin{array}{l}\text { Eagle River above Brush } \\
\text { Creek at Eagle }\end{array}$ & 2 & 2000 & $8 / 14 / 2000$ & $39^{\circ} 38^{\prime} 52^{\prime \prime}$ & $106^{\circ} 50^{\prime} 32^{\prime \prime}$ & 6,500 & 646 & Cryptomonas ovata Ehrenberg & 393 & 3,927 \\
\hline 69 & 393852106503200 & $\begin{array}{l}\text { Eagle River above Brush } \\
\text { Creek at Eagle }\end{array}$ & 2 & 2000 & $8 / 14 / 2000$ & $39^{\circ} 38^{\prime} 52^{\prime \prime}$ & $106^{\circ} 50^{\prime} 32^{\prime \prime}$ & 6,500 & 646 & Cymbella affinis Kützing & 298 & 151,031 \\
\hline 69 & 393852106503200 & $\begin{array}{l}\text { Eagle River above Brush } \\
\text { Creek at Eagle }\end{array}$ & 2 & 2000 & $8 / 14 / 2000$ & $39^{\circ} 38^{\prime} 52^{\prime \prime}$ & $106^{\circ} 50^{\prime} 32^{\prime \prime}$ & 6,500 & 646 & $\begin{array}{l}\text { Diadesmis contenta (Grunow ex Van Heurck) } \\
\text { Mann }\end{array}$ & 199 & 10,292 \\
\hline 69 & 393852106503200 & $\begin{array}{l}\text { Eagle River above Brush } \\
\text { Creek at Eagle }\end{array}$ & 2 & 2000 & $8 / 14 / 2000$ & $39^{\circ} 38^{\prime} 52^{\prime \prime}$ & $106^{\circ} 50^{\prime} 32^{\prime \prime}$ & 6,500 & 646 & Encyonema silesiacum (Bleisch) Mann & 2,288 & $1,077,246$ \\
\hline 69 & 393852106503200 & $\begin{array}{l}\text { Eagle River above Brush } \\
\text { Creek at Eagle }\end{array}$ & 2 & 2000 & $8 / 14 / 2000$ & $39^{\circ} 38^{\prime} 52^{\prime \prime}$ & $106^{\circ} 50^{\prime} 32^{\prime \prime}$ & 6,500 & 646 & Gomphonema minutum (Agardh) Agardh & 2,288 & 396,855 \\
\hline
\end{tabular}


Table 2. Description of sites and algal data collected from selected sites the Eagle River watershed, Colorado, 2000-2001.—Continued

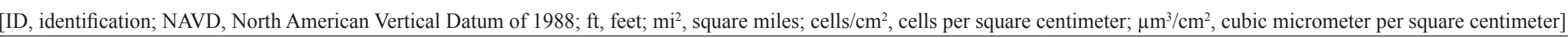

\begin{tabular}{|c|c|c|c|c|c|c|c|c|c|c|c|c|}
\hline $\begin{array}{l}\text { Site } \\
\text { ID }^{1}\end{array}$ & $\begin{array}{l}\text { USGS } \\
\text { station } \\
\text { number }\end{array}$ & Station name & $\begin{array}{c}\text { Replicate } \\
\text { sample } \\
\text { number }\end{array}$ & Year & $\begin{array}{l}\text { Collection } \\
\text { date }\end{array}$ & Latitude & Longitude & $\begin{array}{c}\text { Elevation } \\
\text { NAVD } 88 \\
\text { (ft) }\end{array}$ & $\begin{array}{c}\text { Drainage } \\
\text { area } \\
\left(\mathrm{mi}^{2}\right)\end{array}$ & Algal taxon name & $\begin{array}{c}\text { Total } \\
\text { density } \\
\text { (number of } \\
\text { cells } / \mathrm{cm}^{2} \text { ) }\end{array}$ & $\begin{array}{c}\text { Total } \\
\text { biovolume } \\
\left(\mu^{3} / \mathrm{cm}^{2}\right)\end{array}$ \\
\hline 69 & 393852106503200 & $\begin{array}{l}\text { Eagle River above Brush } \\
\text { Creek at Eagle }\end{array}$ & 2 & 2000 & $8 / 14 / 2000$ & $39^{\circ} 38^{\prime} 52^{\prime \prime}$ & $106^{\circ} 50^{\prime} 32^{\prime \prime}$ & 6,500 & 646 & $\begin{array}{l}\text { Homoeothrix janthina (Bornet et Flahault) } \\
\text { Starmach }\end{array}$ & 333,427 & $10,805,812$ \\
\hline 69 & 393852106503200 & $\begin{array}{l}\text { Eagle River above Brush } \\
\text { Creek at Eagle }\end{array}$ & 2 & 2000 & $8 / 14 / 2000$ & $39^{\circ} 38^{\prime} 52^{\prime \prime}$ & $106^{\circ} 50^{\prime} 32^{\prime \prime}$ & 6,500 & 646 & Melosira varians Agardh & 398 & $2,160,248$ \\
\hline 69 & 393852106503200 & $\begin{array}{l}\text { Eagle River above Brush } \\
\text { Creek at Eagle }\end{array}$ & 2 & 2000 & $8 / 14 / 2000$ & $39^{\circ} 38^{\prime} 52^{\prime \prime}$ & $106^{\circ} 50^{\prime} 32^{\prime \prime}$ & 6,500 & 646 & Meridion circulare (Greville) Agardh & 199 & 129,124 \\
\hline 69 & 393852106503200 & $\begin{array}{l}\text { Eagle River above Brush } \\
\text { Creek at Eagle }\end{array}$ & 2 & 2000 & $8 / 14 / 2000$ & $39^{\circ} 38^{\prime} 52^{\prime \prime}$ & $106^{\circ} 50^{\prime} 32^{\prime \prime}$ & 6,500 & 646 & Navicula cryptocephala Kützing & 199 & 75,373 \\
\hline 69 & 393852106503200 & $\begin{array}{l}\text { Eagle River above Brush } \\
\text { Creek at Eagle }\end{array}$ & 2 & 2000 & $8 / 14 / 2000$ & $39^{\circ} 38^{\prime} 52^{\prime \prime}$ & $106^{\circ} 50^{\prime} 32^{\prime \prime}$ & 6,500 & 646 & $\begin{array}{l}\text { Navicula cryptotenella Lange-Bertalot } \\
\text { ex Krammer et Lange-Bertalot }\end{array}$ & 1,592 & 576,021 \\
\hline 69 & 393852106503200 & $\begin{array}{l}\text { Eagle River above Brush } \\
\text { Creek at Eagle }\end{array}$ & 2 & 2000 & $8 / 14 / 2000$ & $39^{\circ} 38^{\prime} 52^{\prime \prime}$ & $106^{\circ} 50^{\prime} 32^{\prime \prime}$ & 6,500 & 646 & Navicula incertata Hustedt & 99 & 5,143 \\
\hline 69 & 393852106503200 & $\begin{array}{l}\text { Eagle River above Brush } \\
\text { Creek at Eagle }\end{array}$ & 2 & 2000 & $8 / 14 / 2000$ & $39^{\circ} 38^{\prime} 52^{\prime \prime}$ & $106^{\circ} 50^{\prime} 32^{\prime \prime}$ & 6,500 & 646 & Navicula minima Grunow & 398 & 21,132 \\
\hline 69 & 393852106503200 & $\begin{array}{l}\text { Eagle River above Brush } \\
\text { Creek at Eagle }\end{array}$ & 2 & 2000 & $8 / 14 / 2000$ & $39^{\circ} 38^{\prime} 52^{\prime \prime}$ & $106^{\circ} 50^{\prime} 32^{\prime \prime}$ & 6,500 & 646 & Navicula tripunctata (Müller) Bory & 1,890 & $1,788,222$ \\
\hline 69 & 393852106503200 & $\begin{array}{l}\text { Eagle River above Brush } \\
\text { Creek at Eagle }\end{array}$ & 2 & 2000 & $8 / 14 / 2000$ & $39^{\circ} 38^{\prime} 52^{\prime \prime}$ & $106^{\circ} 50^{\prime} 32^{\prime \prime}$ & 6,500 & 646 & Navicula veneta Kützing & 199 & 43,139 \\
\hline 69 & 393852106503200 & $\begin{array}{l}\text { Eagle River above Brush } \\
\text { Creek at Eagle }\end{array}$ & 2 & 2000 & $8 / 14 / 2000$ & $39^{\circ} 38^{\prime} 52^{\prime \prime}$ & $106^{\circ} 50^{\prime} 32^{\prime \prime}$ & 6,500 & 646 & $\begin{array}{l}\text { Nitzschia cf. tubicola } \\
\text { Grunow ex Cleve et Grunow }\end{array}$ & 199 & 48,692 \\
\hline 69 & 393852106503200 & $\begin{array}{l}\text { Eagle River above Brush } \\
\text { Creek at Eagle }\end{array}$ & 2 & 2000 & $8 / 14 / 2000$ & $39^{\circ} 38^{\prime} 52^{\prime \prime}$ & $106^{\circ} 50^{\prime} 32^{\prime \prime}$ & 6,500 & 646 & Nitzschia dissipata (Kützing) Grunow & 5,570 & $1,448,539$ \\
\hline 69 & 393852106503200 & $\begin{array}{l}\text { Eagle River above Brush } \\
\text { Creek at Eagle }\end{array}$ & 2 & 2000 & $8 / 14 / 2000$ & $39^{\circ} 38^{\prime} 52^{\prime \prime}$ & $106^{\circ} 50^{\prime} 32^{\prime \prime}$ & 6,500 & 646 & Nitzschia inconspicua Grunow & 199 & 10,677 \\
\hline 69 & 393852106503200 & $\begin{array}{l}\text { Eagle River above Brush } \\
\text { Creek at Eagle }\end{array}$ & 2 & 2000 & $8 / 14 / 2000$ & $39^{\circ} 38^{\prime} 52^{\prime \prime}$ & $106^{\circ} 50^{\prime} 32^{\prime \prime}$ & 6,500 & 646 & $\begin{array}{l}\text { Nitzschia linearis (Agardh ex Wm. Smith) } \\
\text { Wm. Smith }\end{array}$ & 398 & $1,029,062$ \\
\hline 69 & 393852106503200 & $\begin{array}{l}\text { Eagle River above Brush } \\
\text { Creek at Eagle }\end{array}$ & 2 & 2000 & $8 / 14 / 2000$ & $39^{\circ} 38^{\prime} 52^{\prime \prime}$ & $106^{\circ} 50^{\prime} 32^{\prime \prime}$ & 6,500 & 646 & Nitzschia palea (Kützing) Smith & 99 & 17,240 \\
\hline 69 & 393852106503200 & $\begin{array}{l}\text { Eagle River above Brush } \\
\text { Creek at Eagle }\end{array}$ & 2 & 2000 & $8 / 14 / 2000$ & $39^{\circ} 38^{\prime} 52^{\prime \prime}$ & $106^{\circ} 50^{\prime} 32^{\prime \prime}$ & 6,500 & 646 & Nitzschia paleacea Grunow ex Van Heurck & 199 & 8,175 \\
\hline 69 & 393852106503200 & $\begin{array}{l}\text { Eagle River above Brush } \\
\text { Creek at Eagle }\end{array}$ & 2 & 2000 & $8 / 14 / 2000$ & $39^{\circ} 38^{\prime} 52^{\prime \prime}$ & $106^{\circ} 50^{\prime} 32^{\prime \prime}$ & 6,500 & 646 & Nitzschia sublinearis Hustedt & 398 & $1,041,536$ \\
\hline 69 & 393852106503200 & $\begin{array}{l}\text { Eagle River above Brush } \\
\text { Creek at Eagle }\end{array}$ & 2 & 2000 & $8 / 14 / 2000$ & $39^{\circ} 38^{\prime} 52^{\prime \prime}$ & $106^{\circ} 50^{\prime} 32^{\prime \prime}$ & 6,500 & 646 & Phormidium autumnale (Agardh) Gomont & 55,768 & $5,461,269$ \\
\hline 69 & 393852106503200 & $\begin{array}{l}\text { Eagle River above Brush } \\
\text { Creek at Eagle }\end{array}$ & 2 & 2000 & $8 / 14 / 2000$ & $39^{\circ} 38^{\prime} 52^{\prime \prime}$ & $106^{\circ} 50^{\prime} 32^{\prime \prime}$ & 6,500 & 646 & $\begin{array}{l}\text { Planothidium dubium (Grunow) } \\
\text { Round et Bukhtiyarova }\end{array}$ & 199 & 16,102 \\
\hline 69 & 393852106503200 & $\begin{array}{l}\text { Eagle River above Brush } \\
\text { Creek at Eagle }\end{array}$ & 2 & 2000 & $8 / 14 / 2000$ & $39^{\circ} 38^{\prime} 52^{\prime \prime}$ & $106^{\circ} 50^{\prime} 32^{\prime \prime}$ & 6,500 & 646 & $\begin{array}{l}\text { Planothidium lanceolatum } \\
\text { (Brébisson ex Kützing) Lange-Bertalot }\end{array}$ & 298 & 42,626 \\
\hline 69 & 393852106503200 & $\begin{array}{l}\text { Eagle River above Brush } \\
\text { Creek at Eagle }\end{array}$ & 2 & 2000 & $8 / 14 / 2000$ & $39^{\circ} 38^{\prime} 52^{\prime \prime}$ & $106^{\circ} 50^{\prime} 32^{\prime \prime}$ & 6,500 & 646 & $\begin{array}{l}\text { Reimeria sinuata (Gregory) } \\
\text { Kociolek et Stoermer }\end{array}$ & 5,670 & 937,485 \\
\hline 69 & 393852106503200 & $\begin{array}{l}\text { Eagle River above Brush } \\
\text { Creek at Eagle }\end{array}$ & 2 & 2000 & $8 / 14 / 2000$ & $39^{\circ} 38^{\prime} 52^{\prime \prime}$ & $106^{\circ} 50^{\prime} 32^{\prime \prime}$ & 6,500 & 646 & $\begin{array}{l}\text { Staurosira construens var. venter (Ehrenberg) } \\
\text { Hamilton }\end{array}$ & 199 & 23,894 \\
\hline 69 & 393852106503200 & $\begin{array}{l}\text { Eagle River above Brush } \\
\text { Creek at Eagle }\end{array}$ & 2 & 2000 & $8 / 14 / 2000$ & $39^{\circ} 38^{\prime} 52^{\prime \prime}$ & $106^{\circ} 50^{\prime} 32^{\prime \prime}$ & 6,500 & 646 & Synedra ulna var. contracta Østrup & 597 & 948,815 \\
\hline 69 & 393852106503200 & $\begin{array}{l}\text { Eagle River above Brush } \\
\text { Creek at Eagle }\end{array}$ & 2 & 2000 & $8 / 14 / 2000$ & $39^{\circ} 38^{\prime} 52^{\prime \prime}$ & $106^{\circ} 50^{\prime} 32^{\prime \prime}$ & 6,500 & 646 & $\begin{array}{l}\text { Unknown Rhodophyte Florideophycidae } \\
\text { (chantransia) }\end{array}$ & 5,498 & $19,459,116$ \\
\hline
\end{tabular}


Table 2. Description of sites and algal data collected from selected sites the Eagle River watershed, Colorado, 2000-2001.—Continued

[ID, identification; NAVD, North American Vertical Datum of 1988; ft, feet; $\mathrm{mi}^{2}$, square miles; cells $/ \mathrm{cm}^{2}$, cells per square centimeter; $\mu \mathrm{m}^{3} / \mathrm{cm}^{2}$, cubic micrometer per square centimeter]

\begin{tabular}{|c|c|c|c|c|c|c|c|c|c|c|c|c|}
\hline $\begin{array}{l}\text { Site } \\
\text { ID' }\end{array}$ & $\begin{array}{l}\text { USGS } \\
\text { station } \\
\text { number }\end{array}$ & Station name & $\begin{array}{l}\text { Replicate } \\
\text { sample } \\
\text { number }\end{array}$ & Year & $\begin{array}{l}\text { Collection } \\
\text { date }\end{array}$ & Latitude & Longitude & $\begin{array}{c}\text { Elevation } \\
\text { NAVD } 88 \\
\text { (ft) }\end{array}$ & $\begin{array}{c}\text { Drainage } \\
\text { area } \\
\left(\mathrm{mi}^{2}\right)\end{array}$ & Algal taxon name & $\begin{array}{c}\text { Total } \\
\text { density } \\
\text { (number of } \\
\text { cells } / \mathrm{cm}^{2} \text { ) }\end{array}$ & $\begin{array}{c}\text { Total } \\
\text { biovolume } \\
\left(\mu \mathrm{m}^{3} / \mathrm{cm}^{2}\right)\end{array}$ \\
\hline 71 & 393851106503400 & $\begin{array}{l}\text { Brush Creek at mouth } \\
\text { near Eagle }\end{array}$ & 1 & 2000 & $8 / 14 / 2000$ & $39^{\circ} 38^{\prime} 51^{\prime \prime}$ & $106^{\circ} 50^{\prime} 34^{\prime \prime}$ & 6,500 & 147 & $\begin{array}{l}\text { Achnanthidium minutissimum (Kützing) } \\
\text { Czarnecki }\end{array}$ & 44,275 & $2,438,326$ \\
\hline 71 & 393851106503400 & $\begin{array}{l}\text { Brush Creek at mouth } \\
\text { near Eagle }\end{array}$ & 1 & 2000 & $8 / 14 / 2000$ & $39^{\circ} 38^{\prime} 51^{\prime \prime}$ & $106^{\circ} 50^{\prime} 34^{\prime \prime}$ & 6,500 & 147 & Amphora pediculus (Kützing) Grunow & 35,974 & $3,404,187$ \\
\hline 71 & 393851106503400 & $\begin{array}{l}\text { Brush Creek at mouth } \\
\text { near Eagle }\end{array}$ & 1 & 2000 & $8 / 14 / 2000$ & $39^{\circ} 38^{\prime} 51^{\prime \prime}$ & $106^{\circ} 50^{\prime} 34^{\prime \prime}$ & 6,500 & 147 & Caloneis bacillum (Grunow) Cleve & 1,384 & 595,180 \\
\hline 71 & 393851106503400 & $\begin{array}{l}\text { Brush Creek at mouth } \\
\text { near Eagle }\end{array}$ & 1 & 2000 & $8 / 14 / 2000$ & $39^{\circ} 38^{\prime} 51^{\prime \prime}$ & $106^{\circ} 50^{\prime} 34^{\prime \prime}$ & 6,500 & 147 & Chlamydomonas sp. & 3,002 & 255,152 \\
\hline 71 & 393851106503400 & $\begin{array}{l}\text { Brush Creek at mouth } \\
\text { near Eagle }\end{array}$ & 1 & 2000 & $8 / 14 / 2000$ & $39^{\circ} 38^{\prime} 51^{\prime \prime}$ & $106^{\circ} 50^{\prime} 34^{\prime \prime}$ & 6,500 & 147 & Cocconeis pediculus Ehrenberg & 3,459 & $11,965,525$ \\
\hline 71 & 393851106503400 & $\begin{array}{l}\text { Brush Creek at mouth } \\
\text { near Eagle }\end{array}$ & 1 & 2000 & $8 / 14 / 2000$ & $39^{\circ} 38^{\prime} 51^{\prime \prime}$ & $106^{\circ} 50^{\prime} 34^{\prime \prime}$ & 6,500 & 147 & $\begin{array}{l}\text { Cocconeis placentula var. euglypta } \\
\text { (Ehrenberg) Grunow }\end{array}$ & 6,918 & $4,167,744$ \\
\hline 71 & 393851106503400 & $\begin{array}{l}\text { Brush Creek at mouth } \\
\text { near Eagle }\end{array}$ & 1 & 2000 & $8 / 14 / 2000$ & $39^{\circ} 38^{\prime} 51^{\prime \prime}$ & $106^{\circ} 50^{\prime} 34^{\prime \prime}$ & 6,500 & 147 & Cyclotella meneghiniana Kützing & 692 & 527,725 \\
\hline 71 & 393851106503400 & $\begin{array}{l}\text { Brush Creek at mouth } \\
\text { near Eagle }\end{array}$ & 1 & 2000 & $8 / 14 / 2000$ & $39^{\circ} 38^{\prime} 51^{\prime \prime}$ & $106^{\circ} 50^{\prime} 34^{\prime \prime}$ & 6,500 & 147 & Cymbella affinis Kützing & 8,993 & $4,551,635$ \\
\hline 71 & 393851106503400 & $\begin{array}{l}\text { Brush Creek at mouth } \\
\text { near Eagle }\end{array}$ & 1 & 2000 & $8 / 14 / 2000$ & $39^{\circ} 38^{\prime} 51^{\prime \prime}$ & $106^{\circ} 50^{\prime} 34^{\prime \prime}$ & 6,500 & 147 & Diatoma vulgaris Bory & 4,151 & $15,336,915$ \\
\hline 71 & 393851106503400 & $\begin{array}{l}\text { Brush Creek at mouth } \\
\text { near Eagle }\end{array}$ & 1 & 2000 & $8 / 14 / 2000$ & $39^{\circ} 38^{\prime} 51^{\prime \prime}$ & $106^{\circ} 50^{\prime} 34^{\prime \prime}$ & 6,500 & 147 & Diploneis puella (Schumann) Cleve & 692 & 226,557 \\
\hline 71 & 393851106503400 & $\begin{array}{l}\text { Brush Creek at mouth } \\
\text { near Eagle }\end{array}$ & 1 & 2000 & $8 / 14 / 2000$ & $39^{\circ} 38^{\prime} 51^{\prime \prime}$ & $106^{\circ} 50^{\prime} 34^{\prime \prime}$ & 6,500 & 147 & Encyonema silesiacum (Bleisch) Mann & 28,364 & $13,355,173$ \\
\hline 71 & 393851106503400 & $\begin{array}{l}\text { Brush Creek at mouth } \\
\text { near Eagle }\end{array}$ & 1 & 2000 & $8 / 14 / 2000$ & $39^{\circ} 38^{\prime} 51^{\prime \prime}$ & $106^{\circ} 50^{\prime} 34^{\prime \prime}$ & 6,500 & 147 & Gomphonema minutum (Agardh) Agardh & 2,767 & 480,001 \\
\hline 71 & 393851106503400 & $\begin{array}{l}\text { Brush Creek at mouth } \\
\text { near Eagle }\end{array}$ & 1 & 2000 & $8 / 14 / 2000$ & $39^{\circ} 38^{\prime} 51^{\prime \prime}$ & $106^{\circ} 50^{\prime} 34^{\prime \prime}$ & 6,500 & 147 & Gomphonema olivaceum (Lyngbye) Kützing & 4,843 & $1,666,192$ \\
\hline 71 & 393851106503400 & $\begin{array}{l}\text { Brush Creek at mouth } \\
\text { near Eagle }\end{array}$ & 1 & 2000 & $8 / 14 / 2000$ & $39^{\circ} 38^{\prime} 51^{\prime \prime}$ & $106^{\circ} 50^{\prime} 34^{\prime \prime}$ & 6,500 & 147 & $\begin{array}{l}\text { Homoeothrix janthina (Bornet et Flahault) } \\
\text { Starmach }\end{array}$ & $1,080,643$ & $35,021,831$ \\
\hline 71 & 393851106503400 & $\begin{array}{l}\text { Brush Creek at mouth } \\
\text { near Eagle }\end{array}$ & 1 & 2000 & $8 / 14 / 2000$ & $39^{\circ} 38^{\prime} 51^{\prime \prime}$ & $106^{\circ} 50^{\prime} 34^{\prime \prime}$ & 6,500 & 147 & Luticola nivalis (Ehrenberg) Mann & 1,384 & $1,989,587$ \\
\hline 71 & 393851106503400 & $\begin{array}{l}\text { Brush Creek at mouth } \\
\text { near Eagle }\end{array}$ & 1 & 2000 & $8 / 14 / 2000$ & $39^{\circ} 38^{\prime} 51^{\prime \prime}$ & $106^{\circ} 50^{\prime} 34^{\prime \prime}$ & 6,500 & 147 & Mayamaea atomus (Kützing) Lange-Bertalot & 4,151 & 108,410 \\
\hline 71 & 393851106503400 & $\begin{array}{l}\text { Brush Creek at mouth } \\
\text { near Eagle }\end{array}$ & 1 & 2000 & $8 / 14 / 2000$ & $39^{\circ} 38^{\prime} 51^{\prime \prime}$ & $106^{\circ} 50^{\prime} 34^{\prime \prime}$ & 6,500 & 147 & Merismopedia glauca (Ehrenberg) Kützing & 48,029 & $2,608,521$ \\
\hline 71 & 393851106503400 & $\begin{array}{l}\text { Brush Creek at mouth } \\
\text { near Eagle }\end{array}$ & 1 & 2000 & $8 / 14 / 2000$ & $39^{\circ} 38^{\prime} 51^{\prime \prime}$ & $106^{\circ} 50^{\prime} 34^{\prime \prime}$ & 6,500 & 147 & Navicula capitatoradiata Germain & 24,213 & $9,017,210$ \\
\hline 71 & 393851106503400 & $\begin{array}{l}\text { Brush Creek at mouth } \\
\text { near Eagle }\end{array}$ & 1 & 2000 & $8 / 14 / 2000$ & $39^{\circ} 38^{\prime} 51^{\prime \prime}$ & $106^{\circ} 50^{\prime} 34^{\prime \prime}$ & 6,500 & 147 & $\begin{array}{l}\text { Navicula cryptotenella Lange-Bertalot } \\
\text { ex Krammer et Lange-Bertalot }\end{array}$ & 96,160 & $34,802,601$ \\
\hline 71 & 393851106503400 & $\begin{array}{l}\text { Brush Creek at mouth } \\
\text { near Eagle }\end{array}$ & 1 & 2000 & $8 / 14 / 2000$ & $39^{\circ} 38^{\prime} 51^{\prime \prime}$ & $106^{\circ} 50^{\prime} 34^{\prime \prime}$ & 6,500 & 147 & Navicula gregaria Donkin & 12,452 & $3,112,827$ \\
\hline 71 & 393851106503400 & $\begin{array}{l}\text { Brush Creek at mouth } \\
\text { near Eagle }\end{array}$ & 1 & 2000 & $8 / 14 / 2000$ & $39^{\circ} 38^{\prime} 51^{\prime \prime}$ & $106^{\circ} 50^{\prime} 34^{\prime \prime}$ & 6,500 & 147 & Navicula minima Grunow & 1,384 & 73,484 \\
\hline 71 & 393851106503400 & $\begin{array}{l}\text { Brush Creek at mouth } \\
\text { near Eagle }\end{array}$ & 1 & 2000 & $8 / 14 / 2000$ & $39^{\circ} 38^{\prime} 51^{\prime \prime}$ & $106^{\circ} 50^{\prime} 34^{\prime \prime}$ & 6,500 & 147 & Navicula tripunctata (Müller) Bory & 57,420 & $54,328,094$ \\
\hline 71 & 393851106503400 & $\begin{array}{l}\text { Brush Creek at mouth } \\
\text { near Eagle }\end{array}$ & 1 & 2000 & $8 / 14 / 2000$ & $39^{\circ} 38^{\prime} 51^{\prime \prime}$ & $106^{\circ} 50^{\prime} 34^{\prime \prime}$ & 6,500 & 147 & Navicula veneta Kützing & 51,885 & $11,250,755$ \\
\hline
\end{tabular}


Table 2. Description of sites and algal data collected from selected sites the Eagle River watershed, Colorado, 2000-2001.—Continued

[ID, identification; NAVD, North American Vertical Datum of 1988; ft, feet; $\mathrm{mi}^{2}$, square miles; cells $/ \mathrm{cm}^{2}$, cells per square centimeter; $\mu \mathrm{m}^{3} / \mathrm{cm}^{2}$, cubic micrometer per square centimeter]

\begin{tabular}{|c|c|c|c|c|c|c|c|c|c|c|c|c|}
\hline $\begin{array}{l}\text { Site } \\
\text { ID }^{1}\end{array}$ & $\begin{array}{l}\text { USGS } \\
\text { station } \\
\text { number }\end{array}$ & Station name & $\begin{array}{l}\text { Replicate } \\
\text { sample } \\
\text { number }\end{array}$ & Year & $\begin{array}{l}\text { Collection } \\
\text { date }\end{array}$ & Latitude & Longitude & $\begin{array}{c}\text { Elevation } \\
\text { NAVD } 88 \\
\text { (ft) }\end{array}$ & $\begin{array}{c}\text { Drainage } \\
\text { area } \\
\left(\mathrm{mi}^{2}\right)\end{array}$ & Algal taxon name & $\begin{array}{c}\text { Total } \\
\text { density } \\
\text { (number of } \\
\text { cells/cm²) }\end{array}$ & $\begin{array}{c}\text { Total } \\
\text { biovolume } \\
\left(\mu \mathrm{m}^{3} / \mathrm{cm}^{2}\right)\end{array}$ \\
\hline 71 & 393851106503400 & $\begin{array}{l}\text { Brush Creek at mouth } \\
\text { near Eagle }\end{array}$ & 1 & 2000 & $8 / 14 / 2000$ & $39^{\circ} 38^{\prime} 51^{\prime \prime}$ & $106^{\circ} 50^{\prime} 34^{\prime \prime}$ & 6,500 & 147 & Nitzschia capitellata Hustedt & 2,767 & 693,761 \\
\hline 71 & 393851106503400 & $\begin{array}{l}\text { Brush Creek at mouth } \\
\text { near Eagle }\end{array}$ & 1 & 2000 & $8 / 14 / 2000$ & $39^{\circ} 38^{\prime} 51^{\prime \prime}$ & $106^{\circ} 50^{\prime} 34^{\prime \prime}$ & 6,500 & 147 & Nitzschia dissipata (Kützing) Grunow & 69,180 & $17,989,570$ \\
\hline 71 & 393851106503400 & $\begin{array}{l}\text { Brush Creek at mouth } \\
\text { near Eagle }\end{array}$ & 1 & 2000 & $8 / 14 / 2000$ & $39^{\circ} 38^{\prime} 51^{\prime \prime}$ & $106^{\circ} 50^{\prime} 34^{\prime \prime}$ & 6,500 & 147 & $\begin{array}{l}\text { Nitzschia dissipata var. media } \\
\text { (Hantzsch) Grunow }\end{array}$ & 4,151 & $2,002,154$ \\
\hline 71 & 393851106503400 & $\begin{array}{l}\text { Brush Creek at mouth } \\
\text { near Eagle }\end{array}$ & 1 & 2000 & $8 / 14 / 2000$ & $39^{\circ} 38^{\prime} 51^{\prime \prime}$ & $106^{\circ} 50^{\prime} 34^{\prime \prime}$ & 6,500 & 147 & Nitzschia inconspicua Grunow & 8,302 & 300,175 \\
\hline 71 & 393851106503400 & $\begin{array}{l}\text { Brush Creek at mouth } \\
\text { near Eagle }\end{array}$ & 1 & 2000 & $8 / 14 / 2000$ & $39^{\circ} 38^{\prime} 51^{\prime \prime}$ & $106^{\circ} 50^{\prime} 34^{\prime \prime}$ & 6,500 & 147 & Nitzschia palea (Kützing) Smith & 11,069 & $1,918,354$ \\
\hline 71 & 393851106503400 & $\begin{array}{l}\text { Brush Creek at mouth } \\
\text { near Eagle }\end{array}$ & 1 & 2000 & $8 / 14 / 2000$ & $39^{\circ} 38^{\prime} 51^{\prime \prime}$ & $106^{\circ} 50^{\prime} 34^{\prime \prime}$ & 6,500 & 147 & Nitzschia paleacea Grunow ex Van Heurck & 3,459 & 142,130 \\
\hline 71 & 393851106503400 & $\begin{array}{l}\text { Brush Creek at mouth } \\
\text { near Eagle }\end{array}$ & 1 & 2000 & $8 / 14 / 2000$ & $39^{\circ} 38^{\prime} 51^{\prime \prime}$ & $106^{\circ} 50^{\prime} 34^{\prime \prime}$ & 6,500 & 147 & Phormidium autumnale (Agardh) Gomont & 732,436 & $71,726,832$ \\
\hline 71 & 393851106503400 & $\begin{array}{l}\text { Brush Creek at mouth } \\
\text { near Eagle }\end{array}$ & 1 & 2000 & $8 / 14 / 2000$ & $39^{\circ} 38^{\prime} 51^{\prime \prime}$ & $106^{\circ} 50^{\prime} 34^{\prime \prime}$ & 6,500 & 147 & Pinnularia obscura Krasske & 692 & 241,414 \\
\hline 71 & 393851106503400 & $\begin{array}{l}\text { Brush Creek at mouth } \\
\text { near Eagle }\end{array}$ & 1 & 2000 & $8 / 14 / 2000$ & $39^{\circ} 38^{\prime} 51^{\prime \prime}$ & $106^{\circ} 50^{\prime} 34^{\prime \prime}$ & 6,500 & 147 & $\begin{array}{l}\text { Reimeria sinuata (Gregory) } \\
\text { Kociolek et Stoermer }\end{array}$ & 4,151 & 686,308 \\
\hline 71 & 393851106503400 & $\begin{array}{l}\text { Brush Creek at mouth } \\
\text { near Eagle }\end{array}$ & 1 & 2000 & $8 / 14 / 2000$ & $39^{\circ} 38^{\prime} 51^{\prime \prime}$ & $106^{\circ} 50^{\prime} 34^{\prime \prime}$ & 6,500 & 147 & $\begin{array}{l}\text { Rhoicosphenia abbreviata (Agardh) } \\
\text { Lange-Bertalot }\end{array}$ & 26,980 & $14,368,080$ \\
\hline 71 & 393851106503400 & $\begin{array}{l}\text { Brush Creek at mouth } \\
\text { near Eagle }\end{array}$ & 1 & 2001 & $8 / 15 / 2001$ & $39^{\circ} 38^{\prime} 51^{\prime \prime}$ & $106^{\circ} 50^{\prime} 34^{\prime \prime}$ & 6,500 & 147 & $\begin{array}{l}\text { Achnanthidium minutissimum (Kützing) } \\
\text { Czarnecki }\end{array}$ & 294,214 & $15,952,551$ \\
\hline 71 & 393851106503400 & $\begin{array}{l}\text { Brush Creek at mouth } \\
\text { near Eagle }\end{array}$ & 1 & 2001 & $8 / 15 / 2001$ & $39^{\circ} 38^{\prime} 51^{\prime \prime}$ & $106^{\circ} 50^{\prime} 34^{\prime \prime}$ & 6,500 & 147 & Amphora pediculus (Kützing) Grunow & 493,241 & $47,689,554$ \\
\hline 71 & 393851106503400 & $\begin{array}{l}\text { Brush Creek at mouth } \\
\text { near Eagle }\end{array}$ & 1 & 2001 & $8 / 15 / 2001$ & $39^{\circ} 38^{\prime} 51^{\prime \prime}$ & $106^{\circ} 50^{\prime} 34^{\prime \prime}$ & 6,500 & 147 & Cocconeis pediculus Ehrenberg & 56,247 & $175,579,104$ \\
\hline 71 & 393851106503400 & $\begin{array}{l}\text { Brush Creek at mouth } \\
\text { near Eagle }\end{array}$ & 1 & 2001 & $8 / 15 / 2001$ & $39^{\circ} 38^{\prime} 51^{\prime \prime}$ & $106^{\circ} 50^{\prime} 34^{\prime \prime}$ & 6,500 & 147 & Cymbella affinis Kützing & 82,207 & $41,839,195$ \\
\hline 71 & 393851106503400 & $\begin{array}{l}\text { Brush Creek at mouth } \\
\text { near Eagle }\end{array}$ & 1 & 2001 & $8 / 15 / 2001$ & $39^{\circ} 38^{\prime} 51^{\prime \prime}$ & $106^{\circ} 50^{\prime} 34^{\prime \prime}$ & 6,500 & 147 & Diatoma moniliformis Kützing & 17,307 & $3,158,545$ \\
\hline 71 & 393851106503400 & $\begin{array}{l}\text { Brush Creek at mouth } \\
\text { near Eagle }\end{array}$ & 1 & 2001 & $8 / 15 / 2001$ & $39^{\circ} 38^{\prime} 51^{\prime \prime}$ & $106^{\circ} 50^{\prime} 34^{\prime \prime}$ & 6,500 & 147 & Encyonema brehmii (Hustedt) Mann & 47,593 & $1,312,221$ \\
\hline 71 & 393851106503400 & $\begin{array}{l}\text { Brush Creek at mouth } \\
\text { near Eagle }\end{array}$ & 1 & 2001 & $8 / 15 / 2001$ & $39^{\circ} 38^{\prime} 51^{\prime \prime}$ & $106^{\circ} 50^{\prime} 34^{\prime \prime}$ & 6,500 & 147 & Encyonema silesiacum (Bleisch) Mann & 12,980 & $6,164,808$ \\
\hline 71 & 393851106503400 & $\begin{array}{l}\text { Brush Creek at mouth } \\
\text { near Eagle }\end{array}$ & 1 & 2001 & $8 / 15 / 2001$ & $39^{\circ} 38^{\prime} 51^{\prime \prime}$ & $106^{\circ} 50^{\prime} 34^{\prime \prime}$ & 6,500 & 147 & Epithemia sorex Kützing & 4,327 & $7,467,664$ \\
\hline 71 & 393851106503400 & $\begin{array}{l}\text { Brush Creek at mouth } \\
\text { near Eagle }\end{array}$ & 1 & 2001 & $8 / 15 / 2001$ & $39^{\circ} 38^{\prime} 51^{\prime \prime}$ & $106^{\circ} 50^{\prime} 34^{\prime \prime}$ & 6,500 & 147 & Gomphonema olivaceum (Lyngbye) Kützing & 8,653 & $3,279,090$ \\
\hline 71 & 393851106503400 & $\begin{array}{l}\text { Brush Creek at mouth } \\
\text { near Eagle }\end{array}$ & 1 & 2001 & $8 / 15 / 2001$ & $39^{\circ} 38^{\prime} 51^{\prime \prime}$ & $106^{\circ} 50^{\prime} 34^{\prime \prime}$ & 6,500 & 147 & $\begin{array}{l}\text { Gomphonema pumilum (Grunow) Reichardt } \\
\text { et Lange-Bertalot }\end{array}$ & 8,653 & $1,888,582$ \\
\hline 71 & 393851106503400 & $\begin{array}{l}\text { Brush Creek at mouth } \\
\text { near Eagle }\end{array}$ & 1 & 2001 & $8 / 15 / 2001$ & $39^{\circ} 38^{\prime} 51^{\prime \prime}$ & $106^{\circ} 50^{\prime} 34^{\prime \prime}$ & 6,500 & 147 & $\begin{array}{l}\text { Homoeothrix janthina (Bornet et Flahault) } \\
\text { Starmach }\end{array}$ & $2,239,161$ & $38,544,157$ \\
\hline 71 & 393851106503400 & $\begin{array}{l}\text { Brush Creek at mouth } \\
\text { near Eagle }\end{array}$ & 1 & 2001 & $8 / 15 / 2001$ & $39^{\circ} 38^{\prime} 51^{\prime \prime}$ & $106^{\circ} 50^{\prime} 34^{\prime \prime}$ & 6,500 & 147 & Lyngbya sp. & 702,482 & $97,460,467$ \\
\hline 71 & 393851106503400 & $\begin{array}{l}\text { Brush Creek at mouth } \\
\text { near Eagle }\end{array}$ & 1 & 2001 & $8 / 15 / 2001$ & $39^{\circ} 38^{\prime} 51^{\prime \prime}$ & $106^{\circ} 50^{\prime} 34^{\prime \prime}$ & 6,500 & 147 & Mayamaea atomus (Kützing) Lange-Bertalot & 8,653 & 248,484 \\
\hline
\end{tabular}


Table 2. Description of sites and algal data collected from selected sites the Eagle River watershed, Colorado, 2000-2001.—Continued

[ID, identification; NAVD, North American Vertical Datum of 1988; ft, feet; $\mathrm{mi}^{2}$, square miles; cells $/ \mathrm{cm}^{2}$, cells per square centimeter; $\mu \mathrm{m}^{3} / \mathrm{cm}^{2}$, cubic micrometer per square centimeter]

\begin{tabular}{|c|c|c|c|c|c|c|c|c|c|c|c|c|}
\hline $\begin{array}{l}\text { Site } \\
\text { ID' }\end{array}$ & $\begin{array}{l}\text { USGS } \\
\text { station } \\
\text { number }\end{array}$ & Station name & $\begin{array}{l}\text { Replicate } \\
\text { sample } \\
\text { number }\end{array}$ & Year & $\begin{array}{l}\text { Collection } \\
\text { date }\end{array}$ & Latitude & Longitude & $\begin{array}{c}\text { Elevation } \\
\text { NAVD } 88 \\
\text { (ft) }\end{array}$ & $\begin{array}{c}\text { Drainage } \\
\text { area } \\
\left(\mathrm{mi}^{2}\right)\end{array}$ & Algal taxon name & $\begin{array}{c}\text { Total } \\
\text { density } \\
\text { (number of } \\
\text { cells/cm²) }\end{array}$ & $\begin{array}{c}\text { Total } \\
\text { biovolume } \\
\left(\mu \mathrm{m}^{3} / \mathrm{cm}^{2}\right)\end{array}$ \\
\hline 71 & 393851106503400 & $\begin{array}{l}\text { Brush Creek at mouth } \\
\text { near Eagle }\end{array}$ & 1 & 2001 & $8 / 15 / 2001$ & $39^{\circ} 38^{\prime} 51^{\prime \prime}$ & $106^{\circ} 50^{\prime} 34^{\prime \prime}$ & 6,500 & 147 & Navicula capitatoradiata Germain & 60,573 & $22,650,664$ \\
\hline 71 & 393851106503400 & $\begin{array}{l}\text { Brush Creek at mouth } \\
\text { near Eagle }\end{array}$ & 1 & 2001 & $8 / 15 / 2001$ & $39^{\circ} 38^{\prime} 51^{\prime \prime}$ & $106^{\circ} 50^{\prime} 34^{\prime \prime}$ & 6,500 & 147 & $\begin{array}{l}\text { Navicula cryptotenella Lange-Bertalot } \\
\text { ex Krammer et Lange-Bertalot }\end{array}$ & 467,281 & $124,119,976$ \\
\hline 71 & 393851106503400 & $\begin{array}{l}\text { Brush Creek at mouth } \\
\text { near Eagle }\end{array}$ & 1 & 2001 & $8 / 15 / 2001$ & $39^{\circ} 38^{\prime} 51^{\prime \prime}$ & $106^{\circ} 50^{\prime} 34^{\prime \prime}$ & 6,500 & 147 & Navicula gregaria Donkin & 43,267 & $10,858,292$ \\
\hline 71 & 393851106503400 & $\begin{array}{l}\text { Brush Creek at mouth } \\
\text { near Eagle }\end{array}$ & 1 & 2001 & $8 / 15 / 2001$ & $39^{\circ} 38^{\prime} 51^{\prime \prime}$ & $106^{\circ} 50^{\prime} 34^{\prime \prime}$ & 6,500 & 147 & Navicula lanceolata (Agardh) Ehrenberg & 8,653 & $10,918,696$ \\
\hline 71 & 393851106503400 & $\begin{array}{l}\text { Brush Creek at mouth } \\
\text { near Eagle }\end{array}$ & 1 & 2001 & $8 / 15 / 2001$ & $39^{\circ} 38^{\prime} 51^{\prime \prime}$ & $106^{\circ} 50^{\prime} 34^{\prime \prime}$ & 6,500 & 147 & Navicula minima Grunow & 17,307 & 778,918 \\
\hline 71 & 393851106503400 & $\begin{array}{l}\text { Brush Creek at mouth } \\
\text { near Eagle }\end{array}$ & 1 & 2001 & $8 / 15 / 2001$ & $39^{\circ} 38^{\prime} 51^{\prime \prime}$ & $106^{\circ} 50^{\prime} 34^{\prime \prime}$ & 6,500 & 147 & Navicula tripunctata (Müller) Bory & 393,728 & $358,029,992$ \\
\hline 71 & 393851106503400 & $\begin{array}{l}\text { Brush Creek at mouth } \\
\text { near Eagle }\end{array}$ & 1 & 2001 & $8 / 15 / 2001$ & $39^{\circ} 38^{\prime} 51^{\prime \prime}$ & $106^{\circ} 50^{\prime} 34^{\prime \prime}$ & 6,500 & 147 & Navicula veneta Kützing & 103,840 & $22,926,064$ \\
\hline 71 & 393851106503400 & $\begin{array}{l}\text { Brush Creek at mouth } \\
\text { near Eagle }\end{array}$ & 1 & 2001 & $8 / 15 / 2001$ & $39^{\circ} 38^{\prime} 51^{\prime \prime}$ & $106^{\circ} 50^{\prime} 34^{\prime \prime}$ & 6,500 & 147 & Nitzschia dissipata (Kützing) Grunow & 194,700 & $50,200,587$ \\
\hline 71 & 393851106503400 & $\begin{array}{l}\text { Brush Creek at mouth } \\
\text { near Eagle }\end{array}$ & 1 & 2001 & $8 / 15 / 2001$ & $39^{\circ} 38^{\prime} 51^{\prime \prime}$ & $106^{\circ} 50^{\prime} 34^{\prime \prime}$ & 6,500 & 147 & Nitzschia inconspicua Grunow & 112,494 & $6,075,302$ \\
\hline 71 & 393851106503400 & $\begin{array}{l}\text { Brush Creek at mouth } \\
\text { near Eagle }\end{array}$ & 1 & 2001 & $8 / 15 / 2001$ & $39^{\circ} 38^{\prime} 51^{\prime \prime}$ & $106^{\circ} 50^{\prime} 34^{\prime \prime}$ & 6,500 & 147 & Nitzschia palea var. debilis (Kützing) Grunow & 17,307 & $3,014,223$ \\
\hline 71 & 393851106503400 & $\begin{array}{l}\text { Brush Creek at mouth } \\
\text { near Eagle }\end{array}$ & 1 & 2001 & $8 / 15 / 2001$ & $39^{\circ} 38^{\prime} 51^{\prime \prime}$ & $106^{\circ} 50^{\prime} 34^{\prime \prime}$ & 6,500 & 147 & Nitzschia recta Hantzsch ex Rabenhorst & 4,327 & $6,586,628$ \\
\hline 71 & 393851106503400 & $\begin{array}{l}\text { Brush Creek at mouth } \\
\text { near Eagle }\end{array}$ & 1 & 2001 & $8 / 15 / 2001$ & $39^{\circ} 38^{\prime} 51^{\prime \prime}$ & $106^{\circ} 50^{\prime} 34^{\prime \prime}$ & 6,500 & 147 & Nitzschia sigmoidea (Nitzsch) Ehrenberg & 12,980 & $34,030,513$ \\
\hline 71 & 393851106503400 & $\begin{array}{l}\text { Brush Creek at mouth } \\
\text { near Eagle }\end{array}$ & 1 & 2001 & $8 / 15 / 2001$ & $39^{\circ} 38^{\prime} 51^{\prime \prime}$ & $106^{\circ} 50^{\prime} 34^{\prime \prime}$ & 6,500 & 147 & Nitzschia sublinearis Hustedt & 34,613 & $90,605,657$ \\
\hline 71 & 393851106503400 & $\begin{array}{l}\text { Brush Creek at mouth } \\
\text { near Eagle }\end{array}$ & 1 & 2001 & $8 / 15 / 2001$ & $39^{\circ} 38^{\prime} 51^{\prime \prime}$ & $106^{\circ} 50^{\prime} 34^{\prime \prime}$ & 6,500 & 147 & Phormidium autumnale (Agardh) Gomont & $31,545,833$ & $3,058,531,683$ \\
\hline 71 & 393851106503400 & $\begin{array}{l}\text { Brush Creek at mouth } \\
\text { near Eagle }\end{array}$ & 1 & 2001 & $8 / 15 / 2001$ & $39^{\circ} 38^{\prime} 51^{\prime \prime}$ & $106^{\circ} 50^{\prime} 34^{\prime \prime}$ & 6,500 & 147 & $\begin{array}{l}\text { Planothidium lanceolatum } \\
\text { (Brébisson ex Kützing) Lange-Bertalot }\end{array}$ & 8,653 & $1,185,388$ \\
\hline 71 & 393851106503400 & $\begin{array}{l}\text { Brush Creek at mouth } \\
\text { near Eagle }\end{array}$ & 1 & 2001 & $8 / 15 / 2001$ & $39^{\circ} 38^{\prime} 51^{\prime \prime}$ & $106^{\circ} 50^{\prime} 34^{\prime \prime}$ & 6,500 & 147 & $\begin{array}{l}\text { Reimeria sinuata (Gregory) } \\
\text { Kociolek et Stoermer }\end{array}$ & 25,960 & $4,375,298$ \\
\hline 71 & 393851106503400 & $\begin{array}{l}\text { Brush Creek at mouth } \\
\text { near Eagle }\end{array}$ & 1 & 2001 & $8 / 15 / 2001$ & $39^{\circ} 38^{\prime} 51^{\prime \prime}$ & $106^{\circ} 50^{\prime} 34^{\prime \prime}$ & 6,500 & 147 & $\begin{array}{l}\text { Rhoicosphenia abbreviata (Agardh) } \\
\text { Lange-Bertalot }\end{array}$ & 103,840 & $53,736,276$ \\
\hline 71 & 393851106503400 & $\begin{array}{l}\text { Brush Creek at mouth } \\
\text { near Eagle }\end{array}$ & 1 & 2001 & $8 / 15 / 2001$ & $39^{\circ} 38^{\prime} 51^{\prime \prime}$ & $106^{\circ} 50^{\prime} 34^{\prime \prime}$ & 6,500 & 147 & $\begin{array}{l}\text { Staurosirella pinnata (Ehrenberg) } \\
\text { Williams et Round }\end{array}$ & 8,653 & 835,638 \\
\hline 71 & 393851106503400 & $\begin{array}{l}\text { Brush Creek at mouth } \\
\text { near Eagle }\end{array}$ & 1 & 2001 & $8 / 15 / 2001$ & $39^{\circ} 38^{\prime} 51^{\prime \prime}$ & $106^{\circ} 50^{\prime} 34^{\prime \prime}$ & 6,500 & 147 & Surirella minuta Brébisson & 25,960 & $22,920,851$ \\
\hline 71 & 393851106503400 & $\begin{array}{l}\text { Brush Creek at mouth } \\
\text { near Eagle }\end{array}$ & 1 & 2001 & $8 / 15 / 2001$ & $39^{\circ} 38^{\prime} 51^{\prime \prime}$ & $106^{\circ} 50^{\prime} 34^{\prime \prime}$ & 6,500 & 147 & Unknown alga flagellate $(<10 \mu)$ & 812,245 & $78,058,729$ \\
\hline 71 & 393851106503400 & $\begin{array}{l}\text { Brush Creek at mouth } \\
\text { near Eagle }\end{array}$ & 1 & 2001 & $8 / 15 / 2001$ & $39^{\circ} 38^{\prime} 51^{\prime \prime}$ & $106^{\circ} 50^{\prime} 34^{\prime \prime}$ & 6,500 & 147 & $\begin{array}{l}\text { Unknown Cyanophyte Oscillatoriales } \\
\text { (no sheath) }\end{array}$ & 373,194 & $5,536,533$ \\
\hline 72 & 09069000 & Eagle River at Gypsum & 1 & 2000 & $8 / 14 / 2000$ & $39^{\circ} 39^{\prime} 00^{\prime \prime}$ & $106^{\circ} 57^{\prime} 06^{\prime \prime}$ & 6,276 & 842 & $\begin{array}{l}\text { Achnanthidium minutissimum (Kützing) } \\
\text { Czarnecki }\end{array}$ & 141,151 & $7,773,449$ \\
\hline 72 & 09069000 & Eagle River at Gypsum & 1 & 2000 & $8 / 14 / 2000$ & $39^{\circ} 39^{\prime} 00^{\prime \prime}$ & $106^{\circ} 57^{\prime} 06^{\prime \prime}$ & 6,276 & 842 & Amphora pediculus (Kützing) Grunow & 7,208 & 682,065 \\
\hline 72 & 09069000 & Eagle River at Gypsum & 1 & 2000 & $8 / 14 / 2000$ & $39^{\circ} 39^{\prime} 00^{\prime \prime}$ & $106^{\circ} 57^{\prime} 06^{\prime \prime}$ & 6,276 & 842 & $\begin{array}{l}\text { Cocconeis placentula var. euglypta } \\
\text { (Ehrenberg) Grunow }\end{array}$ & 601 & 361,855 \\
\hline 72 & 09069000 & Eagle River at Gypsum & 1 & 2000 & $8 / 14 / 2000$ & $39^{\circ} 39^{\prime} 00^{\prime \prime}$ & $106^{\circ} 57^{\prime} 06^{\prime \prime}$ & 6,276 & 842 & $\begin{array}{l}\text { Cocconeis placentula var. lineata (Ehrenberg) } \\
\text { Van Heurck }\end{array}$ & 5,406 & $5,663,915$ \\
\hline
\end{tabular}


Table 2. Description of sites and algal data collected from selected sites the Eagle River watershed, Colorado, 2000-2001.—Continued

[ID, identification; NAVD, North American Vertical Datum of 1988; ft, feet; $\mathrm{mi}^{2}$, square miles; cells $/ \mathrm{cm}^{2}$, cells per square centimeter; $\mu \mathrm{m}^{3} / \mathrm{cm}^{2}$, cubic micrometer per square centimeter]

\begin{tabular}{|c|c|c|c|c|c|c|c|c|c|c|c|c|}
\hline $\begin{array}{l}\text { Site } \\
\text { ID }^{1}\end{array}$ & $\begin{array}{l}\text { USGS } \\
\text { station } \\
\text { number }\end{array}$ & Station name & $\begin{array}{c}\text { Replicate } \\
\text { sample } \\
\text { number }\end{array}$ & Year & $\begin{array}{l}\text { Collection } \\
\text { date }\end{array}$ & Latitude & Longitude & $\begin{array}{c}\text { Elevation } \\
\text { NAVD } 88 \\
\text { (ft) }\end{array}$ & $\begin{array}{c}\text { Drainage } \\
\text { area } \\
\left(\mathrm{mi}^{2}\right)\end{array}$ & Algal taxon name & $\begin{array}{c}\text { Total } \\
\text { density } \\
\text { (number of } \\
\text { cells/cm²) }\end{array}$ & $\begin{array}{c}\text { Total } \\
\text { biovolume } \\
\left(\mu \mathrm{m}^{3} / \mathrm{cm}^{2}\right)\end{array}$ \\
\hline 72 & 09069000 & Eagle River at Gypsum & 1 & 2000 & $8 / 14 / 2000$ & $39^{\circ} 39^{\prime} 00^{\prime \prime}$ & $106^{\circ} 57^{\prime} 06^{\prime \prime}$ & 6,276 & 842 & Cyclotella meneghiniana Kützing & 1,201 & 916,371 \\
\hline 72 & 09069000 & Eagle River at Gypsum & 1 & 2000 & $8 / 14 / 2000$ & $39^{\circ} 39^{\prime} 00^{\prime \prime}$ & $106^{\circ} 57^{\prime} 06^{\prime \prime}$ & 6,276 & 842 & Cymbella affinis Kützing & 12,613 & $6,383,773$ \\
\hline 72 & 09069000 & Eagle River at Gypsum & 1 & 2000 & $8 / 14 / 2000$ & $39^{\circ} 39^{\prime} 00^{\prime \prime}$ & $106^{\circ} 57^{\prime} 06^{\prime \prime}$ & 6,276 & 842 & Encyonema minutum (Hilse) Mann & 21,022 & $4,498,467$ \\
\hline 72 & 09069000 & Eagle River at Gypsum & 1 & 2000 & $8 / 14 / 2000$ & $39^{\circ} 39^{\prime} 00^{\prime \prime}$ & $106^{\circ} 57^{\prime} 06^{\prime \prime}$ & 6,276 & 842 & Encyonema silesiacum (Bleisch) Mann & 137,547 & $64,764,236$ \\
\hline 72 & 09069000 & Eagle River at Gypsum & 1 & 2000 & $8 / 14 / 2000$ & $39^{\circ} 39^{\prime} 00^{\prime \prime}$ & $106^{\circ} 57^{\prime} 06^{\prime \prime}$ & 6,276 & 842 & Gomphonema parvulum (Kützing) Kützing & 5,406 & $1,207,402$ \\
\hline 72 & 09069000 & Eagle River at Gypsum & 1 & 2000 & $8 / 14 / 2000$ & $39^{\circ} 39^{\prime} 00^{\prime \prime}$ & $106^{\circ} 57^{\prime} 06^{\prime \prime}$ & 6,276 & 842 & $\begin{array}{l}\text { Homoeothrix janthina (Bornet et Flahault) } \\
\text { Starmach }\end{array}$ & $11,952,927$ & $387,374,469$ \\
\hline 72 & 09069000 & Eagle River at Gypsum & 1 & 2000 & $8 / 14 / 2000$ & $39^{\circ} 39^{\prime} 00^{\prime \prime}$ & $106^{\circ} 57^{\prime} 06^{\prime \prime}$ & 6,276 & 842 & Navicula minima Grunow & 1,201 & 63,801 \\
\hline 72 & 09069000 & Eagle River at Gypsum & 1 & 2000 & $8 / 14 / 2000$ & $39^{\circ} 39^{\prime} 00^{\prime \prime}$ & $106^{\circ} 57^{\prime} 06^{\prime \prime}$ & 6,276 & 842 & Nitzschia fonticola Grunow & 10,812 & $1,073,625$ \\
\hline 72 & 09069000 & Eagle River at Gypsum & 1 & 2000 & $8 / 14 / 2000$ & $39^{\circ} 39^{\prime} 00^{\prime \prime}$ & $106^{\circ} 57^{\prime} 06^{\prime \prime}$ & 6,276 & 842 & Nitzschia inconspicua Grunow & 4,204 & 225,643 \\
\hline 72 & 09069000 & Eagle River at Gypsum & 1 & 2000 & $8 / 14 / 2000$ & $39^{\circ} 39^{\prime} 00^{\prime \prime}$ & $106^{\circ} 57^{\prime} 06^{\prime \prime}$ & 6,276 & 842 & Nitzschia palea (Kützing) Smith & 4,805 & 832,785 \\
\hline 72 & 09069000 & Eagle River at Gypsum & 1 & 2000 & $8 / 14 / 2000$ & $39^{\circ} 39^{\prime} 00^{\prime \prime}$ & $106^{\circ} 57^{\prime} 06^{\prime \prime}$ & 6,276 & 842 & $\begin{array}{l}\text { Phormidium autumnale } \\
\text { (Agardh) Gomont }\end{array}$ & $1,204,484$ & $117,954,185$ \\
\hline 72 & 09069000 & Eagle River at Gypsum & 1 & 2000 & $8 / 14 / 2000$ & $39^{\circ} 39^{\prime} 00^{\prime \prime}$ & $106^{\circ} 57^{\prime} 06^{\prime \prime}$ & 6,276 & 842 & $\begin{array}{l}\text { Reimeria sinuata (Gregory) } \\
\text { Kociolek et Stoermer }\end{array}$ & 32,435 & $5,362,852$ \\
\hline 72 & 09069000 & Eagle River at Gypsum & 1 & 2000 & $8 / 14 / 2000$ & $39^{\circ} 39^{\prime} 00^{\prime \prime}$ & $106^{\circ} 57^{\prime} 06^{\prime \prime}$ & 6,276 & 842 & $\begin{array}{l}\text { Rhoicosphenia abbreviata (Agardh) } \\
\text { Lange-Bertalot }\end{array}$ & 1,201 & 639,732 \\
\hline 72 & 09069000 & Eagle River at Gypsum & 1 & 2000 & $8 / 14 / 2000$ & $39^{\circ} 39^{\prime} 00^{\prime \prime}$ & $106^{\circ} 57^{\prime} 06^{\prime \prime}$ & 6,276 & 842 & Scenedesmus acutus Meyen & 107,235 & $9,738,362$ \\
\hline 72 & 09069000 & Eagle River at Gypsum & 1 & 2000 & $8 / 14 / 2000$ & $39^{\circ} 39^{\prime} 00^{\prime \prime}$ & $106^{\circ} 57^{\prime} 06^{\prime \prime}$ & 6,276 & 842 & Stigeoclonium lubricum (Dillwyn) Kützing & 28,724 & $42,634,084$ \\
\hline 72 & 09069000 & Eagle River at Gypsum & 1 & 2000 & $8 / 14 / 2000$ & $39^{\circ} 39^{\prime} 00^{\prime \prime}$ & $106^{\circ} 57^{\prime} 06^{\prime \prime}$ & 6,276 & 842 & $\begin{array}{l}\text { Unknown Rhodophyte Florideophycidae } \\
\text { (chantransia) }\end{array}$ & 13,404 & $47,440,651$ \\
\hline 72 & 09069000 & Eagle River at Gypsum & 1 & 2001 & $8 / 15 / 2001$ & $39^{\circ} 39^{\prime} 00^{\prime \prime}$ & $106^{\circ} 57^{\prime} 06^{\prime \prime}$ & 6,276 & 842 & $\begin{array}{l}\text { Achnanthidium minutissimum (Kützing) } \\
\text { Czarnecki }\end{array}$ & 27,672 & $1,500,385$ \\
\hline 72 & 09069000 & Eagle River at Gypsum & 1 & 2001 & $8 / 15 / 2001$ & $39^{\circ} 39^{\prime} 00^{\prime \prime}$ & $106^{\circ} 57^{\prime} 06^{\prime \prime}$ & 6,276 & 842 & Amphora pediculus (Kützing) Grunow & 5,051 & 488,379 \\
\hline 72 & 09069000 & Eagle River at Gypsum & 1 & 2001 & $8 / 15 / 2001$ & $39^{\circ} 39^{\prime} 00^{\prime \prime}$ & $106^{\circ} 57^{\prime} 06^{\prime \prime}$ & 6,276 & 842 & Caloneis bacillum (Grunow) Cleve & 1,318 & 566,831 \\
\hline 72 & 09069000 & Eagle River at Gypsum & 1 & 2001 & $8 / 15 / 2001$ & $39^{\circ} 39^{\prime} 00^{\prime \prime}$ & $106^{\circ} 57^{\prime} 06^{\prime \prime}$ & 6,276 & 842 & Cocconeis pediculus Ehrenberg & 220 & 685,552 \\
\hline 72 & 09069000 & Eagle River at Gypsum & 1 & 2001 & $8 / 15 / 2001$ & $39^{\circ} 39^{\prime} 00^{\prime \prime}$ & $106^{\circ} 57^{\prime} 06^{\prime \prime}$ & 6,276 & 842 & $\begin{array}{l}\text { Cocconeis placentula var. euglypta } \\
\text { (Ehrenberg) Grunow }\end{array}$ & 1,757 & $1,043,951$ \\
\hline 72 & 09069000 & Eagle River at Gypsum & 1 & 2001 & $8 / 15 / 2001$ & $39^{\circ} 39^{\prime} 00^{\prime \prime}$ & $106^{\circ} 57^{\prime} 06^{\prime \prime}$ & 6,276 & 842 & $\begin{array}{l}\text { Cocconeis placentula var. lineata (Ehrenberg) } \\
\text { Van Heurck }\end{array}$ & 12,079 & $12,738,342$ \\
\hline 72 & 09069000 & Eagle River at Gypsum & 1 & 2001 & $8 / 15 / 2001$ & $39^{\circ} 39^{\prime} 00^{\prime \prime}$ & $106^{\circ} 57^{\prime} 06^{\prime \prime}$ & 6,276 & 842 & Cymbella affinis Kützing & 1,757 & 894,192 \\
\hline 72 & 09069000 & Eagle River at Gypsum & 1 & 2001 & $8 / 15 / 2001$ & $39^{\circ} 39^{\prime} 00^{\prime \prime}$ & $106^{\circ} 57^{\prime} 06^{\prime \prime}$ & 6,276 & 842 & Encyonema brehmii (Hustedt) Mann & 3,514 & 96,882 \\
\hline 72 & 09069000 & Eagle River at Gypsum & 1 & 2001 & $8 / 15 / 2001$ & $39^{\circ} 39^{\prime} 00^{\prime \prime}$ & $106^{\circ} 57^{\prime} 06^{\prime \prime}$ & 6,276 & 842 & Encyonema minutum (Hilse) Mann & 12,079 & $2,607,038$ \\
\hline 72 & 09069000 & Eagle River at Gypsum & 1 & 2001 & $8 / 15 / 2001$ & $39^{\circ} 39^{\prime} 00^{\prime \prime}$ & $106^{\circ} 57^{\prime} 06^{\prime \prime}$ & 6,276 & 842 & Encyonema silesiacum (Bleisch) Mann & 7,247 & $3,442,098$ \\
\hline 72 & 09069000 & Eagle River at Gypsum & 1 & 2001 & $8 / 15 / 2001$ & $39^{\circ} 39^{\prime} 00^{\prime \prime}$ & $106^{\circ} 57^{\prime} 06^{\prime \prime}$ & 6,276 & 842 & Gomphonema olivaceum (Lyngbye) Kützing & 220 & 83,221 \\
\hline 72 & 09069000 & Eagle River at Gypsum & 1 & 2001 & $8 / 15 / 2001$ & $39^{\circ} 39^{\prime} 00^{\prime \prime}$ & $106^{\circ} 57^{\prime} 06^{\prime \prime}$ & 6,276 & 842 & Gomphonema parvulum (Kützing) Kützing & 36,676 & $8,014,504$ \\
\hline 72 & 09069000 & Eagle River at Gypsum & 1 & 2001 & $8 / 15 / 2001$ & $39^{\circ} 39^{\prime} 00^{\prime \prime}$ & $106^{\circ} 57^{\prime} 06^{\prime \prime}$ & 6,276 & 842 & $\begin{array}{l}\text { Gomphonema pumilum (Grunow) } \\
\text { Reichardt et Lange-Bertalot }\end{array}$ & 439 & 95,862 \\
\hline 72 & 09069000 & Eagle River at Gypsum & 1 & 2001 & $8 / 15 / 2001$ & $39^{\circ} 39^{\prime} 00^{\prime \prime}$ & $106^{\circ} 57^{\prime} 06^{\prime \prime}$ & 6,276 & 842 & $\begin{array}{l}\text { Homoeothrix janthina (Bornet et Flahault) } \\
\text { Starmach }\end{array}$ & $3,852,646$ & $66,318,133$ \\
\hline 72 & 09069000 & Eagle Riv & 1 & 2001 & $8 / 15 / 2001$ & $39^{\circ} 39^{\prime} 00^{\prime \prime}$ & $106^{\circ} 57^{\prime} 06^{\prime \prime}$ & 6,276 & 842 & Mayamaea atomus (Kützing) Lange-Bertalot & 2,635 & 75,676 \\
\hline 72 & 09069000 & Eagle River at Gypsum & 1 & 2001 & $8 / 15 / 2001$ & $39^{\circ} 39^{\prime} 00^{\prime \prime}$ & $106^{\circ} 57^{\prime} 06^{\prime \prime}$ & 6,276 & 842 & Navicula capitatoradiata Germain & 439 & 164,246 \\
\hline 72 & 09069000 & Eagle River at Gypsum & 1 & 2001 & $8 / 15 / 2001$ & $39^{\circ} 39^{\prime} 00^{\prime \prime}$ & $106^{\circ} 57^{\prime} 06^{\prime \prime}$ & 6,276 & 842 & $\begin{array}{l}\text { Navicula cryptotenella Lange-Bertalot } \\
\text { ex Krammer et Lange-Bertalot }\end{array}$ & 2,416 & 641,685 \\
\hline 72 & 09069000 & Eagle River at Gypsum & 1 & 2001 & $8 / 15 / 2001$ & $39^{\circ} 39^{\prime} 00^{\prime \prime}$ & $106^{\circ} 57^{\prime} 06^{\prime \prime}$ & 6,276 & 842 & Navicula gregaria Donkin & 439 & 110,231 \\
\hline 72 & 09069000 & Eagle River at Gypsum & 1 & 2001 & $8 / 15 / 2001$ & $39^{\circ} 39^{\prime} 00^{\prime \prime}$ & $106^{\circ} 57^{\prime} 06^{\prime \prime}$ & 6,276 & 842 & Navicula lanceolata (Agardh) Ehrenberg & 878 & $1,108,439$ \\
\hline 72 & 09069000 & Eagle River at Gypsum & 1 & 2001 & $8 / 15 / 2001$ & $39^{\circ} 39^{\prime} 00^{\prime \prime}$ & $106^{\circ} 57^{\prime} 06^{\prime \prime}$ & 6,276 & 842 & Navicula minima Grunow & 3,514 & 158,148 \\
\hline
\end{tabular}


Table 2. Description of sites and algal data collected from selected sites the Eagle River watershed, Colorado, 2000-2001.—Continued

[ID, identification; NAVD, North American Vertical Datum of 1988; ft, feet; $\mathrm{mi}^{2}$, square miles; cells $/ \mathrm{cm}^{2}$, cells per square centimeter; $\mu \mathrm{m}^{3} / \mathrm{cm}^{2}$, cubic micrometer per square centimeter]

\begin{tabular}{|c|c|c|c|c|c|c|c|c|c|c|c|c|}
\hline $\begin{array}{l}\text { Site } \\
\text { ID' }\end{array}$ & $\begin{array}{l}\text { USGS } \\
\text { station } \\
\text { number }\end{array}$ & Station name & $\begin{array}{l}\text { Replicate } \\
\text { sample } \\
\text { number }\end{array}$ & Year & $\begin{array}{l}\text { Collection } \\
\text { date }\end{array}$ & Latitude & Longitude & $\begin{array}{c}\text { Elevation } \\
\text { NAVD } 88 \\
\text { (ft) }\end{array}$ & $\begin{array}{c}\text { Drainage } \\
\text { area } \\
\left(\mathrm{mi}^{2}\right)\end{array}$ & Algal taxon name & $\begin{array}{c}\text { Total } \\
\text { density } \\
\text { (number of } \\
\text { cells/cm²) }\end{array}$ & $\begin{array}{c}\text { Total } \\
\text { biovolume } \\
\left(\mu \mathrm{m}^{3} / \mathrm{cm}^{2}\right)\end{array}$ \\
\hline 72 & 09069000 & Eagle River at Gypsum & 1 & 2001 & $8 / 15 / 2001$ & $39^{\circ} 39^{\prime} 00^{\prime \prime}$ & $106^{\circ} 57^{\prime} 06^{\prime \prime}$ & 6,276 & 842 & Navicula tripunctata (Müller) Bory & 878 & 798,820 \\
\hline 72 & 09069000 & Eagle River at Gypsum & 1 & 2001 & $8 / 15 / 2001$ & $39^{\circ} 39^{\prime} 00^{\prime \prime}$ & $106^{\circ} 57^{\prime} 06^{\prime \prime}$ & 6,276 & 842 & Navicula veneta Kützing & 878 & 193,950 \\
\hline 72 & 09069000 & Eagle River at Gypsum & 1 & 2001 & $8 / 15 / 2001$ & $39^{\circ} 39^{\prime} 00^{\prime \prime}$ & $106^{\circ} 57^{\prime} 06^{\prime \prime}$ & 6,276 & 842 & $\begin{array}{l}\text { Nitzschia cf. tubicola } \\
\text { Grunow ex Cleve et Grunow }\end{array}$ & 439 & 143,337 \\
\hline 72 & 09069000 & Eagle River at Gypsum & 1 & 2001 & $8 / 15 / 2001$ & $39^{\circ} 39^{\prime} 00^{\prime \prime}$ & $106^{\circ} 57^{\prime} 06^{\prime \prime}$ & 6,276 & 842 & Nitzschia fonticola Grunow & 2,635 & 262,158 \\
\hline 72 & 09069000 & Eagle River at Gypsum & 1 & 2001 & $8 / 15 / 2001$ & $39^{\circ} 39^{\prime} 00^{\prime \prime}$ & $106^{\circ} 57^{\prime} 06^{\prime \prime}$ & 6,276 & 842 & Nitzschia inconspicua Grunow & 14,934 & 525,926 \\
\hline 72 & 09069000 & Eagle River at Gypsum & 1 & 2001 & $8 / 15 / 2001$ & $39^{\circ} 39^{\prime} 00^{\prime \prime}$ & $106^{\circ} 57^{\prime} 06^{\prime \prime}$ & 6,276 & 842 & Nitzschia palea var. debilis (Kützing) Grunow & 1,977 & 344,246 \\
\hline 72 & 09069000 & Eagle River at Gypsum & 1 & 2001 & $8 / 15 / 2001$ & $39^{\circ} 39^{\prime} 00^{\prime \prime}$ & $106^{\circ} 57^{\prime} 06^{\prime \prime}$ & 6,276 & 842 & Phormidium autumnale (Agardh) Gomont & 256,530 & $24,871,934$ \\
\hline 72 & 09069000 & Eagle River at Gypsum & 1 & 2001 & $8 / 15 / 2001$ & $39^{\circ} 39^{\prime} 00^{\prime \prime}$ & $106^{\circ} 57^{\prime} 06^{\prime \prime}$ & 6,276 & 842 & $\begin{array}{l}\text { Reimeria sinuata (Gregory) } \\
\text { Kociolek et Stoermer }\end{array}$ & 9,224 & $1,554,593$ \\
\hline 72 & 09069000 & Eagle River at Gypsum & 1 & 2001 & $8 / 15 / 2001$ & $39^{\circ} 39^{\prime} 00^{\prime \prime}$ & $106^{\circ} 57^{\prime} 06^{\prime \prime}$ & 6,276 & 842 & $\begin{array}{l}\text { Rhoicosphenia abbreviata (Agardh) } \\
\text { Lange-Bertalot }\end{array}$ & 1,977 & $1,022,845$ \\
\hline 72 & 09069000 & Eagle River at Gypsum & 1 & 2001 & $8 / 15 / 2001$ & $39^{\circ} 39^{\prime} 00^{\prime \prime}$ & $106^{\circ} 57^{\prime} 06^{\prime \prime}$ & 6,276 & 842 & Scenedesmus ecornis (Ralfs) Chodat & 15,642 & 364,209 \\
\hline 72 & 09069000 & Eagle River at Gypsum & 1 & 2001 & $8 / 15 / 2001$ & $39^{\circ} 39^{\prime} 00^{\prime \prime}$ & $106^{\circ} 57^{\prime} 06^{\prime \prime}$ & 6,276 & 842 & Unknown alga flagellate $(<10 \mu)$ & 18,771 & $1,803,892$ \\
\hline 73 & 393858106570900 & Gypsum Creek at mouth & 1 & 2000 & $8 / 14 / 2000$ & $39^{\circ} 38^{\prime} 58^{\prime \prime}$ & $106^{\circ} 57^{\prime} 09^{\prime \prime}$ & 6,280 & 103 & $\begin{array}{l}\text { Achnanthidium minutissimum (Kützing) } \\
\text { Czarnecki }\end{array}$ & 637,905 & $35,130,631$ \\
\hline 73 & 393858106570900 & Gypsum Creek at mouth & 1 & 2000 & $8 / 14 / 2000$ & $39^{\circ} 38^{\prime} 58^{\prime \prime}$ & $106^{\circ} 57^{\prime} 09^{\prime \prime}$ & 6,280 & 103 & Amphora pediculus (Kützing) Grunow & 41,244 & $3,902,901$ \\
\hline 73 & 393858106570900 & Gypsum Creek at mouth & 1 & 2000 & $8 / 14 / 2000$ & $39^{\circ} 38^{\prime} 58^{\prime \prime}$ & $106^{\circ} 57^{\prime} 09^{\prime \prime}$ & 6,280 & 103 & Cocconeis pediculus Ehrenberg & 19,247 & $66,580,334$ \\
\hline 73 & 393858106570900 & Gypsum Creek at mouth & 1 & 2000 & $8 / 14 / 2000$ & $39^{\circ} 38^{\prime} 58^{\prime \prime}$ & $106^{\circ} 57^{\prime} 09^{\prime \prime}$ & 6,280 & 103 & $\begin{array}{l}\text { Cocconeis placentula var. euglypta } \\
\text { (Ehrenberg) Grunow }\end{array}$ & 4,124 & $2,484,726$ \\
\hline 73 & 393858106570900 & Gypsum Creek at mouth & 1 & 2000 & $8 / 14 / 2000$ & $39^{\circ} 38^{\prime} 58^{\prime \prime}$ & $106^{\circ} 57^{\prime} 09^{\prime \prime}$ & 6,280 & 103 & Cymbella affinis Kützing & 10,998 & $5,566,346$ \\
\hline 73 & 393858106570900 & Gypsum Creek at mouth & 1 & 2000 & $8 / 14 / 2000$ & $39^{\circ} 38^{\prime} 58^{\prime \prime}$ & $106^{\circ} 57^{\prime} 09^{\prime \prime}$ & 6,280 & 103 & Diatoma vulgaris Bory & 2,750 & $10,159,514$ \\
\hline 73 & 393858106570900 & Gypsum Creek at mouth & 1 & 2000 & $8 / 14 / 2000$ & $39^{\circ} 38^{\prime} 58^{\prime \prime}$ & $106^{\circ} 57^{\prime} 09^{\prime \prime}$ & 6,280 & 103 & Encyonema silesiacum (Bleisch) Mann & 63,241 & $29,776,914$ \\
\hline 73 & 393858106570900 & Gypsum Creek at mouth & 1 & 2000 & $8 / 14 / 2000$ & $39^{\circ} 38^{\prime} 58^{\prime \prime}$ & $106^{\circ} 57^{\prime} 09^{\prime \prime}$ & 6,280 & 103 & $\begin{array}{l}\text { Encyonopsis microcephala (Grunow) } \\
\text { Krammer }\end{array}$ & 9,624 & 599,875 \\
\hline 73 & 393858106570900 & Gypsum Creek at mouth & 1 & 2000 & $8 / 14 / 2000$ & $39^{\circ} 38^{\prime} 58^{\prime \prime}$ & $106^{\circ} 57^{\prime} 09^{\prime \prime}$ & 6,280 & 103 & Fragilaria vaucheriae (Kützing) Petersen & 4,124 & 853,177 \\
\hline 73 & 393858106570900 & Gypsum Creek at mouth & 1 & 2000 & $8 / 14 / 2000$ & $39^{\circ} 38^{\prime} 58^{\prime \prime}$ & $106^{\circ} 57^{\prime} 09^{\prime \prime}$ & 6,280 & 103 & $\begin{array}{l}\text { Geissleria acceptata (Hustedt) Lange-Bertalot } \\
\text { et Metzeltin }\end{array}$ & 2,750 & 282,248 \\
\hline 73 & 393858106570900 & Gypsum Creek at mouth & 1 & 2000 & $8 / 14 / 2000$ & $39^{\circ} 38^{\prime} 58^{\prime \prime}$ & $106^{\circ} 57^{\prime} 09^{\prime \prime}$ & 6,280 & 103 & Gomphonema olivaceum (Lyngbye) Kützing & 4,124 & $1,419,072$ \\
\hline 73 & 393858106570900 & Gypsum Creek at mouth & 1 & 2000 & $8 / 14 / 2000$ & $39^{\circ} 38^{\prime} 58^{\prime \prime}$ & $106^{\circ} 57^{\prime} 09^{\prime \prime}$ & 6,280 & 103 & Gomphonema parvulum (Kützing) Kützing & 5,499 & $1,228,263$ \\
\hline 73 & 393858106570900 & Gypsum Creek at mouth & 1 & 2000 & $8 / 14 / 2000$ & $39^{\circ} 38^{\prime} 58^{\prime \prime}$ & $106^{\circ} 57^{\prime} 09^{\prime \prime}$ & 6,280 & 103 & $\begin{array}{l}\text { Gomphonema pumilum (Grunow) } \\
\text { Reichardt et Lange-Bertalot }\end{array}$ & 5,499 & $1,604,562$ \\
\hline 73 & 393858106570900 & Gypsum Creek at mouth & 1 & 2000 & $8 / 14 / 2000$ & $39^{\circ} 38^{\prime} 58^{\prime \prime}$ & $106^{\circ} 57^{\prime} 09^{\prime \prime}$ & 6,280 & 103 & Hantzschia amphioxys (Ehrenberg) Grunow & 5,499 & $5,745,250$ \\
\hline 73 & 393858106570900 & Gypsum Creek at mouth & 1 & 2000 & $8 / 14 / 2000$ & $39^{\circ} 38^{\prime} 58^{\prime \prime}$ & $106^{\circ} 57^{\prime} 09^{\prime \prime}$ & 6,280 & 103 & $\begin{array}{l}\text { Homoeothrix janthina (Bornet et Flahault) } \\
\text { Starmach }\end{array}$ & $1,083,727$ & $35,121,800$ \\
\hline 73 & 393858106570900 & Gypsum Creek a & 1 & 2000 & $8 / 14 / 2000$ & $39^{\circ} 38^{\prime} 58^{\prime \prime}$ & $106^{\circ} 57^{\prime} 09^{\prime \prime}$ & 6,280 & 103 & Navicula capitatoradiata Germain & 2,750 & $1,023,977$ \\
\hline 73 & 393858106570900 & Gypsum Creek at mouth & 1 & 2000 & $8 / 14 / 2000$ & $39^{\circ} 38^{\prime} 58^{\prime \prime}$ & $106^{\circ} 57^{\prime} 09^{\prime \prime}$ & 6,280 & 103 & $\begin{array}{l}\text { Navicula cryptotenella Lange-Bertalot } \\
\text { ex Krammer et Lange-Bertalot }\end{array}$ & 75,614 & $27,366,281$ \\
\hline 73 & 393858106 & Gypst & 1 & 2000 & 2000 & $39^{\circ}$ & "09" & 6,280 & 10 & Navicula minima Grunow & 2,750 & 146,033 \\
\hline 73 & 393858106570900 & Gypsum Creek at mouth & 1 & 2000 & $8 / 14 / 2000$ & $39^{\circ} 38^{\prime} 58^{\prime \prime}$ & $106^{\circ} 57^{\prime} 09^{\prime \prime}$ & 6,280 & 103 & Navicula tripunctata (Müller) Bory & 19,247 & $18,210,866$ \\
\hline 73 & 393858106570900 & Gypsum Creek at mouth & 1 & 2000 & $8 / 14 / 2000$ & $39^{\circ} 38^{\prime} 58^{\prime \prime}$ & $106^{\circ} 57^{\prime} 09^{\prime \prime}$ & 6,280 & 103 & Navicula veneta Kützing & 23,372 & $5,067,871$ \\
\hline 73 & 393858106570900 & Gypsum Creek at mouth & 1 & 2000 & $8 / 14 / 2000$ & $39^{\circ} 38^{\prime} 58^{\prime \prime}$ & $106^{\circ} 57^{\prime} 09^{\prime \prime}$ & 6,280 & 103 & Nitzschia dissipata (Kützing) Grunow & 30,246 & $7,865,017$ \\
\hline 73 & 393858106570900 & Gypsum Creek at mouth & 1 & 2000 & $8 / 14 / 2000$ & $39^{\circ} 38^{\prime} 58^{\prime \prime}$ & $106^{\circ} 57^{\prime} 09^{\prime \prime}$ & 6,280 & 103 & Phormidium autumnale (Agardh) Gomont & $2,279,015$ & $223,182,106$ \\
\hline 73 & 393858106570900 & Gypsum Creek at mouth & 1 & 2000 & $8 / 14 / 2000$ & $39^{\circ} 38^{\prime} 58^{\prime \prime}$ & $106^{\circ} 57^{\prime} 09^{\prime \prime}$ & 6,280 & 103 & $\begin{array}{l}\text { Planothidium dubium (Grunow) } \\
\text { Round et Bukhtiyarova }\end{array}$ & 4,124 & 333,816 \\
\hline 73 & 393858106570900 & Gypsum Creek at mouth & 1 & 2000 & $8 / 14 / 2000$ & $39^{\circ} 38^{\prime} 58^{\prime \prime}$ & $106^{\circ} 57^{\prime} 09^{\prime \prime}$ & 6,280 & 103 & $\begin{array}{l}\text { Reimeria sinuata (Gregory) } \\
\text { Kociolek et Stoermer }\end{array}$ & 2,750 & 454,626 \\
\hline 73 & 393858106570900 & Gypsum Creek at mouth & 1 & 2000 & $8 / 14 / 2000$ & $39^{\circ} 38^{\prime} 58^{\prime \prime}$ & $106^{\circ} 57^{\prime} 09^{\prime \prime}$ & 6,280 & 103 & $\begin{array}{l}\text { Unknown Rhodophyte Florideophycidae } \\
\text { (chantransia) }\end{array}$ & 159,372 & 309 \\
\hline
\end{tabular}


Table 2. Description of sites and algal data collected from selected sites the Eagle River watershed, Colorado, 2000-2001.-Continued

[ID, identification; NAVD, North American Vertical Datum of 1988; ft, feet; $\mathrm{mi}^{2}$, square miles; cells $/ \mathrm{cm}^{2}$, cells per square centimeter; $\mu \mathrm{m}^{3} / \mathrm{cm}^{2}$, cubic micrometer per square centimeter]

\begin{tabular}{|c|c|c|c|c|c|c|c|c|c|c|c|c|}
\hline $\begin{array}{l}\text { Site } \\
\text { ID' }\end{array}$ & $\begin{array}{l}\text { USGS } \\
\text { station } \\
\text { number }\end{array}$ & Station name & $\begin{array}{c}\text { Replicate } \\
\text { sample } \\
\text { number }\end{array}$ & Year & $\begin{array}{l}\text { Collection } \\
\text { date }\end{array}$ & Latitude & Longitude & $\begin{array}{c}\text { Elevation } \\
\text { NAVD } 88 \\
\text { (ft) }\end{array}$ & $\begin{array}{c}\text { Drainage } \\
\text { area } \\
\left(\mathrm{mi}^{2}\right)\end{array}$ & Algal taxon name & $\begin{array}{c}\text { Total } \\
\text { density } \\
\text { (number of } \\
\text { cells } / \mathrm{cm}^{2} \text { ) }\end{array}$ & $\begin{array}{c}\text { Total } \\
\text { biovolume } \\
\left(\mu \mathrm{m}^{3} / \mathrm{cm}^{2}\right)\end{array}$ \\
\hline 73 & 393858106570900 & Gypsum Creek at mouth & 1 & 2001 & $8 / 15 / 2001$ & $39^{\circ} 38^{\prime} 58^{\prime \prime}$ & $106^{\circ} 57^{\prime} 09^{\prime \prime}$ & 6,280 & 103 & $\begin{array}{l}\text { Achnanthidium minutissimum (Kützing) } \\
\text { Czarnecki }\end{array}$ & 561,019 & $30,418,942$ \\
\hline 73 & 393858106570900 & Gypsum Creek at mouth & 1 & 2001 & $8 / 15 / 2001$ & $39^{\circ} 38^{\prime} 58^{\prime \prime}$ & $106^{\circ} 57^{\prime} 09^{\prime \prime}$ & 6,280 & 103 & Amphora pediculus (Kützing) Grunow & 51,900 & $5,018,047$ \\
\hline 73 & 393858106570900 & Gypsum Creek at mouth & 1 & 2001 & $8 / 15 / 2001$ & $39^{\circ} 38^{\prime} 58^{\prime \prime}$ & $106^{\circ} 57^{\prime} 09^{\prime \prime}$ & 6,280 & 103 & Caloneis bacillum (Grunow) Cleve & 7,414 & $3,189,403$ \\
\hline 73 & 393858106570900 & Gypsum Creek at mouth & 1 & 2001 & $8 / 15 / 2001$ & $39^{\circ} 38^{\prime} 58^{\prime \prime}$ & $106^{\circ} 57^{\prime} 09^{\prime \prime}$ & 6,280 & 103 & Chlamydomonas sp. & 6,169 & $12,209,837$ \\
\hline 73 & 393858106570900 & Gypsum Creek at mouth & 1 & 2001 & $8 / 15 / 2001$ & $39^{\circ} 38^{\prime} 58^{\prime \prime}$ & $106^{\circ} 57^{\prime} 09^{\prime \prime}$ & 6,280 & 103 & Cocconeis pediculus Ehrenberg & 6,179 & $19,287,082$ \\
\hline 73 & 393858106570900 & Gypsum Creek at mouth & 1 & 2001 & $8 / 15 / 2001$ & $39^{\circ} 38^{\prime} 58^{\prime \prime}$ & $106^{\circ} 57^{\prime} 09^{\prime \prime}$ & 6,280 & 103 & $\begin{array}{l}\text { Cocconeis placentula var. lineata (Ehrenberg) } \\
\text { Van Heurck }\end{array}$ & 1,236 & $1,303,186$ \\
\hline 73 & 393858106570900 & Gypsum Creek at mouth & 1 & 2001 & $8 / 15 / 2001$ & $39^{\circ} 38^{\prime} 58^{\prime \prime}$ & $106^{\circ} 57^{\prime} 09^{\prime \prime}$ & 6,280 & 103 & Cyclotella meneghiniana Kützing & 12,357 & $8,873,202$ \\
\hline 73 & 393858106570900 & Gypsum Creek at mouth & 1 & 2001 & $8 / 15 / 2001$ & $39^{\circ} 38^{\prime} 58^{\prime \prime}$ & $106^{\circ} 57^{\prime} 09^{\prime \prime}$ & 6,280 & 103 & Cyclotella striata (Kützing) Grunow & 1,236 & 617,862 \\
\hline 73 & 393858106570900 & Gypsum Creek at mouth & 1 & 2001 & $8 / 15 / 2001$ & $39^{\circ} 38^{\prime} 58^{\prime \prime}$ & $106^{\circ} 57^{\prime} 09^{\prime \prime}$ & 6,280 & 103 & Cymbella affinis Kützing & 9,886 & $5,031,376$ \\
\hline 73 & 393858106570900 & Gypsum Creek at mouth & 1 & 2001 & $8 / 15 / 2001$ & $39^{\circ} 38^{\prime} 58^{\prime \prime}$ & $106^{\circ} 57^{\prime} 09^{\prime \prime}$ & 6,280 & 103 & Encyonema brehmii (Hustedt) Mann & 3,707 & 102,212 \\
\hline 73 & 393858106570900 & Gypsum Creek at mouth & 1 & 2001 & $8 / 15 / 2001$ & $39^{\circ} 38^{\prime} 58^{\prime \prime}$ & $106^{\circ} 57^{\prime} 09^{\prime \prime}$ & 6,280 & 103 & Encyonema silesiacum (Bleisch) Mann & 13,593 & $6,455,919$ \\
\hline 73 & 393858106570900 & Gypsum Creek at mouth & 1 & 2001 & $8 / 15 / 2001$ & $39^{\circ} 38^{\prime} 58^{\prime \prime}$ & $106^{\circ} 57^{\prime} 09^{\prime \prime}$ & 6,280 & 103 & Encyonopsis cesatii (Rabenhorst) Krammer & 2,471 & $4,582,064$ \\
\hline 73 & 393858106570900 & Gypsum Creek at mouth & 1 & 2001 & $8 / 15 / 2001$ & $39^{\circ} 38^{\prime} 58^{\prime \prime}$ & $106^{\circ} 57^{\prime} 09^{\prime \prime}$ & 6,280 & 103 & $\begin{array}{l}\text { Encyonopsis microcephala (Grunow) } \\
\text { Krammer }\end{array}$ & 8,650 & 550,531 \\
\hline 73 & 393858106570900 & Gypsum Creek at mouth & 1 & 2001 & $8 / 15 / 2001$ & $39^{\circ} 38^{\prime} 58^{\prime \prime}$ & $106^{\circ} 57^{\prime} 09^{\prime \prime}$ & 6,280 & 103 & Fragilaria vaucheriae (Kützing) Petersen & 2,471 & 486,904 \\
\hline 73 & 393858106570900 & Gypsum Creek at mouth & 1 & 2001 & $8 / 15 / 2001$ & $39^{\circ} 38^{\prime} 58^{\prime \prime}$ & $106^{\circ} 57^{\prime} 09^{\prime \prime}$ & 6,280 & 103 & $\begin{array}{l}\text { Geissleria acceptata (Hustedt) } \\
\text { Lange-Bertalot et Metzeltin }\end{array}$ & 2,471 & 253,697 \\
\hline 73 & 393858106570900 & Gypsum Creek at mouth & 1 & 2001 & $8 / 15 / 2001$ & $39^{\circ} 38^{\prime} 58^{\prime \prime}$ & $106^{\circ} 57^{\prime} 09^{\prime \prime}$ & 6,280 & 103 & $\begin{array}{l}\text { Gomphonema angustatum (Kützing) } \\
\text { Rabenhorst }\end{array}$ & 1,236 & 487,768 \\
\hline 73 & 393858106570900 & Gypsum Creek at mouth & 1 & 2001 & $8 / 15 / 2001$ & $39^{\circ} 38^{\prime} 58^{\prime \prime}$ & $106^{\circ} 57^{\prime} 09^{\prime \prime}$ & 6,280 & 103 & Gomphonema minutum (Agardh) Agardh & 2,471 & 201,930 \\
\hline 73 & 393858106570900 & Gypsum Creek at mouth & 1 & 2001 & $8 / 15 / 2001$ & $39^{\circ} 38^{\prime} 58^{\prime \prime}$ & $106^{\circ} 57^{\prime} 09^{\prime \prime}$ & 6,280 & 103 & $\begin{array}{l}\text { Gomphonema pumilum (Grunow) } \\
\text { Reichardt et Lange-Bertalot }\end{array}$ & 4,943 & $1,078,780$ \\
\hline 73 & 393858106570900 & Gypsum Creek at mouth & 1 & 2001 & $8 / 15 / 2001$ & $39^{\circ} 38^{\prime} 58^{\prime \prime}$ & $106^{\circ} 57^{\prime} 09^{\prime \prime}$ & 6,280 & 103 & $\begin{array}{l}\text { Homoeothrix janthina (Bornet et Flahault) } \\
\text { Starmach }\end{array}$ & $1,313,973$ & $22,618,289$ \\
\hline 73 & 393858106570900 & Gypsum Creek at mouth & 1 & 2001 & $8 / 15 / 2001$ & $39^{\circ} 38^{\prime} 58^{\prime \prime}$ & $106^{\circ} 57^{\prime} 09^{\prime \prime}$ & 6,280 & 103 & Lyngbya sp. & $2,263,982$ & $314,098,839$ \\
\hline 73 & 393858106570900 & Gypsum Creek at mouth & 1 & 2001 & $8 / 15 / 2001$ & $39^{\circ} 38^{\prime} 58^{\prime \prime}$ & $106^{\circ} 57^{\prime} 09^{\prime \prime}$ & 6,280 & 103 & Mayamaea atomus (Kützing) Lange-Bertalot & 2,471 & 70,969 \\
\hline 73 & 393858106570900 & Gypsum Creek at mouth & 1 & 2001 & $8 / 15 / 2001$ & $39^{\circ} 38^{\prime} 58^{\prime \prime}$ & $106^{\circ} 57^{\prime} 09^{\prime \prime}$ & 6,280 & 103 & $\begin{array}{l}\text { Navicula cryptotenella Lange-Bertalot } \\
\text { ex Krammer et Lange-Bertalot }\end{array}$ & 45,722 & $12,144,697$ \\
\hline 73 & 393858106570900 & Gypsum Creek at mouth & 1 & 2001 & $8 / 15 / 2001$ & $39^{\circ} 38^{\prime} 58^{\prime \prime}$ & $106^{\circ} 57^{\prime} 09^{\prime \prime}$ & 6,280 & 103 & Navicula minima Grunow & 4,943 & 222,464 \\
\hline 73 & 393858106570900 & Gypsum Creek at mouth & 1 & 2001 & $8 / 15 / 2001$ & $39^{\circ} 38^{\prime} 58^{\prime \prime}$ & $106^{\circ} 57^{\prime} 09^{\prime \prime}$ & 6,280 & 103 & Navicula stroemii Hustedt & 4,943 & 897,236 \\
\hline 73 & 393858106570900 & Gypsum Creek at mouth & 1 & 2001 & $8 / 15 / 2001$ & $39^{\circ} 38^{\prime} 58^{\prime \prime}$ & $106^{\circ} 57^{\prime} 09^{\prime \prime}$ & 6,280 & 103 & Navicula tripunctata (Müller) Bory & 17,300 & $15,731,607$ \\
\hline 73 & 393858106570900 & Gypsum Creek at mouth & 1 & 2001 & $8 / 15 / 2001$ & $39^{\circ} 38^{\prime} 58^{\prime \prime}$ & $106^{\circ} 57^{\prime} 09^{\prime \prime}$ & 6,280 & 103 & Navicula veneta Kützing & 9,886 & $2,182,606$ \\
\hline 73 & 393858106570900 & Gypsum Creek at mouth & 1 & 2001 & $8 / 15 / 2001$ & $39^{\circ} 38^{\prime} 58^{\prime \prime}$ & $106^{\circ} 57^{\prime} 09^{\prime \prime}$ & 6,280 & 103 & Nitzschia dissipata (Kützing) Grunow & 4,943 & $1,274,452$ \\
\hline 73 & 393858106570900 & Gypsum Creek at mouth & 1 & 2001 & $8 / 15 / 2001$ & $39^{\circ} 38^{\prime} 58^{\prime \prime}$ & $106^{\circ} 57^{\prime} 09^{\prime \prime}$ & 6,280 & 103 & Phormidium autumnale (Agardh) Gomont & $7,007,858$ & $679,448,126$ \\
\hline 73 & 393858106570900 & Gypsum Creek at mouth & 1 & 2001 & $8 / 15 / 2001$ & $39^{\circ} 38^{\prime} 58^{\prime \prime}$ & $106^{\circ} 57^{\prime} 09^{\prime \prime}$ & 6,280 & 103 & Unknown alga flagellate $(<10 \mu)$ & 104,871 & $10,078,373$ \\
\hline 73 & 393858106570900 & Gypsum Creek at mouth & 1 & 2001 & $8 / 15 / 2001$ & $39^{\circ} 38^{\prime} 58^{\prime \prime}$ & $106^{\circ} 57^{\prime} 09^{\prime \prime}$ & 6,280 & 103 & $\begin{array}{l}\text { Unknown Rhodophyte Florideophycidae } \\
\text { (chantransia) }\end{array}$ & 111,040 & $710,710,100$ \\
\hline
\end{tabular}


Publishing support provided by:

Denver Publishing Service Center, Denver, Colorado

Manuscript approved for publication, April 7, 2010

For more information concerning this publication, contact: Director, USGS Colorado Water Science Center

Box 25046, Mail Stop 415

Denver, CO 80225

(303) 236-4882

Or visit the Colorado Water Science Center Web site at: http://co.water.usgs.gov/

This publication is available online at: http://pubs.usgs.gov/ds/502/ 



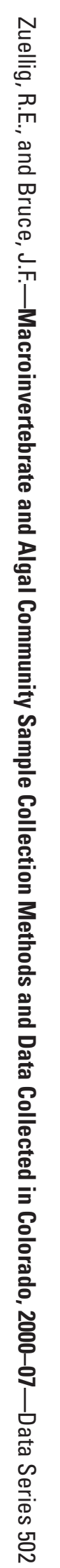

